\title{
Understanding the lives of adolescents and young adults (UDAYA) in Bihar, India
}

\author{
K.G. Santhya \\ Population Council \\ Rajib Acharya \\ Population Council \\ Neelanjana Pandey \\ Population Council \\ Santosh Kumar Singh \\ Population Council \\ Shilpi Rampal \\ Population Council
}

See next page for additional authors

Follow this and additional works at: https://knowledgecommons.popcouncil.org/departments_sbsr-pgy

Part of the Demography, Population, and Ecology Commons, Family, Life Course, and Society Commons, International Public Health Commons, and the Maternal and Child Health Commons How does access to this work benefit you? Let us know!

\section{Recommended Citation}

Santhya, K.G., Rajib Acharya, Neelanjana Pandey, Santosh Kumar Singh, Shilpi Rampal, A.J. Francis Zavier, and Ashish Kumar Gupta. 2017. "Understanding the lives of adolescents and young adults (UDAYA) in Bihar, India." New Delhi: Population Council. 


\section{Authors}

K.G. Santhya, Rajib Acharya, Neelanjana Pandey, Santosh Kumar Singh, Shilpi Rampal, A.J. Francis Zavier, and Ashish Kumar Gupta

This report is available at Knowledge Commons: https://knowledgecommons.popcouncil.org/departments_sbsr-pgy/ 


\section{- POPULATION COUNCIL}

Ideas. Evidence. Impact.

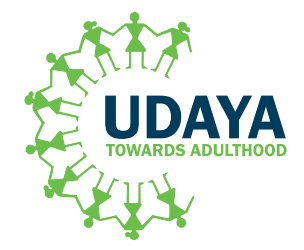

\section{Understanding the lives of adolescents and young adults (UDAYA) in Bihar, India}
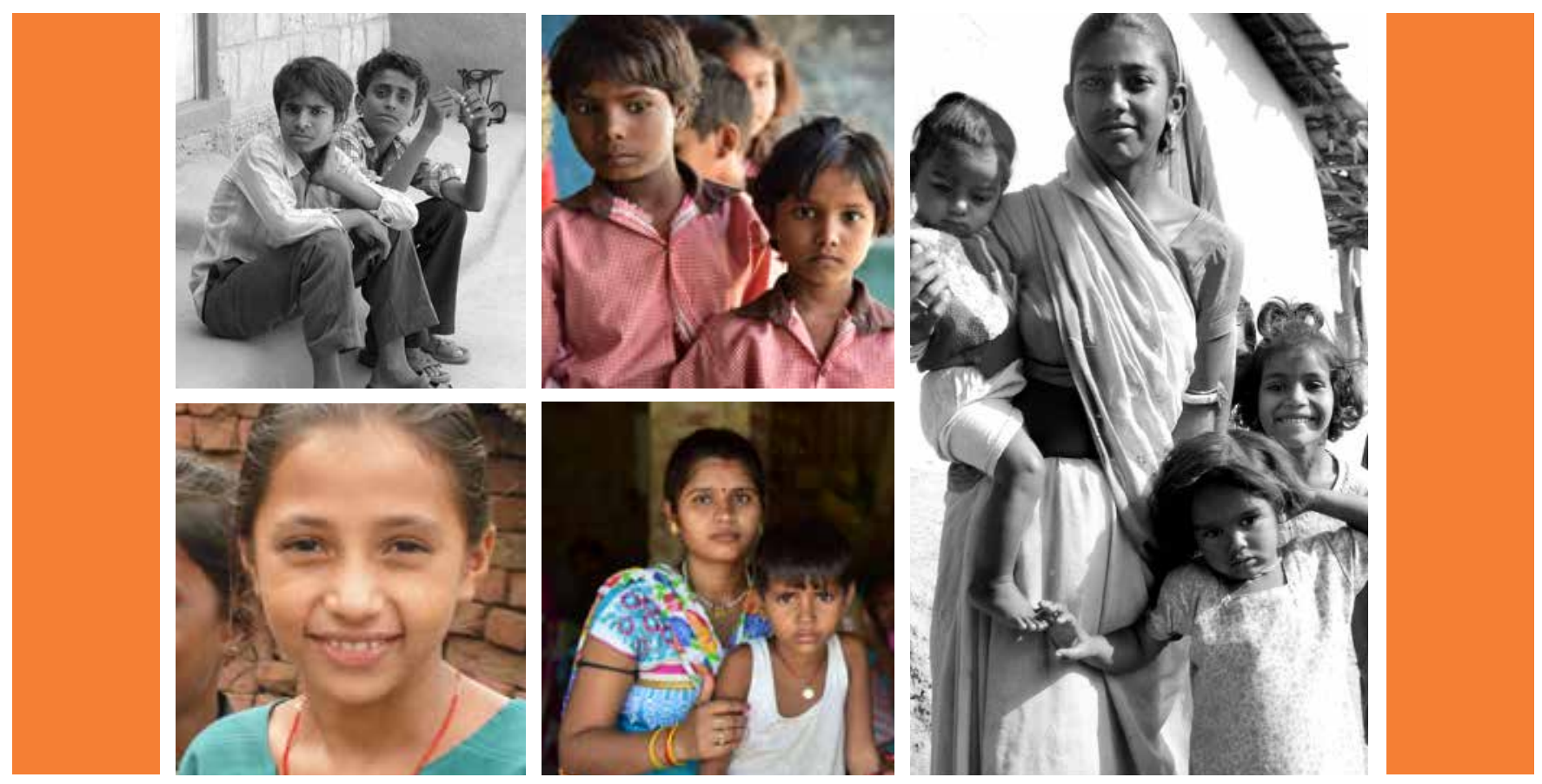

K G Santhya

Rajib Acharya

Neelanjana Pandey

Santosh Kumar Singh

Shilpi Rampal

A J Francis Zavier

Ashish Kumar Gupta 


\section{POPULATION COUNCIL}

Ideas. Evidence. Impact.

The Population Council confronts critical health and development issues-from stopping the spread of HIV to improving reproductive health and ensuring that young people lead full and productive lives. Through biomedical, social science, and public health research in 50 countries, we work with our partners to deliver solutions that lead to more effective policies, programs, and technologies that improve lives around the world. Established in1952 and headquartered in New York, the Council is a nongovernmental, nonprofit organization governed by an international board of trustees.

For additional copies, please contact:

Population Council

Zone 5A, Ground Floor

India Habitat Centre, Lodi Road

New Delhi, India 110003

Phone: 91-11-24642901

Email: info.india@popcouncil.org

Website: www.popcouncil.org

\section{Suggested citation:}

Santhya, K. G., R. Acharya, N. Pandey et al. 2017. Understanding the lives of adolescents and young adults (UDAYA) in Bihar, India. New Delhi: Population Council.

\section{Authors' contributions:}

KG Santhya conceptualized the study, participated in its design and implementation, guided data analysis, wrote the report, and made critical revisions and finalized the report. Rajib Acharya conceptualised the study, participated in its design and implementation, and provided technical support during data analysis. Neelanjana Pandey conducted most of the data analysis and provided technical support to field implementation. Santosh Singh managed field implementation and contributed to data management and analysis. Shilpi Rampal contributed to field implementation, data management and analysis. A J Francis Zavier contributed to data management. Ashish Kumar Gupta contributed to data management.

\section{Copyright: @ 2017 The Population Council, Inc.}




\title{
Understanding the lives of adolescents and young adults (UDAYA) in Bihar, India
}

\author{
K G Santhya \\ Rajib Acharya \\ Neelanjana Pandey \\ Santosh Kumar Singh \\ Shilpi Rampal \\ A J Francis Zavier \\ Ashish Kumar Gupta
}

\section{6}





\section{Table of Contents}

Preface

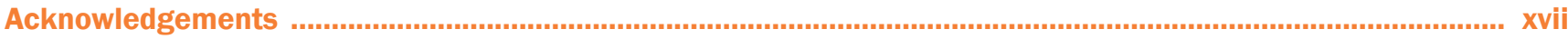

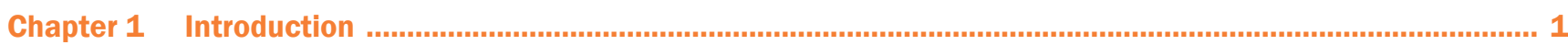

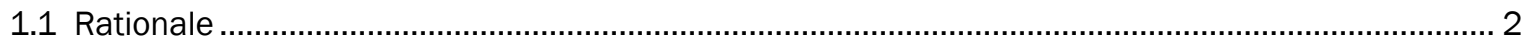

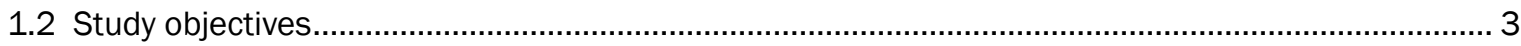

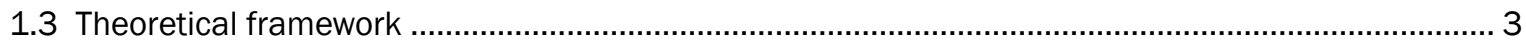

1.4 Bihar: Overview of demographic and socio-economic features ..................................................... 6

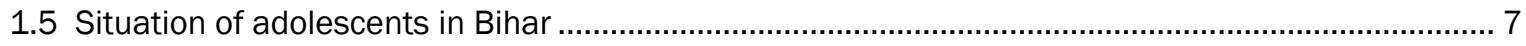

1.6 Study design and sample size estimation for individual interviews................................................. 9

1.7 Study instruments .................................................................................................................. 10

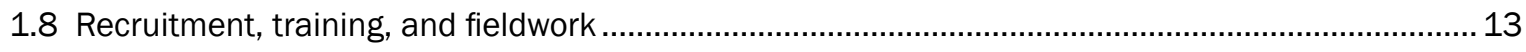

1.9 Ethical considerations ...................................................................................................... 14

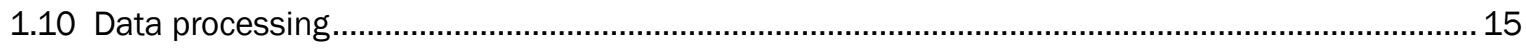

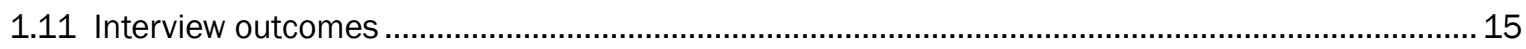

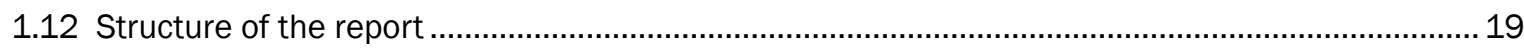

Chapter 2 Socio-Economic profile of surveyed households

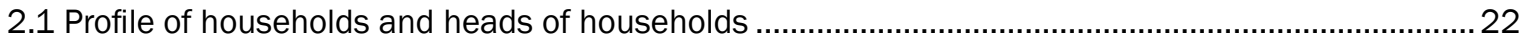

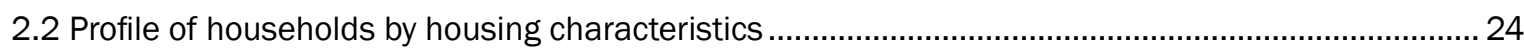

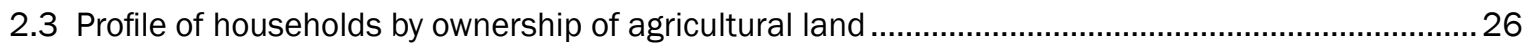

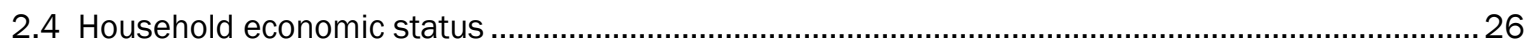

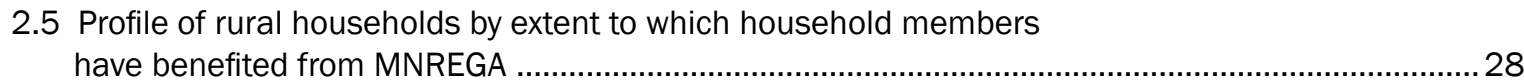

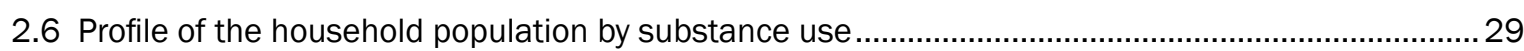

2.7 Background characteristics of surveyed adolescents ......................................................................... 30

Chapter 3 Education

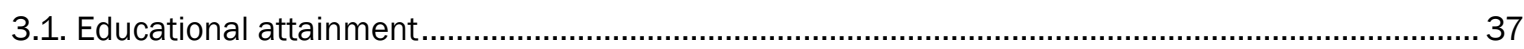

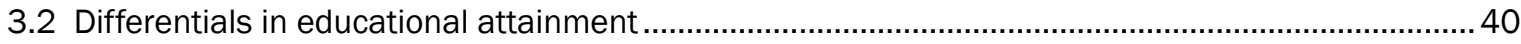

3.3 School retention and class completion ........................................................................................ 42

3.4 Reasons for never enrolling in school or school discontinuation ..................................................... 44

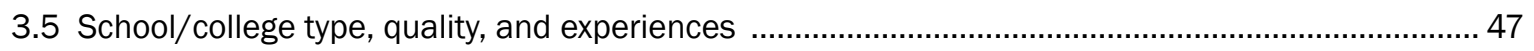

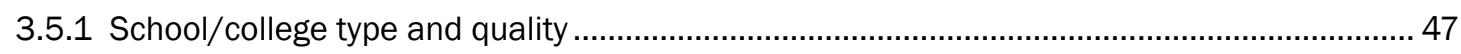

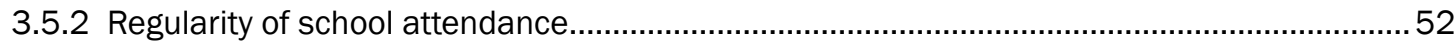

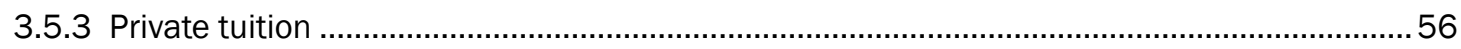

3.5.4 Academic performance perceptions and leadership position ............................................. 57

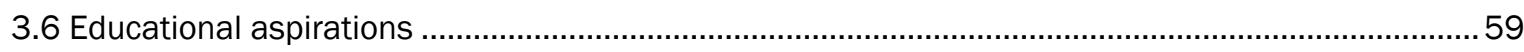

3.7 Awareness and utilisation of entitlements from school.............................................................. 60

3.7.1 Awareness and participation in Meena Manch programme................................................... 66

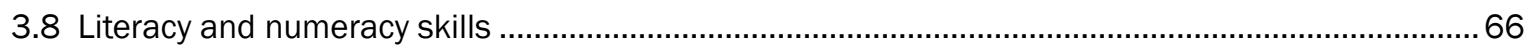

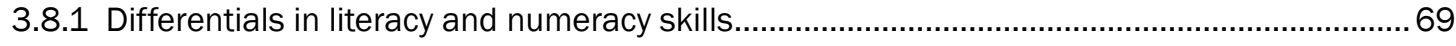




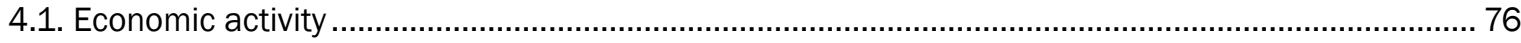

4.2 Employment-seeking and preference of work sector among adolescents..................................... 81

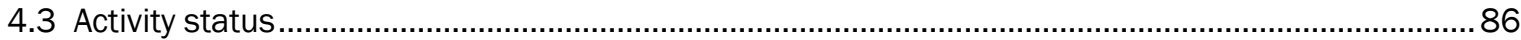

4.4 Participation in vocational training programmes and unmet need for vocational training.............. 88

4.4.1 Participation in vocational training programmes and related experiences..........................88

4.4.2 Unmet need for vocational training programmes and willingness to participate in such programmes............................................................................................................ 91

4.5 Awareness and utilisation of government programmes for skill-building and

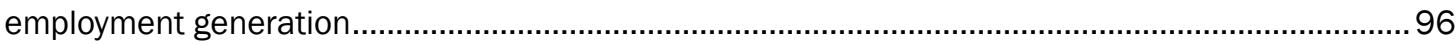

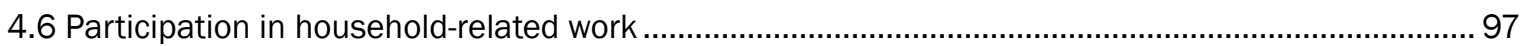

$\begin{array}{ll}4.7 \text { Migration experiences } & 99\end{array}$

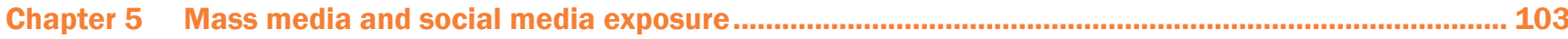

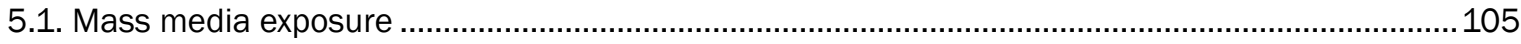

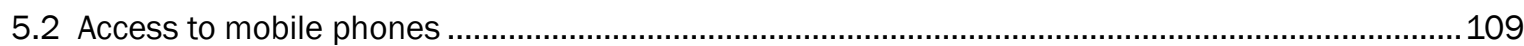

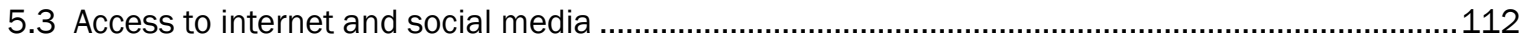

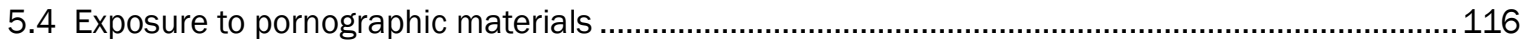

5.5 Perpetration and experience of harassment through mobile phones or the internet ....................119

5.6 Perceived benefits of using mobile phones, the internet, and social media 120

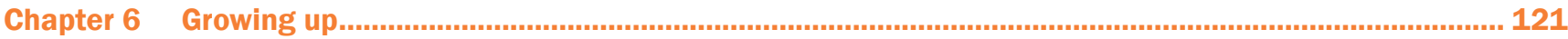

6.1 Peer networks and interactions ........................................................................................ 124

6.1.1 Size of peer networks and frequency and places of interactions with peers.....................124

6.1.2 Membership in organised groups .................................................................................128

6.2 Family life and interaction with parents ............................................................................... 130

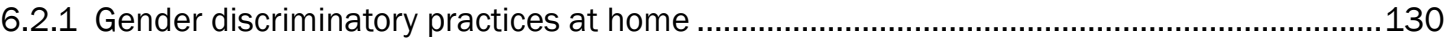

6.2.2 Exposure to parental violence........................................................................................ 134

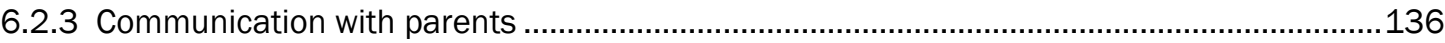

6.3 Role models, confidantes, and sources for learning social behaviours......................................138

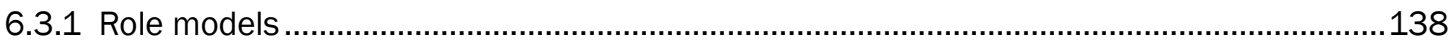

6.3.2 Leading confidante on personal matters........................................................................ 141

6.3.3 Sources for learning social behaviours.......................................................................... 144

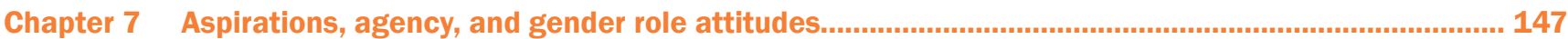

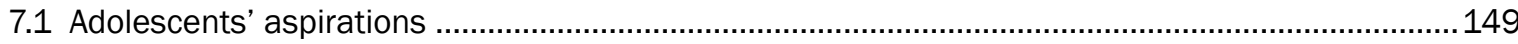

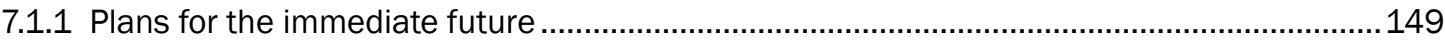

7.1.2 Aspirations for adulthood years .................................................................................. 151

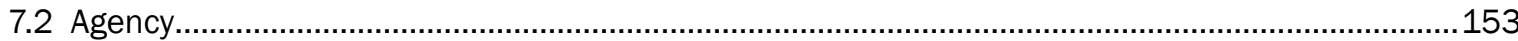

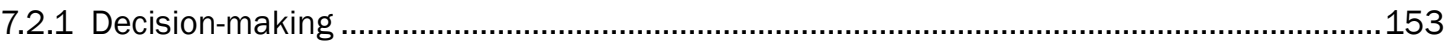

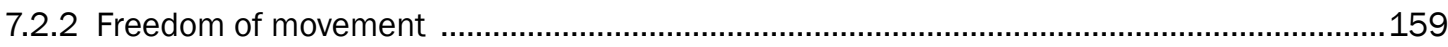

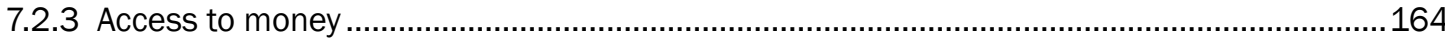

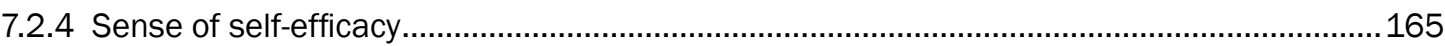

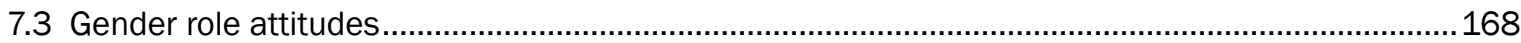


8.1 Awareness of sexual and reproductive matters

8.1.1 Awareness of matters related to sex and pregnancy ...................................................... 177

8.1.2 Awareness of prenatal sex determination tests .............................................................182

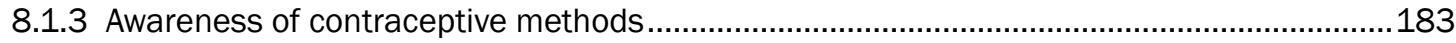

8.1.4 Awareness of HIV/AIDS and other sexually transmitted infections (STIs) ...........................186

8.1.5: Awareness of maternal and newborn care practices.........................................................193

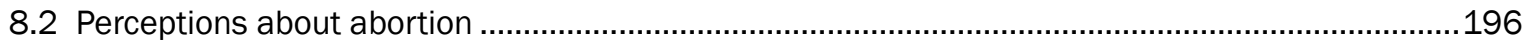

8.3 Knowledge of law on minimum age of marriage ..............................................................198

8.4 Sources of information on sexual and reproductive matters and access to family life education or sex education .............................................................................. 199

8.4.1 Sources of information on puberty and sexual and reproductive matters ...........................199

8.4.2 Access to family life education or sex education ...............................................................205

Chapter 9 Romantic and sexual relationships

9.1 Questionnaire module on romantic and sexual relationships ..................................................212

9.2 Romantic relationships among older adolescents..................................................................213

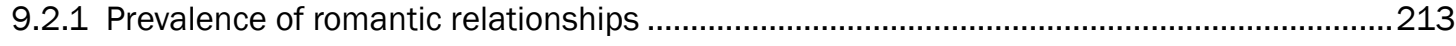

9.2.2 Physical intimacy and sex with a romantic partner ........................................................215

9.2.3 Characteristics of sexual experiences within premarital romantic relationships .................216

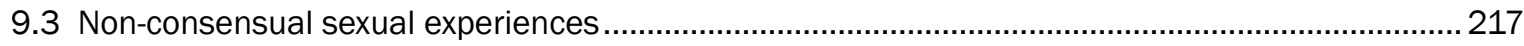

9.4 Sexual experiences within romantic and other relationships among older adolescents ..............220

9.4.1 Extent of sexual experiences ..........................................................................................220

9.4.2 Sexual risk behaviours in premarital relationships............................................................224

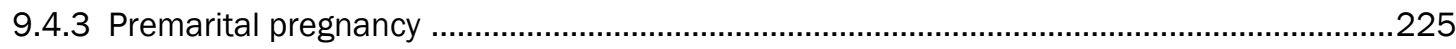

9.5 Same-sex relationship among older adolescents 226

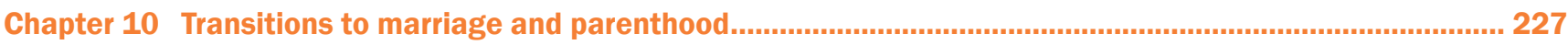

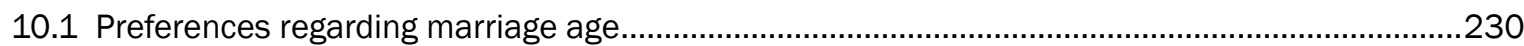

10.2 Marriage planning and extent of adolescents' participation in it ...............................................232

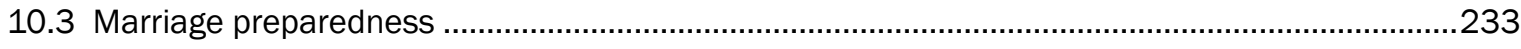

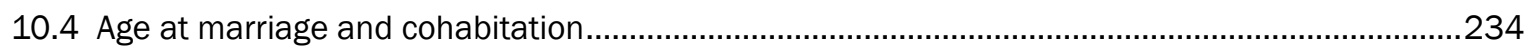

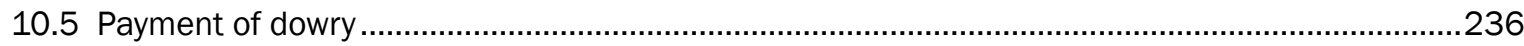

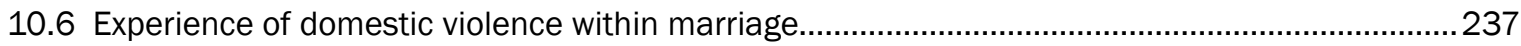

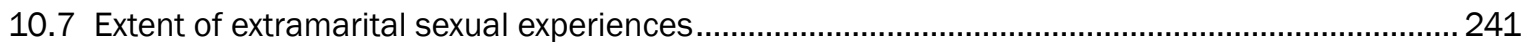

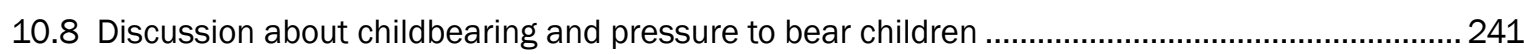

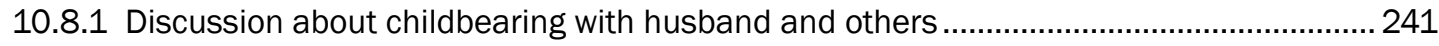

10.8.2 Pressure to bear a child soon after marriage ..............................................................242

10.8.3 Preferred interval for first birth ............................................................................ 242

10.9 Contraceptive practices within marriage $\quad 242$

10.9.1 Ever and current use of contraceptive methods........................................................243 
10.9.2 Length of interval between cohabitation and initiation of contraceptive use ...................245

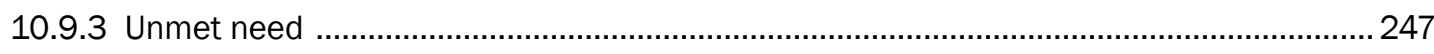

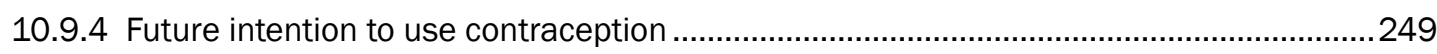

10.10 Transition to motherhood $\quad 250$

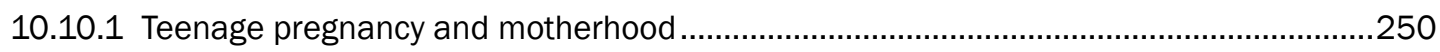

10.10.2 Reproductive history of married older girls ............................................................252

10.10.2.1 Pregnancy loss and infant and child death ................................................253

10.10.2.2 Wantedness of recent pregnancies .......................................................254

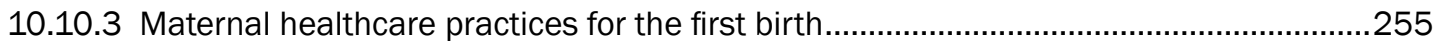

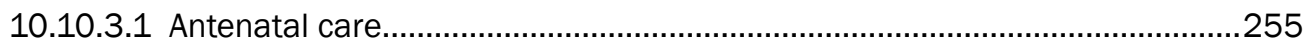

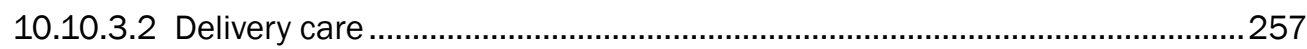

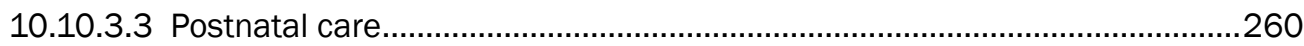

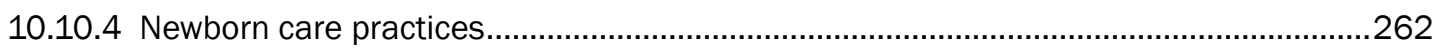

10.10.4.1 Breastfeeding practices ......................................................................262

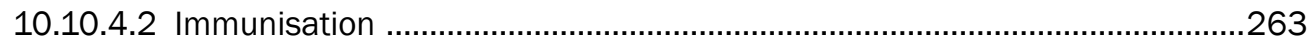

10.11 Reach of programmes to promote maternal, newborn, and child health 264

Chapter 11 Health and health-Seeking behaviour

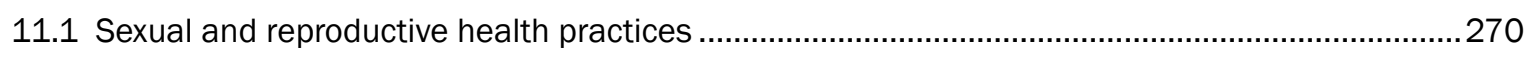

11.1.1 Menstrual hygiene practices ..................................................................................2

11.1.2 Recent experience of sexual and reproductive health problems

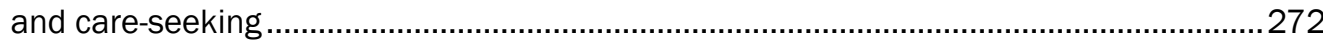

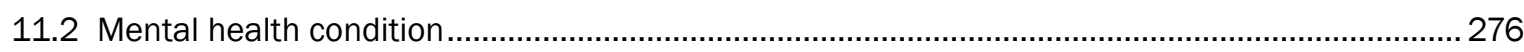

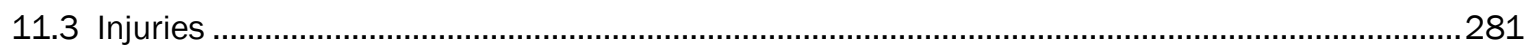

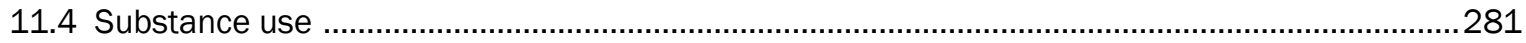

11.5 Engagement in sports and games or other physical activities .................................................28

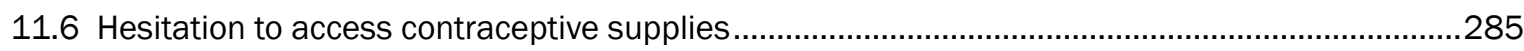

11.7 Awareness and reach of government programmes intended to impart health information to adolescents and meet their health needs .............................................................28

11.7.1 Awareness of the Rashtriya Kishor Swasthya Karyakram (RKSK) ..................................286

11.7.2 Health services received in school settings ...................................................................286

11.7.3 Awareness of frontline workers (FLWs) and interactions with them ................................287

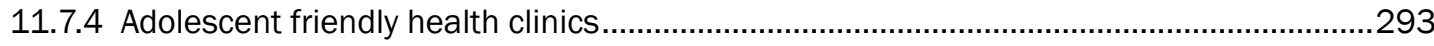

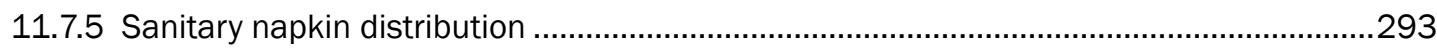

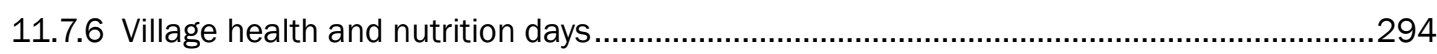

Chapter 12 Dietary habits and nutrition situation

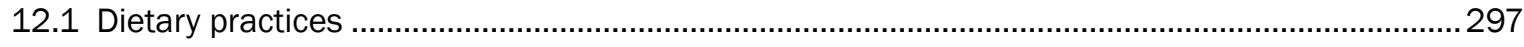

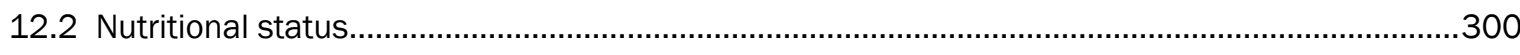

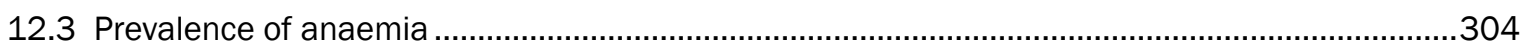

12.4 Awareness and use of government programmes intended to improve nutritional status of adolescents 
12.4.1 Weekly iron and folic acid supplementation programme.................................................307

12.4.2 Health check-ups for assessing nutritional status and food supplementation ................310

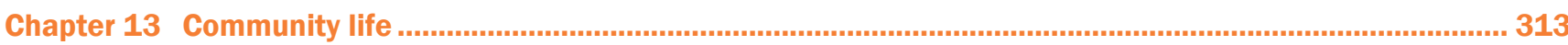

13.1 Perceptions about political matters and participation in political processes ................................315

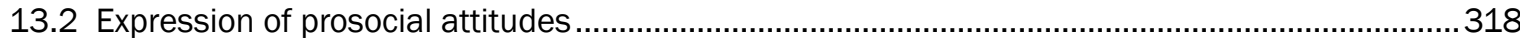

13.3 Acceptance of violence as a means of conflict resolution .............................................................321

13.4 Engagement in antisocial behaviours: physical fights, bullying, robbing, and

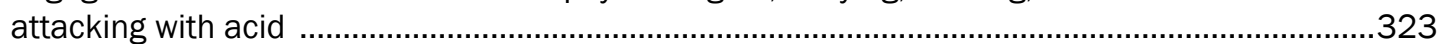

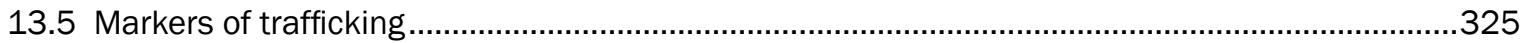

Chapter 14 Way forward

- Universalise quality secondary education attainment...................................................................330

- Prepare adolescents for skilled employment .................................................................................332

• Empower adolescents and establish egalitarian norms...................................................................334

- Promote good health and informed health choices ..............................................................................336

- Delay marriage and recognise the vulnerabilities of married girls ....................................................338

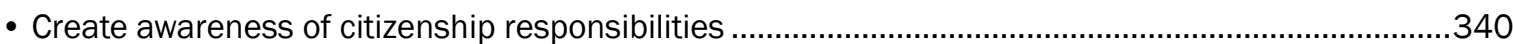

- Realise the potential of the mass media and new technologies to

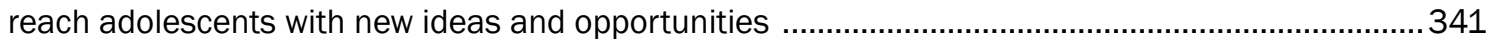

- Reach parents and families with new ideas about child socialisation ...............................................341

- Remove hindrances to awareness and use of entitlements ...............................................................342

• Ensure the inclusion of the most vulnerable .................................................................................342

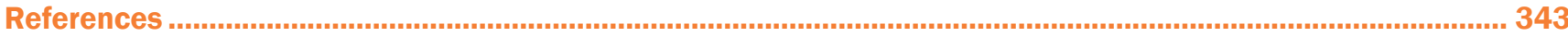

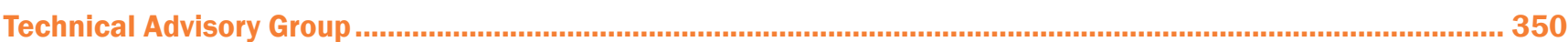

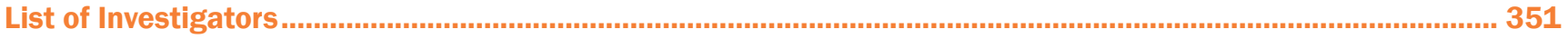




\section{List of Tables}

\section{Chapter 1 Introduction}

Table 1.1: $\quad$ Selected socio-demographic indicators, Bihar and India, 2010-16 ……............................................

Table 1.2: $\quad$ Selected socio-demographic characteristics of adolescents, Bihar, 2005-16 .......................................

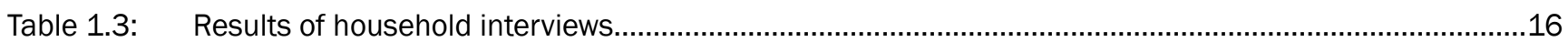

Table 1.4: Results of eligible respondent interviews ..........................................................................................16

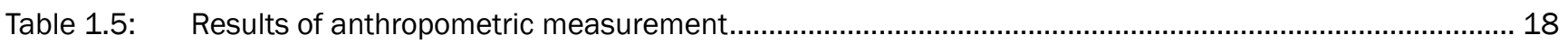

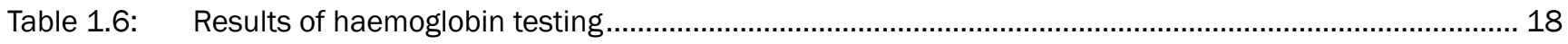

\section{Chapter 2 Socio-Economic profile of surveyed households}

Table 2.1: Socio-demographic characteristics of households and heads of households........................................ 22

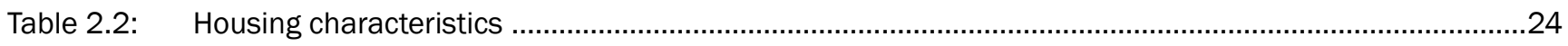

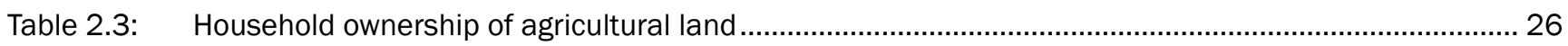

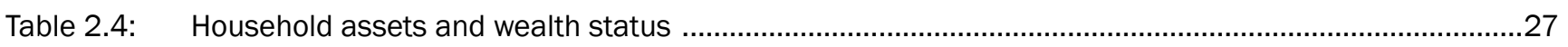

Table 2.5 Rural households that had benefited from the MNREGA scheme …..................................................... 28

Table 2.6: Substance use among household population ................................................................................. 29

Table 2.7: Background characteristics of surveyed adolescents ...................................................................... 30

\section{Chapter 3 Education}

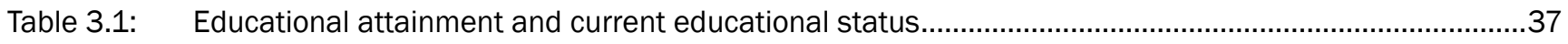

Table 3.2: Educational attainment of adolescents by selected background characteristics ...................................41

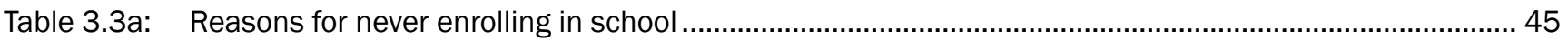

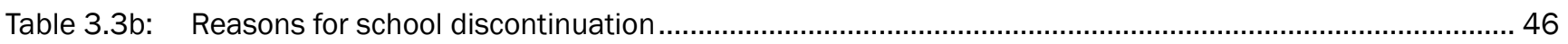

Table 3.4: Enrolment in private educational institutions ....................................................................................... 49

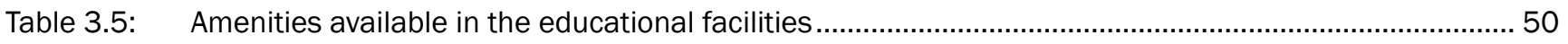

Table 3.6: Regularity of school attendance and reasons for absenteeism ........................................................... 54

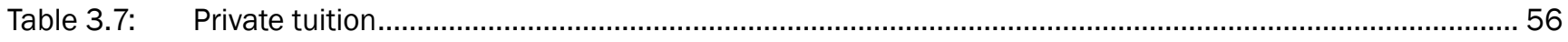

Table 3.8: $\quad$ Academic performance perceptions and leadership position in school ............................................... 58

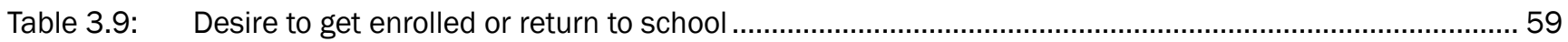

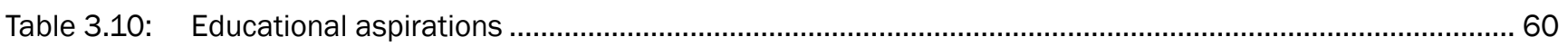

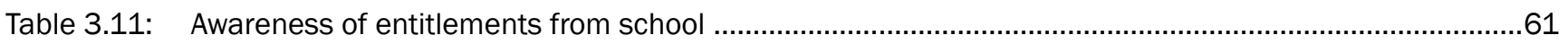

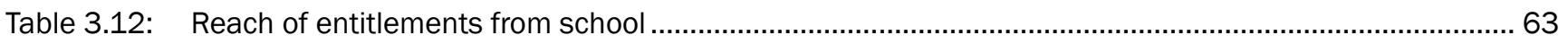

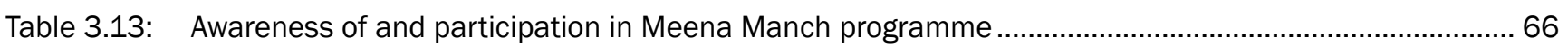

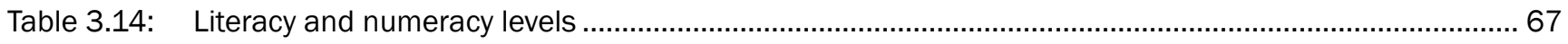

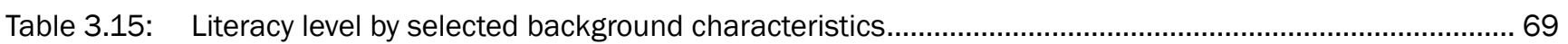

Table 3.16: Numeracy levels by selected background characteristics.....................................................................71

\section{Chapter 4 Economic activity, household work, and migration}

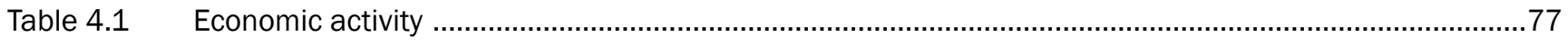

Table 4.2: Engagement in paid work in the 12 months preceding the interview by

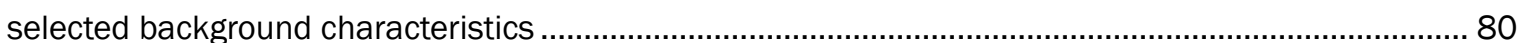


Table 4.3: Employment-seeking by selected background characteristics ……..................................................... 82

Table 4.4: Adolescents' preferences on work sector for employment.................................................................... 83

Table 4.5: Reasons for preferring government jobs .............................................................................................. 84

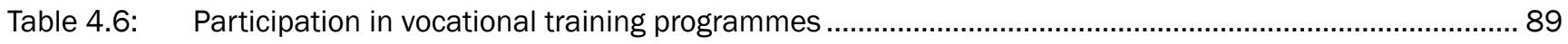

Table 4.7: Experience of exposure to vocational training.......................................................................................91

Table 4.8: Unmet need for vocational training programmes …....................................................................... 92

Table 4.9: Willingness of adolescents to participate in vocational training programmes ....................................... 94

Table 4.10: Awareness of government programmes for skill-building and employment generation ......................... 96

Table 4.11: Access to government programmes for employment generation .......................................................97

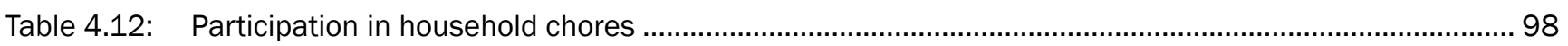

Table 4.13: Duration of residence at the current usual place of residence ........................................................... 100

Table 4.14: Migration experiences........................................................................................................................ 100

Table 4.15: Adolescents' perceived interest in migrating outside the state ........................................................... 102

\section{Chapter 5 Mass media and social media exposure}

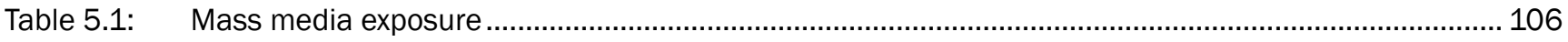

Table 5.2: $\quad$ Frequent exposure to the mass media by selected background characteristics.................................... 108

Table 5.3: $\quad$ Ownership of mobile phones by selected background characteristics .............................................. 111

Table 5.4: Use of mobile phones for entertainment and information .................................................................112

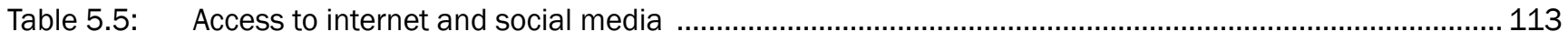

Table 5.6: $\quad$ Access to internet or social media by selected background characteristics .......................................115

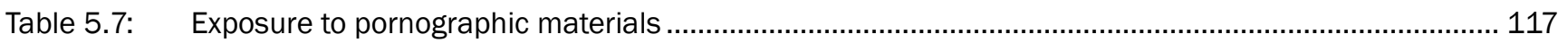

Table 5.8: $\quad$ Experience of harassment through mobile phones or the internet .....................................................119

Table 5.9: $\quad$ Perceived benefits of using mobile phones, the internet, and social media.......................................... 120

Chapter 6 Growing Up

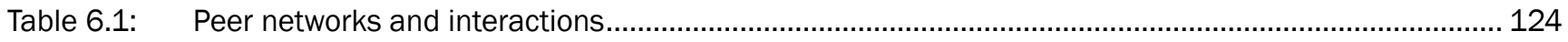

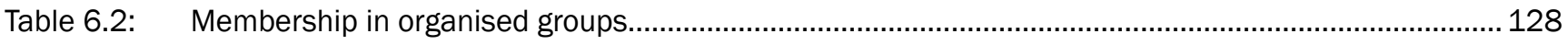

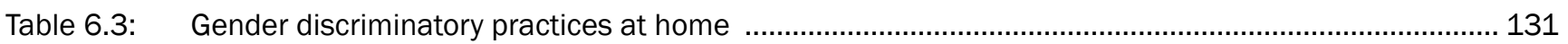

Table 6.4: Gender discriminatory experiences at home by selected background characteristics ......................... 133

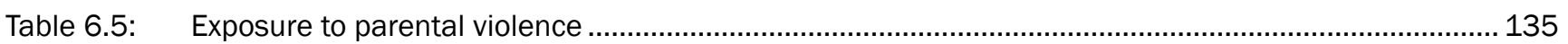

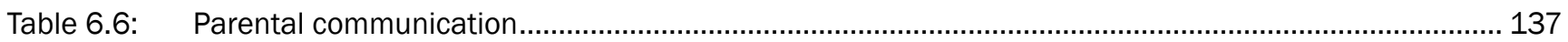

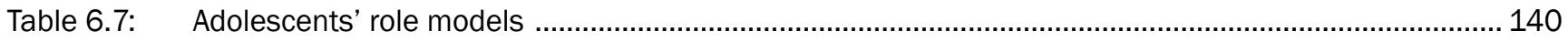

Table 6.8: Leading confidante on personal matters ................................................................................ 142

Table 6.9: $\quad$ Persons from whom or sources from which adolescents learned social behaviours............................. 144

\section{Chapter 7 Aspirations, agency, and gender role attitudes}

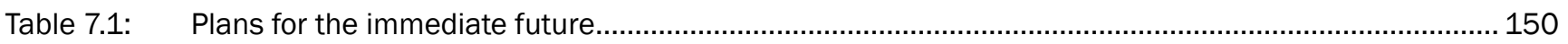

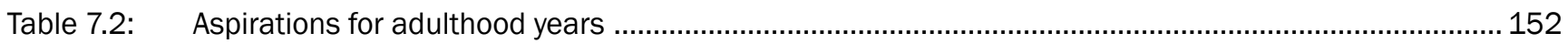

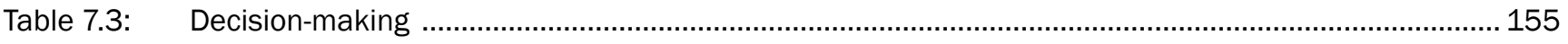

Table 7.4: Decision-making autonomy by selected background characteristics .................................................. 158

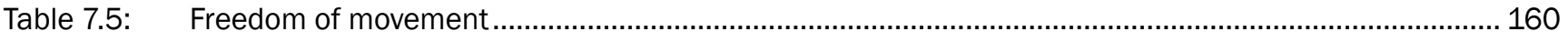

Table 7.6: Freedom of movement by selected background characteristics ....................................................... 162 
Table 7.7 Access to money

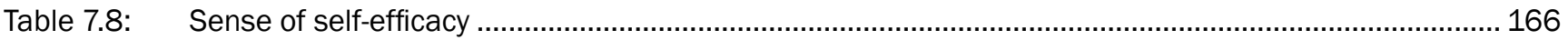

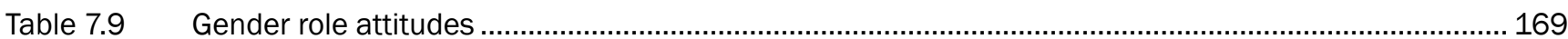

Table 7.10: $\quad$ Adherence to egalitarian gender role attitudes by selected background characteristics ..................... 173

\section{Chapter 8 Awareness of sexual and reproductive health matters}

Table 8.1: $\quad$ Awareness of sex- and pregnancy-related matters

Table 8.2a: Awareness of sex- and pregnancy-related matters among younger adolescents by selected background characteristics

Table 8.2b: Awareness of sex- and pregnancy-related matters among older adolescents by selected background characteristics 181

Table 8.3: $\quad$ Awareness of prenatal sex determination tests 183

Table 8.4 Awareness of selected modern contraceptive methods 184

Table 8.5: Specific knowledge of at least one modern contraceptive method. 185

Table 8.6: Awareness of HIV/AIDS 187

Table 8.7: Comprehensive awareness of HIV/AIDS. 189

Table 8.8: $\quad$ Awareness of STIs other than HIV/AIDS 191

Table 8.9: Awareness of maternal and newborn care practices. 194

Table 8.10: Awareness of maternal and newborn care practices by selected background characteristics 195

Table 8.11: Perceptions about abortion 197

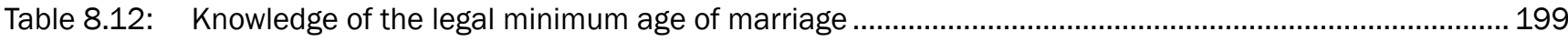

Table 8.13: Sources of information on puberty and sexual and reproductive matters... 200

Table 8.14: Preferred sources of information on puberty and sexual and reproductive matters .............................203

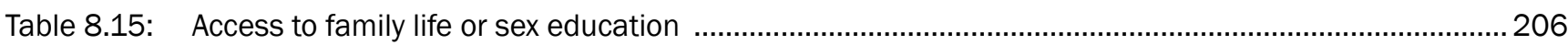

Table 8.16: Exposure to family life or sex education by selected background characteristics. 208

\section{Chapter 9 Romantic and sexual relationships}

Table 9.1: $\quad$ Premarital romantic relationships of older adolescents.

Table 9.2: $\quad$ Prevalence of premarital romantic relationships among older adolescents by selected background characteristics

Table 9.3: $\quad$ Characteristics of sexual experiences of older adolescents within premarital romantic relationships......

Table 9.4: $\quad$ Non-consensual sexual experiences among younger adolescents ...................................................218

Table 9.5: Non-consensual sexual experiences among older adolescents....

Table 9.6: Overall premarital sexual experiences of older adolescents with opposite-sex partners 221

Table 9.7: Overall premarital sexual experiences of older adolescents with opposite-sex partners by selected background characteristics

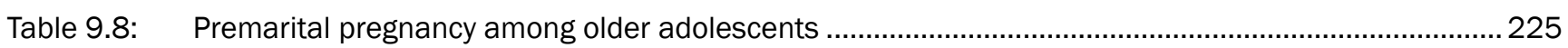

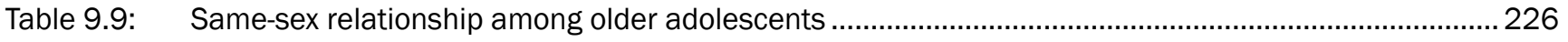

\section{Chapter 10 Transitions to marriage and parenthood}

Table 10.1 Preferred age for marriage 230

Table 10.2 Perceptions of parental preferences for age of marriage for respondents 
Table 10.3: Congruence and dissonance of adolescents' preferences with perceived parental preferences for age of marriage for adolescents................................................................ 232

Table 10.4: Age at initiation of marriage-related discussion.................................................................................. 233

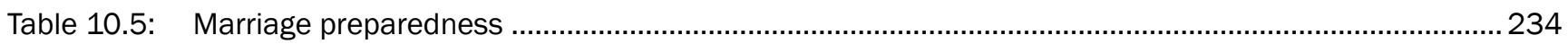

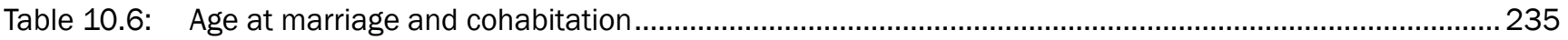

Table 10.7: Age at marriage by selected background characteristics...................................................................... 235

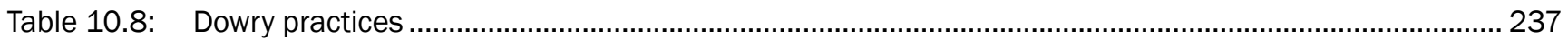

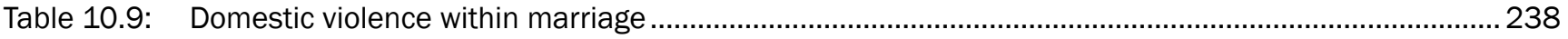

Table 10.10: Domestic violence within marriage by background characteristics..................................................... 240

Table 10.11: Discussion about childbearing with husband and others ...................................................................241

Table 10.12: Pressure to bear a child soon after marriage..................................................................................... 242

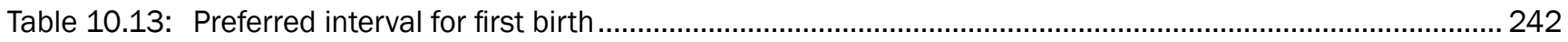

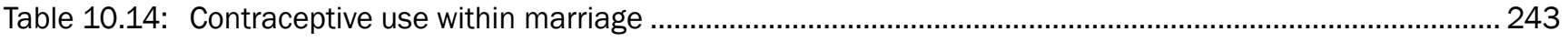

Table 10.15: Current contraceptive use within marriage by background characteristics .......................................... 244

Table 10.16: Length of interval between cohabitation and initiation of contraceptive use ..................................... 245

Table 10.17: Reasons for not using contraception to delay the first birth ............................................................ 246

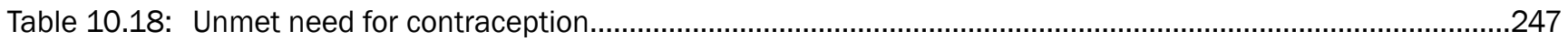

Table 10.19: Unmet need for contraception by background characteristics ….................................................... 248

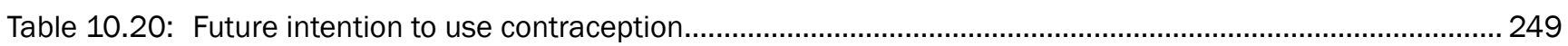

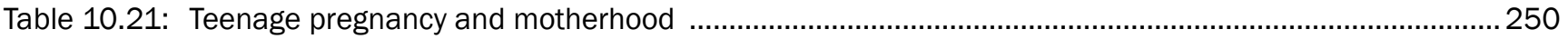

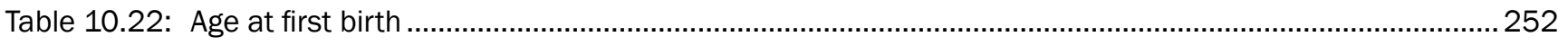

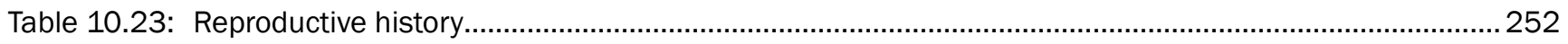

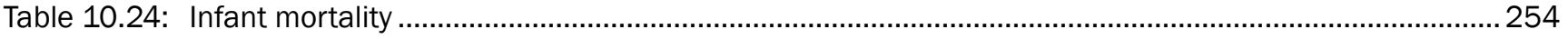

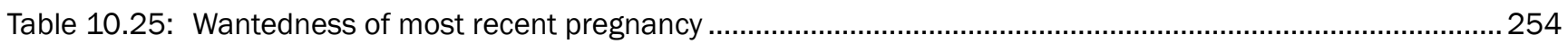

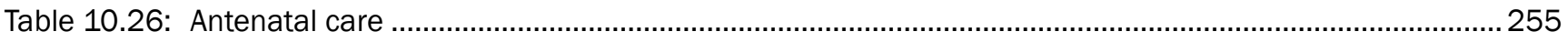

Table 10.27: Antenatal care by selected background characteristics ................................................................. 256

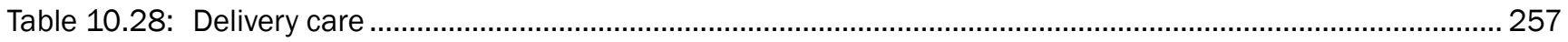

Table 10.29: Institutional delivery and skilled attendance for first birth by selected background characteristics .... 258

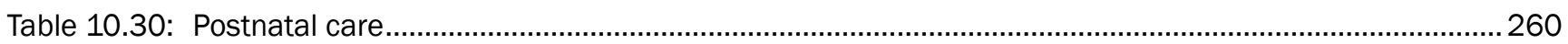

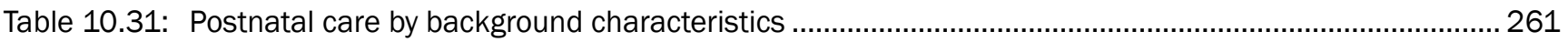

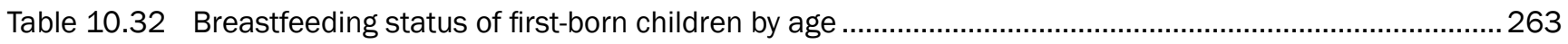

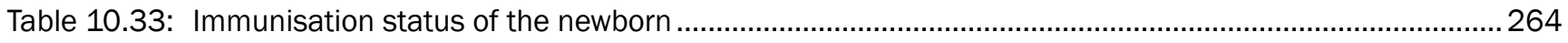

Table 10.34: Benefits received from schemes to promote maternal, newborn, and child health ............................2265

Chapter 11 Health and health-seeking behaviour

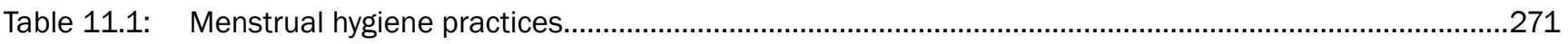

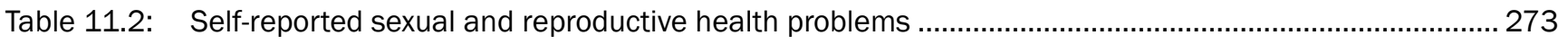

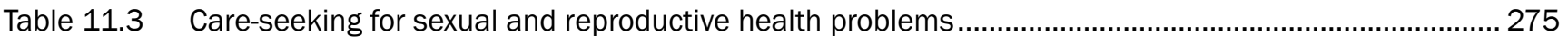

Table 11.4: Prevalence of depression-related symptoms ................................................................................... 277

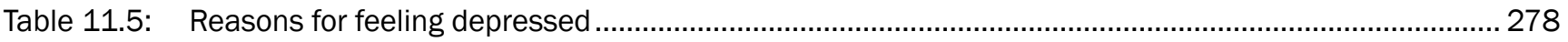

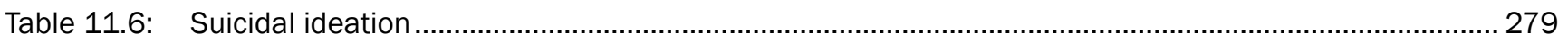

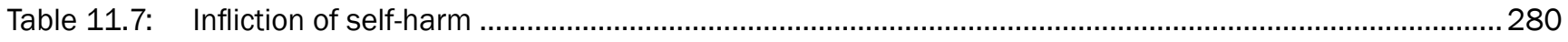




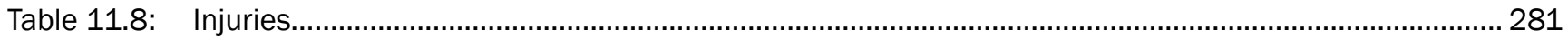

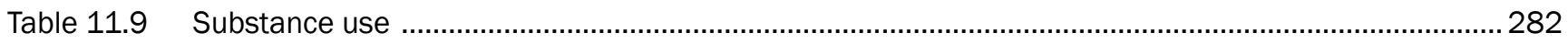

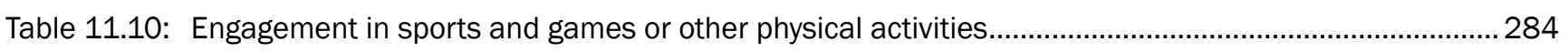

Table 11.11: Hesitation to access contraceptive supplies .......................................................................................... 285

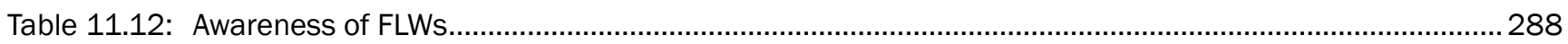

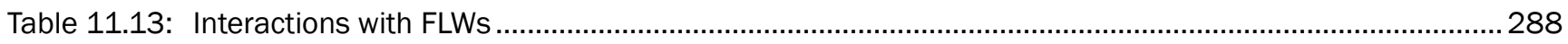

Table 11.14: Interactions with FLWs by selected background characteristics .........................................................289

Table 11.15: Health-related information or services received from an ASHA ........................................................... 291

Table 11.16: Health-related information and services received from an anganwadi worker ...................................293

\section{Chapter 12 Dietary habits and nutrition situation}

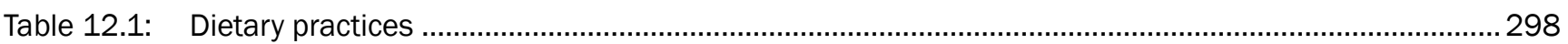

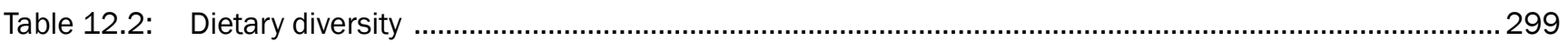

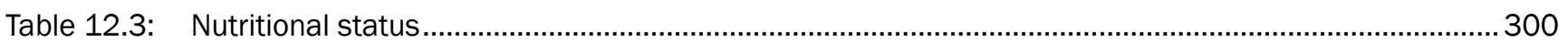

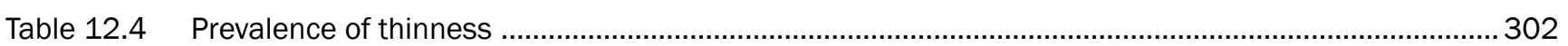

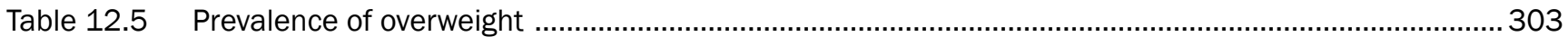

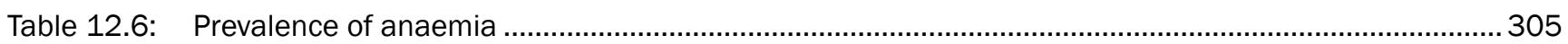

Table 12.7: Prevalence of moderate to severe anaemia ............................................................................ 306

Table 12.8: $\quad$ Awareness and receipt of weekly iron and folic acid supplementation (WIFS) programme ..................308

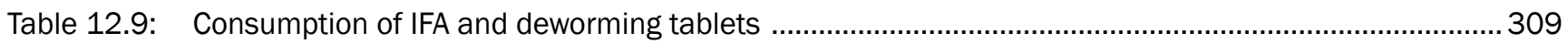

Table 12.10: Health check-up to assess nutritional status and provision of nutritional supplementation ................ 310

\section{Chapter 13 Community life}

Table 13.1: Perceptions about political matters and participation in political processes ..................................... 316

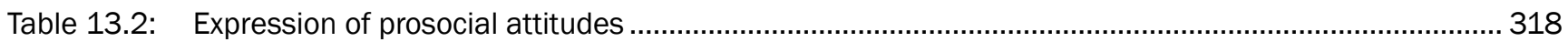

Table 13.3: Expression of prosocial attitudes by background characteristics........................................................ 320

Table 13.4: Acceptance of violence as a means of conflict resolution.................................................................... 322

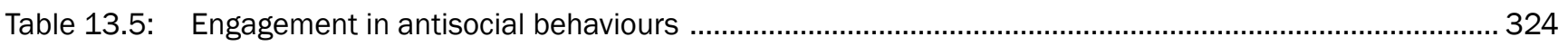

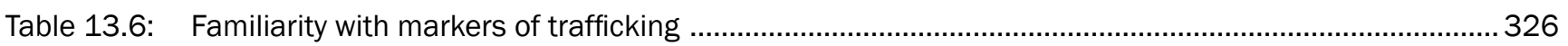




\section{List of Figures}

Figure 3.1: Percentage of adolescents who had achieved selected educational milestones, according to residence, Bihar, 2016

Figure 3.2: Percentage of adolescents in ages 15-19 who were in school at ages 10,12, and 15,1 according to residence, Bihar, 2016

Figure 3.3a: Cumulative percentage of adolescents in ages 15-19 who had completed

each year of education (Classes 1-13), combined, Bihar, 2016

Figure 3.3b: Cumulative percentage of adolescents in ages 15-19 who had completed each year of education (Classes 1-13), urban, Bihar, 2016

Figure 3.3c: Cumulative percentage of adolescents in ages 15-19 who had completed each year of education (Classes 1-13), rural, Bihar, 2016

Figure 3.4: Percentage of adolescents who were ever enrolled in school1 by type of educational facility in which they were enrolled at the time of the interview or at the time of discontinuing their education, according to residence, Bihar, 2016

Figure 3.5: Percentage of adolescents who reported availability of all four amenities in the school 1 in which they were enrolled at the time of the interview or at the time of discontinuing their education by current schooling status and type of school, Bihar, 2016.

Figure 3.6: Percentage of unmarried adolescents who were enrolled in school/college1 at the time of the interview reporting that they attended school regularly by type of school in which they were enrolled, Bihar, 2016.

Figure 3.7: Percentage of adolescents who could read a Class 2 text fluently in Hindi and solve a simple division problem, according to residence, Bihar, 2016 68

Figure 4.1a: Activity status among adolescent boys in ages 15-19, by age, Bihar, 2016. 87

Figure 4.1b: Activity status among unmarried girls in ages 15-19, by age, Bihar, 2016 . .87

Figure 4.1c: Activity status among married girls in ages 15-19, by age, Bihar, 2016.

Figure 5.1: Percentage of adolescents who owned or who could access a family member's mobile phone, according to residence, Bihar, 2016

Figure 5.2 Percentage of adolescents who were exposed to pornographic materials by way of films or the internet, according to residence, Bihar, 2016

Figure 6.1: Percent distribution of adolescents with at least one friend by the frequency of interacting with their friends, Bihar, 2016.

Figure 6.2: Percentage of unmarried adolescents in co-residence with opposite-sex siblings who are up to three years younger or older reporting experience of gender discriminatory practices at home, according to residence, Bihar, 2016

Figure 6.3: Percentage of adolescents who reported having a role model, according to residence, Bihar, 2016..

Figure 8.1: Percentage of adolescents in ages 15-19 reporting awareness of selected sex- and pregnancy-related matters, according to residence, Bihar, 2016

Figure 8.2: Percentage of adolescents in ages 15-19 who reported correct specific knowledge of selected modern contraceptive methods, according to residence, Bihar, 2016

Figure 8.3a: Percentage of adolescents in ages 15-19 reporting comprehensive awareness of HIV/AIDS by educational level, Bihar, 2016

Figure 8.3b: Percentage of adolescents in ages 15-19 reporting comprehensive awareness of HIV/AIDS by wealth quintile, Bihar, 2016 
Figure 8.4: Percentage of adolescents in ages 15-19 by awareness of HIV/AIDS, comprehensive knowledge about HIV/AIDS, and awareness of STIs, Bihar, 2016

Figure 8.5: Percentage of adolescents in ages 13-19 who had received family life or sex education, according to residence, Bihar, 2016.

Figure 8.6: Percentage of adolescents in ages 15-19 reporting knowledge of selected sexual and reproductive matters according to whether they had or had not received family life or sex education, Bihar, 2016

Figure 9.1: Percentage of adolescents in ages 15-19 reporting a premarital romantic relationship by experiences of physical intimacy and sex with their romantic partner, according to residence, Bihar, 2016

Figure 9.2: Percentage of adolescents in ages 15-19 reporting any premarital sexual experiences (in face-to-face interview or anonymous format), according to residence, Bihar, 2016.

Figure 9.3: Premarital sexual risk behaviours of older adolescents

Figure 10.1: Percentage of adolescents in ages 10-19 reporting that their parents had sought their opinion about marriage age, according to residence, Bihar, 2016.

Figure 10.2: Percentage of married girls in ages 15-19 reporting ever experience of emotional, physical, and sexual violence perpetrated by their husband, according to residence, Bihar, 2016

Figure 10.3: Percent distribution of married girls in ages 15-19 who had cohabited for at least two years by length of interval between cohabitation and first birth, according to residence, Bihar, 2016

Figure 10.4: Percentage of married girls in ages 15-19 reporting breastfeeding practices for their first child, according to residence, Bihar, 2016

Figure 11.1: Percentage of adolescents reporting that they had inflicted acts of self-harm in the 12 months preceding the interview, according to residence, Bihar, 2016 280

Figure 11.2: Percentage of adolescents who reported awareness of a peer education programme, according to residence, Bihar, 2016

Figure 11.3: Percentage of adolescents enrolled in school/college at the time of the interview reporting health-related information or services at school in the year preceding the interview, according to residence, Bihar, 2016

Figure 11.4: Awareness and reach of sanitary napkin distribution scheme among girls who had begun menstruating, according to residence, Bihar, 2016.

Figure 11.5: Awareness of and attendance at village health and nutrition days, rural Bihar, 2016 294

Figure 13.1: Percentage of adolescents who condoned violence to resolve conflicts in selected situations, according to residence, Bihar, 2016 


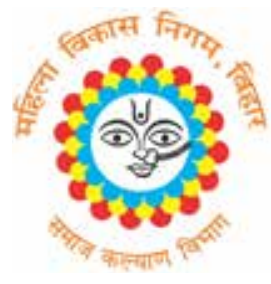

Women Development Corporation, Bihar

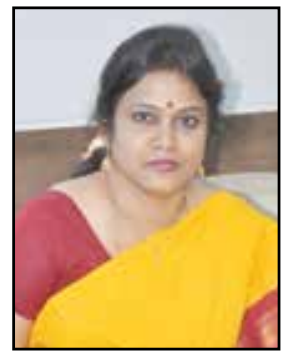

(Department of Social Welfare), Government of Bihar

2nd Floor, Indira Bhawan, R. C. Singh Path, Bailey Road, Patna - 800001 (Bihar)

Adolescence represents a unique phase in the life of a person; no longer children, not yet adults, this phase marks a passage from childhood to adulthood. It is a well-known fact that the future depends on the investments we make today in this population, in ensuring that they are healthy, well educated, skilled and prepared for future challenges.

The Government is committed to the overall development and well-being of adolescents' which is evident in the numerous policies and programmes that address the needs of adolescents or place adolescents at the centre. The National Youth Policy 2014, the National Health Policy 2017, the Right of Children to Free and Compulsory Education Act, 2009, the draft National Educational Policy 2016, the National Policy on Skill Development and Entrepreneurship have all recognized the importance of the young. The Sarva Shiksha Abhiyan, the Rashtriya Madhyamik Shiksha Abhiyan, the Rashtriya Kishor Swasthya Karyakram, the National Skill Development Mission, the Kishori Shakti Yojana, the SABLA programme and the Nehru Yuva Kendra Sangathan are but some examples of the emphasis we place on adolescent well-being.

The Government of Bihar has also emphasised the well-being of adolescents as a key priority. The Government has declared a state-wide campaign against child marriage and dowry. Many schemes have been launched, the best known of which is the bicycle scheme, in which the Government of Bihar provides secondary school-going adolescent girls with bicycles, an entitlement intended to remove transportation barriers for schooling and to reduce school drop-out rates. Recently, Women Development Corporation, Department of Social Welfare, has taken an initiative to set up an Adolescent cell with support from UNICEF to facilitate comprehensive and integrated delivery of programmes to meet the needs of adolescents in the state.

While the state has launched and implemented these programmes for adolescents, it has been difficult to assess in detail the reach and effects of these programmes, and the specific needs of different groups of adolescents. In this context, Understanding the lives of adolescents and young adults (UDAYA) is an ambitious project aimed at filling this gap and providing this evidence. Under project UDAYA, a survey was conducted in the entire state of Bihar of over 10,000 adolescents. It provides information on boys and girls from both rural and urban areas of the state, as well as on both younger (ages 10-14) and older (ages 15-19) adolescents, boys and girls, and among girls aged 15-19, those married and unmarried.

The report provides a wealth of information - much for the first time - on every dimension of adolescent life: education, skilling and work force participation, family life; child marriage, health and child-bearing. It provides evidence on the magnitude and patterns of sexual and reproductive behaviours in and outside of marriage, and it discusses the extent to which adolescents are aware of health-promoting practices, and their own entitlements to health, education, skilling and other services. Importantly, it brings out differences between various groups of adolescents in our state, highlighting the disadvantages faced by girls as compared with boys, socially disadvantaged castes and tribes as compared with others, and of course, the poor as compared to the better off. Findings provide important indicators against which the impact of programmes may be measured, and will go a long way in guiding policy, programmes and schemes intended to fill the unmet needs of adolescents in Bihar. Much needed are regular surveys of this nature that will inform the government about the changing needs of the young, and the impact of its programmes on adolescent wellbeing.

Insights provided will be valuable for policy makers, programme implementers, rights advocates and researchers alike who are committed to addressing the needs of this population in transition to adulthood. This is a valuable report and I express my appreciation to the Population Council for undertaking this ambitious state-wide project.

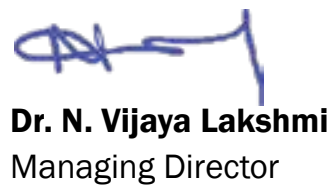





\section{Acknowledgements}

'Understanding the lives of adolescents and young adults (UDAYA) in Bihar and Uttar Pradesh', the programme of research by the Population Council has benefitted immeasurably from the contributions of many. We are grateful to the Ministry of Health and Family Welfare, Government of India, for supporting this study from its inception and take this opportunity to express our gratitude to Smt. Vandana Gurnani, Joint Secretary, Maternal Health Division, Ministry of Health and Family Welfare; Dr. Rakesh Kumar, former Joint Secretary, Ministry of Health and Family Welfare; and Dr. Sushma Dureja, Deputy Commissioner, (Adolescent Health), Ministry of Health and Family Welfare for their support throughout the project. We would also like to acknowledge the significant contribution of Dr. Sushma Dureja as a representative of the Ministry of Health and Family Welfare in our Technical Advisory Group.

In preparing for this study, we sought insights from representatives of many departments of the Government of Bihar - Dr.Y.N. Pathak, State Programme Officer, Adolescent Programme, Department of Health and Family Welfare;Dr. Neelam Gupta, former Managing Director, Women Development Corporation; Dr. N. Vijaya Lakshmi, Managing Director, Women Development Corporation; Mr. C. Sridhar, State Project Director, Bihar Education Council, Department of Education; Mr. Pankaj Dixit, Bihar Skill Development Mission, Department of Labour and Employment; and Mr. Arvind Thakur, former Director, Student, Youth and Welfare, Department of Youth Art and Culture. We are grateful to the representatives of these departments for sharing with us their perspectives on the kinds of issues that we needed to address.

The Department of Health and Family Welfare offered us, in addition, their unstinting support at all stages of the project, and we are grateful to Mr. Brijesh Mehrotra, former Principal Secretary, Department of Health and Family Welfare, Mr. Jitendra Srivastava, former Mission Director, National Health Mission, Bihar Health Society, and many other individuals in the state who encouraged our work and provided us guidance in the course of project implementation and the dissemination of key findings. The smooth functioning of fieldwork was due, in large part, to the support of the state health department, and we would like to acknowledge the contribution of all, including staff at the district headquarters level and primary health centre level.

The study received generous financial and technical support from the Bill and Melinda Gates Foundation and the David and Lucile Packard Foundation; we are grateful for their financial support as well as for useful comments and suggestions provided by Diva Dhar, Katherine Hay, and Priya Nanda of the Gates Foundation, and Lana Dakan, Anand Sinha, Aarushi Khanna of the Packard Foundation, and Anupam Shukla (formerly with the Packard Foundation) over the course of the project. We are also grateful to Lester Coutinho of the Gates Foundation (and formerly with the Packard Foundation) who played a key role in supporting us in pursuing the idea of UDAYA; and to both the Packard Foundation and the John D. and Catherine T. MacArthur Foundation for their support to the Youth in India: Situation and Needs Study on which UDAYA made maximal use.

We are grateful to our Technical Advisory Group (TAG) members for their guidance, which ensured that our study did indeed address all the key issues that require policy and programme attention. We appreciate their contribution during meetings of the TAG and in various one-on-one discussions during the course of the project. We are also grateful to them for providing peer-review of the study report. We were privileged that individuals with a wide range of expertise, from youth health and development to survey and qualitative approaches and ethics in research, agreed to serve as technical committee members. Our technical advisory group-Sushma Dureja, Shireen Jejeebhoy, Manak Matiyani, Vikram Patel, Vinod K Paul, T. K. Roy, A. K. Shiva Kumar, Venkatesh Srinivasan, Ravi Verma, Sheila C. Vir, and Wilima Wadhwa-supported the project from conceptualisation to completion. Their guidance at various stages of the study was central in enabling us to confront methodological, ethical and analytical challenges that arose over the course of the study, and is gratefully acknowledged. We would like to record our deep appreciation, moreover, to T. K. Roy for giving us so generously of his time in finalizing the sampling design for the study. We would also like to acknowledge our TAG members as well as Sulabha Parasuraman and Prachi Khandeparkar who provided peer review of an earlier draft of this report.

Given that our study probed a number of highly sensitive matters, including adolescents' sexual and reproductive behaviours and mental health situation, it was an ethical imperative that those in need of information or services would be provided appropriate materials and referrals, respectively. We are grateful to those who provided services to our respondents in need. Specifically, we would like to acknowledge the services provided by the public health 
facilities of the state of Bihar when our respondents visited the facilities for referral services and to Vandrevala Foundation for services they provided through their helpline to our respondents who wished to receive counseling for mental health concerns.

The Office of the Registrar General, New Delhi, and the State Census Offices in each state generously provided the project with information and maps pertaining to the 2011 Census. Their role in enabling the study to implement its sample design is gratefully acknowledged.

Our special thanks go to Shireen Jejeebhoy who was responsible for conceptualising and developing the project. She led the project activities in the early days of the project and continued to provide technical support to the team as a member of the Technical Advisory Group and a peer reviewer of the report. We are deeply indebted to her for so generously sharing her ideas and time and for her guidance throughout the project.

At the Population Council, several colleagues have supported us in both the technical and administrative aspects of this study and we acknowledge their huge contribution in making this study possible. We are grateful to M.A. Jose for ably managing the administrative aspects, including the fieldwork of the project; Komal Saxena for her editorial contributions, for coordinating the printing of the report and for her eye for perfection and her commitment to ensuring that the report was printed in a timely way; and Sapna Desai for reviewing the report. We would like to express our appreciation to Avina Sarna and Niranjan Saggurti, former and current Country Directors, respectively, Population Council, who supported the project on behalf of the Population Council. We would like to thank Annu Kurien, our technical editor for her editorial contributions which have made the report more readable and accurate. We also appreciate the efforts of KG Venkateswaran and his team at Auriga Consultancy and Management Services and Sashwat Dash and his team at Mensa Design Private Limited who worked around the clock, made several rounds of revisions, and delivered the report to us in a timely manner.

We acknowledge with thanks the contribution of our teams of young and enthusiastic interviewers-about 100 in allin eliciting information on difficult topics with sensitivity and skill. They were required to overcome discomfort when asking about intimate experiences and to record many disturbing experiences narrated by adolescents, which they did professionally and empathetically. It was due to their skill and ability to engage with adolescents in non-judgmental ways that this study was so well received by study participants.

We would also like to record our appreciation of the support and kindness of the people in the villages and urban neighbourhoods in which we conducted our study, and specifically the panchayat members and community leaders. While initially sceptical about the study, community members opened their homes to us and acknowledged the importance of this study for the health and development of future generations. Indeed, despite the sensitive issues covered, not a single study community refused our field teams entry. The trust and support of the people are gratefully acknowledged. Finally, and most importantly, we would like to thank the adolescents who welcomed us, generously gave their time and shared so many intimate details of their lives with us. We hope that the evidence generated in this report will be useful in influencing the design and content of programmes intended to meet their multiple needs and enable them to make a safe transition to adulthood.

K G Santhya

Rajib Acharya

Neelanjana Pandey

Santosh Kumar Singh

Shilpi Rampal

A J Francis Zavier

Ashish Kumar Gupta 


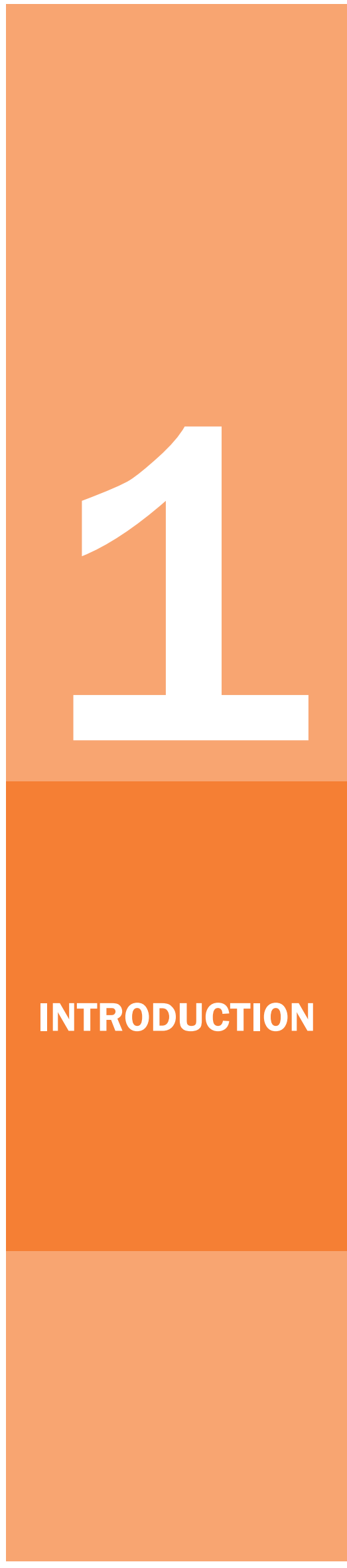




\subsection{Rationale}

Today, about 253 million people in India-one-fifth of the country's population-are adolescents, that is, those in the ages 10-19 years (Office of the Registrar General and Census Commissioner, India,2015a). Globally, every fifth adolescent lives in India (United Nations, 2015a). India has articulated its commitment to protect and promote the health and rights of adolescents and meet their development needs through the formulation of numerous policies and programmes, which are being implemented over the course of this century particularly. The National Population Policy, 2000, the National Youth Policy, 2014, the Sarva Shiksha Abhiyan, the Rashtriya Madhyamik Shiksha Abhiyan, the National Skill Development Mission, the SABLA scheme, and the Rashtriya Kishor Swasthya Karyakram (RKSK) are notable examples of the country's commitment to address the health and development needs of adolescents.

Despite these commitments, a recent synthesis of evidence on the health and development situation of adolescents and youth in India observes that Indian adolescents and youth are, for the most part, unprepared to meet the needs of a globalising world. Few complete high school, considerable numbers receive poor quality education, and many lack livelihood skills and employment opportunities. In addition, the health of many is compromised and gender gaps and gaps between the socio-economically disadvantaged and advantaged persist among adolescents (Santhya and Jejeebhoy, 2014). It further notes that while the demographic dividend will accrue naturally to some extent because of changes in the age structure and the dependency burden, India will not be able to reap the full impact of this demographic opportunity without an educated and a productive, skilled, and healthy youth population. Therefore, there is clearly a need for a commitment to ensure that guidelines in policies are translated into reality for adolescents, that programmes do indeed reach adolescents, that the scope and content of the programmes are expanded, and that promising lessons are assimilated and scaled-up.

According to The State of the World's Children 2011, the Lancet Commission on Adolescent Health and Wellbeing, 2016, and The State of the World Population 2016, major gaps in data on adolescents pose one of the biggest challenges in promoting their rights. These reports argue for a deeper level of disaggregation of data on adolescents and causal analyses of their experiences, which can serve as a foundation for programmes and policies and as a measure to monitor progress (UNICEF, 2011; Pattonet al., 2016; UNFPA, 2016). In India, too, the absence of longitudinal data that are essential to understand the factors that determine rather than those that are associated with healthy transitions from childhood to adolescence and adulthood and successive cross-sectional data that are important to establish the levels of key markers of these transitions at various points in time have thwarted the designing of optimal programmes as well as rigorous assessment of the reach and effectiveness of on-going programmes.

While the Youth in India: Situation and Needs study and the various rounds of the National Family Health Survey (NFHS) do provide important insights on adolescents, there are major gaps in data that need to be addressed. These surveys, for example, have used a cross-sectional design, and the ability of cross-sectional data to provide evidence on causal relationships is limited (National Research Council [NRC] and Institute of Medicine [IOM], 2005). Moreover, although there have been a number of recently launched public sector programmes that focus specifically on adolescents and youth or include them in the target audience, evidence on the reach of these programmes and the extent to which access to them has affected the well-being of adolescents is sparse. Finally, although it is increasingly recognised that investments in adolescents should start in early adolescence (that is, at ages 10-14), neither the NFHS nor the Youth Study had gathered data on young adolescents.

In short, both longitudinal data and successive cross-sectional data are urgently needed to understand adolescents' transition to adulthood. A longitudinal data-gathering exercise among adolescents would go a long way in enabling an assessment of factors, both social and programmatic, that influence the quality of later life. At the same time, successive cross-sectional data are important to establish the levels of key markers of transitions to adulthood experienced by adolescents at various points in time and to assess the extent to which their situation of has changed over time, presumably because of increased investments in them. 


\subsection{Study objectives}

The goal of the programme of research titled 'Understanding the lives of adolescents and young adults (UDAYA) in

Bihar and Uttar Pradesh' is to establish the levels, patterns, and trends in the situation of younger (10-14) and older $(15-19)$ adolescents and to assess factors that influence the quality of transitions they make. The specific objectives of UDAYA are to:

- explore the situation of adolescents, with a focus on assessing the extent to which both younger and older adolescents have acquired a set of assets that can help them make a healthy, safe, and successful transition from adolescence to young adulthood in the states of Bihar and Uttar Pradesh;

- describe the extent to which the situation of adolescents has changed over time; and

- assess factors that determine the accumulation or loss of assets and the quality of transitions from adolescence to young adulthood.

The study is designed to provide robust insights on how investments in adolescents influence their life course by the time they reach young adulthood;enable evidence-based decisions on the types of programmes worthy of scale-up; and furnish important baseline indicators against which the long-term impact of programmes can be measured.

The study uses both cross-sectional and longitudinal designs. The cross-sectional component entails interviewing independent samples of unmarried boys in ages 10-14 and 15-19 (hereafter referred to as younger and older boys, respectively), unmarried girls in ages 10-14 and 15-19 (hereafter referred to as younger girls and unmarried older girls, respectively), and married girls in ages 15-19 (hereafter referred to as married older girls) in both rural and urban settings in Bihar and Uttar Pradesh at two points in time. The first round of cross-sectional surveys was conducted in 2015-16 and the second round will be conducted in 2018-19. The longitudinal component comprises: (1) re-interviewing in 2015-16 the sample of unmarried girls and boys and married girls in ages 15-19 who were first interviewed in 2007 as part of the Youth Study and were at the time of the re-interview in ages 23-27 in Bihar; and (2) re-interviewing in 2018-19 the sample of adolescents who were interviewed for the first time in 2015-16 in Bihar and Uttar Pradesh.

This report focuses on the findings from the first round of cross-sectional surveys of adolescents conducted during January-July 2016 in Bihar.

The Bill and Melinda Gates Foundation and the David and Lucile Packard Foundation provided the funding for UDAYA, and the Population Council, New Delhi, conducted the study. The design and implementation of this study were guided by the Technical Advisory Committee, headed by the Joint Secretary, Ministry of Health and Family Welfare (MOHFW), Government of India.

\subsection{Theoretical framework}

The design and content of UDAYA are guided by a theoretical framework that draws on the transitions to adulthood framework (National Research Council [NRC] and Institute of Medicine [IOM], 2005) and the asset-building framework (Sebstad and Bruce, 2004; Bruce, Temin, and Hallman, 2012). Following the NRC and IOM framework on the transitions to adulthood, this study aims to measure the quality of transitions to young adulthood experienced by adolescents with respect to five critical facets of their life (see Block D in Figure 1.1). These include: (1) work roles-non-experience of child labour (that is, non-engagement in economic activities before the age of 15 years) and, for those engaged in work, engagement in paid full-time employment, that is, for the most part of the year, and employment in skilled rather than unskilled occupations; (2) entry into sexual life-safe and consensual entry into sexual life before marriage for those initiating sexual relations prior to marriage; (3) marriage-marriage delayed till at least the legal minimum age (18 years for girls and 21 years for boys), with full participation in marriage-related decisions, including decisions about when and whom to marry and the quality of the marital relationship defined with respect to spousal communication and violence-free relationships; (4) parenthood-childbearing delayed till after adolescence (after age 19), adoption of contraception before first pregnancy (among those who want to delay their first pregnancy) and immediately after first birth, and adoption of healthy practices during pregnancy, delivery, and the post-partum period for the first birth to ensure the health of the mother and the newborn; and (5) citizenship- 
exercise of voting rights, participation in community-led activities, and non-involvement in community-level violence. We noted that the exercise of informed choice and the realisation of aspirations cut across all of the above-mentioned facets of successful transitions to adulthood.

The assets acquired in adolescence influence considerably the nature of these transitions. They can prepare adolescents for meeting day-to-day needs, dealing with life cycle events, coping with emergencies, crises, and unexpected events, and taking advantage of opportunities that come their way. In other words, they help reduce adolescents' vulnerabilities and expand their opportunities. Drawing on the asset-building framework (Sebstad and Bruce, 2004; Bruce,Temin, and Hallman, 2012), this study categorises assets into human, social, financial, and physical assets (see Block $C$ in Figure 1.1). Human assets include skills (such as, completion of age-appropriate grades, literacy and numeracy skills, and acquisition of vocational skills); knowledge (such as, knowledge of health-promoting actions, including in areas of nutrition, sanitation, sexual and reproductive matters, adolescent entitlements, and programmes and schemes relevant to adolescents); agency (such as, decision-making autonomy, mobility, and self-efficacy); attitudes and beliefs (such as, adherence to gender-egalitarian norms, secular attitudes, and healthy perceptions about political processes); and health (such as, nutritional status, general health status, mental health status, and healthy lifestyles, including physical activity and non-abuse of substances). Social assets focus on relationships and social networks and comprise the availability of/access to friends, mentors, and other trusted relationships and group memberships. Financial assets include access to cash, savings, and financial literacy. Physical assets are more tangible than social or human assets and include personal items, access to safe social spaces, and access to various tools that often have or produce monetary value.

Parental factors, the media, and community-level factors play a crucial role in providing adolescents the supportive environment necessary for the acquisition of assets and healthy, safe, and successful transitions to young adulthood (Block B, Figure 1.1). Parental-level factors include, notably, the extent of parental control over adolescents, extent of parental support, the depth of communication between parents and adolescents, violence-both witnessed and experienced-within the family, and family economic status. The influence of the media is manifested through exposure of adolescents to the mass media and their exposure to information and communication technologies, including social media and mobile phones. Other characteristics of the immediate environment of adolescents that influence their transition to adulthood include their access to: the health system, including both health facilities and skilled healthcare providers; economic resources, including employment opportunities; educational resources, including access to quality primary and secondary schools; entitlements; and a safe,that is, non-threatening community environment.

Finally, the environment for adolescents and youth at the state and national level is reflected in policies, programmes, implemented by various government departments as well as those sponsored by bilateral and multilateral donors, private foundations, and non-governmental organisations (NGOs), budgetary allocations for such programmes, and enforcement of laws relevant to adolescents. These legal, policy, and programme efforts are intended to contribute to the comprehensive development of adolescents and youth (Block A, Figure 1.1). We observed that programmes of relevance to adolescents in the state fall into four thematic areas: (1) education programmes, including the Sarva Shiksha Abhiyan and the Rashtriya Madhyamik Shiksha Abhiyan, and educational incentive schemes, including scholarships and non-monetary incentives such as free textbooks, uniforms, bicycles, and laptops; (2) livelihoods and economic empowerment programmes, including the National Skill Development Initiative; (3) empowerment programmes, including SABLA/Kishori Shakti Yojana, programmes under the Nehru Yuva Kendra Sangathan (NYKS), and the Adolescence Education Programme; and (4) health programmes, including activities promoted through the newly launched Rashtriya Kishor Swasthya Karykram (RKSK) and its predecessor, the National Adolescent Reproductive and Sexual Health Strategy.

As will be seen in subsequent chapters, our study sought to gather insights on the facets of transitions to adulthood as well as on assets and the family, media, and community environment that influence these transitions. 

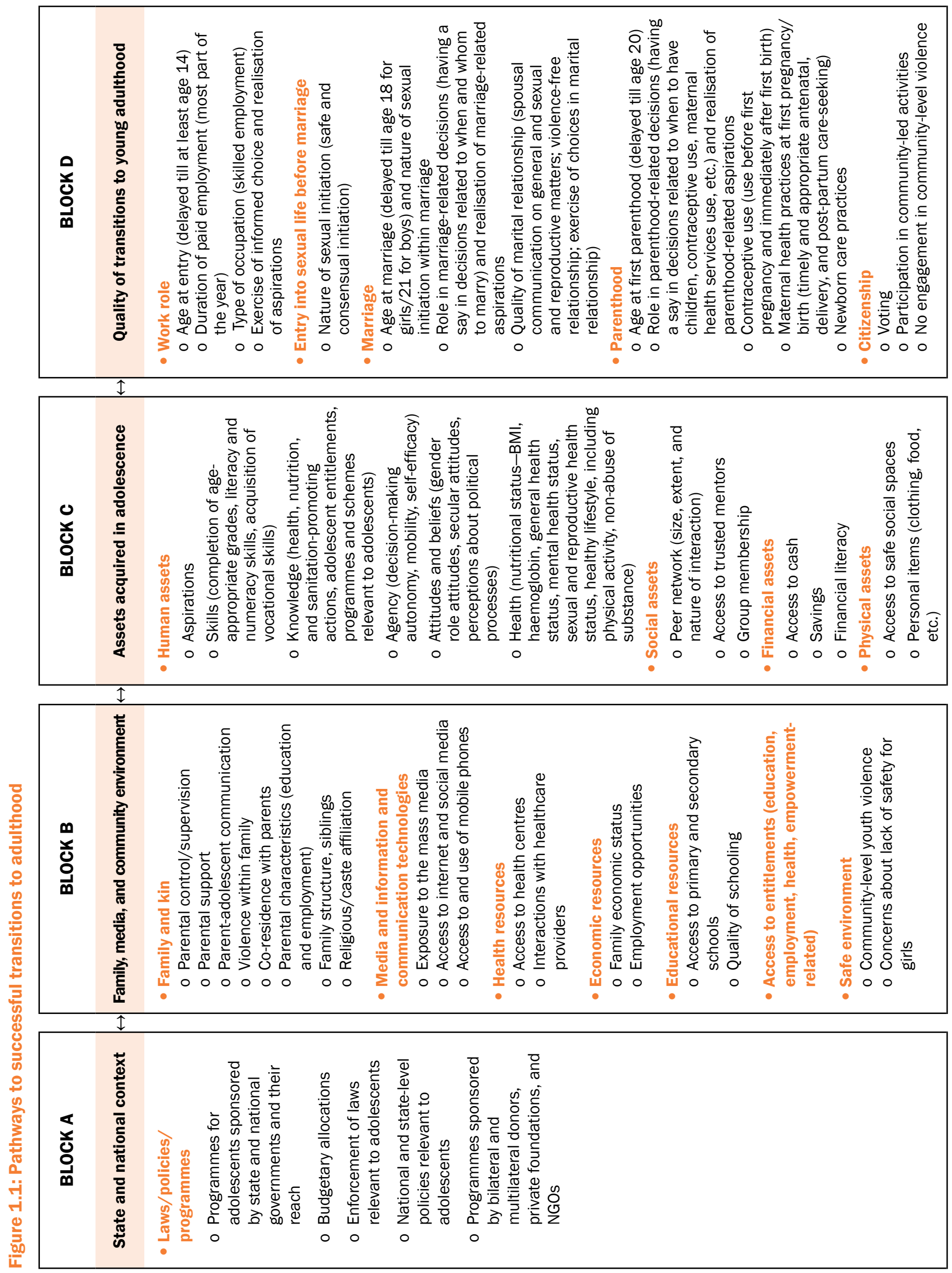


\subsection{Bihar: Overview of demographic and socio-economic features}

Bihar is India's twelfth largest state in land area, covering a total of 94,163 square kilometres; it contains 38 districts divided into two geographic regions, namely, North Bihar Plain and South Bihar Plain (Government of Bihar, n.d.). While Bihar is India's twelfth largest state in land area, it is the state with the third largest population in the country. In 2011, it had a population of 104.1 million, which accounted for nine percent of India's population (Office of the Registrar General and Census Commissioner, India, 2013). The sex ratio in Bihar (918 females per 1,000 males) is lower than that for India as a whole (943). Population density in the state was 1,106 persons per square kilometre in 2011 (Office of the Registrar General and Census Commissioner, India, 2013). The distribution of the population by religion indicates that 83 percent of the state's population were Hindu and 17 percent were Muslim (Office of the Registrar General and Census Commissioner, India, 2015b). Scheduled castes and scheduled tribes constituted 16 percent and one percent, respectively, of the state's total population (Office of the Registrar General and Census Commissioner, India, 2013).

The state is characterised by a large rural population; just 11 percent of the state's population resided in urban areas in 2011. It has witnessed large-scale migration both within the state and to other states. According to the 2011 census, the total number of migrants was 29 million by place of last residence. ${ }^{1}$ Bihar accounted for six percent of the total number of migrants in India (Office of the Registrar General and Census Commissioner, India, 2015c).

Economically, Bihar displays a mixed picture. With a Gross State Domestic Product (GSDP) of Rs 343,054 at current prices in 2013-14, it ranked eleventh among the states of India in GSDP and accounted for three percent of the national GDP (Planning Commission, 2014). However, at constant prices (2004-05), the GSDP growth, at about 10-11 percent annually, has somewhat stagnated in the recent past. Moreover, its per capita income of Rs 31,199 in 2013-14 was the lowest among all the states and union territories in India and well below the national average of Rs 74,380 (Ministry of Statistics and Programme Implementation, 2015). Furthermore, 34 percent of its population was estimated to be living below the poverty line in 2011-12, with mild differences between those residing in urban (31\%) and those residing in rural (34\%) areas (Planning Commission, 2014). Unemployment rates were relatively low; in 2011-12, three percent of males and eight percent of females in rural areas and 4.5 percent of males and 16.5 percent of females in urban areas were unemployed for a major part of the year, as measured by the usual principal status (adjusted) definition (National Sample Survey Organization, 2014).

Bihar lags behind the rest of India on many social indicators. The literacy rate (62\%), for example, was lower than that of the national average $(73 \%)$ and differences by sex with regard to literacy were considerable (literacy rate of $71 \%$ for males versus 52\% for females) (Office of the Registrar General and Census Commissioner, India, 2013).

The state's performance in the health sector is also poor. While life expectancy among males was almost two years higher in Bihar than that for India as a whole-67.8 and 66.4 years, respectively, during 2010-14, life expectancy among females was almost two years lower in the state than that for India as a whole-68.4 and 69.6 years, respectively (Office of the Registrar General and Census Commissioner, India, 2016). With a maternal mortality ratio of 208 per 100,000 live births in 2011-13, the state recorded the sixth highest ratio among all the states in India (Office of the Registrar General and Census Commissioner, India, 2015d). The state's infant mortality rate (48 per 1,000 live births) is higher than the national average (41 per 1,000 live births) (International Institute for Population Sciences [IIPS], 2017a; 2017b). The fertility rate is also higher in Bihar than that for India on average. Indeed, the total fertility rate in the state (3.4) is the highest among all of the states of India and well above the national average (2.2) (IIPS, 2017a; 2017b). The current use of modern contraceptive methods was as low as 23 percent compared with 48 percent at the national level, while as many as 21 percent of currently married women in the ages 15-49 had reported an unmet need for contraception compared with 13 percent at the national level (IIPS, 2017a; 2017b).

$\overline{1}$ A person is considered a migrant by place of last residence, if she/he had last resided at a place other than her/his place of enumeration. 
Selected socio-demographic indicators for India and Bihar are presented in Table 1.1.

Table 1.1: Selected socio-demographic indicators, Bihar and India, 2010-16

\begin{tabular}{|c|c|c|}
\hline Socio-demographic Indicators & Bihar & India \\
\hline Population, 2011 (million) ${ }^{1}$ & 104.1 & 1,210.6 \\
\hline Adolescent (ages 10-19) population, $2011(\%)^{2}$ & 22.5 & 20.9 \\
\hline Sex ratio, 2011 (females per 1,000 males) ${ }^{1}$ & 918 & 943 \\
\hline Child sex ratio, 2011 (ages 0-6) ${ }^{1}$ & 935 & 919 \\
\hline Population belonging to Hindu religion, $2011(\%)^{3}$ & 82.7 & 79.8 \\
\hline Population belonging to Muslim religion, $2011(\%)^{3}$ & 16.9 & 14.2 \\
\hline Population belonging to scheduled castes, $2011(\%)^{1}$ & 15.9 & 16.6 \\
\hline Population belonging to scheduled tribes, $2011(\%)^{1}$ & 1.3 & 8.6 \\
\hline Urban population, $2011(\%)^{1}$ & 11.3 & 31.2 \\
\hline Population density, 2011 (persons per square kilometre) ${ }^{1}$ & 1,106 & 382 \\
\hline Population living below poverty line, $2011-12(\%)^{4}$ & 33.7 & 21.9 \\
\hline Male literacy rate, $2011(\%)^{1}$ & 71.2 & 80.9 \\
\hline Female literacy rate, $2011(\%)^{1}$ & 51.5 & 64.6 \\
\hline Male life expectancy, 2010-14 (years) ${ }^{5}$ & 67.8 & 66.4 \\
\hline Female life expectancy, 2010-14 (years) ${ }^{5}$ & 68.4 & 69.6 \\
\hline Infant mortality rate, $2015-16$ (per 1,000 live births) ${ }^{6,7}$ & 48 & 41 \\
\hline Total fertility rate, $2015-16$ (births per woman) ${ }^{6,7}$ & 3.4 & 2.2 \\
\hline Skilled attendance at birth, $2015-16(\%)^{6,7}$ & 70.0 & 81.4 \\
\hline Contraceptive prevalence rate (modern methods), $2015-16(\%)^{6,7}$ & 23.3 & 47.8 \\
\hline Unmet need for contraception, $2015-16(\%)^{6,7}$ & 21.2 & 12.9 \\
\hline
\end{tabular}

Notes: ${ }^{1}$ Office of the Registrar General of India and Census Commissioner, India, 2013. ${ }^{2}$ Office of the Registrar General of India and Census Commissioner, India, 2015a. ${ }^{3}$ Office of the Registrar General of India and Census Commissioner, India, 2015b. ${ }^{4}$ Planning Commission, 2014. ${ }^{5}$ Office of the Registrar General of India and Census Commissioner, India, 2016. ${ }^{6} I I P S, 2017 a .7 I P S, 2017 \mathrm{~b}$.

\subsection{Situation of adolescents in Bihar}

Adolescents, that is, those in ages 10-19, constitute a total of 23.4 million and account for 23 percent of the population of Bihar (Office of the Registrar General and Census Commissioner, India, 2015a).

Available evidence, summarised in Table 1.2, highlights that the situation of adolescents in Bihar is characterised by poor levels of educational attainment, with wide differences by sex in enrolment, high levels of unemployment, particularly among girls, considerable vulnerability in sexual and reproductive health matters, limited agency, particularly among adolescent girls, and limited access to health services.

Table 1.2: Selected socio-demographic characteristics of adolescents, Bihar, 2005-16

\begin{tabular}{lc}
\hline Socio-demographic Indicators & Bihar \\
\hline Adolescent (ages 10-19) population, 2011 (million) & 23.4 \\
Literacy rate among adolescent boys, $2011(\%)^{1}$ & 83.9 \\
Literacy rate among adolescent girls, $2011(\%)^{1}$ & 77.4 \\
Gross enrolment ratio among children (ages 6-10), 2011-12 ${ }^{2}$ & 99.0 \\
\hline
\end{tabular}


Table 1.2 Cont.

\begin{tabular}{|c|c|}
\hline Socio-demographic Indicators & Bihar \\
\hline Gross enrolment ratio among children (ages 11-13), 2011-12² & 65.2 \\
\hline Gross enrolment ratio among children (ages 14-15), 2011-12² & 48.4 \\
\hline Gender parity index (Classes 1-8), 2011-12² & 1.0 \\
\hline Gender parity index (Classes 9-10), 2011-12² & 0.9 \\
\hline Gender parity index (Classes 11-12), 2011-12² & 0.9 \\
\hline Unemployment rate among boys (ages $15-19$ ), rural, $2011-12^{3}$ & 19.5 \\
\hline Unemployment rate among boys (ages $15-19$ ), urban, $2011-12^{3}$ & 17.3 \\
\hline Unemployment rate among girls (ages $15-19)$, rural, $2011-12^{3}$ & 42.5 \\
\hline Unemployment rate among girls (ages 15-19), urban, 2011-123 & 100.0 \\
\hline Women (ages 20-24) married by age 18, 2015-16 (\%) & 39.1 \\
\hline Women (ages 15-19) who have begun childbearing, 2015-16 (\%) ${ }^{4}$ & 12.2 \\
\hline Married girls (ages 15-19) who participated in decisions regarding their own healthcare, $2005-06(\%)^{5}$ & 31.0 \\
\hline Married girls (ages 15-19) who had the freedom to visit a health facility on their own, 2005-06 (\%) & 13.0 \\
\hline Married girls (ages 15-19) who owned an account in a bank or post office, $2005-06(\%)^{5}$ & 2.8 \\
\hline Married girls (ages 15-19) who experienced physical or sexual violence within marriage, $2005-06(\%)^{5}$ & 44.4 \\
\hline Boys (ages 15-19) who had comprehensive knowledge of HIV/AIDS, 2005-06 (\%) ${ }^{5}$ & 24.3 \\
\hline Girls (ages 15-19) who had comprehensive knowledge of HIV/AIDS, 2005-06 (\%) & 12.8 \\
\hline Married girls (ages 15-19) who practised contraception, 2005-06 (\%) ${ }^{5}$ & 4.3 \\
\hline
\end{tabular}

Notes: ${ }^{1}$ Office of the Registrar General of India and Census Commissioner, India, 2015a. ${ }^{2}$ Ministry of Human Resource Development, 2014. ${ }^{3}$ National Sample Survey Organization, 2014. ${ }^{4}$ IIPS, 2017a. ${ }^{5}$ IIPS and Macro International, 2007.

The Bihar state government has articulated its commitment to promoting adolescent health and development in a number of state-level policies.

In the field of education, apart from centrally sponsored schemes such as Sarva Shiksha Abhiyan and the Rashtriya Madhyamik Shiksha Abhiyan, the state has initiated several schemes to encourage education such as the Mukhyamantri Balak and Balika Cycle Yojana, the Mukhyamantri Poshak Yojana, and the Mukhyamantri Protsahan Yojana. Under the Mukhyamantri Balak and Balika Cycle Yojana, boys and girls enrolled in Class 9 in government-run and government-aided schools are awarded a one-time amount of Rs 2,500 to buy a cycle in order to improve their access to secondary schools and reduce dropout rates (Department of Education, Government of Bihar, 2014a). Similarly, the Mukhyamantri Poshak Yojana provides Rs 1,000 per annum to boys and girls in Classes $6-8$ to buy school uniforms (Department of Education, Government of Bihar, 2014b). The Mukhyamantri Balika Protsahan Yojana for Girls' Higher Education was launched in order to provide financial assistance to meritorious girls, encourage them to pursue university education, and create an environment wherein girls are valued and considered equal to boys. Under this scheme, girls from all categories (that is, scheduled castes, scheduled tribes, general castes, etc.) who have passed Class 10 exams with a first division are provided Rs 10,000 to support their further studies. Several other scholarship schemes also are being implemented in the state (Department of Education, Government of Bihar, 2014c).

The state government has also expressed its commitment to skilling its adolescents and youth. In 2012, the state set up a target of skilling 10 million youth through skill development schemes managed by 15 government departments. In 2015, the state launched the Kushal Yuva Programme, which seeks to impart computer literacy, soft skills, and communication skills to 15-25-year-olds who have discontinued formal education after completing secondary or senior secondary education (Department of Labour Resources, Government of Bihar, n.d.). The Bihar Start-Up Policy 2016, likewise, seeks to introduce and promote entrepreneurship education among the youth (Department of Industries, Government of Bihar, 2016).

Efforts have also been made to roll out selected components of the Rashtriya Kishor Swasthya Karyakram. Initiatives such as the adolescent friendly clinics, known as YUVA clinics, are operational in district hospitals and all community 
health centres and primary health centres (PHCs) in 10 high priority districts. In other districts, they are operational in only district hospitals, and, as of now, some 180 YUVA clinics are operational in the state. Furthermore, 361 medical officers have been trained as master trainers and 441 auxiliary nurse midwives (ANMs) have been trained to serve as counsellors. The peer educator scheme has been introduced in 50 percent of the blocks in the state. In addition, the sanitary napkin distribution scheme is operational in 144 blocks of 10 districts in the state. The Weekly Iron and Folic Acid (WIFS) programme is designed to be implemented in both rural and urban areas, through government/ government-aided/municipal schools (for school going boys and girls in Classes 6-12) and through anganwadi centres (for out-of-school adolescent girls). The programme aims to cover approximately 20.4 million adolescents of Bihar. Similarly, the deworming programme covers children and adolescents (from ages 1-19 years) and is implemented in 24 districts through schools and anganwadi centres. Lastly, the Adolescent Education Programme (AEP) has been implemented in nine districts among adolescents who are in Class 9 or Class 11 and studying in government and government-aided schools (Personal communication with department official, Department of Health, Government of Bihar).

In order to empower girls and to address gender issues, several initiatives, both centrally sponsored and state sponsored, are underway in the state. The Kishori Balika Yojana, formerly known as SABLA, is being implemented in 12 districts, targeting out-of-school girls in ages 11-14 and school going and out-of-school girls in ages 14-18. The scheme contains a nutrition component and a non-nutrition component; the latter includes health check-ups, health education, life skills education, WIFS distributions, and vocational training to out-of-school girls in ages 16-18 (Directorate of Integrated Child Development Services, Government of Bihar, n.d.). The Mukhyamantri Kanya Suraksha Yojana (MMKSY), initiated in 2007-08, targets girls in ages 0-3 from below poverty line families (up to two girl children per family) across the state. The main objective of this scheme is to encourage birth registration within one year of birth, provide monetary support to families to discourage gender-biased sex selection, sex-selective abortion, and encourage families to delay the marriage of their daughters. An amount of Rs 2,000 is deposited in the name of the girl child on her birth, and the amount with interest is paid when the girl turns 18 years of age (Department of Social Welfare, Government of Bihar, 2008). The Mukhyamantri Kanya Vivah Yojana provides financial assistance to girls when they get married as a measure to encourage marriage registration, to prevent child marriage, and to prevent domestic violence. Under the scheme (focused on families with an annual income of less than Rs 60,000) an amount of Rs 5,000 is provided to girls at the time of their marriage; the amount (either in the form of a cheque or demand draft) is deposited in the name of the girl only (Department of Social Welfare, Government of Bihar, n.d.).

\subsection{Study design and sample size estimation for individual interviews}

UDAYA was designed to provide estimates for the state as a whole as well as for the urban and rural areas of the state for each of the five categories of respondents, namely younger boys in ages 10-14, older boys in ages 15-19, younger girls in ages 10-14, unmarried older girls in ages 15-19, and married older girls in ages 15-19. The study was not designed to provide estimates at district or sub-district levels. The required sample for each sub-group of adolescents was determined at 920 younger boys, 2,350 older boys, 630 younger girls, 3,750 unmarried older girls, and 2,700 married older girls in the state. The corresponding sample size for biomarkers for each sub-group was fixed at 920, 920,630,600, and 600, respectively; in other words, biomarkers were to be collected from all younger adolescents and a sub-sample of older adolescents. In order to achieve the above-mentioned number of individual interviews with unmarried adolescents, we needed to cover approximately 36,000 households in the state. We further determined that a total of 150 primary sampling units (PSUs)-villages in rural areas and census wards in urban areas-would have to be visited in the state in order to conduct interviews in the required number of households.

The study treated rural and urban areas of the state as independent sampling domains and, therefore, drew sample areas independently for each of these two domains. The 150 PSUs were further divided equally into rural and urban areas, that is, 75 for rural respondents and 75 for urban respondents. Within each sampling domain, we adopted a multi-stage systematic sampling design. The 2011 census list of villages and wards (each consisting of several census enumeration blocks [CEBs] of 100-200 households) served as the sampling frame for the selection of villages and wardsin rural and urban areas, respectively. This list was stratified using four variables, namely, region, village/ward size, proportion of the population belonging to scheduled castes and scheduled tribes, and female literacy. 
The household sample in rural areas was selected in three stages, while in urban areas it was selected in four stages. In rural areas, villages were first selected systematically from the stratified list as described above, with selection probability proportional to size (PPS). In urban areas, 75 wards were first selected systematically with probability proportional to size, and within each selected ward, CEBs were then arranged by their administrative number and one CEB was randomly selected. Several CEBs adjacent to the selected CEB were merged to ensure at least 500 households for listing.

A complete mapping and household listing operation was carried out in each selected PSU (or in selected segments or linked villages as appropriate). Based on this list, a PSU was divided into two nearly equal segments and one segment was randomly chosen for conducting interviews of females and the other for interviews of males. The list of households within each segment provided the necessary frame for selecting households within the segment. The number of household interviews to be conducted was fixed at 90 in the male segment and 150 in the female segment in each PSU in order to achieve our targeted sample of unmarried boys and girls. Households to be interviewed were selected with equal probability from the list using systematic sampling. The value of the interval (between one selected household and the next) was determined in advance to ensure a self-weighing design. No replacement for selected households was allowed even if a selected household could not be contacted after several attempts.

Within each selected household, no more than one respondent per category was interviewed, which resulted in a maximum of three interviews from any household-one younger girl, one unmarried older girl, and one married older girl in the female segment and one younger boy, one older boy, and one married older girl in the male segment. In case more than one respondent from a single category was found in the household, one respondent was selected randomly using the Kish table. No replacement of the respondent thus selected was allowed.

\subsection{Study instruments}

We developed a total of five questionnaires for the study: a household questionnaire, administered in each selected household; and four individual questionnaires for each of the age groups-younger boys, older boys, younger girls, and unmarried and married older girls.

We administered the household questionnaire to list all usual residents of each household and to collect basic information on each listed household member, including his or her age, sex, marital status, relationship to the head of the household, and education, and information on the religion and caste of the head of the household. We inquired whether household members owned the house in which they resided or any other house and whether they owned agricultural land. Other questions we posed sought information on the number of rooms the residence contained and the kinds of amenities available, including the type of toilet facility, the main source of lighting, the main type of cooking fuel, and the main source of drinking water. The survey also inquired about the household's ownership of 15 consumer durables. Finally, information was sought on whether any adolescent boys or girls from the household were residing in hostels to pursue their education at the time of the interview and the kind of school they were attending. We also probed whether any household members had obtained employment under the Mahatma Gandhi National Rural Employment Guarantee Act (MNREGA) scheme in the year preceding the interview. Finally, we probed the prevalence of substance use by household members.

The development of individual questionnaires was informed by survey instruments used for other studies, notably, the instruments used in the Youth Study (IIPS and Population Council, 2010), a study of adolescents in Rajasthan (Jejeebhoy and Acharya, 2014), and a study of younger and older adolescents in Madhya Pradesh and Uttar Pradesh (Santhya et al., 2013). We also drew on tools developed by ASER (Annual Status of Education Report) to assess basic literacy and numeracy skills (ASER Centre, 2017), the tools used in the SEHER project by Sangath and the Patient Health Questionnaire (PHQ-9) to assess the mental health condition of adolescents (Kroenke, Spitzer, and Williams, 2001), and the Gender Equitable Men (GEM) scale (Pulerwitz and Barker, 2008). Finally, our survey instrument drew upon the questionnaire used in NFHS-4 (IIPS, 2014).

We employed individual questionnaires to interview eligible adolescents who usually resided in the selected households. Boys and girls in ages 10-14 and 15-19 as well as currently married girls in ages 15-19 were eligible for interview. Widowed and divorced girls were excluded from the survey. Since we were aware that exploring sensitive issues with young adolescents has the potential to cause harm, we ensured that survey instruments contained 
only age-appropriate questions for young adolescents, as we had done for our earlier studies. Keeping in mind the sensitive nature of the questions, we divided the questionnaire into several sections and arranged them in such a way that the most sensitive questions were administered towards the middle of the interview. This strategy of asking a series of non-sensitive questions in the early part of the interview served two purposes: it enabled the interviewer and the respondents to build a rapport before sensitive questions were posed; it also permitted the investigator to maintain privacy for sensitive questions, as interested bystanders would usually leave while questions in the early sections were posed.

The individual questionnaires collected information on the following topics:

Background characteristics: Interviewers recorded the age of respondents; their education and schooling, including attendance, perceptions of performance, awareness and reach of entitlements from school, and quality of school or college attended;their work patterns, including housework and paid employment, employment preferences, and awareness and utilisation of government schemes that provide support for self-employment and MNREGA; vocational skills training, including awareness and utilisation of government schemes to impart vocational skills training; their future aspirations, in general, and those related to schooling and vocational skills training, in particular;and migration experiences.

We administered, additionally, a Life Event Calendar (LEC), adapted from that used in the Youth Study, to older adolescents to obtain information on their education and work across a span of time starting from when they were 10 years old. This system of recording life events is considered to be one of the most effective approaches to minimise recall error.

Media exposure: Interviewers asked respondents whether they were exposed to newspapers, television, or the internet and whether they watched pornographic films or read pornographic magazines. They also asked respondents about their access to mobile phones, exposure to social media, and receipt of health information via mobile phones or social media.

Parental interaction/relationship: The interviewers posed detailed questions to all respondents, excluding married older girls, about the extent of parent-child communication on everyday activities as well as sexual and reproductive issues and their perceptions about parental closeness and socialisation experiences at home. Questions were also asked to assess the extent to which respondents had ever witnessed parental violence or had been the victim of violence perpetrated by a parent across a span beginning from the time the respondents were 10 years old, and such experiences were additionally probed among these respondents for the year preceding the interview.

Communication, mobility, and decision-making: This section of the questionnaire collected information on the person in whom adolescents were most likely to confide about matters related to experiences of bullying, friendships, and relationships with the opposite sex and sexual and reproductive health problems. The interviewer also asked detailed questions on decision-making and mobility of the respondents.

Gender and self-efficacy: In order to evaluate the respondents' gender role attitudes and level of self-efficacy, the interview contained questions that probed opinions about a range of gender-related issues, such as, the importance of boys' vis-à-vis girls' education, housework, and freedom of movement. The interview also included questions to capture their ability to express their opinion to elders in the family and to confront someone who said or did something wrong to the respondents.

Awareness of sexual and reproductive matters: This section of the questionnaire probed adolescents' awareness about sexual relations, pregnancy, contraceptive methods, HIV/AIDS and sexually transmitted infections (STIs), maternal and newborn care practices, the legal minimum age of marriage, and perceptions about a woman's right to terminate a pregnancy. It also probed adolescents' preferred and actual sources of information on sexual matters, the extent to which they had obtained formal sex education or family life education, and their experiences and perceptions about this education. It included questions that assessed adolescents' awareness of the Rashtriya Kishor Swasthya Karykram as well as their awareness of and interactions with frontline workers-anganwaadi workers (AWWs) and accredited social health activists (ASHAs).

Connectediness and friendship: Questions relating to connectedness and friendship explored respondents' friendship networks, including the size of the network and the frequency of interaction with friends. It also probed adolescents' membership in various clubs and groups. 
Premarital romantic heterosexual relationships: This was a highly sensitive section, conducted only if complete privacy was assured. The section started by probing experiences of respondents with regard to premarital romantic partnerships and, if reported, interviewers asked detailed questions on the nature of such relationships. Questions were designed to gradually probe sensitive behaviours, for example, starting with questions on hugging, kissing, and finally questions on having sex with the partner. We believe that this gradual progression of questions was more culturally appropriate than a single question on premarital sex, and this provided insights into the range of behaviours experienced by adolescents. If sex with a premarital romantic partner was reported, a host of questions that probed consensual sexual relations and condom use followed.

Marriage process: Questions in this section covered marriage planning and the participation of the respondents in decision-making related to marriage. We also probe down experience of respondents or the experience of an acquaintance with respect to marriage-related trafficking.

Married life: For married girls, the interview contained detailed questions about their married life. These included the nature of marriage, acquaintance with spouse before marriage, transactions near the time of marriage and afterwards, and age at cohabitation. Questions also covered marital relationship issues, including spousal communication, marital violence, pregnancy experiences and outcomes, maternal and newborn care practices, and the extent to which respondents had benefited from maternal health schemes and contraceptive practices.

Same-sex, paid, and forced sexual experiences: This was the second highly sensitive section in the questionnaire and contained a series of questions on respondents' personal experience of several types of sexual encounters; for example, paid or exchange sex, forced sex perpetrated on the respondents, casual sex, and sex with a same-sex partner. Among male respondents, additional questions sought to elicit information about relations with sex workers and married women and whether they had ever perpetrated forced sex. The interview also sought information from all married older girls about their experiences of extramarital sexual relations. Among respondents who reported any of these experiences, interviewers probed about their age at first experience of such a sexual encounter, whether or not they had used condoms in their sexual encounters, and whether they had ever experienced a premarital pregnancy.

Health and health-seeking: This section collected information on respondents' experience of symptoms suggestive of genital infections in the three months preceding the interview and related treatment-seeking; experience of injuries in the three months prior to the interview; engagement in physical activities in the month preceding the interview; and typical dietary habits. It also contained questions to assess respondents' awareness of various health schemes supported by the government and the extent to which respondents had benefited from these schemes. Further, this section sought information from female respondents about menstrual hygiene practices and their awareness of the sanitary napkin distribution scheme and whether they had benefited from this scheme. It included the administering of the Patient Health Questionnaire (PHQ-9), developed for use in field conditions (Kroenke, Spitzer, and William, 2001), to assess respondents' mental health in the two weeks preceding the interview and issues related to selfharm.

Substance use and violence: Interviewers posed a series of questions to respondents about consumption of tobacco products, alcohol, or drugs and in case consumption was reported, they asked questions about the frequency of use of such substance. Additional questions sought respondents' assessments of the frequency with which young people in their neighbourhoods engaged in violence (fights or beatings) and their own participation in such violence.

Political participation: The questionnaire collected information on respondents' opinions about political processes, the extent to which they held secular attitudes, and their participation in political activities.

Assessment of literacy and numeracy: Using tools developed by ASER (ASER Centre, 2017), we assessed literacy (assessing ability to read in Hindi) and numeracy levels among survey participants who had ever attended school.

Sealed envelope response: However carefully designed and culturally sensitive the survey questions may have been, the possibility that adolescents would deliberately with hold information about their sexual experiences in a faceto-face interview could not be discounted. Drawing from the Youth Study, we included an anonymous (but linked) reporting method in our survey in which interviewers asked 15-19-year-olds to respond to two questions that were framed according to whether the respondents were girls or boys or married girls: 
1. Have you ever had sex with a boy/man [directed at unmarried girls]?

Did you ever have sex with a boy/man before marriage [directed at married girls]?

Have you ever had sex with a girl/woman [directed at boys]?

2. Has a boy/man ever forced you to have sex with him [directed at unmarried girls]?

Did a boy/man ever force you to have sex with him before marriage [directed at married girls]?

Have you ever forced a girl/woman to have sex with you [directed at boys]?

Interviewers first explained the technique to respondents, emphasising in particular its confidential nature. The interviewer then gave each respondent two blank cards and asked him or her to simply mark a ' $V$ ' or an ' $X$ ' on the cards to indicate that she/he had or had not experienced premarital sex, respectively. Similarly, the interviewer asked female respondents to indicate whether they had or had not experienced forced sex, while male respondents had to indicate whether they had or had not perpetrated forced sex on a girl/woman. Once marked, the respondent placed the cards inside an envelope provided by the interviewer, sealed the envelope, and returned it to the interviewer. Unique identification numbers linked the individual's questionnaire with his or her responses in the sealed envelope.

Biomarker measurements: The survey also included biomarker measurements. Two health investigators on each survey team measured the height and weight of selected survey participants. Height and weight data are used for assessing nutritional levels of adolescents. The health investigators also took blood samples to measure haemoglobin levels to evaluate the prevalence of anaemia. Haemoglobin levels were measured in the field using portable HemoCue instruments, which provide test results in less than one minute. All respondents were given an informational brochure about anaemia and proper nutrition, adapted from the brochure used in the NFHS. The health investigators also referred severely anaemic respondents to local public health facilities for treatment.

The study's Technical Advisory Committee extensively reviewed draft tools, which were then translated into Hindi, extensively pre-tested, and finalised after appropriate modifications. We used the computer-assisted personal interviewing (CAPI) technique, which uses mini-laptops for data collection, with built-in quality checks, and which eliminates the data-entry stage required in interviews recorded on paper.

\subsection{Recruitment, training, and fieldwork}

A total of 100 young men and women underwent interviewer training and 35 young men underwent training for household mapping and listing exercises. On the basis of performance, 80 young men and women were recruited as field investigators and 30 young men were recruited for the household mapping and listing exercise.

Population Council staff conducted the training of interviewers, while external experts from Pratham and Sangath were engaged for training interviewers in administering the ASER tool and the PHQ-9 questionnaire. Household listing investigators underwent at wo-day training, during which they were familiarised with household listing procedures. Training for field investigators for the main survey lasted three weeks and included lectures and interactive sessions. Efforts were also made to enable trainees to overcome their inhibitions about discussing sexual and reproductive health matters and to orient them on required action if a respondent was in distress or sought referral. Trainees were familiarised with each module of the questionnaire, complicated concepts and questions, and their underlying rationale. Roleplays and mock interviews were conducted with reference to each module. Towards the end of the training programme, field practice sessions were organised where trainees were taken to a village and an urban slum setting and asked to conduct interviews. The training team monitored each trainee's progress on a regular basis and selected as interviewers only those trainees who demonstrated a full understanding of the questionnaire as well as the ability to ask questions appropriately and record responses accurately.

Training of health investigators for collecting biomarkers comprised training in methods of blood collection, haemoglobin measurement, height/weight measurement, ethical requirements, and biohazard waste disposal. External experts with experience in training health coordinators for the NFHS served as resource persons. The training entailed classroom teaching, practice sessions in the classroom, and practice sessions in the community.

The household mapping and listing exercise was conducted by 15 teams in the state, and each team comprised one mapper and one lister. During the household mapping and listing exercise, the team collected, in addition to the usual information (name and address of the head of household), information about whether there were any married girls in 
ages 15-19 among the usual residents of the household; this information was used to contact and interview married girls in ages 15-19 from non-selected households in the male and female segment of the PSU.

Interviewers for the main interview were divided into 10 teams, and each team consisted of three male and five female investigators; these included two investigators-one male and one female-trained in collecting biomarker samples. Male interviewers interviewed boys and female interviewers interviewed girls. Each team comprised one field editor, who was responsible for back-checks and quality control of interviews, and one supervisor, who was responsible for the overall management of fieldwork and team-related logistics as well as for assisting in field editing and back-checking.

One field coordinator was assigned to oversee fieldwork and ensure that correct survey procedures were followed and data quality was maintained. Population Council staff made regular visits to monitor and supervise data collection operations. Each team regularly filled quality control sheets, which gave the team and the Population Council staff an overview of the quality of on-going fieldwork. These control sheets were designed to provide information on response rates in each PSU covered and track interviewer performance. In addition, the Population Council staff generated field quality tables from the data received from the field team on a regular basis.

\subsection{Ethical considerations}

A study of this nature raises several ethical concerns. We adopted several measures to ensure that research ethics were followed.

First, to address our concern that if interviews with boys and girls were conducted in the same geographical segments, they could lead to teasing, harassment, and harm to girls' reputations, we decided that the interviews of boys and girls would be undertaken in separate segments of each PSU. Similarly, in each household, only one individual from any category was selected for interview in case interviewing more than one respondent in any one category caused conflict within the family. In case respondents from more than one category were selected from a particular household, interviews were conducted separately but simultaneously.

Second, adolescents themselves contributed, albeit indirectly, to the development of the questionnaire. In the course of the pilot testing of the instruments, adolescents informed our study teams of various adolescent behaviours. They also described the ways in which they referred to these sensitive behaviours, and in order to minimise discomfort during questioning, the scenarios and terminologies described by adolescents themselves were adapted for use in our questionnaire on such sensitive topics.

Third, we recognised ethical concerns about causing potential harm to young adolescents (aged 14 years or below), even if unintentional, by including them in research studies. Based on our earlier experiences of working with young adolescents, we made the survey questions age-appropriate-for example, we did not probe sexual and reproductive health matters in-depth with young adolescents, but, rather, probed them in an age-appropriate manner.

Fourth, interviewers underwent extensive training in ethical issues. We laid emphasis on explaining the content of the questionnaire, the respondent's right to refuse to participate or answer any question, and the requirement of informed consent. At the same time, we trained interviewers on how to ask sensitive questions-regarding sexual experience, domestic violence, forced sex, and, in particular,mental health-in empathetic and non-judgemental ways and emphasised the importance of offering to refer those in need to appropriate nearby organisations or guiding them about telephone helplines.

Fifth, before entering a PSU, teams were instructed to apprise community leaders about the study and seek their support for its implementation in the community. This step ensured that community support was forthcoming and enabled team members to build a rapport with the community easily. We found that despite the sensitive nature of the questions, we were refused permission in only one PSU on the grounds of study content.

Sixth, even though consent was sought from each individual to be interviewed, among unmarried adolescents in ages 10-17, consent was also sought from a parent or guardian. Consent was also taken for assessing BMI and haemoglobin levels for the sub-sample of adolescents selected for the collection of biomarkers.

Seventh, names were never recorded in the computer form in which data were collected. In order to preserve the confidentiality of the respondent or the parent/guardian, signing the consent form was optional; however, the 
interviewer was required to sign a statement that she or he had explained the content of the consent form to the respondent or parent.

Eighth, interviewers made every effort to maintain privacy in the course of the interview. Interviewers were permitted to skip to relatively non-sensitive sections in case the interview was observed by parents or other family members. If possible, particularly among boys, interviews were held outside the home-often in a nearby field-in order to ensure privacy. Each team assigned one interviewer to conduct parallel discussion sessions with bystanders, which provided privacy for the interview. This proved particularly useful in interviews with girls. Finally, interviewers were instructed that if privacy could not be ensured, the interview must be terminated without asking sensitive questions. Owing to these strategies, few interviews had to be terminated for want of privacy and in no case was a respondent's privacy breached.

Finally, the study team realised that this would be one of the first opportunities that many adolescents would have had to discuss intimate matters and that respondents might also request information on sexual and reproductive issues or seek counselling or treatment for a health problem, including mental health problems. Therefore, the team approached NGOs that conduct youth or health-related activities at the district level and helplines that work at national or sub-national level and sought their consent for referring any adolescent in need to their organisation. Many NGOs agreed, and adolescents in need were later referred to these organisations along with a note that the individual had been part of the study. At the same time, field team members themselves built a rapport with public health authorities and referred to their facilities those who preferred to seek public services, including those who were found to be anaemic, and again, with a note that the individual had been part of the study.

\subsection{Data processing}

As mentioned earlier, the interviews were conducted using computer-assisted personal interview (CAPI) method; a special software package was developed using CSPro6.1 for entering the responses in the computerised questionnaire. The team supervisors uploaded all completed interviews on a daily basis onto a designated drop box. The raw data were validated and cleaned to remove possible inconsistencies. The analysis of data was carried out using Stata 13.1.

\subsection{Interview outcomes}

Table 1.3 provides response rates for household interviews by residence;the combined sample represents findings for both rural and urban areas. A total of 35,586 households were selected for interview. Four percent among these could not be contacted because the house could not be located or was vacant, all ofthe household members were absent over an extended period of time, or no competent respondent was available at home at the time of the visit. It is to be noted that less than one percent of selected households refused to be interviewed. In total, the response to the household questionnaire was high (97\%). A total of 16,840 and 17,060 interviews were successfully completed in urban and rural areas, respectively. Response rates in urban and rural areas were identical (96\% and 99\%, respectively).

Table 1.4 presents similar findings with regard to interviews with eligible respondents. The combined sample in the table represents findings for both rural and urban areas. In total, 10,433 interviews were completed: 1,012 with younger boys, 1,821 with older boys, 764 with younger girls, 3,428 with unmarried older girls, and 3,408 with married older girls. It is to be noted that the sample size achieved had exceeded the target among younger boys and girls and married older girls. It fell short of the target among older boys, particularly in rural areas, and unmarried older girls, but it was more than the minimum required sample. Response rates for individual interviews were in the range of 90-93 percent for boys and 92-94 percent for girls. Response rates did not differ by residence across any category of adolescents. The main reason for non-response was that the respondent was not at home (3-7\%). In two percent or fewer cases, respondents refused to be interviewed or parents refused to permit their son/daughter to be interviewed; the refusal rate ranged from two percent or less in urban areas to less than one percent in rural areas. We attribute the low refusal rates to the strategies described earlier to address ethical concerns, which, at the same time, enabled the development of considerable rapport and trust between the study communities and our interview teams. 
Table 1.3: Results of household interviews

Percent distribution of surveyed households by results of interviews, according to residence (unweighted), Bihar, 2016

\begin{tabular}{|c|c|c|c|c|c|c|}
\hline \multirow{2}{*}{ Result of interviews } & \multicolumn{2}{|c|}{ Combined } & \multicolumn{2}{|c|}{ Urban } & \multicolumn{2}{|c|}{ Rural } \\
\hline & Percent & Number & Percent & Number & Percent & Number \\
\hline a. Interview completed & 95.3 & 33,900 & 94.1 & 16,840 & 96.5 & 17,060 \\
\hline $\begin{array}{l}\text { b. Respondent or competent respondent } \\
\text { not at home at the time of visit }\end{array}$ & 2.3 & 828 & 3.3 & 583 & 1.4 & 245 \\
\hline $\begin{array}{l}\text { c. All household members were absent for } \\
\text { extended period of time }\end{array}$ & 1.5 & 530 & 1.3 & 238 & 1.7 & 292 \\
\hline d. Postponed & 0.1 & 18 & 0.1 & 16 & 0.0 & 2 \\
\hline e. Refused & 0.4 & 126 & 0.7 & 123 & 0.0 & 3 \\
\hline f. Dwelling vacant/destroyed/not found & 0.5 & 170 & 0.5 & 94 & 0.4 & 76 \\
\hline g. Not a dwelling & 0.0 & 14 & 0.0 & 6 & 0.1 & 8 \\
\hline Total households selected & 100 & 35,586 & 100 & 17,900 & 100 & 17,686 \\
\hline Response rate (RR) & 97.2 & & 95.9 & & 98.6 & \\
\hline
\end{tabular}

Note: The response rate $(R R)$ was calculated as: $R R=(a /(a+b+d+e) \star 100$.

Table 1.4: Results of eligible respondent interviews

Percent distribution of eligible respondents by results of interviews, according to residence (unweighted), Bihar, 2016

\begin{tabular}{|c|c|c|c|c|c|c|c|c|c|c|}
\hline \multirow[t]{2}{*}{ Results of interviews } & \multicolumn{2}{|c|}{$\begin{array}{c}\text { Boys } \\
(10-14)\end{array}$} & \multicolumn{2}{|c|}{$\begin{array}{l}\text { Boys } \\
(15-19)\end{array}$} & \multicolumn{2}{|c|}{$\begin{array}{c}\text { Girls } \\
(10-14)\end{array}$} & \multicolumn{2}{|c|}{$\begin{array}{c}\text { Girls } \\
(15-19)\end{array}$} & \multicolumn{2}{|c|}{$\begin{array}{c}\text { Married girls } \\
(15-19)\end{array}$} \\
\hline & Percent & Number & Percent & Number & Percent & Number & Percent & Number & Percent & Number \\
\hline \multicolumn{11}{|c|}{ Combined } \\
\hline a. Interview completed & 93.2 & 1,012 & 90.2 & 1,821 & 94.2 & 764 & 94.3 & 3,428 & 92.0 & 3,408 \\
\hline b. Respondent not at home & 3.7 & 40 & 5.8 & 116 & 3.1 & 25 & 4.0 & 144 & 7.2 & 265 \\
\hline c. Postponed & 1.1 & 12 & 1.5 & 31 & 0.6 & 5 & 0.6 & 23 & 0.5 & 18 \\
\hline d. Respondent refused & 0.1 & 1 & 0.4 & 8 & 0.5 & 4 & 0.3 & 9 & 0.1 & 2 \\
\hline e. Parent refused & 0.5 & 5 & 1.1 & 22 & 0.5 & 4 & 0.4 & 13 & 0.2 & 6 \\
\hline f. Partly completed & 0.2 & 2 & 0.2 & 4 & 0.0 & 0 & 0.0 & 0 & 0.0 & 1 \\
\hline $\begin{array}{l}\text { g. Respondent } \\
\text { incapacitated }\end{array}$ & 1.3 & 14 & 0.8 & 17 & 1.1 & 9 & 0.5 & 18 & 0.1 & 5 \\
\hline Total selected & 100.0 & 1,086 & 100.0 & 2,019 & 100.0 & 811 & 100.0 & 3,635 & 100.0 & 3,705 \\
\hline Response rate (RR) & 93.2 & & 90.2 & & 94.2 & & 94.3 & & 92.0 & \\
\hline \multicolumn{11}{|c|}{ Urban } \\
\hline a. Interview completed & 91.3 & 452 & 89.2 & 1,008 & 93.0 & 387 & 93.7 & 1,738 & 93.4 & 1,366 \\
\hline b. Respondent not at home & 3.6 & 18 & 5.6 & 63 & 3.1 & 13 & 4.2 & 78 & 6.0 & 87 \\
\hline c. Postponed & 2.0 & 10 & 2.0 & 22 & 0.7 & 3 & 0.9 & 16 & 0.4 & 6 \\
\hline d. Respondent refused & 0.2 & 1 & 0.5 & 6 & 1.0 & 4 & 0.2 & 3 & 0.1 & 1 \\
\hline e. Parent refused & 0.6 & 3 & 1.9 & 21 & 1.0 & 4 & 0.6 & 11 & 0.2 & 3 \\
\hline f. Partly completed & 0.4 & 2 & 0.3 & 3 & 0.0 & 0 & 0.0 & 0 & 0.0 & 0 \\
\hline $\begin{array}{l}\text { g. Respondent } \\
\text { incapacitated }\end{array}$ & 1.8 & 9 & 0.6 & 7 & 1.2 & 5 & 0.5 & 9 & 0.0 & 0 \\
\hline Total selected & 100.0 & 495 & 100.0 & 1,130 & 100.0 & 416 & 100.0 & 1,855 & 100.0 & 1,463 \\
\hline Response rate (RR) & 91.3 & & 89.2 & & 93.0 & & 93.7 & & 93.4 & \\
\hline
\end{tabular}


Table 1.4 Cont.

\begin{tabular}{|c|c|c|c|c|c|c|c|c|c|c|}
\hline \multirow[t]{2}{*}{ Results of interviews } & \multicolumn{2}{|c|}{$\begin{array}{c}\text { Boys } \\
(10-14)\end{array}$} & \multicolumn{2}{|c|}{$\begin{array}{c}\text { Boys } \\
(15-19)\end{array}$} & \multicolumn{2}{|c|}{$\begin{array}{c}\text { Girls } \\
(10-14)\end{array}$} & \multicolumn{2}{|c|}{$\begin{array}{c}\text { Girls } \\
(15-19)\end{array}$} & \multicolumn{2}{|c|}{$\begin{array}{l}\text { Married girls } \\
\text { (15-19) }\end{array}$} \\
\hline & Percent & Number & Percent & Number & Percent & Number & Percent & Number & Percent & Number \\
\hline \multicolumn{11}{|c|}{ Rural } \\
\hline a. Interview completed & 94.8 & 560 & 91.5 & 813 & 95.4 & 377 & 94.9 & 1,690 & 91.1 & 2,042 \\
\hline $\begin{array}{l}\text { b. Respondent not at } \\
\text { home }\end{array}$ & 3.7 & 22 & 6.0 & 53 & 3.0 & 12 & 3.7 & 66 & 7.9 & 178 \\
\hline c. Postponed & 0.3 & 2 & 1.0 & 9 & 0.5 & 2 & 0.4 & 7 & 0.5 & 12 \\
\hline d. Respondent refused & 0.0 & 0 & 0.2 & 2 & 0.0 & 0 & 0.3 & 6 & 0.0 & 1 \\
\hline e. Parent refused & 0.3 & 2 & 0.1 & 1 & 0.0 & 0 & 0.1 & 2 & 0.1 & 3 \\
\hline f. Partly completed & 0.0 & 0 & 0.1 & 1 & 0.0 & 0 & 0.0 & 0 & 0.0 & 1 \\
\hline $\begin{array}{l}\text { g. Respondent } \\
\text { incapacitated }\end{array}$ & 0.9 & 5 & 1.1 & 10 & 1.0 & 4 & 0.5 & 9 & 0.2 & 5 \\
\hline Total selected & 100.0 & 591 & 100.0 & 889 & 100.0 & 395 & 100.0 & 1,780 & 100.0 & 2,242 \\
\hline Response rate (RR) & 94.8 & & 91.5 & & 95.4 & & 94.9 & & 91.1 & \\
\hline
\end{tabular}

Note: The response rate $(R R)$ was calculated as: $R R=(a / a+b+d+e+f+g) \star 100$.

Tables 1.5 and 1.6 present findings with regard to biomarker measurements, that is, anthropometric measurement (Table 1.5) and haemoglobin testing (Table 1.6). The combined sample in both tables represents the findings for rural and urban areas taken together. Health investigators completed anthropometric measurement for 4,229 adolescents-966 younger boys, 654 older boys, 737 younger girls, 530 unmarried older girls, and 1,342 married older girls. We found that the sample size achieved had exceeded the target for all categories of adolescents, except for older boys and unmarried older girls, among whom it fell short of the target, but had exceeded the minimum required sample size. Response rates for anthropometric measurement were in the range of 91-96 percent for boys and 94-97 percent for girls-older boys registered the lowest response rate (91\%) and younger girls registered the highest response rate $(97 \%)$. The main reason for non-response was that the respondents were not at home when the health investigator visited them for taking the measurements, which was found particularly among older boys (2-6\% among boys and $2-3 \%$ among girls); such respondents were mostly those who were currently attending school or were engaged in paid work. In 2-4 percent of cases, respondents refused to undergo anthropometric measurement or parents refused to give permission to our teams for taking the measurements of their son/daughter. Refusals were slightly higher among all categories of adolescents, other than among younger girls, in urban than in rural areas (5-6\% versus 1-3\%); no such differences were observed for younger girls.

Table 1.6 presents similar findings with regard to haemoglobin testing. The testing was completed for 4,162 adolescents-955 younger boys, 648 older boys, 723 younger girls, 519 unmarried older girls, and 1,317 married older girls. As with anthropometric measurement, the sample size achieved exceeded the target among all categories of adolescents, except for older boys and unmarried older girls,among whom it fell short of the target, but had exceeded the minimum required sample size. Response rates for haemoglobin testing were in the range of 90-94 percent for boys and 92-95 percent for girls-older boys registered the lowest response rate (90\%), and younger girls registered the highest response rate (95\%). Response rates were higher in rural than urban areas for younger boys and married older girls, but the differences were narrow for the other three categories of adolescents. As shown with anthropometric measurement, the main reason for non-response was that the respondents were not at home when the health investigator visited them for taking the measurement, which was found particularly among older boys (2-6\% among boys and $2-3 \%$ among girls). Respondents refusing to undergo haemoglobin testing or parents refusing permission for taking blood samples from their son/daughter constituted 3-6 percent of cases. Refusals were higher across all categories in urban than in rural areas (6-7\% versus $1 \%$ among boys and $3-8 \%$ versus $3-4 \%$ among girls). 
Table 1.5: Results of anthropometric measurement

Percent distribution of eligible respondents by results of anthropometric measurement, according to residence (unweighted), Bihar, 2016

\begin{tabular}{|c|c|c|c|c|c|c|c|c|c|c|}
\hline \multirow{2}{*}{$\begin{array}{l}\text { Results of anthropometric } \\
\text { measurement }\end{array}$} & \multicolumn{2}{|c|}{$\begin{array}{c}\text { Boys } \\
(10-14)\end{array}$} & \multicolumn{2}{|c|}{$\begin{array}{c}\text { Boys } \\
(15-19) \\
\end{array}$} & \multicolumn{2}{|c|}{$\begin{array}{c}\text { Girls } \\
(10-14)\end{array}$} & \multicolumn{2}{|c|}{$\begin{array}{c}\text { Girls } \\
(15-19)\end{array}$} & \multicolumn{2}{|c|}{$\begin{array}{l}\text { Married girls } \\
(15-19) \\
\end{array}$} \\
\hline & Percent & Number & Percent & Number & Percent & Number & Percent & Number & Percent & Number \\
\hline \multicolumn{11}{|c|}{ Combined } \\
\hline a. Measurement completed & 95.5 & 966 & 91.2 & 654 & 96.5 & 737 & 93.6 & 530 & 94.0 & 1,342 \\
\hline b. Respondent refused & 0.4 & 4 & 0.8 & 6 & 0.5 & 4 & 1.6 & 9 & 2.1 & 30 \\
\hline c. Parents refused & 2.2 & 22 & 2.4 & 17 & 1.2 & 9 & 2.5 & 14 & 1.0 & 14 \\
\hline d. Respondent disabled/unwell & 0.1 & 1 & 0.0 & 0 & 0.0 & 0 & 0.2 & 1 & 0.2 & 3 \\
\hline e. Respondent not at home & 1.9 & 19 & 5.6 & 40 & 1.8 & 14 & 2.1 & 12 & 2.7 & 39 \\
\hline Total selected & 100.0 & 1,012 & 100.0 & 717 & 100.0 & 764 & 100.0 & 566 & 100.0 & 1,428 \\
\hline Response rate (RR) & 95.5 & & 91.2 & & 96.5 & & 93.6 & & 94.0 & \\
\hline \multicolumn{11}{|c|}{ Urban } \\
\hline a. Measurement completed & 92.5 & 418 & 89.9 & 375 & 97.2 & 376 & 91.7 & 265 & 90.2 & 443 \\
\hline b. Respondent refused & 0.9 & 4 & 1.4 & 6 & 0.5 & 2 & 2.4 & 7 & 3.5 & 17 \\
\hline c. Parents refused & 4.0 & 18 & 3.6 & 15 & 1.0 & 4 & 3.1 & 9 & 1.6 & 8 \\
\hline d. Respondent disabled/unwell & 0.0 & 0 & 0.0 & 0 & 0.0 & 0 & 0.0 & 0 & 0.4 & 2 \\
\hline e. Respondent not at home & 2.7 & 12 & 5.0 & 21 & 1.3 & 5 & 2.8 & 8 & 4.3 & 21 \\
\hline Total selected & 100.0 & 452 & 100.0 & 417 & 100.0 & 387 & 100.0 & 289 & 100.0 & 491 \\
\hline Response rate (RR) & 92.5 & & 89.9 & & 97.2 & & 91.7 & & 90.2 & \\
\hline \multicolumn{11}{|c|}{ Rural } \\
\hline a. Measurement completed & 97.9 & 548 & 93.0 & 279 & 95.8 & 361 & 95.7 & 265 & 95.9 & 899 \\
\hline b. Respondent refused & 0.0 & 0 & 0.0 & 0 & 0.5 & 2 & 0.7 & 2 & 1.4 & 13 \\
\hline c. Parents refused & 0.7 & 4 & 0.7 & 2 & 1.3 & 5 & 1.8 & 5 & 0.6 & 6 \\
\hline d. Respondent disabled/unwell & 0.2 & 1 & 0.0 & 0 & 0.0 & 0 & 0.4 & 1 & 0.1 & 1 \\
\hline e. Respondent not at home & 1.3 & 7 & 6.3 & 19 & 2.4 & 9 & 1.4 & 4 & 1.9 & 18 \\
\hline Total selected & 100.0 & 560 & 100.0 & 300 & 100.0 & 377 & 100.0 & 277 & 100.0 & 937 \\
\hline Response rate (RR) & 97.9 & & 93.0 & & 95.8 & & 95.7 & & 95.9 & \\
\hline
\end{tabular}

Note: The response rate $(R R)$ was calculated as: $R R=(a / a+b+c+d+e) \star 100$.

\section{Table 1.6: Results of haemoglobin testing}

Percent distribution of eligible respondents by results of haemoglobin testing, according to residence (unweighted), Bihar, 2016

\begin{tabular}{|c|c|c|c|c|c|c|c|c|c|c|}
\hline \multirow{2}{*}{$\begin{array}{l}\text { Results of haemoglobin } \\
\text { testing }\end{array}$} & \multicolumn{2}{|c|}{$\begin{array}{c}\text { Boys } \\
(10-14)\end{array}$} & \multicolumn{2}{|c|}{$\begin{array}{c}\text { Boys } \\
(15-19)\end{array}$} & \multicolumn{2}{|c|}{$\begin{array}{c}\text { Girls } \\
(10-14)\end{array}$} & \multicolumn{2}{|c|}{$\begin{array}{l}\text { Girls } \\
(15-19)\end{array}$} & \multicolumn{2}{|c|}{$\begin{array}{l}\text { Married girls } \\
(15-19)\end{array}$} \\
\hline & Percent & Number & Percent & Number & Percent & Number & Percent & Number & Percent & Number \\
\hline \multicolumn{11}{|c|}{ Combined } \\
\hline a. Blood tested & 94.4 & 955 & 90.4 & 648 & 94.6 & 723 & 91.7 & 519 & 92.2 & 1,317 \\
\hline b. Respondent refused & 0.8 & 8 & 1.1 & 8 & 1.6 & 12 & 2.8 & 16 & 3.3 & 47 \\
\hline c. Parents refused & 2.8 & 28 & 2.7 & 19 & 1.7 & 13 & 3.0 & 17 & 1.1 & 15 \\
\hline $\begin{array}{l}\text { d. Respondent disabled/ } \\
\text { unwell }\end{array}$ & 0.1 & 1 & 0.0 & 0 & 0.0 & 0 & 0.2 & 1 & 0.2 & 3 \\
\hline e. Respondent not at home & 1.9 & 19 & 5.6 & 40 & 1.8 & 14 & 1.9 & 11 & 2.9 & 41 \\
\hline Total selected & 100.0 & 1,012 & 100.0 & 717 & 100.0 & 764 & 100.0 & 566 & 100.0 & 1,428 \\
\hline Response rate (RR) & 94.4 & & 90.4 & & 94.6 & & 91.7 & & 92.2 & \\
\hline
\end{tabular}


Table 1.6 Cont.

\begin{tabular}{|c|c|c|c|c|c|c|c|c|c|c|}
\hline \multirow{2}{*}{$\begin{array}{l}\text { Results of haemoglobin } \\
\text { testing }\end{array}$} & \multicolumn{2}{|c|}{$\begin{array}{c}\text { Boys } \\
(10-14)\end{array}$} & \multicolumn{2}{|c|}{$\begin{array}{c}\text { Boys } \\
(15-19)\end{array}$} & \multicolumn{2}{|c|}{$\begin{array}{c}\text { Girls } \\
(10-14)\end{array}$} & \multicolumn{2}{|c|}{$\begin{array}{c}\text { Girls } \\
(15-19)\end{array}$} & \multicolumn{2}{|c|}{$\begin{array}{l}\text { Married girls } \\
(15-19)\end{array}$} \\
\hline & Percent & Number & Percent & Number & Percent & Number & Percent & Number & Percent & Number \\
\hline \multicolumn{11}{|c|}{ Urban } \\
\hline a. Blood tested & 90.5 & 409 & 89.0 & 371 & 95.4 & 369 & 89.6 & 259 & 87.6 & 430 \\
\hline b. Respondent refused & 1.6 & 7 & 1.9 & 8 & 1.8 & 7 & 3.8 & 11 & 5.7 & 28 \\
\hline c. Parents refused & 5.1 & 23 & 4.1 & 17 & 1.6 & 6 & 3.8 & 11 & 1.6 & 8 \\
\hline $\begin{array}{l}\text { d. Respondent disabled/ } \\
\text { unwell }\end{array}$ & 0.0 & 0 & 0.0 & 0 & 0.0 & 0 & 0.0 & 0 & 0.4 & 2 \\
\hline e. Respondent not at home & 2.7 & 12 & 5.0 & 21 & 1.3 & 5 & 2.4 & 7 & 4.5 & 22 \\
\hline Total selected & 100.0 & 452 & 100.0 & 417 & 100.0 & 387 & 100.0 & 289 & 100.0 & 491 \\
\hline Response rate (RR) & 90.5 & & 89.0 & & 95.4 & & 89.6 & & 87.6 & \\
\hline \multicolumn{11}{|c|}{ Rural } \\
\hline a. Blood tested & 97.5 & 546 & 92.3 & 277 & 93.9 & 354 & 93.9 & 260 & 94.7 & 887 \\
\hline b. Respondent refused & 0.2 & 1 & 0.0 & 0 & 1.3 & 5 & 1.8 & 5 & 2.0 & 19 \\
\hline c. Parents refused & 0.9 & 5 & 0.7 & 2 & 1.9 & 7 & 2.2 & 6 & 0.8 & 7 \\
\hline $\begin{array}{l}\text { d. Respondent disabled/ } \\
\text { unwell }\end{array}$ & 0.2 & 1 & 0.0 & 0 & 0.0 & 0 & 0.4 & 1 & 0.1 & 1 \\
\hline e. Respondent not at home & 1.3 & 7 & 6.3 & 19 & 2.4 & 9 & 1.4 & 4 & 2.0 & 19 \\
\hline Total selected & 100.0 & 560 & 100.0 & 300 & 100.0 & 377 & 100.0 & 277 & 100.0 & 937 \\
\hline Response rate (RR) & 97.5 & & 92.3 & & 93.9 & & 93.9 & & 94.7 & \\
\hline
\end{tabular}

Note: The response rate $(R R)$ was calculated as: $R R=(a / a+b+c+d+e) * 100$.

\subsection{Structure of the report}

This section presents the structure of the report. Chapter 2 provides a socio-demographic profile of the surveyed population and respondents. Chapters 3,4 , and 5 discuss educational attainment patterns, economic and noneconomic activity experiences, and media exposure of adolescents, respectively. Chapter 6 discusses growingup issues, including adolescents' relationships with parents and peers. Chapters 7 and 8 focus on adolescents' autonomy and gender role attitudes and awareness of sexual and reproductive health matters, respectively. Chapter 9 describes the extent of premarital romantic relationships and the experience of premarital sexual relations among adolescents. Chapter 10 discusses the transition to marriage and experiences in early married life. Chapter 11 presents information on health and health-seeking behaviours and substance use. Chapter 12 focuses on dietary habits and nutritional status of adolescents. Chapter 13 describes civic and political participation and related attitudes. Finally, Chapter 14 offers recommendations for programmes and research.

In view of the heterogeneity of adolescents by sex, marital status, and rural or urban residence, in each chapter, tables describe separate findings for each of the five categories of adolescents residing in urban areas and for those residing in rural areas. Findings for the combined sample represent both rural and urban areas.

All means, medians, and percentages indicated in the tables have been weighted using normalised weights for the total population. However, in order to show the total number of adolescents interviewed, unweighted numbers of respondents (Ns) are provided in each table. Because numbers are unweighted and percentages are weighted, we caution readers against deriving numbers based on the percentages provided in the tables. We also note that disaggregated estimates by socio-demographic characteristics do not control for the effect of confounding factors. Finally, we did not conduct any tests of significance to examine whether differences across various categories of adolescents (that is, younger versus older adolescents, boys versus girls, unmarried versus married girls, or rural versus urban adolescents) were statistically significant. Rather, we highlighted differences of five percentage points or more between any two categories. This is because differences of five percentage points or more were likely to be statistically significant with sufficient power given the large sample size that the study covered. We also decided against presenting results of statistical tests of significance, keeping in mind the broad spectrum of audiences we aim for this report. 



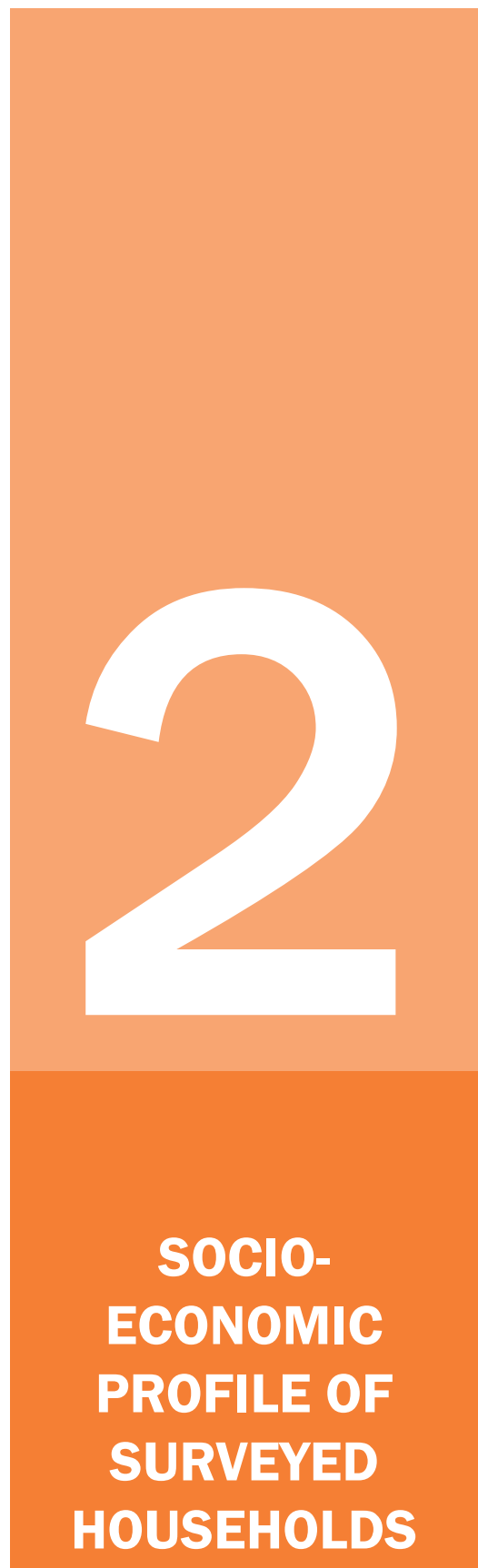

\begin{tabular}{c}
$17 \%$ \\
of heads of \\
households were \\
female \\
\hline $65 \%$ \\
of households \\
contained at least \\
one literate \\
member aged 18 \\
and above \\
tobacco products \\
of households \\
contained at least \\
one member who \\
of households \\
lived in low-quality \\
houses \\
\hline $28 \%$ \\
of households
\end{tabular}

\section{A Snapshot}

\begin{tabular}{|c|c|}
\hline $\begin{array}{c}51 \% \\
\text { of heads of } \\
\text { households had no } \\
\text { schooling }\end{array}$ & $\begin{array}{l}\text { Households } \\
\text { contained an } \\
\text { average of } \\
5 \\
\text { members }\end{array}$ \\
\hline $\begin{array}{c}39 \% \\
\text { of households } \\
\text { contained at least } \\
\text { one literate } \\
\text { female member } \\
\text { aged } 18 \text { and } \\
\text { above }\end{array}$ & $\begin{array}{c}99 \% \\
\text { of households } \\
\text { owned their } \\
\text { house }\end{array}$ \\
\hline $\begin{array}{l}64 \% \\
\text { of households } \\
\text { had electricity }\end{array}$ & $\begin{array}{c}99 \% \\
\text { of households } \\
\text { used piped water } \\
\text { or water obtained } \\
\text { from a } \\
\text { hand-pump or a } \\
\text { covered well for } \\
\text { drinking }\end{array}$ \\
\hline $\begin{array}{l}14 \% \\
\text { of households } \\
\text { used liquid } \\
\text { petroleum gas for } \\
\text { cooking }\end{array}$ & $\begin{array}{c}4 \% \\
\text { of rural } \\
\text { households had } \\
\text { benefited from } \\
\text { the MNREGA } \\
\text { scheme in the } \\
\text { year preceding } \\
\text { the interview }\end{array}$ \\
\hline $\begin{array}{l}29 \% \\
\text { of households } \\
\text { contained at least } \\
\text { one member who } \\
\text { consumed alcohol }\end{array}$ & $\begin{array}{l}5 \% \\
\text { of households } \\
\text { contained at least } \\
\text { one member who } \\
\text { consumed drugs }\end{array}$ \\
\hline $\begin{array}{l}72-82 \% \\
\text { dolescents' mothers } \\
\text { no formal education }\end{array}$ & \\
\hline
\end{tabular}

Rural disadvantage was apparent in many indicators of socio-economic status

- schooling of household heads, literate household members, low-quality housing, access to electricity, access to toilet facilities, use of liquid petroleum gas for cooking, wealth status, and consumption of tobacco products

POPULATION COUNCIL

Ideas. Evidence. Impact.

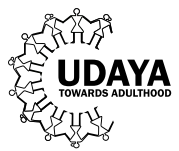


This chapter presents household-and respondent-level profiles of the surveyed population. First, drawing on data from the household questionnaire, we profile surveyed households on the basis of their socio-demographic and housing characteristics and economic status. Thereafter, the chapter presents our findings on selected socio-demographic characteristics of households that have benefited from the Mahatma Gandhi National Rural Employment Guarantee Act (MNREGA). It then goes on to present our findings on the extent of any substance use among household members. Finally, drawing on data from individual questionnaires, we present the background characteristics of adolescent respondents.

\subsection{Profile of households and heads of households}

Table 2.1 presents selected characteristics pertaining to households and heads of households, according to residence. Findings highlight that heads of households were predominantly male (83\%), and more urban than rural areas had male heads of households ( $89 \%$ versus $82 \%$ ). Heads of households were typically aged 35 years and above (76\%), with similar distributions in both rural and urban households.

Distributions by religion show that 86 percent of household heads were Hindu and 14 percent were Muslim. This distribution closely resembles that obtained in the 2011 census of the state (Hindu, 83\%; Muslim, 17\%; not shown in Table 2.1). Differences by religion of heads of households between rural and urban households were narrow. As far as caste of heads of households is concerned, the largest group belonged to other backward castes (64\%), followed by scheduled castes and general castes (22\% and $13 \%$, respectively). Scheduled tribes constituted just one percent of heads of households. This distribution somewhat resembles that obtained in the 2011 census (scheduled castes, 16\%; scheduled tribes, 1\%; not shown in Table 2.1). Differences by caste between rural and urban household heads indicate that there was a some what larger proportion of scheduled caste heads of households in the rural population than in the urban population (23\% versus $15 \%$ ) and conversely, a smaller proportion from general castes (12\% versus $26 \%$ ).

Educational attainment levels show that half of all heads of households had no schooling and another one-sixth had only 1-7 years of schooling. Heads of households in urban areas were better educated than their rural counterparts.

Households contained an average of five members, with little variation between rural and urban households.

Two-thirds (65\%) of households contained at least one literate male or female member aged 18 and above.

There were marked differences between rural and urban households in the proportion of literate members they contained-85 percent and 63 percent of urban and rural households, respectively, contained at least one literate member aged 18 and above. Two-fifths of households (39\%) in contrast contained at least one female member aged 18 and above who was literate, which was reported by 37 percent of households in rural areas and 64 percent of households in urban areas.

Finally, one percent or fewer households contained at least one adolescent boy or girl staying in a hostel to pursue studies, and there was little difference between rural and urban areas in this regard.

\section{Table 2.1: Socio-demographic characteristics of households and heads of households}

Percent distribution of surveyed households by selected socio-demographic characteristics of heads of households and household size, and percentage of households by literate members, according to residence, Bihar, 2016

\begin{tabular}{lccc}
\hline Socio-demographic characteristics & Combined (percent) & Urban (percent) & Rural (percent) \\
\hline Sex of household head & & & \\
Male & 83.0 & 88.5 & 82.4 \\
Female & 17.0 & 11.5 & 17.6 \\
Age of household head & & & \\
Below 25 & 4.3 & 4.1 & 4.3 \\
$25-34$ & 20.1 & 16.8 & 20.4 \\
$35-44$ & 24.3 & 25.4 & 24.1 \\
$45-54$ & 19.6 & 22.6 & 19.2 \\
55 and above & 31.8 & 31.2 & 31.9 \\
\hline
\end{tabular}


Table 2.1 Cont.

\begin{tabular}{|c|c|c|c|}
\hline Socio-demographic characteristics & Combined (percent) & Urban (percent) & Rural (percent) \\
\hline \multicolumn{4}{|l|}{ Religion of household head } \\
\hline Hindu & 86.2 & 82.9 & 86.6 \\
\hline Muslim & 13.6 & 16.8 & 13.2 \\
\hline Christian & 0.2 & 0.2 & 0.2 \\
\hline Other $^{1}$ & 0.0 & 0.1 & 0.0 \\
\hline \multicolumn{4}{|l|}{ Caste/tribe of household head } \\
\hline SC & 22.0 & 15.0 & 22.8 \\
\hline ST & 1.2 & 0.5 & 1.3 \\
\hline OBC & 63.6 & 58.9 & 64.1 \\
\hline General $^{2}$ & 13.2 & 25.7 & 11.8 \\
\hline \multicolumn{4}{|l|}{$\begin{array}{l}\text { Educational levelof household head (in years of schooling } \\
\text { completed) }\end{array}$} \\
\hline None $^{3}$ & 51.0 & 29.9 & 53.4 \\
\hline $1-7$ & 16.0 & 12.9 & 16.4 \\
\hline $8-10$ & 21.9 & 25.6 & 21.4 \\
\hline $11-12$ & 5.3 & 9.8 & 4.8 \\
\hline Above 12 & 5.8 & 21.8 & 4.0 \\
\hline \multicolumn{4}{|l|}{ Number of members in the household } \\
\hline 1 & 2.7 & 3.6 & 2.6 \\
\hline 2 & 10.3 & 9.6 & 10.4 \\
\hline 3 & 12.6 & 11.5 & 12.7 \\
\hline 4 & 18.3 & 20.1 & 18.2 \\
\hline 5 & 19.6 & 20.2 & 19.5 \\
\hline 6 & 15.1 & 14.2 & 15.2 \\
\hline 7 or more & 21.3 & 20.8 & 21.4 \\
\hline Mean household size (number of members) & 5.0 & 5.0 & 5.0 \\
\hline \multicolumn{4}{|l|}{$\begin{array}{l}\text { Percentage of households with literate members and } \\
\text { adolescents studying in a hostel }\end{array}$} \\
\hline Households with at least one literate member aged 18 and above & 65.4 & 84.7 & 63.2 \\
\hline $\begin{array}{l}\text { Households with at least one female literate member aged } 18 \\
\text { and above }\end{array}$ & 39.3 & 64.1 & 36.5 \\
\hline $\begin{array}{l}\text { Households with at least one adolescent boy staying in a hostel } \\
\text { to pursue studies }\end{array}$ & 1.0 & 0.9 & 1.0 \\
\hline $\begin{array}{l}\text { Households with at least one adolescent girl staying in a hostel } \\
\text { to pursue studies }\end{array}$ & 0.2 & 0.4 & 0.2 \\
\hline Number of households & 33,900 & 16,840 & 17,060 \\
\hline
\end{tabular}

Notes: All Ns are unweighted. OBC: other backward caste. SC: scheduled caste. ST: scheduled tribe. ${ }^{1}$ Includes Buddhist/Neo-Buddhist, Sikh, Jain, and no specified religion. ${ }^{2}$ Includes all those not belonging to SCs, STs, or OBCs. ${ }^{3}$ Includes non-literate and literate with no formal schooling. 


\subsection{Profille of households by housing characteristics}

Table 2.2 provides information on ownership of residence, quality of housing, access to basic amenities, and number of persons per room in a house. The responses in the household questionnaire provided the information on housing, and, for housing type, interviewer observations provided the relevant information.

Almost all households (99\%) owned their house, regardless of residence in rural or urban areas. Interviewers observed that 33 percent of households lived in kachcha houses (constructed from mud, thatch, or other low-quality materials), 46 percent lived in semi-pucca houses (constructed by using a mix of low-and high-quality materials), and 21 percent lived in pucca houses (constructed entirely from cement, masonry, or other high-quality materials). More urban than rural households lived in pucca houses (63\% versus $16 \%)$

About half of residential structures contained 2-3 rooms (51\%) and one-third (32\%) contained just one room, which more rural than urban households reported (33\% versus $25 \%$ ). Somewhat more urban than rural households reported houses with four or more rooms (26\% versus $16 \%)$. The mean number of persons per room was 2.7 , while rural and urban households had 2.8 and 2.4 persons, respectively.

We sought information from respondents about their household's main source of lighting and drinking water. We also gathered information on toilet facilities typically accessed and cooking fuel generally used. As Table 2.2 shows, about three-fifths (64\%) of the households had electricity which suggests a four-fold increase in access to electricity between the 2011 census and the UDAYA survey (16\% in the 2011 census; Office of the Registrar General and Census Commissioner, India, 2015e); urban households were far more likely than rural households to report the use of electricity (91\% versus $60 \%)$. The main source of drinking water for the majority of households (99\%) was either piped water or water obtained from a hand-pump or a covered well, with no difference between rural and urban households in this regard. These facilities were reported as self-owned for 68 percent of households ( $77 \%$ of urban households and $67 \%$ of rural households) and as public or shared facilities for 31 percent (22\% of urban households and $32 \%$ of rural households). While not strictly comparable, the findings from the 2011 census show that 93 percent of households had access to an improved source of drinking water, which includes water from treated sources, covered well, hand-pump, tube well, or bore well (Office of the Registrar General and Census Commissioner, India, 2015f).

Just 28 percent of households reported access to a toilet facility of any kind compared with 23 percent as assessed in the 2011 census (Office of the Registrar General and Census Commissioner, India, 2015g). There were large differences between rural and urban households in access to toilets-22 percent of rural households compared with78 percent of urban households had access to some kind of toilet facility. One-quarter (24\%) of all households had access to a flush toilet, which 19 percent of rural households and 73 percent of urban households reported.

Finally, the main source of cooking fuel was coal, charcoal, wood, crop residue, or dung cakes which 86 percent of households reported as their cooking fuel; 92 percent of rural households and 32 percent of urban households so reported. In contrast, just 14 percent of households reported liquid petroleum gas (LPG) as their cooking fuel, which was reported by eight percent in rural areas and 67 percent in urban areas.

Table 2.2: Housing characteristics

Percent distribution of surveyed households by selected housing characteristics, according to residence, Bihar, 2016

\begin{tabular}{lccc}
\hline Housing characteristics & Combined (percent) & Urban (percent) & Rural (percent) \\
\hline Ownership of residence & & & \\
Yes & 99.3 & 96.9 & 99.5 \\
No & 0.7 & 3.1 & 0.5 \\
Type of house & & & \\
Kachcha & 33.2 & 11.3 & 35.7 \\
Semi-pucca & 46.1 & 25.7 & 48.4 \\
Pucca & 20.8 & 63.0 & 16.0 \\
\hline
\end{tabular}


Table 2.2 Cont.

\begin{tabular}{|c|c|c|c|}
\hline Housing characteristics & Combined (percent) & Urban (percent) & Rural (percent) \\
\hline \multicolumn{4}{|l|}{ Number of rooms in the house ${ }^{1}$} \\
\hline 1 & 31.7 & 24.6 & 32.5 \\
\hline $2-3$ & 51.4 & 49.4 & 51.6 \\
\hline $4-5$ & 12.8 & 19.9 & 12.0 \\
\hline 6 or more & 4.1 & 6.0 & 3.9 \\
\hline \multicolumn{4}{|l|}{ Average number of persons per room } \\
\hline Up to 2 & 60.5 & 69.7 & 59.4 \\
\hline $3-4$ & 25.6 & 19.2 & 26.3 \\
\hline $5-6$ & 10.8 & 8.6 & 11.1 \\
\hline More than 6 & 3.1 & 2.6 & 3.2 \\
\hline Mean number of persons per room & 2.7 & 2.4 & 2.8 \\
\hline \multicolumn{4}{|l|}{ Source of lighting } \\
\hline Electricity & 63.5 & 91.4 & 60.4 \\
\hline Kerosene & 34.4 & 8.0 & 37.4 \\
\hline Other lighting sources ${ }^{2}$ & 2.0 & 0.6 & 2.2 \\
\hline \multicolumn{4}{|l|}{ Source of drinking water } \\
\hline Own piped water/hand-pump/covered well & 68.3 & 76.8 & 67.3 \\
\hline Public piped water/hand-pump/covered well & 30.6 & 22.0 & 31.5 \\
\hline Own open well & 0.4 & 0.2 & 0.4 \\
\hline Public open well & 0.4 & 0.6 & 0.4 \\
\hline Other water sources ${ }^{3}$ & 0.4 & 0.4 & 0.4 \\
\hline \multicolumn{4}{|l|}{ Toilet facility } \\
\hline Own flush toilet & 18.2 & 55.1 & 14.1 \\
\hline Shared flush toilet & 6.2 & 18.1 & 4.8 \\
\hline Own pit toilet & 2.4 & 3.1 & 2.3 \\
\hline Shared pit toilet & 0.9 & 2.0 & 0.8 \\
\hline No toilet facility & 72.2 & 21.6 & 77.9 \\
\hline \multicolumn{4}{|l|}{ Main type of fuel used for cooking } \\
\hline Liquid petroleum gas & 13.8 & 67.4 & 7.8 \\
\hline Kerosene & 0.3 & 0.4 & 0.3 \\
\hline Wood/crop residue/dung cakes/coal/charcoal & 85.7 & 32.0 & 91.8 \\
\hline Other types of fuel ${ }^{4}$ & 0.1 & 0.2 & 0.1 \\
\hline Number of households & 33,900 & 16,840 & 17,060 \\
\hline
\end{tabular}

Notes: All Ns are unweighted. ${ }^{1}$ Excludes toilets/bathrooms but includes kitchen. ${ }^{2}$ Includes oil, gas, etc. ${ }^{3}$ Includes water from spring, river, stream, pond, lake, dam, rain, water tanker truck, and water can bottles. ${ }^{4}$ Includes electricity, straw, shrubs, and grass. 


\subsection{Profille of households by ownership of agricultural land}

Table 2.3 presents information on ownership of agricultural land (irrigated and non-irrigated) for households in both rural and urban areas. Most households either owned no land (64\%) or had marginal holdings (33\%). These proportions were much higher for urban households ( $85 \%$ and $12 \%$, respectively) than for rural households (61\% and $35 \%$, respectively). One-third of households reported owning some irrigated land.

\section{Table 2.3: Household ownership of agricultural land}

Percent distribution of surveyed households by size of agricultural land owned and percentage of households owning irrigated land, according to residence, Bihar, 2016

\begin{tabular}{lccc}
\hline Landholding & Combined (percent) & Urban (percent) & Rural (percent) \\
\hline Landholding (in acres) & & & \\
Landless & 63.8 & 85.2 & 61.4 \\
Marginal ( $\leq 2.50)$ & 32.5 & 11.9 & 34.9 \\
Small (2.51-5) & 2.5 & 1.7 & 2.6 \\
Medium (5.01-10) & 0.9 & 0.8 & 0.9 \\
Large (>10) & 0.3 & 0.4 & 0.2 \\
Percentage owning any irrigated land & 31.2 & 11.8 & 33.3 \\
Number of households & $\mathbf{3 3 , 9 0 0}$ & $\mathbf{1 6 , 8 4 0}$ & $\mathbf{1 7 , 0 6 0}$ \\
\hline
\end{tabular}

Notes: All Ns are unweighted. Column totals may not equal 100\% because of don't know' responses.

\subsection{Household economic status}

The survey measured household economic status, using a wealth index composed of household asset data on ownership of selected durable goods, including means of transportation, as well as data on access to a number of amenities. The wealth index was constructed by allocating the following scores to a household's reported assets or amenities:

Type of house: 2 for pucca; 1 for semi-pucca; 0 for kachcha.

Agricultural land owned: 5 for more than 10 acres; 4 for 5.1-10 acres; 3 for 2.6-5 acres; 2 for less than 2.6 acres, or if the household owns some land but does not know how much; 0 for no land.

Irrigated land owned: 1 for any irrigated land; 0 for no irrigated land.

Access to toilet facility: 4 for own flush toilet; 2 for shared flush toilet or own pit toilet; 1 for shared pit toilet or other types of toilet; 0 for no toilet facility.

Cooking fuel used: 2 for liquid petroleum gas, electricity, or bio-gas; 1 for kerosene, wood, crop residue, dung cakes, coal, or charcoal; 0 for other types of cooking fuel, for example, straw, shrubs, or grass.

Access to drinking water facility: 4 for own piped water, hand-pump, or covered well; 3 for own open well; 2 for public or shared piped water, hand-pump, or covered well; 1 for public or shared open well; 0 for other sources of drinking water, for example, surface water, water tanker/truck, or rainwater.

Access to electricity: 3 for electricity; 0 for no electricity.

Ownership of household assets: 4 for car or truck; 3 each for motorcycle or scooter, refrigerator, computer/laptop, telephone (landline or mobile), colour television; 2 each for bicycle, electric fan, sewing machine, thresher, water pump, animal-drawn cart; 1 for watch or clock; 0 for each of the above items that the household does not possess. 
Index scores so constructed ranged from 0 to 57 . Households were then ranked according to the index score. This ranked sample was divided into quintiles-that is, five groups, each containing an equal number of households-with the first quintile representing households of the lowest (poorest) wealth status and the fifth quintile representing households with the highest (wealthiest) status. Wealth quintiles were developed at the state level on the basis of the weighted sample for the whole state.

Table 2.4 presents the findings. As far as ownership of household assets was concerned, the items most likely to be owned were a telephone (92\%), a bicycle (68\%), a watch or clock (56\%), an electric fan (48\%), and a television set (22\%). There were considerable differences between rural and urban households, with rural households far less likely than urban households to report ownership of most items. Thus, while 88 percent of urban households owned an electric fan, just 44 percent of rural households owned one; and while 66 percent of urban households owned a television set, just 17 percent of rural households owned one. Just five percent of all households did not own a single item in the list of assets, and the difference between urban and rural households on this measure was negligible.

The distribution of households by wealth quintiles shows that about three-fifths (57\%) of urban households were in the wealthiest (fifth) quintile; in contrast, only one-sixth (16\%) of rural households were in this quintile. Likewise, 22 percent of rural households were in the poorest (first) quintile of the index compared with only six percent of urban households.

\section{Table 2.4: Household assets and wealth status}

Percentage of surveyed households owning selected household assets and percent distribution of households by wealth quintile, according to residence, Bihar, 2016

\begin{tabular}{|c|c|c|c|}
\hline Housing characteristics & Combined (percent) & Urban (percent) & Rural (percent) \\
\hline \multicolumn{4}{|l|}{ Assets owned } \\
\hline Electric fan & 48.0 & 87.6 & 43.5 \\
\hline Television & 21.5 & 65.8 & 16.6 \\
\hline Sewing machine & 13.5 & 30.2 & 11.7 \\
\hline Telephone (landline/mobile) & 92.0 & 96.7 & 91.4 \\
\hline Personal computer/laptop & 2.2 & 11.6 & 1.1 \\
\hline Refrigerator & 4.8 & 30.1 & 1.9 \\
\hline Watch/clock & 56.3 & 82.7 & 53.3 \\
\hline Bicycle & 67.7 & 68.1 & 67.7 \\
\hline Motorcycle/scooter & 15.5 & 34.4 & 13.4 \\
\hline Animal-drawn cart & 0.4 & 0.4 & 0.4 \\
\hline Car/truck & 1.0 & 4.3 & 0.7 \\
\hline Water pump & 7.9 & 22.0 & 6.3 \\
\hline Thresher & 0.8 & 0.3 & 0.9 \\
\hline Tractor & 1.2 & 0.5 & 1.2 \\
\hline None of the above & 4.8 & 1.4 & 5.2 \\
\hline \multicolumn{4}{|l|}{ Wealth quintile } \\
\hline First & 20.0 & 6.0 & 21.6 \\
\hline Second & 20.0 & 5.7 & 21.6 \\
\hline Third & 20.0 & 8.8 & 21.3 \\
\hline Fourth & 20.0 & 22.7 & 19.7 \\
\hline Fifth & 20.0 & 56.8 & 15.8 \\
\hline Number of households & 33,900 & 16,840 & 17,060 \\
\hline
\end{tabular}

Note: All Ns are unweighted. 


\subsection{Profile of rural households by extent to which household members have benefited from MNREGA}

In total, just four percent of rural households had benefited from the MNREGA scheme in the year preceding the interview. Findings presented in Table 2.5 show that the extent to which rural households had benefited from the scheme did not differ by socio-demographic characteristics of heads of the households.

\section{Table 2.5 Rural households that had benefited from the MNREGA scheme}

Percentage of surveyed rural households that had benefited from the MNREGA scheme in the year preceding the interview by selected socio-demographic characteristics of heads of households, Bihar, 2016

\begin{tabular}{|c|c|c|}
\hline Socio-demographic characteristics & Percent & Number \\
\hline \multicolumn{3}{|l|}{ Sex of household head } \\
\hline Male & 4.2 & 14,104 \\
\hline Female & 2.4 & 2,956 \\
\hline \multicolumn{3}{|l|}{ Age of household head } \\
\hline Below 25 & 2.4 & 730 \\
\hline $25-34$ & 3.5 & 3,443 \\
\hline $35-44$ & 4.2 & 4,132 \\
\hline $45-54$ & 4.9 & 3,283 \\
\hline 55 and above & 3.6 & 5,472 \\
\hline \multicolumn{3}{|l|}{ Religion of household head } \\
\hline Hindu & 4.3 & 14,902 \\
\hline Muslim & 1.7 & 2,121 \\
\hline Christian & $(2.8)$ & 31 \\
\hline Other ${ }^{1}$ & * & 6 \\
\hline \multicolumn{3}{|l|}{ Caste/tribe of household head } \\
\hline SC & 7.4 & 3,898 \\
\hline ST & 4.5 & 203 \\
\hline OBC & 3.0 & 10,965 \\
\hline General $^{2}$ & 2.1 & 1,994 \\
\hline \multicolumn{3}{|c|}{ Educational level of household head (in years of schooling completed) } \\
\hline None $^{3}$ & 4.2 & 9,039 \\
\hline $1-7$ & 4.3 & 2,788 \\
\hline $8-10$ & 3.5 & 3,710 \\
\hline $11-12$ & 2.5 & 829 \\
\hline Above 12 & 2.2 & 694 \\
\hline \multicolumn{3}{|l|}{ Wealth quintile } \\
\hline First & 5.0 & 5,406 \\
\hline Second & 4.7 & 5,103 \\
\hline Third & 4.4 & 3,499 \\
\hline Fourth & 3.0 & 2,048 \\
\hline Fifth & 1.9 & 1,004 \\
\hline
\end{tabular}


Table 2.5 Cont.

\begin{tabular}{lrr}
\hline Socio-demographic characteristics & Percent & Number \\
\hline Landholding (in acres) & 4.7 & 10,458 \\
Landless & 2.8 & 5,974 \\
Marginal ( $\leq 2.50)$ & 1.6 & 425 \\
Small $(2.51-5)$ & 0.0 & 159 \\
Medium (5.01-10) & $(2.0)$ & 44 \\
Large $(>10)$ & $\mathbf{3 . 9}$ & $\mathbf{1 7 , 0 6 0}$ \\
Total & & $\mathbf{0}$ \\
\hline
\end{tabular}

Notes: All Ns are unweighted. *Percentage not shown as this was based on fewer than 25 unweighted cases. () Based on $25-49$ unweighted cases. OBC: other backward caste. SC: scheduled caste. ST: scheduled tribe. ${ }^{1}$ Includes Buddhist/Neo-Buddhist, Sikh, Jain, and no specified religion. ${ }^{2}$ Includes all those not belonging to SCS, STs, or OBCs. ${ }^{3}$ Includes non-literate and literate with no formal schooling.

\subsection{Profille of the household population by substance use}

Table 2.6 summarises findings related to substance use among members of the surveyed households. Findings highlight that consumption of tobacco products was widespread-at least one household member consumed tobacco products in 68 percent of the households. Findings show, moreover,very wide differences by sex in substance use-a larger proportion of households reported consumption of tobacco products by male members than female members (66\% versus $5 \%)$. There were noticeable differences between rural and urban households in substance use-more rural than urban households contained at least one member who consumed tobacco products (69\% versus $60 \%$ ).

Fewer households contained at least one member who consumed alcohol (29\%). Almost all of these households contained a male member who consumed alcohol, and less than one percent of households contained a female member who consumed alcohol. Findings also show that differences between rural and urban households in alcohol consumption were mild.

Even fewer households contained at least one member who consumed drugs (5\%), and almost all of these households reported drug use by a male member; there was little difference between rural and urban households with regard to drug use by household members.

\section{Table 2.6: Substance use among household population}

Percentage of households by substance use among household members, according to residence, Bihar, 2016

\begin{tabular}{|c|c|c|c|}
\hline Substance use by household members & Combined (percent) & Urban (percent) & Rural (percent) \\
\hline \multicolumn{4}{|l|}{ Tobacco } \\
\hline At least one household member & 68.1 & 59.7 & 69.0 \\
\hline Only male members & 63.1 & 56.5 & 63.9 \\
\hline Only female members & 1.9 & 1.0 & 2.0 \\
\hline Both male and female members & 3.1 & 2.2 & 3.2 \\
\hline \multicolumn{4}{|l|}{ Alcohol } \\
\hline At least one household member & 29.3 & 26.4 & 29.6 \\
\hline Only male members & 29.0 & 26.1 & 29.3 \\
\hline Only female members & 0.1 & 0.2 & 0.1 \\
\hline Both male and female members & 0.1 & 0.1 & 0.2 \\
\hline \multicolumn{4}{|l|}{ Drugs } \\
\hline At least one household member & 5.2 & 5.1 & 4.1 \\
\hline Only male members & 4.9 & 3.9 & 5.0 \\
\hline Only female members & 0.2 & 0.2 & 0.1 \\
\hline Both male and female members & 0.1 & 0.1 & 0.0 \\
\hline Number of households & 33,900 & 16,840 & 17,060 \\
\hline
\end{tabular}

Note: All Ns are unweighted. 


\subsection{Background characteristics of surveyed adolescents}

We interviewed a total of 10,433 adolescents. Table 2.7 presents the socio-demographic characteristics of surveyed adolescents. Age profiles show that the married girls were older than their unmarried counterparts, with 66 percent of married older girls compared with 22 percent of unmarried older girls falling into the age group of 18-19 years. Among older adolescents (but not among younger ones), there were differences between those from rural areas and those from urban areas. Urban adolescents were older than rural adolescents-34 percent of urban boys compared with 26 percent of rural boys fell into the age group of 18-19 years; the corresponding proportions were 29 percent and 21 percent for unmarried older girls and 75 percent and 65 percent for married older girls.

The distribution of adolescents by religion was fairly similar to that observed for the heads of households $-84-88$ percent of adolescents were Hindu and 12-16 percent were Muslim. Differences in religious distribution by age, sex, place of residence, and, among older girls, by marital status were mild.

The caste-wise distribution was generally similar to that observed for the heads of households-two-thirds (64-67\%) belonged to other backward castes, 20-26 percent belonged to scheduled castes, $7-15$ percent belonged to general castes, and less than one percent belonged to scheduled tribes. Differences by age and gender were mild. However, there were notable differences by marital status-a smaller proportion of married older girls than their unmarried counterparts belonged to general castes ( $7 \%$ versus $15 \%$ ). Caste differences between rural adolescents and urban adolescents were also evident; urban adolescents were more likely than rural adolescents to belong to general castes $(12-25 \%$ versus $7-13 \%)$.

Table 2.7: Background characteristics of surveyed adolescents

Percent distribution of surveyed adolescents by selected background characteristics, according to residence, Bihar, 2016

\begin{tabular}{|c|c|c|c|c|c|c|c|c|c|c|}
\hline \multirow[t]{2}{*}{ Background characteristics } & \multicolumn{2}{|c|}{$\begin{array}{c}\text { Boys } \\
(10-14)\end{array}$} & \multicolumn{2}{|c|}{$\begin{array}{c}\text { Boys } \\
(15-19)\end{array}$} & \multicolumn{2}{|c|}{$\begin{array}{c}\text { Girls } \\
(10-14)\end{array}$} & \multicolumn{2}{|c|}{$\begin{array}{c}\text { Girls } \\
(15-19)\end{array}$} & \multicolumn{2}{|c|}{$\begin{array}{c}\text { Married girls } \\
(15-19)\end{array}$} \\
\hline & Percent & Number & Percent & Number & Percent & Number & Percent & Number & Percent & Number \\
\hline \multicolumn{11}{|c|}{ Combined } \\
\hline \multicolumn{11}{|l|}{ Age } \\
\hline $10-12$ & 64.0 & 634 & NA & NA & 58.2 & 446 & NA & NA & NA & NA \\
\hline $13-14$ & 36.0 & 378 & NA & NA & 41.8 & 318 & NA & NA & NA & NA \\
\hline $15-17$ & NA & NA & 73.4 & 1,267 & NA & NA & 78.1 & 2,553 & 33.6 & 1,096 \\
\hline $18-19$ & NA & NA & 26.6 & 554 & NA & NA & 21.9 & 875 & 66.4 & 2,312 \\
\hline \multicolumn{11}{|l|}{ Religion } \\
\hline Hindu & 85.7 & 868 & 85.9 & 1,577 & 84.6 & 618 & 83.8 & 2,721 & 88.3 & 2,956 \\
\hline Muslim & 14.1 & 142 & 14.0 & 242 & 15.4 & 144 & 15.8 & 700 & 11.5 & 443 \\
\hline Other ${ }^{1}$ & * & 2 & * & 2 & * & 2 & * & 7 & * & 9 \\
\hline \multicolumn{11}{|l|}{ Caste } \\
\hline SC & 20.9 & 206 & 21.3 & 350 & 21.4 & 142 & 19.5 & 582 & 26.2 & 903 \\
\hline ST & * & 8 & * & 24 & * & 5 & * & 23 & * & 21 \\
\hline OBC & 65.3 & 635 & 63.6 & 1,131 & 67.2 & 496 & 65.2 & 2,149 & 65.7 & 2,216 \\
\hline General $^{2}$ & 12.9 & 163 & 13.3 & 316 & 10.8 & 121 & 14.6 & 674 & 7.3 & 268 \\
\hline \multicolumn{11}{|l|}{ Wealth quintile } \\
\hline First & 12.2 & 93 & 6.9 & 81 & 15.1 & 88 & 10.1 & 238 & 13.4 & 436 \\
\hline Second & 23.2 & 154 & 17.8 & 196 & 17.9 & 109 & 15.5 & 352 & 19.0 & 572 \\
\hline Third & 22.7 & 180 & 21.5 & 276 & 21.7 & 125 & 19.9 & 491 & 23.0 & 713 \\
\hline Fourth & 22.1 & 232 & 28.6 & 460 & 23.5 & 163 & 26.3 & 815 & 26.4 & 864 \\
\hline Fifth & 19.8 & 353 & 25.3 & 808 & 21.8 & 279 & 28.2 & 1,532 & 18.2 & 823 \\
\hline
\end{tabular}


Table 2.7 Cont.

\begin{tabular}{|c|c|c|c|c|c|c|c|c|c|c|}
\hline \multirow[t]{2}{*}{ Background characteristics } & \multicolumn{2}{|c|}{$\begin{array}{c}\text { Boys } \\
(10-14)\end{array}$} & \multicolumn{2}{|c|}{$\begin{array}{c}\text { Boys } \\
(15-19)\end{array}$} & \multicolumn{2}{|c|}{$\begin{array}{c}\text { Girls } \\
(10-14)\end{array}$} & \multicolumn{2}{|c|}{$\begin{array}{c}\text { Girls } \\
(15-19)\end{array}$} & \multicolumn{2}{|c|}{$\begin{array}{l}\text { Married girls } \\
\text { (15-19) }\end{array}$} \\
\hline & Percent & Number & Percent & Number & Percent & Number & Percent & Number & Percent & Number \\
\hline \multicolumn{11}{|l|}{$\begin{array}{l}\text { Mother's education (in years } \\
\text { of schooling completed) }\end{array}$} \\
\hline None $^{3}$ & 78.0 & 692 & 76.8 & 1,173 & 77.7 & 522 & 72.1 & 2,175 & 82.4 & 2,802 \\
\hline $1-7$ & 8.2 & 106 & 8.4 & 192 & 10.6 & 87 & 9.1 & 370 & 8.5 & 283 \\
\hline $8-9$ & 6.2 & 76 & 6.3 & 157 & 4.2 & 51 & 8.8 & 302 & 4.7 & 160 \\
\hline 10 and above & 7.5 & 138 & 8.5 & 299 & 7.5 & 104 & 10.0 & 581 & 4.4 & 163 \\
\hline Total & 100.0 & 1,012 & 100.0 & 1,821 & 100.0 & 764 & 100.0 & 3,428 & 100.0 & 3,408 \\
\hline \multicolumn{11}{|c|}{ Urban } \\
\hline \multicolumn{11}{|l|}{ Age } \\
\hline 10-12 & 64.6 & 284 & NA & NA & 54.8 & 219 & NA & NA & NA & NA \\
\hline $13-14$ & 35.4 & 168 & NA & NA & 45.2 & 168 & NA & NA & NA & NA \\
\hline $15-17$ & NA & NA & 66.1 & 667 & NA & NA & 70.8 & 1,228 & 24.8 & 373 \\
\hline 18-19 & NA & NA & 33.9 & 341 & NA & NA & 29.2 & 510 & 75.2 & 993 \\
\hline \multicolumn{11}{|l|}{ Religion } \\
\hline Hindu & 82.9 & 377 & 84.8 & 855 & 78.6 & 291 & 77.4 & 1,293 & 82.8 & 1,150 \\
\hline Muslim & 17.1 & 75 & 15.1 & 152 & 21.2 & 94 & 22.5 & 443 & 16.4 & 210 \\
\hline Other ${ }^{1}$ & * & 0 & * & 1 & * & 2 & * & 2 & * & 6 \\
\hline \multicolumn{11}{|l|}{ Caste } \\
\hline SC & 16.7 & 78 & 16.5 & 173 & 11.3 & 56 & 14.9 & 251 & 22.7 & 353 \\
\hline ST & * & 4 & * & 5 & * & 2 & $\star$ & 8 & * & 5 \\
\hline $\mathrm{OBC}$ & 57.9 & 267 & 60.9 & 615 & 66.5 & 244 & 60.0 & 1,052 & 64.4 & 866 \\
\hline General $^{2}$ & 23.3 & 103 & 22.1 & 215 & 21.8 & 85 & 24.6 & 427 & 12.4 & 142 \\
\hline \multicolumn{11}{|l|}{ Wealth quintile } \\
\hline First & * & 23 & * & 20 & * & 24 & $(2.4)$ & 46 & 5.2 & 105 \\
\hline Second & * & 19 & $(4.2)$ & 45 & (9.1) & 34 & 4.1 & 76 & 7.4 & 142 \\
\hline Third & $(9.8)$ & 49 & 8.2 & 79 & $(9.6)$ & 35 & 7.6 & 141 & 11.8 & 188 \\
\hline Fourth & 18.9 & 96 & 22.7 & 233 & 17.3 & 75 & 19.4 & 335 & 26.6 & 376 \\
\hline Fifth & 63.1 & 265 & 63.2 & 631 & 59.4 & 219 & 66.4 & 1,140 & 49.1 & 555 \\
\hline \multicolumn{11}{|l|}{$\begin{array}{l}\text { Mother's education (in years } \\
\text { of schooling completed) }\end{array}$} \\
\hline None $^{3}$ & 49.8 & 241 & 52.5 & 539 & 47.3 & 210 & 50.9 & 912 & 78.0 & 1,099 \\
\hline $1-7$ & 13.6 & 58 & 12.4 & 120 & 16.7 & 57 & 12.2 & 214 & 8.5 & 117 \\
\hline $8-9$ & $(13.2)$ & 46 & 10.8 & 111 & $(8.4)$ & 36 & 10.1 & 176 & 5.7 & 69 \\
\hline 10 and above & 23.4 & 107 & 24.2 & 238 & 27.6 & 84 & 26.8 & 436 & 7.8 & 81 \\
\hline Total & 100.0 & 452 & 100.0 & 1,008 & 100.0 & 387 & 100.0 & 1,738 & 100.0 & 1,366 \\
\hline \multicolumn{11}{|c|}{ Rural } \\
\hline \multicolumn{11}{|l|}{ Age } \\
\hline $10-12$ & 64.0 & 350 & NA & NA & 58.6 & NA & NA & NA & NA & NA \\
\hline 13-14 & 36.0 & 210 & NA & NA & 41.4 & NA & NA & NA & NA & NA \\
\hline $15-17$ & NA & NA & 74.3 & 600 & NA & 227 & 79.0 & 1,325 & 34.6 & 723 \\
\hline 18-19 & NA & NA & 25.7 & 213 & NA & 150 & 21.0 & 365 & 65.4 & 1,319 \\
\hline
\end{tabular}


Table 2.7 Cont.

\begin{tabular}{|c|c|c|c|c|c|c|c|c|c|c|}
\hline \multirow[t]{2}{*}{ Background characteristics } & \multicolumn{2}{|c|}{$\begin{array}{c}\text { Boys } \\
(10-14)\end{array}$} & \multicolumn{2}{|c|}{$\begin{array}{c}\text { Boys } \\
(15-19)\end{array}$} & \multicolumn{2}{|c|}{$\begin{array}{c}\text { Girls } \\
(10-14)\end{array}$} & \multicolumn{2}{|c|}{$\begin{array}{c}\text { Girls } \\
(15-19)\end{array}$} & \multicolumn{2}{|c|}{$\begin{array}{l}\text { Married girls } \\
\qquad(15-19)\end{array}$} \\
\hline & Percent & Number & Percent & Number & Percent & Number & Percent & Number & Percent & Number \\
\hline \multicolumn{11}{|l|}{ Religion } \\
\hline Hindu & 86.1 & 491 & 86.1 & 722 & 85.3 & 327 & 84.5 & 1,428 & 88.9 & 1,806 \\
\hline Muslim & 13.8 & 67 & 13.8 & 90 & 14.7 & 50 & 15.0 & 257 & 11.0 & 233 \\
\hline Other $^{1}$ & * & 2 & * & 1 & * & 0 & * & 5 & * & 3 \\
\hline \multicolumn{11}{|l|}{ Caste } \\
\hline SC & 21.4 & 128 & 21.9 & 177 & 22.7 & 86 & 20.1 & 331 & 26.6 & 550 \\
\hline ST & * & 4 & * & 19 & * & 3 & * & 15 & * & 16 \\
\hline OBC & 66.2 & 368 & 64.0 & 516 & 67.3 & 252 & 65.8 & 1,097 & 65.8 & 1,350 \\
\hline General $^{2}$ & 11.7 & 60 & 12.2 & 101 & $(9.4)$ & 36 & 13.4 & 247 & 6.7 & 126 \\
\hline \multicolumn{11}{|l|}{ Wealth quintile } \\
\hline First & 13.1 & 70 & 7.5 & 61 & 16.4 & 64 & 11.0 & 192 & 14.4 & 331 \\
\hline Second & 25.5 & 135 & 19.5 & 151 & 19.0 & 75 & 16.9 & 276 & 20.3 & 430 \\
\hline Third & 24.2 & 131 & 23.2 & 197 & 23.2 & 90 & 21.4 & 350 & 24.2 & 525 \\
\hline Fourth & 22.5 & 136 & 29.3 & 227 & 24.3 & 88 & 27.1 & 480 & 26.4 & 488 \\
\hline Fifth & 14.7 & 88 & 20.6 & 177 & 17.3 & 60 & 23.6 & 392 & 14.7 & 268 \\
\hline \multicolumn{11}{|l|}{$\begin{array}{l}\text { Mother's education (in years } \\
\text { of schooling completed) }\end{array}$} \\
\hline None $^{3}$ & 81.4 & 451 & 79.8 & 634 & 81.4 & 312 & 74.7 & 1,263 & 82.9 & 1,703 \\
\hline $1-7$ & (7.6) & 48 & 7.9 & 72 & $(9.8)$ & 30 & 8.8 & 156 & 8.5 & 166 \\
\hline $8-9$ & $(5.4)$ & 30 & (5.8) & 46 & * & 15 & 8.6 & 126 & 4.6 & 91 \\
\hline 10 and above & (5.6) & 31 & 6.6 & 61 & * & 20 & 8.0 & 145 & 4.0 & 82 \\
\hline Total & 100.0 & 560 & 100.0 & 813 & 100.0 & 377 & 100.0 & 1,690 & 100.0 & 2,042 \\
\hline
\end{tabular}

Notes: All Ns are unweighted. *Percentage not shown as this was based on fewer than 25 unweighted cases. () Based on 25-49 unweighted cases. NA: not applicable. OBC: other backward caste. SC: scheduled caste. ST: scheduled tribe. ${ }^{1}$ Includes Buddhist/Neo-Buddhist, Sikh, Jain, and no specified religion. ${ }^{2}$ Includes all those not belonging to SCs, STs, or OBCs. ${ }^{3}$ Includes non-literate and literate with no formal schooling.

Household economic status distributions, as measured by wealth quintiles, were generally similar for girls and boys. There were, however, differences in the distribution of younger and older adolescents, unmarried and married older girls, and rural and urban adolescents on the basis of wealth quintiles. Younger adolescents were more likely than older adolescents to belong to households in the poorest quintile (12\% of younger boys versus $7 \%$ of older boys and $15 \%$ of younger girls versus $10 \%$ of unmarried older girls) and conversely, less likely to belong to households in the wealthiest quintile (20\% versus $25 \%$ among boys and $22 \%$ versus $28 \%$ among girls). Married older girls were less likely than unmarried older girls to belong to households in the wealthiest quintile (18\% versus $28 \%$ ). Rural adolescents were less likely than their urban counterparts to belong to households in the wealthiest quintile (15-24\% versus $49-66 \%)$.

The study also inquired about the years of schooling that mothers of adolescents had successfully completed. Mothers of the majority of adolescents had no formal education-mothers of 72-82 percent of adolescents had no formal education. Except for mothers of married older girls, more mothers of rural than urban adolescents had no formal education (75-81\% versus 47-53\%). However, the differences were modest for married older girls,among whom 78 percent of mothers from urban areas compared with 83 percent of mothers from rural areas had no formal education. Mothers of just 4-10 percent of adolescents had completed 10 or more years of education; fewer mothers of rural adolescents, other than married older girls, had completed 10 or more years of education, compared with their urban counterparts (6-8\% versus $23-28 \%$ ); differences were negligible for the mothers of married older girls. 


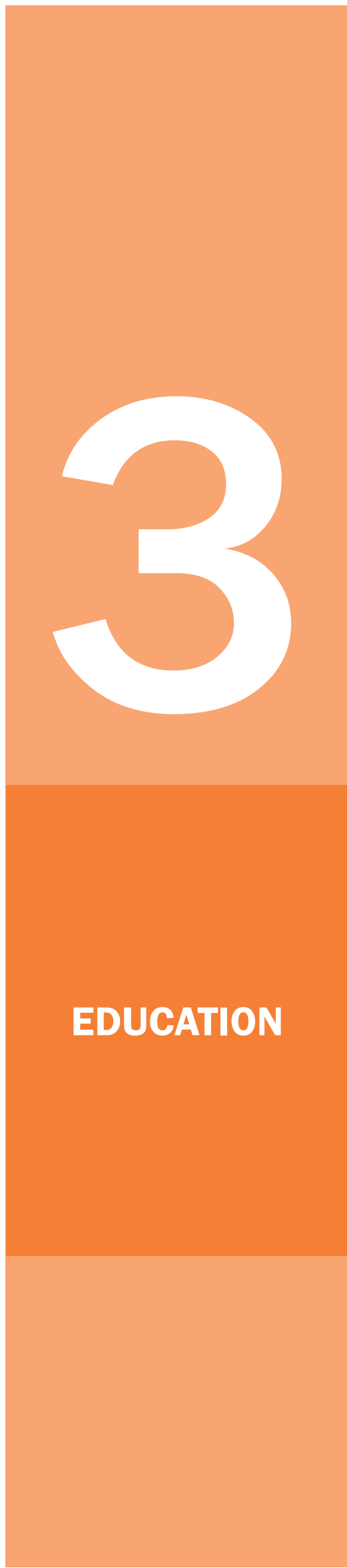

\section{A Snapshot}

\section{Educational attainment, school attendance, and learning outcomes}

Enrolment in school is nearly universal, except among older girls:

- $99 \%$ of younger boys

- $97 \%$ of older boys

- $95 \%$ of younger girls

- $91 \%$ of unmarried older girls

- $71 \%$ of married older girls were ever enrolled in school
Regular attendance is not common:

- $60 \%$ of younger boys

- $70 \%$ of older boys

- $62 \%$ of younger girls

- $59 \%$ of unmarried older girls

- $48 \%$ of married older girls who were currently enrolled in a school/ college reported attendance on all days of the week preceding the interview
Current enrolment in school is far from universal, particularly among older adolescents:

- $94 \%$ of younger boys

- $80 \%$ of older boys

- $90 \%$ of younger girls

- $72 \%$ of unmarried older girls

- $18 \%$ of married older girls were enrolled in a school/college or distance education programme at the time of the interview

Not all adolescents in ages 15-19 have completed primary school:

- $79 \%$ of older boys

- $73 \%$ of older girls

- $46 \%$ of married older girls had completed eight or more years of schooling
Completion of secondary school among adolescents in ages 18-19 is limited:

- $60 \%$ of boys

- $64 \%$ of girls

- $26 \%$ of married girls had completed 10 or more years of schooling 


\section{Learning levels are mediocre}

- $86 \%$ of younger boys

- $77 \%$ of older boys

- $83 \%$ of younger girls

- $69 \%$ of unmarried older girls

- $58 \%$ of married older girls who had completed Classes 8-9 were able to read a Class 2 text fluently in Hindi
- $72 \%$ of younger boys

- $66 \%$ of older boys

- $72 \%$ of younger girls

- $50 \%$ of unmarried older girls

- $33 \%$ of married older girls who had completed Classes 8-9 were able to solve a simple division problem

The gender gap has disappeared on many indicators of education-ever enrolment in school among younger adolescents, median years of schooling completed, and completion of secondary education-yet school retention, regular attendance, and learning outcomes are gendered

Married older girls are disadvantaged on many indicators of education-enrolment in school, school continuation, completion of primary and secondary education, and acquisition of literacy and numeracy skills

While rural disadvantage is not apparent in ever enrolment in school and school retention, it persists in regular attendance, completion of secondary education, and learning outcomes

First-generation learners have a long way to catchup in primary and secondary school completion and learning outcomes

\section{Facilities/school infrastructure}

Enrolment in government educational institutions is widespread:

- $86 \%$ of younger boys

- $84 \%$ of older boys

- 91\% each of younger girls and unmarried older girls, and

- $94 \%$ of married older girls who were enrolled in a school/college at the time of interview were enrolled in government educational institutions
Access to drinking water in schools is nearly universal:

- $97 \%$ of younger boys

- $98 \%$ of older boys

- $98 \%$ of younger girls, and

- $97 \%$ each of unmarried older girls and married older girls had access to drinking water in the school in which they were studying (if in school/college at the time of the interview) or in the last school they had attended (if they had discontinued schooling) 


\section{A Snapshot}

Most adolescents had access to toilet facilities in working condition:

- $68 \%$ of younger boys

- $76 \%$ of older boys

- $85 \%$ of younger girls

- $88 \%$ of unmarried older girls, and

- $86 \%$ of married older girls had access to toilet facilities in working condition in the school in which they were studying (if in school/college at the time of the interview) or in the last school they had attended (if they had discontinued schooling)
The majority of adolescents sought private tuition:

- $68 \%$ of younger boys

- $61 \%$ of older boys

- $61 \%$ of younger girls

- $50 \%$ of unmarried older girls, and

- $20 \%$ of married older girls who were enrolled in a school/college at the time of the interview had taken private tuition in the month prior to the interview

\section{Aspirations and entitlements}

Educational aspirations are high:

- $54 \%$ of younger boys

- $79 \%$ of older boys

- $87 \%$ of married older girls who were currently enrolled in a school/college aspired to complete at least senior secondary education (Class 12)
- $59 \%$ of younger girls

- $84 \%$ of unmarried older girls, and

Awareness and reach of entitlements from school are widespread among adolescents who were enrolled in a class eligible to receive entitlements at the time of the interview or in the year preceding the interview in a government school:

- $99 \%$ each of younger boys and older boys

- $99 \%$ of younger girls

- $100 \%$ of unmarried older girls, and

- $97 \%$ of married older girls were aware of provision of free uniforms

- $98 \%$ of older boys

- $98 \%$ of unmarried older girls, and

- $99 \%$ of married older girls were aware of scholarships
- 99\% of younger boys

- $98 \%$ of older boys

- $99 \%$ of younger girls, and

- 98\% each of unmarried and married older girls were aware of provision of free textbooks

- $82 \%$ of younger boys

- $74 \%$ of older boys

- $92 \%$ of younger girls, and

- $94 \%$ of unmarried older girls had received the midday meal on the last day that he/she had attended school 


\section{A Snapshot}

- $90 \%$ of younger boys

- $78 \%$ of older boys

- $94 \%$ of younger girls

- $96 \%$ of unmarried older girls, and

- 93\% of married older girls had received free uniforms or money to buy uniforms

- $55 \%$ of older boys

- $72 \%$ of unmarried older girls, and

- $66 \%$ of married older girls had received a scholarship
- $92 \%$ of younger boys

- $83 \%$ of older boys

- 94\% of younger girls

- $86 \%$ of unmarried older girls, and

- 94\% of married older girls had received free textbooks or money to buy textbooks

- $73 \%$ of older boys

- $82 \%$ of unmarried older girls, and

- $85 \%$ of married older girls had received money to buy a bicycle 
In India, several programmes have been initiated to promote universal school enrolment and school completion. These include the Sarva Shiksha Abhiyan, which aims to universalise elementary education (Ministry of Human Resource Development [MOHRD], 2011); the Rashtriya Madhyamik Shiksha Abhiyan, which seeks to provide universal access to secondary education by 2017 and enhance and universalise retention by 2020 (MOHRD, 2009); and the recently launched Beti Bachao Beti Padhao, a nationwide campaign exhorting people to celebrate and educate the girl child (Ministry of Women and Child Development [MOWCD], 2015). Statistics show, moreover, that educational attainment levels have increased, the percentage who have never been to school has declined, and differences by sex in education attainment levels have diminished (MOHRD, 2016a). Even so, the 2011 census data show that just 42 percent of women in ages 18-24 and 49 percent of men in the same age group had completed Class 10 (Office of the Registrar General and Census Commissioner, India, 2015h). These low educational attainment levels point to the sluggish progress of adolescents in successfully completing secondary education. Equally concerning is evidence from recent studies in India that highlights the poor learning levels among both girls and boys transitioning into secondary education (ASER Centre, 2017; Educational Initiatives, 2010; National Council of Educational Research and Training [NCERT], 2012). This chapter examines the educational attainment and school attendance among adolescents, the type and quality of the educational institutions they most recently attended, their schooling experiences, their educational aspirations, their awareness of entitlements from school and the reach of those entitlements, and their literacy and numeracy skills.

\subsection{Educational attainment}

The survey conducted under UDAYA sought to ascertain whether respondents were ever enrolled in school and, if so, the number of years of schooling successfully completed and current enrolment status. It also recorded the enrolment status of older adolescents from age 10 onwards by using a Life Event Calendar (LEC).

Findings presented in Table 3.1 highlight that school enrolment was nearly universal and differences by sex in enrolment were modest among all adolescents other than married older girls: just 1-3 percent of younger and older boys and 5-9 percent of younger girls and unmarried older girls had never been to school. However, as many as 29 percent of married older girls had never been to school. Findings show, moreover, that differences between rural adolescents and urban adolescents with regard to non-enrolment in school were mild, except for married older girls, among whom a larger proportion of rural than urban respondents had never attended school (30\% versus $23 \%$ ).

\section{Table 3.1: Educational attainment and current educational status}

Percent distribution of adolescents by years of schooling successfully completed, median years of schooling, and percentage currently in school, according to residence, Bihar, 2016

\begin{tabular}{|c|c|c|c|c|c|}
\hline Schooling status & $\begin{array}{c}\text { Boys } \\
(10-14)\end{array}$ & $\begin{array}{c}\text { Boys } \\
(15-19)\end{array}$ & $\begin{array}{c}\text { Girls } \\
(10-14)\end{array}$ & $\begin{array}{c}\text { Girls } \\
(15-19)\end{array}$ & $\begin{array}{l}\text { Married girls } \\
\qquad(15-19)\end{array}$ \\
\hline \multicolumn{6}{|c|}{ Combined (percent) } \\
\hline \multicolumn{6}{|c|}{ Completed years of schooling and current schooling status } \\
\hline None $^{1}$ & 1.3 & 3.4 & 4.9 & 8.6 & 29.4 \\
\hline $1-4$ & 33.2 & 3.4 & 29.7 & 4.3 & 6.8 \\
\hline $5-7$ & 49.4 & 14.5 & 51.9 & 14.7 & 17.4 \\
\hline $8-9$ & 16.1 & 49.2 & 13.5 & 40.6 & 24.8 \\
\hline $10-11$ & NA & 19.9 & NA & 22.2 & 13.0 \\
\hline 12 and above & NA & 9.6 & NA & 9.7 & 8.6 \\
\hline Median years of schooling & 5 & 9 & 5 & 9 & 7 \\
\hline Currently in school & 93.7 & 78.3 & 90.1 & 66.2 & 13.4 \\
\hline Attending distance education programmes & 0.0 & 1.2 & 0.0 & 5.3 & 4.6 \\
\hline Number of respondents & 1,012 & 1,821 & 764 & 3,428 & 3,408 \\
\hline
\end{tabular}


Table 3.1 Cont.

\begin{tabular}{|c|c|c|c|c|c|}
\hline Schooling status & $\begin{array}{c}\text { Boys } \\
(10-14)\end{array}$ & $\begin{array}{c}\text { Boys } \\
(15-19)\end{array}$ & $\begin{array}{c}\text { Girls } \\
(10-14)\end{array}$ & $\begin{array}{c}\text { Girls } \\
(15-19)\end{array}$ & $\begin{array}{l}\text { Married girls } \\
\text { (15-19) }\end{array}$ \\
\hline \multicolumn{6}{|c|}{ Urban (percent) } \\
\hline \multicolumn{6}{|c|}{ Completed years of schooling and current schooling status } \\
\hline None $^{1}$ & 1.8 & 4.1 & 3.4 & 5.2 & 23.3 \\
\hline $1-4$ & 34.8 & 3.7 & 28.4 & 3.1 & 4.9 \\
\hline $5-7$ & 47.4 & 10.6 & 47.8 & 9.6 & 14.8 \\
\hline $8-9$ & 16.1 & 33.3 & 20.4 & 32.2 & 26.2 \\
\hline $10-11$ & NA & 28.3 & NA & 28.9 & 16.2 \\
\hline 12 and above & NA & 20.0 & NA & 21.0 & 14.6 \\
\hline Median years of schooling & 5 & 9 & 6 & 9 & 8 \\
\hline Currently in school & 94.0 & 76.2 & 92.0 & 72.3 & 14.3 \\
\hline Attending distance education programmes & 0.0 & 2.3 & 0.1 & 6.4 & 7.3 \\
\hline Number of respondents & 452 & 1,008 & 387 & 1,738 & 1,366 \\
\hline \multicolumn{6}{|c|}{ Rural (percent) } \\
\hline \multicolumn{6}{|c|}{ Completed years of schooling and current schooling status } \\
\hline None $^{1}$ & 1.2 & 3.3 & 5.0 & 9.0 & 30.1 \\
\hline $1-4$ & 33.0 & 3.4 & 29.9 & 4.4 & 7.0 \\
\hline $5-7$ & 49.7 & 15.0 & 52.5 & 15.3 & 17.7 \\
\hline $8-9$ & 16.1 & 51.1 & 12.6 & 41.5 & 24.6 \\
\hline $10-11$ & NA & 18.8 & NA & 21.4 & 12.6 \\
\hline 12 and above & NA & 8.3 & NA & 8.4 & 7.9 \\
\hline Median years of schooling & 5 & 9 & 5 & 9 & 7 \\
\hline Currently in school & 93.7 & 78.6 & 89.8 & 65.5 & 13.3 \\
\hline Attending distance education programmes & 0.0 & 1.0 & 0.0 & 5.1 & 4.3 \\
\hline Number of respondents & 560 & 813 & 377 & 1,690 & 2,042 \\
\hline
\end{tabular}

Notes: All Ns are unweighted. NA: not applicable. IIncludes non-literate and literate with no formal schooling.

The average number of years of education among adolescents was five years for younger boys and girls and 7-9 years for older boys and girls. No differences by sex were observed in this regard. Among girls, there were differences by marital status-unmarried older girls, on average, had two more years of schooling than their married counterparts (9 years versus 7 years). There were no differences in median years of schooling between those from rural areas and those from urban areas among younger and older boys and unmarried older girls. However, there were differences among younger girls and married older girls. Younger girls and married older girls in urban areas typically had one more year of schooling than their rural counterparts ( 6 years in urban areas for younger girls versus 5 years in rural areas; 8 years in urban areas for married older girls versus 7 years in rural areas).

Figure 3.1 presents the percentage of adolescents who had achieved selected educational milestones among those in ages 10-14 who had completed Class 5, those in ages 15-19 who had completed Class 8 , and those in ages 18-19 who had completed Class 10. 
Figure 3.1: Percentage of adolescents who had achieved selected educational milestones, according to residence, Bihar, 2016
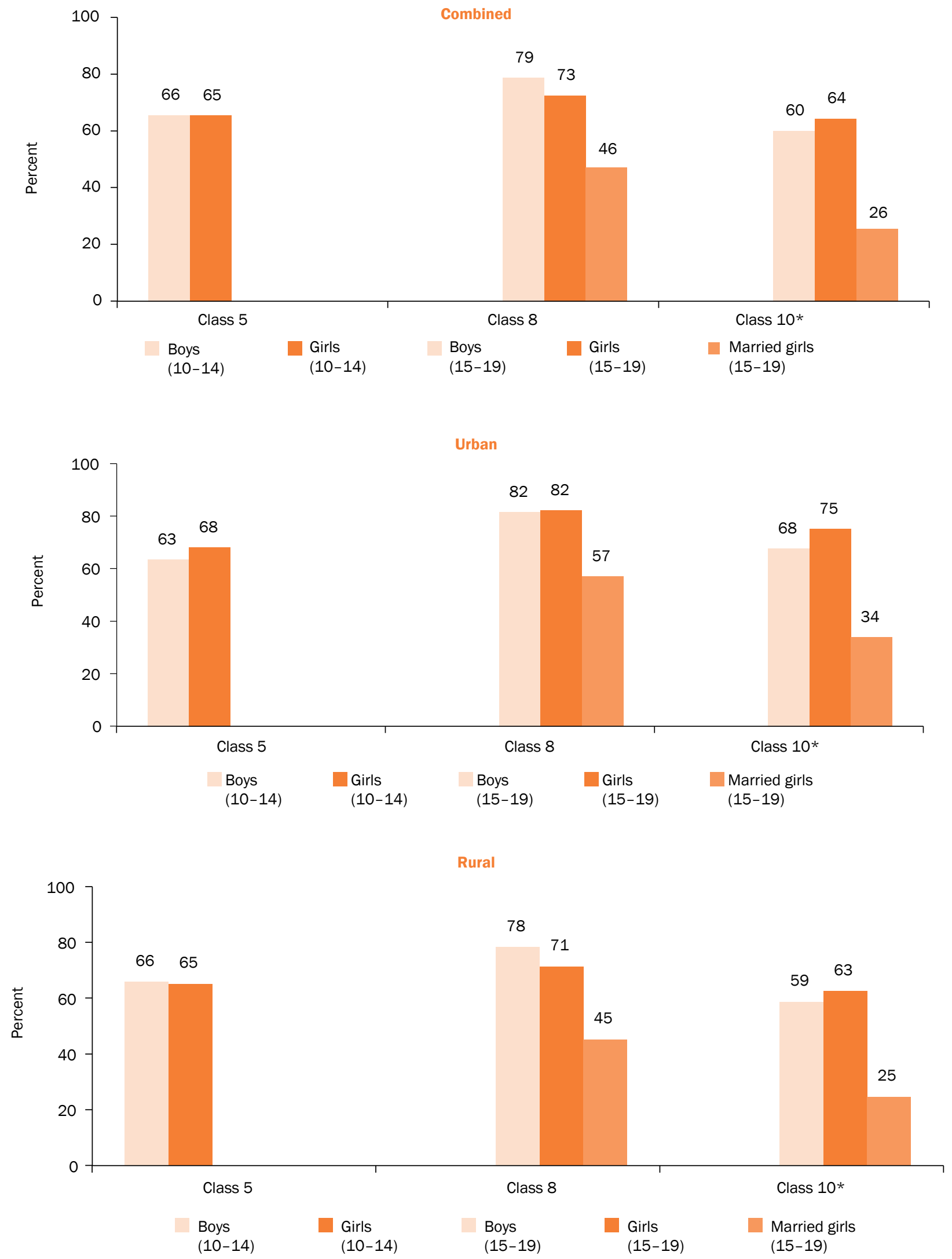

Note: *Adolescents in ages $18-19$ years. 
Findings reiterate that while differences by sex in the attainment of selected educational milestones had disappeared at the lower levels (that is, at Class 5), some mild differences persisted at higher levels (that is, at Classes 8 and 10). Specifically, 66 percent and 65 percent of boys and girls, respectively, among those in ages 10-14 had completed five or more years of schooling. Among older adolescents, however, 79 percent of boys compared with 73 percent of unmarried girls had completed eight or more years of schooling. Finally, among adolescents in ages 18-19, those who had completed 10 or more years of schooling constituted 60 percent among boys and 64 percent among unmarried girls. Among girls in ages 15-19, differences by marital status were wide: 73 percent of unmarried girls compared with 46 percent of married girls had completed eight or more years of schooling, and among 18-19-yearold girls, 64 percent of unmarried girls compared with 26 percent of married girls had completed 10 or more years of schooling. We mention that disparities by marital status may be wider than those reflected here, because the unmarried were younger than the married and a larger proportion of the unmarried than the married were pursuing their education at the time of the interview. Differences in educational attainment levels between adolescents of rural areas and those from urban areas were mixed. Specifically, among younger adolescents, we observed no differences with regard to the completion of Class 5 in both urban and rural areas (63-68\% of younger boys and girls in urban areas versus $65-66 \%$ of those in rural areas). Among older boys, we observed no differences with regard to the completion of Class 8 , but among those in ages 18-19, more urban than rural boys had completed Class 10 ( $68 \%$ of urban boys versus $59 \%$ of rural boys). Among unmarried and married older girls, more urban girls compared with rural girls had completed Class 8 ( $82 \%$ of urban unmarried older girls versus $71 \%$ of rural unmarried older girls; $57 \%$ of urban married older girls versus $45 \%$ of rural married older girls). Likewise, among unmarried and married girls in ages $18-19$, more urban than rural girls had completed Class 10 ( $75 \%$ of urban unmarried girls versus $63 \%$ of rural unmarried girls; $34 \%$ of urban married girls versus $25 \%$ of rural married girls).

Findings presented in Table 3.1 also show that retention in school was far from universal even among younger adolescents despite the introduction of the Right to Education Act, 2009, that has made primary education free and compulsory. Furthermore, we found that there were differences by sex in the extent of school retention, with more boys than girls likely to be enrolled in a regular school. At the time of interview, 94 percent of younger boys and 90 percent of younger girls were in school. This proportion fell to 78 percent and 66 percent among older boys and unmarried older girls, respectively, and to 13 percent among married older girls. Differences in school retention between those from rural areas and those from urban areas were negligible among all categories of adolescents, except for unmarried older girls, among whom somewhat more urban than rural respondents were enrolled in a school or college at the time of the interview (72\% versus $66 \%$ ). Finally, some 1-5 percent of older adolescents were currently pursuing distance education programmes, with little differences by sex, place of residence, or-for older girls-marital status.

\subsection{Differentials in educational attainment}

Differentials in educational levels of adolescent boys and girls, measured with respect to percentage of younger adolescents who had completed five or more years of schooling and percentage of older adolescents who had completed 10 or more years of schooling, are presented in Table 3.2. In general, findings suggest a positive association between age and years of education completed among adolescents, irrespective of sex. Differences by religion indicate that adolescents from the Muslim community tended to be more disadvantaged than adolescents belonging to the Hindu community across all categories of adolescents, except among older boys. Among younger adolescents, 56 percent of Muslim boys had completed at least five years of education compared with 67 percent of Hindu boys; the corresponding proportions by religion among younger girls were 54 percent and 68 percent. Among unmarried older girls, similarly, while 24 percent of Muslim girls had completed at least 10 years of education, 33 percent of Hindu girls had done so. Similar patterns were observed among married older girls ( $14 \%$ and $23 \%$ for Muslim and Hindu girls, respectively).

Caste differences were marked among younger and older adolescents. Those belonging to general castes were the most likely to have completed five or more years of schooling among adolescents in ages 10-14 and the most likely to have completed 10 or more years of schooling among adolescents in ages 15-19, while both younger and older adolescents who belonged to scheduled castes were the least likely to have completed these respective educational milestones. Among younger adolescents, for example, 74 percent of boys belonging to general castes compared with 65 percent of those belonging to scheduled castes had completed five or more years of schooling; the corresponding 
proportions among younger girls were 75 percent and 63 percent. Similar differences were noted among older adolescents with regard to the completion of 10 or more years of schooling ( $42 \%$ and $25 \%$ among older boys; $52 \%$ and $18 \%$ among unmarried older girls; and $30 \%$ and $15 \%$ among married older girls).

Findings show that there is a positive association between the economic status of adolescents' households, measured in wealth quintiles, and adolescents' educational attainment levels, particularly among older adolescents. Among younger boys, 58 percent of boys from households in the poorest (first) quintile had completed five or more years of schooling, compared with 71 percent of those from households in the wealthiest (fifth) quintile. Among younger girls, the differences by household wealth index were inconsistent. Among older adolescents, completion of 10 or more years of schooling steadily increased with the household wealth index, regardless of sex, and, among older girls, of marital status. Specifically, 12 percent of boys from the poorest quintile households compared with 41 percent of those from the wealthiest quintile households had completed 10 or more years of schooling; the corresponding proportions among unmarried older girls were 12 percent and 55 percent and among married older girls, they were six percent and 47 percent.

Findings also show an association between years of schooling completed by adolescents and their mother's level of education. Regardless of the age and sex of adolescents and the marital status of older girls, adolescents whose mother had no schooling were less likely than those whose mother had completed 10 or more years of schooling to have completed selected educational milestones, that is, at least Class 5 among younger adolescents and at least Class 10 among older adolescents. Furthermore, educational attainment levels increased steadily with the educational attainment levels of mothers among younger boys and unmarried and married older girls (but not among older boys and younger girls). Among unmarried older girls whose mother had no education, for example, only 22 percent had completed at least Class 10 compared with 70 percent of those whose mother had completed 10 or more years of schooling; the corresponding proportions among married older girls were 18 percent and 76 percent.

\section{Table 3.2: Educational attainment of adolescents by selected background characteristics}

Percentage of younger adolescents who had completed five or more years of schooling and older adolescents who had completed 10 or more years of schooling, according to selected background characteristics, Bihar, 2016

\begin{tabular}{|c|c|c|c|c|c|}
\hline Background characteristics (percent) & $\begin{array}{c}\text { Boys } \\
(10-14)\end{array}$ & $\begin{array}{c}\text { Girls } \\
(10-14)\end{array}$ & $\begin{array}{c}\text { Boys } \\
(15-19)\end{array}$ & $\begin{array}{c}\text { Girls } \\
(15-19)\end{array}$ & $\begin{array}{l}\text { Married girls } \\
(15-19)\end{array}$ \\
\hline \multicolumn{6}{|l|}{ Age } \\
\hline $10-12$ & 51.3 & 50.7 & NA & NA & NA \\
\hline $13-14$ & 90.9 & 85.9 & NA & NA & NA \\
\hline $15-17$ & NA & NA & 18.5 & 22.9 & 13.5 \\
\hline $18-19$ & NA & NA & 60.0 & 64.3 & 25.7 \\
\hline \multicolumn{6}{|l|}{ Religion $^{1}$} \\
\hline Hindu & 67.1 & 67.6 & 30.1 & 33.3 & 22.7 \\
\hline Muslim & 55.6 & 53.5 & 25.8 & 24.4 & 13.7 \\
\hline \multicolumn{6}{|l|}{ Caste $^{2}$} \\
\hline SC & 64.5 & 63.4 & 25.1 & 18.1 & 15.2 \\
\hline $\mathrm{OBC}$ & 63.8 & 64.4 & 28.1 & 31.6 & 23.2 \\
\hline General $^{3}$ & 73.9 & 74.7 & 41.6 & 51.9 & 30.2 \\
\hline \multicolumn{6}{|l|}{ Wealth quintile } \\
\hline First & 58.4 & 48.1 & 11.9 & 11.8 & 6.2 \\
\hline Second & 63.5 & 53.9 & 25.6 & 15.2 & 10.9 \\
\hline Third & 64.1 & 66.5 & 20.8 & 23.6 & 14.4 \\
\hline Fourth & 68.4 & 81.0 & 32.9 & 31.6 & 25.5 \\
\hline Fifth & 70.8 & 69.0 & 40.6 & 54.5 & 47.2 \\
\hline
\end{tabular}


Table 3.2 Cont.

\begin{tabular}{|c|c|c|c|c|c|}
\hline Background characteristics (percent) & $\begin{array}{c}\text { Boys } \\
(10-14)\end{array}$ & $\begin{array}{c}\text { Girls } \\
(10-14)\end{array}$ & $\begin{array}{c}\text { Boys } \\
(15-19)\end{array}$ & $\begin{array}{c}\text { Girls } \\
(15-19)\end{array}$ & $\begin{array}{l}\text { Married girls } \\
(15-19)\end{array}$ \\
\hline \multicolumn{6}{|l|}{$\begin{array}{l}\text { Mother's education (in years of schooling } \\
\text { completed) }\end{array}$} \\
\hline None $^{4}$ & 63.1 & 62.6 & 26.3 & 22.1 & 17.8 \\
\hline $1-7$ & 68.7 & 81.4 & 34.4 & 50.6 & 24.1 \\
\hline $8-9$ & 75.7 & 72.4 & 29.5 & 50.4 & 31.8 \\
\hline 10 and above & 78.9 & 67.6 & 53.9 & 70.1 & 76.3 \\
\hline Total & 65.5 & 65.4 & 29.5 & 31.9 & 21.6 \\
\hline
\end{tabular}

Notes: NA: not applicable; OBC: other backward caste; SC: scheduled caste; ST: scheduled tribe. ${ }^{1}$ Percentages not shown for those belonging to other religions as less than one percent of surveyed adolescents belonged to other religions. ${ }^{2}$ Percentages not shown for those belonging to STs as less than one percent of surveyed adolescents belonged to STs. ${ }^{3}$ Includes all those not belonging to SCs, STs, or OBCs. ${ }^{4}$ Includes non-literate and literate with no formal schooling.

\subsection{School retention and class completion}

Figure 3.2 presents school retention percentages among adolescents of ages 15-19. The survey sought to establish whether study participants were in school at ages 10,12, and 15, that is, the ages before or after the attainment of puberty for many. Several findings are notable. First, school retention declined steadily as boys and girls transitioned from early adolescence to late adolescence. While 94 percent of boys and 88 percent of unmarried girls were in school at age 10, fewer ( $85 \%$ and $80 \%$, respectively) were in school at age 15; the corresponding decline was steeper among married girls ( $64 \%$ to $45 \%)$. Second, at each of these ages, somewhat more boys than unmarried girls were in school (94\% versus $88 \%$ at age $10 ; 92 \%$ versus $87 \%$ at age 12 ; and $85 \%$ versus $80 \%$ at age 15 ). Third, among girls, a larger proportion of unmarried than married girls were in school at each of these ages (88\% versus $64 \%$ at age 10 ; $87 \%$ versus $61 \%$ at age 12 ; and $80 \%$ versus $45 \%$ at age 15 ). Finally, while similar proportions of boys were in school at each of these ages in rural and urban areas, more urban than rural unmarried and married girls were in school at each of these ages.

Figure 3.2: Percentage of adolescents in ages $15-19$ who were in school at ages 10,12 , and $15,{ }^{1}$ according to residence, Bihar, 2016

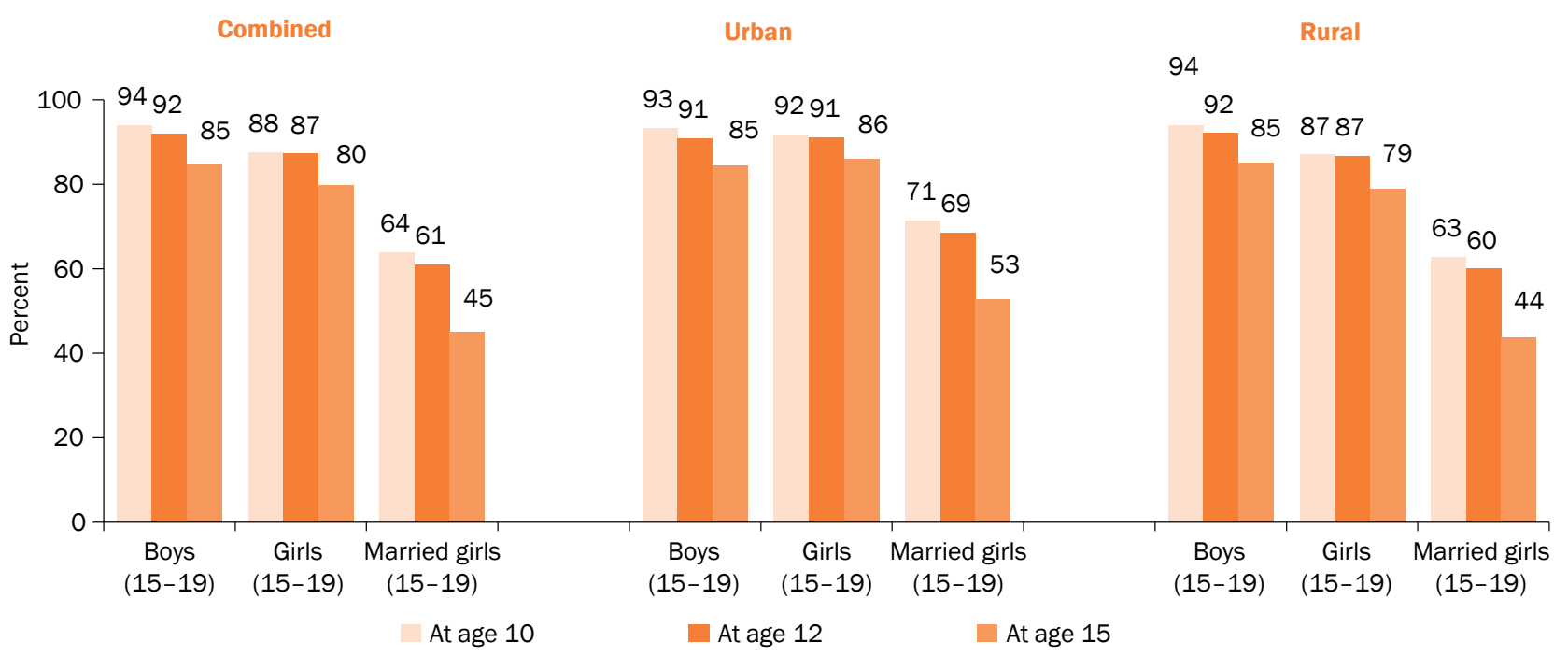

Note: ${ }^{1}$ Includes those who were pursuing their education through distance education programmes. 
Using life table techniques, the survey presents in Figures 3.3a-3.3c the cumulative percentages of older adolescents (all adolescents with at least one year of schooling) who had completed each year of education from Class 2 to Class $13 .{ }^{1}$ Findings show that over 90 percent of boys and unmarried girls who had completed at least one year of schooling remained in school up to Class 8 (89-90\%), while a similar proportion of married girls remained in school up to Class 5 (90\%). Declines in school completion became more evident thereafter. Indeed, major declines (five percentage points or more annually) in school completion levels occurred at different classes for boys, unmarried girls, and married girls. For boys, such a decline occurred between Classes 12 and 13; specifically, while 78 percent of boys had completed Class 12, those who had completed Class 13 constituted 62 percent. For unmarried girls, such declines occurred between Classes 8 and 9 (90\% to 85\%), Classes 9 and 10 (85\% to 79\%), Classes 10 and 11 (79\% to $72 \%)$ and Classes 12 and 13 (71\% to 51\%). Such declines in school completion levels occurred as early as Classes 5-6 among married girls: while 90 percent of married girls had completed Class 5, just 80 percent had completed Class 6 , which highlights the disadvantaged family environment of girls who get married in adolescent ages. Moreover, such declines continued steadily in subsequent classes among married girls.

\section{Figure 3.3a: Cumulative percentage of adolescents in ages 15-19 who had completed each year of education} (Classes 1-13), combined, Bihar, 2016

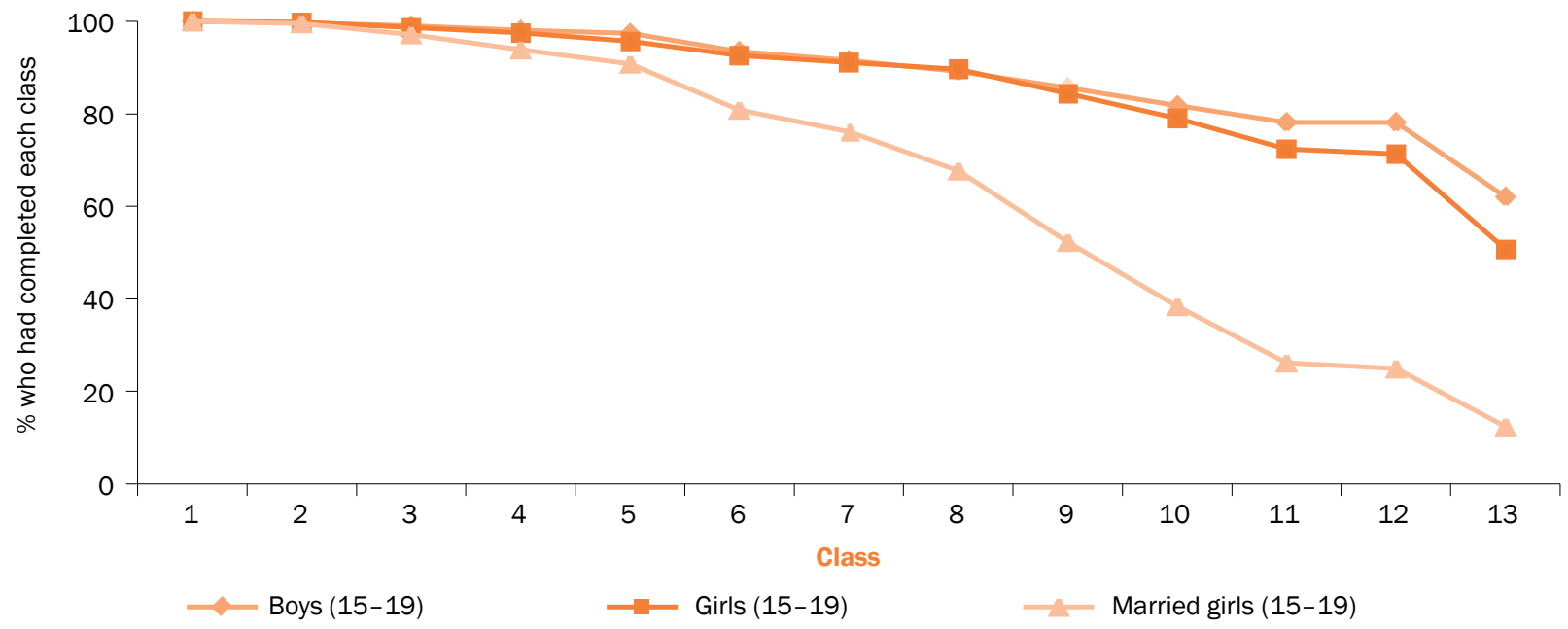

Note: Nine boys, 24 unmarried older girls, and 19 married older girls who reported that they had completed 14 years or more of education were excluded from the analysis, since children typically get enrolled in Class 1 after they have completed six years of age and are, therefore, unlikely to have completed 14 years of schooling by age 19.

Figure 3.3b: Cumulative percentage of adolescents in ages 15-19 who had completed each year of education (Classes 1-13), urban, Bihar, 2016

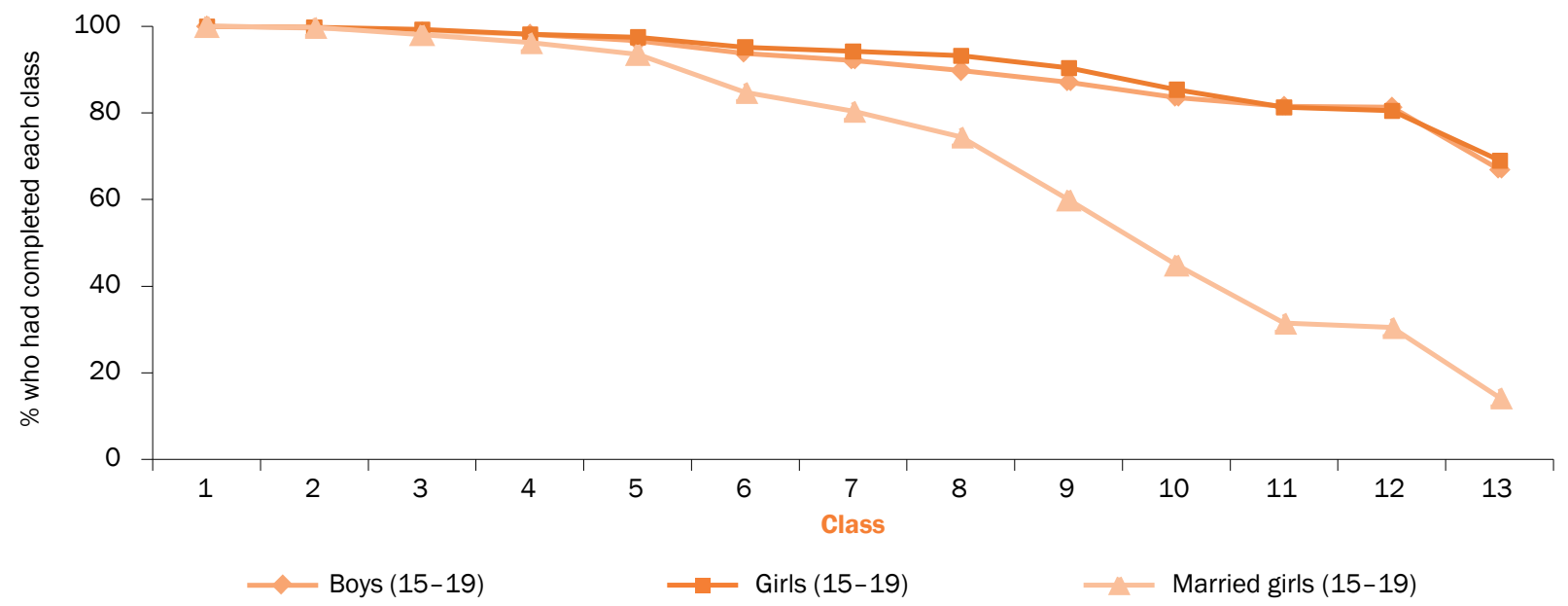

\footnotetext{
${ }^{1}$ Classes above 12 refer to years of college attended.
} 
Figure 3.3c: Cumulative percentage of adolescents in ages 15-19 who had completed each year of education (Classes 1-13), rural, Bihar, 2016

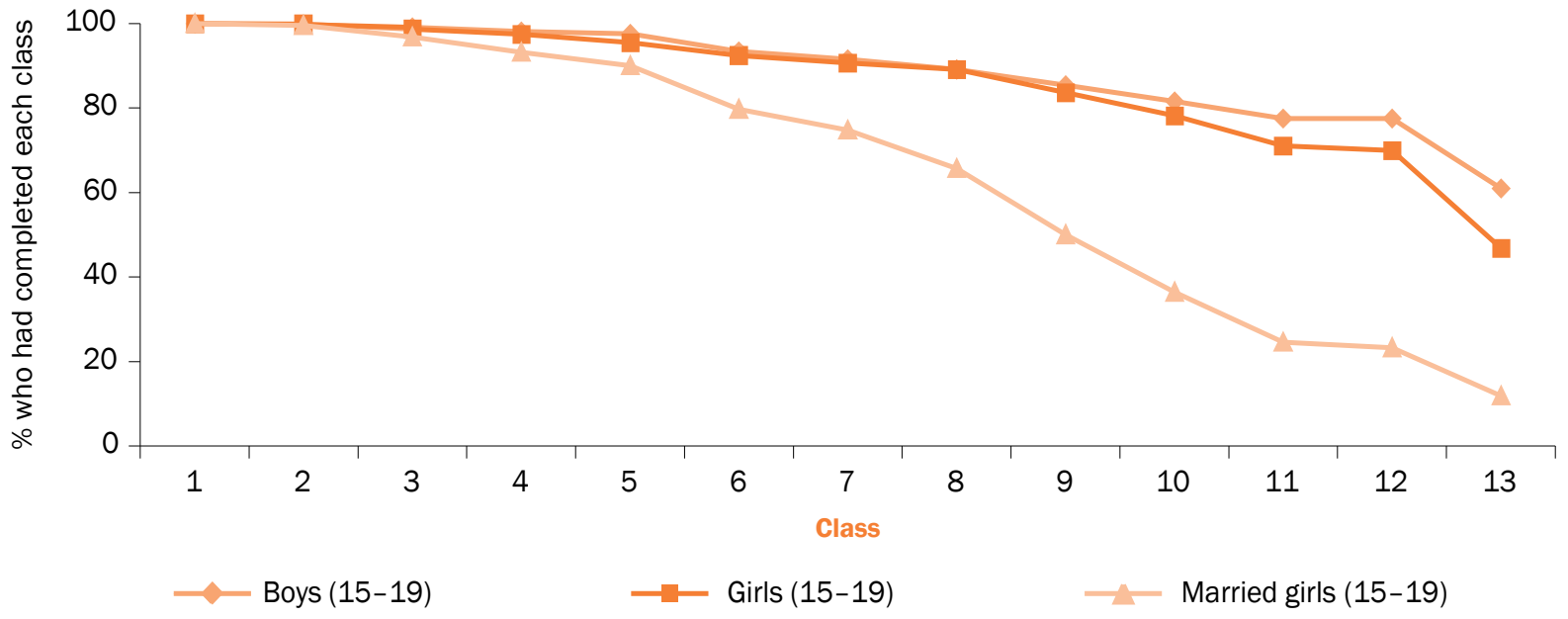

As seen above, differences by sex in school completion levels were evident among older adolescents. Major declines in school completion occurred earlier among girls than boys; for example, a decline of five percentage points or more annually first occurred between Classes 8 and 9 among unmarried girls compared with such declines between Classes 12 and 13 among boys. Moreover, boys were more likely to remain in school than girls after Class 10 . As described earlier, marital status differences in school continuation were evident among girls, with steep declines occurring earlier among married than among unmarried girls. The patterns of school completion in rural and urban areas resembled that of the combined sample described above (Figures 3.3b and 3.3c).

\subsection{Reasons for never enrolling in school or school discontinuation}

The survey probed the reasons for never enrolling in school from adolescents who so reported. It also probed the reasons for discontinuation of schooling among adolescents-that is, among younger adolescents who had discontinued schooling at the time of the interview and among older adolescents who had discontinued schooling before completing Class 12. Responses on reasons for those who had never gone to school have been grouped into five categories: economic reasons (work on the family farm or business, wage-earning work, family poverty, that is, the family could not afford to send the respondent to school); housework-related reasons (required for care of siblings or housework); attitude-or perception-related reasons (unsafe to send children to school, education not considered necessary by respondent or parents, respondent's lack of interest); school-related reasons (school located too far away, appropriate transport not available, poor quality school and infrastructure, poor quality of teaching, including corporal punishment perpetrated by teachers, lack of female teachers); and health-related reasons (health problems of respondent, illness or death of a family member). It is to be noted that since the number of younger adolescents who were never enrolled in a school or who had discontinued their schooling at the time of the interview was small, findings on younger adolescents are not described in this section.

Table 3.3a shows that attitudes or perceptions on education were the key reason for never enrolling in school across all categories of older adolescents. Thus, among older adolescents, three-fifths of boys and girls, including married girls, cited one attitude- or perception-related reason (61-62\%). The respondent's lack of interest predominated among attitude- or perception-related reasons among boys, while parental perceptions that education is not necessary and respondent's lack of interest together predominated among girls. The second most commonly cited reason was that related to economic factors, particularly that the family could not afford to keep the respondent in school-23 percent of boys and 27-28 percent of unmarried and married girls reported an economic reason. Notable proportions of unmarried and married girls attributed their non-enrolment in school to housework-related reasons as well (24-29\% percent of unmarried and married girls). Only a few adolescents (7-10\%) cited school-related reasons. Finally, 14 percent of boys, and nine percent of unmarried, and 10 percent of married girls cited a health-related reason for their never having enrolled in school. 
Table 3.3a: Reasons for never enrolling in school

Percentage of adolescents in ages 15-19 who were never enrolled in school by reasons, Bihar, 2016

\begin{tabular}{|c|c|c|c|}
\hline Reasons (percent) & $\begin{array}{c}\text { Boys } \\
(15-19)\end{array}$ & $\begin{array}{c}\text { Girls } \\
(15-19)\end{array}$ & $\begin{array}{c}\text { Married girls } \\
(15-19)\end{array}$ \\
\hline \multicolumn{4}{|l|}{ Economic reasons } \\
\hline Required for work on family farm/business & 7.5 & 10.1 & 5.8 \\
\hline Required for outside work for payment in cash/kind & 7.0 & 8.5 & 5.2 \\
\hline Family could not afford it (cost too much) & 17.0 & 13.4 & 19.5 \\
\hline At least one economic reason & 22.5 & 27.5 & 27.3 \\
\hline \multicolumn{4}{|l|}{ Housework-related reasons } \\
\hline Required for household work & 0.0 & 26.5 & 20.0 \\
\hline Required for care of siblings & 4.6 & 9.0 & 4.8 \\
\hline At least one housework-related reason & 4.6 & 29.3 & 23.5 \\
\hline \multicolumn{4}{|l|}{ Attitudes and perceptions of parents and adolescents } \\
\hline Not safe to send girls/boys to school & 0.0 & 1.1 & 2.0 \\
\hline Education not considered necessary (respondent) & 3.7 & 8.4 & 8.9 \\
\hline Education not considered necessary (parents) & 5.1 & 36.2 & 28.2 \\
\hline Respondent not interested in studies & 56.0 & 19.1 & 26.1 \\
\hline At least one attitude-/perception-related reason & 61.6 & 60.9 & 62.1 \\
\hline \multicolumn{4}{|l|}{ School-related reasons } \\
\hline School too far away/transport not available & 4.2 & 6.6 & 7.0 \\
\hline $\begin{array}{l}\text { Poor quality of school facilities and teaching, includir } \\
\text { of corporal punishment, lack of female teachers }\end{array}$ & 3.0 & 1.7 & 2.9 \\
\hline At least one school-related reason & 7.1 & 8.3 & 9.7 \\
\hline \multicolumn{4}{|l|}{ Health-related reasons } \\
\hline Respondent's illness & 13.1 & 1.6 & 0.2 \\
\hline IIIness or death of a family member & 1.2 & 7.7 & 9.3 \\
\hline At least one health-related reason & 14.2 & 9.3 & 9.6 \\
\hline Number who were never enrolled in school & 57 & 237 & 1,047 \\
\hline
\end{tabular}

Note: All Ns are unweighted.

Table 3.3b reports findings for older adolescents who had discontinued their education before completing Class 12. In addition to the five sets of reasons included above, an additional category-early transition into adult roles, which contained such reasons as marriage and employment-was included.

As with never enrolling in school, the most frequently cited reason among older adolescents for school discontinuation was related to attitudes and perceptions-52 percent of boys cited at least one attitude- or perception-related reason as did 40 percent and 36 percent of unmarried girls and married girls, respectively. The leading attitude- or perception-related reason among boys was respondent's lack of interest in studies (45\%), and the leading reasons among girls were parental perceptions that education is not necessary (13-15\%) and respondent's lack of interest in studies (14-18\%). A considerable proportion of adolescents reported economic and housework-related reasons for their discontinuation of school. Specifically, 44 percent of boys and 14-27 percent of girls attributed their school discontinuation to economic reasons. While boys were likely to cite work on the family farm or business, wageearning work, and family poverty (15-19\%), girls cited primarily family poverty (11-20\%). Some 15-22 percent of girls cited housework-related reasons. Findings also show that girls were more likely than boys to attribute their school 
discontinuation to school-related reasons-14-23 percent of girls and eight percent of boys cited at least one schoolrelated reason. Some eight percent of boys and 9-13 percent of girls cited health-related reasons for discontinuing schooling. About two-fifths of married girls reported that they had discontinued their education because they had got engaged or married. Findings also show that concerns about girls' safety or experience of menstruation were rarely cited as a reason for school discontinuation (2-3\% and less than $1 \%$, respectively).

Among girls, differences by marital status in reported reasons were apparent- married girls were less likely than their unmarried counterparts to report economic reasons (14\% versus $27 \%$ ), housework-related reasons (15\% versus $22 \%$ ), and school-related reasons (14\% versus $23 \%$ ) and more likely to report reasons related to transition into adult roles (37\% versus $0.1 \%)$.

\section{Table 3.3b: Reasons for school discontinuation}

Percentage of adolescents in ages 15-19 who had discontinued schooling before completing Class 12 by reasons, Bihar, 2016

\begin{tabular}{lccc}
\hline Reasons (percent) & Boys & Girls & Married girls \\
\hline
\end{tabular}

\section{Economic reasons}

Required for work on family farm/business

$\begin{array}{rrr}18.5 & 4.6 & 2.6 \\ 17.4 & 3.1 & 1.3 \\ 14.6 & 19.6 & 11.4 \\ \mathbf{4 3 . 7} & \mathbf{2 6 . 7} & \mathbf{1 4 . 1}\end{array}$

\section{At least one economic reason}

43.7

26.7

14.1

\section{Housework-related reasons}

Required for household work

Required for care of siblings

\section{At least one housework-related reason}

\section{6}

\section{5}

14.7

Attitudes and perceptions of parents and adolescents

Not safe to send girls/boys to school

Education not considered necessary (respondent)

Education not considered necessary (parents)

Respondent not interested in studies

At least one attitude-/perception-related reason

\section{School-related reasons}

School too far away/transport not available

Poor quality of school facilities and teaching, including perpetration of corporal punishment, lack of female teachers

Failure

$$
\begin{aligned}
& 3.2 \\
& 4.1
\end{aligned}
$$

At least one school-related reason

\section{Health-related reasons}

Respondent's illness

IIIness or death of a family member

Started menstruating 
Table 3.3b Cont.

\begin{tabular}{|c|c|c|c|}
\hline Reasons (percent) & $\begin{array}{c}\text { Boys } \\
(15-19)\end{array}$ & $\begin{array}{c}\text { Girls } \\
(15-19)\end{array}$ & $\begin{array}{c}\text { Married girls } \\
(15-19)\end{array}$ \\
\hline \multicolumn{4}{|l|}{ Transition into adult roles } \\
\hline Got job & 0.5 & 0.1 & 0.0 \\
\hline Got married/engaged & NA & NA & 36.6 \\
\hline At least one reason related to transition into adult roles & 0.5 & 0.1 & 36.6 \\
\hline \multicolumn{4}{|l|}{ Other reasons } \\
\hline Session result awaited & 0.0 & 3.4 & 0.5 \\
\hline Migrated to another place & 2.1 & 0.5 & 0.3 \\
\hline Number who discontinued schooling before completing Class 12 & 297 & 557 & 1,639 \\
\hline
\end{tabular}

Notes: All Ns are unweighted. NA: not applicable.

\subsection{School/college type, quality, and experiences}

Interviewers asked respondents about the kind of school or college in which they were enrolled at the time of interview $^{2}$ or at the time of discontinuing their education and the facilities available in that school or college. They also asked respondents about their experiences: their attendance in class in the week prior to the interview; whether private coaching was received; their perceptions about their performance in the last class in which they were enrolled; and whether they had held a leadership position in the school.

\subsubsection{School/college type and quality}

Figure 3.4 presents findings on the type of educational institutions in which adolescents were enrolled at the time of the interview or at the time of discontinuing their education among those who were ever enrolled in school. The vast majority of adolescents, regardless of age and sex, and, among older girls, of marital status, were enrolled in a government educational institution-84-86 percent of boys and 91-94 percent of girls. Just 14-16 percent of boys and 6-9 percent of girls were enrolled in a private educational institution. Findings also highlight that adolescents in urban areas, excluding married older girls, were less likely than their rural counterparts to report a government educational institution. Specifically, 53 percent of younger boys in urban areas compared with 90 percent of rural younger boys were enrolled in a government educational institution; the corresponding proportions among older boys were 70 percent and 86 percent; among younger girls, the proportions were 62 percent and 95 percent; and among unmarried older girls, they were 81 percent and 93 percent.

\footnotetext{
${ }^{2}$ Excludes those who were pursuing their studies through distance education programmes.
} 
Figure 3.4: Percentage of adolescents who were ever enrolled in school ${ }^{1}$ by type of educational facility in which they were enrolled at the time of the interview or at the time of discontinuing their education, according to residence, Bihar, 2016
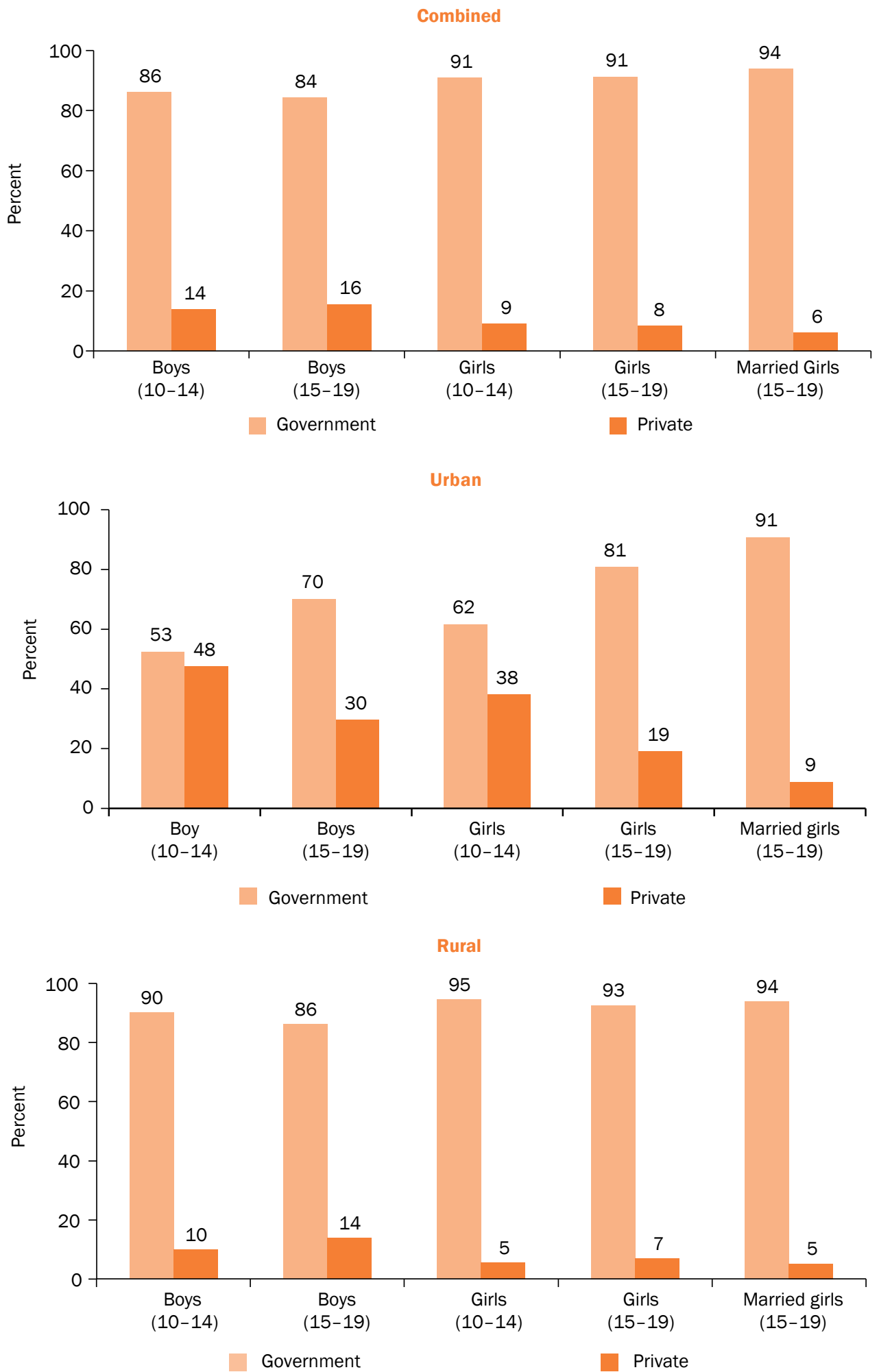

Notes: ${ }^{1}$ Excludes those who were continuing education through distance education courses at the time of the interview. Percentages may not add up to $100 \%$ owing to 'do not remember' responses. 
Findings presented in Table 3.4 show that enrolment in private educational institutions differed by such socio-demographic characteristics as caste, household wealth, current school attendance, and mother's education. Differences by age were evident only for older boys, among whom 25 percent of those in ages 18-19 were enrolled in a private institution, as compared with 12 percent of those in ages 15-17. Adolescents belonging to scheduled castes were the least likely to be enrolled in a private institution across all categories of adolescents, while those belonging to general castes were the most likely to be enrolled in a private institution (6-12\% versus $24-35 \%$ among boys; and $1-6 \%$ versus $10-22 \%$ among younger girls and unmarried older girls; differences were negligible among married older girls). Enrolment in a private institution increased steadily with household wealth index, and the wealth gap was steeper among younger than older adolescents: four percent of younger boys from the poorest households reported a private school compared with 40 percent from the wealthiest households; the corresponding proportions among older boys were 11 percent and 23 percent; for younger girls they were two percent and 29 percent; for unmarried older girls, they were six percent and 14 percent; and for married older girls, they were three percent and 10 percent. Enrolment in a private institution was associated with current schooling status; a larger proportion of adolescents who were pursuing their education at the time of the interview were enrolled in a private institution than those who had discontinued their education, across all categories of adolescents (14-18\% versus $5-6 \%$ among boys and $9-13 \%$ versus $2-5 \%$ among girls). There was also a positive association between enrolment in a private institution and mother's educational attainment. Thus, five percent of younger girls whose mother had no education compared with 43 percent of those whose mother had completed 10 or more years of schooling were enrolled in a private institution; differences, while not as wide, were evident among other categories of adolescents as well.

\section{Table 3.4: Enrolment in private educational institutions}

Percentage of adolescents who were enrolled in a private educational institution at the time of the interview or at the time of discontinuing their education by selected background characteristics, Bihar, 2016

\begin{tabular}{|c|c|c|c|c|c|}
\hline $\begin{array}{l}\text { Background characteristics }{ }^{1} \\
\text { (percent) }\end{array}$ & $\begin{array}{c}\text { Boys } \\
(10-14)\end{array}$ & $\begin{array}{c}\text { Boys } \\
(15-19)\end{array}$ & $\begin{array}{c}\text { Girls } \\
(10-14)\end{array}$ & $\begin{array}{c}\text { Girls } \\
(15-19)\end{array}$ & $\begin{array}{l}\text { Married girls } \\
\quad(15-19)\end{array}$ \\
\hline \multicolumn{6}{|l|}{ Age } \\
\hline $10-12$ & 13.6 & NA & 9.3 & NA & NA \\
\hline $13-14$ & 14.2 & NA & 8.7 & NA & NA \\
\hline $15-17$ & NA & 12.2 & NA & 7.5 & 4.5 \\
\hline $18-19$ & NA & 24.8 & NA & 11.2 & 6.1 \\
\hline \multicolumn{6}{|l|}{ Religion ${ }^{2}$} \\
\hline Hindu & 13.3 & 15.4 & 8.7 & 8.7 & 5.3 \\
\hline Muslim & 17.0 & 16.0 & 10.6 & 5.4 & 7.0 \\
\hline \multicolumn{6}{|l|}{ Caste $^{3}$} \\
\hline SC & 6.4 & 12.3 & 1.0 & 5.5 & 4.4 \\
\hline OBC & 12.2 & 15.0 & 9.4 & 8.7 & 5.6 \\
\hline General $^{4}$ & 34.7 & 24.4 & 21.8 & 10.3 & 6.6 \\
\hline \multicolumn{6}{|l|}{ Wealth quintile } \\
\hline First & 3.5 & 10.8 & 2.4 & 5.6 & 2.6 \\
\hline Second & 5.8 & 6.0 & 0.1 & 7.2 & 4.1 \\
\hline Third & 9.7 & 14.2 & 2.6 & 4.2 & 4.4 \\
\hline Fourth & 8.6 & 16.8 & 6.2 & 6.5 & 5.0 \\
\hline Fifth & 39.6 & 22.6 & 29.0 & 14.0 & 9.8 \\
\hline \multicolumn{6}{|l|}{ Current schooling status } \\
\hline Yes & 14.2 & 17.7 & 9.4 & 9.3 & 12.5 \\
\hline No & $(5.6)$ & 5.0 & $(2.3)$ & 4.5 & 3.7 \\
\hline
\end{tabular}


Table 3.4 Cont.

\begin{tabular}{|c|c|c|c|c|c|}
\hline $\begin{array}{l}\text { Background characteristics }{ }^{1} \\
\text { (percent) }\end{array}$ & $\begin{array}{c}\text { Boys } \\
(10-14)\end{array}$ & $\begin{array}{c}\text { Boys } \\
(15-19)\end{array}$ & $\begin{array}{c}\text { Girls } \\
(10-14)\end{array}$ & $\begin{array}{c}\text { Girls } \\
(15-19)\end{array}$ & $\begin{array}{c}\text { Married girls } \\
(15-19)\end{array}$ \\
\hline \multicolumn{6}{|c|}{$\begin{array}{l}\text { Mother's education (in years of schooling } \\
\text { completed) }\end{array}$} \\
\hline None $^{5}$ & 8.3 & 12.7 & 5.2 & 6.1 & 5.0 \\
\hline $1-7$ & 19.9 & 17.5 & 3.2 & 11.4 & 6.2 \\
\hline $8-9$ & 36.4 & 17.6 & 29.9 & 9.2 & 8.8 \\
\hline 10 and above & 45.2 & 35.9 & 42.9 & 19.5 & 8.0 \\
\hline Total & 13.8 & 15.5 & 9.0 & 8.2 & 5.5 \\
\hline
\end{tabular}

Notes: ( ) Based on 25-49 unweighted cases. NA: not applicable; OBC: other backward caste; SC: scheduled caste; ST: scheduled tribe. ${ }^{1}$ Excludes those who were pursuing their education through distance education courses at the time of the interview. ${ }^{2}$ Percentages not shown for those belonging to other religions as less than one percent of surveyed adolescents belonged to other religions. ${ }^{3}$ Percentages not shown for those belonging to STs as less than one percent of surveyed adolescents belonged to STs. ${ }^{4}$ Includes all those not belonging to SCs, STs, or OBCs. ${ }^{5}$ ncludes non-literate and literate with no formal schooling.

Table 3.5 presents findings on the availability of selected amenities in the educational institutions in which adolescents were enrolled at the time of the interview or at the time of discontinuing their education. Adolescents were asked about the availability of drinking water, a toilet facility in working condition, a playground, and library facilities.

\section{Table 3.5: Amenities available in the educational facilities}

Percentage of adolescents who were ever enrolled in school by characteristics of educational facility in which they were enrolled at the time of the interview or at the time of discontinuing their education, according to residence, Bihar, 2016

\begin{tabular}{|c|c|c|c|c|c|}
\hline Facility characteristics & $\begin{array}{c}\text { Boys } \\
(10-14)\end{array}$ & $\begin{array}{c}\text { Boys } \\
(15-19)\end{array}$ & $\begin{array}{c}\text { Girls } \\
(10-14)\end{array}$ & $\begin{array}{c}\text { Girls } \\
(15-19)\end{array}$ & $\begin{array}{c}\text { Married girls } \\
(15-19)\end{array}$ \\
\hline \multicolumn{6}{|c|}{ Combined (percent) } \\
\hline \multicolumn{6}{|l|}{ Available amenities } \\
\hline Drinking water & 96.5 & 98.0 & 97.9 & 96.8 & 97.0 \\
\hline Toilet facility in working condition & 68.2 & 75.7 & 84.7 & 87.5 & 85.9 \\
\hline Separate toilet facility for girls & $\mathrm{Na}$ & $\mathrm{Na}$ & 74.4 & 79.1 & 80.3 \\
\hline Playground & 76.6 & 83.4 & 92.9 & 90.9 & 89.1 \\
\hline Library & 22.9 & 48.2 & 31.3 & 50.8 & 43.9 \\
\hline All of the above & 17.9 & 39.3 & 24.7 & 42.0 & 39.1 \\
\hline Number ever enrolled in school/college ${ }^{1}$ & 998 & 1,729 & 729 & 2,981 & 2,194 \\
\hline \multicolumn{6}{|c|}{ Urban (percent) } \\
\hline \multicolumn{6}{|l|}{ Available amenities } \\
\hline Drinking water & 94.7 & 97.6 & 97.2 & 96.1 & 98.3 \\
\hline Toilet facility in working condition & 82.7 & 85.7 & 88.3 & 91.7 & 90.5 \\
\hline Separate toilet facility for girls & $\mathrm{Na}$ & $\mathrm{Na}$ & 74.5 & 84.7 & 83.1 \\
\hline Playground & 76.9 & 84.5 & 81.7 & 90.6 & 90.7 \\
\hline Library & 36.9 & 60.0 & 34.9 & 62.5 & 50.1 \\
\hline All of the above & 32.0 & 51.8 & 27.7 & 55.1 & 45.0 \\
\hline Number ever enrolled in school/college ${ }^{1}$ & 444 & 946 & 371 & 1,536 & 902 \\
\hline
\end{tabular}


Table 3.5 Cont.

\begin{tabular}{|c|c|c|c|c|c|}
\hline Facility characteristics & $\begin{array}{c}\text { Boys } \\
(10-14)\end{array}$ & $\begin{array}{c}\text { Boys } \\
(15-19)\end{array}$ & $\begin{array}{c}\text { Girls } \\
(10-14)\end{array}$ & $\begin{array}{c}\text { Girls } \\
(15-19)\end{array}$ & $\begin{array}{l}\text { Married girls } \\
\qquad(15-19)\end{array}$ \\
\hline \multicolumn{6}{|c|}{ Rural (percent) } \\
\hline \multicolumn{6}{|l|}{ Available amenities } \\
\hline Drinking water & 96.7 & 98.1 & 98.0 & 96.9 & 96.9 \\
\hline Toilet facility in working condition & 66.5 & 74.5 & 84.3 & 86.9 & 85.3 \\
\hline Separate toilet facility for girls & $\mathrm{Na}$ & $\mathrm{Na}$ & 74.4 & 78.4 & 79.9 \\
\hline Playground & 76.5 & 83.2 & 94.3 & 90.9 & 89.0 \\
\hline Library & 21.3 & 46.8 & 30.9 & 49.4 & 43.2 \\
\hline All of the above & 16.3 & 37.8 & 24.4 & 40.4 & 38.3 \\
\hline Number ever enrolled in school/college ${ }^{1}$ & 554 & 783 & 358 & 1,445 & 1,292 \\
\hline
\end{tabular}

Notes: All Ns are unweighted. Na: not asked. ${ }^{1}$ Excludes those who were pursuing their education through distance education courses at the time of the interview.

Almost all adolescents, irrespective of age, sex, and rural or urban residence, had access to drinking water (97-98\%). Access to a playground was reported by 77-83 percent of boys and 89-93 percent of girls. Younger girls from rural schools were more likely than younger girls from urban schools to report access to playgrounds ( $94 \%$ versus $82 \%$ among girls). Girls were more likely to report access to toilets in working condition than boys (85-88\% versus 68-76\%). There were pronounced differences in reports between adolescents, other than younger girls, from rural and urban areas with regard to toilet facilities; urban adolescents were more likely than rural adolescents to report access to toilet facilities. Girls were asked, additionally, about the availability of separate toilet facilities for them in their schools/colleges-74 percent of younger girls and 79-80 percent of unmarried and married older girls reported access to separate toilet facilities for girls. Differences between reports of adolescents from rural and urban areas on availability of separate toilet facilities for girls were narrow, except that more urban than rural unmarried older girls reported access to separate toilet facilities for girls (85\% versus $78 \%$ ). Fewer adolescents reported library facilities, with markedly more of older than younger adolescents, more of girls than boys among younger adolescents, and more of urban than rural adolescents reporting this facility. Thus, 48 percent of older boys compared with 23 percent of younger boys reported library facilities; similarly, 44-51 percent of unmarried and married older girls compared with 31 percent of younger girls reported library facilities. Differences in reports of access to library facilities by sex were observed among younger adolescents (but not among older adolescents)-31 percent of younger girls compared with 23 percent of younger boys reported access to library facilities. Differences in reports of access to library facilities between adolescents from rural and those from urban areas were also pronounced, with urban adolescents, other than younger girls, more likely than rural adolescents to report access to library facilities (37-60 percent of urban boys versus 21-47 percent of rural boys; 50-63 percent of urban unmarried and married older girls versus 43-49 percent of their rural counterparts).

Availability of all four amenities-drinking water, a playground, toilets, and libraries-was limited. More of older than younger adolescents reported the availability of all these amenities. Specifically, among boys, 39 percent of older boys compared with 18 percent of younger boys reported the availability of all four amenities at their school; the corresponding proportions among girls were 39-42 percent among unmarried and married older girls and 25 percent among younger girls. Differences by sex were apparent among younger adolescents; somewhat larger percentages of girls than boys reported the availability of all four amenities (25\% versus $18 \%$ ). Differences between rural and urban areas in availability of the four amenities were also notable across most categories of adolescents, except among younger girls; more urban than rural adolescents reported the availability of all four amenities (32-52\% versus $16-38 \%$ among boys, and $45-55 \%$ versus $38-40 \%$ among unmarried and married older girls). Differences between younger girls from rural areas and those from urban areas were modest in this regard.

Figure 3.5 presents the percentage of adolescents who reported the availability of all four amenities by current enrolment status and the type of school in which they were enrolled. Adolescents who reported the availability of all four amenities were more likely to be the ones studying at the time of the interview than those who had discontinued their education across all categories of adolescents, except for younger girls, which suggests that amenities in schools may have played a role in the continuation of schooling. Adolescents enrolled in private educational facilities were more likely than those enrolled in government institutions to report the availability of all four amenities. 
Figure 3.5: Percentage of adolescents who reported availability of all four amenities in the school ${ }^{1}$ in which they were enrolled at the time of the interview or at the time of discontinuing their education by current schooling status and type of school, Bihar, 2016

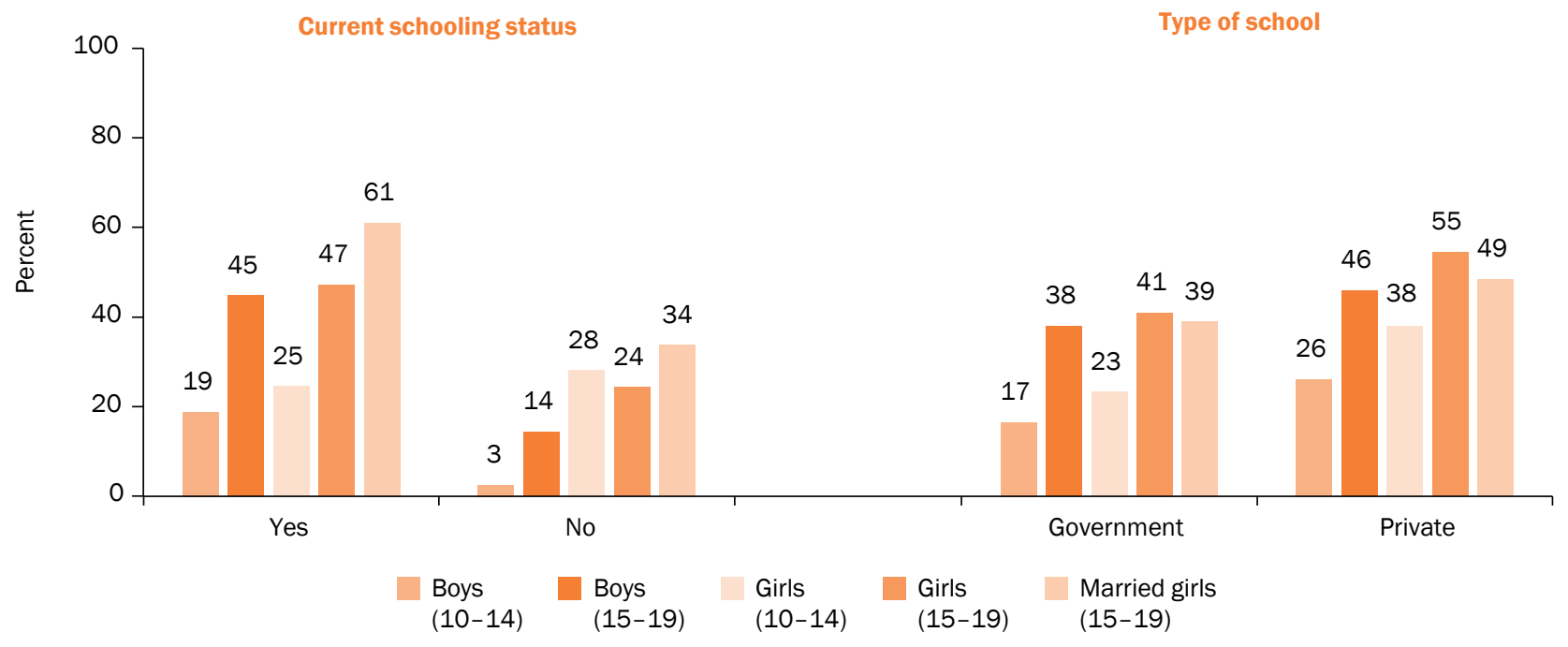

Note: ${ }^{1}$ Excludes those who were pursuing their education through distance education courses at the time of the interview.

\subsubsection{Regularity of school attendance}

The survey measured school attendance by eliciting information from survey participants who were currently enrolled in a school/college about the number of days they had attended school in the week (six days) preceding the day of the interview. Regular attendance is defined as attendance in school on all of the six days in the week prior to the interview. We found that 25-53 percent of boys and 14-45 percent of girls reported that they missed school just because the school/college was not in session, and hence these respondents were considered as having attended school regularly for the purpose of the analysis presented in this section. It may be noted that the survey took place from January to July, during part of which time schools were closed for summer vacations in Bihar.

Table 3.6 presents adolescents' responses about the regularity of their school attendance and highlights considerable absenteeism in the week prior to the interview among all categories of adolescents. Regular attendance varied by age among boys-younger boys were less likely than older boys to report that they had attended school on all days (60\% versus $70 \%$ ); no such marked differences were apparent among girls, except for married older girls ( $62 \%$ of younger girls, $59 \%$ of unmarried older girls, and $48 \%$ of married older girls). Differences in regular attendance by sex were negligible among younger adolescents, but marked among older adolescents-boys were more likely than girls to have attended school on all days ( $70 \%$ of boys versus $59 \%$ of unmarried older girls). Differences in regular attendance by marital status among older girls show that unmarried girls were more likely than their married counterparts to have attended school on all days (59\% versus $48 \%$ ). Differences between rural and urban adolescents were observed for younger boys and all categories of girls, among whom those in urban areas were more likely than their rural counterparts to have attended school regularly ( $75 \%$ versus $58 \%$ among younger boys; $70 \%$ versus $61 \%$ among younger girls; $65 \%$ versus $58 \%$ among unmarried older girls; and $57 \%$ versus $47 \%$ among married older girls).

Findings presented in Figure 3.6 show that regular attendance differed by type of school in which adolescents were enrolled, although the patterns differed across categories of adolescents. Among younger adolescents, those enrolled in private schools were more likely than those enrolled in government schools to report regular attendance $(77 \%$ versus $57 \%$ among younger boys and $81 \%$ versus $60 \%$ among younger girls). A reverse pattern was apparent for older boys, among whom a slightly larger proportion of those in government schools than in private institutions reported regular attendance ( $71 \%$ versus $66 \%)$. No such difference was evident among unmarried older girls. 
Figure 3.6: Percentage of unmarried adolescents who were enrolled in school/college ${ }^{1}$ at the time of the interview reporting that they attended school regularly by type of school in which they were enrolled, Bihar, 2016

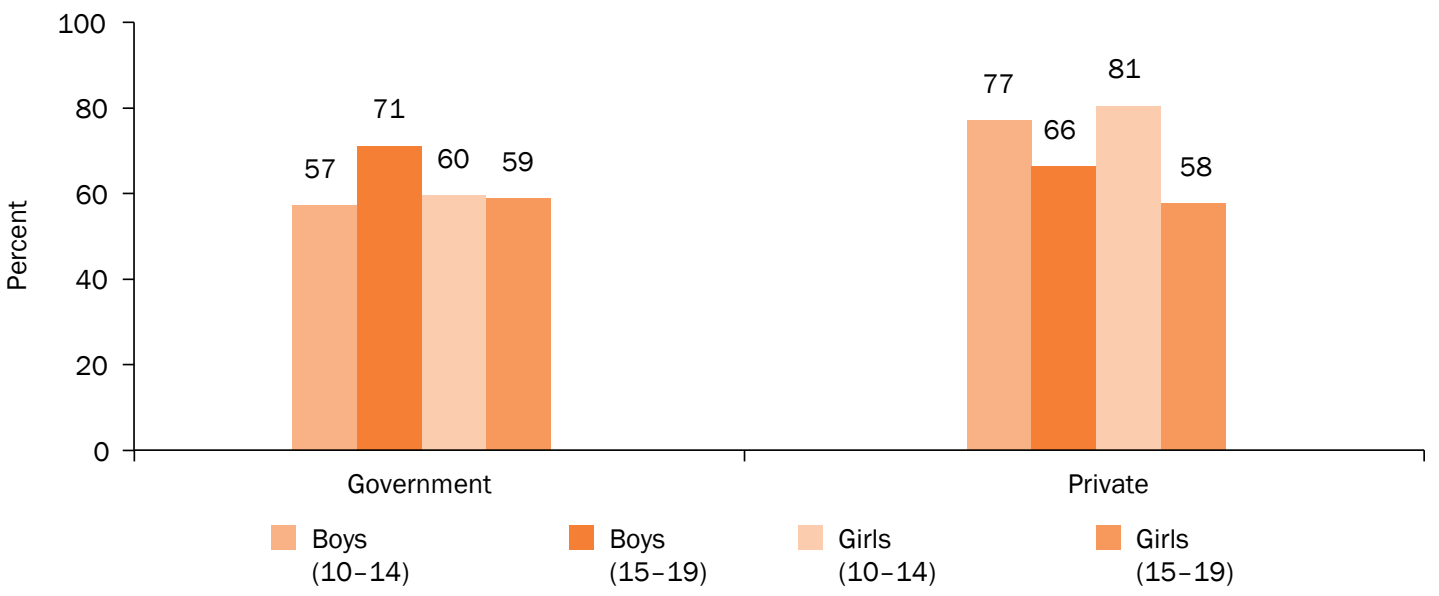

Note: ${ }^{1}$ Excludes married older girls and those who were pursuing their education through distance education courses at the time of the interview.

Table 3.6 also lists the reasons cited by adolescents who were studying at the time of the interview for missing school/college on any day in the week prior to the interview. Differences by age and sex were marked. Reasons related to housework or a family function and attitude-related reasons topped the list of reasons among younger boys (26-31\%); other frequently mentioned reasons among younger boys included economic reasons (20\%) and school-related reasons (19\%). Among older boys, school-related reasons, mainly, poor quality of teaching and teacher absenteeism, and economic reasons, namely, their having to work on the family farm or business or for pay, topped the list of reasons (22-38\%); also indicated were reasons related to housework or to a family function $(17 \%)$ and attitude-related reasons (18\%). In contrast, reasons related to housework or to a family function, particularly housework, topped the list of reasons among younger girls (38\%), followed by attitude-related (20\%) and health-related (19\%) reasons. For older girls, school-related reasons, mainly, poor quality of teaching and teacher absenteeism and lack of transportation or their having no one to escort them to school (53\% of unmarried older girls and $38 \%$ of married older girls), followed by reasons related to housework or a family function (18\% of unmarried older girls and $35 \%$ of married older girls) were the leading reasons for absenteeism. Hardly any girls ( $2 \%$ or fewer) missed school/college because of menstruation-related reasons. Finally, some 18 percent of married girls reported marriage- or pregnancy-related reasons for missing school.

Reasons listed by adolescents in rural and in urban areas were similar to those described above for the combined sample. Even so, rural adolescents, other than married older girls, were more likely than urban adolescents to report economic reasons (21-24\% versus 5-9\% among boys and $10-16 \%$ versus $2-3 \%$ among younger girls and unmarried older girls). Rural younger girls and unmarried older girls were also more likely than their urban counterparts to list housework or a family function (39\% versus $29 \%$ among younger girls and $19 \%$ versus $13 \%$ among unmarried older girls), but a reverse pattern was observed for married older girls (33\% versus $43 \%$ ). While rural older boys were less likely than urban older boys to attribute absenteeism to school-related reasons (37\% versus $46 \%$ ), a reverse pattern was evident for married older girls (39\% versus 32\%). Younger adolescents in urban areas were more likely than their rural counterparts to list health-related reasons (30-32\% versus 11-18\%). Finally, urban married older girls were more likely than their rural counterparts to report marriage or pregnancy for absenteeism (29\% versus $15 \%)$. 


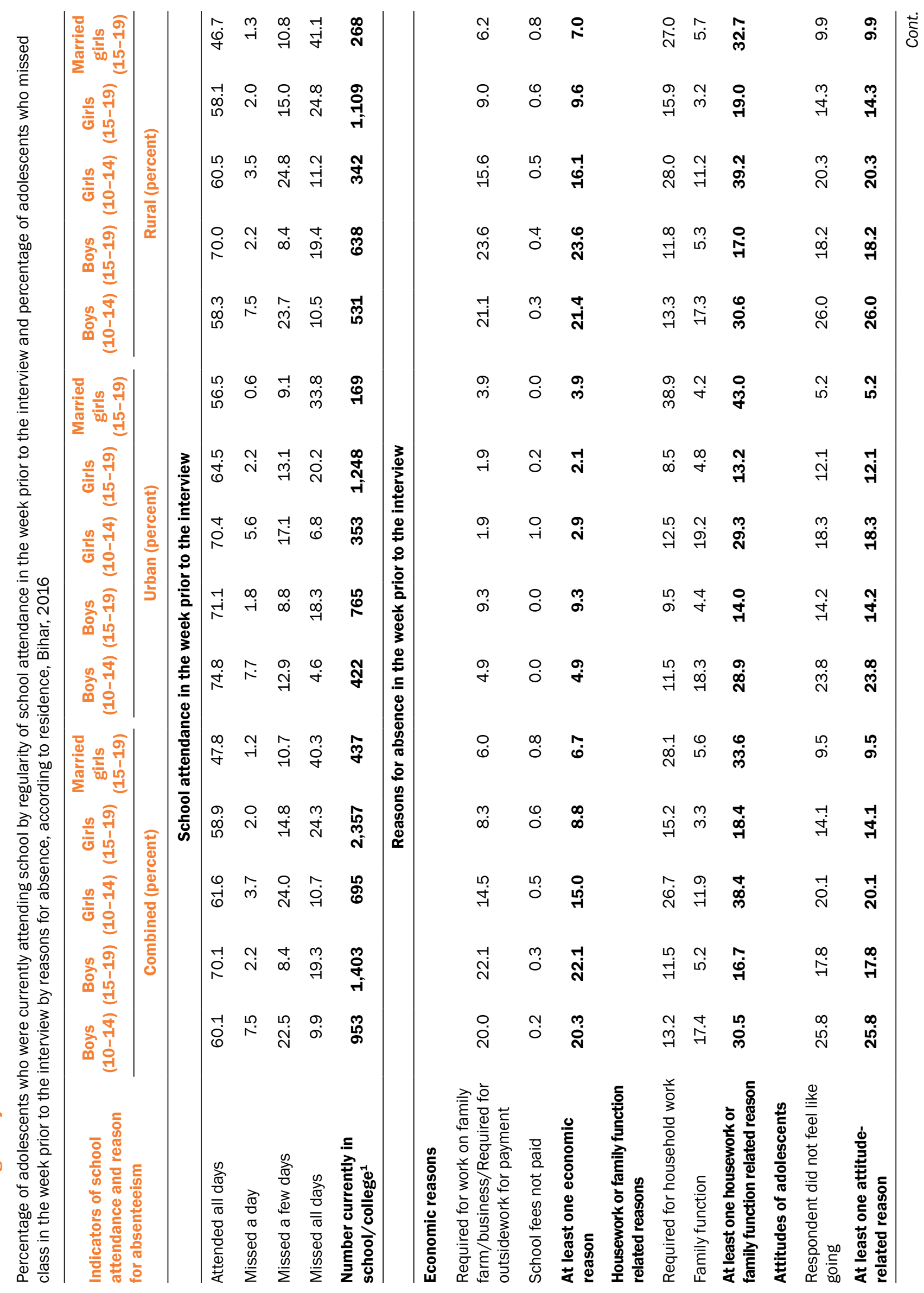




\begin{tabular}{|c|c|c|c|c|c|c|c|c|c|c|c|c|c|c|c|c|c|c|c|c|c|}
\hline 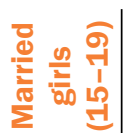 & & & $\stackrel{\circ}{\circ}$ & 옴 & $\stackrel{-1}{\sigma}$ & $\stackrel{+}{\circ}$ & $\begin{array}{l}\infty \\
\stackrel{\infty}{\rightarrow}\end{array}$ & 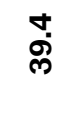 & & 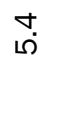 & $\stackrel{\circ}{\circ}$ & $\stackrel{\circ}{i}$ & $\stackrel{⿱}{N}$ & & $\stackrel{\circ}{\circ}$ & 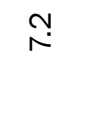 & 롬 & $\begin{array}{l}\stackrel{\infty}{ } \\
\text { స్ }\end{array}$ & $\stackrel{m}{\sim}$ & مُ & 옥 \\
\hline 올 & $=$ & & $\stackrel{\sim}{0}$ & $\begin{array}{l}\stackrel{0}{\oplus} \\
\ddot{m}\end{array}$ & $\stackrel{\llcorner}{\sim}$ & $\stackrel{\leftrightarrow}{\mathrm{r}}$ & $\begin{array}{l}\stackrel{9}{ } \\
\stackrel{\leftrightarrow}{\rightarrow}\end{array}$ & $\begin{array}{l}0 \\
\text { ஸิ }\end{array}$ & & $\begin{array}{l}\llcorner \\
\infty \\
\infty\end{array}$ & $\stackrel{0}{+}$ & $\stackrel{+}{+}$ & $\stackrel{+}{\vec{H}}$ & & $\stackrel{\circ}{\sim}$ & חָ & $\stackrel{\circ}{\circ}$ & $\stackrel{\circ}{\circ}$ & Oִ. & $\stackrel{ન}{-}$ & \& \\
\hline 을 & 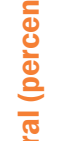 & & $\stackrel{\circ}{\circ}$ & مْ & $\stackrel{\text { L }}{\rightarrow}$ & $\begin{array}{l}\infty \\
0^{\circ}\end{array}$ & $\begin{array}{l}\circ \\
\stackrel{\circ}{ }\end{array}$ & 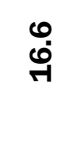 & & $\begin{array}{l}\stackrel{0}{\oplus} \\
\stackrel{\sim}{\rightarrow}\end{array}$ & $\stackrel{m}{\sim}$ & $\stackrel{m}{0}$ & $\stackrel{\infty}{\stackrel{\infty}{A}}$ & & $\stackrel{m}{m}$ & $\stackrel{\circ}{\circ}$ & $\Sigma$ & $\Sigma$ & $\S$ & $\stackrel{\circ}{\circ}$ & $\underset{\exists}{\mathscr{J}}$ \\
\hline 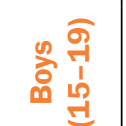 & 童 & & $\stackrel{\circ}{\circ}$ & ஸ̃ & $\stackrel{\infty}{\sim}$ & $\stackrel{\circ}{\circ}$ & $\stackrel{\llcorner}{\sim}$ & $\underset{\text { N̦ }}{\text { Nat }}$ & & ه্ & $\stackrel{m}{\sim}$ & $\Sigma$ & ஸุ & & & $\stackrel{\infty}{\infty}$ & $\S$ & $\Sigma$ & $\Sigma$ & $\stackrel{\varphi}{m}$ & $\stackrel{\infty}{\stackrel{్}{\top}}$ \\
\hline 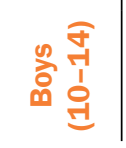 & & & $\stackrel{\infty}{\circ}$ & $\begin{array}{l}\underset{\sim}{\oplus} \\
\stackrel{\sim}{-}\end{array}$ & $\begin{array}{l}\infty \\
\dot{\omega}\end{array}$ & $\stackrel{\circ}{\circ}$ & $\stackrel{\circ}{\circ}$ & ণั & & $\ddot{\circ}$ & $\underset{\sim}{\sim}$ & $\S$ & フุ. & & $\stackrel{ナ}{\check{r}}$ & $\stackrel{\sim}{r}$ & $\S$ & $\S$ & $\Sigma$ & $\stackrel{\infty}{\rightarrow}$ & $\stackrel{\infty}{\sim}$ \\
\hline 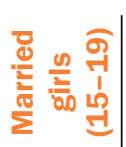 & & & $\stackrel{\circ}{\circ}$ & $\stackrel{+}{\stackrel{+}{\sigma}}$ & $\begin{array}{l}\stackrel{9}{\circ} \\
\stackrel{-}{1}\end{array}$ & $\stackrel{\circ}{\circ}$ & $\begin{array}{l}\infty \\
\ddot{0}\end{array}$ & $\underset{\text { N }}{\stackrel{H}{\text { J }}}$ & & $\stackrel{\text { ?ִ }}{\sim}$ & ت્ન & $\stackrel{\circ}{\circ}$ & $\hat{\infty}$ & & $\stackrel{\circ}{\circ}$ & $\stackrel{+}{\circ}$ & $\begin{array}{l}\stackrel{1}{0} \\
\stackrel{\infty}{N}\end{array}$ & $\stackrel{\text { ָे }}{\mathrm{N}}$ & $\stackrel{m}{r}$ & $\stackrel{\circ}{\circ}$ & N \\
\hline 올 & ت्ञ & & $\stackrel{\varphi}{\circ}$ & $\stackrel{-}{\text { Pे }}$ & $\underset{\text { กี }}{\stackrel{7}{7}}$ & $\stackrel{-}{-}$ & $\begin{array}{l}\circ \\
\infty\end{array}$ & 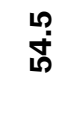 & & 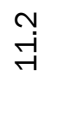 & $\stackrel{N}{\sim}$ & $\tilde{0}$ & $\stackrel{-}{+}$ & & $\stackrel{-}{+}$ & $\begin{array}{l}m \\
\infty\end{array}$ & $\stackrel{+}{0}$ & $\stackrel{+}{\circ}$ & $\stackrel{\circ}{\circ}$ & $\stackrel{\varphi}{\dot{m}}$ & 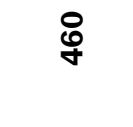 \\
\hline 을 & 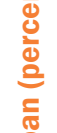 & & $\stackrel{\circ}{\circ}$ & $\begin{array}{l}0 \\
\stackrel{9}{\circ}\end{array}$ & $\stackrel{m}{i} \stackrel{r}{r}$ & $\stackrel{-1}{m}$ & ○. & 올 & & 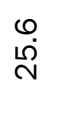 & مْ & $\tilde{0}$ & नें & & $\stackrel{m}{\sim}$ & $\stackrel{1}{\circ}$ & $\Sigma$ & $\Sigma$ & 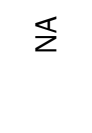 & ָั & $\stackrel{m}{7}$ \\
\hline 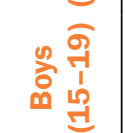 & 은 & & $\stackrel{\Upsilon}{0}$ & ْ̊ & $\stackrel{\varphi}{\varphi}$ & $\stackrel{m}{m}$ & $\stackrel{m}{m}$ & $\begin{array}{l}9 \\
\text { i⿱ }\end{array}$ & & $\underset{\bullet}{\oplus}$ & $\stackrel{\varphi}{\leftrightarrow}$ & $\Sigma$ & ำ & & $\stackrel{\infty}{i}$ & $\stackrel{ }{\stackrel{-}{ }}$ & $\Sigma$ & $\Sigma$ & $\Sigma$ & $\begin{array}{l}m \\
\infty\end{array}$ & สิ \\
\hline 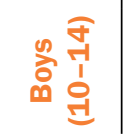 & & & $\stackrel{\circ}{\circ}$ & $\stackrel{+}{0}$ & 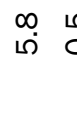 & $\stackrel{\text { ?ִ }}{\circ}$ & $\stackrel{\circ}{\rightarrow}$ & $\stackrel{\vec{g}}{\vec{g}}$ & & $\underset{\sim}{\stackrel{\sim}{N}}$ & $\stackrel{\leftrightarrow}{i}$ & $\S$ & 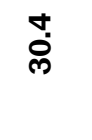 & & $\begin{array}{l}\infty \\
\stackrel{\infty}{\circ}\end{array}$ & $\stackrel{+}{m}$ & $\S$ & $\Sigma$ & $\S$ & $\stackrel{1}{0}$ & $\stackrel{9}{7}$ \\
\hline 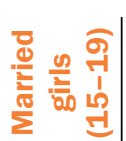 & & & $\stackrel{\circ}{\circ}$ & $\stackrel{\circ}{\circ}$ & $\ddot{m}$ & $\stackrel{m}{\infty}$ & $\stackrel{\sim}{\stackrel{\sim}{\sim}}$ & $\begin{array}{l}\infty \\
\infty \\
\infty\end{array}$ & & $\begin{array}{l}\bullet \\
\stackrel{\circ}{0}\end{array}$ & $\stackrel{-1}{0}$ & $\stackrel{\infty}{\rightarrow}$ & $\stackrel{\text { ?ִ }}{\Gamma}$ & & $\stackrel{\circ}{\circ}$ & $\begin{array}{l}0 \\
\dot{0}\end{array}$ & $\begin{array}{l}m \\
\stackrel{\leftrightarrow}{\theta}\end{array}$ & $\begin{array}{l}0 \\
\stackrel{M}{\sim}\end{array}$ & $\stackrel{\infty}{\sim}$ & $\underset{⿱ 宀}{\stackrel{\circ}{*}}$ & ฟิ \\
\hline ํㅗㄹ & 焉 & & ָָ & $\begin{array}{l}\stackrel{0}{ } \\
\stackrel{m}{m}\end{array}$ & $\stackrel{0}{\infty}$ & $\begin{array}{l}\stackrel{0}{+} \\
\stackrel{+}{0}\end{array}$ & 곰 & $\begin{array}{l}\infty \\
\text { ஸ̂ં }\end{array}$ & & $\begin{array}{l}\infty \\
\infty \\
\infty\end{array}$ & $\stackrel{0}{\leftrightarrow}$ & $\stackrel{m}{r}$ & İ & & ָ̃ & $\begin{array}{l}\stackrel{\llcorner}{0} \\
0\end{array}$ & $\stackrel{\circ}{\circ}$ & $\stackrel{\circ}{\circ}$ & $\stackrel{\circ}{\circ}$ & $\stackrel{+}{+}$ & న్న \\
\hline 을 & 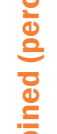 & & $\stackrel{\circ}{\circ}$ & $\stackrel{+}{\vec{H}}$ & ح & $\stackrel{\circ}{\text { ㄱ }}$ & $\stackrel{\llcorner}{\forall}$ & $\begin{array}{l}\text { L } \\
\text { G }\end{array}$ & & $\stackrel{\sim}{\underset{\sim}{\sim}}$ & $\stackrel{+}{+}$ & $\stackrel{m}{0}$ & 옴 & & $\stackrel{\triangleright}{\grave{m}}$ & $\stackrel{\circ}{\circ}$ & $\Sigma$ & $\Sigma$ & $\Sigma$ & ִָ & 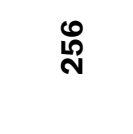 \\
\hline م. & है & & $\stackrel{\circ}{\circ}$ & mं & $\stackrel{\leftrightarrow}{\wedge}$ & $\stackrel{\circ}{\circ}$ & $\stackrel{m}{\sim}$ & $\underset{\infty}{-1}$ & & ه़ & $\stackrel{N}{N}$ & $\Sigma$ & $\underset{\infty}{\text { พ }}$ & & ثิ & $\stackrel{\varphi}{\dot{\sim}}$ & $\Sigma$ & $\Sigma$ & $\Sigma$ & $\stackrel{\leftrightarrow}{\forall}$ & ฟั \\
\hline 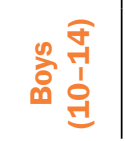 & & & $\stackrel{\infty}{\infty}$ & $\stackrel{\vec{n}}{\vec{\sim}}$ & $\stackrel{\infty}{\infty}$ & $\stackrel{\circ}{\circ}$ & $\stackrel{?}{\circ}$ & $\begin{array}{l}\infty \\
\infty \\
\sim\end{array}$ & & $\stackrel{\text { ㄱ. }}{\rightarrow}$ & $\stackrel{+}{+}$ & $\Sigma$ & ثี & & $\stackrel{\varphi}{\dot{m}}$ & $\stackrel{\infty}{\rightarrow}$ & $\Sigma$ & $\Sigma$ & $\Sigma$ & $\stackrel{\sim}{\mathrm{r}}$ & 卢 \\
\hline 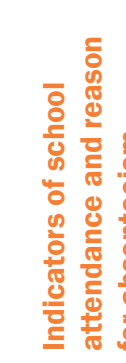 & & 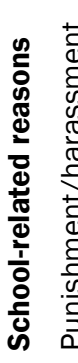 & 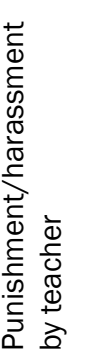 & 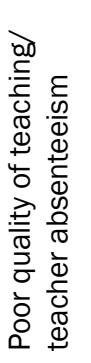 & 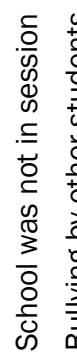 & 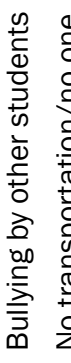 & 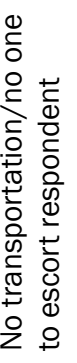 & 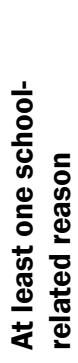 & 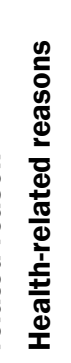 & 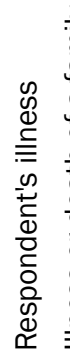 & 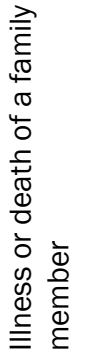 & 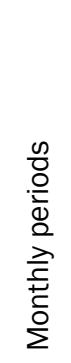 & 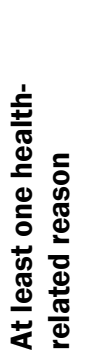 & 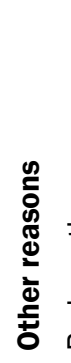 & 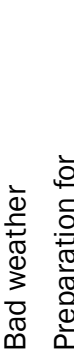 & 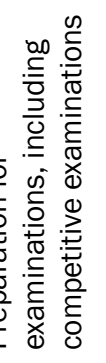 & 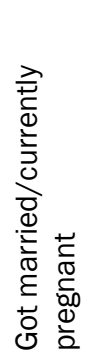 & 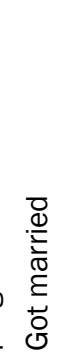 & 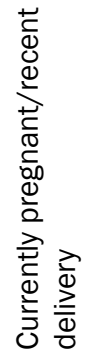 & 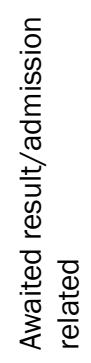 & 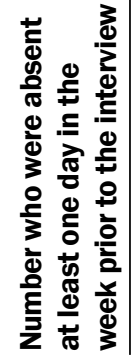 \\
\hline
\end{tabular}




\subsubsection{Private tuition}

A notable proportion of adolescents, other than married older girls, who were pursuing their education at the time of the interview ${ }^{3}$ reported that they had taken private tuition in the month prior to the interview-68 percent and 61 percent of younger and older boys, respectively, and 61 percent and 50 percent of younger girls and unmarried older girls, respectively (Table 3.7). Fewer married older girls, however, so reported (20\%). Differences between those from rural and those from urban areas were apparent among older adolescents; however, the patterns differed. Among older boys and unmarried older girls, urban respondents were more likely than rural respondents to have taken private tuition (69\% versus $60 \%$ among older boys and $56 \%$ versus $49 \%$ among unmarried older girls). A reverse pattern was observed among married older girls (12\% versus $21 \%$ ).

Among older adolescents, a larger proportion of those in ages 15-17 took private tuition compared with those in ages $18-19$ (64\% versus $48 \%$ among boys; $52 \%$ versus $37 \%$ among unmarried girls; and $34 \%$ versus $6 \%$ among married girls).

Differences by religion suggest that Hindu adolescents were more likely than Muslim adolescents to have taken private tuition across all categories of adolescents, except for married older girls. Thus, 62-70 percent of Hindu boys compared with 52-60 percent of Muslim boys had taken private tuition in the month preceding the interview. The corresponding proportions among younger girls and unmarried older girls were 52-63 percent and 36-46 percent. There were caste-wise differences also among younger adolescents-younger boys and girls from scheduled castes were less likely than those from other castes to have taken private tuition (63\% versus $70-71 \%$ among younger boys and $52 \%$ versus $62-68 \%$ among younger girls).

Private tuition increased, though not steadily, with household wealth index across all categories of adolescents except for married older girls: for example, 60 percent of younger boys belonging to the poorest households compared with 77 percent of younger boys from the wealthiest households had taken private tuition in the month prior to the interview as had 38 percent and 74 percent of younger girls, respectively. A reverse pattern was observed for married older girls among whom the practice of taking private tuition decreased with household wealth index; for example, 26 percent of married girls belonging to the poorer households (second quintile) compared with 14 percent of married girls from the wealthiest households had taken private tuition.

Interestingly, the practice of taking private tuition did not differ by the type of educational institution in which respondents were enrolled at the time of the interview, except for younger girls, among whom those enrolled in private institutions were more likely than those enrolled in government institutions to have taken private tuition ( $71 \%$ versus $60 \%)$.

Finally, the practice of taking private tuition did not differ by educational attainment of mothers, except for younger girls and unmarried older girls, among whom a larger proportion of those whose mother had completed Class 10 or above had taken private tuition compared with those whose mother had no education (88\% versus 56\% among younger girls and 55\% versus $48 \%$ among unmarried older girls).

\section{Table 3.7: Private tuition}

Percentage of adolescents currently enrolled in a school/college ${ }^{1}$ who had taken private tuition in the month prior to the interview by selected background characteristics, Bihar, 2016

\begin{tabular}{lcccrr}
\hline $\begin{array}{l}\text { Background characteristics } \\
\text { (percent) }\end{array}$ & $\begin{array}{c}\text { Boys } \\
(10-14)\end{array}$ & $\begin{array}{c}\text { Boys } \\
(15-19)\end{array}$ & $\begin{array}{c}\text { Girls } \\
(10-14)\end{array}$ & $\begin{array}{c}\text { Girls } \\
(15-19)\end{array}$ & $\begin{array}{c}\text { Married girls } \\
(15-19)\end{array}$ \\
\hline Age & 68.1 & NA & 60.5 & NA & NA \\
$10-12$ & 69.1 & NA & 61.8 & NA & NA \\
$13-14$ & NA & 64.3 & NA & 52.4 & 34.1 \\
$15-17$ & NA & 47.5 & NA & 36.8 & 5.9 \\
$18-19$ & \multicolumn{7}{c}{ Cont. } \\
\multicolumn{2}{l}{ Excludes those who were pursuing their education through distance education programmes. }
\end{tabular}


Table 3.7 Cont.

\begin{tabular}{|c|c|c|c|c|c|}
\hline $\begin{array}{l}\text { Background characteristics } \\
\text { (percent) }\end{array}$ & $\begin{array}{c}\text { Boys } \\
(10-14)\end{array}$ & $\begin{array}{c}\text { Boys } \\
(15-19)\end{array}$ & $\begin{array}{c}\text { Girls } \\
(10-14)\end{array}$ & $\begin{array}{c}\text { Girls } \\
(15-19)\end{array}$ & $\begin{array}{l}\text { Married girls } \\
\text { (15-19) }\end{array}$ \\
\hline \multicolumn{6}{|l|}{ Religion $^{2}$} \\
\hline Hindu & 69.9 & 62.0 & 63.3 & 51.5 & 19.7 \\
\hline Muslim & 59.5 & 51.8 & 46.1 & 35.7 & (19.1) \\
\hline \multicolumn{6}{|l|}{ Caste $^{3}$} \\
\hline SC & 62.7 & 59.8 & 51.8 & 48.0 & 17.8 \\
\hline OBC & 69.7 & 61.3 & 62.2 & 50.0 & 21.2 \\
\hline General $^{4}$ & 70.8 & 59.4 & 68.2 & 50.5 & $(12.6)$ \\
\hline \multicolumn{6}{|l|}{ Wealth quintile } \\
\hline First & 60.0 & $(72.5)$ & 37.9 & 39.5 & * \\
\hline Second & 64.1 & 54.2 & 60.0 & 50.0 & 26.3 \\
\hline Third & 69.0 & 62.7 & 58.9 & 48.9 & 20.9 \\
\hline Fourth & 68.6 & 55.1 & 62.5 & 48.5 & 19.2 \\
\hline Fifth & 77.0 & 66.0 & 74.1 & 53.2 & 13.8 \\
\hline \multicolumn{6}{|l|}{ Type of school } \\
\hline Government & 68.4 & 60.4 & 59.9 & 49.4 & 19.6 \\
\hline Private & 68.6 & 60.8 & 71.0 & 52.8 & 19.4 \\
\hline \multicolumn{6}{|l|}{$\begin{array}{l}\text { Mother's education (in years of } \\
\text { schooling completed) }\end{array}$} \\
\hline None $^{5}$ & 66.8 & 60.5 & 56.1 & 47.9 & 20.6 \\
\hline $1-7$ & 78.0 & 60.2 & 70.3 & 53.3 & (15.9) \\
\hline $8-9$ & 79.5 & 62.5 & 66.1 & 52.1 & (18.1) \\
\hline 10 and above & 65.4 & 59.7 & 87.8 & 54.5 & 19.3 \\
\hline \multicolumn{6}{|l|}{ Place of residence } \\
\hline Urban & 69.7 & 69.0 & 64.2 & 56.4 & 11.9 \\
\hline Rural & 68.3 & 59.5 & 60.4 & 48.9 & 20.6 \\
\hline Total & 68.4 & 60.5 & 60.8 & 49.7 & 19.7 \\
\hline
\end{tabular}

Notes: * Percentage not shown as this was based on fewer than 25 unweighted cases. () Based on 25-49 unweighted cases. NA: not applicable; OBC: other backward caste; SC: scheduled caste; ST: scheduled tribe. ${ }^{1}$ Excludes those who were pursuing their education through distance education courses at the time of the interview. ${ }^{2}$ Percentages not shown for those belonging to other religions as less than one percent of surveyed adolescents belonged to other religions. ${ }^{3}$ Percentages not shown for those belonging to STs as less than one percent of surveyed adolescents belonged to STs. ${ }^{4}$ Includes all those not belonging to SCs, STs, or OBCs. ${ }^{5}$ Includes non-literate and literate with no formal schooling.

\subsubsection{Academic performance perceptions and leadership position}

We probed the academic performance (self-reported) during the last academic year of survey participants who were pursuing their education at the time of the interview ${ }^{4}$ and also whether they had held a leadership position, that is, served as a prefect or monitor, in the class they were currently attending or had last attended (Table 3.8). More girls than boys reported that they had performed well in the last academic year (42\% versus 36\% among younger adolescents and $40-45 \%$ versus 36\% among older adolescents). A larger proportion of urban adolescents reported that they had performed well compared with rural adolescents, except among older boys. Among younger boys, for example, 46 percent of urban boys compared with 35 percent of rural boys so reported; the corresponding proportions among girls were 53 percent and 41 percent among younger girls, 52 percent and 44 percent among

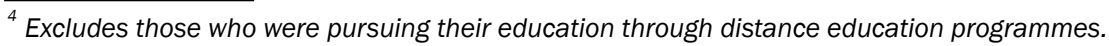


unmarried older girls, and 45 percent and 39 percent among married older girls. Findings also show that 15-17 percent of boys and 9-15 percent of girls had served as a prefect or monitor in the class in which they were currently attending or had last attended. Differences between rural and urban adolescents show that urban younger adolescents were more likely than their rural counterparts to have held such a leadership position (28\% versus $16 \%$ among younger boys and $27 \%$ versus $14 \%$ among younger girls).

\section{Table 3.8: Academic performance perceptions and leadership position in school}

Percentage of adolescents currently enrolled in a regular school/college by their academic performance perceptions and leadership position in the class most recently attended, according to residence, Bihar, 2016

\begin{tabular}{|c|c|c|c|c|c|}
\hline School performance characteristics & $\begin{array}{c}\text { Boys } \\
(10-14)\end{array}$ & $\begin{array}{c}\text { Boys } \\
(15-19)\end{array}$ & $\begin{array}{c}\text { Girls } \\
(10-14)\end{array}$ & $\begin{array}{c}\text { Girls } \\
(15-19)\end{array}$ & $\begin{array}{c}\text { Married girls } \\
(15-19)\end{array}$ \\
\hline \multicolumn{6}{|c|}{ Combined (percent) } \\
\hline \multicolumn{6}{|l|}{ Performance in the last academic year (self-reported) } \\
\hline Poor & 3.4 & 5.0 & 1.7 & 2.9 & 2.3 \\
\hline Average & 60.8 & 59.4 & 56.0 & 52.5 & 57.9 \\
\hline Well & 35.9 & 35.6 & 42.2 & 44.6 & 39.8 \\
\hline \multicolumn{6}{|c|}{$\begin{array}{l}\text { Leadership position in the class currently attending or last } \\
\text { attended }\end{array}$} \\
\hline Served as prefect/monitor in the class & 17.3 & 14.8 & 14.9 & 12.3 & 8.6 \\
\hline Number currently enrolled in a school/college ${ }^{1}$ & 953 & 1,403 & 693 & 2,357 & 437 \\
\hline \multicolumn{6}{|c|}{ Urban (percent) } \\
\hline \multicolumn{6}{|l|}{ Performance in the last academic year (self-reported) } \\
\hline Poor & 1.4 & 2.2 & 1.4 & 2.1 & 1.7 \\
\hline Average & 52.2 & 63.6 & 45.3 & 45.8 & 53.7 \\
\hline Well & 46.4 & 34.2 & 53.2 & 52.1 & 44.6 \\
\hline \multicolumn{6}{|c|}{$\begin{array}{l}\text { Leadership position in the class currently attending or last } \\
\text { attended }\end{array}$} \\
\hline Served as prefect/monitor in the class & 28.0 & 15.6 & 26.9 & 14.9 & 5.8 \\
\hline Number currently enrolled in a school/college ${ }^{1}$ & 422 & 765 & 353 & 1,247 & 169 \\
\hline \multicolumn{6}{|c|}{ Rurall (percent) } \\
\hline \multicolumn{6}{|c|}{ Performance in the last academic year (self-reported) } \\
\hline Poor & 3.6 & 5.3 & 1.8 & 3.0 & 2.3 \\
\hline Average & 61.8 & 58.9 & 57.4 & 53.3 & 58.4 \\
\hline Well & 34.6 & 35.7 & 40.8 & 43.6 & 39.2 \\
\hline \multicolumn{6}{|c|}{$\begin{array}{l}\text { Leadership position in the class currently attending or last } \\
\text { attended }\end{array}$} \\
\hline Served as prefect/monitor in the class & 16.1 & 14.7 & 13.5 & 12.0 & 9.0 \\
\hline Number currently enrolled in a school/college ${ }^{1}$ & 531 & 638 & 340 & 1,110 & 268 \\
\hline
\end{tabular}

Notes: All Ns are unweighted. ${ }^{1}$ Excludes those who were pursuing their education through distance education courses at the time of the interview. 


\subsection{Educational aspirations}

The survey sought to assess educational aspirations of survey participants. Specifically, it probed the perceptions of those who had never been enrolled in school about their interest in getting enrolled in school; and of those who had discontinued their education, about their interest in returning to school. It also elicited information from those who were pursuing their education about the level of education they wished to achieve. Table 3.9 presents findings for older adolescents on whether those who had never enrolled in school desired to enrol in school or and whether those who had discontinued their education before completing Class 12 desired to return to school. It is to be noted that the number of younger adolescents who were never enrolled in school or who had discontinued their education at the time of the interview was small and, therefore, findings related to them are not described in Table 3.9.

Findings show that among older adolescents who were never enrolled in school, a substantial proportion expressed a desire to enrol in school-one-third of boys and unmarried girls and about one-fifth of married girls. Differences by place of residence were modest.

Among the older adolescents who had discontinued their education before completing Class 12, a large proportion, particularly girls, expressed a desire to return to school-33 percent of boys, 55 percent of unmarried girls, and 39 percent of married girls. While fewer urban than rural boys expressed a desire to return to school (29\% versus $34 \%)$, more urban unmarried and married girls than their rural counterparts expressed a desire to return to school (62\% versus 54\% among unmarried girls and 44\% versus 38\% among married girls).

\section{Table 3.9: Desire to get enrolled or return to school}

Percentage of adolescents in ages 15-19 never enrolled in school or had discontinued their education, expressing a desire to enrol in school or return to school, according to residence, Bihar, 2016

\begin{tabular}{|c|c|c|c|}
\hline Desire to get enrolled or return to school & $\begin{array}{c}\text { Boys } \\
(15-19)\end{array}$ & $\begin{array}{c}\text { Girls } \\
(15-19)\end{array}$ & $\begin{array}{c}\text { Married girls } \\
\quad(15-19)\end{array}$ \\
\hline \multicolumn{4}{|l|}{ Combined (percent) } \\
\hline Desire to get enrolled in school & 33.9 & 33.0 & 18.4 \\
\hline Number who were never enrolled in school & 57 & 237 & 1,047 \\
\hline Desire to return to school & 33.4 & 54.8 & 38.8 \\
\hline Number who had discontinued their education before completing Class 12 & 297 & 556 & 1,639 \\
\hline \multicolumn{4}{|l|}{ Urban (percent) } \\
\hline Desire to get enrolled in school & $(34.6)$ & 37.2 & 20.5 \\
\hline Number who were never enrolled in school & 36 & 93 & 381 \\
\hline Desire to return to school & 29.3 & 61.7 & 43.9 \\
\hline Number who had discontinued their education before completing Class 12 & 162 & 254 & 666 \\
\hline \multicolumn{4}{|l|}{ Rural (percent) } \\
\hline Desire to get enrolled in school & * & 32.7 & 18.2 \\
\hline Number who were never enrolled in school & 21 & 144 & 666 \\
\hline Desire to return to school & 33.9 & 54.2 & 38.2 \\
\hline Number who had discontinued their education before completing Class 12 & 135 & 302 & 973 \\
\hline
\end{tabular}

Note: All Ns are unweighted. *Percentage not shown as this was based on fewer than 25 unweighted cases. () Based on $25-49$ unweighted cases. 


\section{Table 3.10: Educational aspirations}

Percentage of adolescents currently enrolled in school/college by level of education they aspire to achieve, according to residence, Bihar, 2016

\begin{tabular}{|c|c|c|c|c|c|}
\hline Level of education adolescents aspire to achieve & $\begin{array}{c}\text { Boys } \\
(10-14)\end{array}$ & $\begin{array}{c}\text { Boys } \\
(15-19)\end{array}$ & $\begin{array}{c}\text { Girls } \\
(10-14)\end{array}$ & $\begin{array}{c}\text { Girls } \\
(15-19)\end{array}$ & $\begin{array}{c}\text { Married girls } \\
\qquad(15-19)\end{array}$ \\
\hline \multicolumn{6}{|c|}{ Combined (percent) } \\
\hline At least class 10 & 76.5 & 85.4 & 82.9 & 95.7 & 95.6 \\
\hline At least class 12 & 54.3 & 78.9 & 59.2 & 84.1 & 87.2 \\
\hline At least graduation or professional courses & 33.3 & 68.4 & 38.7 & 67.5 & 70.8 \\
\hline Cannot say/do not know & 18.9 & 14.2 & 13.8 & 3.1 & 3.9 \\
\hline Number currently enrolled in school/college ${ }^{1}$ & 953 & 1,403 & 693 & 2,357 & 437 \\
\hline \multicolumn{6}{|c|}{ Urban (percent) } \\
\hline At least class 10 & 78.8 & 89.9 & 85.3 & 95.2 & 97.5 \\
\hline At least class 12 & 65.2 & 87.7 & 69.4 & 91.0 & 91.5 \\
\hline At least graduation or professional courses & 48.9 & 80.7 & 54.5 & 81.8 & 75.4 \\
\hline Cannot say/do not know & 19.6 & 9.8 & 12.8 & 4.4 & 2.5 \\
\hline Number currently enrolled in school/college ${ }^{1}$ & 422 & 765 & 353 & 1,247 & 169 \\
\hline \multicolumn{6}{|c|}{ Rural (percent) } \\
\hline At least class 10 & 76.2 & 84.9 & 82.6 & 95.7 & 95.3 \\
\hline At least class 12 & 53.0 & 77.8 & 57.9 & 83.2 & 86.7 \\
\hline At least graduation or professional courses & 31.5 & 66.9 & 36.7 & 65.6 & 70.2 \\
\hline Cannot say/do not know & 18.8 & 14.7 & 13.9 & 2.9 & 4.1 \\
\hline Number currently enrolled in school/college ${ }^{1}$ & 531 & 638 & 340 & 1,110 & 268 \\
\hline
\end{tabular}

Notes: All Ns are unweighted. ${ }^{1}$ Excludes those who were pursuing their education through distance education courses at the time of the interview.

Findings, presented in Table 3.10, indicate that the vast majority of adolescents who were currently pursuing their education in a school/college ${ }^{5}$ aspired to complete at least a senior secondary education/college (Classes 12 and above); 54 percent of younger boys and 79 percent of older boys aspired to do so as did 59 percent of younger girls and 84-87 percent of unmarried and married older girls. Indeed, as many as 33 percent of younger boys and 68 percent of older boys aspired to complete a college education or more or a professional course as did 39 percent of younger girls and 68-71 percent of unmarried and married older girls. While differences by sex were modest, differences by place of residence were marked; more urban adolescents aspired to complete senior secondary education or even college education or a professional course, compared with their rural counterparts.

\subsection{Awareness and utilisation of entitlements from school}

Many schemes that seek to encourage schooling have been implemented in Bihar, such as schemes for the provision of midday meals, scholarships, stipends, uniforms, textbooks, and bicycles. We assessed the awareness and reach of selected entitlements among survey participants who were eligible to receive those benefits, ${ }^{6}$ that is, those who were enrolled in a class eligible for entitlements at the time of the interview or in the year preceding the interview in a government school. We restricted the analysis to those who were enrolled in such classes at the time of the interview or in the year preceding the interview to reflect the current reach of the entitlements. Table 3.11 presents findings on eligible adolescents' awareness of selected entitlements from school.

\footnotetext{
${ }^{5}$ Excludes those who were pursuing their education through distance education programmes.

${ }^{6}$ With the implementation of the Right to Education Act, students enrolled in Classes 1-8 in government and government-aided schools are entitled to get free midday meals, uniforms, and textbooks. Students enrolled in Class 9 and above are entitled to apply for scholarship schemes sponsored by the government. Students enrolled in Class 9 are entitled to receive Rs 2,500 to purchase a bicycle.
} 
Findings indicate that a majority of eligible adolescents were aware of most of these schemes. Thus, 98-99 percent of boys and 97-100 percent of girls who were enrolled in a class eligible for entitlements at the time of the interview or in the year preceding the interview in a government school reported that they were aware that students are entitled to receive free uniforms and textbooks. Differences in awareness levels by age, sex, rural or urban residence, and,among older girls, by marital status were muted.

Likewise, 98-99 percent of boys and 98-100 percent of girls who were currently studying or had attended a class eligible for entitlements in the year preceding the interview in a government school had heard about scholarships to which students are entitled. Again, differences in awareness levels by age, sex, rural or urban residence, and, among older girls, by marital status were muted.

Finally, 95-98 percent of boys and 90-100 percent of girls who were currently studying or had attended a class eligible for entitlements in the year preceding the interview in a government school had heard about the bicycle scheme. Again, differences in awareness levels by age, sex, rural or urban residence, and, among older girls, by marital status were muted.

\section{Table 3.11: Awareness of entitlements from school}

Percentage of eligible adolescents reporting awareness of selected entitlements from school, according to residence, Bihar, 2016

\begin{tabular}{|c|c|c|c|c|c|}
\hline Entitlements & $\begin{array}{c}\text { Boys } \\
(10-14)\end{array}$ & $\begin{array}{c}\text { Boys } \\
(15-19)\end{array}$ & $\begin{array}{c}\text { Girls } \\
(10-14)\end{array}$ & $\begin{array}{c}\text { Girls } \\
(15-19)\end{array}$ & $\begin{array}{l}\text { Married girls } \\
(15-19)\end{array}$ \\
\hline \multicolumn{6}{|c|}{ Combined (percent) } \\
\hline Free uniforms/money to buy uniforms & 99.0 & 98.5 & 99.3 & 99.5 & 96.8 \\
\hline Free textbooks & 99.0 & 97.9 & 99.2 & 97.6 & 97.7 \\
\hline Number eligible to receive the entitlement ${ }^{1}$ & 657 & 341 & 535 & 753 & 191 \\
\hline Scholarships & 98.5 & 97.9 & 99.7 & 98.2 & 99.1 \\
\hline Number eligible to receive the entitlement ${ }^{2}$ & 122 & 969 & 85 & 1,850 & 565 \\
\hline Free bicycle/money to buy bicycle & 95.0 & 98.4 & 89.6 & 99.2 & 99.9 \\
\hline Number eligible to receive the entitlement ${ }^{3}$ & 122 & 468 & 85 & 859 & 184 \\
\hline \multicolumn{6}{|c|}{ Urban (percent) } \\
\hline Free uniforms/money to buy uniforms & 98.9 & 96.8 & 99.1 & 99.2 & 95.9 \\
\hline Free textbooks & 98.3 & 97.1 & 99.0 & 97.5 & 98.6 \\
\hline Number eligible to receive the entitlement ${ }^{1}$ & 199 & 119 & 213 & 291 & 69 \\
\hline Scholarships & $(100.0)$ & 93.7 & $(97.9)$ & 96.3 & 99.1 \\
\hline Number eligible to receive the entitlement ${ }^{2}$ & 45 & 493 & 46 & 949 & 240 \\
\hline Free bicycle/money to buy bicycle & $(96.8)$ & 97.2 & $(90.4)$ & 98.8 & 98.6 \\
\hline Number eligible to receive the entitlement ${ }^{3}$ & 45 & 178 & 46 & 348 & 68 \\
\hline \multicolumn{6}{|c|}{ Rural (percent) } \\
\hline Free uniforms/money to buy uniforms & 99.0 & 98.6 & 99.3 & 99.5 & 96.9 \\
\hline Free textbooks & 99.1 & 98.0 & 99.3 & 97.7 & 97.6 \\
\hline Number eligible to receive the entitlement ${ }^{1}$ & 458 & 222 & 322 & 462 & 122 \\
\hline Scholarships & 98.4 & 98.4 & $(100.0)$ & 98.5 & 99.1 \\
\hline Number eligible to receive the entitlement ${ }^{2}$ & 77 & 476 & 39 & 901 & 325 \\
\hline Free bicycle/money to buy bicycle & 94.9 & 98.4 & $(89.4)$ & 99.2 & 100.0 \\
\hline Number eligible to receive the entitlement ${ }^{3}$ & 77 & 290 & 39 & 511 & 116 \\
\hline
\end{tabular}

Notes: All Ns are unweighted. () Based on 25-49 unweighted cases. ${ }^{1}$ Number of adolescents enrolled in Classes 1-8 at the time of the interview or completed Classes 1-8 in the year preceding the interview in a government school. ${ }^{2}$ Number of adolescents completed or enrolled in Class 9 or above in the year preceding the interview in a government school. ${ }^{3}$ Number of adolescents enrolled in Class 9 at the time of interview or completed Class 9 in the year preceding the interview in a government school. 
Table 3.12 presents findings on the extent to which survey participants who were enrolled in a class eligible for entitlements at the time of the interview or in the year preceding the interview in a government school had benefited from the various entitlements in the year preceding the interview.

Findings show that large proportions of adolescents had benefited from these entitlements. Among adolescents who were enrolled in classes eligible for entitlements at the time of the interview, 82 percent of younger boys and 92 percent of younger girls had received the midday meal on the last day that he/she had attended school; the corresponding proportions among older boys and unmarried older girls were 74 percent and 94 percent. The table shows that there were differences in the reports of adolescents between those from rural areas and those from urban areas, with rural adolescents more likely than their urban counterparts to have received the midday meal (83\% versus $70 \%$ among younger boys; $75 \%$ versus $68 \%$ among older boys; $92 \%$ versus $83 \%$ among younger girls; and $95 \%$ versus $83 \%$ among unmarried older girls).

The reach of the free uniform scheme was also widespread. Among adolescents who were enrolled in classes eligible for entitlements at the time of the interview or in the year preceding the interview, 90 percent of younger boys and 94 percent of younger girls reported that they had received free uniforms or money to buy uniforms in the year preceding the interview as had 78 percent of older boys and 93-96 percent of unmarried and married older girls. Differences between adolescents from rural areas and those from urban areas were evident only among younger boys in this regard, with rural younger boys more likely than their urban counterparts to have received free uniforms (91\% versus $83 \%)$.

A large proportion of adolescents who were enrolled in classes eligible for entitlements at the time of the interview or in the year preceding the interview reported that they had received free textbooks or money to buy textbooks in the year preceding the interview $(92 \%$ and $83 \%$ of younger and older boys, respectively; $94 \%$ of younger girls and $86-94 \%$ of unmarried and married older girls). Differences in reports of adolescents from rural and urban areas were evident among boys and unmarried older girls; rural respondents were more likely than their urban counterparts to have received free textbooks (92\% versus $83 \%$ among younger boys; $83 \%$ versus $76 \%$ among older boys; and $86 \%$ versus $80 \%$ among older unmarried girls).

Compared with the reach of the entitlements described above, the reach of scholarship schemes was somewhat limited, particularly among older adolescents. Among younger adolescents who were enrolled in eligible classes at the time of the interview or in the year preceding the interview, 78 percent of boys and 93 percent of girls had received a scholarship in the year preceding the interview. The corresponding proportions among older adolescents were 55 percent among boys, 72 percent among unmarried girls, and 66 percent among married girls. Rural adolescents, other than younger girls, were more likely than urban respondents to have received scholarships ( $79 \%$ versus $68 \%$ among younger boys; $57 \%$ versus $35 \%$ among older boys; $74 \%$ versus $50 \%$ among unmarried older girls; and $67 \%$ versus $58 \%$ among married older girls).

Finally, the reach of the bicycle scheme differed between younger and older adolescents, girls and boys, and rural and urban adolescents. A larger proportion of older than younger adolescents enrolled in classes eligible for bicycles at the time of the interview or in the year preceding the interview reported that they had received a bicycle or money to buy it in the year preceding the interview (73\% versus $47 \%$ among boys and $82-85 \%$ versus $58 \%$ among girls). More girls than boys so reported (58\% versus $47 \%$ among younger adolescents and $82-85 \%$ versus $73 \%$ among older adolescents). More of urban than rural younger boys had received a bicycle or money to buy it (57\% versus $46 \%$ ). However, among younger girls, somewhat fewer urban than rural girls so reported (53\% versus 59\%), while differences between those in rural areas and those in urban areas were narrow among unmarried and married older girls. 


\section{Table 3.12: Reach of entitlements from school}

Percent distribution of eligible adolescents by receipt of selected entitlements from school, according to residence, Bihar, 2016

\begin{tabular}{|c|c|c|c|c|c|}
\hline Type of entitlements received & $\begin{array}{l}\text { Boys } \\
(10-14)\end{array}$ & $\begin{array}{l}\text { Boys } \\
(15-19)\end{array}$ & $\begin{array}{c}\text { Girls } \\
(10-14)\end{array}$ & $\begin{array}{c}\text { Girls } \\
(15-19)\end{array}$ & $\begin{array}{l}\text { Married girls } \\
(15-19)\end{array}$ \\
\hline \multicolumn{6}{|c|}{ Combined (percent) } \\
\hline \multicolumn{6}{|l|}{ Midday meal on the last day that respondent attended school } \\
\hline Received & 82.4 & 74.3 & 91.6 & 94.0 & * \\
\hline Not received & 15.3 & 21.2 & 7.6 & 4.4 & * \\
\hline Not entitled ${ }^{1}$ & 2.2 & 4.5 & 0.9 & 1.6 & * \\
\hline Number currently enrolled in classes eligible for midday meal ${ }^{2}$ & 557 & 85 & 461 & 252 & 24 \\
\hline \multicolumn{6}{|c|}{$\begin{array}{l}\text { Uniform/money to buy uniforms in the class in which they were } \\
\text { enrolled at the time of the interview or in the year preceding the interview }\end{array}$} \\
\hline Received & 90.2 & 78.1 & 94.1 & 95.8 & 93.3 \\
\hline Not received & 7.5 & 17.3 & 5.0 & 3.4 & 3.5 \\
\hline Not entitled ${ }^{1}$ & 1.3 & 3.1 & 0.2 & 0.4 & 0.0 \\
\hline Not aware of scheme & 1.0 & 1.5 & 0.7 & 0.5 & 1.6 \\
\hline \multicolumn{6}{|l|}{$\begin{array}{l}\text { Free textbooks in the class in which they were enrolled } \\
\text { at the time of the interview or in the year preceding the interview }\end{array}$} \\
\hline Received & 91.8 & 82.5 & 93.5 & 85.7 & 93.5 \\
\hline Not received & 6.5 & 11.2 & 5.4 & 7.6 & 2.1 \\
\hline Not entitled ${ }^{1}$ & 0.7 & 4.2 & 0.4 & 4.4 & 2.1 \\
\hline Not aware of scheme & 1.0 & 2.1 & 0.8 & 2.4 & 0.7 \\
\hline $\begin{array}{l}\text { Number enrolled in classes eligible for free textbooks and uniform } \\
\text { the time of the interview or in the year preceding the interview }{ }^{3}\end{array}$ & 657 & 341 & 535 & 753 & 191 \\
\hline \multicolumn{6}{|l|}{$\begin{array}{l}\text { Scholarship in the class in which they were enrolled } \\
\text { at the time of the interview or in the year preceding the interview }\end{array}$} \\
\hline Received & 77.8 & 55.1 & 92.9 & 71.5 & 66.3 \\
\hline Not received & 18.4 & 38.0 & 5.9 & 24.2 & 30.7 \\
\hline Not entitled ${ }^{1}$ & 2.3 & 4.8 & 0.9 & 2.6 & 2.1 \\
\hline Not aware of scheme & 1.5 & 2.1 & 0.3 & 1.8 & 0.9 \\
\hline $\begin{array}{l}\text { Number enrolled in classes eligible for scholarships at the time of } \\
\text { interview or in the year preceding the interview }\end{array}$ & 122 & 969 & 85 & 1,850 & 565 \\
\hline \multicolumn{6}{|c|}{$\begin{array}{l}\text { Bicycle/money to buy bicycle in the class in which they were } \\
\text { enrolled at the time of the interview or in the year preceding the interview }\end{array}$} \\
\hline Received & 47.0 & 72.8 & 57.9 & 81.5 & 85.0 \\
\hline Not received & 38.1 & 22.0 & 26.2 & 16.4 & 14.8 \\
\hline Not entitled ${ }^{1}$ & 9.9 & 3.6 & 5.5 & 1.4 & 0.1 \\
\hline Not aware of scheme & 5.0 & 1.6 & 10.4 & 0.8 & 0.1 \\
\hline $\begin{array}{l}\text { Number enrolled in classes eligible for bicycle sat the time of the } \\
\text { interview or in the year preceding the interview }\end{array}$ & 122 & 466 & 85 & 858 & 175 \\
\hline
\end{tabular}


Table 3.12 Cont.

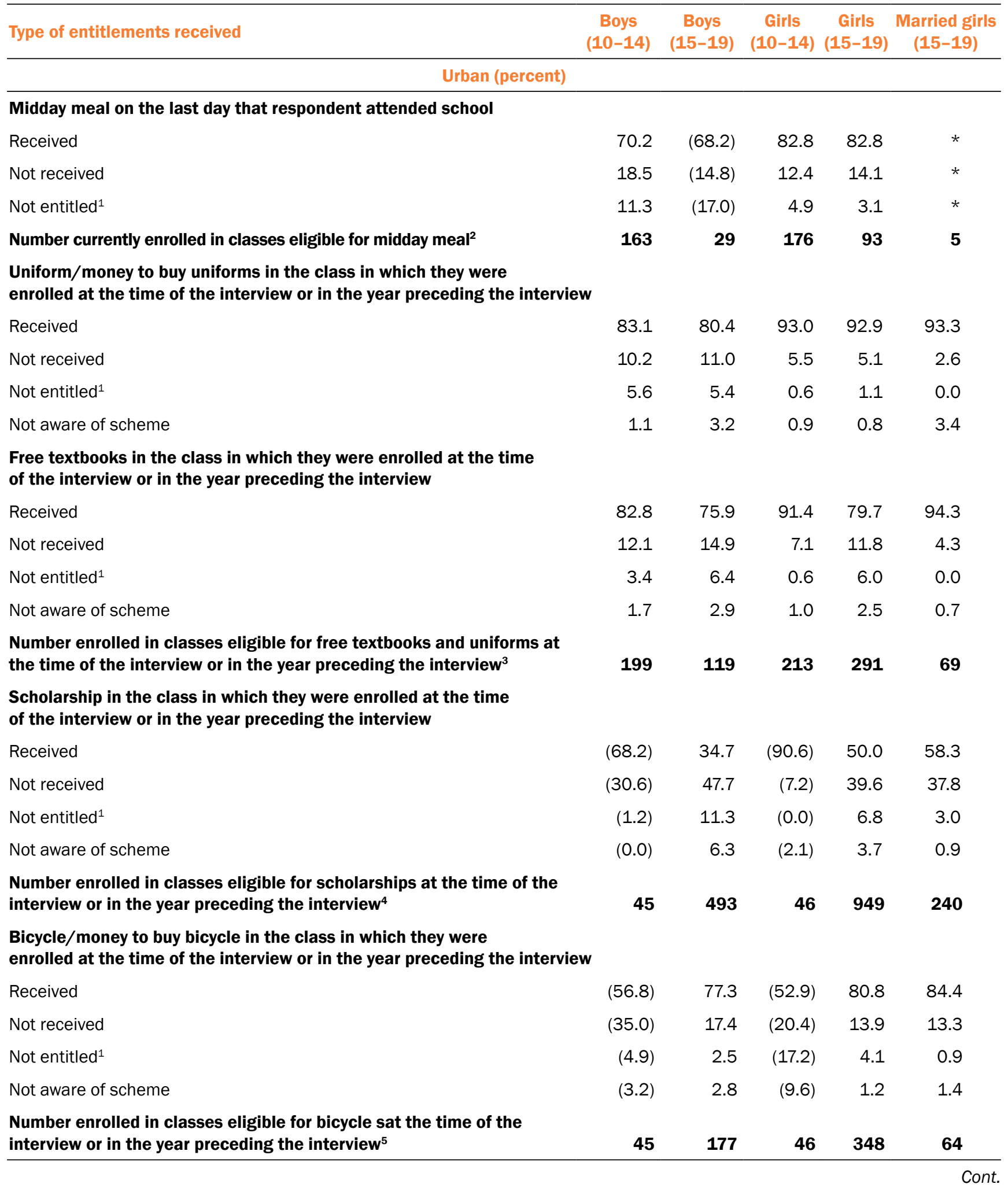


Table 3.12 Cont.

\begin{tabular}{ll} 
Type of entitlements received & \\
\hline Rural (percent)
\end{tabular}

Midday meal on the last day that respondent attended school

Received

Not received

Not entitled ${ }^{1}$

Number currently enrolled in classes eligible for midday meal ${ }^{2}$

Boys Boys Girls Girls Married girls

$(10-14) \quad(15-19) \quad(10-14)(15-19) \quad(15-19)$

Uniform/money to buy uniforms in the class in which they were

enrolled at the time of the interview or in the year preceding the interview

Received

Not received

Not entitled ${ }^{1}$

Not aware of scheme

Free textbooks in the class in which they were enrolled at the time of the interview or in the year preceding the interview

Received

Not received

Not entitled ${ }^{1}$

Not aware of scheme

Number enrolled in classes eligible for free textbooks and uniforms at the time of the interview or in the year preceding the interview ${ }^{3}$

$\begin{array}{rrrrr}83.2 & 74.6 & 92.2 & 94.7 & \text { * } \\ 15.1 & 21.5 & 7.2 & 3.8 & \text { * } \\ 1.7 & 3.9 & 0.6 & 1.5 & \text { * } \\ \mathbf{3 9 4} & \mathbf{5 6} & \mathbf{2 8 5} & \mathbf{1 5 9} & \mathbf{1 9}\end{array}$

Scholarship in the class in which they were enrolled at the time of the interview or in the year preceding the interview

Received

Not received

$\begin{array}{rrrrr}90.7 & 78.0 & 94.2 & 96.0 & 93.3 \\ 7.3 & 17.6 & 4.9 & 3.2 & 3.6 \\ 1.0 & 3.0 & 0.1 & 0.3 & 0.0 \\ 1.0 & 1.4 & 0.7 & 0.5 & 1.5\end{array}$

Not entitled ${ }^{1}$

Not aware of scheme

Number enrolled in classes eligible for scholarships at the time of the interview or in the year preceding the interview ${ }^{4}$

$\begin{array}{rrrrr}2.4 & 82.8 & 93.6 & 86.1 & 93.4 \\ 6.2 & 11.1 & 5.2 & 7.3 & 1.8 \\ 0.5 & 4.1 & 0.4 & 4.3 & 2.4 \\ 0.9 & 2.0 & 0.7 & 2.3 & 0.8 \\ & & & & \\ \mathbf{4 5 8} & \mathbf{2 2 2} & \mathbf{3 2 2} & \mathbf{4 6 2} & \mathbf{1 2 2}\end{array}$

Bicycle/money to buy bicycle in the class in which they were enrolled at the time of the interview or in the year preceding the interview

Received

Not received

$$
46.0
$$

$\begin{array}{rrrrr}78.8 & 57.4 & (93.2) & 74.2 & 67.3 \\ 17.2 & 36.9 & (5.7) & 22.3 & 29.8 \\ 2.4 & 4.1 & (1.1) & 2.0 & 2.0 \\ 1.6 & 1.6 & (0.0) & 1.5 & 0.9 \\ & & & & \\ \mathbf{7 7} & \mathbf{4 7 6} & \mathbf{3 9} & \mathbf{9 0 1} & \mathbf{3 2 5}\end{array}$

Not entitled ${ }^{1}$

\section{4}

$81.5 \quad 85.0$

Not aware of scheme

10.4

22.3

$16.6 \quad 15.0$

Number enrolled in classes eligible for bicycle sat the time of the interview or in the year preceding the interview ${ }^{5}$

$$
5.1
$$$$
3.6
$$

1.1

0.0

1.6

$0.8 \quad 0.0$

77

289

39

510

111

Note: All Ns are unweighted. NA: not applicable. *Percentage not shown as this was based on fewer than 25 unweighted cases. () Based on 2549 unweighted cases. ${ }^{1}$ Includes those who reported that they were not eligible as they were enrolled in schools in which the scheme was not offered. ${ }^{2}$ Number of adolescents currently enrolled in Classes $1-8$ in a government school. ${ }^{3}$ Number of adolescents enrolled in Classes 1-8 at the time of the interview or had completed Classes 1-8 in the year preceding the interview in a government school. ${ }^{4}$ Number of adolescents enrolled in Class 9 or above at the time of the interview or who had completed Class 9 or above in the year preceding the interview in a government school. ${ }^{5}$ Number of adolescents enrolled in Class 9 at the time of interview or who had completed Class 9 in the year preceding the interview in a government school. 


\subsubsection{Awareness and participation in Meena Manch programme}

The survey probed the awareness of respondents of the Meena Manch programme and their participation in it. The Meena Manch is a school-based forum intended to promote the value and rights of the girl child through manchs (clubs)set up in upper primary schools (UNICEF, n.d.).

Findings presented in Table 3.13 show that 16-17 percent of boys and 33-40 percent of girls who were enrolled in classes eligible to participate in this programme at the time of the interview or in the year preceding the interview in a government school had heard about the Meena Manch programme. More rural than urban adolescents were aware of it among older boys and married older girls; 17 percent of older boys and 42 percent of married older girls in rural areas compared with 12 percent and 28 percent of their respective counterparts in urban areas had heard about the programme. However, participation in the activities of the programme was reported by just 4-6 percent of boys and 10-12 percent of girls. While participation in Meena Manch programme did not differ among older adolescents between those from rural and those from urban areas, more urban than rural younger girls had participated in it $(21 \%$ versus $10 \%)$.

\section{Table 3.13: Awareness of and participation in Meena Manch programme}

Percentage of eligible adolescents reporting awareness of and participation in Meena Manch programme, according to residence, Bihar, 2016

\begin{tabular}{|c|c|c|c|c|c|}
\hline Awareness and participation & $\begin{array}{c}\text { Boys } \\
(10-14)\end{array}$ & $\begin{array}{c}\text { Boys } \\
(15-19)\end{array}$ & $\begin{array}{c}\text { Girls } \\
(10-14)\end{array}$ & $\begin{array}{c}\text { Girls } \\
(15-19)\end{array}$ & $\begin{array}{c}\text { Married } \\
\text { girls } \\
\text { (15-19) }\end{array}$ \\
\hline \multicolumn{6}{|c|}{ Combined (percent) } \\
\hline Aware of Meena Manch programme & 15.9 & 16.9 & 34.1 & 32.8 & 40.1 \\
\hline Participated in Meena Manch programme & 6.2 & 3.9 & 10.9 & 10.3 & 11.9 \\
\hline Number eligible to participate in Meena Manch $^{1}$ & 333 & 327 & 256 & 699 & 182 \\
\hline \multicolumn{6}{|c|}{ Urban (percent) } \\
\hline Aware of Meena Manch programme & 18.1 & 12.3 & 32.6 & 33.9 & 27.7 \\
\hline Participated in Meena Manch programme & 5.2 & 3.0 & 21.4 & 11.3 & 10.2 \\
\hline Number eligible to participate in Meena Manch ${ }^{1}$ & 100 & 113 & 105 & 260 & 66 \\
\hline \multicolumn{6}{|c|}{ Rural (percent) } \\
\hline Aware of Meena Manch programme & 15.7 & 17.2 & 34.2 & 32.7 & 41.5 \\
\hline Participated in Meena Manch programme & 6.2 & 3.9 & 9.9 & 10.2 & 12.0 \\
\hline Number eligible to participate in Meena Manch $^{1}$ & 233 & 214 & 151 & 439 & 116 \\
\hline
\end{tabular}

Notes: All Ns are unweighted. ${ }^{1}$ Number of adolescents who were enrolled in Classes 6-8 at the time of the interview or adolescents in ages 15-19 who had completed Classes $6-8$ in the year preceding the interview in a government school.

\subsection{Literacy and numeracy skills}

Using tools developed by ASER (ASER, 2017), we assessed literacy (assessing ability to read in Hindi) and numeracy levels among all survey participants who were ever enrolled in school. The literacy assessment tool consists of four levels: recognition of letters, ability to read words, ability to read a short paragraph (Class 1 level text), and ability to read a longer 'story' (Class 2 level text). The respondent is marked at the highest level which she/he can read comfortably, that is, with no more than three mistakes. The numeracy assessment tool, likewise, consists of four levels: recognition of single-digit numbers (1-9), recognition of double-digit numbers (11-99), and ability to perform a two-digit subtraction sum with carry over and a three-digit division sum. The respondent is marked at the highest level which she/he can do correctly. Table 3.14 summarises literacy and numeracy levels among all survey participants who were ever enrolled in school. 
Findings highlight poor learning levels among adolescents-between one-half and three-quarters of adolescents were able to read a Class 2 text fluently in Hindi. Older adolescents were more likely to read fluently than younger adolescents (74\% of older boys versus $56 \%$ of younger boys and $69 \%$ of unmarried older girls versus $51 \%$ of younger girls). Differences by sex were mild. Among older girls, however, differences by marital status were evident, with married girls less likely than their unmarried counterparts to read fluently (53\% versus $69 \%$ ). Indeed, the reading levels among married older girls were similar to that of younger adolescents. Differences in literacy skills between adolescents of rural areas and those of urban areas were wide across all categories; urban adolescents were more likely than rural adolescents to read fluently ( $72-75 \%$ versus $49-54 \%$ among younger adolescents and $65-85 \%$ versus $51-73 \%$ among older adolescents). Findings also show that 12-24 percent of boys and 15-28 percent of girls were able to read only letters or words fluently; indeed, 4-7 percent of boys and 7-12 percent of girls could not read even a single letter.

Numeracy levels were also poor. Numeracy levels varied by sex, marital status (among older girls), and place of residence. A larger proportion of boys than girls were able to solve a division problem ( $54 \%$ of younger boys versus $38 \%$ of younger girls and $63 \%$ of older boys versus $51 \%$ of unmarried older girls). Among older girls, the unmarried were more likely than the married to do so (51\% versus 31\%). Differences in numeracy levels between adolescents of rural areas and those of urban areas were apparent, with urban adolescents more likely than their rural counterparts to solve a division problem (55-63\% versus $36-52 \%$ among younger adolescents; $66-73 \%$ versus $49-62 \%$ among older boys and unmarried older girls; and 39\% versus 30\% among married older girls). As many as 20-31 percent of boys and 29-46 percent of girls were able to recognise only single-or double-digit numbers; indeed, 1-4 percent could not recognise even single-digit numbers.

\section{Table 3.14: Literacy and numeracy levels}

Percentage distribution of adolescents who were ever enrolled in school by levels of literacy and numeracy, according to residence, Bihar, 2016

\begin{tabular}{|c|c|c|c|c|c|}
\hline Literacy and numeracy levels & $\begin{array}{c}\text { Boys } \\
(10-14)\end{array}$ & $\begin{array}{c}\text { Boys } \\
(15-19)\end{array}$ & $\begin{array}{c}\text { Girls } \\
(10-14)\end{array}$ & $\begin{array}{c}\text { Girls } \\
(15-19)\end{array}$ & $\begin{array}{c}\text { Married girls } \\
\text { (15-19) }\end{array}$ \\
\hline \multicolumn{6}{|c|}{ Combined (percent) } \\
\hline \multicolumn{6}{|l|}{ Literacy levels } \\
\hline Can read Class 2 text & 56.0 & 73.9 & 51.4 & 68.9 & 52.9 \\
\hline Can read Class 1 text & 12.6 & 10.5 & 8.9 & 9.5 & 13.0 \\
\hline Can read words & 5.5 & 4.9 & 6.9 & 4.3 & 7.4 \\
\hline Can read letters & 18.5 & 6.8 & 20.6 & 10.3 & 15.4 \\
\hline Cannot read even letters & 7.4 & 3.9 & 12.2 & 6.9 & 11.4 \\
\hline \multicolumn{6}{|l|}{ Numeracy levels } \\
\hline Can solve a division problem & 53.5 & 63.4 & 38.4 & 51.0 & 30.6 \\
\hline Can solve a subtraction problem & 12.9 & 16.0 & 15.9 & 17.1 & 19.3 \\
\hline Can recognise double-digit numbers & 18.7 & 16.3 & 21.5 & 19.3 & 30.1 \\
\hline Can recognise single-digit numbers & 12.4 & 3.2 & 20.5 & 10.0 & 16.3 \\
\hline Cannot recognise even single-digit numbers & 2.6 & 1.2 & 3.8 & 2.7 & 3.6 \\
\hline Number ever enrolled in school & 998 & 1,764 & 730 & 3,191 & 2,361 \\
\hline \multicolumn{6}{|c|}{ Urban (percent) } \\
\hline \multicolumn{6}{|l|}{ Literacy levels } \\
\hline Can read Class 2 text & 74.8 & 85.3 & 72.2 & 85.1 & 65.1 \\
\hline Can read Class 1 text & 7.2 & 6.6 & 7.7 & 5.3 & 8.5 \\
\hline Can read words & 3.2 & 1.7 & 3.6 & 2.0 & 6.3 \\
\hline Can read letters & 9.2 & 4.1 & 12.4 & 4.8 & 12.3 \\
\hline Cannot read even letters & 5.7 & 2.4 & 4.1 & 2.8 & 7.7 \\
\hline
\end{tabular}


Table 3.14 Cont.

\begin{tabular}{|c|c|c|c|c|c|}
\hline Literacy and numeracy levels & $\begin{array}{c}\text { Boys } \\
(10-14)\end{array}$ & $\begin{array}{c}\text { Boys } \\
(15-19)\end{array}$ & $\begin{array}{c}\text { Girls } \\
(10-14)\end{array}$ & $\begin{array}{c}\text { Girls } \\
(15-19)\end{array}$ & $\begin{array}{c}\text { Married girls } \\
(15-19)\end{array}$ \\
\hline \multicolumn{6}{|l|}{ Numeracy levels } \\
\hline Can solve a division problem & 62.5 & 73.3 & 55.3 & 65.8 & 38.9 \\
\hline Can solve a subtraction problem & 16.9 & 12.3 & 19.4 & 15.5 & 20.2 \\
\hline Can recognise double-digit numbers & 14.4 & 11.7 & 14.7 & 12.8 & 26.4 \\
\hline Can recognise single-digit numbers & 5.4 & 2.5 & 9.6 & 5.0 & 11.5 \\
\hline Cannot recognise even single-digit numbers & 0.8 & 0.2 & 1.0 & 0.9 & 3.0 \\
\hline Number ever enrolled in school & 444 & 972 & 372 & 1,645 & 985 \\
\hline \multicolumn{6}{|c|}{ Rural (percent) } \\
\hline \multicolumn{6}{|l|}{ Literacy levels } \\
\hline Can read Class 2 text & 53.8 & 72.5 & 48.8 & 66.9 & 51.4 \\
\hline Can read Class 1 text & 13.3 & 11.0 & 9.0 & 10.0 & 13.6 \\
\hline Can read words & 5.8 & 5.3 & 7.3 & 4.6 & 7.5 \\
\hline Can read letters & 19.6 & 7.1 & 21.6 & 11.0 & 15.8 \\
\hline Cannot read even letters & 7.6 & 4.1 & 13.2 & 7.4 & 11.8 \\
\hline \multicolumn{6}{|l|}{ Numeracy levels } \\
\hline Can solve a division problem & 52.4 & 62.1 & 36.3 & 49.1 & 29.6 \\
\hline Can solve a subtraction problem & 12.4 & 16.5 & 15.4 & 17.3 & 19.2 \\
\hline Can recognise double-digit numbers & 19.2 & 16.8 & 22.3 & 20.1 & 30.6 \\
\hline Can recognise single-digit numbers & 13.2 & 3.3 & 21.8 & 10.6 & 16.9 \\
\hline Cannot recognise even single-digit numbers & 2.8 & 1.3 & 4.1 & 3.0 & 3.7 \\
\hline Number ever enrolled in school & 554 & 792 & 358 & 1,546 & 1,376 \\
\hline
\end{tabular}

Note: All Ns are unweighted.

Figure 3.7 shows the percentage of adolescents who could both read a Class 2 text and solve a simple division problem-44 percent of younger boys and 58 percent of older boys were thus literate and numerate as were 35 percent of younger girls, 47 percent of unmarried older girls, and 27 percent of married older girls. Urban adolescents were more likely than rural adolescents to be both literate and numerate.

Figure 3.7: Percentage of adolescents who could read a Class 2 text fluently in Hindi and solve a simple division problem, according to residence, Bihar, 2016

Adolescents who could read Class 2 text and solve a division problem

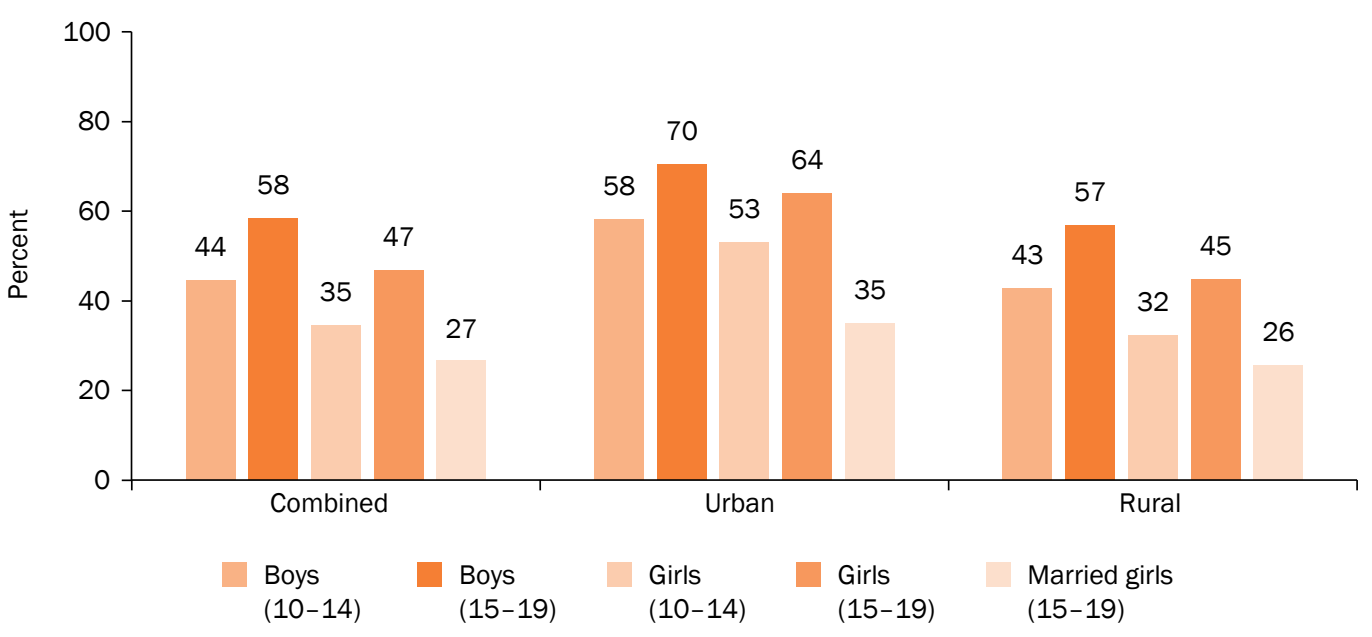




\subsubsection{Differentials in literacy and numeracy skills}

Table 3.15 describes differentials in adolescents' ability to read a Class 2 text. Findings show that literacy skills measured thus increased with age among all categories. Among younger adolescents, for example, 46-47 percent of those in ages 10-12 were able to read a Class 2 text fluently compared with 59-72 percent of those in ages 13-14, and, among older adolescents, 50-71 percent of those in ages 15-17 compared with 55-81 percent of those in ages 18-19 were able to do so. Differences by religion were modest for the most part; even so, Hindu boys were somewhat more likely than Muslim boys to display literacy levels expected of Class 2 students ( $57 \%$ versus $48 \%$ among younger boys and $75 \%$ versus $69 \%$ among older boys). Caste-wise differences were notable: across all categories of adolescents, those belonging to scheduled castes were the least likely to display literacy levels expected of Class 2 students, while those belonging to general castes were the most likely to do so.

Not surprisingly, the literacy level steadily increased with years of schooling completed across all categories of adolescents. However, it is notable that even among those who had completed primary education (that is, Class 8 or more), not all could read a Class 2 text fluently; among those who had completed Classes 8-9,for example, 77-86 percent of boys and 58-83 percent of girls could do so. Findings also highlight a tendency to lose reading skills over time; at the same level of years of schooling completed, younger adolescents were more likely than older adolescents to read a Class 2 text fluently. Thus,among those who had completed 1-4 years of schooling, 32 percent of younger boys compared with 18 percent of older boys could read a Class 2 text fluently; a similar pattern held among girls too $(32 \%$ versus $4 \%)$. We draw attention to the possibility of a selectivity bias in the sub-sample of adolescents in ages 15-19 who had completed only 1-4 years of schooling, that is, they could be the ones with low academic performance in Classes 1-4 whose poor performance inhibited progress to the next class. Literacy levels increased steadily with household wealth index across all categories of adolescents.

A larger proportion of adolescents who were pursuing their education at the time of the interview were able to read a Class 2 text fluently than those who had discontinued their education across all categories of adolescents (53-59\% versus $9-16 \%$ among younger adolescents and $77-81 \%$ versus $38-44 \%$ among older adolescents). Literacy levels were higher among those who reported that they had performed well in the last class than those who did not report so across all categories of adolescents. Findings also show that adolescents who had attended a private educational facility recently were more likely than those who had attended a government educational facility to display literacy levels expected of Class 2 students (81\% versus $49-52 \%$ among younger adolescents and $76-88 \%$ versus $49-72 \%$ among older adolescents). Those who had taken private tuition in the month prior to the interview were more likely than those who had not to read a Class 2 text fluently among younger adolescents and older boys (64\% versus $37-46 \%$ among younger adolescents and $85 \%$ versus $74 \%$ among older boys). While this difference was modest among unmarried older girls, among married older girls, those who had taken private tuition were less likely to read a Class 2 text fluently than those who had not (74\% versus $83 \%)$. Literacy levels among adolescents increased with the educational attainment of their mother across all categories of adolescents. Thus, 44 percent of younger girls whose mother had no education compared with 93 percent of those whose mother had completed 10 or more years of schooling were able to read a Class 2 text fluently.

\section{Table 3.15: Literacy level by selected background characteristics}

Percentage of adolescents who had ever attended school who can read a Class 2 text in Hindi fluently by selected background characteristics, Bihar, 2016

\begin{tabular}{lrrrrr}
\hline Background characteristics (percent) & $\begin{array}{c}\text { Boys } \\
(10-14)\end{array}$ & $\begin{array}{c}\text { Boys } \\
(15-19)\end{array}$ & $\begin{array}{c}\text { Girls } \\
(10-14)\end{array}$ & $\begin{array}{c}\text { Girls } \\
(15-19)\end{array}$ & $\begin{array}{c}\text { Married girls } \\
(15-19)\end{array}$ \\
\hline Age & & & & & \\
$10-12$ & 47.2 & NA & 46.4 & NA & NA \\
$13-14$ & 71.5 & NA & 58.6 & NA & NA \\
$15-17$ & NA & 71.3 & NA & 66.0 & 49.6 \\
$18-19$ & NA & 81.4 & NA & 79.2 & 54.6 \\
Religion & & & & & \\
Hindu & 57.1 & 74.8 & 51.2 & 68.6 & 52.7 \\
Muslim & 48.3 & 68.8 & 52.4 & 69.2 & 54.4 \\
\hline
\end{tabular}


Education

Table 3.15 Cont.

\begin{tabular}{|c|c|c|c|c|c|}
\hline Background characteristics (percent) & $\begin{array}{c}\text { Boys } \\
(10-14)\end{array}$ & $\begin{array}{c}\text { Boys } \\
(15-19)\end{array}$ & $\begin{array}{c}\text { Girls } \\
(10-14)\end{array}$ & $\begin{array}{c}\text { Girls } \\
(15-19)\end{array}$ & $\begin{array}{l}\text { Married girls } \\
\qquad(15-19)\end{array}$ \\
\hline \multicolumn{6}{|l|}{ Caste $^{2}$} \\
\hline SC & 43.1 & 71.6 & 33.4 & 51.8 & 43.3 \\
\hline OBC & 56.3 & 72.8 & 53.4 & 69.1 & 54.6 \\
\hline General $^{3}$ & 74.8 & 83.9 & 73.0 & 87.8 & 65.5 \\
\hline \multicolumn{6}{|l|}{ Completed years of schooling } \\
\hline $1-4$ & 32.4 & 17.5 & 31.9 & 3.6 & 3.6 \\
\hline $5-7$ & 62.1 & 35.1 & 54.4 & 36.5 & 23.7 \\
\hline $8-9$ & 85.8 & 77.2 & 82.9 & 68.8 & 58.0 \\
\hline $10-11$ & NA & 93.3 & NA & 90.6 & 80.6 \\
\hline 12 and above & NA & 96.0 & NA & 97.7 & 94.0 \\
\hline \multicolumn{6}{|l|}{ Wealth quintile } \\
\hline First & 41.5 & 58.6 & 26.6 & 40.1 & 38.5 \\
\hline Second & 45.1 & 67.8 & 33.6 & 50.7 & 41.4 \\
\hline Third & 49.2 & 66.4 & 41.7 & 64.0 & 48.0 \\
\hline Fourth & 59.5 & 74.5 & 64.1 & 71.3 & 51.1 \\
\hline Fifth & 80.8 & 87.6 & 75.4 & 86.1 & 73.9 \\
\hline \multicolumn{6}{|l|}{ Current schooling status ${ }^{4}$} \\
\hline Yes & 58.5 & 80.6 & 53.4 & 76.6 & 81.4 \\
\hline No & $(9.3)$ & 43.7 & $(15.6)$ & 38.4 & 42.4 \\
\hline \multicolumn{6}{|c|}{ Self-perceptions about performance in the last class } \\
\hline Poor & $(22.7)$ & 73.2 & * & 72.0 & * \\
\hline Average & 57.8 & 74.5 & 47.3 & 73.8 & 76.0 \\
\hline Well & 62.9 & 91.6 & 61.7 & 80.3 & 89.5 \\
\hline \multicolumn{6}{|l|}{ Type of school } \\
\hline Government & 52.0 & 72.0 & 48.5 & 66.1 & 48.5 \\
\hline Private & 81.0 & 85.0 & 80.5 & 87.6 & 76.3 \\
\hline \multicolumn{6}{|l|}{ Had private tuition } \\
\hline Yes & 64.1 & 85.1 & 64.2 & 78.1 & 74.4 \\
\hline No & 46.4 & 73.6 & 36.7 & 75.2 & 83.1 \\
\hline \multicolumn{6}{|c|}{ Mother's education (in years of schooling completed) } \\
\hline None $^{5}$ & 50.3 & 70.6 & 43.7 & 60.7 & 48.6 \\
\hline $1-7$ & 59.1 & 79.3 & 66.4 & 77.8 & 57.8 \\
\hline $8-9$ & 86.2 & 79.7 & 74.0 & 91.9 & 68.1 \\
\hline 10 and above & 85.9 & 93.4 & 92.6 & 93.0 & 80.2 \\
\hline Total & 56.0 & 73.6 & 51.4 & 68.9 & 52.9 \\
\hline
\end{tabular}

Notes: * Percentage not shown as this was based on fewer than 25 unweighted cases. () Based on 25-49 unweighted cases. NA: not applicable; OBC: other backward caste; SC: scheduled caste; ST: scheduled tribe. ${ }^{1}$ Percentages not shown for those belonging to other religions as less than one percent of surveyed adolescents belonged to other religions. ${ }^{2}$ Percentages not shown for those belonging to STs as less than one percent of surveyed adolescents belonged to STs. ${ }^{3}$ Includes all those not belonging to SCs, STs, or OBCs. ${ }^{4}$ Percentages not shown for adolescents who were pursuing their education through distance education courses at the time of interview or those who never went to school. ${ }^{5}$ Includes non-literate and literate with no formal schooling. 
Table 3.16 describes differentials in the highest level of numeracy attained, that is, ability to solve a division problem. Findings show that numeracy skills increased with age among younger adolescents and older boys. Among younger boys, for example, 48 percent of those in ages 10-12 were able to solve a division problem compared with 63 percent of those images 13-14; the corresponding proportions among younger girls were 32 percent and 48 percent, and among older boys, the proportion for 15-17-year-olds was 61 percent, and for 18-19-year-olds, it was 70 percent.

\section{Table 3.16: Numeracy levels by selected background characteristics}

Percentage of adolescents who were ever enrolled in school who can solve a division problem by selected background characteristics, Bihar, 2016

\begin{tabular}{|c|c|c|c|c|c|}
\hline Background characteristics (percent) & $\begin{array}{l}\text { Boys } \\
(10-14)\end{array}$ & $\begin{array}{c}\text { Boys } \\
(15-19)\end{array}$ & $\begin{array}{c}\text { Girls } \\
(10-14)\end{array}$ & $\begin{array}{c}\text { Girls } \\
(15-19)\end{array}$ & $\begin{array}{l}\text { Married girls } \\
(15-19)\end{array}$ \\
\hline \multicolumn{6}{|l|}{ Age } \\
\hline $10-12$ & 48.1 & NA & 31.7 & NA & NA \\
\hline $13-14$ & 62.9 & NA & 48.1 & NA & NA \\
\hline $15-17$ & NA & 61.1 & NA & 50.0 & 29.3 \\
\hline $18-19$ & NA & 69.9 & NA & 54.3 & 31.3 \\
\hline \multicolumn{6}{|l|}{ Religion $^{1}$} \\
\hline Hindu & 54.9 & 65.3 & 40.1 & 52.6 & 32.3 \\
\hline Muslim & 43.2 & 50.9 & 28.6 & 41.0 & 15.9 \\
\hline \multicolumn{6}{|l|}{ Caste $^{2}$} \\
\hline SC & 42.5 & 61.3 & 28.1 & 35.4 & 21.5 \\
\hline OBC & 55.6 & 64.2 & 38.0 & 52.9 & 33.4 \\
\hline General $^{3}$ & 62.7 & 64.9 & 59.4 & 60.7 & 31.7 \\
\hline \multicolumn{6}{|l|}{ Completed years of schooling } \\
\hline $1-4$ & 32.6 & 5.4 & 19.6 & 0.3 & 2.0 \\
\hline $5-7$ & 61.6 & 29.3 & 40.5 & 23.0 & 7.8 \\
\hline $8-9$ & 71.5 & 65.8 & 72.1 & 50.1 & 33.4 \\
\hline $10-11$ & NA & 80.8 & NA & 68.7 & 45.0 \\
\hline 12 and above & NA & 87.2 & NA & 78.3 & 69.5 \\
\hline \multicolumn{6}{|l|}{ Wealth quintile } \\
\hline First & 40.0 & 40.1 & 25.2 & 29.1 & 19.6 \\
\hline Second & 50.3 & 58.3 & 12.3 & 37.4 & 23.3 \\
\hline Third & 49.0 & 61.4 & 36.6 & 44.3 & 24.7 \\
\hline Fourth & 50.3 & 64.4 & 46.3 & 49.7 & 31.6 \\
\hline Fifth & 73.6 & 73.1 & 59.5 & 68.5 & 44.7 \\
\hline \multicolumn{6}{|l|}{ Current schooling status ${ }^{4}$} \\
\hline Yes & 56.3 & 70.7 & 40.1 & 58.7 & 56.1 \\
\hline No & $(0.6)$ & 29.7 & $(9.2)$ & 22.0 & 20.8 \\
\hline \multicolumn{6}{|c|}{ Self-perceptions about performance in the last class } \\
\hline Poor & $(50.8)$ & 73.4 & * & 47.5 & * \\
\hline Average & 56.4 & 67.2 & 33.3 & 55.3 & 52.5 \\
\hline Well & 56.7 & 76.2 & 49.7 & 63.4 & 63.6 \\
\hline
\end{tabular}


Table 3.16 Cont.

\begin{tabular}{|c|c|c|c|c|c|}
\hline Background characteristics (percent) & $\begin{array}{c}\text { Boys } \\
(10-14)\end{array}$ & $\begin{array}{c}\text { Boys } \\
(15-19)\end{array}$ & $\begin{array}{c}\text { Girls } \\
(10-14)\end{array}$ & $\begin{array}{c}\text { Girls } \\
(15-19)\end{array}$ & $\begin{array}{l}\text { Married girls } \\
\quad(15-19)\end{array}$ \\
\hline \multicolumn{6}{|l|}{ Type of school } \\
\hline Government & 50.7 & 61.1 & 34.9 & 48.2 & 26.8 \\
\hline Private & 70.8 & 75.2 & 74.3 & 71.9 & 42.7 \\
\hline \multicolumn{6}{|l|}{ Had private tuition } \\
\hline Yes & 61.7 & 76.2 & 51.5 & 61.8 & 63.3 \\
\hline No & 44.7 & 62.4 & 22.3 & 55.6 & 54.3 \\
\hline \multicolumn{6}{|c|}{ Mother's education (in years of schooling completed) } \\
\hline None $^{5}$ & 49.4 & 60.9 & 29.1 & 43.0 & 27.6 \\
\hline $1-7$ & 55.9 & 61.9 & 58.7 & 59.8 & 32.3 \\
\hline $8-9$ & 67.0 & 73.3 & 65.6 & 71.5 & 43.2 \\
\hline 10 and above & 81.5 & 79.1 & 85.7 & 75.6 & 51.9 \\
\hline Total & 53.5 & 63.4 & 38.4 & 51.0 & 30.6 \\
\hline
\end{tabular}

Notes: * Percentage not shown as this was based on fewer than 25 unweighted cases. () Based on 25-49 unweighted cases. NA: not applicable; OBC: other backward caste; SC: scheduled caste; ST: scheduled tribe. ${ }^{1}$ Percentages not shown for those belonging to other religions as less than one percent of surveyed adolescents belonged to other religions. ${ }^{2}$ Percentages not shown for those belonging to STs as less than one percent of surveyed adolescents belonged to STs. ${ }^{3}$ Includes all those not belonging to SCs, STs, or OBCs. ${ }^{4}$ Percentages not shown for adolescents who were pursuing their education through distance education courses at the time of interview or those who never went to school. ${ }^{5}$ Includes non-literate and literate with no formal schooling.

Differences by religion show that Hindu adolescents were more likely than Muslim adolescents to score better in arithmetic. Caste-wise differences were notable-across all categories of adolescents, except among older boys, adolescents belonging to scheduled castes were less likely than those who belonged to other castes to solve a division problem.

Not surprisingly, numeracy level steadily increased with years of schooling completed across all five categories of adolescents. However, it is notable that even among those who had completed primary education (that is, Class 8 or more), not all could solve a division problem; among those who had completed Classes 8-9,for example, 66-72 percent of boys and 33-72 percent of girls could do so. As with literacy skills, adolescents tended to lose numeracy skills over time. Thus, between younger and older adolescents with the same level of years of schooling completed, younger adolescents were more likely than older adolescents to solve a division problem. Among those who had completed 1-4 years of schooling, 33 percent of younger boys compared with five percent of older boys solved a division problem; a similar pattern occurred among girls too ( $20 \%$ versus $2 \%$ or less). Numeracy levels increased steadily with household wealth index across all categories of adolescents.

A larger proportion of adolescents who were pursuing their education at the time of the interview were able to solve a division problem compared with the proportion of adolescents who had discontinued their education across all categories (56-71\% versus $1-30 \%$ among boys and $40-59 \%$ versus $9-22 \%$ among girls).

Numeracy levels were higher among girls (but not among boys) who reported that they had performed well in the last class attended than those who did not so report. Even so, just 57 percent of younger boys and 76 percent of older boys who reported that they had performed well in the previous class were able to solve a division problem as did 50 percent of younger girls and 63-64 percent of older girls. Findings also show that adolescents who were enrolled in a private educational facility at the time of the interview or in the year preceding the interview were more likely than those who were enrolled in a government educational facility to display numeracy skills ( $71-75 \%$ versus $51-61 \%$ among boys and $43-74 \%$ versus $27-48 \%$ among girls). Those who had taken private tuition in the month prior to the interview were more likely than those who had not to display numeracy skills $(62-76 \%$ versus $45-62 \%$ among boys and $52-63 \%$ versus $22-56 \%$ among girls). Numeracy levels among adolescents increased with the educational attainment of their mother across all categories of adolescents. Thus, 49 percent of younger boys whose mother had no education compared with 82 percent of those whose mother had completed 10 or more years of schooling were able to solve a division problem. 


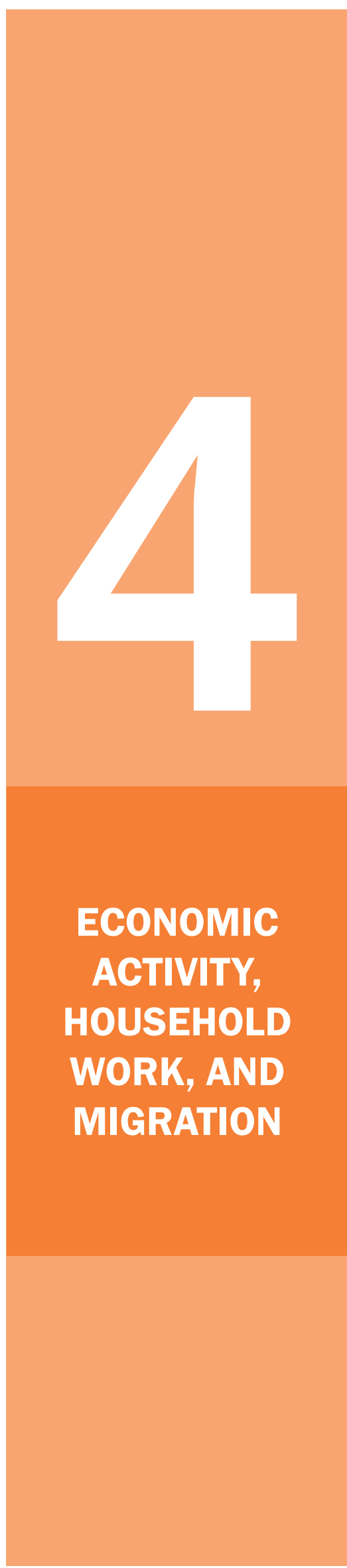

\section{A Snapshot}

\section{Economic activity}

Engagement in paid or unpaid work in adolescence is widespread:

- $49 \%$ of younger boys

- $80 \%$ of older boys

- $42 \%$ of younger girls

- $49 \%$ of unmarried older girls

- $48 \%$ of married older girls had ever been engaged in paid or unpaid work

Notable proportions were initiated into paid work in childhood, that is, before 14 years of age:

- $4 \%$ of older boys

- $7 \%$ of unmarried older girls

- $10 \%$ of married older girls
- $44 \%$ of younger boys

- $78 \%$ of older boys

- $39 \%$ of younger girls

- $47 \%$ of unmarried older girls

- $28 \%$ of married older girls had ever been engaged in paid or unpaid work in the year preceding the interview

Many are actively seeking paid employment:

- $24 \%$ of older boys

- $11 \%$ of unmarried older girls

- $10 \%$ of married older girls

Many combine studying with working:

at 10 years of age

- $17 \%$ of older boys

- $15 \%$ of unmarried older girls

- $13 \%$ of married older girls were studying and working
Agricultural labour and unskilled nonagricultural labour are the leading occupations among those who were engaged in paid work in the preceding year:

- $71 \%$ of older boys

- $77 \%$ of unmarried older girls

- $83 \%$ of married older girls at 15 years of age

- $31 \%$ of older boys

- $29 \%$ of unmarried older girls

- $14 \%$ of married older girls were studying and working

\section{POPULATION}




\section{A Snapshot}

Significant proportions of girls are neither studying nor working:
at 10 years of age
at 15 years of age
- $8 \%$ of unmarried older girls
- $8 \%$ of unmarried older girls
- $24 \%$ of married older girls were neither studying nor working
- $32 \%$ of married older girls were neither studying nor working

Participation in domestic chores is gendered:
- $78 \%$ of younger boys
- $82 \%$ of older boys
- $92 \%$ of younger girls

- $97 \%$ of unmarried older girls

- $100 \%$ of married older girls had done domestic chores on the day preceding the interview

The female disadvantage is apparent in many indicators:

- Girls are less likely than boys to be engaged in paid or unpaid work

- More likely to be neither studying nor working in adolescence

- More likely to be engaged in domestic chores and

- More likely to have an unmet need for vocational skills training

Restrictions on married adolescent girls are evident-Married older girls were less likely than unmarried older girls to have been engaged in paid or unpaid work in the year preceding the interview and more likely to have been neither studying nor working from early adolescence onwards

\section{Livelihood skill-building}

Few had ever attended a formal vocational training programme:

- $8 \%$ of older boys

- $12 \%$ of unmarried older girls

- $16 \%$ of married older girls
Vocational skills acquired are gendered-the predominant skills were:

- Computer training among boys and

- Tailoring among girls

The private sector is the major player in imparting vocational training:

- $78 \%$ of older boys

- $70 \%$ of unmarried older girls

- $79 \%$ of married older girls who had attended a vocational training programme received the training in a private institution 


\section{A Snapshot}

Unmet need for vocational skills training is substantial:

- $81 \%$ of boys

- $91 \%$ of unmarried older girls

- $83 \%$ of married older girls were interested in attending vocational training programmes
- $10 \%$ of older boys

- $36 \%$ of unmarried older girls

- $38 \%$ of married older girls had at some time wanted to attend a course but could not do so

\section{Training and employment-related entitlements}

Awareness of entitlements is limited:

- $18 \%$ of older boys

- $22 \%$ of unmarried older girls, and

- $15 \%$ of married older girls had heard about the Bihar Skill Development Mission
- $4 \%$ of older boys

- $5 \%$ of unmarried older girls, and

- $4 \%$ of married older girls were aware of any vocational training centres that offer training under the Bihar Skill Development Mission
- $8 \%$ of older boys

- $6 \%$ of unmarried older girls, and

- $4 \%$ of married older girls were aware of employment exchanges or counselling centres
- $52 \%$ of older boys, and

- 34\% each of unmarried and married older girls were aware of MNREGA

Reach of entitlements is limited:

- $2 \%$ of boys and less than $1 \%$ of unmarried and married girls in ages 18-19 had ever sought services from employment exchanges or counselling centres
- $1 \%$ of boys, none of the unmarried girls, and

- 1\% of marriedgirls in ages 18-19 in rural areas had got employment under the MNREGA scheme

\section{Migration}

Except for married older girls, not many were migrants at their current place of residence:

- $17 \%$ of older boys

- $10 \%$ of unmarried older girls

- $87 \%$ of married older girls were migrants
Few adolescents prefer to migrate outside their state, given a choice:

- $9 \%$ of older boys

- $14 \%$ of unmarried older girls

- $6 \%$ of married older girls 
Recent employment statistics show that the unemployment rate among adolescents and youth in India is higher than that of the total population of the country (National Sample Survey Organization [NSSO], 2014). Reflecting India's commitments towards meeting the employment needs of its citizens, including those of adolescents and youth, and towards safeguarding children and adolescents from labour-related exploitation, new policies and programmatic initiatives were launched in the country recently. Notable among these new initiatives is the National Policy on Skill Development and Entrepreneurship 2015 that seeks to 'make quality vocational training aspirational for both youth and employers whereby youth see it as a matter of choice and employers acknowledge the productivity linked to a skilled workforce' (Ministry of Skill Development and Entrepreneurship, 2015).As far as children and adolescents are concerned, the amended Child Labour (Prohibition and Regulation) Amendment Act, 2016, seeks to prohibit the employment of children below 14 years in all occupations, except in non-hazardous family occupations and other work specified in the Act, and the employment of adolescents in ages 14-18 in hazardous occupations and processes (Ministry of Labour and Employment, 2016). Against this background, we explore here the economic activity of adolescents, their employment-seeking practices and preferences regarding the sector in which they would like to work, their vocational skill-building experiences and preferences, their awareness of government programmes for skill-building and employment generation, and their participation in household-related work. The chapter also describes adolescents' migration experiences.

\subsection{Economic activity}

Entry into the labour market and economic independence characterise adolescence for many boys and girls. This section presents an assessment of the economic activity and occupational status of adolescents. In order to assess economic activity, we asked respondents whether they had ever worked for or without remuneration ${ }^{1}$ and whether they had worked in the 12 months preceding the interview, and, if so, the type of work in which they were engaged and the number of months they had worked for pay in the year preceding the interview. It is to be noted that the measure of what constitutes work among adolescents in the year prior to the interview covers a wide range of experiences that go beyond criteria typically considered to measure employment rate. Based on the usual principal status definition, employment rate is defined as the proportion of those who had worked for the major part of the year preceding the interview from among the whole labour force, which constitutes those who worked and those who sought work for the major part of the year. Our definition of work represents the percentage of adolescents who worked for any length of time during the year preceding the interview out of all adolescents, irrespective of whether they were in the labour force or not in the year preceding the interview.

Findings presented in Table 4.1 show that a large proportion of adolescents had been engaged in paid or unpaid work at some point in their lives-49 percent to 80 percent of boys and 42 percent to 49 percent of girls. Moreover, adolescents were far more likely to have engaged in unpaid than paid work (48-73\% versus $7-28 \%$ among boys and $39-41 \%$ versus $8-18 \%$ among girls). Work profiles also varied widely by age, sex, and residence in rural or urban areas. As expected, younger adolescents were less likely than older adolescents to have ever worked (49\% versus $80 \%$ among boys and $42 \%$ versus $48-49 \%$ among girls) as were girls compared with boys. Differences by marital status in engagement in work among older girls were mild.

More rural than urban adolescents had ever worked: 52-83 percent versus 25-55 percent of boys, and 45-52 percent versus 17-29 percent of girls. Findings, moreover, indicate that differences between rural and urban areas described above were mainly due to the differences in engagement in unpaid work; rural adolescents were more likely than their urban counterparts to have engaged in unpaid work.

Many older adolescents, particularly girls, were initiated into paid work in childhood, that is, before they were 14 years old; four percent of boys and 7-10 percent of unmarried and married girls reported that they had engaged in paid work before they were 14 years old. Engagement in paid work in childhood did not differ between rural and urban adolescents.

\footnotetext{
${ }^{1}$ Respondents were asked whether, aside from housework, they had done any work that was unpaid, such as work on the family farm or in the family business (unpaid work) and whether they had done any work for which they got paid in cash or kind (paid work).
} 


\section{Table 4.1 Economic activity}

Percentage of adolescents who had ever worked and who had worked in the last 12 months, and percent distribution of adolescents who had been engaged in paid work in the last 12 months by duration of work and main occupation, according to residence, Bihar, 2016

\begin{tabular}{|c|c|c|c|c|c|}
\hline Economic activity & $\begin{array}{c}\text { Boys } \\
(10-14)\end{array}$ & $\begin{array}{l}\text { Boys } \\
(15-19)\end{array}$ & $\begin{array}{c}\text { Girls } \\
(10-14)\end{array}$ & $\begin{array}{c}\text { Girls } \\
(15-19)\end{array}$ & $\begin{array}{l}\text { Married girls } \\
\text { (15-19) }\end{array}$ \\
\hline \multicolumn{6}{|c|}{ Combined (percent) } \\
\hline \multicolumn{6}{|l|}{ Ever worked } \\
\hline Paid work & 7.2 & 28.4 & 8.4 & 18.1 & 17.3 \\
\hline Unpaid work & 47.5 & 72.8 & 38.6 & 40.7 & 39.6 \\
\hline Either paid or unpaid work & 49.0 & 80.0 & 41.9 & 49.1 & 48.0 \\
\hline Started working for pay before age 14 & NA & 4.4 & NA & 7.2 & 10.2 \\
\hline \multicolumn{6}{|c|}{ Ever worked in the 12 months prior to the interview } \\
\hline Paid work & 6.2 & 25.6 & 8.1 & 16.8 & 11.0 \\
\hline Unpaid work & 42.5 & 70.9 & 35.8 & 39.2 & 20.7 \\
\hline Either paid or unpaid work & 43.7 & 78.2 & 38.8 & 47.1 & 27.7 \\
\hline Number of respondents & 1,012 & 1,821 & 764 & 3,428 & 3,408 \\
\hline \multicolumn{6}{|c|}{ Duration of paid work in the $\mathbf{1 2}$ months prior to the interview } \\
\hline Most of the year (6 months or more) & 8.7 & 29.4 & 17.2 & 33.5 & 34.3 \\
\hline Part of the year ( $3-5$ months) & 9.9 & 20.5 & 10.8 & 21.1 & 34.7 \\
\hline Rarely (less than 3 months) & 76.6 & 50.1 & 71.8 & 45.0 & 28.1 \\
\hline \multicolumn{6}{|l|}{ Main occupation (paid work) } \\
\hline Agricultural labour & 33.6 & 8.0 & 89.2 & 69.4 & 75.6 \\
\hline Unskilled non-agricultural labour & 60.4 & 63.0 & 9.9 & 7.3 & 7.7 \\
\hline Administrative/managerial/clerical & 0.0 & 1.3 & 0.0 & 0.1 & 0.1 \\
\hline Skilled labour & 0.0 & 21.4 & 0.9 & 22.6 & 15.8 \\
\hline Business & 0.0 & 4.3 & 0.0 & 0.3 & 0.8 \\
\hline Others & 6.0 & 0.7 & 0.0 & 0.3 & 0.0 \\
\hline $\begin{array}{l}\text { Number engaged in paid work in the } \\
\text { interview }\end{array}$ & 51 & 468 & 52 & 480 & 360 \\
\hline \multicolumn{6}{|c|}{ Urban (percent) } \\
\hline \multicolumn{6}{|l|}{ Ever worked } \\
\hline Paid work & 4.6 & 27.7 & 5.7 & 13.7 & 15.2 \\
\hline Unpaid work & 22.5 & 39.8 & 13.1 & 14.2 & 18.8 \\
\hline Either paid or unpaid work & 24.8 & 55.0 & 17.2 & 24.4 & 29.3 \\
\hline Started working for pay before age 14 & NA & 5.6 & NA & 3.0 & 7.4 \\
\hline \multicolumn{6}{|c|}{ Ever worked in the 12 months prior to the interview } \\
\hline Paid work & 3.7 & 25.4 & 4.6 & 11.8 & 8.0 \\
\hline Unpaid work & 19.8 & 36.9 & 12.5 & 12.5 & 7.9 \\
\hline Either paid or unpaid work & 22.0 & 52.9 & 15.9 & 21.5 & 14.2 \\
\hline Number of respondents & 452 & 1,008 & 387 & 1,738 & 1,366 \\
\hline
\end{tabular}


Table 4.1 Cont.

\begin{tabular}{|c|c|c|c|c|c|}
\hline Economic activity & $\begin{array}{c}\text { Boys } \\
(10-14)\end{array}$ & $\begin{array}{l}\text { Boys } \\
(15-19)\end{array}$ & $\begin{array}{l}\text { Girls } \\
(10-14)\end{array}$ & $\begin{array}{l}\text { Girls } \\
(15-19)\end{array}$ & $\begin{array}{l}\text { Married girls } \\
\text { (15-19) }\end{array}$ \\
\hline \multicolumn{6}{|c|}{ Duration of paid work in the $\mathbf{1 2}$ months prior to the interview } \\
\hline Most of the year (6 months or more) & * & 53.3 & * & 52.8 & 48.6 \\
\hline Part of the year (3-5 months) & * & 22.4 & * & 14.4 & 24.4 \\
\hline Rarely (less than 3 months) & * & 24.2 & * & 32.8 & 25.9 \\
\hline \multicolumn{6}{|l|}{ Main occupation (paid work) } \\
\hline Agricultural labour & * & 4.3 & * & 24.7 & 34.6 \\
\hline Unskilled non-agricultural labour & * & 56.4 & * & 16.0 & 29.7 \\
\hline Administrative/managerial/clerical & * & 1.7 & * & 1.5 & 1.0 \\
\hline Skilled labour & * & 26.4 & * & 56.8 & 32.2 \\
\hline Business & * & 7.3 & * & 0.0 & 2.2 \\
\hline Others & * & 2.9 & * & 1.0 & 0.3 \\
\hline $\begin{array}{l}\text { Number engaged in paid work in the } \\
\text { interview }\end{array}$ & 17 & 264 & 20 & 201 & 120 \\
\hline \multicolumn{6}{|c|}{ Rural (percent) } \\
\hline \multicolumn{6}{|l|}{ Ever worked } \\
\hline Paid work & 7.5 & 28.5 & 8.8 & 18.6 & 17.6 \\
\hline Unpaid work & 50.4 & 76.9 & 41.7 & 43.8 & 42.0 \\
\hline Either paid or unpaid work & 51.8 & 83.1 & 44.9 & 52.0 & 50.1 \\
\hline Started working for pay before age 14 & NA & 4.2 & NA & 7.7 & 10.5 \\
\hline \multicolumn{6}{|c|}{ Ever worked in the 12 months prior to the interview } \\
\hline Paid work & 6.5 & 25.6 & 8.5 & 17.4 & 11.4 \\
\hline Unpaid work & 45.2 & 75.1 & 38.7 & 42.4 & 22.1 \\
\hline Either paid or unpaid work & 46.2 & 81.4 & 41.6 & 50.2 & 29.3 \\
\hline Number of respondents & 560 & 813 & 377 & 1,690 & 2,042 \\
\hline \multicolumn{6}{|c|}{ Duration of paid work in the $\mathbf{1 2}$ months prior to the interview } \\
\hline Most of the year (6 months or more) & $(7.0)$ & 26.5 & $(15.5)$ & 32.0 & 33.1 \\
\hline Part of the year ( $3-5$ months) & $(10.5)$ & 20.2 & $(11.2)$ & 21.6 & 35.6 \\
\hline Rarely (less than 3 months) & $(77.3)$ & 53.3 & $(73.3)$ & 46.0 & 28.2 \\
\hline \multicolumn{6}{|l|}{ Main occupation (paid work) } \\
\hline Agricultural labour & $(35.1)$ & 8.5 & $(92.9)$ & 73.0 & 78.8 \\
\hline Unskilled non-agricultural labour & $(58.5)$ & 63.8 & $(7.1)$ & 6.6 & 6.0 \\
\hline Administrative/managerial/clerical & $(0.0)$ & 1.2 & $(0.0)$ & 0.0 & 0.0 \\
\hline Skilled labour & $(0.0)$ & 20.8 & $(0.0)$ & 19.8 & 14.5 \\
\hline Business & $(0.0)$ & 3.9 & $(0.0)$ & 0.3 & 0.7 \\
\hline Others & $(6.4)$ & 0.5 & $(0.0)$ & 0.2 & 0.0 \\
\hline $\begin{array}{l}\text { Number engaged in paid work in the } \\
\text { interview }\end{array}$ & 34 & 204 & 32 & 279 & 240 \\
\hline
\end{tabular}

Notes: All Ns are unweighted. *Percentage not shown as this was based on fewer than 25 unweighted cases. () Based on 25-49 unweighted cases. Column totals may not equal $100 \%$ owing to missing cases or 'do not know' responses. 
Percentages of adolescents who worked in the last 12 months largely mirrored lifetime economic activity for all categories of adolescents, except for married older girls. Fewer married older girls reported economic activity in the last 12 months compared with lifetime economic activity (28\% versus $48 \%$ ), a finding that may be attributed to their difficulty in combining economic activity with childbearing and childrearing activities, on the one hand, and the tendency of married girls to be secluded from outside work, on the other.

Findings also indicate that among adolescents who worked for remuneration in the year prior to the interview, 9-17 percent of younger adolescents and 29-34 percent of older adolescents had worked for six months or more. While differences by sex with regard to the duration they had worked were muted among older adolescents, they were apparent among younger adolescents, with more girls working for most of the year than boys (17\% of younger girls versus $9 \%$ of younger boys). Among older girls, differences by marital status were narrow. Finally, differences between older adolescents in rural and urban areas suggest that a larger proportion of adolescents in urban than rural areas reported working for most of the year (53\% versus $27 \%$ of older boys and $49-53 \%$ versus $32-33 \%$ of unmarried and married older girls).

Occupational distributions of those engaged in remunerated work in the 12 months preceding the interview show that agricultural labour and unskilled non-agricultural labour were the leading occupations taken up by younger and older adolescents, and, additionally, skilled labour was a leading occupation taken up by older adolescents. Even so, we observed considerable age and sex differences in the proportion of adolescents reporting these occupations. Younger adolescents were more likely than older adolescents to mention agricultural labour (34\% versus $8 \%$ among boys and $89 \%$ versus $69-76 \%$ among girls) and less likely to mention skilled labour (none versus $21 \%$ among boys and $1 \%$ versus $16-23 \%$ among girls). Girls were more likely than boys to mention agricultural labour ( $89 \%$ versus $34 \%$ among younger adolescents and $69-76 \%$ versus $8 \%$ among older adolescents) and less likely to cite unskilled non-agricultural labour ( $10 \%$ versus $60 \%$ among younger adolescents and $7-8 \%$ versus $63 \%$ among older adolescents). Differences by marital status in type of work among older girls were modest at best; even so, a somewhat larger proportion of married girls than unmarried girls reported agricultural labour ( $76 \%$ versus $69 \%$ ), but a smaller proportion reported unskilled non-agricultural labour (16\% versus $23 \%$ ). Occupational distributions of older adolescents varied between rural and urban areas. Older boys in rural areas were more likely than their urban counterparts to list unskilled non-agricultural labour (64\% versus 56\%), but somewhat less likely to list skilled labour (21\% versus $26 \%$ ). Among unmarried and married older girls, while more rural than urban respondents listed agricultural labour (73-79\% versus $25-35 \%)$, fewer rural respondents mentioned unskilled non-agricultural labour (6-7\% versus $16-30 \%)$ and skilled labour (15-20\% versus $32-57 \%)$.

Differentials in engagement in paid work in the year preceding the interview are presented in Table 4.2. Findings show that engagement in paid work increased with age among older boys (23\% among 15-17-year-old boys to $34 \%$ among 18-19-year-old boys) and younger girls (5\% among 10-12-year-old girls to 12\% among 13-14-year-old girls). Differences by religion were modest, except for younger boys, among whom more Muslim boys than Hindu boys had engaged in paid work in the year preceding the interview (17\% versus 4\%). Caste-wise differences were wide, except among younger boys-adolescents belonging to scheduled castes were the most likely to have been engaged in paid work in the year preceding the interview, while those belonging to general castes were the least likely to have been thus engaged (33\% versus $16 \%$ among older boys, $19-33 \%$ versus $0-8 \%$ among younger girls and unmarried and married older girls).

Among older adolescents, poorly educated adolescents were more likely than the better educated to report engagement in paid work; differences were negligible among younger adolescents. Moreover, engagement in paid work was inversely associated with current schooling status across all categories of adolescents, except for married older girls. Findings also show an inverse association between household wealth status and engagement in paid work. Finally, engagement in paid work was inversely associated with mother's education across most categories of adolescents. 
Table 4.2: Engagement in paid work in the 12 months preceding the interview by selected background characteristics

Percentage of adolescents who were engaged in paid work in the 12 months preceding the interview by selected background characteristics, Bihar, 2016

\begin{tabular}{|c|c|c|c|c|c|}
\hline Background characteristics (percent) & $\begin{array}{c}\text { Boys } \\
(10-14)\end{array}$ & $\begin{array}{c}\text { Boys } \\
(15-19)\end{array}$ & $\begin{array}{c}\text { Girls } \\
(10-14)\end{array}$ & $\begin{array}{c}\text { Girls } \\
(15-19)\end{array}$ & $\begin{array}{l}\text { Married girls } \\
\qquad(15-19)\end{array}$ \\
\hline \multicolumn{6}{|l|}{ Age } \\
\hline $10-12$ & 4.8 & NA & 5.1 & NA & NA \\
\hline $13-14$ & 8.8 & NA & 12.2 & NA & NA \\
\hline $15-17$ & NA & 22.6 & NA & 16.3 & 12.6 \\
\hline $18-19$ & NA & 33.8 & NA & 18.7 & 10.2 \\
\hline \multicolumn{6}{|l|}{ Religion $^{1}$} \\
\hline Hindu & 4.4 & 25.9 & 8.9 & 17.6 & 11.5 \\
\hline Muslim & 17.2 & 24.0 & 3.3 & 13.0 & 7.6 \\
\hline \multicolumn{6}{|l|}{ Caste $^{2}$} \\
\hline SC & 11.6 & 32.6 & 19.3 & 32.7 & 20.0 \\
\hline $\mathrm{OBC}$ & 3.6 & 24.7 & 5.8 & 14.1 & 8.4 \\
\hline General $^{3}$ & 11.3 & 15.9 & 0.1 & 7.5 & 1.0 \\
\hline \multicolumn{6}{|l|}{ Completed years of schooling } \\
\hline None $^{4}$ & * & 56.4 & $(20.8)$ & 41.6 & 18.9 \\
\hline $1-4$ & 5.9 & 58.1 & 8.4 & 25.4 & 19.2 \\
\hline $5-7$ & 5.8 & 33.8 & 6.7 & 23.6 & 8.2 \\
\hline $8-9$ & 7.4 & 22.6 & 8.1 & 12.7 & 6.5 \\
\hline $10-11$ & NA & 17.4 & NA & 7.3 & 5.8 \\
\hline 12 and above & NA & 23.2 & NA & 19.8 & 4.3 \\
\hline \multicolumn{6}{|l|}{ Current schooling status ${ }^{5}$} \\
\hline Yes & 4.1 & 17.8 & 6.3 & 12.5 & 7.4 \\
\hline No & $(42.9)$ & 54.9 & $(28.3)$ & 20.9 & 8.1 \\
\hline \multicolumn{6}{|l|}{ Wealth quintile } \\
\hline First & 6.6 & 39.8 & 9.8 & 34.8 & 22.8 \\
\hline Second & 9.7 & 34.8 & 19.4 & 26.2 & 16.3 \\
\hline Third & 10.1 & 31.1 & 7.2 & 15.3 & 8.4 \\
\hline Fourth & 3.4 & 21.7 & 5.8 & 15.0 & 8.9 \\
\hline Fifth & 0.8 & 15.0 & 0.8 & 8.1 & 3.2 \\
\hline \multicolumn{6}{|c|}{ Mother's education (in years of schooling completed) } \\
\hline None $^{4}$ & 7.6 & 29.1 & 10.3 & 19.2 & 12.2 \\
\hline $1-7$ & 3.3 & 16.5 & 0.5 & 9.6 & 8.1 \\
\hline $8-9$ & 0.4 & 19.3 & 1.1 & 14.3 & 4.0 \\
\hline 10 and above & 0.2 & 7.9 & 0.0 & 8.5 & 2.0 \\
\hline Total & 6.2 & 25.6 & 8.1 & 16.8 & 11.0 \\
\hline
\end{tabular}

Notes: *Percentage not shown as this was based on fewer than 25 unweighted cases. () Based on 25-49 unweighted cases. NA: not applicable; OBC: other backward caste; SC: scheduled caste; ST: scheduled tribe. ${ }^{1}$ Percentages not shown for those belonging to other religions as less than one percent of surveyed adolescents belonged to other religions. ${ }^{2}$ Percentages not shown for those belonging to STs as less than one percent of surveyed adolescents belonged to STs. ${ }^{3}$ Includes all those not belonging to SCs, STs, or OBCs. ${ }^{4}$ Includes non-literate and literate with no formal schooling. ${ }^{5}$ Percentages not shown for adolescents who were pursuing their education through distance education courses at the time of interview or those who never went to school. 
The survey sought to ascertain from participants in ages 15-19 whether they were actively seeking paid employment (for example, sending applications, enquiring about job opportunities with others, looking at job advertisements, and so on) at the time of the interview, and, if so, the sector in which they would like to work and the reasons for their preference.

Findings, presented in Table 4.3, show that among older adolescents, 24 percent of boys and 10-11 percent of girls were actively seeking paid employment at the time of the interview, with little differences between rural and urban areas in the proportions of adolescents seeking employment. Age differences show that the proportion of older adolescents who were actively seeking paid employment increased with age, except among married girls; thus, 19 percent of 15-17-year-old boys compared with 39 percent of 18-19-year-old boys reported that they were actively seeking paid employment, and the corresponding proportions among unmarried girls were eight percent and 20 percent. The level of employment-seeking did not differ much by religion and caste, except for unmarried older girls, among whom those who belonged to general castes were more likely than those who belonged to other castes to report that they were seeking paid employment (16\% versus 9-10\%). Differences by educational levels highlight that boys and girls who had completed 12 or more years of schooling were more likely than those with fewer years of schooling to report that they were seeking paid employment (59\% versus $14-44 \%$ among boys; $34 \%$ versus $4-13 \%$ among unmarried girls; and $27 \%$ versus 5-18\% among married girls).

While a larger proportion of boys who were out of school at the time of the interview had reported that they were actively seeking paid employment compared with those who were pursuing their education (31\% versus $22 \%$ ), no such difference was observed among unmarried older girls. However, a reverse pattern was noted among married older girls $(18 \%$ of those who were pursuing their education were seeking employment versus $9 \%$ of those who were not). Though differences by literacy and numeracy skills were apparent, this association differed for boys and girls. Among boys, a larger proportion of those who lacked basic literacy (that is, could not read a Class 2 text fluently in Hindi) and numeracy skills (that is, could not solve a simple division problem) than those with better literacy and numeracy skills reported that they were actively seeking paid employment (30-31\% versus 20-21\%). On the contrary, among both unmarried and married girls, a larger proportion of those who were literate and numerate than those who were not reported employment-seeking (14-21\% versus 6-8\%).

Findings also show that boys and girls who had been working in the year preceding the interview were more likely than those who had not been working to report employment-seeking (39\% versus 19\% among boys and $15-16 \%$ versus $9-10 \%$ among girls); these findings can be attributed to the likelihood that boys and girls already engaged in work were seeking better job opportunities and those who had not been engaged in paid work were pursuing studies. Differences in employment-seeking practices did not differ much by household wealth index.

Finally, employment-seeking differed by mother's education among boys and girls. Boys whose mother had never been to school were the most likely to report employment-seeking, while those whose mother had completed 10 or more years were the least likely to report so (25\% and $17 \%$, respectively); a reverse pattern was observed for unmarried and married girls, among whom employment-seeking increased steadily with mother's education-from nine percent among those whose mother had never been to school to 15-18 percent among those whose mother had completed secondary education and above. 
4 Economic activity, household work, and migration

Table 4.3: Employment-seeking by selected background characteristics

Percentage of adolescents in ages 15-19 who were actively seeking employment at the time of the interview by selected background characteristics, Bihar, 2016

\begin{tabular}{|c|c|c|c|}
\hline Background characteristics (percent) & $\begin{array}{c}\text { Boys } \\
(15-19)\end{array}$ & $\begin{array}{c}\text { Girls } \\
(15-19)\end{array}$ & $\begin{array}{l}\text { Married girls } \\
(15-19)\end{array}$ \\
\hline \multicolumn{4}{|l|}{ Age } \\
\hline $15-17$ & 18.5 & 7.9 & 10.7 \\
\hline $18-19$ & 39.4 & 20.3 & 9.8 \\
\hline \multicolumn{4}{|l|}{ Religion $^{1}$} \\
\hline Hindu & 24.8 & 10.7 & 10.6 \\
\hline Muslim & 19.8 & 9.9 & 6.5 \\
\hline \multicolumn{4}{|l|}{ Caste $^{2}$} \\
\hline SC & 23.4 & 9.0 & 11.4 \\
\hline $\mathrm{OBC}$ & 24.1 & 9.7 & 10.0 \\
\hline General $^{3}$ & 23.4 & 16.2 & 6.5 \\
\hline \multicolumn{4}{|l|}{ Completed years of schooling } \\
\hline None $^{4}$ & 44.0 & 4.0 & 4.7 \\
\hline $1-4$ & 30.1 & 8.2 & 6.5 \\
\hline $5-7$ & 14.4 & 4.6 & 5.9 \\
\hline $8-9$ & 16.3 & 7.3 & 10.4 \\
\hline $10-11$ & 28.9 & 13.2 & 18.1 \\
\hline 12 and above & 59.1 & 34.2 & 27.1 \\
\hline \multicolumn{4}{|l|}{ Current schooling status ${ }^{5}$} \\
\hline Yes & 21.5 & 10.6 & 18.0 \\
\hline No & 31.4 & 10.4 & 9.3 \\
\hline \multicolumn{4}{|l|}{ Literacy levels } \\
\hline Can read Class 2 text fluently & 21.3 & 13.6 & 17.4 \\
\hline No & 31.1 & 5.5 & 5.8 \\
\hline \multicolumn{4}{|l|}{ Numeracy levels } \\
\hline Can solve a simple division problem & 20.3 & 14.1 & 21.1 \\
\hline No & 30.0 & 7.5 & 7.1 \\
\hline \multicolumn{4}{|c|}{ Paid work in the 12 months prior to the interview } \\
\hline Yes & 38.5 & 14.5 & 16.0 \\
\hline No & 19.1 & 9.8 & 9.4 \\
\hline \multicolumn{4}{|l|}{ Wealth quintile } \\
\hline First & 19.0 & 4.9 & 9.3 \\
\hline Second & 27.9 & 10.1 & 7.2 \\
\hline Third & 24.3 & 7.3 & 9.7 \\
\hline Fourth & 24.1 & 10.1 & 11.0 \\
\hline Fifth & 22.5 & 15.6 & 13.1 \\
\hline
\end{tabular}


Table 4.3 Cont.

\begin{tabular}{|c|c|c|c|}
\hline Background characteristics (percent) & $\begin{array}{c}\text { Boys } \\
(15-19)\end{array}$ & $\begin{array}{c}\text { Girls } \\
(15-19)\end{array}$ & $\begin{array}{c}\text { Married girls } \\
(15-19)\end{array}$ \\
\hline \multicolumn{4}{|c|}{ Mother's education (in years of schooling completed) } \\
\hline None $^{4}$ & 25.3 & 9.1 & 9.4 \\
\hline $1-7$ & 22.9 & 14.1 & 10.5 \\
\hline $8-9$ & 20.9 & 10.1 & 17.7 \\
\hline 10 and above & 16.8 & 18.3 & 15.4 \\
\hline \multicolumn{4}{|l|}{ Place of residence } \\
\hline Urban & 22.3 & 13.4 & 10.8 \\
\hline Rural & 24.3 & 10.3 & 10.0 \\
\hline Total & 24.1 & 10.6 & 10.1 \\
\hline
\end{tabular}

Notes: OBC: other backward caste; SC: scheduled caste; ST: scheduled tribe. ${ }^{1}$ Percentages not shown for those belonging to other religions as less than one percent of surveyed adolescents belonged to other religions. ${ }^{2}$ Percentages not shown for those belonging to STs as less than one percent of surveyed adolescents belonged to STs. ${ }^{3}$ Includes all those not belonging to SCs, STs, or OBCs. ${ }^{4}$ Includes non-literate and literate with no formal schooling. ${ }^{5}$ Percentages not shown for adolescents who were pursuing their education through distance education courses at the time of interview or those who never went to school.

Table 4.4 reports the preference of adolescents in ages 15-19 who were actively seeking paid employment at the time of the interview regarding the sector in which they would like to work. Several findings are noteworthy. First, a large proportion of adolescents preferred to work in the government sector than in the private sector. Specifically, 60 percent of boys and 68 percent and 48 percent of unmarried girls and married girls, respectively, preferred to work in the government sector. In contrast, just nine percent of boys and 1-3 percent of girls expressed a preference to work in the private sector, and 16 percent of boys and 23-31 percent of girls were willing to work in either sector. Second, 12 percent of boys and 4-10 percent of girls reported that they would prefer to take up self-employment. Third, a small proportion of boys (4\%) and girls (5-9\%) reported that they had never thought about the sector in which they would like to work. Differences in employment preferences between rural and urban adolescents show that more urban adolescents preferred a government job compared with rural adolescents (68\% versus 59\% among boys; $75 \%$ versus $67 \%$ among unmarried girls; and $54 \%$ versus $47 \%$ among married girls) or to tale up self-employment ( $16 \%$ versus $11 \%$ among boys and $14 \%$ versus $9 \%$ among married girls). On other hand, more rural than urban boys and unmarried girls were willing to work in either a government job or private sector job ( $17 \%$ versus $7 \%$ among boys and $24 \%$ versus $18 \%$ among unmarried girls). Finally, more married girls in rural than urban areas reported that they had never thought about the sector in which they would like to work (10\% versus $2 \%$ ).

\section{Table 4.4: Adolescents' preferences on work sector for employment}

Percent distribution of adolescents in ages 15-19 who were actively seeking paid employment by preferred sector for employment, according to residence, Bihar, 2016

\begin{tabular}{|c|c|c|c|}
\hline Sector & $\begin{array}{l}\text { Boys } \\
(15-19)\end{array}$ & $\begin{array}{l}\text { Girls } \\
(15-19)\end{array}$ & $\begin{array}{l}\text { Married girls } \\
\quad(15-19)\end{array}$ \\
\hline \multicolumn{4}{|c|}{ Combined (percent) } \\
\hline Government & 59.9 & 67.6 & 47.5 \\
\hline Private & 9.2 & 0.7 & 3.0 \\
\hline Self-employed & 11.5 & 4.3 & 9.8 \\
\hline Any & 15.7 & 22.8 & 30.8 \\
\hline Never thought about it/no plans to take up a job & 3.6 & 4.6 & 9.0 \\
\hline $\begin{array}{l}\text { Number of respondents who were actively seeking paid employment } \\
\text { at the time of the interview }\end{array}$ & 438 & 404 & 333 \\
\hline
\end{tabular}


Table 4.4 Cont.

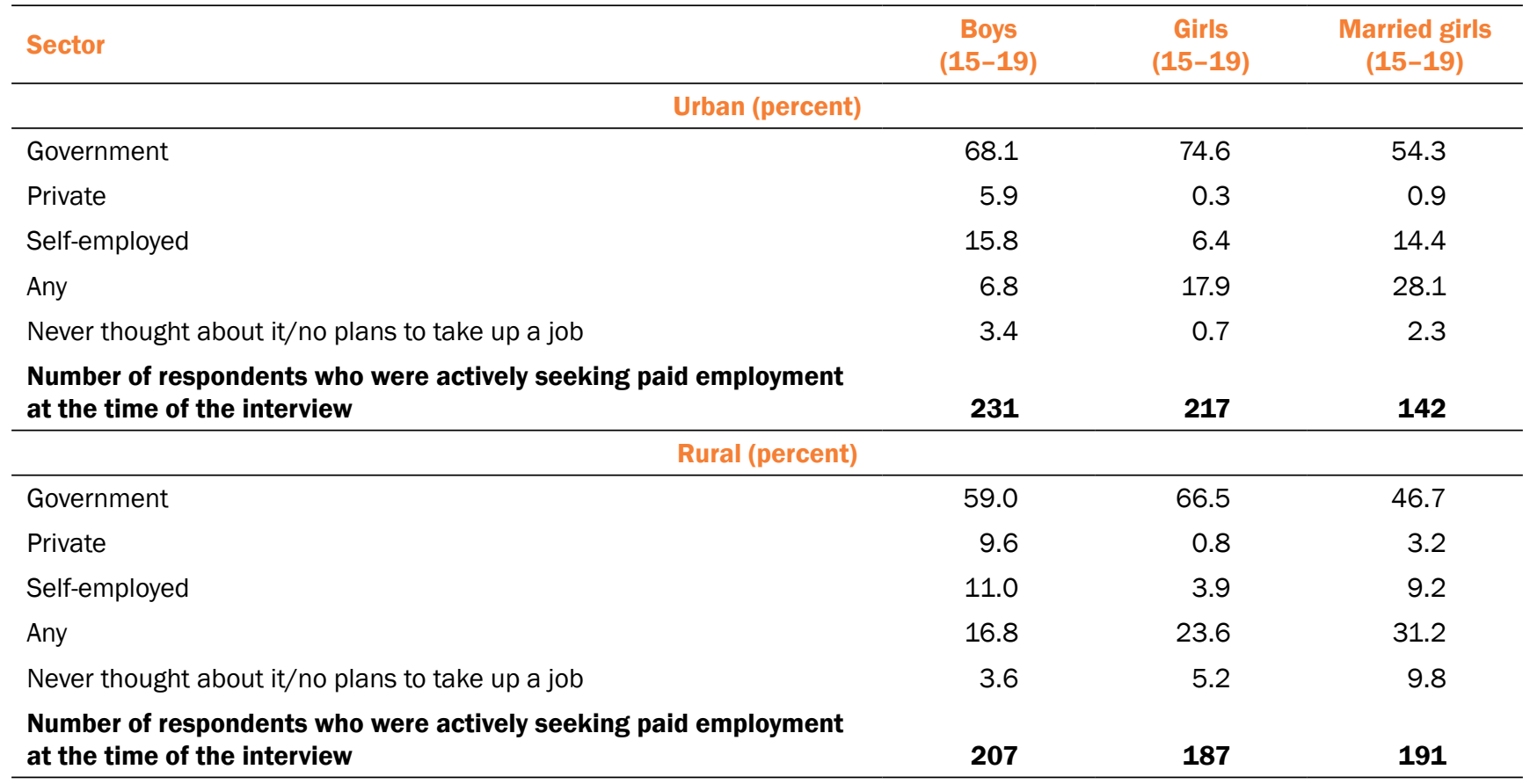

Note: All Ns are unweighted.

We probed the reasons for the preferences that adolescents expressed for working in the government sector. Findings presented in Table 4.5 show that the leading reasons for preferring a government sector job were perceptions of job security, financial security (higher salary, regular payment, provision of pension and increment), normative preference, perceptions that workload is less in the government than the private sector, and perceptions about opportunities to serve the public. Specifically, 57 percent of boys and 41-55 percent of girls who preferred to work in the government sector reported that they preferred to do so because of job security. The second most frequently cited reason for preferring to work in the government sector was perceptions of financial security, as cited by 54 percent of boys and 36-37 percent of girls. Smaller proportions of adolescents-17-25 percent-perceived that government jobs offer higher salaries, 7-20 percent believed that salary payment is regular in the government sector, 14-15 percent felt that government jobs guarantee a pension, and 4-7 percent thought that salary increments are provided in the government sector. Some 35 percent of boys and 33-37 percent of girls reported that they preferred to work in the government sector because of perceptions that everyone prefers to do so. A few-7-13 percent-believed that the workload is less in the government than the private sector, and 10-13 percent held that government jobs offer opportunities to serve the public.

\section{Table 4.5: Reasons for preferring government jobs}

Percentage of adolescents in ages 15-19 who preferred a government job by reported reasons, according to residence, Bihar, 2016

\begin{tabular}{|c|c|c|c|}
\hline Reasons & $\begin{array}{c}\text { Boys } \\
(15-19)\end{array}$ & $\begin{array}{c}\text { Girls } \\
(15-19)\end{array}$ & $\begin{array}{c}\text { Married girls } \\
(15-19)\end{array}$ \\
\hline \multicolumn{4}{|c|}{ Combined (percent) } \\
\hline Everyone prefers a government job & 35.3 & 32.6 & 37.4 \\
\hline Job security & 57.3 & 54.7 & 41.4 \\
\hline \multicolumn{4}{|l|}{ Financial reasons } \\
\hline Higher salary & 25.2 & 17.4 & 21.3 \\
\hline Regular payment & 19.9 & 7.8 & 7.0 \\
\hline Availability of pension & 13.6 & 15.4 & 13.9 \\
\hline Provision of increment & 7.3 & 4.4 & 4.7 \\
\hline At least one financial reason & 53.6 & 36.0 & 36.5 \\
\hline
\end{tabular}


Table 4.5 Cont.

\begin{tabular}{|c|c|c|c|}
\hline Reasons & $\begin{array}{c}\text { Boys } \\
(15-19)\end{array}$ & $\begin{array}{c}\text { Girls } \\
(15-19)\end{array}$ & $\begin{array}{l}\text { Married girls } \\
(15-19)\end{array}$ \\
\hline Less workload & 13.1 & 6.5 & 9.0 \\
\hline Can help public & 9.5 & 12.7 & 11.9 \\
\hline Better marriage prospects & 1.7 & 0.6 & 0.0 \\
\hline No specific reason & 7.7 & 9.4 & 14.8 \\
\hline Number of respondents who preferred a government job & 277 & 287 & 170 \\
\hline \multicolumn{4}{|c|}{ Urban (percent) } \\
\hline Everyone prefers a government job & 31.0 & 44.5 & 32.3 \\
\hline Job security & 66.7 & 54.2 & 57.7 \\
\hline \multicolumn{4}{|l|}{ Financial reasons } \\
\hline Higher salary & 27.3 & 23.9 & 22.8 \\
\hline Regular payment & 13.8 & 10.0 & 8.0 \\
\hline Availability of pension & 21.4 & 16.6 & 17.4 \\
\hline Provision of increment & 7.8 & 3.8 & 8.6 \\
\hline At least one financial reason & 52.0 & 40.1 & 42.5 \\
\hline Less workload & 15.7 & 12.5 & 10.2 \\
\hline Can help public & 9.0 & 15.0 & 15.0 \\
\hline Better marriage prospects & 2.2 & 0.4 & 0.0 \\
\hline No specific reason & 2.5 & 3.7 & 6.9 \\
\hline Number of respondents who preferred a government job & 157 & 161 & 78 \\
\hline \multicolumn{4}{|c|}{ Rural (percent) } \\
\hline Everyone prefers a government job & 35.9 & 30.5 & 38.2 \\
\hline Job security & 56.0 & 54.7 & 39.0 \\
\hline \multicolumn{4}{|l|}{ Financial reasons } \\
\hline Higher salary & 24.9 & 16.2 & 21.1 \\
\hline Regular payment & 20.7 & 7.4 & 6.8 \\
\hline Availability of pension & 12.6 & 15.2 & 13.4 \\
\hline Provision of increment & 7.3 & 4.5 & 4.2 \\
\hline At least one financial reason & 53.8 & 35.3 & 35.6 \\
\hline Less workload & 12.8 & 5.5 & 8.9 \\
\hline Can help public & 9.5 & 12.3 & 11.5 \\
\hline Better marriage prospects & 1.7 & 0.6 & 0.0 \\
\hline No specific reasons & 8.4 & 10.4 & 15.9 \\
\hline Number of respondents who preferred a government job & 120 & 126 & 92 \\
\hline
\end{tabular}

Notes: All Ns are unweighted. Column totals may exceed $100 \%$ owing to multiple responses.

The reasons listed by rural and urban adolescents differed somewhat. Urban boys were more likely than rural boys to mention perceptions that jobs in the government sector are secure (67\% versus $56 \%)$ and that government jobs guarantee a pension ( $21 \%$ versus $13 \%$ ), but less likely to believe that salary payment is regular in the government sector (14\% versus $21 \%)$.Urban unmarried girls were more likely than their rural counterparts to mention normative 
preference (45\% versus $31 \%$ ) and perceptions of higher salary (24\% versus $16 \%$ ) and of less workload (13\% versus $6 \%)$. Finally, rural married girls were less likely than their urban counterparts to mention perceptions of job security (39\% versus $58 \%$ ) and of financial security (36\% versus $43 \%)$ and were more likely to cite normative preference (38\% versus $32 \%)$.

\subsection{Activity status}

Many boys and girls discontinue schooling and enter the labour market in adolescence, some combine schooling and work, and some others are neither studying nor working. Data collected through the Life Event Calendar component administered to older adolescents provided an opportunity to explore the pattern of these events (that is, only studying, ${ }^{2}$ only working, both studying and working, and neither studying nor working) in adolescents' lives across a span from when they were 10 years old until the time of the survey, and these are presented in Figures 4.1a-4.1c. We mention that data for married girls, shown in Figure 4.1c, convey the situation prior to and following marriage.

Patterns among older adolescents varied widely by sex of the respondent and, among girls, by marital status as well. A comparison of findings presented in Figures 4.1a-4.1c shows, first, that the proportion of adolescents reporting school enrolment declined across all groups as they transitioned out of early adolescence into late adolescence. Thus, while 94 percent of boys and 88 percent of unmarried girls were in school (a small minority of these were also working) at age 10, the percentage who remained in school at age 15 fell to 85 percent for boys and 79 percent for unmarried girls. Among married girls, in contrast, school discontinuation was marked even by age 10; indeed, school enrolment was just 64 percent at age 10 among married girls, which was the percentage among boys and unmarried girls in their late adolescence.

Second, a large proportion of boys reported that they had combined studying with working; this proportion increased from 17 percent at age 10 to 47-55 percent at ages 14-19. Fewer girls, particularly the married, had done so; 15-29 percent of unmarried girls had combined studying with working at any age as had 2-17 percent of married girls.

Third, exit from school was accompanied by a steady rise in work participation as age increased among boys, but with a much more gradual rise among unmarried girls. However, a different pattern was observed among married girls; while work participation increased gradually till age 15, it thereafter started declining, perhaps coinciding with transition to marriage and motherhood. Findings also show that more boys than girls were working from age 13 onwards and this gender gap widened with age.

Fourth, the age at which more adolescents were working than they were in school occurred at age 18 for boys and married girls, while it did not occur till age 19 among unmarried girls.

Finally, significant proportions of girls, particularly married girls, were neither studying nor working from the age of 10 onwards. Among boys, a small proportion (5\% or fewer) was neither studying nor working at any age. Among girls, the proportions who were neither working nor studying increased by age, particularly among married girls. At age 10, eight percent of unmarried girls and 24 percent of married girls were neither working nor studying; this proportion remained the same for unmarried girls (8\%) at age 15 but increased to 32 percent for married girls, and at age 19, the proportion increased to 24 percent and 66 percent for unmarried girls and married girls, respectively.

Figures $4.1 \mathrm{~b}$ and $4.1 \mathrm{c}$ suggest that patterns of activity status differed between married and unmarried girls. For one, married girls were less likely than the unmarried to be in school at each age. Thus, 64 percent and 88 percent of married girls and unmarried girls, respectively, were in school (a small minority of these were also working) at age 10 , and the percentages of those who remained in school fell thereafter. At age 19, for example, only 14 percent of married girls were pursuing their education compared with 54 percent of unmarried girls. Second, while a similar or slightly larger proportion of married girls than unmarried girls were working till the age of 14 , more unmarried than married girls were working from age 15 onwards. Third, more married girls than unmarried girls were neither studying nor working from the age of 10 onwards. Finally, the age at which more girls were working than studying in school was 18 years among married girls; this crossover did not occur among the unmarried until age 19.

\footnotetext{
${ }^{2}$ Includes those who were pursuing their education through distance education programmes.
} 
Figure 4.1a: Activity status among adolescent boys in ages 15-19, by age, Bihar, 2016

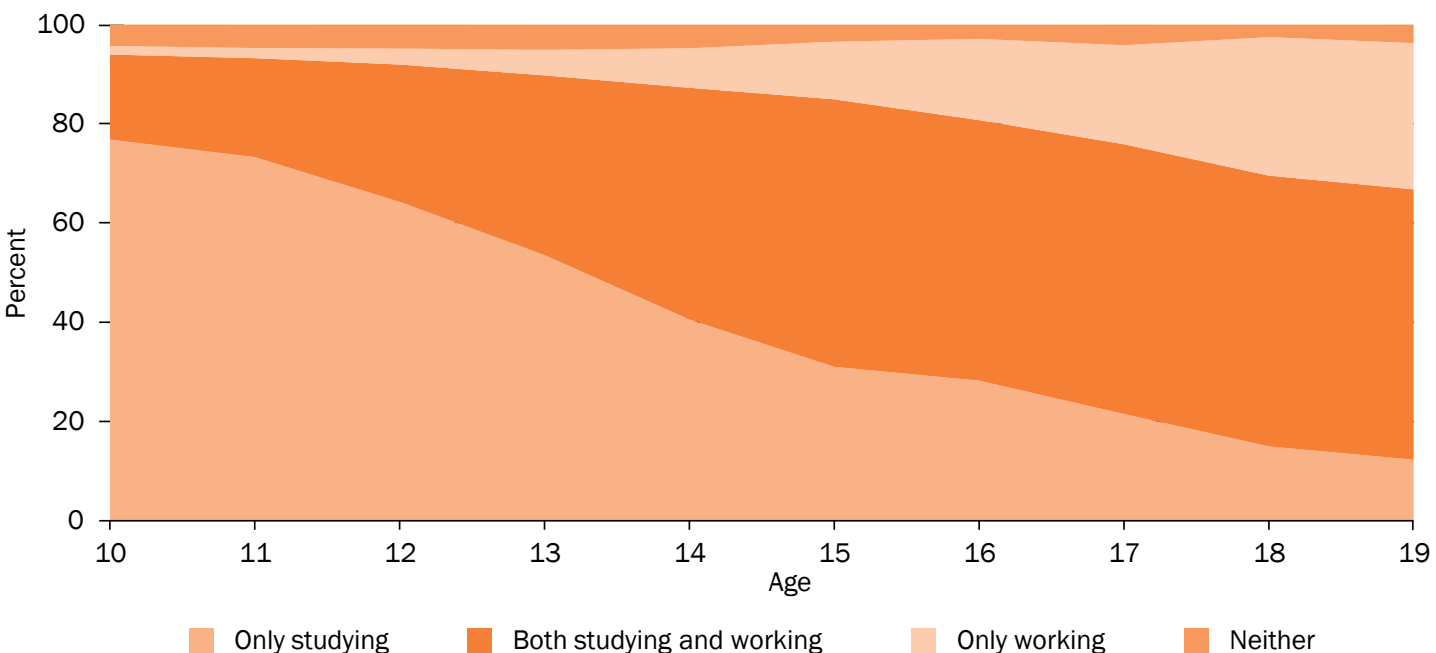

Figure 4.1b: Activity status among unmarried girls in ages 15-19, by age, Bihar, 2016

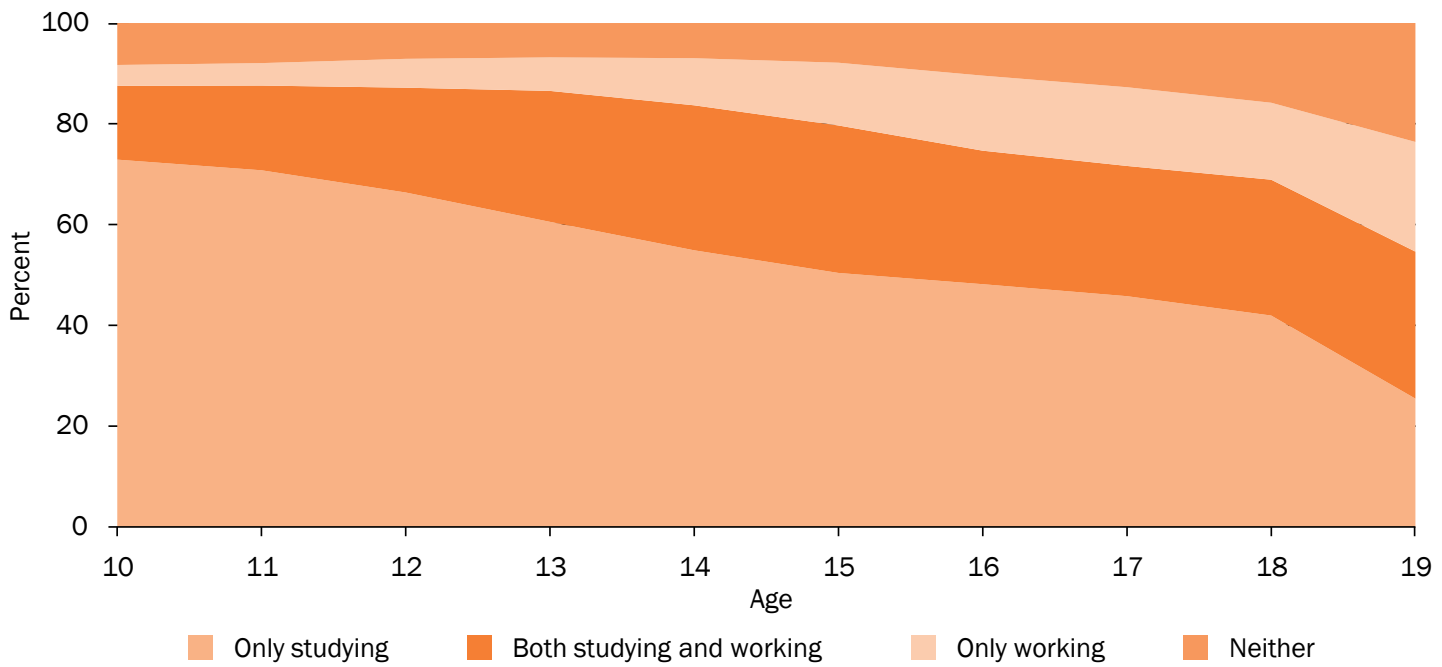

Figure 4.1c: Activity status among married girls in ages 15-19, by age, Bihar, 2016

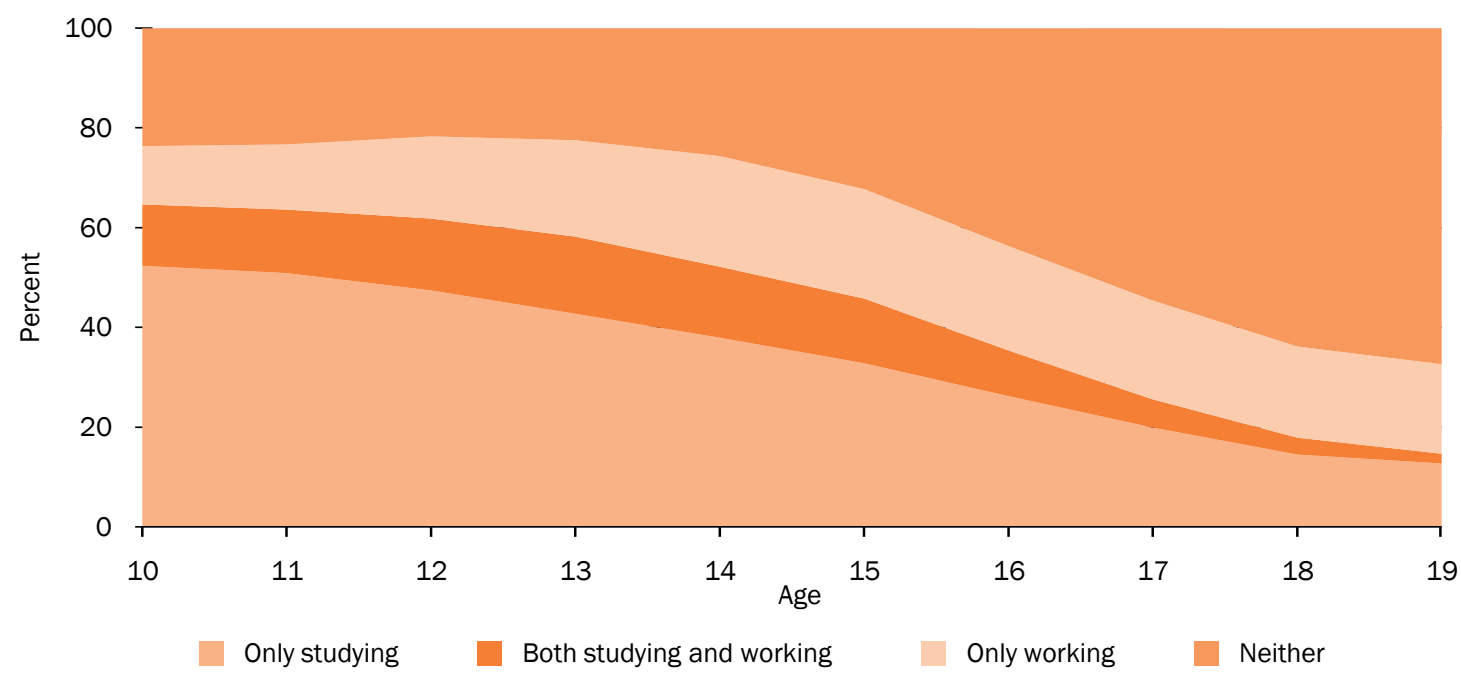




\subsection{Participation in vocational training programmes and unmet need for} vocational training

The Government of Bihar has expressed its commitment to skilling its adolescents and youth and a number of vocational training opportunities are available to adolescents through government organisations, as well as through non-government and private organisations. In 2012, the state set up a target of skilling 10 million youth through skill development schemes managed by 15 government departments. In 2015, the state launched the Kushal Yuva Programme which seeks to impart computer literacy and soft skills and communication skills to 15-25 year olds who have discontinued their formal education after completing secondary or senior secondary education (Department of Labour Resources, Government of Bihar, n.d.). The Bihar Start-Up Policy 2016, likewise, seeks to introduce and promote entrepreneurship education among youth (Department of Industries, Government of Bihar, 2016). Our study inquired about whether respondents in ages 15-19 had attended any vocational training programmes/courses conducted by a government, private, or non-governmental institution and, if they had, we sought information on the kinds of programmes they had attended and experiences related to such programmes, unmet need for vocational skills training, and the kinds of programmes they would like to attend, if offered.

\subsubsection{Participation in vocational training programmes and related experiences}

Findings, presented in Table 4.6, indicate that only a few older adolescents had ever attended a formal vocational training programme, that is, a vocational training programme/course conducted by a government, private, or non-governmental institution-eight percent of boys and 12-16 percent of unmarried and married girls had ever attended a formal vocational training programme. Differences by residence in rural or urban areas were modest, except that unmarried girls in urban areas were more likely than their rural counterparts to have ever attended a formal vocational training programme (21\% versus $11 \%$ ), a finding that could be attributed to better access to such programmes in urban than rural areas. Very few adolescents had attended a formal vocational training programme in the year preceding the interview ( $5 \%$ of boys and $7-8 \%$ of girls); differences between those from rural and those from urban areas in this regard were muted except that more unmarried girls in urban than rural areas had attended a training programme in the last year (14\% versus $8 \%$ ).

The kind of training received by adolescents who had attended a vocational training programme in the year preceding the interview varied widely by sex of the respondent and residence in rural or urban areas. The leading training programmes that boys attended were computer training (65\%), auto mechanics or electrical work (19\%), and tailoring (8\%). Training programmes predominantly attended by unmarried and married girls differed from the programmes attended by boys. Among girls, the most commonly reported training programmes were tailoring, computer training, and beauty parlour skills; far more married than unmarried girls opted for tailoring (88\% versus 69\%); far fewer married than unmarried girls opted for computer training (7\% versus 19\%); and similar proportions of married girls and unmarried girls opted for beauty parlour skills training (4-7\%).

Training that rural and urban adolescents received also differed, with urban adolescents considerably less likely than rural adolescents to report training in more traditional activities. We found, however, that the number of adolescents who had attended a vocational training programme was small in rural and urban areas, and hence, findings need to be interpreted with caution. Urban boys, for example, were less likely than their rural counterparts to report training in tailoring ( $2 \%$ versus $9 \%$ ) and auto mechanics or electrical work (14\% versus $20 \%$ ), and, conversely, more likely to report computer training (70\% versus $64 \%$ ). Among unmarried and married girls, likewise, those from urban areas were less likely than their rural counterparts to report tailoring (44\% versus $75 \%$ among unmarried girls and $79 \%$ versus $88 \%$ among married girls), but were more likely to report training in computer skills than their rural counterparts (39\% versus $15 \%$ among unmarried girls and $13 \%$ versus $6 \%$ among married girls).

A large proportion of adolescents who had attended a formal vocational training programme had attended the programme in a private institution-78 percent of boys and 70-79 percent of unmarried and married girls (Table 4.6). Another 19 percent of boys and 18-27 percent of girls had attended the programme in a government institution. The type of institution attended by adolescents in rural and urban areas differed among unmarried and married girls, but not among boys. Although private institutions predominated in both urban and rural areas, fewer urban than rural girls had attended a private institution (62-69\% versus $72-80 \%$ ) and, conversely, more urban than rural girls had attended a government institution (24-31\% versus $17-26 \%$ ). 
Of those adolescents who had attended a formal vocational training programme in the year preceding the interview, two-fifths, regardless of sex and, among girls, of marital status, had completed the course/s attended. Some 40 percent of boys, 27 percent of unmarried girls, and 11 percent of married girls reported that they were still attending the course/s at the time of the interview. Differences between rural and urban areas show that boys in urban areas were more likely than boys in rural areas to have completed the course/s (53\% versus $39 \%)$. A reverse pattern was observed among married girls; fewer urban than rural girls reported that they had completed the course/s (35\% versus $42 \%)$.

\section{Table 4.6: Participation in vocational training programmes}

Percentage of adolescents in ages 15-19 who ever attended a formal vocational training programme and those who attended a vocational training programme in the 12 months prior to the interview by type of programme attended, type of institution that conducted the course, and completion status of the course attended, according to residence, Bihar, 2016

\begin{tabular}{|c|c|c|c|}
\hline Programmes/courses attended & $\begin{array}{l}\text { Boys } \\
(15-19)\end{array}$ & $\begin{array}{c}\text { Girls } \\
(15-19)\end{array}$ & $\begin{array}{l}\text { Married girls } \\
\quad(15-19)\end{array}$ \\
\hline \multicolumn{4}{|l|}{ Combined (percent) } \\
\hline Ever attended a formal vocational training programme & 7.8 & 11.9 & 15.9 \\
\hline $\begin{array}{l}\text { Attended a formal vocational training programme in the } 12 \text { months prior to the } \\
\text { interview }\end{array}$ & 5.4 & 8.2 & 6.6 \\
\hline Number of respondents & 1,821 & 3,428 & 3,408 \\
\hline \multicolumn{4}{|l|}{ Types of programmes/courses attended } \\
\hline Tailoring & 8.2 & 69.3 & 87.5 \\
\hline Fashion designing & 0.3 & 0.0 & 0.9 \\
\hline Handicrafts/painting/embroidery/cooking & 0.4 & 1.0 & 0.2 \\
\hline Masonry/plumbing & 0.1 & 0.0 & 0.0 \\
\hline Auto mechanics/electric work & 18.8 & 0.0 & 0.0 \\
\hline Typing/shorthand/English language & 4.3 & 3.1 & 0.0 \\
\hline Computer training & 64.9 & 19.1 & 6.8 \\
\hline Nurse's aid & 0.2 & 0.2 & 0.0 \\
\hline Beauty parlour skills & 0.0 & 7.2 & 4.0 \\
\hline Performing arts & 0.2 & 0.0 & 0.0 \\
\hline Sports/physical education & 0.0 & 0.1 & 0.6 \\
\hline Mobile repairing & 2.5 & 0.0 & 0.0 \\
\hline \multicolumn{4}{|l|}{ Type of institution that conducted the course ${ }^{1}$} \\
\hline Government & 19.2 & 26.7 & 17.8 \\
\hline Private & 77.8 & 70.1 & 79.0 \\
\hline Non-governmental organisation & 2.7 & 2.7 & 2.3 \\
\hline \multicolumn{4}{|l|}{ Completion of the course/s attended } \\
\hline Completed the course/s attended & 41.5 & 38.6 & 40.9 \\
\hline Attending the course at the time of interview & 40.0 & 27.3 & 11.4 \\
\hline $\begin{array}{l}\text { Number who attended a formal vocational training programme in the } 12 \\
\text { months prior to the interview }\end{array}$ & 127 & 380 & 214 \\
\hline
\end{tabular}


Table 4.6 Cont.

\begin{tabular}{|c|c|c|c|}
\hline Programmes/courses attended & $\begin{array}{l}\text { Boys } \\
(15-19)\end{array}$ & $\begin{array}{l}\text { Girls } \\
(15-19)\end{array}$ & $\begin{array}{l}\text { Married girls } \\
\qquad(15-19)\end{array}$ \\
\hline \multicolumn{4}{|l|}{ Urban (percent) } \\
\hline Ever attended a formal vocational training programme & 11.9 & 21.3 & 18.8 \\
\hline Attended a formal vocational training programme in the 12 months prior to the interview & 8.2 & 14.3 & 6.5 \\
\hline Number of respondents & 1,008 & 1,738 & 1,366 \\
\hline \multicolumn{4}{|l|}{ Types of programmes/courses attended } \\
\hline Tailoring & 2.1 & 44.4 & 79.1 \\
\hline Fashion designing & 1.5 & 0.0 & 0.0 \\
\hline Handicrafts/painting/embroidery/cooking & 2.6 & 1.6 & 2.4 \\
\hline Masonry/plumbing & 0.8 & 0.0 & 0.0 \\
\hline Auto mechanics/electric work & 13.6 & 0.0 & 0.0 \\
\hline Typing/shorthand/English language & 3.6 & 4.8 & 0.0 \\
\hline Computer training & 70.1 & 38.9 & 13.2 \\
\hline Nurse's aid & 1.3 & 0.8 & 0.0 \\
\hline Beauty parlour skills & 0.0 & 9.1 & 5.3 \\
\hline Performing arts & 1.1 & 0.0 & 0.0 \\
\hline Sports/physical education & 0.0 & 0.4 & 0.0 \\
\hline Mobile repairing & 3.2 & 0.0 & 0.0 \\
\hline \multicolumn{4}{|l|}{ Type of institution that conducted the course ${ }^{1}$} \\
\hline Government & 19.3 & 31.4 & 24.4 \\
\hline Private & 76.5 & 61.5 & 68.6 \\
\hline Non-governmental organisation & 2.3 & 6.7 & 4.3 \\
\hline \multicolumn{4}{|l|}{ Completion of the course/s attended } \\
\hline Completed the course/s attended & 52.5 & 42.0 & 34.8 \\
\hline Attending the course at the time of interview & 28.2 & 32.8 & 15.5 \\
\hline $\begin{array}{l}\text { Number who attended a formal vocational training programme in the } 12 \\
\text { months prior to the interview }\end{array}$ & 81 & 241 & 81 \\
\hline \multicolumn{4}{|l|}{ Rural (percent) } \\
\hline Ever attended a formal vocational training programme & 7.3 & 10.8 & 15.6 \\
\hline Attended a formal vocational training programme in the 12 months prior to the interview & 5.1 & 7.5 & 6.7 \\
\hline Number of respondents & 813 & 1,690 & 2,042 \\
\hline \multicolumn{4}{|l|}{ Types of programmes/courses attended } \\
\hline Tailoring & $(9.4)$ & 75.0 & 88.4 \\
\hline Fashion designing & $(0.0)$ & 0.0 & 1.0 \\
\hline Handicrafts/painting/embroidery/cooking & $(0.0)$ & 0.8 & 0.0 \\
\hline Masonry/plumbing & $(0.0)$ & 0.0 & 0.0 \\
\hline Auto mechanics/electric work & $(19.9)$ & 0.0 & 0.0 \\
\hline Typing/shorthand/English language & $(4.4)$ & 2.7 & 0.0 \\
\hline Computer training & (63.9) & 14.6 & 6.0 \\
\hline Nurse's aid & $(0.0)$ & 0.0 & 0.0 \\
\hline Beauty parlour skills & $(0.0)$ & 6.8 & 3.9 \\
\hline Performing arts & 0.0 & 0.0 & 0.0 \\
\hline Sports/physical education & $(0.0)$ & 0.0 & 0.7 \\
\hline Mobile repairing & $(2.4)$ & 0.0 & 0.0 \\
\hline
\end{tabular}


Table 4.6 Cont.

\begin{tabular}{|c|c|c|c|}
\hline Programmes/courses attended & $\begin{array}{c}\text { Boys } \\
(15-19)\end{array}$ & $\begin{array}{c}\text { Girls } \\
(15-19)\end{array}$ & $\begin{array}{l}\text { Married girls } \\
(15-19)\end{array}$ \\
\hline \multicolumn{4}{|l|}{ Type of institution that conducted the course ${ }^{1}$} \\
\hline Government & $(19.2)$ & 25.7 & 17.0 \\
\hline Private & $(78.0)$ & 72.1 & 80.2 \\
\hline Non-governmental organisation & $(2.8)$ & 1.8 & 2.0 \\
\hline \multicolumn{4}{|l|}{ Completion of the course/s attended } \\
\hline Completed the course/s attended & (39.3) & 37.8 & 41.5 \\
\hline Attending the course at the time of interview & $(42.3)$ & 26.1 & 11.0 \\
\hline $\begin{array}{l}\text { Number who attended a formal vocational } t \\
\text { months prior to the interview }\end{array}$ & 46 & 139 & 133 \\
\hline
\end{tabular}

Notes: All Ns are unweighted. () Based on 25-49 unweighted cases. ${ }^{1}$ Less than two percent did not know whether the institution that conducted the course was a government institution, private institution, or non-governmental organisation.

Table 4.7 presents findings related to the experiences of adolescents who had completed a vocational training course in the year preceding the interview. Of those who had completed a vocational training course in the year prior to the interview, only a small proportion of boys and girls had received a certificate upon completion of the training course (33\% of boys and $15-38 \%$ of girls). Among girls, moreover, the unmarried were more likely than the married to have received a certificate (38\% versus $15 \%)$. The vast majority of those who had completed the training course reported that they felt competent to use the skill acquired-79 percent of boys and 86-89 percent of girls. Far fewer reported that they had obtained employment in the same trade after completing the course-14 percent of boys and 2-4 percent of unmarried and married girls. We note that we did not collect data on duration of work or the amount of income generated by such work and, therefore, we refer to work as that done for any duration or any amount of income generated.

\section{Table 4.7: Experience of exposure to vocational training}

Percentage of adolescents in ages 15-19 who had completed at least one vocational training programme in the year prior to the interview by their experiences related to vocational training, Bihar, 2016

\begin{tabular}{|c|c|c|c|}
\hline Experiences related to vocational training (percent) & $\begin{array}{c}\text { Boys } \\
(15-19)\end{array}$ & $\begin{array}{c}\text { Girls } \\
(15-19)\end{array}$ & $\begin{array}{l}\text { Married girls } \\
(15-19)\end{array}$ \\
\hline Received a certificate after completion of the training course & 32.8 & 38.0 & 15.1 \\
\hline Felt competent enough to use the skill acquired & 78.6 & 85.7 & 89.2 \\
\hline Got employment in the same trade after completing the course & 14.2 & 3.7 & 2.3 \\
\hline $\begin{array}{l}\text { Number of respondents who had completed a vocational training } \\
\text { course in one year prior to the interview }\end{array}$ & 56 & 148 & 82 \\
\hline
\end{tabular}

Notes: All Ns are unweighted. Given the small number of participants who had completed a vocational training course in the year prior to the interview in the combined sample, findings are not shown separately for rural and urban samples.

\subsubsection{Unmet need for vocational training programmes and willingness to participate in such programmes}

We assessed unmet need for vocational training in two ways. First, we asked respondents in ages 15-19 whether they had ever wanted to attend a vocational course but were not able to do so for any reason. Second, we asked them whether they would be interested in attending a vocational course in the next one year if they got support to do so. It is to be noted that while the former measured unmet need for vocational training programmes ever in life, the latter tried to capture current unmet need for such programmes. Table 4.8 presents findings related to percentage of adolescents who had ever wanted to attend a course but were not able to do so and the reasons for this. ${ }^{3}$ The reasons mentioned were categorised into supply-side factors (respondent was not selected, lack of awareness about training centres that offer the course, lack of training centres in the vicinity of home,or that the training facility was closed) and demand-side factors (uncertainty about the employment potential of the courses, lack of awareness of appropriate course to take up, cost, family members' objections, lack of time, health-related reasons, and so on).

\footnotetext{
${ }^{3}$ Refers to all adolescents regardless of whether they were attending a vocational training programme at the time of the interview or not.
} 
A larger proportion of girls than boys noted that they had at some time experienced an unmet need for vocational training, that is, they had wanted to attend a course but could not do so-36-38 percent of girls as opposed to 10 percent of boys. Differences between those from rural and those from urban areas were modest. The leading reasons for their not being able to attend the course across all categories of adolescents were related to demand-side issues, as reported by 83 percent of boys and 79-86 percent of girls with an unmet need. Leading among the demandside reasons were lack of affordability, as cited by 58 percent of boys and 42 percent of girls; lack of time, including courses clashing with studies and housework-related responsibilities, as mentioned by 19 percent of boys and 31-33 percent of girls; and, among girls, objections by family members, as mentioned by 15-21 percent. Some 18 percent of boys and 24-29 percent of girls reported at least one supply-side reason for their not being able to attend a course. Leading among the supply-side reasons were lack of training centres in the vicinity of their home, as cited by 11 percent of boys and 17-23 percent of girls, and lack of awareness about training centres that offer the course, as mentioned by seven percent each of boys and girls.

As seen above, differences by sex were observed in the reasons given for unmet need for attending vocational training programmes. Boys were less likely than girls to mention lack of training centres in the vicinity of their home, family members' objections, and lack of time, including courses clashing with studies and housework-related responsibilities, but more likely to mention lack of affordability. Differences by marital status were modest, although unmarried girls were more likely than the married to cite distance to the training centre as a reason (23\% versus 17\%). There were also differences between those from rural and those from urban areas. Rural boys and unmarried girls were more likely than their urban counterparts to attribute their unmet need to supply-side factors (19\% versus $12 \%$ among boys and $30 \%$ versus $20 \%$ among unmarried girls). Additionally, among boys, rural respondents were less likely than urban respondents to mention demand-side factors ( $82 \%$ versus $88 \%$ ). Finally, more married girls in rural than urban areas mentioned lack of affordability (43\% versus 34\%).

\section{Table 4.8: Unmet need for vocational training programmes}

Percentage of adolescents in ages 15-19 who could not fulfil their desire to attend a vocational training programme and the reasons for it, according to residence, Bihar, 2016

\begin{tabular}{|c|c|c|c|}
\hline Unmet need for vocational training programmes & $\begin{array}{c}\text { Boys } \\
(15-19)\end{array}$ & $\begin{array}{c}\text { Girls } \\
(15-19)\end{array}$ & $\begin{array}{c}\text { Married girls } \\
\text { (15-19) }\end{array}$ \\
\hline \multicolumn{4}{|l|}{ Combined (percent) } \\
\hline Had wanted at some time to attend a vocational training programme, but could not do so & 10.3 & 35.8 & 37.5 \\
\hline Number of respondents & 1,821 & 3,428 & 3,408 \\
\hline \multicolumn{4}{|l|}{ Reasons for unmet need } \\
\hline \multicolumn{4}{|l|}{ Supply-side reasons } \\
\hline Was not selected & 0.1 & 0.8 & 0.6 \\
\hline Did not know a training centre that offers the course & 7.4 & 6.5 & 7.3 \\
\hline No training centre nearby & 10.5 & 23.2 & 16.6 \\
\hline Training centre closed & 0.4 & 0.6 & 0.1 \\
\hline At least one supply-side reason & 18.4 & 29.0 & 23.6 \\
\hline \multicolumn{4}{|l|}{ Demand-side reasons } \\
\hline Not sure about the employment potential & 0.0 & 0.8 & 0.4 \\
\hline Did not know which course to take up & 4.8 & 1.5 & 1.2 \\
\hline Cannot afford the cost of attending the course & 58.1 & 42.2 & 41.6 \\
\hline Objections from family & 1.8 & 14.6 & 21.2 \\
\hline Clashes with studies/no time/needed for housework & 19.3 & 31.2 & 32.6 \\
\hline Family member's illness or death/own illness & 0.1 & 0.4 & 0.6 \\
\hline Got married & 0.0 & 0.0 & 4.3 \\
\hline No one to escort her/him & 0.0 & 0.1 & 0.1 \\
\hline At least one demand-side reason & 83.0 & 78.9 & 85.9 \\
\hline No specific reason & 2.4 & 1.8 & 2.7 \\
\hline Number of respondents with an unmet need for vocational training programme & 196 & 1,215 & 1,265 \\
\hline
\end{tabular}


Table 4.8 Cont.

\begin{tabular}{|c|c|c|c|}
\hline Unmet need for vocational training programmes & $\begin{array}{c}\text { Boys } \\
(15-19)\end{array}$ & $\begin{array}{c}\text { Girls } \\
(15-19)\end{array}$ & $\begin{array}{l}\text { Married girls } \\
(15-19)\end{array}$ \\
\hline \multicolumn{4}{|l|}{ Urban (percent) } \\
\hline Had wanted at some time to attend a vocational training programme, but could not do so & 10.0 & 35.3 & 37.9 \\
\hline Number of respondents & 1,008 & 1,738 & 1,366 \\
\hline \multicolumn{4}{|l|}{ Reasons for unmet need } \\
\hline \multicolumn{4}{|l|}{ Supply-side reasons } \\
\hline Was not selected & 0.7 & 1.6 & 1.2 \\
\hline Did not know a training centre that offers the course & 4.3 & 5.8 & 5.0 \\
\hline No training centre nearby & 7.5 & 12.6 & 14.5 \\
\hline Training centre closed & 0.0 & 1.3 & 0.8 \\
\hline At least one supply-side reason & 12.4 & 20.4 & 20.0 \\
\hline \multicolumn{4}{|l|}{ Demand-side reasons } \\
\hline Not sure about the employment potential & 0.0 & 0.7 & 0.7 \\
\hline Did not know which course to take up & 1.9 & 1.1 & 1.2 \\
\hline Cannot afford the cost of attending the course & 55.8 & 41.4 & 33.6 \\
\hline Objections from family & 3.2 & 13.0 & 26.1 \\
\hline Clashes with studies/no time/needed for housework & 30.5 & 36.5 & 31.9 \\
\hline Family member's illness or death/own illness & 1.3 & 0.4 & 0.8 \\
\hline Got married & 0.0 & 0.2 & 6.2 \\
\hline No one to escort her/him & 0.0 & 0.2 & 0.0 \\
\hline At least one demand-side reason & 88.2 & 81.4 & 84.3 \\
\hline No specific reason & 1.9 & 2.0 & 1.7 \\
\hline Number of respondents with an unmet need for vocational training programme & 110 & 607 & 526 \\
\hline \multicolumn{4}{|l|}{$\begin{array}{ll} & \text { Rural (percent) } \\
\end{array}$} \\
\hline Had wanted at some time to attend a vocational training programme, but could not do so & 10.4 & 35.8 & 37.4 \\
\hline Number of respondents & 813 & 1,690 & 2,042 \\
\hline \multicolumn{4}{|l|}{ Reasons for unmet need } \\
\hline \multicolumn{4}{|l|}{ Supply-side reasons } \\
\hline Was not selected & 0.0 & 0.7 & 0.5 \\
\hline Did not know a training centre that offers the course & 7.8 & 6.6 & 7.5 \\
\hline No training centre nearby & 10.9 & 24.4 & 16.9 \\
\hline Training centre closed & 0.4 & 0.5 & 0.1 \\
\hline At least one supply-side reason & 19.1 & 30.0 & 24.0 \\
\hline \multicolumn{4}{|l|}{ Demand-side reasons } \\
\hline Not sure about the employment potential & 0.0 & 0.8 & 0.3 \\
\hline Did not know which course to take up & 5.2 & 1.6 & 1.2 \\
\hline Cannot afford the cost of attending the course & 58.4 & 42.3 & 42.5 \\
\hline Objections from family & 1.6 & 14.8 & 20.6 \\
\hline Clashes with studies/no time/needed for housework & 18.0 & 30.6 & 32.7 \\
\hline Family member's illness or death/own illness & 0.0 & 0.4 & 0.5 \\
\hline Got married & 0.0 & 0.0 & 4.1 \\
\hline No one to escort her/him & 0.0 & 0.1 & 0.1 \\
\hline At least one demand-side reason & 82.4 & 78.6 & 86.1 \\
\hline No specific reason & 2.5 & 1.8 & 2.8 \\
\hline Number of respondents with an unmet need for vocational training programme & 86 & 608 & 739 \\
\hline
\end{tabular}

Note: All Ns are unweighted. 
Large proportions of adolescents-81 percent of boys and 83-91 percent of girls-reported interest in attending vocational training programmes, as shown in Table 4.9. Among girls, more unmarried than married girls expressed interest in attending such vocational training (91\% versus $83 \%$ ). Differences in the proportions of adolescents who expressed interest for vocational training between those from rural and those from urban areas were negligible.

Skills in which adolescents wished to be trained mirrored the patterns revealed above for the skills in which some of them had been trained. The majority of girls wished to be trained in areas such as tailoring ( $76 \%$ and $87 \%$ of unmarried girls and married girls, respectively), handicrafts (15-16\%), beauty parlour skills (14-16\%), and computer skills ( $40 \%$ of unmarried girls and $12 \%$ of married girls). Boys' preferences, in contrast, were focused on computer training (61\%), auto mechanics or electrical work (31\%), and training in typing, shorthand, or English language skills (9\%). The proportion of adolescents who wished to be trained in specific skills differed between rural and urban areas. Among boys, a larger proportion in urban than rural areas preferred to be trained in typing, shorthand, and English language skills (16\% versus $8 \%$ ). Among unmarried and married girls, those in urban areas were more likely than their rural counterparts to express an interest in computer skills (47\% versus 39\% among unmarried girls and $19 \%$ versus $12 \%$ among married girls) and beauty parlour skills (27\% versus $15 \%$ among unmarried girls and $22 \%$ versus $13 \%$ among married girls). Among unmarried girls, additionally, those in urban areas were less likely than their rural counterparts to express an interest in tailoring (52\% versus $79 \%$ ) and more likely to report an interest in typing, shorthand, and English language skills (13\% versus $5 \%)$.

\section{Table 4.9: Willingness of adolescents to participate in vocational training programmes}

Percentage of adolescents in ages 15-19 interested in participating in vocational training programmes by type of programme, according to residence, Bihar, 2016

\begin{tabular}{lrrr}
\hline Programmes/courses & \multicolumn{1}{c}{$\begin{array}{c}\text { Boys } \\
(15-19)\end{array}$} & $\begin{array}{c}\text { Girls } \\
(\mathbf{1 5}-19)\end{array}$ & $\begin{array}{c}\text { Married girls } \\
(\mathbf{1 5}-19)\end{array}$ \\
\hline \multicolumn{1}{c}{ Combined (percent) } & & & \\
\hline Interested in participating in a vocational training programme & 81.3 & 91.2 & 83.1 \\
Number of respondents & $\mathbf{1 , 8 2 1}$ & $\mathbf{3 , 4 2 8}$ & $\mathbf{3 , 4 0 8}$ \\
Type of programme in which respondents wished to participate & & & \\
Tailoring & 3.9 & 75.8 & 86.6 \\
Fashion designing & 0.5 & 2.3 & 2.2 \\
Handicrafts/painting/embroidery/cooking & 1.8 & 15.9 & 15.0 \\
Masonry/plumbing/carpentry & 3.1 & 0.0 & 0.1 \\
Auto mechanics/electric work & 30.5 & 0.1 & 0.0 \\
Typing/shorthand/English language & 9.0 & 6.1 & 1.6 \\
Computer training & 61.4 & 39.6 & 12.4 \\
Nurse's aid/nursing & 1.2 & 1.9 & 1.4 \\
Poultry/goat-rearing/farm work & 0.3 & 0.0 & 0.0 \\
Driving & 4.3 & 0.6 & 0.1 \\
Beauty parlour skills & & 16.2 & 13.9 \\
Performing arts & 0.3 & 1.0 & 0.2 \\
Accountancy/hotel management/marketing & 0.6 & 0.0 & 0.0 \\
Mobile repairing & 0.1 & 0.0 & $\mathbf{2 , 7 8 2}$ \\
Number interested in participating in a vocational training programme & $\mathbf{1 , 4 5 6}$ & $\mathbf{3 , 1 5 0}$ & \\
\hline
\end{tabular}


Table 4.9 Cont.

\begin{tabular}{|c|c|c|c|}
\hline Programmes/courses & $\begin{array}{c}\text { Boys } \\
(15-19)\end{array}$ & $\begin{array}{c}\text { Girls } \\
(15-19)\end{array}$ & $\begin{array}{l}\text { Married girls } \\
\qquad(15-19)\end{array}$ \\
\hline \multicolumn{4}{|l|}{ Urban (percent) } \\
\hline Interested in participating in a vocational training programme & 79.7 & 90.8 & 84.5 \\
\hline Number of respondents & 1,008 & 1,738 & 1,366 \\
\hline \multicolumn{4}{|l|}{ Type of programme in which respondents wished to participate } \\
\hline Tailoring & 0.9 & 52.3 & 83.1 \\
\hline Fashion designing & 0.4 & 5.6 & 2.1 \\
\hline Handicrafts/painting/embroidery/cooking & 2.9 & 18.2 & 13.0 \\
\hline Masonry/plumbing/carpentry & 2.9 & 0.0 & 0.0 \\
\hline Auto mechanics/electric work & 26.0 & 0.0 & 0.0 \\
\hline Typing/shorthand/English language & 15.7 & 13.4 & 1.9 \\
\hline Computer training & 60.1 & 47.2 & 19.1 \\
\hline Nurse's aid/nursing & 1.7 & 1.4 & 1.4 \\
\hline Poultry/goat-rearing/farm work & 0.2 & 0.1 & 0.0 \\
\hline Driving & 3.2 & 1.1 & 0.0 \\
\hline Beauty parlour skills & 0.1 & 27.0 & 21.5 \\
\hline Performing arts & 3.2 & 5.3 & 0.6 \\
\hline Accountancy/hotel management/marketing & 1.0 & 0.1 & 0.0 \\
\hline Mobile repairing & 2.8 & 0.0 & 0.0 \\
\hline Number interested in participating in a vocational training programme & 799 & 1,581 & 1,121 \\
\hline \multicolumn{4}{|l|}{ Rural (percent) } \\
\hline Interested in participating in a vocational training programme & 81.5 & 91.3 & 83.0 \\
\hline Number of respondents & 813 & 1,690 & 2,042 \\
\hline \multicolumn{4}{|l|}{ Type of programme in which respondents wished to participate } \\
\hline Tailoring & 4.2 & 78.6 & 87.0 \\
\hline Fashion designing & 0.5 & 1.9 & 2.2 \\
\hline Handicrafts/painting/embroidery/cooking & 1.7 & 15.7 & 15.3 \\
\hline Masonry/plumbing/carpentry & 3.1 & 0.0 & 0.1 \\
\hline Auto mechanics/electric work & 31.0 & 0.1 & 0.0 \\
\hline Typing/shorthand/English language & 8.2 & 5.2 & 1.6 \\
\hline Computer training & 61.6 & 38.7 & 11.6 \\
\hline Nurse's aid/nursing & 1.2 & 1.9 & 1.4 \\
\hline Poultry/goat-rearing/farm work & 0.3 & 0.0 & 0.0 \\
\hline Driving & 4.4 & 0.5 & 0.1 \\
\hline Beauty parlour skills & 0.3 & 14.9 & 13.1 \\
\hline Performing arts & 0.2 & 0.5 & 0.1 \\
\hline Accountancy/hotel management/marketing & 0.0 & 0.0 & 0.0 \\
\hline Mobile repairing & 0.5 & 0.0 & 0.0 \\
\hline Number interested in participating in a vocational training programme & 657 & 1,569 & 1,661 \\
\hline
\end{tabular}

Notes: All Ns are unweighted. Column totals may exceed $100 \%$ owing to multiple responses. 


\subsection{Awareness and utilisation of government programmes for skill-building and employment generation}

Several programmes, such as those under the National Skill Development Mission and the Mahatma Gandhi National Rural Employment Guarantee Act (MNREGA), have been implemented by the central and state governments to equip young people and adults with skills required for employment and to help them find employment. They have also institute demployment exchange centres and facilitated the provision of loans for self-employment to achieve this aim. This survey probed awareness of these programmes from those in ages 15-19 and the extent to which those in ages 18-19 had benefited from some of these programmes. Findings are presented in Tables 4.10 and 4.11.

Findings presented in Table 4.10 show that 18 percent of boys and 15-22 percent of girls had heard about the Bihar Skill Development Mission. Differences in awareness of this programme between rural and urban adolescents show that a larger proportion of urban than rural adolescents were aware of it (28\% versus $17 \%$ among boys and $22-31 \%$ versus $15-21 \%$ among girls). In contrast, relatively few adolescents were aware of any vocational training centres that offer training under this mission-just 4-5 percent of boys and girls were aware of such centres, and, again, with hardly any difference between rural and urban adolescents.

Findings also show that only a small proportion of adolescents were aware of employment exchanges or counselling centres-eight percent of boys and 4-6 percent of girls were aware of such centres; boys and unmarried girls in urban areas were somewhat more likely than their rural counterparts to report awareness of employment exchanges ( $14 \%$ versus $7 \%$ among boys and $13 \%$ versus $6 \%$ among unmarried girls). Considerable proportions of adolescents were aware of MNREGA, which was reported by more boys than girls (52\% versus $34 \%$ ). Not surprisingly, more rural than urban adolescents among boys and married girls had heard about it (53\% versus $43 \%$ among boys and $35 \%$ versus $25 \%$ among married girls). Considerable proportions also reported awareness of schemes that give loans to men and women for self-employment-44 percent of boys and 53-57 percent of girls had heard about such schemes. Differences between rural and urban areas in this regard show that more urban respondents among boys and unmarried girls were aware of it, compared with their rural counterparts (51\% versus $43 \%$ among boys and $62 \%$ versus $52 \%$ among unmarried girls).

\section{Table 4.10: Awareness of government programmes for skill-buillding and employment generation}

Percentage of adolescents in ages 15-19 reporting awareness of government programmes for skill-building and employment generation, according to residence, Bihar, 2016

\begin{tabular}{|c|c|c|c|}
\hline Government programmes for skill-building and employment generation & $\begin{array}{c}\text { Boys } \\
(15-19)\end{array}$ & $\begin{array}{c}\text { Girls } \\
(15-19)\end{array}$ & $\begin{array}{l}\text { Married girls } \\
\text { (15-19) }\end{array}$ \\
\hline \multicolumn{4}{|l|}{ Combined (percent) } \\
\hline Bihar Skill Development Mission & 18.1 & 21.9 & 15.3 \\
\hline Vocational training centres that offer training under the Bihar Skill Development Mission & 3.9 & 5.4 & 3.8 \\
\hline Employment exchange or employment counselling centres & 8.0 & 6.4 & 4.2 \\
\hline Mahatma Gandhi National Rural Employment Guarantee Act & 51.9 & 34.0 & 33.5 \\
\hline Schemes that give loans to men and women for self-employment & 44.2 & 53.4 & 57.4 \\
\hline Number of respondents & 1,821 & 3,428 & 3,408 \\
\hline \multicolumn{4}{|l|}{ Urban (percent) } \\
\hline Bihar Skill Development Mission & 27.6 & 30.9 & 21.9 \\
\hline Vocational training centres that offer training under Bihar Skill Development Mission & 6.9 & 9.1 & 4.2 \\
\hline Employment exchange or employment counselling centres & 14.3 & 12.7 & 5.5 \\
\hline Mahatma Gandhi National Rural Employment Guarantee Act & 42.8 & 31.3 & 24.5 \\
\hline Schemes that give loans to men and women for self-employment & 50.6 & 62.3 & 60.6 \\
\hline Number of respondents & 1,008 & 1,738 & 1,366 \\
\hline
\end{tabular}


Table 4.10 Cont.

\begin{tabular}{|c|c|c|c|}
\hline Government programmes for skill-building and employment generation & $\begin{array}{c}\text { Boys } \\
(15-19)\end{array}$ & $\begin{array}{c}\text { Girls } \\
(15-19)\end{array}$ & $\begin{array}{l}\text { Married girls } \\
\quad(15-19)\end{array}$ \\
\hline \multicolumn{4}{|l|}{ Rural (percent) } \\
\hline Bihar Skill Development Mission & 17.0 & 20.8 & 14.6 \\
\hline Vocational training centres that offer training under Bihar Skill Development Mission & 3.5 & 5.0 & 3.8 \\
\hline Employment exchange or employment counselling centres & 7.2 & 5.6 & 4.0 \\
\hline Mahatma Gandhi National Rural Employment Guarantee Act & 53.0 & 34.3 & 34.5 \\
\hline Schemes that give loans to men and women for self-employment & 43.4 & 52.4 & 57.0 \\
\hline Number of respondents & 813 & 1,690 & 2,042 \\
\hline
\end{tabular}

Note: All Ns are unweighted.

Table 4.11 shows that hardly any adolescents in ages 18-19 had benefited from employment-generation schemes. Two percent or fewer adolescents, for example, had ever sought services from the employment exchange or counselling centres. Likewise, one percent or fewer adolescents in ages 18-19 had ever taken a loan under the government scheme that gives loans to men and women for self-employment. One percent or fewer adolescents in rural areas reported that they had got employment under the MNREGA scheme.

Table 4.11: Access to government programmes for employment generation

Percentage of adolescents in ages 18-19 reporting their having accessed government programmes for employment generation, according to residence, Bihar, 2016

\begin{tabular}{|c|c|c|c|}
\hline Government programmes for employment generation & $\begin{array}{l}\text { Boys } \\
(18-19)\end{array}$ & $\begin{array}{c}\text { Girls } \\
(18-19)\end{array}$ & $\begin{array}{l}\text { Married girls } \\
\qquad(18-19)\end{array}$ \\
\hline \multicolumn{4}{|l|}{ Combined (percent) } \\
\hline Ever sought services from an employment exchange or employment counselling centres & 2.0 & 0.1 & 0.2 \\
\hline $\begin{array}{l}\text { Took a loan under the government scheme that gives loans to men and women for } \\
\text { self-employment in the year prior to the interview }\end{array}$ & 0.7 & 0.1 & 1.0 \\
\hline Number of respondents in ages 18-19 & 554 & 875 & 2,312 \\
\hline \multicolumn{4}{|l|}{ Urban (percent) } \\
\hline Ever sought services from an employment exchange or employment counselling centres & 1.8 & 0.9 & 0.2 \\
\hline $\begin{array}{l}\text { Took a loan under the government scheme that gives loans to men and women for } \\
\text { self-employment in the year prior to the interview }\end{array}$ & 0.7 & 0.6 & 1.6 \\
\hline Number of respondents in ages 18-19 & 341 & 510 & 993 \\
\hline \multicolumn{4}{|l|}{ Rural (percent) } \\
\hline Ever sought services from an employment exchange or employment counselling centres & 2.0 & 0.0 & 0.2 \\
\hline Got employment under MNREGA in the year prior to the interview* & 0.7 & 0.0 & 0.9 \\
\hline $\begin{array}{l}\text { Took a loan under the government scheme that gives loans to men and women for } \\
\text { self-employment in the year prior to the interview }\end{array}$ & 4.4 & 0.0 & 0.4 \\
\hline Number of respondents in ages 18-19 & 213 & 365 & 1,319 \\
\hline
\end{tabular}

Note: All Ns are unweighted. *This question was asked for rural adolescents only.

\subsection{Participation in household-related work}

The survey also inquired into the extent to which respondents participated in domestic chores. All respondents were asked whether they had been engaged in domestic chores inside the house, that is, housework, such as cooking, cleaning, etc., and other chores, such as taking care of children/younger siblings; and also whether they had been engaged in domestic chores outside the house, such as shopping for groceries for the family, and tasks, such as collecting firewood, fetching water,or cattle-grazing (for rural areas) and paying electricity or phone bills (for urban areas), on the day preceding the interview. 
Findings, presented in Table 4.12, highlight the age- and sex-stratified nature of adolescents' participation in domestic chores. Among boys, differences by age were evident; thus, 61 percent of younger boys and 66 percent of older boys had been engaged in chores inside the house and 55 percent and 62 percent, respectively, had been engaged in chores outside the house the preceding day. On the whole, 78-82 percent of boys were engaged in any domestic chores the preceding day. Among girls, age-wise differences varied by the type of activity: younger girls were somewhat less likely than unmarried and married older girls to have been engaged in chores inside the house (89\% versus $97-99 \%$ ), while they were more likely to have been engaged in chores outside the house (59\% versus $32-51 \%)$, which reflects the restrictions on girls as they grow into late adolescence, and particularly once married. On the whole, 92-100 percent of girls had performed household chores the preceding day.

There were significant differences by sex. Girls were more likely than boys to be engaged in work inside the home and less likely to be engaged in tasks outside the home that violated norms restricting their mobility, particularly in late adolescence. Thus, 89-99 percent of all categories of girls had been engaged in chores inside the house on the day preceding the interview, compared with 61-66 percent of all boys. In contrast, 62 percent of older boys had done chores outside the house the preceding day, compared with 32-51 percent of unmarried and married older girls. The difference between younger boys and girls was negligible in this regard.

Participation in household chores varied by type of activity among unmarried and married older girls. Married older girls were less likely than unmarried older girls to have performed chores outside the house the preceding day ( $32 \%$ versus 51\%). These findings indicate the increased restrictions placed on the mobility of married girls.

Patterns differed in rural and urban areas, although not consistently across all the categories of adolescents and the type of activity. Across all categories of adolescents, rural adolescents were more likely than urban adolescents to have performed household chores the preceding day. Moreover, across all categories of girls, rural adolescents were more likely than urban adolescents to have been engaged in chores outside the house.

\section{Table 4.12: Participation in household chores}

Percentage of adolescents reporting participation in selected household chores on the day prior to the interview, according to residence, Bihar, 2016

\begin{tabular}{|c|c|c|c|c|c|}
\hline Types of chores & $\begin{array}{c}\text { Boys } \\
(10-14)\end{array}$ & $\begin{array}{l}\text { Boys } \\
(15-19)\end{array}$ & $\begin{array}{c}\text { Girls } \\
(10-14)\end{array}$ & $\begin{array}{c}\text { Girls } \\
(15-19)\end{array}$ & $\begin{array}{l}\text { Married girls } \\
\text { (15-19) }\end{array}$ \\
\hline \multicolumn{6}{|c|}{ Combined (percent) } \\
\hline Housework ${ }^{1}$ & 39.9 & 48.8 & 81.0 & 95.4 & 98.7 \\
\hline Taking care of children/younger siblings in the family & 41.9 & 41.7 & 62.2 & 60.3 & 74.6 \\
\hline Chores inside the house & 61.2 & 66.0 & 89.4 & 96.9 & 99.4 \\
\hline Shopping & 42.0 & 50.8 & 42.8 & 30.7 & 14.4 \\
\hline Other tasks ${ }^{2}$ & 29.6 & 27.7 & 38.1 & 37.6 & 26.6 \\
\hline Chores outside the house & 55.1 & 61.8 & 58.8 & 51.0 & 31.9 \\
\hline At least one of the above chores & 78.3 & 82.0 & 92.4 & 97.4 & 99.5 \\
\hline Number of respondents & 1,012 & 1,821 & 764 & 3,428 & 3,408 \\
\hline \multicolumn{6}{|c|}{ Urban (percent) } \\
\hline Housework $^{1}$ & 29.5 & 45.3 & 74.1 & 92.2 & 98.5 \\
\hline Taking care of children/younger siblings in the family & 33.6 & 36.5 & 55.0 & 51.2 & 72.5 \\
\hline Chores inside the house & 50.1 & 60.1 & 84.7 & 94.3 & 99.2 \\
\hline Shopping & 50.4 & 62.0 & 43.2 & 33.3 & 16.1 \\
\hline Other tasks ${ }^{2}$ & 15.2 & 15.6 & 19.3 & 16.0 & 14.3 \\
\hline Chores outside the house & 55.6 & 66.1 & 48.2 & 40.0 & 24.4 \\
\hline At least one of the above chores & 72.2 & 80.2 & 90.0 & 95.2 & 99.3 \\
\hline Number of respondents & 452 & 1,008 & 387 & 1,738 & 1,366 \\
\hline
\end{tabular}


Table 4.12 Cont.

\begin{tabular}{|c|c|c|c|c|c|}
\hline Types of chores & $\begin{array}{c}\text { Boys } \\
(10-14)\end{array}$ & $\begin{array}{c}\text { Boys } \\
(15-19)\end{array}$ & $\begin{array}{c}\text { Girls } \\
(10-14)\end{array}$ & $\begin{array}{c}\text { Girls } \\
(15-19)\end{array}$ & $\begin{array}{c}\text { Married girls } \\
\qquad(15-19)\end{array}$ \\
\hline \multicolumn{6}{|c|}{ Rural (percent) } \\
\hline Housework $^{1}$ & 41.1 & 49.2 & 81.9 & 95.8 & 98.8 \\
\hline Taking care of children/younger siblings in the family & 42.9 & 42.4 & 63.1 & 61.4 & 74.8 \\
\hline Chores inside the house & 62.5 & 66.8 & 89.9 & 97.2 & 99.4 \\
\hline Shopping & 41.0 & 49.4 & 42.8 & 30.4 & 14.1 \\
\hline Other tasks ${ }^{2}$ & 31.3 & 29.2 & 40.4 & 40.2 & 28.0 \\
\hline Chores outside the house & 55.1 & 61.2 & 60.1 & 52.3 & 32.8 \\
\hline At least one of the above chores & 79.0 & 82.2 & 92.7 & 97.7 & 99.5 \\
\hline Number of respondents & 560 & 813 & 377 & 1,690 & 2,042 \\
\hline
\end{tabular}

Notes: All Ns are unweighted. ${ }^{1}$ Includes cooking, cleaning, etc. ${ }^{2}$ Respondents were given examples of other tasks such as collecting firewood, fetching water, cattle-grazing, etc.

\subsection{Migration experiences}

Migration exposes adolescents to conditions that may lead to both empowerment and vulnerability. In order to assess migration-related experiences among adolescents, we posed questions to respondents in ages 15-19 about the duration of residence at their current usual place of residence and the nature of their migration experiences.

Table 4.13 describes findings related to older respondents' duration of residence at the current usual place of residence. The vast majority of boys (82\%) and unmarried girls $(90 \%)$ had resided since birth in the village or urban ward in which they were interviewed. Thus, 17 percent of boys and 10 percent of girls were migrants. Specifically, six percent of boys had moved into their current place of residence five or more years ago and 11 percent had done so less than five years ago. Likewise, six percent of girls had moved into their current place of residence five or more years ago and four percent had done so less than five years ago. Among married girls, in contrast, just 13 percent had resided at their current usual place of residence since birth, while 87 percent had migrated to their current place of residence after marriage. ${ }^{4}$

Differences in migration patterns between adolescents from rural and those from urban areas were marked. More boys and unmarried girls from urban than rural areas had migrated ( $28 \%$ versus $16 \%$ among boys and $22 \%$ versus $9 \%$ among girls). Moreover, adolescents in urban areas were more likely to be long-term migrants (that is, those who had migrated five or more years ago) compared with their rural counterparts: 15 percent of boys in urban areas compared to five percent in rural areas had migrated into the current place of residence five or more years ago; the corresponding proportions among unmarried girls were 14 percent and five percent.

The nature of migration experienced by older adolescents is summarised in Table 4.14. The major reason for migration among boys was that related to their education, followed by family migration and work-related migration: 34 percent of boys reported that they had moved into their current place of residence for education-related reasons; 26 percent migrated because their family had moved; and 20 percent attributed their migration to work-related reasons. Among unmarried girls, the leading reasons were family migration (56\%), followed by education-related reasons (29\%). Very few unmarried girls had migrated owing to work-related reasons (3\%). Some 17 percent of boys and 12 percent of girls cited economic distress experienced by family. As seen above, boys were more likely than girls to have migrated for education and work-related reasons, but less likely to have migrated because of family migration. Almost all married girls who had migrated into their current place of residence cited marriage-related migration.

\footnotetext{
${ }^{4}$ The small minority of married girls (3\%) who had migrated less than five years ago as well as five or more years ago had migrated with their family or because of economic distress faced by the family.
} 
Table 4.13: Duration of residence at the current usual place of residence

Percent distribution of adolescents in ages $15-19$ by duration of residence at the current usual place of residence, according to residence, Bihar, 2016

\begin{tabular}{|c|c|c|c|}
\hline Duration of residence & $\begin{array}{c}\text { Boys } \\
(15-19)\end{array}$ & $\begin{array}{c}\text { Girls } \\
(15-19)\end{array}$ & $\begin{array}{c}\text { Married girls } \\
(15-19)\end{array}$ \\
\hline \multicolumn{4}{|c|}{ Combined (percent) } \\
\hline Always/since birth & 81.9 & 89.7 & 12.9 \\
\hline Since marriage & NA & NA & 84.6 \\
\hline 5 or more years & 6.3 & 6.0 & 0.5 \\
\hline Less than 5 years & 10.8 & 4.2 & 2.0 \\
\hline Number of respondents & 1,821 & 3,428 & 3,408 \\
\hline \multicolumn{4}{|c|}{ Urban (percent) } \\
\hline Always/since birth & 71.4 & 77.6 & 10.6 \\
\hline Since marriage & NA & NA & 84.1 \\
\hline 5 or more years & 14.9 & 13.5 & 1.0 \\
\hline Less than 5 years & 13.2 & 8.5 & 4.3 \\
\hline Number of respondents & 1,008 & 1,738 & 1,366 \\
\hline \multicolumn{4}{|c|}{ Rural (percent) } \\
\hline Always/since birth & 83.2 & 91.2 & 13.1 \\
\hline Since marriage & NA & NA & 84.7 \\
\hline 5 or more years & 5.2 & 5.1 & 0.5 \\
\hline Less than 5 years & 10.5 & 3.7 & 1.7 \\
\hline Number of respondents & 813 & 1,690 & 2,042 \\
\hline
\end{tabular}

Notes: All Ns are unweighted. NA: not applicable

Adolescents in rural and urban areas cited similar reasons,though we noted some differences. Urban boys and unmarried girls were more likely than their rural counterparts to report family-related migration (41\% versus $23 \%$ among boys and $67 \%$ versus $52 \%$ among unmarried girls), and urban boys, additionally, were more likely than rural boys to have migrated for educational purposes (43\% versus 33\%). On the other hand, urban boys, but not urban unmarried girls, were less likely than rural boys to cite work-related reasons (9\% versus 23\%), and both urban boys and unmarried girls were less likely than their rural counterparts to cite economic distress-related reasons (7\% versus $19 \%$ among boys and 5\% versus 15\% among unmarried girls) for moving into the current place of residence.

\section{Table 4.14: Migration experiences}

Percentage of adolescents in ages 15-19 who had migrated to their current usual place of residence and the nature of migration experiences, according to residence, Bihar, 2016

\begin{tabular}{|c|c|c|c|}
\hline Nature of migration experiences & $\begin{array}{c}\text { Boys } \\
(15-19)\end{array}$ & $\begin{array}{c}\text { Girls } \\
(15-19)\end{array}$ & $\begin{array}{c}\text { Married girls } \\
(15-19)\end{array}$ \\
\hline \multicolumn{4}{|c|}{ Combined (percent) } \\
\hline Migrated to the current usual place of residence & 17.1 & 10.2 & 87.1 \\
\hline Number of respondents & 1,821 & 3,428 & 3,408 \\
\hline \multicolumn{4}{|l|}{ Reasons for migration } \\
\hline Marriage & NA & NA & 97.1 \\
\hline Moved with family & 25.8 & 55.5 & 1.2 \\
\hline Education related & 34.4 & 28.7 & 0.3 \\
\hline
\end{tabular}


Table 4.14 Cont.

\begin{tabular}{|c|c|c|c|}
\hline Nature of migration experiences & $\begin{array}{c}\text { Boys } \\
(15-19)\end{array}$ & $\begin{array}{c}\text { Girls } \\
(15-19)\end{array}$ & $\begin{array}{l}\text { Married girls } \\
\qquad(15-19)\end{array}$ \\
\hline Work related & 20.4 & 3.4 & 0.2 \\
\hline Economic distress of the family & 16.5 & 12.3 & 1.0 \\
\hline Number of respondents who experienced migration & 404 & 541 & 3,016 \\
\hline \multicolumn{4}{|l|}{ Respondent's involvement in migration-related decision } \\
\hline Own volition & 83.3 & 47.8 & 52.8 \\
\hline Forced by others & 4.2 & 3.4 & 10.3 \\
\hline Advised by others & 12.5 & 48.7 & 36.8 \\
\hline $\begin{array}{l}\text { Number of respondents who migrated for reasons oth } \\
\text { migration or marriage }\end{array}$ & 264 & 202 & 60 \\
\hline \multicolumn{4}{|c|}{ Urban (percent) } \\
\hline Migrated to the current usual place of residence & 28.0 & 22.0 & 89.4 \\
\hline Number of respondents & 1,008 & 1,738 & 1,366 \\
\hline \multicolumn{4}{|l|}{ Reasons for migration } \\
\hline Marriage & NA & NA & 93.8 \\
\hline Moved with family & 40.6 & 66.8 & 3.4 \\
\hline Education related & 43.3 & 26.5 & 1.0 \\
\hline Work related & 9.2 & 1.9 & 0.3 \\
\hline Economic distress of the family & 7.0 & 4.8 & 1.5 \\
\hline Number of respondents who experienced migration & 281 & 377 & 1,224 \\
\hline \multicolumn{4}{|l|}{ Respondent's involvement in migration-related decision } \\
\hline Own volition & 82.3 & 56.9 & $(57.3)$ \\
\hline Forced by others & 0.9 & 2.8 & $(13.9)$ \\
\hline Advised by others & 16.8 & 40.3 & $(28.8)$ \\
\hline $\begin{array}{l}\text { Number of respondents who migrated for reasons oth } \\
\text { migration or marriage }\end{array}$ & 167 & 124 & 29 \\
\hline \multicolumn{4}{|c|}{ Rural (percent) } \\
\hline Migrated to the current usual place of residence & 15.7 & 8.8 & 86.9 \\
\hline Number of respondents & 813 & 1,690 & 2,042 \\
\hline \multicolumn{4}{|l|}{ Reasons for migration } \\
\hline Marriage & NA & NA & 97.5 \\
\hline Moved with family & 22.5 & 52.2 & 0.9 \\
\hline Education related & 32.5 & 29.4 & 0.2 \\
\hline Work related & 22.9 & 3.9 & 0.2 \\
\hline Economic distress of the family & 18.7 & 14.5 & 1.0 \\
\hline Number of respondents who experienced migration & 123 & 164 & 1,792 \\
\hline \multicolumn{4}{|l|}{ Respondent's involvement in migration-related decision } \\
\hline Own volition & 83.4 & 46.0 & $(51.9)$ \\
\hline Forced by others & 4.8 & 3.6 & $(9.6)$ \\
\hline Advised by others & 11.8 & 50.5 & $(38.5)$ \\
\hline $\begin{array}{l}\text { Number of respondents who migrated for reasons oth } \\
\text { migration or marriage }\end{array}$ & 97 & 78 & 31 \\
\hline
\end{tabular}

Notes: All Ns are unweighted. () Based on 25-49 unweighted cases. 
Among those who had migrated for reasons other than family or marriage-related migration, we probed adolescents' own involvement in migration-related decisions. Findings show that the majority of adolescents, particularly boys, had migrated of their own accord-83 percent of boys and 48 percent of unmarried girls who had migrated for reasons other than family migration or marriage. The remaining 17 percent of boys and 52 percent of unmarried girls reported that they were forced or advised to do so. Among married girls who had migrated for reasons other than family migration or marriage, 53 percent reported that they had migrated of their own accord. There were notable differences between rural and urban areas among unmarried girls-more urban than rural girls had migrated voluntarily (57\% versus $46 \%)$.

\section{Table 4.15: Adolescents' perceived interest in migrating outside the state}

Percent distribution of adolescents in ages $15-19$ by their preferences to stay in their own state or elsewhere, according to residence, Bihar, 2016

\begin{tabular}{|c|c|c|c|}
\hline Preferences & $\begin{array}{c}\text { Boys } \\
(15-19)\end{array}$ & $\begin{array}{c}\text { Girls } \\
(15-19)\end{array}$ & $\begin{array}{l}\text { Married girls } \\
(15-19)\end{array}$ \\
\hline \multicolumn{4}{|c|}{ Combined (percent) } \\
\hline Stay in his/her own state & 88.5 & 75.4 & 78.6 \\
\hline Go elsewhere & 9.4 & 13.6 & 5.8 \\
\hline Not sure & 2.1 & 11.0 & 15.6 \\
\hline Number of respondents & 1,821 & 3,428 & 3,408 \\
\hline \multicolumn{4}{|c|}{ Urban (percent) } \\
\hline Stay in his/her own state & 85.0 & 72.9 & 75.4 \\
\hline Go elsewhere & 13.6 & 20.2 & 6.9 \\
\hline Not sure & 1.4 & 6.8 & 17.7 \\
\hline Number of respondents & 1,008 & 1,738 & 1,366 \\
\hline \multicolumn{4}{|c|}{ Rural (percent) } \\
\hline Stay in his/her own state & 88.9 & 75.6 & 79.0 \\
\hline Go elsewhere & 8.8 & 12.8 & 5.6 \\
\hline Not sure & 2.2 & 11.5 & 15.4 \\
\hline Number of respondents & 813 & 1,690 & 2,042 \\
\hline
\end{tabular}

Note: All Ns are unweighted.

We also asked all adolescents in ages 15-19 whether they would prefer to stay in their state or go elsewhere if they were able to pursue their dreams/earn well. Findings show that the vast majority preferred to stay in their state, given a choice-89 percent of boys and 75-79 percent of girls (Table 4.15). Just 6-14 percent preferred to migrate outside their state, while the remaining were unsure about it. Differences between those from rural and those from urban areas were mild. 


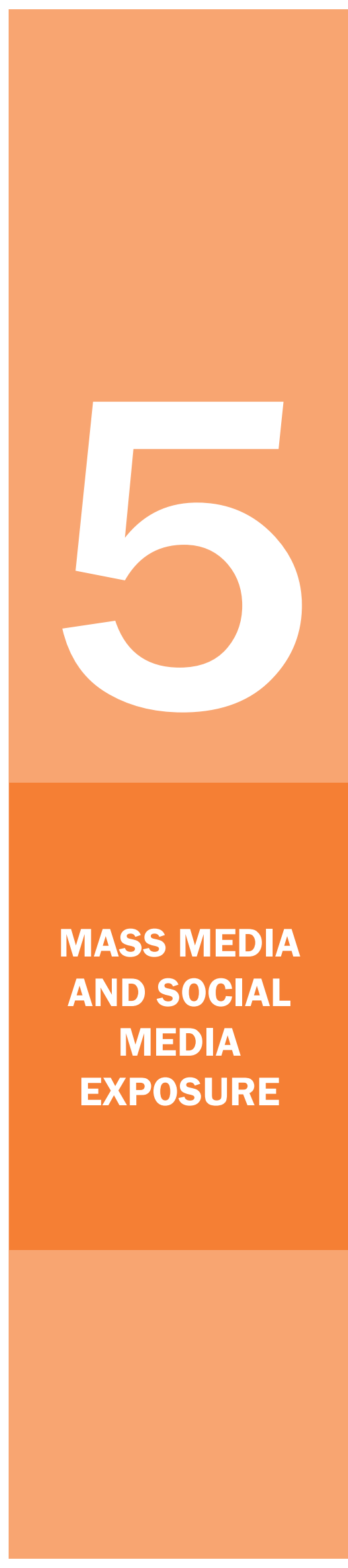

\section{A Snapshot}

Exposure to the mass media is widespread:

- $83 \%$ of younger boys

- $86 \%$ of older boys

- $77 \%$ of younger girls

- $74 \%$ of unmarried older girls

- $61 \%$ of married older girls were exposed to television
- $26 \%$ of younger boys

- $32 \%$ of older boys

- $12 \%$ of younger girls

- $13 \%$ of unmarried older girls

- $10 \%$ of married older girls were exposed to radio programmes

Among adolescents with five or more years of schooling:

- $62 \%$ of younger boys

- $81 \%$ of older boys

- $54 \%$ of younger girls

- $66 \%$ of unmarried older girls

- $41 \%$ of married older girls were exposed to print media

The reach of mobile phones is extensive:

- $10 \%$ of younger boys

- $55 \%$ of older boys

- less than $1 \%$ of younger girls

- $7 \%$ of unmarried older girls

- $37 \%$ of married older girls owned a mobile phone
- $66 \%$ of younger boys

- $37 \%$ of older boys

- $83 \%$ of younger girls

- $85 \%$ of unmarried older girls

- $60 \%$ of married older girls did not own a phone but could use a family member's phone

Mobile phones are an important source of entertainment-of those who have access to mobile phones:

- $55 \%$ of younger boys

- $69 \%$ of older boys

- $42 \%$ of younger girls

- $52 \%$ of unmarried older girls

- $68 \%$ of married older girls watched films on mobile phones

POPULATION COUNCIL

Ideas. Evidence. Impact.

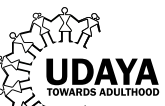

UDAYA 


\section{A Snapshot}

Penetration of internet and social media is limited, except among older boys:

Among those with five or more years of schooling

- $13 \%$ of younger boys

- $39 \%$ of older boys

- $1 \%$ of younger girls

- $7 \%$ of unmarried older girls

- $4 \%$ of married older girls had ever accessed the internet
Among those with five or more years of schooling

- $4 \%$ of younger boys

- $27 \%$ of older boys

- $1 \%$ of younger girls

- $5 \%$ of unmarried older girls

- $3 \%$ of married older girls had ever accessed social media
Parents and other family member's control adolescents' access to the internet-among those who had ever accessed the internet:

- $21 \%$ of younger boys

- $5 \%$ of older boys

- $26 \%$ of unmarried older girls

- $12 \%$ of married older girls required permission to do so
The internet is a source of health information for some-among adolescents who had ever accessed the internet:

- $11 \%$ of younger boys

- $13 \%$ of older boys

- $27 \%$ of unmarried older girls

- $21 \%$ of married older girls had accessed health information from the internet
Sex is not an unmentionable topic:

- $46 \%$ of older boys

- $6 \%$ of unmarried older girls

- $31 \%$ of married older girls were exposed to pornographic materials
Cyber bullying is rare but not unknown:

- Less than 1\% of younger boys

- $2 \%$ of older boys

- $2 \%$ of younger girls

- $7 \%$ of unmarried older girls

- $9 \%$ of married older girls had experienced harassment over mobile phones or the internet

Access to information and communication technology is gendered-girls are less likely than boys to be exposed to the mass media, the internet and social media and to own mobile phones

The rural disadvantage in access to information and communication technology is apparent 
Adolescents today grow up in a world that is increasingly penetrated by mass media and social media, and exposure to these communication channels plays an important role in shaping their attitudes and behaviours. Adolescents gain access to new information through a variety of sources, including print and visual media and, increasingly, mobile phones and the internet. Many are also exposed to pornography through these channels. This survey probed study participants' exposure to mass media and social media, their use of mobile phones, and the extent of their exposure to pornographic materials by way of films and the internet. The study also sought information from participants about their experiences and perpetration of harassment through mobile phones and the internet.

\subsection{Mass media exposure}

A number of questions in the survey elicited information on whether and how frequently adolescents read newspapers, magazines, or books, watched television programmes, watched films, and listened to the radio. Interviewers asked questions regarding exposure to print media to only those who had completed at least five years of education, since this was considered a prerequisite for their ability to read and understand different forms of print media. They also asked adolescents to indicate the frequency of their exposure to each medium. ${ }^{1}$

Findings, presented in Table 5.1, indicate that adolescents were exposed to a variety of media and that they were the most likely to be exposed to television and films and the least likely to be exposed to the radio. They also suggest that differences by sex were wide, with more boys than girls reporting exposure to each medium. Exposure to television and films (including films on television) was reported by 83-91 percent of boys and 61-82 percent of girls. In contrast, exposure to radio was reported by 26-32 percent of boys and 10-13 percent of girls. Among those who had completed five or more years of education, 62-81 percent of boys and 41-66 percent of girls were exposed to print media.

While differences by age were observed among boys, with more of older than younger boys reporting exposure to most media, except television, the differences among girls were modest for the most part, except with respect to print medium exposure. Specifically, 91 percent of older boys compared with 83 percent of younger boys were ever exposed to films; the corresponding proportions with respect to exposure to radio were 32 percent and 26 percent and with respect to print media were 81 percent and 62 percent. Among girls, 66 percent of unmarried older girls compared with 54 percent of younger girls reported exposure to print media. Differences by marital status among older girls were marked with respect to exposure to television, film and print media, with a larger proportion of unmarried older girls than married older girls reporting ever exposure to these media ( $74 \%$ versus $61 \%$ for television, $82 \%$ versus $76 \%$ for films and $66 \%$ versus $44 \%$ for print media).

Differences among adolescents in their exposure to the mass media by their residence in rural or urban areas varied by the type of medium. Across all categories of adolescents, urban adolescents were more likely than their rural counterparts to report exposure to television ( $96-97 \%$ versus $81-85 \%$ among boys and $85-94 \%$ versus $58-75 \%$ among girls), exposure to films, except among younger boys, (97\% versus $90 \%$ among older boys and $89-94 \%$ versus 74-80\% among girls), and exposure to print media among those who had completed five or more years of schooling ( $75-91 \%$ versus $60-79 \%$ among boys and $57-85 \%$ versus $39-64 \%$ among girls). Differences were narrow with respect to exposure to radio.

Fewer adolescents reported frequent exposure to the mass media as defined by daily or weekly exposure. Specifically, 50 percent of boys and 28-44 percent of girls watched television frequently, and 49-55 percent of boys and 34-41 percent of girls watched films frequently. Fewer listened to the radio frequently ( $7-11 \%$ of boys and $3-4 \%$ of girls) or read newspapers, magazines, and other print materials frequently (34-51\% of boys and $8-23 \%$ of girls who had completed Class 5 or above). As seen above, boys were more likely than girls to report frequent exposure to television, films, and print media; however, no such differences were observed with respect to exposure to radio. Differences by age were marginal for the most part, except that younger boys were less likely than older boys to read printed materials frequently (34\% versus 51\%).

\footnotetext{
${ }^{1}$ Respondents were asked whether the frequency of their exposure was 'almost every day', 'at least once a week', 'at least once a month', 'rarely', or 'not at all'. If anyone did not respond in this format but rather as number of days per week, then those who had five or more days of exposure per week were considered to have had a frequency of 'almost every day' and those who had 1-4 days of exposure per week came under 'at least once a week'.
} 
Among girls in ages 15-19, we observed differences by marital status among those reporting frequent exposure to television, films and print media (but not to radio), with unmarried girls more likely than the married to report frequent exposure. Thus, 44 percent of unmarried older girls compared with 28 percent of married older girls watched television frequently, 41 percent of unmarried older girls compared with 34 percent of married older girls watched films frequently, and 23 percent of unmarried older girls compared with 8 percent of married older girls who had completed five or more years of schooling read print materials frequently. Urban adolescents across all categories were more likely than their rural counterparts to report frequent exposure to television, films, and print media; however, no such differences were observed with respect to frequent exposure to radio.

\section{Table 5.1: Mass media exposure}

Percentage of adolescents who were exposed to various mass media, according to residence, Bihar, 2016

\begin{tabular}{|c|c|c|c|c|c|}
\hline Indicators of exposure to the mass media & $\begin{array}{c}\text { Boys } \\
(10-14)\end{array}$ & $\begin{array}{c}\text { Boys } \\
(15-19)\end{array}$ & $\begin{array}{c}\text { Girls } \\
(10-14)\end{array}$ & $\begin{array}{c}\text { Girls } \\
(15-19)\end{array}$ & $\begin{array}{l}\text { Married girls } \\
\qquad(15-19)\end{array}$ \\
\hline \multicolumn{6}{|c|}{ Combined (percent) } \\
\hline \multicolumn{6}{|l|}{ Exposure to television } \\
\hline Exposed & 82.5 & 85.9 & 76.5 & 74.0 & 60.9 \\
\hline Frequently exposed & 50.0 & 49.9 & 43.8 & 44.2 & 27.9 \\
\hline \multicolumn{6}{|l|}{ Exposure to films } \\
\hline Exposed & 83.1 & 90.5 & 79.5 & 81.7 & 75.7 \\
\hline Frequently exposed & 48.8 & 55.1 & 36.8 & 40.5 & 34.2 \\
\hline \multicolumn{6}{|l|}{ Exposure to radio } \\
\hline Exposed & 25.9 & 32.0 & 11.6 & 13.1 & 9.8 \\
\hline Frequently exposed & 6.8 & 10.8 & 3.8 & 4.2 & 3.0 \\
\hline Number of respondents & 1,012 & 1,821 & 764 & 3,428 & 3,408 \\
\hline \multicolumn{6}{|l|}{ Exposure to newspapers/magazines/books ${ }^{1}$} \\
\hline Exposed & 61.9 & 80.5 & 54.3 & 66.1 & 41.2 \\
\hline Frequently exposed & 33.8 & 50.7 & 20.9 & 23.1 & 8.3 \\
\hline Number with 5 or more years of education & 656 & 1,699 & 468 & 3,078 & 2,156 \\
\hline \multicolumn{6}{|c|}{ Urban (percent) } \\
\hline \multicolumn{6}{|l|}{ Exposure to television } \\
\hline Exposed & 96.9 & 95.9 & 92.9 & 93.6 & 85.3 \\
\hline Frequently exposed & 89.5 & 82.2 & 81.4 & 83.3 & 67.8 \\
\hline \multicolumn{6}{|l|}{ Exposure to films } \\
\hline Exposed & 94.3 & 96.9 & 91.1 & 93.9 & 88.7 \\
\hline Frequently exposed & 78.8 & 74.2 & 59.6 & 62.0 & 59.3 \\
\hline \multicolumn{6}{|l|}{ Exposure to radio } \\
\hline Exposed & 23.5 & 26.3 & 11.6 & 17.0 & 9.2 \\
\hline Frequently exposed & 5.3 & 7.0 & 3.1 & 6.2 & 3.0 \\
\hline Number of respondents & 452 & 1,008 & 387 & 1,738 & 1,366 \\
\hline \multicolumn{6}{|l|}{ Exposure to newspapers/magazines/books ${ }^{1}$} \\
\hline Exposed & 74.8 & 91.2 & 74.2 & 84.9 & 57.2 \\
\hline Frequently exposed & 54.1 & 76.4 & 43.1 & 49.0 & 20.3 \\
\hline Number with 5 or more years of education & 271 & 931 & 238 & 1,590 & 918 \\
\hline
\end{tabular}


Table 5.1 Cont.

\begin{tabular}{|c|c|c|c|c|c|}
\hline Indicators of exposure to the mass media & $\begin{array}{c}\text { Boys } \\
(10-14)\end{array}$ & $\begin{array}{c}\text { Boys } \\
(15-19)\end{array}$ & $\begin{array}{c}\text { Girls } \\
(10-14)\end{array}$ & $\begin{array}{c}\text { Girls } \\
(15-19)\end{array}$ & $\begin{array}{l}\text { Married girls } \\
\qquad(15-19)\end{array}$ \\
\hline \multicolumn{6}{|c|}{ Rural (percent) } \\
\hline \multicolumn{6}{|l|}{ Exposure to television } \\
\hline Exposed & 80.8 & 84.6 & 74.5 & 71.7 & 58.1 \\
\hline Frequently exposed & 45.3 & 45.9 & 39.2 & 39.5 & 23.4 \\
\hline \multicolumn{6}{|l|}{ Exposure to films } \\
\hline Exposed & 81.7 & 89.7 & 78.1 & 80.2 & 74.3 \\
\hline Frequently exposed & 45.3 & 52.7 & 34.1 & 37.9 & 31.4 \\
\hline \multicolumn{6}{|l|}{ Exposure to radio } \\
\hline Exposed & 26.2 & 32.7 & 11.6 & 12.6 & 9.9 \\
\hline Frequently exposed & 7.1 & 11.3 & 3.9 & 4.0 & 3.0 \\
\hline Number of respondents & 560 & 813 & 377 & 1,690 & 2,042 \\
\hline \multicolumn{6}{|l|}{ Exposure to newspapers/magazines/books ${ }^{1}$} \\
\hline Exposed & 60.4 & 79.2 & 51.7 & 63.8 & 39.2 \\
\hline Frequently exposed & 31.5 & 47.5 & 18.1 & 19.9 & 6.7 \\
\hline Number with $\mathbf{5}$ or more years of education & 385 & 768 & 230 & 1,488 & 1,238 \\
\hline
\end{tabular}

Notes: All Ns are unweighted. ${ }^{1}$ Question asked only of respondents who had completed five or more years of education.

Table 5.2 describes differentials in frequent exposure to the mass media, as defined by daily or weekly exposure to television, film, radio, or print media, by selected background characteristics. On the whole, 67 percent of younger boys and 79 percent of older boys reported frequent exposure to the mass media, which 56 percent of younger girls and 43-58 percent of unmarried and married older girls also reported. More of urban than rural respondents reported frequent exposure to the mass media across all categories of adolescents.

Findings show that differences in frequent exposure to the mass media increased by age across all categories of adolescents, except for younger girls, and that differences were wide among younger boys and among unmarried and married older girls. Thus, 61 percent of 10-12-year-old boys compared with 79 percent of 13-14-year-old boys were exposed to the mass media frequently as were 56 percent of 15-17-year-old unmarried girls compared with 65 percent of 18-19-year-old unmarried girls and 37 percent of 15-17-year-old married girls compared with 45 percent of 18-19-year-old married girls.

Differences by religion were inconsistent: except among older boys, Hindu respondents were more likely than Muslim respondents to report frequent exposure to the mass media (68\% versus $61 \%$ among younger boys; $57 \%$ versus $52 \%$ among younger girls; $59 \%$ versus $51 \%$ among unmarried older girls; and $43 \%$ versus $38 \%$ among married older girls), while a reverse pattern was observed among older boys ( $78 \%$ versus $87 \%$ among older boys). Caste-wise differentials were observed across all categories of adolescents; adolescents belonging to general castes were more likely than those from other castes to report frequent exposure to the mass media.

Frequent mass media exposure increased with years of schooling completed across all categories of adolescents. It increased, for example, from 67 percent with no schooling to 93 percent with 12 or more years of schooling among older boys, and the corresponding proportions among unmarried older girls were 21 percent and 75 percent, and, among married older girls, they were 31 percent and 72 percent. Findings also highlight the isolation of those who were out of school-across all categories of adolescents, those currently in school were more likely than those out of school to report regular exposure to the mass media.

Differences between those engaged in paid work and those who were not varied-among older boys and younger girls and unmarried older girls, those who were working were less likely than those who were not to report frequent exposure to the mass media ( $76 \%$ versus $81 \%$ among older boys; $42 \%$ versus $57 \%$ among younger girls; and $45 \%$ versus $61 \%$ among unmarried older girls). A reverse pattern was observed for younger boys ( $72 \%$ versus $67 \%$ ), while 
the differences were narrow for married older girls. Frequent exposure to the mass media increased steadily with household economic status across all categories of adolescents. It also increased with years of schooling completed by respondents' mother.

Table 5.2: Frequent exposure to the mass media by selected background characteristics

Percentage of adolescents who were frequently exposed to the mass media by selected background characteristics, Bihar, 2016

\begin{tabular}{|c|c|c|c|c|c|}
\hline $\begin{array}{l}\text { Background characteristics }{ }^{1} \\
\text { (percent) }\end{array}$ & $\begin{array}{c}\text { Boys } \\
(10-14)\end{array}$ & $\begin{array}{c}\text { Boys } \\
(15-19)\end{array}$ & $\begin{array}{c}\text { Girls } \\
(10-14)\end{array}$ & $\begin{array}{c}\text { Girls } \\
(15-19)\end{array}$ & $\begin{array}{l}\text { Married girls } \\
\text { (15-19) }\end{array}$ \\
\hline \multicolumn{6}{|l|}{ Age } \\
\hline $10-12$ & 60.7 & NA & 55.5 & NA & NA \\
\hline $13-14$ & 79.0 & NA & 56.2 & NA & NA \\
\hline $15-17$ & NA & 78.0 & NA & 55.9 & 36.9 \\
\hline $18-19$ & NA & 83.0 & NA & 65.2 & 45.4 \\
\hline \multicolumn{6}{|l|}{ Religion $^{2}$} \\
\hline Hindu & 68.3 & 78.0 & 56.5 & 59.1 & 43.1 \\
\hline Muslim & 60.7 & 87.2 & 51.9 & 50.7 & 37.9 \\
\hline \multicolumn{6}{|l|}{ Caste $^{3}$} \\
\hline SC & 64.2 & 78.2 & 60.9 & 54.2 & 42.8 \\
\hline $\mathrm{OBC}$ & 65.3 & 78.3 & 51.1 & 54.3 & 40.9 \\
\hline General $^{4}$ & 82.8 & 89.8 & 75.2 & 78.8 & 56.1 \\
\hline \multicolumn{6}{|l|}{ Completed years of schooling } \\
\hline None $^{5}$ & * & 67.1 & $(45.1)$ & 20.7 & 31.1 \\
\hline $1-4$ & 63.0 & 56.1 & 55.1 & 36.2 & 31.3 \\
\hline $5-7$ & 66.6 & 68.3 & 51.1 & 47.8 & 36.3 \\
\hline $8-9$ & 82.6 & 80.3 & 79.0 & 63.7 & 46.8 \\
\hline $10-11$ & NA & 84.2 & NA & 65.2 & 55.1 \\
\hline 12 and above & NA & 93.4 & NA & 75.2 & 71.5 \\
\hline \multicolumn{6}{|l|}{ Current schooling status $^{6}$} \\
\hline Yes & 69.1 & 81.3 & 58.1 & 64.5 & 58.2 \\
\hline No & $(47.6)$ & 73.9 & $(25.6)$ & 51.0 & 43.3 \\
\hline \multicolumn{6}{|c|}{ Paid work in the 12 months prior to the interview } \\
\hline Yes & 71.8 & 75.7 & 42.0 & 44.9 & 40.7 \\
\hline No & 67.0 & 80.6 & 57.0 & 60.6 & 42.7 \\
\hline \multicolumn{6}{|l|}{ Wealth quintile } \\
\hline First & 45.7 & 67.3 & 32.0 & 28.5 & 19.1 \\
\hline Second & 51.3 & 64.7 & 39.4 & 33.4 & 26.5 \\
\hline Third & 63.5 & 77.6 & 48.9 & 46.6 & 36.6 \\
\hline Fourth & 79.2 & 79.6 & 61.3 & 63.0 & 47.8 \\
\hline Fifth & 90.3 & 94.0 & 86.6 & 85.4 & 76.1 \\
\hline
\end{tabular}


Table 5.2 Cont.

\begin{tabular}{|c|c|c|c|c|c|}
\hline $\begin{array}{l}\text { Background characteristics }{ }^{1} \\
\text { (percent) }\end{array}$ & $\begin{array}{c}\text { Boys } \\
(10-14)\end{array}$ & $\begin{array}{c}\text { Boys } \\
(15-19)\end{array}$ & $\begin{array}{c}\text { Girls } \\
(10-14)\end{array}$ & $\begin{array}{c}\text { Girls } \\
(15-19)\end{array}$ & $\begin{array}{l}\text { Married girls } \\
\text { (15-19) }\end{array}$ \\
\hline \multicolumn{6}{|c|}{ Mother's education (in years of schooling completed) } \\
\hline None $^{5}$ & 64.0 & 77.5 & 50.3 & 51.1 & 39.7 \\
\hline $1-7$ & 73.8 & 80.1 & 65.5 & 77.0 & 48.6 \\
\hline $8-9$ & 89.6 & 82.8 & 82.4 & 67.4 & 59.3 \\
\hline 10 and above & 76.0 & 92.2 & 84.2 & 82.0 & 66.4 \\
\hline \multicolumn{6}{|l|}{ Place of residence } \\
\hline Urban & 93.9 & 94.6 & 85.2 & 88.4 & 74.5 \\
\hline Rural & 64.1 & 77.4 & 52.2 & 54.3 & 38.9 \\
\hline Total & 67.3 & 79.3 & 55.8 & 58.0 & 42.5 \\
\hline
\end{tabular}

Notes: *Percentage not shown as this was based on fewer than 25 unweighted cases. () Based on 25-49 unweighted cases. NA: not applicable; OBC: other backward caste; SC: scheduled caste; ST: scheduled tribe. ${ }^{1}$ Questions on exposure to newspapers/magazines/story books/ novels were asked of only those who had completed five or more years of education. ${ }^{2}$ Percentages not shown for those belonging to other religions as less than one percent of surveyed adolescents belonged to other religions. ${ }^{3}$ Percentages not shown for those belonging to STs as less than one percent of surveyed adolescents belonged to STs. ${ }^{4}$ Includes all those not belonging to SCs, STs, or OBCs. ${ }^{5}$ Includes nonliterate and literate with no formal schooling. ${ }^{6}$ Percentages not shown for adolescents who were pursuing their education through distance education courses at the time of interview or those who never went to school.

\subsection{Access to mobile phones}

Interviewers asked study participants whether they owned a mobile phone and, if they did not, whether they had access to a family member's mobile phone. Additionally, they asked all those who owned or had access to a family member's mobile phone whether they had ever received any health information through the phone and whether they had ever watched films on the mobile phone.

Findings presented in Figure 5.1 reveal that the large majority of adolescents owned a mobile phone or had access to a family member's mobile phone. Ownership of a mobile phone varied by age and sex and by marital status among older girls. Older adolescents were more likely than younger adolescents to own a mobile phone ( $55 \%$ of older boys versus $10 \%$ of younger boys; $7-37 \%$ of older girls versus less than $1 \%$ of younger girls). As seen above, differences by sex were notable, with boys more likely than girls to own a mobile phone. Among girls in ages 15-19, married girls were more likely than unmarried girls to own a mobile phone (37\% versus $7 \%$ ). Ownership of a mobile phone differed by residence in rural or urban areas among older boys and among unmarried older girls, with urban adolescents more likely than their rural counterparts to own a phone ( $71 \%$ versus $53 \%$ among older boys and $18 \%$ versus $6 \%$ among unmarried older girls). However, no such differences were observed among younger adolescents or married older girls. Some 66 percent and 37 percent of younger and older boys, respectively, reported that they did not own a phone but could use a family member's phone. Among the three categories of girls, 60-85 percent reported access to a family member's phone.

On the whole,76-91 percent of boys and 83-97 percent of girls owned or had access to a family member's mobile phone. Ownership of a mobile phone or access to a family member's mobile phone was more likely to be reported by older adolescents than younger adolescents. Differences by age among boys and girls and by marital status among older girls were modest. However, differences between those from rural and those from urban areas were moderate, except for younger boys, among whom more urban than rural respondents reported access to a mobile phone (83\% versus $75 \%)$. 
Figure 5.1: Percentage of adolescents who owned or who could access a family member's mobile phone, according to residence, Bihar, 2016

$$
\text { Combined Urban Rural }
$$

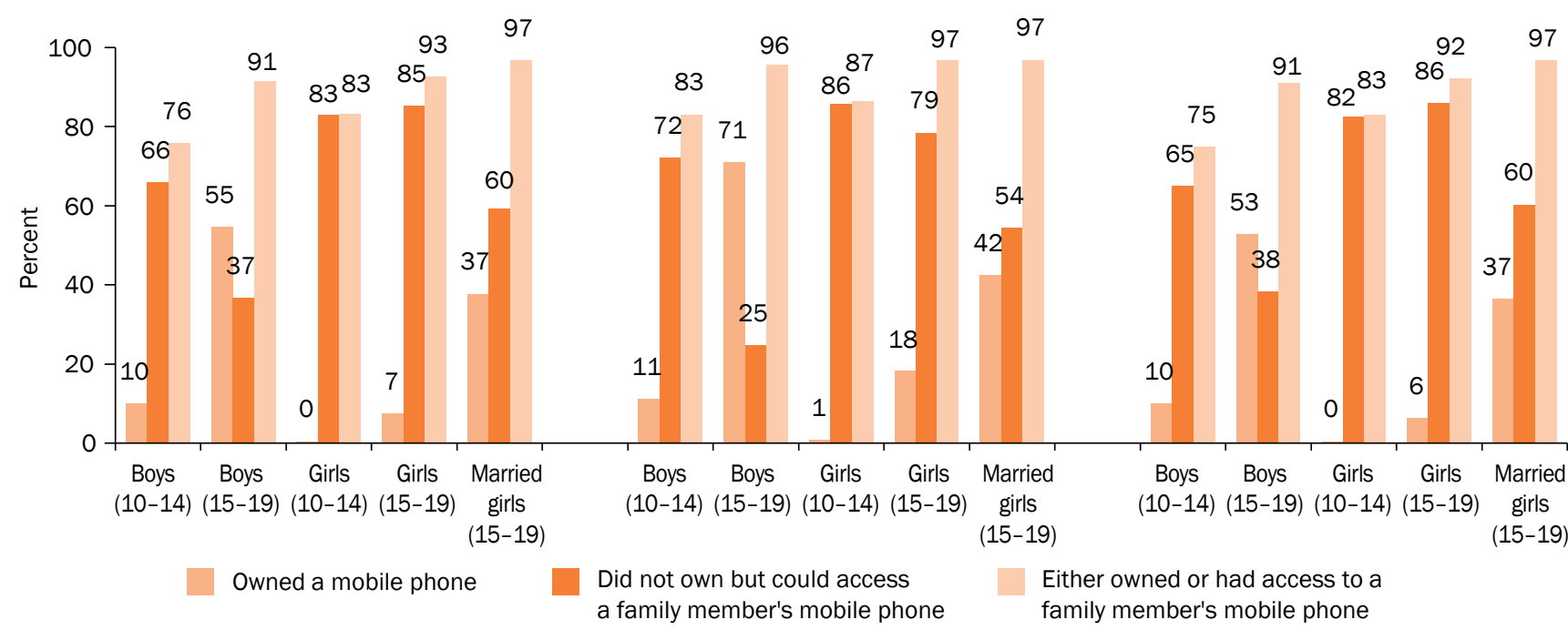

Table 5.3 depicts the differentials in ownership of mobile phones among only older adolescents by selected background characteristics. Findings show that a larger proportion of boys and girls in ages 18-19 owned a mobile phone compared with those images 15-17 (80\% versus 45\% among boys; $15 \%$ versus 5\% among unmarried girls; and 39\% versus 33\% among married girls). Differences by religion were modest, but caste-wise differences show that adolescents belonging to general castes were more likely than those from other castes to own a mobile phone. Differences by educational attainment show that those who had completed 12 or more years of schooling were more likely than those with lower levels of education to own a mobile phone (92\% versus 39-69\% among boys; $19 \%$ versus 4-10\% among unmarried girls; and 51\% versus 27-45\% among married girls). Ownership of mobile phones differed by current schooling status among boys (but not among girls)-out-of-school boys were more likely than boys in school to own a mobile phone (64\% versus 52\%). Boys who were engaged in paid work were more likely than those who were not to possess a phone (67\% versus 50\%), but a reverse pattern was observed among married girls (28\% versus $38 \%$ ), and no difference was evident among unmarried girls. The ownership of mobile phones increased steadily with household wealth status among boys and girls. Finally, a larger proportion of boys and unmarried girls whose mother had completed 10 or more years of schooling owned a mobile phone compared with those whose mother had less than 10 years of schooling, while the differences in this regard were uneven among married girls.

Notable proportions of adolescents who had access to mobile phones had watched films on these phones-55-69 percent of boys and 42-68 percent of girls so reported (Table 5.4). Findings also show that younger adolescents were less likely than older adolescents to have watched films on a mobile phone (55\% versus $69 \%$ among boys and $42 \%$ versus 52-68\% among girls). They further indicate that boys were more likely than girls to have watched films on their mobile phones (55\% of younger boys versus $42 \%$ of younger girls and $69 \%$ of older boys versus $52 \%$ of unmarried older girls). Among older girls, the married were more likely than the unmarried to have done so (68\% versus $52 \%$ ). Finally, rural adolescents were more likely than urban adolescents to have watched films on a mobile phone, perhaps, because of their more limited access to television (as seen in Chapter 2: among rural households, 17\% owned a television compared with $66 \%$ of urban households) and theatres. In contrast, a very small proportion of adolescents (5\% or less) reported that they had received health information through them, with little differences between those from rural and those from urban areas in this regard. 
Table 5.3: Ownership of mobile phones by selected background characteristics

Percentage of adolescents in ages 15-19 who owned a mobile phone by selected background characteristics, Bihar, 2016

\begin{tabular}{|c|c|c|c|}
\hline Background characteristics (percent) & $\begin{array}{c}\text { Boys } \\
(15-19)\end{array}$ & $\begin{array}{c}\text { Girls } \\
(15-19)\end{array}$ & $\begin{array}{c}\text { Married girls } \\
\text { (15-19) }\end{array}$ \\
\hline \multicolumn{4}{|l|}{ Age } \\
\hline $15-17$ & 45.4 & 5.3 & 33.4 \\
\hline $18-19$ & 80.4 & 15.1 & 39.0 \\
\hline \multicolumn{4}{|l|}{ Religion $^{1}$} \\
\hline Hindu & 55.4 & 7.0 & 36.7 \\
\hline Muslim & 50.4 & 9.5 & 40.7 \\
\hline \multicolumn{4}{|l|}{ Caste $^{2}$} \\
\hline SC & 51.8 & 4.4 & 29.3 \\
\hline OBC & 52.5 & 7.0 & 38.8 \\
\hline General $^{3}$ & 68.5 & 13.4 & 51.3 \\
\hline \multicolumn{4}{|l|}{ Completed years of schooling } \\
\hline None $^{4}$ & 65.3 & 4.0 & 26.7 \\
\hline $1-4$ & 41.7 & 4.4 & 29.2 \\
\hline $5-7$ & 39.2 & 4.1 & 43.8 \\
\hline $8-9$ & 46.4 & 5.3 & 38.0 \\
\hline $10-11$ & 69.1 & 10.3 & 45.1 \\
\hline 12 and above & 91.7 & 19.2 & 51.1 \\
\hline \multicolumn{4}{|l|}{ Current schooling status ${ }^{5}$} \\
\hline Yes & 52.0 & 7.3 & 41.8 \\
\hline No & 63.8 & 8.2 & 40.8 \\
\hline \multicolumn{4}{|c|}{ Paid work in the 12 months prior to the interview } \\
\hline Yes & 67.3 & 9.8 & 28.2 \\
\hline No & 50.4 & 7.0 & 38.3 \\
\hline \multicolumn{4}{|l|}{ Wealth quintile } \\
\hline First & 39.8 & 3.8 & 29.0 \\
\hline Second & 53.6 & 4.3 & 32.8 \\
\hline Third & 53.9 & 5.9 & 34.3 \\
\hline Fourth & 50.3 & 5.9 & 41.9 \\
\hline Fifth & 65.1 & 13.0 & 44.3 \\
\hline \multicolumn{4}{|c|}{ Mother's education (in years of schooling completed) } \\
\hline None $^{4}$ & 53.8 & 5.9 & 34.8 \\
\hline $1-7$ & 50.7 & 6.3 & 53.7 \\
\hline $8-9$ & 49.2 & 10.2 & 35.7 \\
\hline 10 and above & 71.3 & 17.2 & 49.9 \\
\hline Total & 54.7 & 7.4 & 37.1 \\
\hline
\end{tabular}

Notes: NA: not applicable; OBC: other backward caste; SC: scheduled caste; ST: scheduled tribe. ${ }^{1}$ Percentages not shown for those belonging to

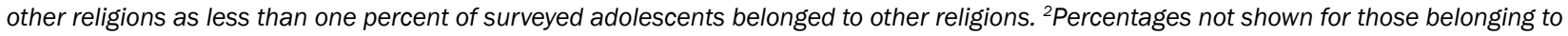
STs as less than one percent of surveyed adolescents belonged to STs. ${ }^{3}$ Includes all those not belonging to SCs, STs, or OBCs. ${ }^{4}$ Includes nonliterate and literate with no formal schooling. ${ }^{5}$ Percentages not shown for adolescents who were pursuing their education through distance education courses at the time of interview or those who never went to school. 


\section{Table 5.4: Use of mobile phones for entertainment and information}

Percentage of adolescents with access to mobile phones reporting that they had watched films and accessed health information on mobile phones, according to residence, Bihar, 2016

\begin{tabular}{|c|c|c|c|c|c|}
\hline Indicators of mobile phone use & $\begin{array}{c}\text { Boys } \\
(10-14)\end{array}$ & $\begin{array}{c}\text { Boys } \\
(15-19)\end{array}$ & $\begin{array}{c}\text { Girls } \\
(10-14)\end{array}$ & $\begin{array}{c}\text { Girls } \\
(15-19)\end{array}$ & $\begin{array}{c}\text { Married girls } \\
(15-19)\end{array}$ \\
\hline \multicolumn{6}{|c|}{ Combined (percent) } \\
\hline \multicolumn{6}{|c|}{$\begin{array}{l}\text { Use of mobile phones for watching films and accessing health } \\
\text { information }\end{array}$} \\
\hline Watched films & 55.0 & 69.2 & 42.3 & 52.2 & 68.4 \\
\hline Received health information & 1.5 & 5.2 & 0.3 & 2.8 & 4.6 \\
\hline Number having access to mobile phones & 798 & 1,708 & 630 & 3,238 & 3,276 \\
\hline \multicolumn{6}{|c|}{ Urban (percent) } \\
\hline \multicolumn{6}{|c|}{$\begin{array}{l}\text { Use of mobile phones for watching films and accessing health } \\
\text { information }\end{array}$} \\
\hline Watched films & 25.8 & 47.8 & 21.0 & 29.2 & 41.3 \\
\hline Received health information & 4.0 & 7.3 & 2.6 & 6.6 & 5.3 \\
\hline Number having access to mobile phones & 374 & 963 & 330 & 1,673 & 1,311 \\
\hline \multicolumn{6}{|c|}{ Rural (percent) } \\
\hline \multicolumn{6}{|c|}{$\begin{array}{l}\text { Use of mobile phones for watching films and accessing health } \\
\text { information }\end{array}$} \\
\hline Watched films & 59.2 & 72.2 & 45.4 & 55.5 & 72.1 \\
\hline Received health information & 1.1 & 5.0 & 0.0 & 2.4 & 4.5 \\
\hline Number having access to mobile phones & 424 & 745 & 300 & 1,565 & 1,965 \\
\hline
\end{tabular}

Note: All Ns are unweighted.

\subsection{Access to internet and social media}

We included a number of questions about adolescents' access to the internet, the frequency with which they accessed the internet, and their exposure to and use of social media, including Facebook, Twitter, WhatsApp, WeChat, and other social media. Additionally, we asked adolescents who had ever accessed the internet whether they needed permission from their parents or guardians to use the internet and whether they had accessed health information from it. It is to be noted that we restricted the related analyses to those who had completed at least five years of education, since this was considered a prerequisite for their ability to gain access to the internet.

Table 5.5 presents findings on adolescents' access to the internet and to social media. Findings confirm that the penetration of internet and social media among adolescents was very limited, except among older boys. While as many as 39 percent of older boys had ever accessed the internet, far fewer younger boys (13\%) and only 1-7 percent of adolescent girls had done so. More of older adolescents than younger adolescents (39\% versus 13\% among boys and $4-7 \%$ versus $1 \%$ among girls) and more of boys than girls (13\% versus $1 \%$ among younger adolescents and $39 \%$ versus 4-7\% among older adolescents) had accessed the internet. As expected, there were wide differences between urban and rural adolescents; a larger proportion of urban than rural adolescents reported access to the internet (32\% versus $11 \%$ of younger boys; $71 \%$ versus 35\% of older boys; $9 \%$ versus none of younger girls; and $11-27 \%$ versus $3-4 \%$ of unmarried and married older girls).

Even fewer adolescents reported frequent exposure as defined by daily or weekly exposure to the internet-five percent of younger boys, 20 percent of older boys, and three percent or less among younger girls and unmarried and married older girls. As with any exposure to the internet, a larger proportion of urban than rural adolescents reported frequent exposure to the internet. 
Very few adolescents, except older boys, had ever accessed social media-27 percent of older boys and 1-4 percent of adolescents in the remaining four categories. As expected, a larger proportion of urban than rural adolescents had ever accessed social media. Frequent exposure to social media (once a day to at least once a week), similarly, was limited-18 percent of older boys and two percent of adolescents or less in the remaining four categories.

Many younger boys (21\%) and unmarried older girls (26\%) reported that they required the permission of their parents or other elders in the family to access the internet. In comparison, fewer older boys (5\%) and married older girls (12\%) required such permission. As seen above, girls were more likely than boys to require permission to access the internet as were unmarried older girls more likely than married older girls ( $26 \%$ versus $12 \%$ ) to do so. Differences between those from rural and those from urban areas with respect to permission to access the internet were modest, except for younger boys, among whom more urban than rural boys required permission.

Among adolescents who had ever accessed the internet, 11-13 percent of boys and 21-27 percent of unmarried and married older girls reported that they had accessed health information from the internet. More of urban than rural respondents, except younger boys, had done so.

\section{Table 5.5: Access to internet and social media}

Percent distribution of adolescents who had completed five or more years of education by frequency of accessing the internet and social media, percentage of adolescents requiring permission to access the internet, and percentage of adolescents who accessed health information from the internet, according to residence, Bihar, 2016

\begin{tabular}{|c|c|c|c|c|c|}
\hline Indicators of access to the internet & $\begin{array}{c}\text { Boys } \\
(10-14)\end{array}$ & $\begin{array}{c}\text { Boys } \\
(15-19)\end{array}$ & $\begin{array}{c}\text { Girls } \\
(10-14)\end{array}$ & $\begin{array}{c}\text { Girls } \\
(15-19)\end{array}$ & $\begin{array}{l}\text { Married girls } \\
\text { (15-19) }\end{array}$ \\
\hline \multicolumn{6}{|c|}{ Combined (percent) } \\
\hline \multicolumn{6}{|l|}{ Frequency of accessing the internet } \\
\hline Almost every day & 1.1 & 8.8 & 0.1 & 1.6 & 0.7 \\
\hline At least once a week & 3.6 & 11.4 & 0.1 & 1.1 & 1.0 \\
\hline At least once a month & 1.9 & 5.4 & 0.2 & 0.8 & 0.4 \\
\hline Rarely & 6.4 & 13.1 & 0.6 & 3.2 & 2.2 \\
\hline Not at all/not heard of the internet & 87.1 & 61.3 & 99.0 & 93.4 & 95.7 \\
\hline \multicolumn{6}{|l|}{ Frequency of accessing social media ${ }^{1}$} \\
\hline Almost every day & 0.6 & 7.5 & 0.1 & 1.3 & 0.8 \\
\hline At least once a week & 1.1 & 10.2 & 0.1 & 1.1 & 0.8 \\
\hline At least once a month & 0.6 & 5.7 & 0.1 & 0.6 & 0.4 \\
\hline Rarely & 1.4 & 3.3 & 0.3 & 1.5 & 0.6 \\
\hline Not at all/not heard of social media & 96.4 & 73.3 & 99.4 & 95.5 & 97.3 \\
\hline Number with 5 or more years of education & 656 & 1,699 & 468 & 3,078 & 2,156 \\
\hline \multicolumn{6}{|c|}{$\begin{array}{l}\text { Permission required to access the internet and adolescents' } \\
\text { use of the internet to access health information }\end{array}$} \\
\hline Required permission to access the internet & 21.0 & 4.9 & * & 25.9 & 11.7 \\
\hline Accessed health information from the internet & 11.4 & 13.0 & * & 27.4 & 20.6 \\
\hline $\begin{array}{l}\text { Number with } 5 \text { or more years of education wh } \\
\text { accessed the internet }\end{array}$ & 127 & 949 & 22 & 469 & 123 \\
\hline
\end{tabular}


Table 5.5 Cont.

\begin{tabular}{|c|c|c|c|c|c|}
\hline Indicators of access to the internet & $\begin{array}{c}\text { Boys } \\
(10-14)\end{array}$ & $\begin{array}{l}\text { Boys } \\
(15-19)\end{array}$ & $\begin{array}{c}\text { Girls } \\
(10-14)\end{array}$ & $\begin{array}{c}\text { Girls } \\
(15-19)\end{array}$ & $\begin{array}{l}\text { Married girls } \\
(15-19)\end{array}$ \\
\hline \multicolumn{6}{|c|}{ Urban (percent) } \\
\hline \multicolumn{6}{|l|}{ Frequency of accessing the internet } \\
\hline Almost every day & 3.9 & 23.6 & 0.7 & 9.2 & 3.1 \\
\hline At least once a week & 11.7 & 24.4 & 1.0 & 6.0 & 3.3 \\
\hline At least once a month & 4.8 & 7.7 & 2.0 & 3.1 & 1.1 \\
\hline Rarely & 11.3 & 14.9 & 5.3 & 9.1 & 3.7 \\
\hline Not at all/not heard of the internet & 68.4 & 29.4 & 91.1 & 72.7 & 88.9 \\
\hline \multicolumn{6}{|l|}{ Frequency of accessing social media ${ }^{1}$} \\
\hline Almost every day & 2.7 & 22.0 & 0.8 & 7.9 & 3.2 \\
\hline At least once a week & 8.4 & 22.7 & 0.7 & 5.0 & 3.0 \\
\hline At least once a month & 2.8 & 8.1 & 1.1 & 3.0 & 1.3 \\
\hline Rarely & 2.4 & 4.8 & 2.5 & 4.1 & 1.4 \\
\hline Not at all/not heard of social media & 83.8 & 42.4 & 95.0 & 79.9 & 91.2 \\
\hline Number with $\mathbf{5}$ or more years of education & 271 & 931 & 238 & 1,590 & 918 \\
\hline \multicolumn{6}{|c|}{$\begin{array}{l}\text { Permission required to access the internet and adolescents' } \\
\text { use of the internet to access health information }\end{array}$} \\
\hline Required permission to access the internet & 39.6 & 7.2 & * & 26.7 & 9.7 \\
\hline Accessed health information from the internet & 9.6 & 24.6 & * & 37.7 & 31.4 \\
\hline $\begin{array}{l}\text { Number with } 5 \text { or more years of education wh } \\
\text { accessed the internet }\end{array}$ & 84 & 655 & 22 & 409 & 82 \\
\hline
\end{tabular}

Rural (percent)

\section{Frequency of accessing the internet}

Almost every day

At least once a week

At least once a month

Rarely

Not at all/not heard of the internet

Frequency of accessing social media ${ }^{1}$

Almost every day

At least once a week

At least once a month

Rarely

Not at all/not heard of social media

Number with $\mathbf{5}$ or more years of education

Permission required to access the internet and adolescents' use of the internet to access health information

Required permission to access the internet

Accessed health information from the internet

Number with 5 or more years of education who had ever accessed the internet

$\begin{array}{rrrrr}0.7 & 7.0 & 0.0 & 0.6 & 0.4 \\ 2.7 & 9.8 & 0.0 & 0.5 & 0.7 \\ 1.5 & 5.2 & 0.0 & 0.5 & 0.3 \\ 5.8 & 12.9 & 0.0 & 2.5 & 2.0 \\ 89.3 & 65.2 & 100.0 & 96.0 & 96.6\end{array}$

$\begin{array}{rrrrr}0.3 & 5.7 & 0.0 & 0.4 & 0.5 \\ 0.3 & 8.7 & 0.0 & 0.6 & 0.6 \\ 0.3 & 5.4 & 0.0 & 0.3 & 0.3 \\ 1.2 & 3.1 & 0.0 & 1.1 & 0.5 \\ 97.8 & 77.1 & 100.0 & 97.5 & 98.1 \\ \mathbf{3 8 5} & \mathbf{7 6 8} & \mathbf{2 3 0} & \mathbf{1 , 4 8 8} & \mathbf{1 , 2 3 8}\end{array}$

Notes: All Ns are unweighted. *Percentage not shown as this was based on fewer than 25 unweighted cases. () Based on 25-49 unweighted cases. ${ }^{1}$ Includes Facebook, Twitter, WhatsApp, WeChat, or other social media. 
Table 5.6 describes differentials in access to internet or social media among those who had completed five or more years of education by selected background characteristics. On the whole, 13 percent of younger boys and 39 percent of older boys reported access to internet or social media as did one percent of younger girls and 4-7 percent of unmarried and married older girls. More of urban than rural respondents reported access to internet or social media across all categories of adolescents.

Findings show that among younger boys, those in ages 13-14 were more likely than those in ages 10-12 to have accessed internet or social media (16\% versus 10\%); likewise, among older boys and unmarried older girls, 18-19 year olds were more likely than $15-17$ year olds to have done so (52\% versus $34 \%$ among older boys and $12 \%$ versus $5 \%$ among unmarried older girls). However, no such differences were observed among younger girls and married older girls. Differences by religion were narrow, except that Muslim younger boys were more likely than their Hindu counterparts to have accessed internet or social media (22\% versus $12 \%)$. Caste-wise differences were wide; adolescents belonging to general castes were more likely than those from other castes to have accessed the internet or social media across all categories of adolescents, except for younger girls. Access to internet or social media, not surprisingly, increased with years of schooling completed. Among younger boys, for example, the proportion accessing internet or social media increased from 11 percent among those with 5-7 years of schooling to 20 percent among those with 8-9 years of schooling; for unmarried and married older girls, the proportion increased from one percent among those with 5-7 years of schooling to 15-25 percent among those with 12 or more years of schooling, and for older boys, correspondingly, the proportion increased from 15 percent to 73 percent. Findings also show that access to internet or social media was the greatest among those who belonged to households in the wealthiest quintile and among those whose mother had completed 10 or more years of schooling. Finally, a larger proportion of urban than rural adolescents reported access to internet or social media.

\section{Table 5.6: Access to internet or social media by selected background characteristics}

Percentage of adolescents with five or more years of education who accessed internet or social media by selected background characteristics, Bihar, 2016

\begin{tabular}{|c|c|c|c|c|c|}
\hline Background characteristics (percent) & $\begin{array}{c}\text { Boys } \\
(10-14)\end{array}$ & $\begin{array}{c}\text { Boys } \\
\text { (15-19) }\end{array}$ & $\begin{array}{c}\text { Girls } \\
(10-14)\end{array}$ & $\begin{array}{c}\text { Girls } \\
(15-19)\end{array}$ & $\begin{array}{c}\text { Married girls } \\
\quad(15-19)\end{array}$ \\
\hline \multicolumn{6}{|l|}{ Age } \\
\hline $10-12$ & 9.7 & NA & 0.4 & NA & NA \\
\hline $13-14$ & 16.1 & NA & 1.5 & NA & NA \\
\hline $15-17$ & NA & 33.9 & NA & 5.1 & 3.4 \\
\hline $18-19$ & NA & 52.1 & NA & 11.7 & 4.7 \\
\hline \multicolumn{6}{|l|}{ Religion $^{1}$} \\
\hline Hindu & 11.5 & 38.6 & 1.1 & 6.4 & 3.8 \\
\hline Muslim & 21.5 & 39.5 & 0.2 & 8.1 & 8.2 \\
\hline \multicolumn{6}{|l|}{ Caste $^{2}$} \\
\hline SC & 7.6 & 35.0 & 0.2 & 3.7 & 4.7 \\
\hline OBC & 12.1 & 36.3 & 1.0 & 5.2 & 3.5 \\
\hline General $^{3}$ & 23.4 & 58.9 & 2.5 & 15.9 & 9.8 \\
\hline \multicolumn{6}{|l|}{ Completed years of schooling } \\
\hline $5-7$ & 10.6 & 15.4 & 0.7 & 0.7 & 0.8 \\
\hline $8-9$ & 20.0 & 32.5 & 2.2 & 3.2 & 2.3 \\
\hline $10-11$ & NA & 54.4 & NA & 8.9 & 5.6 \\
\hline 12 and above & NA & 73.3 & NA & 24.8 & 15.2 \\
\hline
\end{tabular}


Table 5.6 Cont.

\begin{tabular}{|c|c|c|c|c|c|}
\hline Background characteristics (percent) & $\begin{array}{c}\text { Boys } \\
(10-14)\end{array}$ & $\begin{array}{c}\text { Boys } \\
(15-19)\end{array}$ & $\begin{array}{c}\text { Girls } \\
(10-14)\end{array}$ & $\begin{array}{c}\text { Girls } \\
(15-19)\end{array}$ & $\begin{array}{l}\text { Married girls } \\
\text { (15-19) }\end{array}$ \\
\hline \multicolumn{6}{|l|}{ Current schooling status ${ }^{4}$} \\
\hline Yes & 12.9 & 39.2 & 1.1 & 7.2 & 5.7 \\
\hline No & * & 34.3 & * & 2.3 & 2.7 \\
\hline \multicolumn{6}{|c|}{ Paid work in the 12 months prior to the interview } \\
\hline Yes & $(10.0)$ & 37.2 & * & 6.6 & 5.2 \\
\hline No & 13.1 & 39.1 & 1.1 & 6.6 & 4.2 \\
\hline \multicolumn{6}{|l|}{ Wealth quintile } \\
\hline First & 11.3 & 24.3 & $(0.0)$ & 2.3 & 0.7 \\
\hline Second & 3.9 & 22.3 & 0.0 & 1.4 & 1.1 \\
\hline Third & 10.0 & 30.0 & 0.0 & 1.0 & 3.0 \\
\hline Fourth & 12.7 & 41.2 & 0.1 & 3.2 & 2.6 \\
\hline Fifth & 26.4 & 57.1 & 4.3 & 16.5 & 10.6 \\
\hline \multicolumn{6}{|c|}{ Mother's education (in years of schooling completed) } \\
\hline None $^{5}$ & 9.3 & 34.7 & 0.1 & 2.6 & 3.2 \\
\hline $1-7$ & 17.2 & 41.0 & 1.3 & 8.3 & 4.0 \\
\hline $8-9$ & 20.6 & 38.0 & (1.8) & 9.6 & 4.3 \\
\hline 10 and above & 32.3 & 70.3 & 9.0 & 27.0 & 17.1 \\
\hline \multicolumn{6}{|l|}{ Place of residence } \\
\hline Urban & 31.6 & 70.6 & 8.9 & 27.3 & 11.1 \\
\hline Rural & 10.7 & 34.8 & 0.0 & 4.0 & 3.4 \\
\hline Total & 12.9 & 38.7 & 1.0 & 6.6 & 4.3 \\
\hline
\end{tabular}

Notes: * Percentage not shown as this was based on fewer than 25 unweighted cases. () Based on 25-49 unweighted cases. NA: not applicable; OBC: other backward caste; SC: scheduled caste; ST: scheduled tribe. ${ }^{1}$ Percentages not shown for those belonging to other religions as less than one percent of surveyed adolescents belonged to other religions. ${ }^{2}$ Percentages not shown for those belonging to STs as less than one percent of surveyed adolescents belonged to STs. ${ }^{3}$ Includes all those not belonging to SCs, STs, or OBCs. ${ }^{4}$ Percentages not shown for adolescents who were pursuing their education through distance education courses at the time of interview or those who never went to school. ${ }^{5}$ Includes non-literate and literate with no formal schooling.

\subsection{Exposure to pornographic materials}

The survey elicited information from only older adolescents about their exposure to pornographic materials by way of films and the internet (for those who had accessed the internet) and the frequency of exposure. Table 5.7 shows that considerable proportions of boys and married girls and a small proportion of unmarried girls reported such exposure. Specifically, 42 percent of boys had watched 'blue' or pornographic films compared with four percent of unmarried girls and 31 percent of married girls, with little differences in reports between rural and urban adolescents. Among those who watched pornographic films, notable proportions of boys (34\%) and girls (24\%) reported that they watched pornographic films often or sometimes. Differences between rural and urban areas were modest in this regard.

Among the older adolescents exposed to the internet, 48 percent of boys, 32 percent of unmarried girls, and 49 percent of married girls had accessed pornographic materials on the internet; differences in reports of those from rural areas and those from urban areas were modest, except that more urban unmarried girls than their rural counterparts had done so (36\% versus $28 \%$ ). Among these older adolescents who had accessed pornographic materials on the internet, 45 percent of boys and 22-40 percent of girls accessed these materials often or sometimes. 


\section{Table 5.7: Exposure to pornographic materials}

Percentage of adolescents in ages 15-19 who were exposed to different pornographic materials, according to residence, Bihar, 2016

\begin{tabular}{|c|c|c|c|}
\hline Indicators of exposure to pornography & $\begin{array}{c}\text { Boys } \\
(15-19)\end{array}$ & $\begin{array}{c}\text { Girls } \\
(15-19)\end{array}$ & $\begin{array}{c}\text { Married girls } \\
(15-19)\end{array}$ \\
\hline \multicolumn{4}{|c|}{ Combined (percent) } \\
\hline Ever watched a 'blue'/pornographic film & 42.2 & 4.3 & 30.5 \\
\hline Number of respondents & 1,821 & 3,428 & 3,408 \\
\hline \multicolumn{4}{|l|}{ Frequency of watching 'blue'/pornographic films } \\
\hline Rarely & 66.1 & 76.1 & 75.7 \\
\hline Sometimes & 31.4 & 20.7 & 23.1 \\
\hline Often & 2.5 & 3.1 & 1.2 \\
\hline Number who ever watched 'blue'/pornographic films & 831 & 199 & 1,050 \\
\hline Ever accessed pornographic materials on the internet & 48.4 & 31.9 & 48.9 \\
\hline Number who ever accessed internet & 949 & 469 & 123 \\
\hline \multicolumn{4}{|l|}{ Frequency of accessing pornographic materials on the internet } \\
\hline Rarely & 55.3 & 78.1 & 60.1 \\
\hline Sometimes & 41.4 & 18.7 & 21.0 \\
\hline Often & 3.3 & 3.3 & 18.8 \\
\hline Number who ever accessed pornographic materials on the internet & 463 & 173 & 66 \\
\hline \multicolumn{4}{|c|}{ Urban (percent) } \\
\hline Ever watched a 'blue'/pornographic film & 45.9 & 7.1 & 35.9 \\
\hline Number of respondents & 1,008 & 1,738 & 1,366 \\
\hline \multicolumn{4}{|l|}{ Frequency of watching 'blue'/pornographic films } \\
\hline Rarely & 64.5 & 69.9 & 72.4 \\
\hline Sometimes & 33.0 & 25.4 & 25.8 \\
\hline Often & 2.5 & 4.7 & 1.8 \\
\hline Number who ever watched 'blue'/pornographic films & 475 & 127 & 475 \\
\hline Ever accessed pornographic materials on the internet & 49.8 & 36.0 & 48.8 \\
\hline Number who ever accessed internet & 655 & 409 & 82 \\
\hline \multicolumn{4}{|l|}{ Frequency of accessing pornographic materials on the internet } \\
\hline Rarely & 66.6 & 73.1 & $(72.7)$ \\
\hline Sometimes & 30.0 & 20.7 & $(16.8)$ \\
\hline Often & 3.4 & 6.2 & $(10.5)$ \\
\hline Number who ever accessed pornographic materials on the internet & 325 & 153 & 46 \\
\hline
\end{tabular}


Table 5.7 Cont.

\begin{tabular}{|c|c|c|c|}
\hline Indicators of exposure to pornography & $\begin{array}{c}\text { Boys } \\
(15-19)\end{array}$ & $\begin{array}{c}\text { Girls } \\
(15-19)\end{array}$ & $\begin{array}{l}\text { Married girls } \\
\qquad(15-19)\end{array}$ \\
\hline \multicolumn{4}{|c|}{ Rural (percent) } \\
\hline Ever watched a 'blue'/pornographic film & 41.7 & 4.0 & 29.8 \\
\hline Number of respondents & 813 & 1,690 & 2,042 \\
\hline \multicolumn{4}{|l|}{ Frequency of watching 'blue'/pornographic films } \\
\hline Rarely & 66.3 & 77.5 & 76.2 \\
\hline Sometimes & 31.2 & 19.7 & 22.7 \\
\hline Often & 2.5 & 2.8 & 1.1 \\
\hline Number who ever watched 'blue'/pornographic films & 356 & 72 & 575 \\
\hline Ever accessed pornographic materials on the internet & 48.0 & 28.4 & $(48.9)$ \\
\hline Number who ever accessed internet & 294 & 60 & 41 \\
\hline \multicolumn{4}{|l|}{ Frequency of accessing pornographic materials on the internet } \\
\hline Rarely & 52.3 & * & * \\
\hline Sometimes & 44.3 & * & * \\
\hline Often & 3.3 & * & * \\
\hline Number who ever accessed pornographic materials on the internet & 138 & 20 & 20 \\
\hline
\end{tabular}

Notes: All Ns are unweighted. * Percentage not shown as this was based on fewer than 25 unweighted cases. () Based on 25-49 unweighted cases.

On the whole, 46 percent of older boys, six percent of unmarried older girls, and 31 percent of married older girls were exposed to pornographic materials by way of films or the internet (Figure 5.2). More of urban than rural adolescents reported any exposure to pornographic materials.

Figure 5.2 Percentage of adolescents who were exposed to pornographic materials by way of films or the internet, according to residence, Bihar, 2016

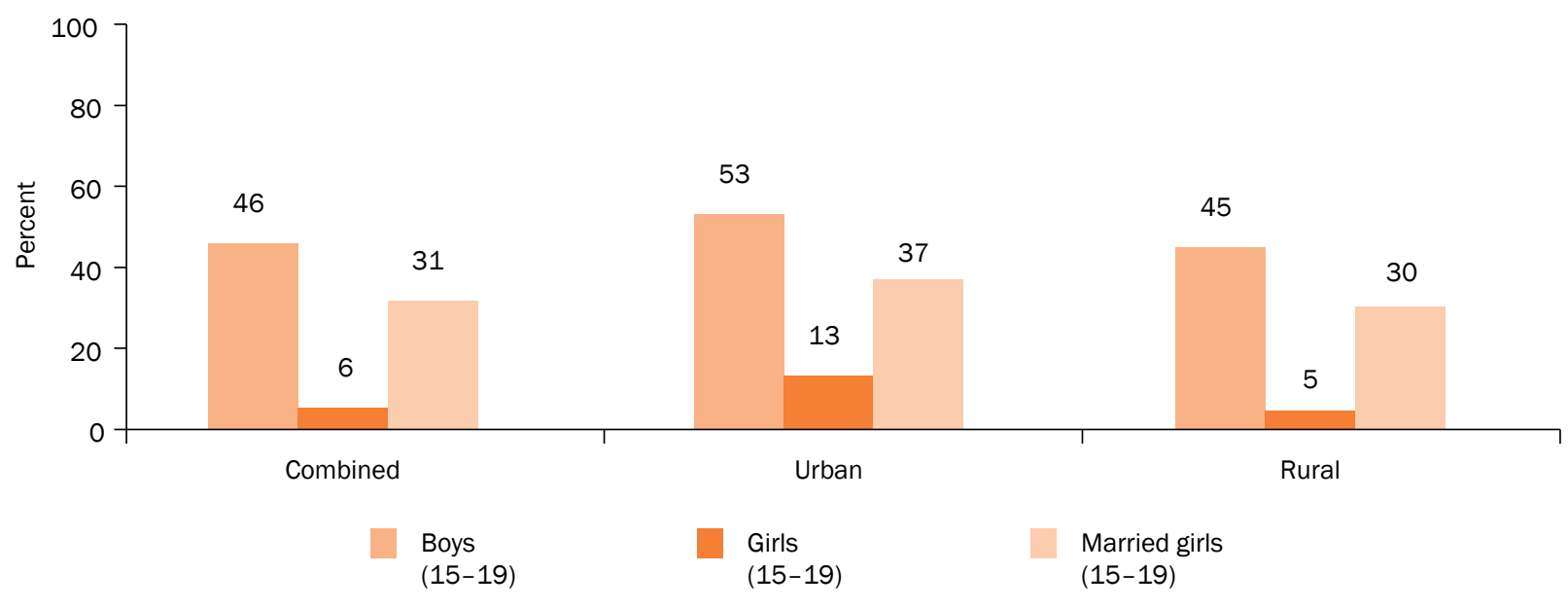




\subsection{Perpetration and experience of harassment throughmobile phones or the internet}

Interviewers asked all participants of UDAYA, regardless of their access to mobile phones or the internet, whether they had experienced harassment through mobile phones or the internet, such as someone spreading rumours or falsehoods, or sharing personal information, or sending compromising pictures about the respondent. Additionally, they asked older boys who had access to mobile phones and the internet whether they had harassed anyone using a mobile phone or the internet.

Findings presented in Table 5.8 show that none of the younger boys and two percent of older boys had experienced harassment over the mobile phone; among girls, two percent of younger girls and 7-8 percent of unmarried and married older girls had so reported. Differences were negligible between rural and urban adolescents in this regard. The proportion of boys and girls who had experienced harassment over the internet was one percent or less. Among older boys who had access to mobile phones, one percent had ever harassed someone using mobile phones ( $2 \%$ and $1 \%$ in urban and rural areas, respectively; not shown in table). Likewise, among older boys who had accessed the internet, two percent had ever harassed someone over the internet ( $2 \%$ and $1 \%$ in urban and rural areas, respectively, not shown in table).

\section{Table 5.8: Experience of harassment through mobile phones or the internet}

Percentage of adolescents who experienced harassment over mobile phones or the internet, according to residence, Bihar, 2016

\begin{tabular}{|c|c|c|c|c|c|}
\hline Indicators of harassment & $\begin{array}{c}\text { Boys } \\
(10-14)\end{array}$ & $\begin{array}{c}\text { Boys } \\
(15-19)\end{array}$ & $\begin{array}{c}\text { Girls } \\
(10-14)\end{array}$ & $\begin{array}{c}\text { Girls } \\
(15-19)\end{array}$ & $\begin{array}{l}\text { Married girls } \\
\qquad(15-19)\end{array}$ \\
\hline \multicolumn{6}{|c|}{ Combined (percent) } \\
\hline \multicolumn{6}{|c|}{ Experience of harassment through: } \\
\hline Mobile phones & 0.0 & 1.9 & 2.0 & 6.9 & 8.2 \\
\hline Internet & 0.1 & 0.7 & 0.2 & 1.2 & 1.3 \\
\hline Any of the above & 0.1 & 2.3 & 2.0 & 7.2 & 8.7 \\
\hline Number of respondents & 1,012 & 1,821 & 764 & 3,428 & 3,408 \\
\hline \multicolumn{6}{|c|}{ Urban (percent) } \\
\hline \multicolumn{6}{|c|}{ Experience of harassment through: } \\
\hline Mobile phones & 0.0 & 3.1 & 1.9 & 9.3 & 8.6 \\
\hline Internet & 0.2 & 1.9 & 0.0 & 2.4 & 0.8 \\
\hline Any of the above & 0.2 & 4.5 & 1.9 & 10.1 & 8.8 \\
\hline Number of respondents & 452 & 1,008 & 387 & 1,738 & 1,366 \\
\hline \multicolumn{6}{|c|}{ Rural (percent) } \\
\hline \multicolumn{6}{|c|}{ Experience of harassment through: } \\
\hline Mobile phones & 0.0 & 1.8 & 2.0 & 6.6 & 8.2 \\
\hline Internet & 0.1 & 0.6 & 0.2 & 1.1 & 1.3 \\
\hline Any of the above & 0.1 & 2.0 & 2.0 & 6.9 & 8.7 \\
\hline Number of respondents & 560 & 813 & 377 & 1,690 & 2,042 \\
\hline
\end{tabular}

Note: All Ns are unweighted. 


\subsection{Perceived benefits of using mobile phones, the internet, and social media}

The survey also collected data on participants' perspectives on whether their use of mobile phones, the internet, and social media had resulted in expanding their friendship networks and enabling them to acquire information. Findings presented in Table 5.9 show that four percent of younger boys and 27 percent of older boys who had access to a mobile phone, the internet, or social media perceived that they had made new friends using these communication technologies as had 2-5 percent of unmarried and married older girls and very few younger girls (0.3\%). Urban adolescents, particularly younger and older boys and unmarried older girls were more likely than their corresponding rural counterparts to have made friends using these platforms (13\% versus 3\% among younger boys; $49 \%$ versus $24 \%$ among older boys; and $14 \%$ versus $4 \%$ among unmarried older girls).

\section{Table 5.9: Perceived benefits of using mobile phones, the internet, and social media}

Percentage of adolescents reporting that they had made new friends and had acquired information using mobile phones, the internet, and social media, according to residence, Bihar, 2016

\begin{tabular}{|c|c|c|c|c|c|}
\hline Indicators of perceived benefits & $\begin{array}{c}\text { Boys } \\
(10-14)\end{array}$ & $\begin{array}{c}\text { Boys } \\
(15-19)\end{array}$ & $\begin{array}{c}\text { Girls } \\
(10-14)\end{array}$ & $\begin{array}{l}\text { Girls } \\
(15-19)\end{array}$ & $\begin{array}{l}\text { Married girls } \\
\qquad(15-19)\end{array}$ \\
\hline \multicolumn{6}{|c|}{ Combined (percent) } \\
\hline Made new friends & 4.2 & 26.5 & 0.3 & 4.7 & 1.8 \\
\hline Acquired information & 12.6 & 37.7 & 9.5 & 20.0 & 15.5 \\
\hline $\begin{array}{l}\text { Number having access to a mobile phones/the } \\
\text { internet/social media }\end{array}$ & 810 & 1,723 & 630 & 3,241 & 3,276 \\
\hline \multicolumn{6}{|c|}{ Urban (percent) } \\
\hline Made new friends & 12.6 & 49.2 & 2.5 & 13.8 & 5.1 \\
\hline Acquired information & 25.6 & 57.7 & 20.7 & 33.8 & 18.0 \\
\hline $\begin{array}{l}\text { Number having access to a mobile phone/the } \\
\text { internet/social media }\end{array}$ & 380 & 972 & 330 & 1,675 & 1,311 \\
\hline \multicolumn{6}{|c|}{ Rural (percent) } \\
\hline Made new friends & 3.1 & 23.5 & 0.0 & 3.6 & 1.4 \\
\hline Acquired information & 11.0 & 35.1 & 8.1 & 18.3 & 15.2 \\
\hline $\begin{array}{l}\text { Number having access to a mobile phone/the } \\
\text { internet/social media }\end{array}$ & 430 & 751 & 300 & 1,566 & 1,965 \\
\hline
\end{tabular}

Note: All Ns are unweighted.

A larger proportion of adolescents agreed that they had acquired information related to various matters using these communication platforms. Older adolescents were more likely than younger adolescents to have reported so (38\% versus 13\% among boys and $16-20 \%$ versus $10 \%$ among girls). Older boys were more likely than their female counterparts to report that they had acquired information over mobile phones, the internet, or social media (38\% versus 16-20\%). Differences by marital status among girls were modest. Differences in reports between rural and urban adolescents were wide among all categories of adolescents, except among married older girls. Urban adolescents were more likely than their rural counterparts to have acquired information, using these channels $(26 \%$ versus $11 \%$ of younger boys; $58 \%$ versus $35 \%$ of older boys; $21 \%$ versus $8 \%$ of younger girls; and $34 \%$ versus $18 \%$ of unmarried older girls). 


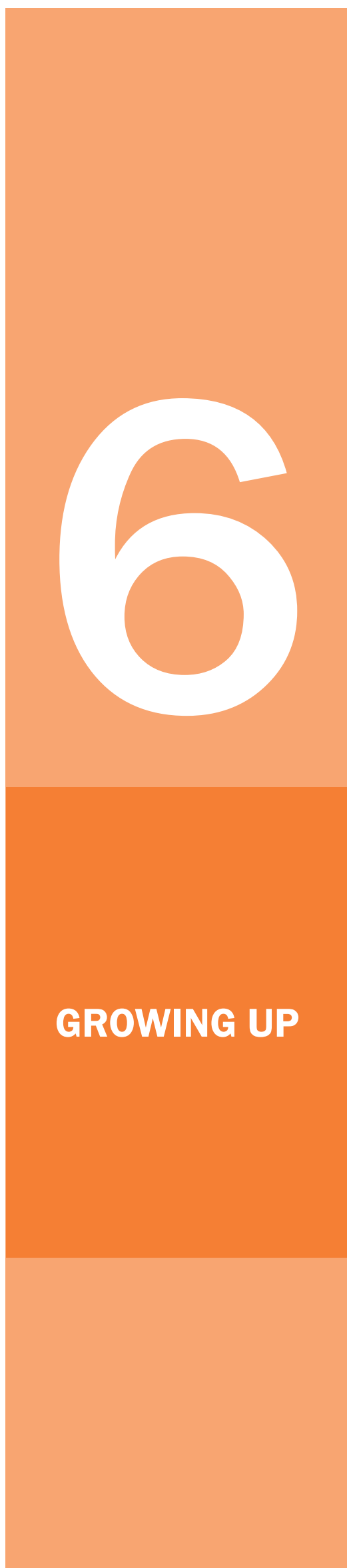

\section{A Snapshot}

Peersare a major source of information and support for adolescents:

- $98 \%$ of younger boys

- $97 \%$ of older boys

- $98 \%$ of younger girls

- $95 \%$ of unmarried older girls

- $94 \%$ of married older girls had at least one friend
- $91 \%$ of younger boys

- $84 \%$ of older boys

- $93 \%$ of younger girls

- $73 \%$ of unmarried older girls

- $12 \%$ of married older girls spent time with their friends often

- $60 \%$ of older boys

- $43 \%$ of unmarried older girls considered friends as their leading confidantes with whom they could discuss opposite-sex relationship matters

Social spaces ${ }^{1}$ to network with peers is limited:

- $47 \%$ of younger boys

- $49 \%$ of older boys

- $15 \%$ of younger girls

- $8 \%$ of unmarried older girls

- $4 \%$ of married older girls met their friends in social spaces
- $3 \%$ of younger boys

- $6 \%$ of older boys

- $2 \%$ of younger girls

- $3 \%$ of unmarried older girls

- $8 \%$ of married older girls were members of any group

Family life is marred by gender discriminatory practices, domestic violence, and limited parent-adolescent communication:
- $20 \%$ of younger boys
- $19 \%$ of older boys
- $42 \%$ of younger girls
- $33 \%$ of unmarried older girls acknowledged at least one form of parental discrimination, with parents favouring sons over daughters

- $18 \%$ each of younger and older boys

- $30 \%$ of younger girls

- $25 \%$ of unmarried older girls

- $32 \%$ of married older girls with both parents alive at the time of the interview had ever witnessed incidents where their father had beaten their mother

${ }^{1}$ Social spaces may be defined as places in which adolescents congregate for the purpose of socialising with their friends, for example, a playground, a park, a garden, girls'/boys' clubs.

\section{POPULATION} COUNCIL

Ideas. Evidence. Impact.

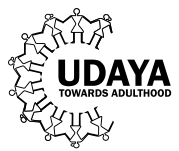




\section{A Snapshot}

Family life is marred by gender discriminatory practices, domestic violence, and limited parent-adolescent communication:

- $69 \%$ of younger boys

- $55 \%$ of older boys

- $56 \%$ of younger girls

- $34 \%$ of unmarried older girls

- $32 \%$ of married older girls with at least one parent alive at the time of the interview had experienced physical violence perpetrated by a parent at some time since they had turned 10 years of age
- $21 \%$ of younger boys

- $27 \%$ of older boys

- $30 \%$ of younger girls

- $26 \%$ of unmarried older girls had discussed general matters, such as their friends, with their father in the year preceding the interview

- $37 \%$ each of younger boys and older boys

- $77 \%$ of younger girls

- $72 \%$ of unmarried older girls had discussed general matters, such as their friends, with their mother in the year preceding the interview

$1 \%$ of younger boys, and $2 \%$ of older boys had discussed such physical changes during adolescence as voice change and facial hair growth with their father in the year preceding the interview as had $4 \%$ of younger boys and $3 \%$ of older boys with their mother

$0.5 \%$ of younger girls and $0.3 \%$ of unmarried older girls had discussed menstruation with their father, and $32 \%$ of younger girls and $74 \%$ of unmarried older girls had done so with their mother in the year preceding the interview

Yet, it is from the family that adolescents learn social behaviours, seek solace when confronted with a problem, and choose their role models:

- $67 \%$ of younger boys

- $69 \%$ of older boys

- $67 \%$ of younger girls

- $63 \%$ of unmarried older girls

- $71 \%$ of married older girls who reported they had a role model indicated that someone from their family was their role model
- $69 \%$ of younger boys

- $44 \%$ of older boys

- $88 \%$ of younger girls

- $86 \%$ of unmarried older girls

- $40 \%$ of married older girls considered their mother as the leading confidante to whom they could turn if they have a problem in their private parts 


\section{A Snapshot}

Yet, it is from the family that adolescents learn social behaviours, seek solace when confronted with a problem, and choose their role models:

- $76 \%$ of younger boys

- $80 \%$ of older boys

- $89 \%$ of younger girls

- $88 \%$ of unmarried older girls

- $89 \%$ of married older girls

reported their mother as their leading source for learning social behaviours

Many adolescents do not have a role model or anyone for supportin case of personal problems:

- $66 \%$ of younger boys

- $60 \%$ of older boys

- $70 \%$ of younger girls

- $69 \%$ of unmarried older girls

- $79 \%$ of married older girls did not have a role model
- $39 \%$ of younger boys (ages 13-14)

- $24 \%$ of older boys

- $28 \%$ of younger girls (ages $13-14$ )

- $21 \%$ of unmarried older girls would not confide in anyone about a relationship with an opposite-sex friend

Awareness of programmes that seek to mobilise adolescents is limited:

- $21 \%$ of younger girls

- $28 \%$ each of unmarried older girls and married older girls were aware of KSY/ SABLA groups
- $20 \%$ of younger boys

- $29 \%$ of older boys

- $17 \%$ of younger girls

- $24 \%$ of unmarried older girls

- $21 \%$ of married older girls

had heard about the NYKS clubs

Gender differences are wide on many indicators among older adolescents-girls are less likely than boys to meet their friends often or in social spaces, to have role models, and to receive social support from their peers, and married older girls are particularly disadvantaged on these matters 
The peer group is, for many adolescents, a central source of both information and support, but at the same time, it is a source of misinformation and pressure to adopt risky behaviours (Bhuiya et al., 2003; Sachdev, 1998; Santhya, Acharya, and Jejeebhoy, 2011; UI Haque and Faizunnisa, 2003). Similarly, safe and supportive families play a significant role in enabling adolescents to achieve good health, including sexual and reproductive health and mental health, and to exercise their rights(Laird et al., 2003; Marta, 1997; Sroufe, 1991; Viner et al., 2012). However, several studies in India note that parentsoften fail to be reliable sources of information and support for adolescents (Garda and Alexander, 2009; International Institute for Population Sciences [IIPS] and Population Council, 2010; Jejeebhoy and Santhya, 2011; Mahajan and Sharma, 2005; Soletti et al., 2009). Studies also highlight how role models can have both positive and negative influences on adolescents (Azmi et al., 2014; Kaur, 2014; Sharma, Grover, and Chaturvedi, 2010).

We explored each of these issues in the survey. This chapter begins with a discussion of adolescents' peer networks, the size of these networks, the frequency and places of interactions with their peers, and their membership in organised groups. It then describes aspects of their family life and interactions with parents, including their socialisation experiences at home and their experiences of violence perpetrated by their parents. Finally, it presents information on the people they considered to be their confidantes for discussing personal matters, their role models, and their sources for learning social behaviours.

\subsection{Peer networks and interactions}

In order to assess the size of peer networks and the extent of peer interaction, we asked respondents about the number of friends they had, how frequently they met, and the places where they met. We also inquired about their membership in formal groups.

\subsubsection{Size of peer networks and frequency and places of interactions with peers}

Findings presented in Table 6.1 show that most adolescents had at least one friend (97-98\% of boys and 94-98\% of girls). They reported on average three friends, regardless of age, sex, and, among girls, of marital status, and 28-32 percent of boys and 32-34 percent of girls reported five or more friends. The size of the peer network varied somewhat by residence in rural or urban areas. Urban boys, irrespective of age, had a larger peer network than their rural counterparts. They reported, on average, four friends compared with three friends reported by their rural counterparts, and they were also more likely to report five or more friends ( $45 \%$ versus $26 \%$ among younger boys and $43 \%$ versus $30 \%$ among older boys). In contrast, somewhat more rural older girls reported five or more friends, compared with their urban counterparts (32-33\% versus $27-28 \%$ ).

\section{Table 6.1: Peer networks and interactions}

Percent distribution of adolescents by number of friends and by frequency of interactions, and percentage reporting places of interactions, according to residence, Bihar, 2016

\begin{tabular}{|c|c|c|c|c|c|}
\hline $\begin{array}{l}\text { Number of friends and frequency and places of } \\
\text { interactions }\end{array}$ & $\begin{array}{l}\text { Boys } \\
(10-14)\end{array}$ & $\begin{array}{l}\text { Boys } \\
(15-19)\end{array}$ & $\begin{array}{l}\text { Girls } \\
(10-14)\end{array}$ & $\begin{array}{l}\text { Girls } \\
(15-19)\end{array}$ & $\begin{array}{l}\text { Married girls } \\
\quad(15-19)\end{array}$ \\
\hline \multicolumn{6}{|c|}{ Combined (percent) } \\
\hline \multicolumn{6}{|l|}{ Number of friends } \\
\hline None & 2.4 & 3.5 & 1.8 & 5.2 & 6.1 \\
\hline $1-2$ & 38.1 & 35.9 & 29.2 & 32.6 & 29.7 \\
\hline $3-4$ & 31.5 & 29.2 & 34.6 & 29.9 & 32.7 \\
\hline 5 or more & 28.0 & 31.5 & 34.4 & 32.3 & 31.6 \\
\hline Median number of friends & 3 & 3 & 3 & 3 & 3 \\
\hline Number of respondents & 1,012 & 1,821 & 764 & 3,428 & 3,408 \\
\hline
\end{tabular}


Table 6.1 Cont.

\begin{tabular}{|c|c|c|c|c|c|}
\hline $\begin{array}{l}\text { Number of friends and frequency and places of } \\
\text { interactions }\end{array}$ & $\begin{array}{l}\text { Boys } \\
(10-14)\end{array}$ & $\begin{array}{l}\text { Boys } \\
(15-19)\end{array}$ & $\begin{array}{c}\text { Girls } \\
(10-14)\end{array}$ & $\begin{array}{c}\text { Girls } \\
(15-19)\end{array}$ & $\begin{array}{l}\text { Married girls } \\
\quad(15-19)\end{array}$ \\
\hline \multicolumn{6}{|l|}{ Frequency of interacting with friends } \\
\hline Never & 0.0 & 0.3 & 0.1 & 0.4 & 3.3 \\
\hline Sometimes & 9.3 & 16.0 & 7.2 & 26.7 & 84.3 \\
\hline Often & 90.6 & 83.7 & 92.7 & 72.9 & 12.4 \\
\hline \multicolumn{6}{|l|}{ Meeting places } \\
\hline School/college & 75.3 & 54.8 & 83.6 & 60.4 & 9.9 \\
\hline Home & 76.8 & 81.0 & 87.6 & 89.6 & 94.7 \\
\hline $\begin{array}{l}\text { Venues outside the home and school, but related to } \\
\text { daily chores }{ }^{1}\end{array}$ & 37.8 & 53.8 & 22.0 & 24.9 & 12.3 \\
\hline $\begin{array}{l}\text { Venues outside the home and school, but not related } \\
\text { to daily chores }{ }^{2}\end{array}$ & 46.6 & 49.1 & 14.5 & 8.4 & 4.1 \\
\hline Number of respondents with at least one friend & 990 & 1,768 & 748 & 3,291 & 3,166 \\
\hline \multicolumn{6}{|c|}{ Urban (percent) } \\
\hline \multicolumn{6}{|l|}{ Number of friends } \\
\hline None & 2.2 & 2.5 & 2.0 & 3.6 & 7.9 \\
\hline $1-2$ & 23.9 & 23.2 & 33.6 & 38.5 & 32.8 \\
\hline $3-4$ & 29.0 & 31.2 & 32.2 & 29.5 & 32.0 \\
\hline 5 or more & 45.0 & 43.0 & 32.2 & 28.4 & 27.3 \\
\hline Median number of friends & 4 & 4 & 3 & 3 & 3 \\
\hline Number of respondents & 452 & 1,008 & 387 & 1,738 & 1,366 \\
\hline \multicolumn{6}{|l|}{ Frequency of interacting with friends } \\
\hline Never & 0.2 & 0.3 & 0.5 & 0.8 & 3.8 \\
\hline Sometimes & 9.5 & 13.5 & 10.6 & 32.8 & 87.0 \\
\hline Often & 90.3 & 86.2 & 88.9 & 66.4 & 9.2 \\
\hline \multicolumn{6}{|l|}{ Meeting places } \\
\hline School/college & 82.5 & 56.1 & 87.3 & 65.0 & 12.0 \\
\hline Home & 74.7 & 75.7 & 77.9 & 85.9 & 92.1 \\
\hline $\begin{array}{l}\text { Venues outside the home and school, but related to } \\
\text { daily chores }{ }^{1}\end{array}$ & 39.9 & 62.3 & 13.8 & 18.1 & 10.3 \\
\hline $\begin{array}{l}\text { Venues outside the home and school, but not related } \\
\text { to daily chores }\end{array}$ & 31.8 & 43.2 & 8.1 & 5.5 & 1.8 \\
\hline Number of respondents with at least one friend & 443 & 985 & 379 & 1,681 & 1,254 \\
\hline
\end{tabular}


Table 6.1 Cont.

\begin{tabular}{|c|c|c|c|c|c|}
\hline $\begin{array}{l}\text { Number of friends and frequency and places of } \\
\text { interactions }\end{array}$ & $\begin{array}{l}\text { Boys } \\
(10-14)\end{array}$ & $\begin{array}{l}\text { Boys } \\
(15-19)\end{array}$ & $\begin{array}{l}\text { Girls } \\
(10-14)\end{array}$ & $\begin{array}{c}\text { Girls } \\
(15-19)\end{array}$ & $\begin{array}{l}\text { Married girls } \\
\quad(15-19)\end{array}$ \\
\hline \multicolumn{6}{|c|}{ Rural (percent) } \\
\hline \multicolumn{6}{|l|}{ Number of friends } \\
\hline None & 2.4 & 3.6 & 1.8 & 5.4 & 5.9 \\
\hline $1-2$ & 39.7 & 37.4 & 28.7 & 31.9 & 29.3 \\
\hline $3-4$ & 31.8 & 29.0 & 34.8 & 30.0 & 32.8 \\
\hline 5 or more & 26.0 & 30.0 & 34.7 & 32.8 & 32.1 \\
\hline Median number of friends & 3 & 3 & 3 & 3 & 3 \\
\hline Number of respondents & 560 & 813 & 377 & 1,690 & 2,042 \\
\hline \multicolumn{6}{|l|}{ Frequency of interacting with friends } \\
\hline Never & 0.0 & 0.3 & 0.0 & 0.4 & 3.2 \\
\hline Sometimes & 9.3 & 16.3 & 6.8 & 26.0 & 84.0 \\
\hline Often & 90.7 & 83.4 & 93.2 & 73.7 & 12.7 \\
\hline \multicolumn{6}{|l|}{ Meeting places } \\
\hline School/college & 74.4 & 54.7 & 83.2 & 59.9 & 9.7 \\
\hline Home & 77.1 & 81.7 & 88.7 & 90.1 & 94.9 \\
\hline $\begin{array}{l}\text { Venues outside the home and school, but related to } \\
\text { daily chores }{ }^{1}\end{array}$ & 37.6 & 52.8 & 23.0 & 25.8 & 12.6 \\
\hline $\begin{array}{l}\text { Venues outside the home and school, but not related } \\
\text { to daily chores }{ }^{2}\end{array}$ & 48.4 & 49.9 & 15.2 & 8.8 & 4.4 \\
\hline Number of respondents with at least one friend & 547 & 783 & 369 & 1,610 & 1,912 \\
\hline
\end{tabular}

Notes: All Ns are unweighted. ${ }^{1}$ Includes such locations as common water tap, hand-pump, or pond from where they fetched water, fields where they went to collect fodder or cut crops, shop or market from where they brought groceries, etc. ${ }^{2}$ Includes such venues as a playground, a park, a garden, girls'/boys' clubs, etc.

Findings show that the majority of adolescents, except married older girls, spent time with their friends often and that interactions with friends differed by age, sex, and by marital status, among older girls (Table 6.1 and Figure 6.1). Younger adolescents were more likely than older adolescents, particularly girls, to report that they often spent time with their friends (91\% versus $84 \%$ among boys and $93 \%$ versus $73 \%$ among girls). Older boys were more likely than unmarried older girls to report frequent interaction with friends ( $84 \%$ versus $73 \%$ ), but no such differences were observed among younger adolescents. Among older girls, unmarried girls were considerably more likely than married girls to have interacted with their friends often (73\% versus $12 \%)$. Indeed, most married older girls reported that they met their friends only sometimes (84\%). Differences in the frequency of peer interactions among adolescents by residence in rural or urban areas were largely muted, except that more unmarried older girls in rural than urban areas reported frequent peer interactions (74\% versus $66 \%$ ). 
Figure 6.1: Percent distribution of adolescents with at least one friend by the frequency of interacting with their friends, Bihar, 2016

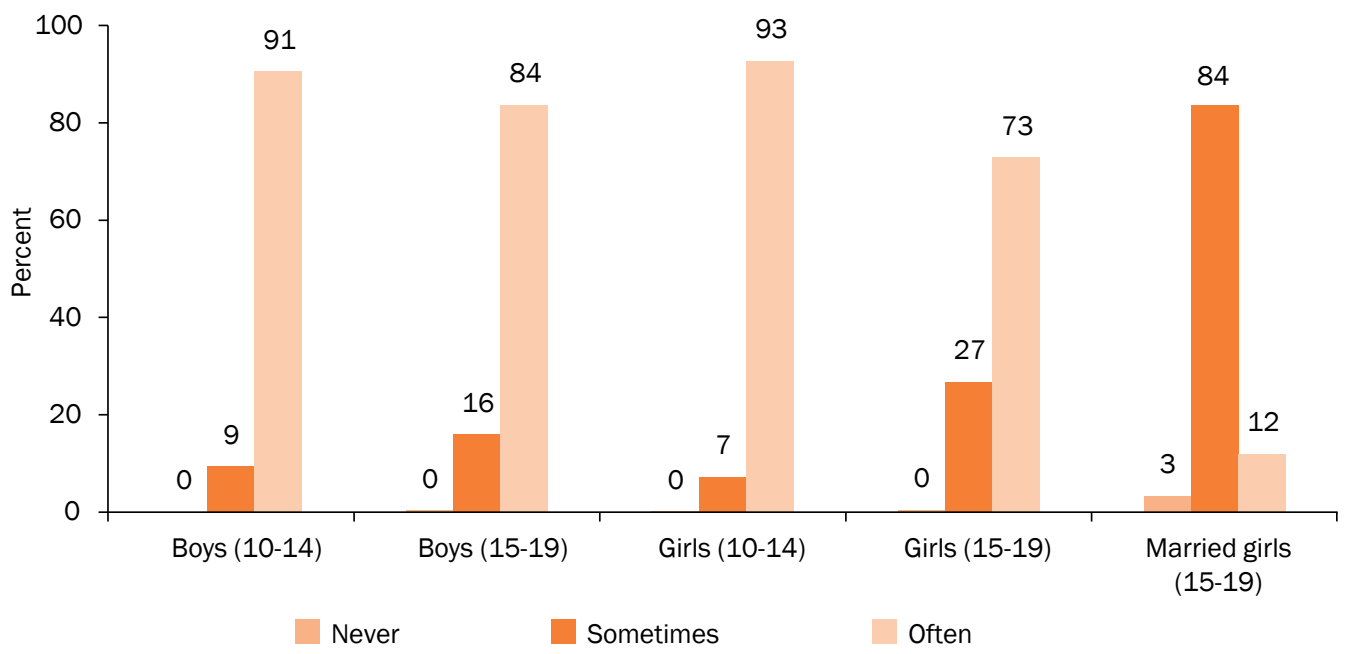

Table 6.1 also summarises responses to the question we posed on places where adolescents typically meet their friends, and this draws attention to the lack of safe social spaces where adolescent girls (and to some extent, adolescent boys) can network with their peers. Most adolescents, irrespective of age, sex, and, among older girls, of marital status, reported that they typically met their friends either in school/college or at each other's homes. Specifically, 75 percent of younger boys and 55 percent of older boys reported that they typically met their friends in their school/college as did 84 percent of younger girls and 60 percent of unmarried older girls. In contrast, just 10 percent of married girls reported that they met their friends in school or college, a finding which is not surprising as only a minority of married older girls were attending school/college at the time of the interview. Some 77 percent and 81 percent of younger and older boys, respectively, reported that they also met their friends in each other's homes; the proportions for girls were 88 percent among younger girls, 90percent among unmarried older girls, and 95 percent among married older girls.

Findings also show that fewer adolescents, particularly girls, met their friends in venues outside the home and school. Specifically, 38 percent of younger boys, 54 percent of older boys, and 12-25 percent of all girls reported that they met their friends in locations that they visited in the course of their daily chores, such as, places to collect water or firewood or a shop in the village. Also, 47-49 percent of boys and 4-15 percent of girls reported that they met their friends in social spaces ${ }^{1}$ such as a playground, a garden, or adolescents' groups or clubs.

We observed that meeting places of adolescents differed by age and sex. Younger boys were more likely than older boys to meet their friends in school settings (75\% versus 55\%), and, conversely, older boys were more likely to meet their friends in locations outside the home and the school, but related to daily chores (54\% versus 38\%). Similarly, younger girls were more likely than unmarried and married older girls to meet their friends in school settings $(84 \%$ of younger girls versus $60 \%$ of unmarried older girls and $10 \%$ of married older girls). We observed differences by sex with regard to meeting venues. Younger boys were less likely than younger girls to meet their friends in schools/ colleges or their home (75-77\% versus $84-88 \%)$, and, similarly, older boys were less likely than unmarried older girls to meet friends in school and college ( $55 \%$ versus $60 \%$ )or in their home ( $81 \%$ versus $90 \%)$. Boys were more likely than girls to meet their friends in locations outside the home and school, but in locations where they went to perform their daily chores (38\% versus $22 \%$ among younger adolescents and $54 \%$ versus $12-25 \%$ among older adolescents) and in social spaces (47\% versus 15\% among younger adolescents and $49 \%$ versus $4-8 \%$ among older adolescents).

The locations where rural and urban adolescents met their friends largely mirrored the locations described above for the combined sample. Differences were, however, notable. Younger boys in urban areas were more likely than their rural counterparts to meet their friends in their school (83\% versus $74 \%$ ), but less likely to do so in social spaces (32\% versus $48 \%$ ). Urban older boys were less likely than rural older boys to meet their friends in each other's homes

1 Social spaces may be defined as places in which adolescents congregate for the purpose of socialising with their friends. 
( $76 \%$ versus $82 \%$ ) or social spaces (43\% versus $50 \%$ ), but more likely to do so in venues outside school and home that were related to daily chores (62\% versus $53 \%$ ). Urban younger girls were less likely than rural younger girls to meet their friends in each other's homes (78\% versus $89 \%)$, venues outside school and home that were related to daily chores (14\% versus $23 \%$ ), and social spaces ( $8 \%$ versus $15 \%$ ). Finally, unmarried older girls in urban areas were less likely than their rural counterparts to report that they typically met their friends in venues outside school and home that were related to daily chores (18\% versus $26 \%$ ).

\subsubsection{Membership in organised groups}

This section presents findings on the membership of adolescents in any organised groups, including groups formed under the aegis of the Kishori Shakti Yojana (KSY)/SABLA ${ }^{2}$ and self-help groups for girls and, for both girls and boys, clubs formed under the Nehru Yuva Kendra Sangathan (NYKS clubs), sports clubs, or any other groups. Further, we asked adolescents who reported that they were not members of any of the clubs mentioned by the interviewer whether they were aware of any of them; those who reported membership of any group were additionally asked whether she or he had ever held a position of leadership in the group.

Table 6.2 presents data on adolescents' awareness of and participation in such groups. On the whole, small proportions of adolescents were members of any group, with little variation by age, sex, or, among older girls, by marital status (3-6\% of boys and $1-8 \%$ of girls). Indeed, large proportions of adolescents were not aware of these groups. Thus, 72-79 percent of younger and older girls were not aware of KSY/SABLA groups. Similarly, 71-80 percent of boys and 76-83 percent of girls had not heard about the NYKS clubs. Differences between those from rural and those from urban areas were muted.

Of those who were members of any group, 11-22 percent of younger and older boys reported that they had held a position of leadership in their group. Only 2-9 percent of unmarried and married older girls reported any leadership roles. Older boys and unmarried older girls in urban areas were more likely than their rural counterparts to have held a position of leadership in their group; for example, 28 percent and 21 percent of older boys and seven percent and one percent of unmarried older girls in urban and rural areas, respectively, had held a position of leadership in their group. A reverse pattern was observed among married older girls among whom fewer urban than rural girls had held a position of leadership in their group (2\% versus $10 \%)$.

\section{Table 6.2: Membership in organised groups}

Percentage of adolescents reporting membership in organised groups, according to residence, Bihar, 2016

\begin{tabular}{|c|c|c|c|c|c|}
\hline Organised groups & $\begin{array}{c}\text { Boys } \\
(10-14)\end{array}$ & $\begin{array}{c}\text { Boys } \\
(15-19)\end{array}$ & $\begin{array}{c}\text { Girls } \\
(10-14)\end{array}$ & $\begin{array}{c}\text { Girls } \\
(15-19)\end{array}$ & $\begin{array}{c}\text { Married girls } \\
(15-19)\end{array}$ \\
\hline \multicolumn{6}{|c|}{ Combined (percent) } \\
\hline \multicolumn{6}{|c|}{ Kishori Shakti Yojana (KSY)/SABLA group } \\
\hline Yes & NA & NA & 0.4 & 1.2 & 1.5 \\
\hline No & NA & NA & 20.7 & 27.2 & 26.0 \\
\hline Not aware of KSY/SABLA & NA & NA & 79.0 & 71.6 & 72.5 \\
\hline \multicolumn{6}{|c|}{ Nehru Yuvak Kendra Sangathan (NYKS) clubs } \\
\hline Yes & 0.4 & 1.6 & 0.3 & 1.1 & 0.5 \\
\hline No & 20.0 & 27.6 & 16.4 & 23.1 & 20.0 \\
\hline Not aware of NYKS youth clubs & 79.6 & 70.8 & 83.3 & 75.8 & 79.5 \\
\hline \multicolumn{6}{|l|}{ Sports clubs } \\
\hline Yes & 2.3 & 3.6 & 0.8 & 0.7 & 0.2 \\
\hline No & 56.9 & 70.0 & 27.0 & 36.5 & 31.0 \\
\hline Not aware of any sports clubs & 40.9 & 26.4 & 72.2 & 62.8 & 68.7 \\
\hline
\end{tabular}

2 Rajiv Gandhi Scheme for Empowerment of Adolescent Girls (RGSEAG) SABLA. 
Table 6.2 Cont.

\begin{tabular}{|c|c|c|c|c|c|}
\hline Organised groups & $\begin{array}{c}\text { Boys } \\
(10-14)\end{array}$ & $\begin{array}{c}\text { Boys } \\
(15-19)\end{array}$ & $\begin{array}{c}\text { Girls } \\
(10-14)\end{array}$ & $\begin{array}{c}\text { Girls } \\
(15-19)\end{array}$ & $\begin{array}{l}\text { Married girls } \\
\qquad(15-19)\end{array}$ \\
\hline \multicolumn{6}{|l|}{ Self-help groups (SHGs) } \\
\hline Yes & NA & NA & NA & 1.0 & 5.9 \\
\hline No & NA & NA & NA & 71.6 & 67.5 \\
\hline Not aware of any SHGs & NA & NA & NA & 27.4 & 26.6 \\
\hline \multicolumn{6}{|l|}{ Any other groups } \\
\hline Yes & 0.4 & 0.8 & 0.0 & 0.0 & 0.3 \\
\hline No & 99.6 & 99.2 & 100.0 & 100.0 & 99.7 \\
\hline Membership in any of the above & 2.6 & 5.8 & 1.4 & 3.4 & 7.8 \\
\hline Number of respondents & 1,012 & $\mathbf{1 , 8 2 1}$ & 764 & 3,428 & 3,408 \\
\hline Held leadership position in any group & $(10.7)$ & 21.6 & * & 2.1 & 8.9 \\
\hline $\begin{array}{l}\text { Number of respondents who reported membership in } \\
\text { an organised group }\end{array}$ & 36 & 113 & 11 & 132 & 251 \\
\hline
\end{tabular}

Urban (percent)

\begin{tabular}{|c|c|c|c|c|c|}
\hline \multicolumn{6}{|l|}{ Kishori Shakti Yojana (KSY)/SABLA group } \\
\hline Yes & NA & NA & 0.4 & 2.1 & 1.9 \\
\hline No & NA & NA & 17.8 & 26.8 & 29.0 \\
\hline Not aware of KSY/SABLA & NA & NA & 81.8 & 71.1 & 69.1 \\
\hline \multicolumn{6}{|l|}{ Nehru Yuvak Kendra Sangathan (NYKS) clubs } \\
\hline Yes & 0.0 & 1.5 & 0.1 & 1.1 & 0.2 \\
\hline No & 16.7 & 27.6 & 14.3 & 22.6 & 20.1 \\
\hline Not aware of NYKS youth clubs & 83.3 & 70.9 & 85.6 & 76.3 & 79.7 \\
\hline \multicolumn{6}{|l|}{ Sports clubs } \\
\hline Yes & 2.8 & 3.6 & 0.0 & 1.0 & 0.5 \\
\hline No & 61.4 & 76.9 & 28.9 & 41.4 & 34.1 \\
\hline Not aware of any sports clubs & 35.8 & 19.4 & 71.1 & 57.5 & 65.5 \\
\hline \multicolumn{6}{|l|}{ Self-help groups (SHGs) } \\
\hline Yes & NA & NA & NA & 1.1 & 3.9 \\
\hline No & NA & NA & NA & 59.1 & 65.7 \\
\hline Not aware of any SHGs & NA & NA & NA & 39.8 & 30.4 \\
\hline \multicolumn{6}{|l|}{ Any other groups } \\
\hline Yes & 0.0 & 1.3 & 0.1 & 0.1 & 0.2 \\
\hline No & 100.0 & 98.7 & 99.9 & 99.9 & 99.8 \\
\hline Membership in any of the above & 2.8 & 5.7 & 0.7 & 4.3 & 6.0 \\
\hline Number of respondents & 452 & 1,008 & 387 & 1,738 & 1,366 \\
\hline Held leadership position in any group & * & 27.6 & * & 7.3 & 2.0 \\
\hline $\begin{array}{l}\text { Number of respondents who reported membership in } \\
\text { an organised group }\end{array}$ & 17 & 61 & 5 & 76 & 80 \\
\hline
\end{tabular}


Table 6.2 Cont.

\begin{tabular}{|c|c|c|c|c|c|}
\hline Organised groups & $\begin{array}{c}\text { Boys } \\
(10-14)\end{array}$ & $\begin{array}{c}\text { Boys } \\
(15-19)\end{array}$ & $\begin{array}{c}\text { Girls } \\
(10-14)\end{array}$ & $\begin{array}{c}\text { Girls } \\
(15-19)\end{array}$ & $\begin{array}{l}\text { Married girls } \\
\qquad(15-19)\end{array}$ \\
\hline \multicolumn{6}{|c|}{ Rural (percent) } \\
\hline \multicolumn{6}{|l|}{ Kishori Shakti Yojana (KSY)/SABLA group } \\
\hline Yes & NA & NA & 0.4 & 1.1 & 1.4 \\
\hline No & NA & NA & 21.0 & 27.2 & 25.7 \\
\hline Not aware of KSY/SABLA & NA & NA & 78.6 & 71.7 & 72.9 \\
\hline \multicolumn{6}{|l|}{ Nehru Yuvak Kendra Sangathan (NYKS) clubs } \\
\hline Yes & 0.5 & 1.6 & 0.3 & 1.1 & 0.5 \\
\hline No & 20.4 & 27.6 & 16.7 & 23.2 & 20.0 \\
\hline Not aware of NYKS youth clubs & 79.2 & 70.8 & 83.0 & 75.8 & 79.5 \\
\hline \multicolumn{6}{|l|}{ Sports clubs } \\
\hline Yes & 2.2 & 3.6 & 0.9 & 0.6 & 0.2 \\
\hline No & 56.3 & 69.1 & 26.7 & 35.9 & 30.7 \\
\hline Not aware of any sports clubs & 41.5 & 27.3 & 72.3 & 63.4 & 69.1 \\
\hline \multicolumn{6}{|l|}{ Self-help groups (SHGs) } \\
\hline Yes & NA & NA & NA & 1.0 & 6.1 \\
\hline No & NA & NA & NA & 73.1 & 67.7 \\
\hline Not aware of any SHGs & NA & NA & NA & 25.9 & 26.2 \\
\hline \multicolumn{6}{|l|}{ Any other groups } \\
\hline Yes & 0.4 & 0.8 & 0.0 & 0.0 & 0.3 \\
\hline No & 99.6 & 99.2 & 100.0 & 100.0 & 99.7 \\
\hline Membership in any of the above & 2.6 & 5.8 & 1.5 & 3.3 & 8.0 \\
\hline Number of respondents & 560 & 813 & 377 & 1,690 & 2,042 \\
\hline Held leadership position in any group & * & 20.9 & * & 1.2 & 10.4 \\
\hline $\begin{array}{l}\text { Number of respondents who reported membership in } \\
\text { an organised group }\end{array}$ & 19 & 52 & 6 & 56 & 171 \\
\hline
\end{tabular}

Notes: All Ns are unweighted. *Percentage not shown as this was based on fewer than 25 unweighted cases. () Based on 25-49 unweighted cases. NA: not applicable.

\subsection{Family life and interaction with parents}

The survey explored a variety of issues that capture the nature of family life and adolescents' interaction with parents in particular.

\subsubsection{Gender discriminatory practices at home}

In order to capture gender discriminatory practices followed by parents, interviewers posed three questions to adolescents (excluding married older girls) who reported co-residing with opposite-sex siblings who were up to three years younger or older than the respondent. We enquired from study participants whether their parents favoured them (among boys) or discriminated against them (among girls) vis-à-vis their opposite-sex siblings in terms of the quantity or quality of food items given, the amount of pocket money given, and the type of school in which they were enrolled, and whether there were differences in parental aspirations for the respondent's education as compared with their opposite-sex sibling. 
Findings presented in Table 6.3 and Figure 6.2 show that notable proportions of adolescents had acknowledged gender discriminatory practices at home, where parents favoured sons over daughters. Specifically, five percent of boys reported that their parents gave them more and/or better quality food than their sisters, and 14-23 percent of girls acknowledged that they were given less and/or poorer quality food than their brothers. Likewise, 12-16 percent of boys acknowledged that they were given more pocket money than their sister was given, while 26-34 percent of girls acknowledged that they were given less pocket money compared with their brother. Moreover, 4-10 percent of boys were expected to complete more years of education compared with that expected of their sister and/or had been enrolled in a school of better quality than that of their sister. Among girls, 17-19 percent reported that they were expected to complete fewer years of education compared with that expected of their brother and/or were enrolled in a poorer quality school than their brother's school. In total, 19-20 percent of boys acknowledged at least one form of practice favouring them by their parents and 33-42 percent of girls acknowledged at least one form of parental discrimination against them.

Differences in gender discriminatory practices by age were muted for boys, but wide among girls, with younger girls more likely than older girls to acknowledge that their parents favoured their brothers with regard to food ( $23 \%$ versus $14 \%$ ) and pocket money (34\% versus $26 \%$ ). They were also more likely to acknowledge at least one form of discrimination ( $42 \%$ versus $33 \%)$.

Differences by sex were wide and more girls than boys perceived discrimination. Acknowledgement of discriminatory practices differed between rural and urban adolescents, particularly among girls. Younger boys in urban areas were less likely than those in rural areas to acknowledge that their parents favoured them with regard to amount of pocket money ( $8 \%$ versus $17 \%)$ and older boys in urban areas were less likely than those in rural areas to report favoured treatment regarding education (4\% versus 10\%). Urban younger and older girls were less likely than their rural counterparts to acknowledge that their parents discriminated against them, regardless of the domain. Finally, urban adolescents, regardless of age and sex, were less likely than their rural counterparts to report gender discrimination by parents in at least one situation (13-14\% versus $20-21 \%$ among boys and $20-28 \%$ versus $35-44 \%$ among girls).

\section{Table 6.3: Gender discriminatory practices at home}

Percentage of unmarried adolescents in co-residence with opposite-sex siblings who are up to three years younger or older reporting gendered treatment at home, according to residence, Bihar, 2016

\begin{tabular}{|c|c|c|c|c|}
\hline $\begin{array}{l}\text { Domains in which parents favoured boys over their sisters or } \\
\text { discriminated against girls vis-à-vis their brothers }\end{array}$ & $\begin{array}{l}\text { Boys } \\
(10-14)\end{array}$ & $\begin{array}{c}\text { Boys } \\
(15-19)\end{array}$ & $\begin{array}{c}\text { Girls } \\
(10-14)\end{array}$ & $\begin{array}{c}\text { Girls } \\
(15-19)\end{array}$ \\
\hline \multicolumn{5}{|c|}{ Combined (percent) } \\
\hline Food & 4.5 & 5.4 & 23.0 & 13.9 \\
\hline Pocket money & 16.2 & 12.0 & 34.1 & 25.6 \\
\hline Education & 3.8 & 9.5 & 18.9 & 16.7 \\
\hline One of the above & 20.4 & 19.2 & 42.0 & 32.9 \\
\hline $\begin{array}{l}\text { Number of respondents in co-residence with brother/sist } \\
\text { age gap of upto three years at the time of the interview }{ }^{1}\end{array}$ & 453 & 692 & 350 & 1,540 \\
\hline \multicolumn{5}{|c|}{ Urban (percent) } \\
\hline Food & 2.7 & 3.9 & 17.3 & 8.0 \\
\hline Pocket money & 8.2 & 10.0 & 22.2 & 14.9 \\
\hline Education & 6.0 & 4.4 & 9.7 & 9.9 \\
\hline One of the above & 12.5 & 13.7 & 28.0 & 19.7 \\
\hline $\begin{array}{l}\text { Number of respondents in co-residence with brother/sist } \\
\text { age gap of upto three years at the time of the interview }\end{array}$ & 202 & 384 & 180 & 813 \\
\hline
\end{tabular}


Table 6.3 Cont.

\begin{tabular}{|c|c|c|c|c|}
\hline $\begin{array}{l}\text { Domains in which parents favoured boys over their sisters or } \\
\text { discriminated against girls vis-à-vis their brothers }\end{array}$ & $\begin{array}{l}\text { Boys } \\
(10-14)\end{array}$ & $\begin{array}{l}\text { Boys } \\
(15-19)\end{array}$ & $\begin{array}{c}\text { Girls } \\
(10-14)\end{array}$ & $\begin{array}{c}\text { Girls } \\
(15-19)\end{array}$ \\
\hline \multicolumn{5}{|l|}{ Rural (percent) } \\
\hline Food & 4.7 & 5.6 & 23.6 & 14.7 \\
\hline Pocket money & 17.2 & 12.2 & 35.4 & 27.1 \\
\hline Education & 3.5 & 10.1 & 19.9 & 17.7 \\
\hline One of the above & 21.4 & 19.8 & 43.5 & 34.7 \\
\hline $\begin{array}{l}\text { Number of respondents in co-residence with brother/sister with } \\
\text { age gap of upto three years at the time of the interview }{ }^{1}\end{array}$ & 251 & 308 & 170 & 727 \\
\hline
\end{tabular}

Notes: All Ns are unweighted. ${ }^{1}$ In ages $+3 /-3$ years.

Figure 6.2: Percentage of unmarried adolescents in co-residence with opposite-sex siblings who are up to three years younger or older reporting experience of gender discriminatory practices at home, according to residence, Bihar, 2016

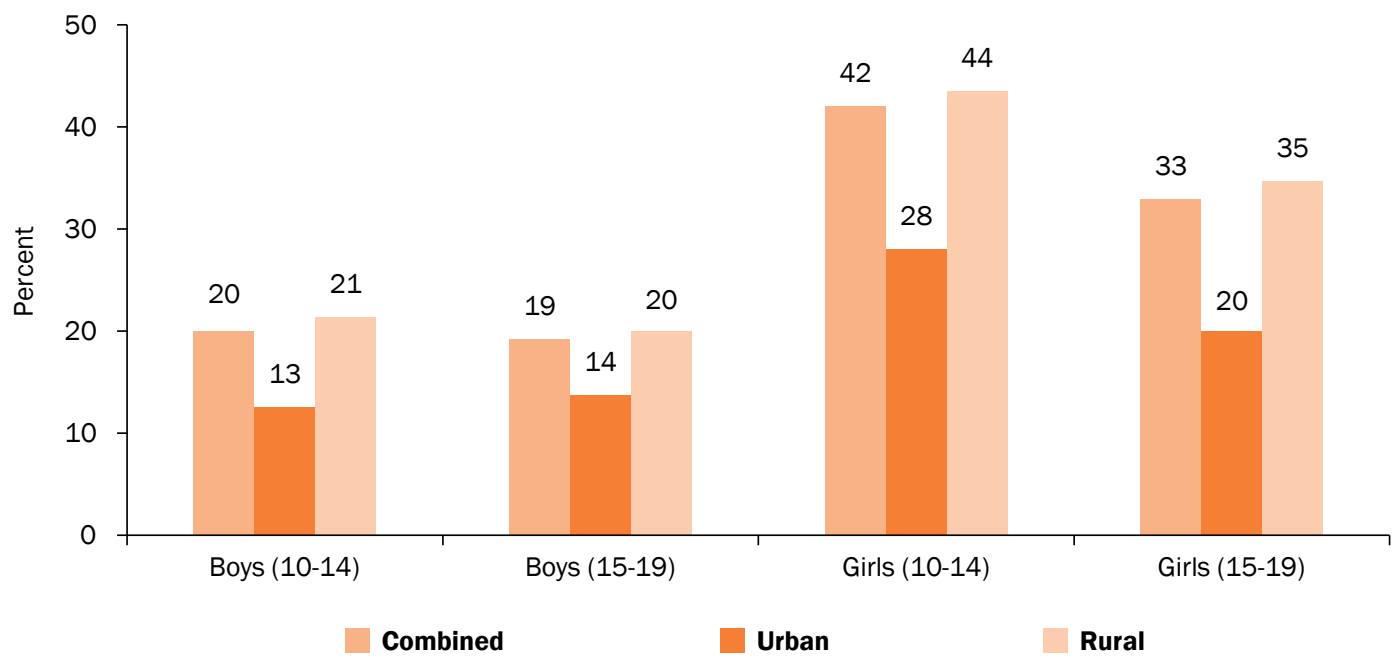

Table 6.4 examines differentials in gender discriminatory practices by selected background characteristics. Findings show that differences in gender discriminatory experiences by age were narrow. Differences by religion were modest among boys, but somewhat pronounced for girls, among whom Hindu girls were more likely to have acknowledged gender discriminatory experiences than their Muslim counterparts (43\% versus 36\% for younger girls and 34\% versus $27 \%$ for unmarried older girls). Differences by caste were not consistent; even so, among younger boys and girls as well as unmarried older girls, gender discriminatory experiences were more likely to be reported by those from households belonging to scheduled castes than those from households belonging to other castes (29\% versus $18-20 \%$ of younger boys; $54 \%$ versus $38-45 \%$ of younger girls; and $38 \%$ versus $26-33 \%$ of unmarried older girls). Differences by educational attainment were apparent, except among older boys; among younger boys and girls and unmarried older girls, acknowledgement of gender discriminatory practices reduced with increased years of schooling. Gender discriminatory experiences were inversely associated with current schooling status among unmarried older girls, but this was not so among older boys.

Differences were observed also by respondents' paid work status among older boys and unmarried older girls, though the patterns differed: older boys who worked for pay were less likely than those who did not to report gender discriminatory experiences (12\% versus $22 \%$ ); older girls who worked for pay were, conversely, more likely to report so (44\% versus $31 \%)$. Differences by household economic status show that adolescents belonging to wealthier households were less likely than those belonging to poorer households to report gender discriminatory practices. Differences by mother's education were observed for all categories, except for younger girls; adolescents whose mothers had 10 or more years of schooling were less likely than those whose mothers had fewer years of education to acknowledge gender discriminatory practices. 
Table 6.4: Gender discriminatory experiences at home by selected background characteristics

Percentage of unmarried adolescents in co-residence with opposite-sex siblings who are up to three years younger or older reporting gendered treatment at home, according to residence, Bihar, 2016

\begin{tabular}{|c|c|c|c|c|}
\hline Background characteristics (percent) & $\begin{array}{c}\text { Boys } \\
(10-14)\end{array}$ & $\begin{array}{c}\text { Boys } \\
(15-19)\end{array}$ & $\begin{array}{c}\text { Girls } \\
(10-14)\end{array}$ & $\begin{array}{c}\text { Girls } \\
(15-19)\end{array}$ \\
\hline \multicolumn{5}{|l|}{ Age } \\
\hline $10-12$ & 21.2 & NA & 41.2 & NA \\
\hline $13-14$ & 19.1 & NA & 43.3 & NA \\
\hline $15-17$ & NA & 19.7 & NA & 34.2 \\
\hline $18-19$ & NA & 17.7 & NA & 28.2 \\
\hline \multicolumn{5}{|l|}{ Religion ${ }^{1}$} \\
\hline Hindu & 19.5 & 20.2 & 43.0 & 34.2 \\
\hline Muslim & 24.9 & 14.4 & 35.8 & 27.1 \\
\hline \multicolumn{5}{|l|}{ Caste $^{2}$} \\
\hline SC & 28.7 & 19.7 & 54.0 & 38.1 \\
\hline $\mathrm{OBC}$ & 17.7 & 19.3 & 37.7 & 32.9 \\
\hline General $^{3}$ & 20.4 & 19.0 & 44.9 & 26.3 \\
\hline \multicolumn{5}{|l|}{ Completed years of schooling } \\
\hline None $^{4}$ & * & * & * & 56.0 \\
\hline $1-4$ & 24.1 & * & 47.9 & 49.0 \\
\hline $5-7$ & 20.8 & 11.8 & 39.0 & 44.1 \\
\hline $8-9$ & 13.0 & 23.1 & $(36.5)$ & 27.7 \\
\hline $10-11$ & NA & 11.1 & NA & 29.3 \\
\hline 12 and above & NA & 20.8 & NA & 19.9 \\
\hline \multicolumn{5}{|l|}{ Current schooling status $^{5}$} \\
\hline Yes & 19.9 & 19.7 & 42.5 & 26.3 \\
\hline No & * & 21.6 & * & 46.9 \\
\hline \multicolumn{5}{|c|}{ Paid work in the 12 months prior to the interview } \\
\hline Yes & * & 11.7 & * & 44.0 \\
\hline No & 19.8 & 21.6 & 40.1 & 30.9 \\
\hline \multicolumn{5}{|l|}{ Wealth quintile } \\
\hline First & $(17.2)$ & * & $(60.6)$ & 36.1 \\
\hline Second & 27.7 & 22.6 & $(50.5)$ & 37.7 \\
\hline Third & 22.6 & 25.0 & 37.6 & 41.4 \\
\hline Fourth & 16.9 & 17.4 & 31.1 & 29.9 \\
\hline Fifth & 16.5 & 13.9 & 39.3 & 25.5 \\
\hline \multicolumn{5}{|c|}{ Mothers education (in years of schooling completed) } \\
\hline None $^{4}$ & 19.4 & 21.5 & 45.2 & 36.9 \\
\hline $1-7$ & 37.4 & 17.2 & $(31.2)$ & 27.8 \\
\hline $8-9$ & $(15.4)$ & 12.1 & $(19.3)$ & 21.6 \\
\hline 10 and above & 6.8 & 7.4 & $(31.2)$ & 16.0 \\
\hline Total & 20.4 & 19.2 & 42.0 & 32.9 \\
\hline
\end{tabular}

Notes: *Percentage not shown as this was based on fewer than 25 unweighted cases. () Based on 25-49 unweighted cases. NA: not applicable; OBC: other backward caste; SC: scheduled caste; ST: scheduled tribe. ${ }^{1}$ Percentages not shown for those belonging to other religions as less than one percent of surveyed adolescents belonged to other religions. ${ }^{2}$ Percentages not shown for those belonging to STs as less than one percent of surveyed adolescents belonged to STs. Includes all those not belonging to SCs, STs, or OBCs. ${ }^{4}$ Includes non-literate and literate with no formal schooling. ${ }^{5}$ Percentages not shown for adolescents who were never enrolled in school or were pursuing their education through distance education courses at the time of interview or those who never went to school. 


\subsubsection{Exposure to parental violence}

Several questions in the survey sought to elicit information on domestic violence, and, if prevalent, the extent to which it characterised family life. Specifically, we asked study participants whether they had ever witnessed incidents where their father had beaten their mother and whether their parents had physically abused them ever (slapping, beating, pulling their hair, pushing, throwing something at them, and so on) since they had turned 10 years of age. Respondents who reported that they had ever experienced physical violence perpetrated by parents were further probed about the forms of violence perpetrated by their parents. All adolescents, excluding married older girls, were additionally asked whether these events had taken place in the year preceding the interview.

Findings presented in Table 6.5 reveal that family life was characterised by domestic violence for many-18 percent of boys and 25-32 percent of girls with both parents alive at the time of the interview had ever witnessed incidents where their father had beaten their mother. Differences by age and residence in rural or urban areas were modest. Some 4-5 percent of boys and 9-18 percent of girls had witnessed incidents where their father had beaten their mother in the year preceding the interview. More of girls than boys and more of younger girls than older girls, had witnessed such violence; differences by residence in rural or urban areas were muted.

Large proportions of adolescents with at least one parent alive at the time of the interview reported that they had experienced physical violence perpetrated by a parent at some time since they had turned 10 years of age. Differences by age and sex were wide. Younger adolescents were more likely than their older counterparts to report the experience of physical violence perpetrated by a parent (69\% versus 55\% among boys and $56 \%$ versus $31-34 \%$ among girls). Boys were more likely than girls to report the experience of physical violence perpetrated by a parent (55-69\% versus 31-56\%). Differences by marital status among older girls were negligible. Differences by residence in rural or urban areas were evident among younger adolescents and among unmarried older adolescents, with rural respondents more likely than urban respondents to report the experience of physical violence by a parent ( $70 \%$ versus $64 \%$ among younger boys; $56 \%$ versus $50 \%$ among older boys; $58 \%$ versus $41 \%$ among younger girls; and $34 \%$ versus $27 \%$ among unmarried older girls).

Experience of physical violence perpetrated by a parent in the year preceding the interview was reported by considerably fewer adolescents (compared with those who reported that they had ever experienced violence by parents), and age differences were marked. Thus, 50 percent of younger boys compared with 12 percent of older boys and 42 percent of younger girls compared with 11 percent of unmarried older girls had experienced physical violence perpetrated by their mother or father in the year prior to the interview. Differences between those from rural and those from urban areas were noted among younger adolescents; more rural than urban adolescents had experienced physical violence in the year preceding the interview.

Among adolescents who had ever experienced violence perpetrated by a parent, slapping was the most common form of physical violence perpetrated, with 54-66 percent of boys and 31-56 percent of girls reporting this form of violence. Other forms of violence reported included punching with a fist or something that could hurt the respondent,kicking, dragging, or beating (13-18\% of boys and $2-9 \%$ of girls), pushing, or shaking, or throwing something at the respondent ( $6 \%$ of boys and $3-6 \%$ of girls), and twisting an arm or pulling hair (1-3\% of boys and $4-10 \%$ of girls). The forms of violence experienced by adolescents in both urban and rural areas were similar. Even so, more boys in rural than urban areas reported experiences of punching with fist or something that could hurt respondent and kicking, dragging, or beating. More of older boys, younger girls, and unmarried older girls in rural areas compared with their urban counterparts reported experiences of slapping. Finally, more of younger girls in rural than urban areas reported experience of pushing, shaking, or throwing something at respondent. 
Table 6.5: Exposure to parental violence

Percentage of adolescents reporting physical violence between parents and their having experienced physical violence perpetrated by a parent, according to residence, Bihar, 2016

\begin{tabular}{|c|c|c|c|c|c|}
\hline Exposure to parental violence & $\begin{array}{l}\text { Boys } \\
(10-14)\end{array}$ & $\begin{array}{l}\text { Boys } \\
(15-19)\end{array}$ & $\begin{array}{l}\text { Girls } \\
(10-14)\end{array}$ & $\begin{array}{l}\text { Girls } \\
(15-19)\end{array}$ & $\begin{array}{l}\text { Married girls } \\
\quad(15-19)\end{array}$ \\
\hline \multicolumn{6}{|c|}{ Combined (percent) } \\
\hline \multicolumn{6}{|l|}{ Physical violence between parents } \\
\hline Father ever beaten mother & 18.3 & 17.8 & 30.0 & 25.4 & 31.8 \\
\hline Father beaten mother in the 12 months prior to the interview & 5.0 & 4.4 & 17.7 & 9.3 & NA \\
\hline Number of respondents with both parents alive & 804 & 1,409 & 608 & 2,685 & 3,328 \\
\hline \multicolumn{6}{|l|}{ Experience of physical violence perpetrated by a parent } \\
\hline Experienced physical violence since age 10 & 69.2 & 55.3 & 56.2 & 33.5 & 31.7 \\
\hline $\begin{array}{l}\text { Experienced physical violence in the } 12 \text { months prior to the } \\
\text { interview }\end{array}$ & 50.2 & 12.1 & 41.9 & 10.7 & NA \\
\hline \multicolumn{6}{|l|}{ Forms of physical violence ever experienced } \\
\hline Slapping & 65.7 & 53.6 & 55.7 & 33.3 & 31.3 \\
\hline Twisting arm/pulling hair & 3.3 & 1.4 & 9.9 & 4.2 & 4.5 \\
\hline Pushing/shaking/throwing something at respondent & 6.1 & 5.7 & 5.5 & 3.0 & 2.5 \\
\hline $\begin{array}{l}\text { Punching with fist or with something that could hurt } \\
\text { respondent/kicking/dragging/beating }\end{array}$ & 18.3 & 13.1 & 8.6 & 2.9 & 2.3 \\
\hline Trying to choke/burning on purpose & 0.0 & 0.0 & 0.3 & 0.0 & 0.0 \\
\hline Threatening/attacking with a knife or gun or any other weapon & 0.0 & 0.0 & 0.0 & 0.0 & 0.0 \\
\hline Number of respondents with at least one parent alive & 982 & 1,715 & 737 & 3,301 & 3,408 \\
\hline \multicolumn{6}{|c|}{ Urban (percent) } \\
\hline \multicolumn{6}{|l|}{ Physical violence between parents } \\
\hline Father ever beaten mother & 14.3 & 13.4 & 29.1 & 22.4 & 30.3 \\
\hline Father beaten mother in the 12 months prior to the interview & 5.6 & 3.5 & 13.8 & 7.9 & NA \\
\hline Number of respondents with both parents alive & 374 & 784 & 322 & 1,388 & 1,341 \\
\hline \multicolumn{6}{|l|}{ Experience of physical violence perpetrated by a parent } \\
\hline Experienced physical violence since age 10 & 64.3 & 49.8 & 41.4 & 26.7 & 27.7 \\
\hline $\begin{array}{l}\text { Experienced physical violence in the } 12 \text { months prior to the } \\
\text { interview }\end{array}$ & 44.2 & 9.2 & 30.4 & 8.1 & NA \\
\hline \multicolumn{6}{|l|}{ Forms of physical violence ever experienced } \\
\hline Slapping & 62.5 & 48.0 & 40.9 & 26.3 & 27.3 \\
\hline Twisting arm/pulling hair & 2.6 & 1.2 & 2.8 & 2.3 & 3.3 \\
\hline Pushing/shaking/throwing something at respondent & 5.2 & 6.3 & 1.6 & 1.5 & 2.2 \\
\hline $\begin{array}{l}\text { Punching with fist or with something that could hurt } \\
\text { respondent/kicking/dragging/beating }\end{array}$ & 11.4 & 8.9 & 5.7 & 1.8 & 1.7 \\
\hline Trying to choke/burning on purpose & 0.1 & 0.0 & 0.0 & 0.0 & 0.0 \\
\hline Threatening/attacking with a knife or gun or any other weapon & 0.0 & 0.2 & 0.0 & 0.0 & 0.0 \\
\hline Number of respondents with at least one parent alive & 435 & 921 & 375 & 1,657 & 1,366 \\
\hline
\end{tabular}


Table 6.5 Cont.

\begin{tabular}{|c|c|c|c|c|c|}
\hline Exposure to parental violence & $\begin{array}{c}\text { Boys } \\
(10-14)\end{array}$ & $\begin{array}{c}\text { Boys } \\
(15-19)\end{array}$ & $\begin{array}{c}\text { Girls } \\
(10-14)\end{array}$ & $\begin{array}{c}\text { Girls } \\
(15-19)\end{array}$ & $\begin{array}{l}\text { Married girls } \\
(15-19)\end{array}$ \\
\hline \multicolumn{6}{|c|}{ Rural (percent) } \\
\hline \multicolumn{6}{|l|}{ Physical violence between parents } \\
\hline Father ever beaten mother & 18.8 & 18.4 & 30.1 & 25.8 & 31.9 \\
\hline Father beaten mother in the 12 months prior to the interview & 4.9 & 4.6 & 18.2 & 9.5 & NA \\
\hline Number of respondents with both parents alive & 430 & 625 & 286 & 1,297 & 1,987 \\
\hline \multicolumn{6}{|l|}{ Experience of physical violence perpetrated by a parent } \\
\hline Experienced physical violence since age 10 & 69.8 & 55.9 & 58.1 & 34.2 & 32.2 \\
\hline Experienced physical violence in the 12 months prior to the interview & 50.9 & 12.4 & 43.4 & 11.0 & NA \\
\hline \multicolumn{6}{|l|}{ Forms of physical violence ever experienced } \\
\hline Slapping & 66.1 & 54.3 & 57.6 & 34.1 & 31.7 \\
\hline Twisting arm/pulling hair & 3.3 & 1.4 & 10.8 & 4.5 & 4.6 \\
\hline Pushing/shaking/throwing something at respondent & 6.2 & 5.7 & 5.9 & 3.2 & 2.6 \\
\hline $\begin{array}{l}\text { Punching with fist or with something that could hurt } \\
\text { respondent/kicking/dragging/beating }\end{array}$ & 19.2 & 13.6 & 9.0 & 3.0 & 2.3 \\
\hline Trying to choke/burning on purpose & 0.0 & 0.0 & 0.3 & 0.0 & 0.0 \\
\hline Threatening/attacking with a knife or gun or any other weapon & 0.0 & 0.0 & 0.0 & 0.0 & 0.0 \\
\hline Number of respondents with at least one parent alive & 547 & 794 & 362 & 1,644 & 2,042 \\
\hline
\end{tabular}

Note: All Ns are unweighted. NA: not applicable.

\subsubsection{Communication with parents}

The survey elicited information regarding the extent of communication with parents from all respondents who reported that their mother or father was alive at the time of interview. We did not include married older girls in our assessment of parent-child communication. We probed communication between parents and adolescents in the year preceding the interview on issues relevant to adolescents, such as school performance, friendship, being teased or bullied, physical changes during adolescence, for example, voice change and facial hair growth (boys)/menstruation (girls), and reproductive processes. We posed questions related to adolescents' being teased or bullied to younger adolescents only, while we posed questions related to reproductive processes to older adolescents only.

Findings, presented in Table 6.6, reveal that communication on even such non-sensitive topics as school performance and friendship was far from universal-for example, just 50-60 percent of boys and 65-67 percent of girls who were pursuing their studies at the time of the interview reported their having discussed their school performance with their father in the year preceding the interview. While approximately the same proportions of younger and older boys who were in school/college had discussed their school/college performance with their mother (56-61\%) as they had with their father, more of younger girls and unmarried older girls had done so with their mother $(84-87 \%)$ than their father.

Of all adolescents, 21-27 percent of boys and 26-30 percent of girls reported that they had discussed their friends with their father in the year preceding the interview. Larger proportions, particularly girls, had discussed their friends with their mother during the same reference period ( $37 \%$ of boys and $72-77 \%$ of girls).

Sensitive topics-such as being teased or bullied, physical changes during adolescence, and reproductive processeswere rarely discussed with either parent, particularly by boys. Thus, only 13 percent of younger boys and six percent of younger girls reported that they had discussed their being teased or bullied with their father in the year preceding the interview, though a larger proportion of younger adolescents had discussed such experiences with their mother during the same reference period (24\% of boys and $35 \%$ of girls). Some 1-2 percent of boys and less than one percent of girls had discussed such physical changes during adolescence as voice change and facial hair growth (boys)/ menstruation (girls) with their father. While a very small proportion of boys had discussed such topics with their mother 
(3-4\%), a considerably larger proportion of girls, particularly unmarried older girls, had done so (32\% of younger girls and $74 \%$ of unmarried older girls). Finally, very few older boys ( $1 \%$ or less) and unmarried older girls (3\% or less)reported that they had discussed reproductive processes with their father or mother in the year prior to the interview.

We observed differences by age with respect to communication on school performance with fathers (but not with mothers). Younger boys (but not girls) who were pursuing their education at the time of the interview were less likely than their older counterparts to have discussed school performance with their father (50\% versus $60 \%)$. While we did not observe differences by age with respect to parent-adolescent communication on physical changes during adolescence among boys, unmarried older girls were more likely than younger girls to have discussed menstruation with their mother, which perhaps reflects that discussion on menstruation is rarely initiated before its onset.

There were differences in the extent of communication by the sex of the study participants as well as the sex of the parents. Older boys were about as likely to discuss all topics with their mother as with their father other than friendships, which more boys discussed with their mother than their father (37\% versus $27 \%$ ). However, the patterns differed among younger boys and younger girls and unmarried older girls. Younger boys were more likely to discuss the topics of friendships and their being teased or bullied with their mother than their father (37\% versus $21 \%$ with regard to the topic of friendship and $24 \%$ versus $13 \%$ with regard to the topic of teasing and bullying), while they were about as likely to discuss school performance and physical changes during adolescence with their mother as with their father. Finally, younger girls and unmarried older girls were more likely to discuss each topic with their mother than their father, except for reproductive processes, which unmarried older girls rarely discussed with either their mother or their father.

Differences by residence in rural or urban areas in communication with parents show greater openness with a parent among urban adolescents compared with rural adolescents with regard to matters related to school performance and friendship, although this was not consistently observed across all categories of adolescents. Younger and older boys in urban areas, for example, were more likely than their rural counterparts to have discussed school performance with their father (62-68\% versus $48-59 \%$ ) as well as their mother (68-70\% versus $54-60 \%)$. Differences were modest among girls, except that more urban than rural unmarried older girls discussed their performance in school with their father (72\% versus 66\%). Similarly, younger and older boys and unmarried older girls in urban areas were more likely than their rural counterparts to have discussed their friends with their father and mother (34-39\% versus $20-26 \%$ with respect to fathers and $48-54 \%$ versus $35 \%$ with respect to mothers among boys; $35 \%$ versus $25 \%$ with respect to fathers and $79 \%$ versus $71 \%$ with respect to mothers among unmarried older girls). Urban younger adolescents were more likely than rural younger adolescents to have discussed their being teased or bullied with their father (19\% versus $12 \%$ among boys and $13 \%$ versus $5 \%$ among girls) and younger girls in urban areas were also more likely to have done so with their mother than those in rural areas (44\% versus $34 \%$ ). Similarly, more urban girls discussed menstruation with their mother compared with rural girls (41\% versus $31 \%$ among younger girls and $79 \%$ versus $73 \%$ among unmarried older girls).

\section{Table 6.6: Parental communication}

Percentage of adolescents ${ }^{1}$ who discussed selected matters with their parents in the year prior to the interview, according to residence, Bihar, 2016

\begin{tabular}{|c|c|c|c|c|c|c|c|c|}
\hline \multirow[b]{2}{*}{ Topic } & \multicolumn{4}{|c|}{ Father } & \multicolumn{4}{|c|}{ Mother } \\
\hline & $\begin{array}{c}\text { Boys } \\
(10-14)\end{array}$ & $\begin{array}{c}\text { Boys } \\
(15-19)\end{array}$ & $\begin{array}{c}\text { Girls } \\
(10-14)\end{array}$ & $\begin{array}{l}\text { Girls } \\
(15-19)\end{array}$ & $\begin{array}{c}\text { Boys } \\
(10-14)\end{array}$ & $\begin{array}{c}\text { Boys } \\
(15-19)\end{array}$ & $\begin{array}{l}\text { Girls } \\
(10-14)\end{array}$ & $\begin{array}{c}\text { Girls } \\
(15-19)\end{array}$ \\
\hline \multicolumn{9}{|c|}{ Combined (percent) } \\
\hline School performance & 49.7 & 59.7 & 65.4 & 66.7 & 55.8 & 60.6 & 83.9 & 87.2 \\
\hline $\begin{array}{l}\text { Number of respondents with at least one } \\
\text { parent alive and currently attending school }\end{array}$ & 925 & 1,321 & 667 & 2,263 & 925 & 1,321 & 667 & 2,263 \\
\hline Friendship & 21.3 & 27.1 & 29.8 & 26.4 & 37.2 & 36.7 & 76.7 & 71.6 \\
\hline Being teased or bullied & 13.0 & NA & 6.1 & NA & 24.0 & NA & 34.9 & NA \\
\hline $\begin{array}{l}\text { Physical changes during adolescence } \\
\text { (boys)/menstruation (girls) }\end{array}$ & 1.0 & 2.4 & 0.5 & 0.3 & 3.6 & 3.3 & 32.1 & 74.0 \\
\hline Reproductive processes & NA & 1.1 & NA & 0.9 & NA & 0.1 & NA & 3.3 \\
\hline $\begin{array}{l}\text { Number of respondents with at least } \\
\text { one parent alive }\end{array}$ & 982 & 1,715 & 737 & 3,301 & 982 & 1,715 & 737 & 3,301 \\
\hline
\end{tabular}


Table 6.6 Cont.

\begin{tabular}{|c|c|c|c|c|c|c|c|c|}
\hline \multirow[b]{2}{*}{ Topic } & \multicolumn{4}{|c|}{ Father } & \multicolumn{4}{|c|}{ Mother } \\
\hline & $\begin{array}{c}\text { Boys } \\
(10-14)\end{array}$ & $\begin{array}{c}\text { Boys } \\
(15-19)\end{array}$ & $\begin{array}{l}\text { Girls } \\
(10-14)\end{array}$ & $\begin{array}{l}\text { Girls } \\
(15-19)\end{array}$ & $\begin{array}{c}\text { Boys } \\
(10-14)\end{array}$ & $\begin{array}{c}\text { Boys } \\
(15-19)\end{array}$ & $\begin{array}{c}\text { Girls } \\
(10-14)\end{array}$ & $\begin{array}{c}\text { Girls } \\
(15-19)\end{array}$ \\
\hline \multicolumn{9}{|c|}{ Urban (percent) } \\
\hline School performance & 62.2 & 68.1 & 69.2 & 71.7 & 69.6 & 67.9 & 86.5 & 88.0 \\
\hline $\begin{array}{l}\text { Number of respondents with at least } \\
\text { one parent alive and currently attending } \\
\text { school }\end{array}$ & 406 & 698 & 342 & 1,184 & 406 & 698 & 342 & 1,184 \\
\hline Friendship & 34.1 & 39.0 & 33.3 & 35.3 & 54.0 & 48.4 & 79.2 & 79.3 \\
\hline Being teased or bullied & 18.9 & NA & 13.1 & NA & 27.2 & NA & 44.0 & NA \\
\hline $\begin{array}{l}\text { Physical changes during adolescence } \\
\text { (boys)/menstruation (girls) }\end{array}$ & 1.0 & 3.2 & 0.0 & 0.6 & 3.9 & 5.2 & 40.5 & 78.9 \\
\hline Reproductive processes & NA & 0.6 & NA & 0.7 & NA & 0.2 & NA & 3.9 \\
\hline $\begin{array}{l}\text { Number of respondents with at least } \\
\text { one parent alive }\end{array}$ & 435 & 921 & 375 & 1,657 & 435 & 921 & 375 & 1,657 \\
\hline \multicolumn{9}{|c|}{ Rural (percent) } \\
\hline School performance & 48.3 & 58.7 & 64.9 & 66.1 & 54.2 & 59.8 & 83.6 & 87.1 \\
\hline $\begin{array}{l}\text { Number of respondents with at least } \\
\text { one parent alive and currently attending } \\
\text { school }\end{array}$ & 519 & 623 & 325 & 1,079 & 519 & 623 & 325 & 1,079 \\
\hline Friendship & 19.8 & 25.8 & 29.4 & 25.4 & 35.3 & 35.4 & 76.3 & 70.7 \\
\hline Being teased or bullied & 12.3 & NA & 5.3 & NA & 23.6 & NA & 33.8 & NA \\
\hline $\begin{array}{l}\text { Physical changes during adolescence } \\
\text { (boys)/menstruation (girls) }\end{array}$ & 1.0 & 2.3 & 0.6 & 0.3 & 3.6 & 3.1 & 31.1 & 73.4 \\
\hline Reproductive processes & NA & 1.1 & NA & 0.9 & NA & 0.1 & NA & 3.3 \\
\hline $\begin{array}{l}\text { Number of respondents with at least } \\
\text { one parent alive }\end{array}$ & 547 & 794 & 362 & 1,644 & 547 & 794 & 362 & 1,644 \\
\hline
\end{tabular}

Notes: All Ns are unweighted. NA: not applicable. ${ }^{1}$ Excludes married older girls.

\subsection{Role models, confidantes, and sources for learning social behaviours}

In addition to probing peer and parental interactions among the study participants of UDAYA, we included questions to elicit information on their role models, confidantes with whom they discussed personal problems, and their sources for learning social behaviours. Findings are described below.

\subsubsection{Role models}

The survey sought to find out whether the respondents had any role models and, if so, whom they considered their role model. Findings presented in Figure 6.3 show that 34-40 percent of boys and 21-31 percent of girls had a role model. Differences by age were narrow among girls in this respect, but more of older than younger boys (40\% versus $34 \%$ ) reported a role model. Moreover, more of older boys than unmarried older girls ( $40 \%$ versus $31 \%$ ), and more of unmarried than married older girls (31\% versus $21 \%$ ) reported a role model. More urban than rural adolescents across all categories had a role model. 


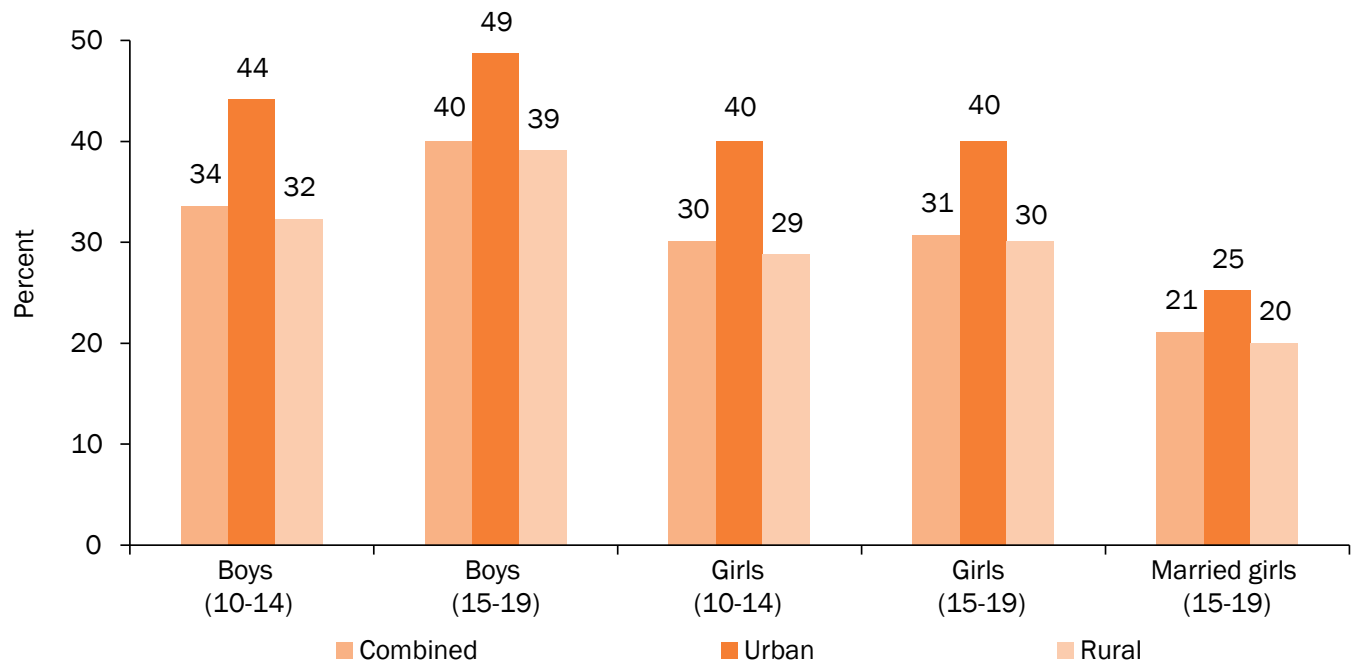

Among those who reported a role model, the majority reported that their role model was someone from their family-67-69 percent of boys and 63-72 percent of girls (Table 6.7). Younger and older boys typically reported their father (11-15\%), brothers (16-19\%), and other relatives (34-37\%) as their role models. Girls on the other hand typically reported as role models their mother (15-29\%), father (9-11\%), brothers $(7-11 \%)$, sisters (10-17\%), and other relatives (21-28\%). Teachers were the leading non-family role models reported by adolescents among all categories of adolescents ( $9-14 \%$ of boys and $21-31 \%$ of girls), followed by friends and neighbours (6-11\% of boys and $6-9 \%$ of girls). Only a small proportion of adolescents-eight percent of boys and 1-3 percent of girls-reported such high profile personalities as actors, politicians, or sports persons as their role models.

The role models cited by younger and older adolescents were similar, except that younger girls were more likely than unmarried and married older girls to list their sisters as their role models (17\% versus $10 \%$ ), but less likely to identify other relatives (21\% versus $26-28 \%$ ). Differences by sex were notable. Boys, regardless of age, were less likely than girls to report a female family member, including mother (4-8\% versus $15-29 \%)$ and sisters (1-2\% versus $10-17 \%)$. In contrast, they were more likely than girls to cite a male family member, particularly brothers $(16-19 \%$ versus $7-11 \%$ ). Additionally, boys were more likely to mention other relatives (34-37\% versus $21-28 \%$ ), but less likely to mention teachers $(9-14 \%$ versus $21-31 \%)$. They were also slightly more likely to mention high profile personalities as their role models ( $8 \%$ versus $1-3 \%$ ).

Role models differed by marital status among older girls. While unmarried older girls were less likely than their married counterparts to mention mothers as their role model (15\% versus $29 \%)$, they were more likely to mention teachers (28\% versus $21 \%)$. Married older girls were more likely than unmarried older girls to report someone in the family in general (72\% versus $63 \%)$.

Finally, though role models listed by rural and urban adolescents were similar for the most part, we observed some differences in their reports. A smaller proportion of younger boys in urban than rural areas cited a family member as their role model (59\% versus $68 \%$ ). Likewise, a smaller proportion of younger girls from urban than rural areas reported sisters (10\% versus $18 \%$ ) and teachers (19\% versus 33\%) as their role model. Finally, unmarried older girls in urban areas were more likely than their counterparts in rural areas to mention their father (17\% versus $8 \%$ ) as their role model, but less likely to cite teachers (16\% versus $30 \%)$. 
Table 6.7: Adolescents' role models

Percentage of adolescents reporting role models by person they considered a role model, according to residence, Bihar, 2016

\begin{tabular}{|c|c|c|c|c|c|}
\hline Person identified as role model & $\begin{array}{c}\text { Boys } \\
(10-14)\end{array}$ & $\begin{array}{c}\text { Boys } \\
(15-19)\end{array}$ & $\begin{array}{c}\text { Girls } \\
(10-14)\end{array}$ & $\begin{array}{c}\text { Girls } \\
(15-19)\end{array}$ & $\begin{array}{c}\text { Married girls } \\
(15-19)\end{array}$ \\
\hline \multicolumn{6}{|c|}{ Combined (percent) } \\
\hline Mother & 8.3 & 3.7 & 19.6 & 14.5 & 28.2 \\
\hline Father & 15.2 & 11.0 & 11.0 & 9.4 & 11.0 \\
\hline Brother & 16.0 & 19.4 & 8.5 & 11.0 & 6.9 \\
\hline Sister & 0.7 & 1.7 & 17.1 & 9.7 & 10.5 \\
\hline Husband & NA & NA & NA & NA & 0.2 \\
\hline Other relatives & 34.0 & 37.0 & 20.8 & 28.1 & 25.9 \\
\hline Friends and neighbours & 6.1 & 11.1 & 5.7 & 8.5 & 6.6 \\
\hline Teachers & 13.9 & 8.5 & 31.1 & 27.8 & 22.1 \\
\hline Actors and singers & 2.0 & 1.2 & 0.7 & 1.0 & 0.1 \\
\hline Politicians & 2.0 & 5.1 & 0.3 & 1.5 & 0.4 \\
\hline Sports persons & 3.1 & 1.3 & 0.6 & 0.3 & 0.0 \\
\hline Men in police or armed forces & 1.3 & 1.5 & 0.7 & 1.1 & 0.8 \\
\hline Technical professionals $^{1}$ & 4.4 & 2.2 & 4.8 & 1.6 & 1.2 \\
\hline Freedom fighters/social activists & 1.1 & 0.0 & 0.0 & 0.1 & 0.0 \\
\hline Community workers & 0.2 & 0.4 & 0.8 & 1.6 & 2.7 \\
\hline Others & 0.8 & 1.2 & 0.2 & 0.5 & 0.1 \\
\hline Someone in the family ${ }^{2}$ & 66.6 & 69.4 & 67.1 & 63.3 & 71.2 \\
\hline High profile personalities ${ }^{3}$ & 8.2 & 7.5 & 1.6 & 2.7 & 0.5 \\
\hline Number of respondents who reported their having a role model & 389 & 813 & 261 & 1,202 & 736 \\
\hline \multicolumn{6}{|c|}{ Urban (percent) } \\
\hline Mother & 3.6 & 5.4 & 16.6 & 12.6 & 31.6 \\
\hline Father & 15.7 & 16.0 & 11.3 & 16.5 & 10.8 \\
\hline Brother & 15.8 & 16.7 & 14.7 & 12.6 & 5.4 \\
\hline Sister & 0.6 & 0.1 & 9.9 & 10.1 & 7.9 \\
\hline Husband & NA & NA & NA & NA & 1.6 \\
\hline Other relatives & 28.5 & 34.3 & 22.1 & 25.8 & 27.9 \\
\hline Friends and neighbours & 10.6 & 6.9 & 6.8 & 7.7 & 8.3 \\
\hline Teachers & 8.8 & 5.3 & 19.1 & 16.3 & 16.8 \\
\hline Actors and singers & 4.8 & 2.8 & 1.2 & 2.8 & 1.1 \\
\hline Politicians & 5.3 & 6.4 & 2.1 & 3.4 & 1.5 \\
\hline Sports persons & 6.7 & 4.1 & 1.3 & 0.6 & 0.0 \\
\hline Men in police or armed forces & 1.0 & 0.5 & 1.8 & 1.6 & 0.9 \\
\hline Technical professionals ${ }^{1}$ & 3.8 & 3.4 & 6.6 & 2.6 & 0.0 \\
\hline Freedom fighters/social activists & 0.6 & 0.0 & 0.0 & 0.3 & 0.0 \\
\hline Community workers & 0.0 & 0.9 & 0.0 & 1.8 & 1.3 \\
\hline Others & 3.0 & 4.5 & 1.3 & 0.7 & 0.0 \\
\hline Someone in the family ${ }^{2}$ & 59.0 & 67.2 & 66.7 & 68.0 & 76.2 \\
\hline High profile personalities ${ }^{3}$ & 17.5 & 13.1 & 4.5 & 6.9 & 2.7 \\
\hline Number of respondents who reported their having a role model & 193 & 492 & 161 & 698 & 326 \\
\hline
\end{tabular}


Table 6.7 Cont.

\begin{tabular}{|c|c|c|c|c|c|}
\hline Person identified as role model & $\begin{array}{c}\text { Boys } \\
(10-14)\end{array}$ & $\begin{array}{c}\text { Boys } \\
(15-19)\end{array}$ & $\begin{array}{c}\text { Girls } \\
(10-14)\end{array}$ & $\begin{array}{c}\text { Girls } \\
(15-19)\end{array}$ & $\begin{array}{c}\text { Married girls } \\
(15-19)\end{array}$ \\
\hline \multicolumn{6}{|c|}{ Rural (percent) } \\
\hline Mother & 9.1 & 3.4 & 20.1 & 14.8 & 27.7 \\
\hline Father & 15.1 & 10.2 & 10.9 & 8.2 & 11.0 \\
\hline Brother & 16.1 & 19.8 & 7.4 & 10.7 & 7.2 \\
\hline Sister & 0.7 & 1.9 & 18.3 & 9.7 & 10.9 \\
\hline Husband & NA & NA & NA & NA & 0.0 \\
\hline Other relatives & 34.9 & 37.4 & 20.6 & 28.5 & 25.6 \\
\hline Friends and neighbours & 5.3 & 11.7 & 5.6 & 8.6 & 6.4 \\
\hline Teachers & 14.7 & 9.0 & 33.1 & 29.7 & 22.9 \\
\hline Actors and singers & 1.6 & 0.9 & 0.6 & 0.7 & 0.0 \\
\hline Politicians & 1.5 & 4.8 & 0.0 & 1.1 & 0.2 \\
\hline Sports persons & 2.5 & 0.8 & 0.5 & 0.2 & 0.0 \\
\hline Men in police or armed forces & 1.4 & 1.6 & 0.6 & 1.0 & 0.8 \\
\hline Technical professionals ${ }^{1}$ & 4.5 & 2.1 & 4.5 & 1.5 & 1.4 \\
\hline Freedom fighters/social activists & 1.1 & 0.0 & 0.0 & 0.1 & 0.0 \\
\hline Community workers & 0.3 & 0.3 & 1.0 & 1.6 & 2.8 \\
\hline Other & 0.4 & 0.7 & 0.0 & 0.4 & 0.1 \\
\hline Someone in the family ${ }^{2}$ & 67.8 & 69.8 & 67.2 & 62.5 & 70.5 \\
\hline High profile personalities ${ }^{3}$ & 6.7 & 6.6 & 1.1 & 2.0 & 0.2 \\
\hline Number of respondents who reported their having a role model & 196 & 321 & 100 & 504 & 410 \\
\hline
\end{tabular}

Notes: All Ns are unweighted. NA: not applicable. Percentages add to more than 100 because of multiple responses. ${ }^{1}$ Includes doctors, engineers, scientists, and civil servants. ${ }^{2}$ Includes parents, siblings, husband, and other relatives. ${ }^{3}$ Includes actors, singers, politicians, freedom fighters, social activists, and sports persons.

\subsubsection{Leading confidante on personal matters}

This section presents findings on the support networks of adolescents. We asked respondents about the individual with whom they would be the most likely to discuss a range of personal matters. These personal matters varied by age, and they included experiences of teasing or bullying and any problem in their private parts for all younger adolescents and, additionally, for those in ages 13-14 years, a relationship with an opposite-sex friend. Among older adolescents, these personal matters included any problem in their private parts, a relationship with an opposite-sex friend or a romantic partner (for unmarried older girls), or a problem in married life (for married older girls). Teasing and bullying were not matters raised for older adolescents.

Findings, reported in Table 6.8, indicate that the person with whom adolescents would be the most likely to discuss personal matters varied considerably by age, sex, and, among older girls, by marital status, as well as by topic. Younger boys and girls tended to consider their mother as the leading confidante on such matters as experience of teasing or bullying ( $51 \%$ of boys and $82 \%$ of girls) and a problem in the private parts ( $69 \%$ of boys and $88 \%$ of girls). Fathers constituted the second choice of confidante on both these matters for younger boys ( $24 \%$ and $20 \%$, respectively), but they were not so for younger girls on such matters (3\% or less). Teachers were also listed as a leading confidante for discussing the experience of teasing or bullying for younger boys (10\%). As far as a relationship with an opposite-sex friend was concerned, younger girls in ages 13-14 cited their mother as the leading confidante (37\%), followed by friends (24\%), while younger boys in ages 13-14 mentioned friends (36\%), followed by mothers (20\%). Notable proportions of younger adolescents (5-9\%) reported that they would not confide in anyone about their experience of teasing or bullying. Similarly, among 13-14-year-old adolescents, 39 percent of boys and 28 percent of girls reported that they would not confide in anyone about a relationship with an opposite-sex friend. 


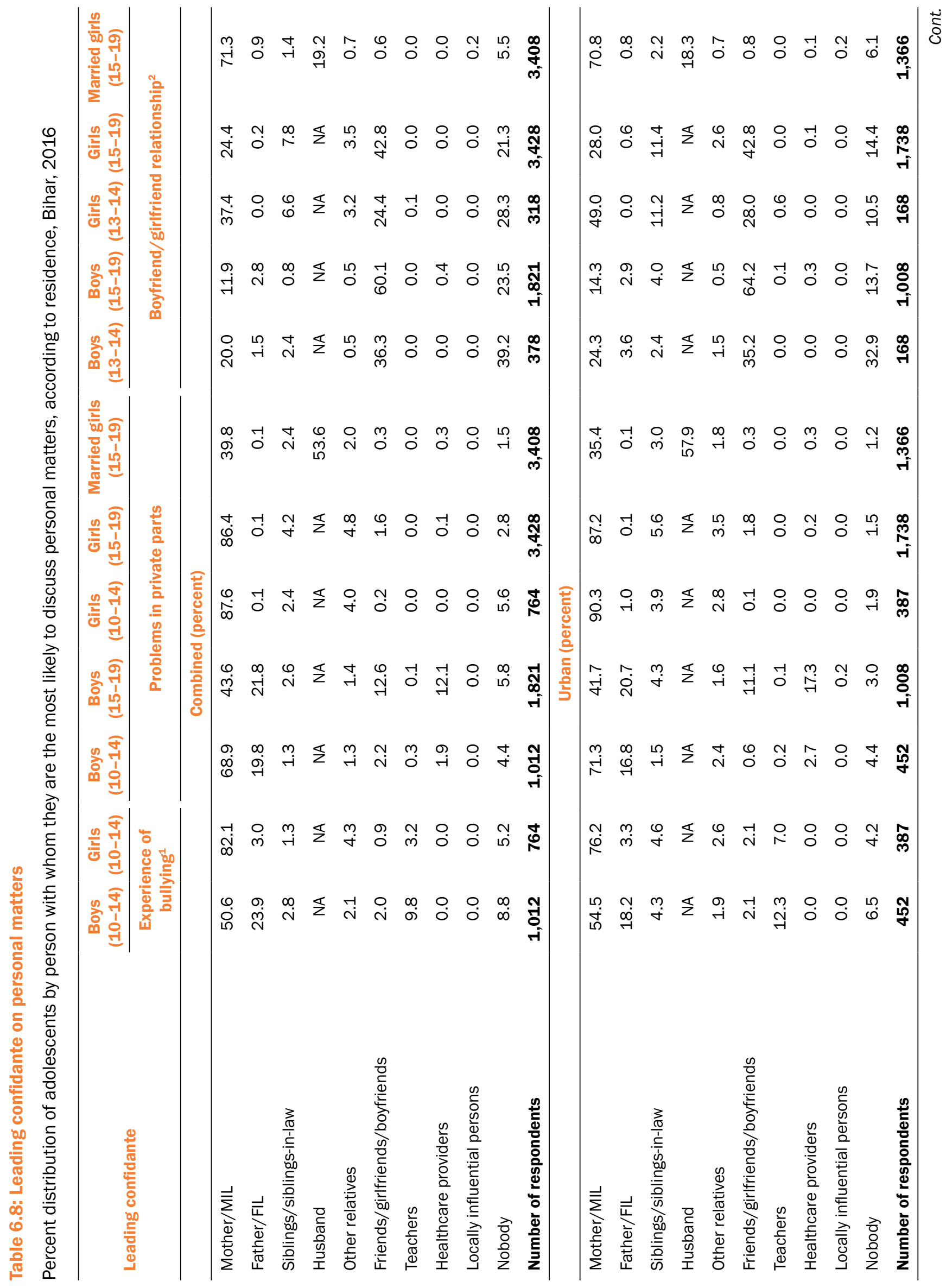




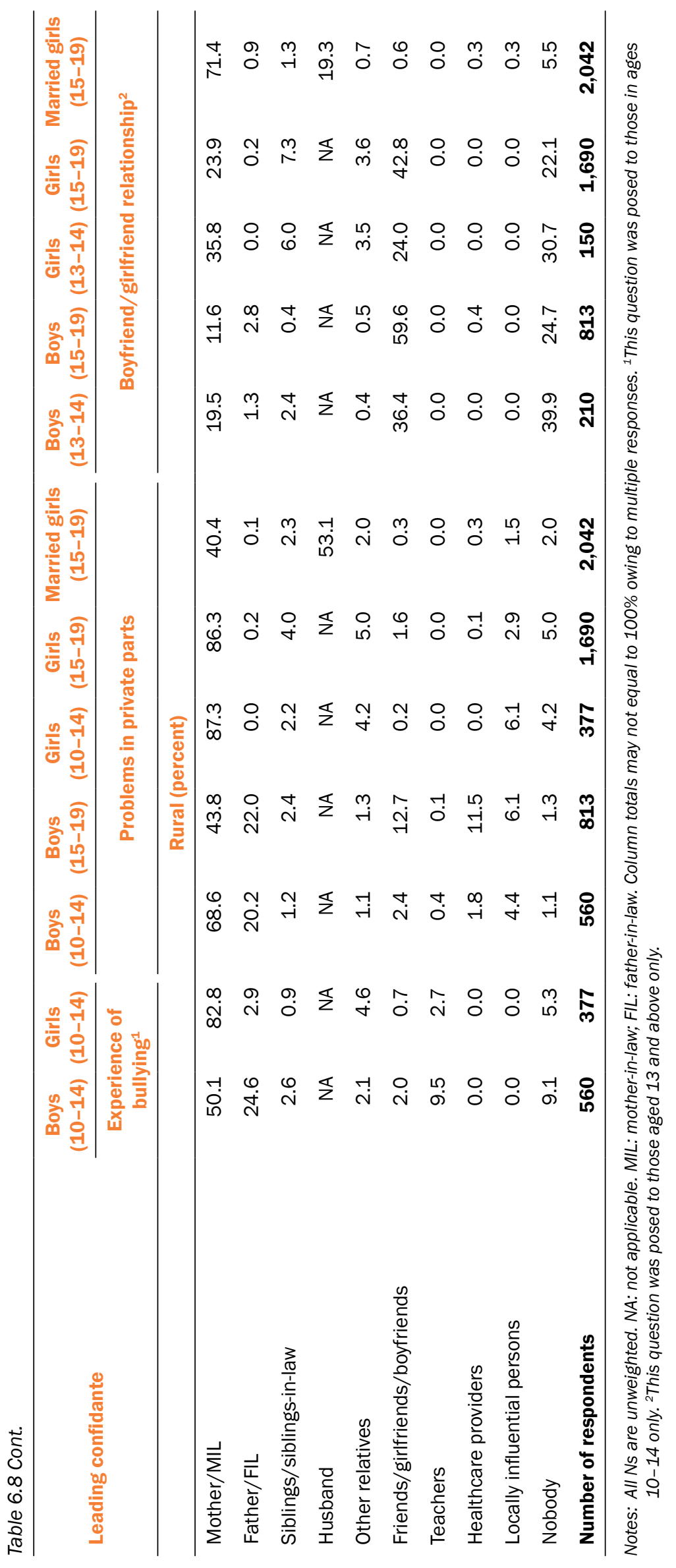


Leading confidantes for older adolescents varied somewhat. Indeed, with regard to a problem in the private parts, the mother constituted the leading confidante for both older boys (44\%) and unmarried older girls (86\%). Boys additionally mentioned their father (22\%), friends (13\%), and healthcare providers (12\%) as their leading confidantes. Married older girls cited their husband (54\%) and their mother (39\%). A completely different picture emerges with regard to the person in whom the respondent is the most likely to confide matters pertaining to opposite-sex friends or romantic partners. Friends were cited as leading confidantes by those in ages $15-19$, excluding married older girls, (60\% of boys and $43 \%$ of girls), followed by mothers ( $12 \%$ of boys and $24 \%$ of girls). Of note is that $21-24$ percent of boys and girls reported that they would not confide relationship matters to anyone. Among married older girls, in contrast, the leading confidante for discussing a problem in their married life was their mother (71\%), followed by their husband (19\%).

Leading confidantes listed by rural and urban adolescents mirrored largely that which was described above for the combined sample, though some differences were notable. Younger boys in urban areas were somewhat less likely than those in rural areas to confide in their fathers about their experience of teasing and bullying (18\% versus $25 \%$ ) as were urban younger girls than rural younger girls to confide in their mothers ( $76 \%$ versus $83 \%)$. In contrast, younger girls in ages 13-14 in urban areas were more likely than rural girls to confide in their mothers about opposite-sex relationships ( $49 \%$ versus $36 \%$ ).

\subsubsection{Sources for learning social behaviours}

Findings about persons from whom or sources from which study participants learned how to behave with others are presented in Table 6.9. Two major sources that adolescents reported, irrespective of age, sex, residence in rural or urban areas, and, among older girls, of marital status, were their parents-notably their mother (reported by $76-80 \%$ of boys and $88-89 \%$ of girls), followed by their father (reported by $71-76 \%$ of boys and $68-71 \%$ of girls). All categories of adolescents cited teachers as their major source for learning social behaviours (42-46\% of boys; $25-28 \%$ of younger girls and unmarried older girls; and $12 \%$ of married older girls). Some $9-10$ percent of boys and 4-11 percent of girls cited a grandparent. Other sources, cited by adolescents, included same-sex siblings (18-21\% of boys and $12-15 \%$ of girls), other relatives (13\% of older boys and $15-22 \%$ of girls), brothers (11-15\% of unmarried and married older girls) and friends (16\% of older boys). A small minority-5-7 percent of boys and 3-5 percent of girls-did not identify any sources for learning social behaviours.

\section{Table 6.9: Persons from whom or sources from which adolescents learned social behaviours}

Percentage of adolescents reporting persons from whom or sources from which they learned how to behave with others, according to residence, Bihar, 2016

\begin{tabular}{lrrrrr}
\hline Persons/sources & $\begin{array}{c}\text { Boys } \\
(\mathbf{1 0}-\mathbf{1 4})\end{array}$ & $\begin{array}{c}\text { Boys } \\
(\mathbf{1 5}-\mathbf{1 9})\end{array}$ & $\begin{array}{c}\text { Girls } \\
(\mathbf{1 0}-\mathbf{1 4})\end{array}$ & $\begin{array}{c}\text { Girls } \\
(\mathbf{1 5}-\mathbf{1 9})\end{array}$ & $\begin{array}{c}\text { Married girls } \\
(\mathbf{1 5}-\mathbf{1 9})\end{array}$ \\
\hline Combined (percent) & & & & & \\
\hline Mother & 76.3 & 79.8 & 89.2 & 88.3 & 88.9 \\
Father & 70.8 & 76.1 & 68.0 & 70.7 & 69.9 \\
Brother & 17.9 & 21.4 & 8.8 & 14.7 & 10.9 \\
Sister & 8.2 & 5.5 & 14.6 & 14.6 & 12.3 \\
Grandparents & 10.2 & 8.6 & 10.5 & 8.2 & 4.2 \\
Other relatives & 8.3 & 12.5 & 14.7 & 18.6 & 22.3 \\
Friends & 7.3 & 15.8 & 3.7 & 7.9 & 5.0 \\
Teacher & 45.5 & 42.3 & 27.5 & 24.6 & 11.9 \\
Films/TV/internet & 0.4 & 0.1 & 0.4 & 0.9 & 0.5 \\
Husband & NA & NA & NA & NA & 7.5 \\
None & 7.2 & 4.8 & 3.0 & 4.1 & 4.5 \\
Others & 0.3 & 0.2 & 0.0 & 0.3 & 0.2 \\
Number of respondents & $\mathbf{1 , 0 1 2}$ & $\mathbf{1 , 8 2 1}$ & $\mathbf{7 6 4}$ & $\mathbf{3 , 4 2 8}$ & $\mathbf{3 , 4 0 8}$ \\
\hline & & & & & Cont.
\end{tabular}


Table 6.9 Cont.

\begin{tabular}{|c|c|c|c|c|c|}
\hline Persons/sources & $\begin{array}{c}\text { Boys } \\
(10-14)\end{array}$ & $\begin{array}{c}\text { Boys } \\
(15-19)\end{array}$ & $\begin{array}{c}\text { Girls } \\
(10-14)\end{array}$ & $\begin{array}{c}\text { Girls } \\
(15-19)\end{array}$ & $\begin{array}{l}\text { Married girls } \\
\quad(15-19)\end{array}$ \\
\hline \multicolumn{6}{|c|}{ Urban (percent) } \\
\hline Mother & 84.4 & 83.1 & 92.6 & 90.1 & 90.2 \\
\hline Father & 80.6 & 78.9 & 76.3 & 73.3 & 73.0 \\
\hline Brother & 16.8 & 17.9 & 11.7 & 14.7 & 8.9 \\
\hline Sister & 10.1 & 5.8 & 15.1 & 16.7 & 10.5 \\
\hline Grandparents & 11.7 & 8.0 & 11.9 & 8.4 & 3.5 \\
\hline Other relatives & 13.0 & 11.3 & 16.5 & 18.5 & 21.5 \\
\hline Friends & 10.9 & 22.1 & 6.3 & 10.3 & 6.2 \\
\hline Teacher & 52.3 & 38.9 & 37.1 & 30.3 & 14.3 \\
\hline Films/TV/internet & 0.4 & 1.3 & 1.1 & 1.9 & 1.0 \\
\hline Husband & NA & NA & NA & NA & 10.9 \\
\hline None & 0.9 & 3.5 & 1.1 & 1.2 & 2.4 \\
\hline Others & 0.4 & 1.0 & 0.4 & 0.5 & 0.1 \\
\hline Number of respondents & 452 & 1,008 & 387 & 1,738 & 1,366 \\
\hline \multicolumn{6}{|c|}{ Rural (percent) } \\
\hline Mother & 75.3 & 79.4 & 88.8 & 88.1 & 88.7 \\
\hline Father & 69.6 & 75.7 & 66.9 & 70.4 & 69.6 \\
\hline Brother & 18.1 & 21.9 & 8.4 & 14.7 & 11.1 \\
\hline Sister & 8.0 & 5.4 & 14.5 & 14.4 & 12.5 \\
\hline Grandparents & 10.1 & 8.7 & 10.3 & 8.2 & 4.2 \\
\hline Other relatives & 7.8 & 12.7 & 14.5 & 18.6 & 22.4 \\
\hline Friends & 6.9 & 15.0 & 3.4 & 7.6 & 4.9 \\
\hline Teacher & 44.7 & 42.7 & 26.3 & 24.0 & 11.6 \\
\hline Films/TV/internet & 0.4 & 0.0 & 0.3 & 0.7 & 0.5 \\
\hline Husband & NA & NA & NA & NA & 7.1 \\
\hline None & 8.0 & 5.0 & 3.2 & 4.4 & 5.0 \\
\hline Others & 0.2 & 0.1 & 0.0 & 0.3 & 0.2 \\
\hline Number of respondents & 560 & 813 & 377 & 1,690 & 2,042 \\
\hline
\end{tabular}

Notes: All Ns are unweighted. NA: not applicable. Percentages add to more than 100 because of multiple responses.

Differences by age were narrow, except that younger boys were less likely than older boys to cite friends (7\% versus $16 \%)$. As observed above, differences by sex were notable. Boys were less likely than girls to report mothers $(76-80 \%$ versus $88-89 \%)$, sisters ( $6-8 \%$ versus $12-15 \%)$, and other relatives ( $8-13 \%$ versus $15-22 \%)$. On the contrary, they were more likely than girls to mention brothers (18-21\% versus $9-15 \%)$ and teachers (42-46\% versus $12-28 \%$ ), and older boys were more likely to mention friends( $16 \%$ versus $5-8 \%)$. Differences by marital status were negligible, except that more unmarried older girls reported teachers as a source for learning social behaviours compared with married older girls (25\% versus $12 \%$ ). The sources for learning social behaviours listed by rural and urban adolescents largely mirrored the pattern described above for the combined sample. Even so, more of urban than rural respondents mentioned their mother ( $84 \%$ versus $75 \%$ among younger boys), father ( $81 \%$ versus $70 \%$ among younger boys and $76 \%$ versus $67 \%$ among younger girls), teachers (52\% versus $45 \%$ among younger boys; $37 \%$ versus $26 \%$ among younger girls; and $30 \%$ versus $24 \%$ among unmarried older girls), and friends (22\% versus $15 \%$ among older boys) as their sources for learning social behaviours. 



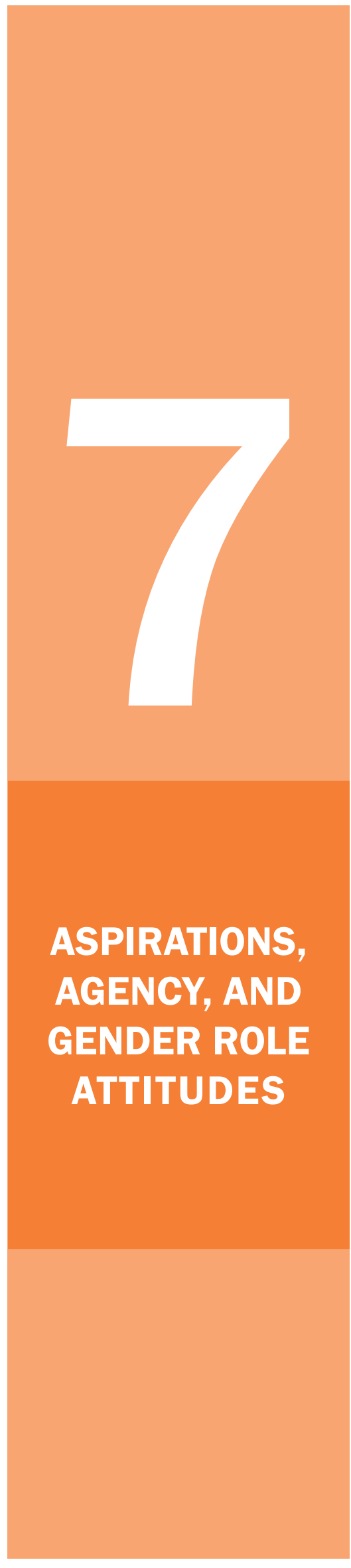

\section{A Snapshot}

Education and livelihood-related aspirations dominate adolescents' plans for the immediate future, that is, the next three years:

- $89 \%$ of younger boys

- $66 \%$ of older boys

- $88 \%$ of younger girls

- $66 \%$ of unmarried older girls,and

- $17 \%$ of married older girls wish to continue their studies or return to school in the immediate future
- $15 \%$ of younger boys

- $56 \%$ of older boys

- $11 \%$ of younger girls

- $48 \%$ of unmarried older girls

- $45 \%$ of married older girls wish to work for pay or attend a vocational skills training course

Assuming the role of a spouse, parent, or homemaker seldom figure in adolescents' plan for the immediate future, except among married older girls:

- None of the younger boys

- $1 \%$ of older boys

- $5 \%$ of younger girls

- $13 \%$ of unmarried older girls

- $46 \%$ of married older girls

wish to get married, become a parent, or assume the role of a homemaker

Long-term aspirations are gendered:

- $23 \%$ of younger boys

- $29 \%$ of older boys

- $8 \%$ each of younger girls and unmarried older girls

- $2 \%$ of married older girls aspire for a position in the police or armed forces
- $13 \%$ of younger boys
- $11 \%$ of older boys
- $29 \%$ of younger girls
- $33 \%$ of unmarried older girls
- $17 \%$ of married older girls aspire to become a teacher

Many adolescents are without any long-term aspirations:

- $35 \%$ of younger boys

- $30 \%$ of older boys

- $42 \%$ of younger girls

- $35 \%$ of unmarried older girls

- $49 \%$ of married older girls

have not thought about what profession or vocation they would like to follow in the future

POPULATION COUNCIL

Ideas. Evidence. Impact.

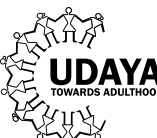




\section{A Snapshot}

Agency is limited:

- $26 \%$ of younger boys

- $51 \%$ of older boys

- $17 \%$ of younger girls

- $28 \%$ of unmarried older girls

- $25 \%$ of married older girls

believe that they would be able to decide independently the level of schooling that they want for themselves

- $29 \%$ of younger boys

- $52 \%$ of older boys

- $28 \%$ of younger girls

- $50 \%$ of unmarried older girls

- $34 \%$ of married older girls own a savings account

- $26 \%$ of younger boys

- $27 \%$ of older boys

- $33 \%$ of younger girls

- $25 \%$ of unmarried older girls

- $17 \%$ of married older girls perceive that they would be able to express their views to elders in their family most of the time
- $72 \%$ of younger boys

- $96 \%$ of older boys

- $44 \%$ of younger girls

- $47 \%$ of unmarried older girls

- $21 \%$ of married older girls are allowed to visit selected locations unescorted

- $29 \%$ of younger boys

- $72 \%$ of older boys

- $26 \%$ of younger girls

- $66 \%$ of unmarried older girls

- $64 \%$ of married older girls who owned an account operate it themselves

Stereotypical notions about gender roles are held by substantial proportion of adolescents, particularly boys:

- $29 \%$ of younger boys

- $53 \%$ of older boys

- $44 \%$ of younger girls

- $61 \%$ of unmarried older girls

- $58 \%$ of married older girls believe that girls should be allowed to decide when they should marry

Gender differences are wide on many indicators-girls are less likely than boys to have some say in personal matters and freedom to visit selected locations unescorted

Married girls are particularly disadvantaged-married girls are less likely than their unmarried counterparts to report education-related aspirations, more likely to desire to assume the role of a parent or homemaker, more likely to be undecided about their immediate future plans or about the profession or vocation they would like to follow in adulthood, and less likely to have freedom to visit selected locations unescorted 
In this chapter, we focus on key characteristics that define adolescents' ability to navigate their lives in an informed and equitable manner-their aspirations for the future, their ability to make informed choices, and their gender role attitudes. Aspirations provide a yardstick to help adolescents weigh how different choices will help or hinder their chances of achieving their desired goals, and, further, they serve as a motivational force to expend efforts required to achieve their goals (Camarena et al., 1998). Agency has been defined as the capacity to make choices through the acquisition of a sense of self and a sense of personal competence (National Research Council [NRC] and Institute of Medicine [IOM], 2005) and the ability to make strategic life choices (Kabeer, 2001) that affect well-being and exert influence over life matters (Mensch, 2006). The central elements of the capacity to make choices include decision-making capacity, freedom of movement, a sense of self-worth, and access to resources (Malhotra, Schuler, and Boender, 2002). Other sources note that agency comes from a sense of empowerment, which is defined as the process of changing the distribution of power, both in interpersonal relations and in institutions throughout society, and encompasses cognitive, psychological, political, and economic components (Stromquist, 1995; Stromquist and Fischman, 2009). Aspirations and agency are likely to be critical for the realisation of positive development and health outcomes among adolescents, and, at the same time, the exercise of informed choice and the realisation of aspirations may be viewed as salient indicators of successful and quality transitions to adulthood. Gender role attitudes represent beliefs about appropriate behaviours for women and men and girls and boys; as such, adolescents adhering to traditional notions of masculinity and femininity that espouse male superiority and female submissiveness may fail to realise their aspirations and to demonstrate their agency, which may hinder the exercise of informed choices.

In India, studies assessing adolescents' aspirations, agency, and gender role attitudes are limited. This study formulated several questions with a view to measure adolescents' aspirations, agency, and gender role attitudes, and the findings are described here.

\subsection{Adolescents' aspirations}

In addition to direct questions on educational and vocational skill aspirations of adolescents (see Chapters 3 and 4), this survey included questions that sought information about what study participants would like to do in the immediate future, that is, in the next three years, and what profession or vocation they would like to follow in the more distant future.

\subsubsection{Plans for the immediate future}

Findings presented in Table 7.1 reveal that adolescents' plans for the immediate future differed by age, sex, and, among older girls, by marital status. The vast majority of younger boys and girls-89 percent and 88 percent, respectively-reported that they would like to continue their studies or return to school, although notable proportions reported aspirations related to livelihood-generation, namely, working for pay or attending a vocational skills training course (15\% of boys and $11 \%$ of girls). In contrast, and not surprisingly, the vast majority of older adolescents, other than married older girls, reported both studies- and livelihood-related plans-66 percent and 56 percent, respectively, of older boys and 66 percent and 48 percent, respectively, of unmarried older girls. A few unmarried older girls reported plans to get married or assume the role of a homemaker ( $7 \%$ for each). Married girls, on the other hand, reported aspirations related to livelihood generation (45\%), becoming a mother (17\%), or assuming the role of a homemaker (40\%), while just 17 percent reported aspirations to pursue studies. Finally, 5-7 percent of boys and 8-21 percent of girls were undecided about their immediate future plans.

Differences by sex in immediate plans for the future were evident, particularly among older adolescents. Among younger adolescents, 12 percent of boys compared with four percent of girls planned to start working for pay. Among older adolescents, girls were more inclined to attend a vocational training course (28-37\% of girls versus $10 \%$ of boys), but less inclined to start working for pay (15-20\% versus $41 \%)$. In addition, unmarried and married older girls were more likely than older boys to report that they would like to assume any one of the following roles-that of spouse (not applicable to married older girls), parent, or homemaker-(13\% of unmarried older girls; $46 \%$ of married older girls; and $1 \%$ of older boys). It is also notable that more girls than boys were undecided about their immediate future plans (15-21\% versus $5 \%)$. 
Aspirations, agency, and gender role attitudes

Table 7.1: Plans for the immediate future

Percentage of adolescents reporting their plans for the next three years, according to residence, Bihar, 2016

\begin{tabular}{|c|c|c|c|c|c|}
\hline Plans for the immediate future & $\begin{array}{c}\text { Boys } \\
(10-14)\end{array}$ & $\begin{array}{c}\text { Boys } \\
(15-19)\end{array}$ & $\begin{array}{c}\text { Girls } \\
(10-14)\end{array}$ & $\begin{array}{c}\text { Girls } \\
(15-19)\end{array}$ & $\begin{array}{c}\text { Married girls } \\
\qquad(15-19)\end{array}$ \\
\hline \multicolumn{6}{|c|}{ Combined (percent) } \\
\hline Continue to study/return to school & 88.9 & 66.3 & 87.7 & 65.7 & 16.9 \\
\hline \multicolumn{6}{|l|}{ Livelihood-generation plans } \\
\hline Attend a vocational training course & 1.7 & 10.2 & 7.6 & 36.5 & 28.3 \\
\hline Start working for pay & 11.5 & 40.6 & 3.6 & 14.7 & 20.4 \\
\hline Continue working for pay & 2.2 & 12.2 & 2.1 & 6.6 & 9.2 \\
\hline Any of the above & 14.8 & 55.8 & 11.4 & 48.3 & 45.2 \\
\hline \multicolumn{6}{|l|}{ Marriage or parenthood plans } \\
\hline Get married & 0.0 & 1.0 & 1.4 & 7.0 & NA \\
\hline Become a father/mother & 0.0 & 0.0 & 0.0 & 0.2 & 16.9 \\
\hline Homemaker & 0.0 & 0.4 & 3.4 & 7.0 & 39.8 \\
\hline Any of the above & 0.0 & 1.4 & 4.5 & 12.5 & 45.7 \\
\hline Others & 0.0 & 0.0 & 0.0 & 0.1 & 0.1 \\
\hline Did not think about it & 7.0 & 4.7 & 7.9 & 14.5 & 20.8 \\
\hline Number of respondents & 1,012 & 1,821 & 764 & 3,428 & 3,408 \\
\hline \multicolumn{6}{|c|}{ Urban (percent) } \\
\hline Continue to study/return to school & 93.5 & 71.8 & 90.8 & 73.8 & 22.0 \\
\hline \multicolumn{6}{|l|}{ Livelihood-generation plans } \\
\hline Attend a vocational training course & 3.9 & 11.9 & 9.0 & 36.6 & 28.3 \\
\hline Start working for pay & 12.4 & 37.7 & 1.6 & 22.6 & 19.0 \\
\hline Continue working for pay & 2.3 & 19.2 & 1.6 & 6.2 & 8.5 \\
\hline Any of the above & 15.1 & 59.2 & 12.1 & 53.1 & 44.6 \\
\hline \multicolumn{6}{|l|}{ Marriage or parenthood plans } \\
\hline Get married & 0.0 & 0.4 & 0.7 & 4.6 & NA \\
\hline Become a father/mother & 0.0 & 0.0 & 0.0 & 0.3 & 17.1 \\
\hline Homemaker & 0.0 & 0.0 & 1.5 & 3.9 & 40.9 \\
\hline Any of the above & 0.0 & 0.4 & 1.7 & 7.9 & 47.3 \\
\hline Others & 0.0 & 0.0 & 0.0 & 0.1 & 0.0 \\
\hline Did not think about it & 2.4 & 2.3 & 4.8 & 8.5 & 18.0 \\
\hline Number of respondents & 452 & 1,008 & 387 & 1,738 & 1,366 \\
\hline \multicolumn{6}{|c|}{ Rural (percent) } \\
\hline Continue to study/return to school & 88.3 & 65.6 & 87.3 & 64.7 & 16.4 \\
\hline \multicolumn{6}{|l|}{ Livelihood-generation plans } \\
\hline Attend a vocational training course & 1.5 & 10.0 & 7.4 & 36.5 & 28.2 \\
\hline Start working for pay & 11.4 & 41.0 & 3.9 & 13.7 & 20.5 \\
\hline Continue working for pay & 2.2 & 11.3 & 2.1 & 6.6 & 9.2 \\
\hline Any of the above & 14.8 & 55.4 & 11.3 & 47.7 & 45.3 \\
\hline
\end{tabular}


Table 7.1 Cont.

\begin{tabular}{|c|c|c|c|c|c|}
\hline Plans for the immediate future & $\begin{array}{c}\text { Boys } \\
(10-14)\end{array}$ & $\begin{array}{c}\text { Boys } \\
(15-19)\end{array}$ & $\begin{array}{c}\text { Girls } \\
(10-14)\end{array}$ & $\begin{array}{c}\text { Girls } \\
(15-19)\end{array}$ & $\begin{array}{l}\text { Married girls } \\
\qquad(15-19)\end{array}$ \\
\hline \multicolumn{6}{|l|}{ Marriage or parenthood plans } \\
\hline Get married & 0.0 & 1.0 & 1.4 & 7.3 & NA \\
\hline Become a father/mother & 0.0 & 0.0 & 0.0 & 0.2 & 16.9 \\
\hline Homemaker & 0.0 & 0.4 & 3.6 & 7.4 & 39.7 \\
\hline Any of the above & 0.0 & 1.5 & 4.8 & 13.1 & 45.5 \\
\hline Others & 0.0 & 0.0 & 0.0 & 0.1 & 0.1 \\
\hline Did not think about it & 7.6 & 5.0 & 8.2 & 15.2 & 21.1 \\
\hline Number of respondents & 560 & 813 & 377 & 1,690 & 2,042 \\
\hline
\end{tabular}

Notes: All Ns are unweighted. NA: not applicable. Percentages add to more than 100 because of multiple responses.

Differences in plans for the immediate future by marital status were notable among older girls. While a larger proportion of unmarried older girls (66\%) wished to continue/get back to their studies in the next three years (compared with $17 \%$ of married older girls) and to attend a vocational training course (37\% versus $28 \%$ ), a larger proportion of married older girls perceived that they would become a mother or would assume the role of a homemaker within the upcoming three years ( $17 \%$ and $40 \%$ compared with $0.2 \%$ and $7 \%$ of unmarried older girls).

Plans for the immediate future articulated by rural and urban adolescents were similar. Even so, there were some differences: somewhat more respondents from urban than rural areas had plans to continue their studies; more of older boys from urban than rural areas had plans to continue paid work; and more unmarried older girls in urban areas had plans to start paid work compared with those from rural areas.

\subsubsection{Aspirations for adulthood years}

Table 7.2 presents findings on adolescents' long-term aspirations, that is, the profession or vocation they would like to follow when they reach adulthood. Younger boys aspired mainly for a position in the police or armed forces (23\%) or aspired to be an engineer or a scientist (14\%), a teacher (13\%), or a doctor (12\%). Older boys primarily aspired for a position in the police or armed forces (29\%) or to become an engineer or a scientist (12\%), or a teacher (11\%). The leading aspirations of younger girls included becoming a teacher (29\%) or a doctor (16\%); the leading aspiration for unmarried older girls was to become a teacher (33\%), which married older girls also reported (17\%) along with aspirations to be homemakers (15\%) or tailors (11\%). Findings also show that large proportions of adolescents did not think about what profession or vocation they would like to follow in the future, which more girls than boys reported (35-49\% of girls, and $30-35 \%$ of boys).

Differences in aspirations by age were modest for the most part. However, as seen above, aspirations were clearly gendered. More boys than girls reported that they would like to become an engineer or a scientist (12-14\% of boys versus $0-4 \%$ of girls), or have a position in the police or armed forces (23-29\% of boys versus $2-8 \%$ of girls). In contrast, more girls than boys reported that they would like to become a teacher (17-33\% of girls versus $11-13 \%$ of boys). Aspirations differed by marital status among older girls; unmarried older girls were more likely than married older girls to report that they would like to become a teacher (33\% versus $17 \%$ ) or a doctor (9\% versus 1\%), or have a position in the police or armed force ( $8 \%$ versus $2 \%$ ), but they were less likely to report that they would like to become a homemaker ( $3 \%$ versus $15 \%$ ) or a tailor ( $5 \%$ versus $11 \%$ ) or that they had not thought about what profession or vocation they would like to follow in the future (35\% versus $49 \%$ ). 


\section{Table 7.2: Aspirations for adulthood years}

Percentage of adolescents reporting the profession or vocation they would like to follow in the future, according to residence, Bihar, 2016

\begin{tabular}{|c|c|c|c|c|c|}
\hline Aspirations for adulthood & $\begin{array}{c}\text { Boys } \\
(10-14)\end{array}$ & $\begin{array}{c}\text { Boys } \\
(15-19)\end{array}$ & $\begin{array}{c}\text { Girls } \\
(10-14)\end{array}$ & $\begin{array}{c}\text { Girls } \\
(15-19)\end{array}$ & $\begin{array}{c}\text { Married girls } \\
(15-19)\end{array}$ \\
\hline \multicolumn{6}{|c|}{ Combined (percent) } \\
\hline Staff of police/armed forces & 22.5 & 29.3 & 7.9 & 8.3 & 1.6 \\
\hline Doctor & 11.6 & 5.9 & 16.3 & 8.6 & 1.4 \\
\hline Engineer/scientist & 14.1 & 12.0 & 3.8 & 2.4 & 0.2 \\
\hline Start a business & 2.2 & 6.5 & 0.0 & 0.7 & 3.7 \\
\hline Teacher & 13.0 & 11.0 & 28.7 & 33.4 & 16.6 \\
\hline Homemaker & 0.0 & 0.0 & 1.5 & 3.4 & 15.0 \\
\hline Tailor & 0.5 & 1.0 & 1.1 & 5.4 & 11.0 \\
\hline Beautician & 0.0 & 0.1 & 0.1 & 1.0 & 1.3 \\
\hline Auxiliary nurse midwife/nurse/AWW/ASHA & 0.0 & 0.0 & 3.6 & 4.7 & 6.1 \\
\hline Plumber/electrician/driver & 1.1 & 3.5 & 0.1 & 0.1 & 0.0 \\
\hline Artist, sportsperson, fashion designer & 1.8 & 0.6 & 0.2 & 0.3 & 0.1 \\
\hline Lawyer & 0.8 & 0.2 & 0.2 & 0.3 & 0.0 \\
\hline Accounting and finance services & 1.5 & 2.6 & 1.0 & 4.4 & 0.8 \\
\hline Aviation services & 0.0 & 0.2 & 0.1 & 0.0 & 0.0 \\
\hline Government services & 2.6 & 4.1 & 0.2 & 1.0 & 0.2 \\
\hline Others & 0.7 & 0.6 & 0.1 & 0.2 & 0.0 \\
\hline Did not think about it & 34.7 & 29.8 & 41.9 & 35.0 & 48.5 \\
\hline Number of respondents & 1,012 & 1,821 & 764 & 3,428 & 3,408 \\
\hline \multicolumn{6}{|c|}{ Urban (percent) } \\
\hline Staff of police/armed forces & 25.0 & 27.4 & 13.6 & 9.3 & 2.2 \\
\hline Doctor & 15.9 & 4.7 & 27.8 & 12.3 & 1.7 \\
\hline Engineer/scientist & 21.7 & 21.8 & 10.1 & 5.9 & 0.8 \\
\hline Start a business & 3.2 & 12.1 & 0.0 & 1.6 & 2.6 \\
\hline Teacher & 3.2 & 3.5 & 21.4 & 24.3 & 19.0 \\
\hline Homemaker & 0.0 & 0.1 & 0.6 & 1.6 & 15.0 \\
\hline Tailor & 0.0 & 0.3 & 1.0 & 3.3 & 11.6 \\
\hline Beautician & 0.0 & 0.1 & 0.8 & 1.7 & 2.0 \\
\hline Auxiliary nurse midwife/nurse/AWW/ASHA & 0.0 & 0.1 & 1.2 & 2.9 & 4.4 \\
\hline Plumber/electrician/driver & 0.3 & 3.2 & 0.0 & 0.2 & 0.1 \\
\hline Artist, sportsperson, fashion designer & 3.7 & 2.2 & 0.6 & 1.4 & 0.2 \\
\hline Lawyer & 0.5 & 0.5 & 0.8 & 1.8 & 0.4 \\
\hline Accounting and finance services & 3.7 & 6.2 & 3.6 & 13.1 & 2.0 \\
\hline Aviation services & 0.3 & 0.3 & 0.6 & 0.1 & 0.0 \\
\hline Government services & 4.3 & 6.7 & 2.3 & 3.0 & 0.7 \\
\hline Others & 0.5 & 0.6 & 0.8 & 0.8 & 0.1 \\
\hline Did not think about it & 25.5 & 19.9 & 24.0 & 25.3 & 44.6 \\
\hline Number of respondents & 452 & 1,008 & 387 & 1,738 & 1,366 \\
\hline
\end{tabular}


Table 7.2 Cont.

\begin{tabular}{|c|c|c|c|c|c|}
\hline Aspirations for adulthood & $\begin{array}{c}\text { Boys } \\
(10-14)\end{array}$ & $\begin{array}{c}\text { Boys } \\
(15-19)\end{array}$ & $\begin{array}{c}\text { Girls } \\
(10-14)\end{array}$ & $\begin{array}{c}\text { Girls } \\
(15-19)\end{array}$ & $\begin{array}{l}\text { Married girls } \\
(15-19)\end{array}$ \\
\hline \multicolumn{6}{|c|}{ Rural (percent) } \\
\hline Staff of police/armed forces & 22.3 & 29.6 & 7.2 & 8.2 & 1.5 \\
\hline Doctor & 11.1 & 6.1 & 14.9 & 8.1 & 1.3 \\
\hline Engineer/scientist & 13.2 & 10.7 & 3.0 & 2.0 & 0.1 \\
\hline Start a business & 2.1 & 5.8 & 0.0 & 0.6 & 3.8 \\
\hline Teacher & 14.2 & 11.9 & 29.6 & 34.5 & 16.4 \\
\hline Homemaker & 0.0 & 0.0 & 1.6 & 3.6 & 15.0 \\
\hline Tailor & 0.6 & 1.1 & 1.2 & 5.6 & 10.9 \\
\hline Beautician & 0.0 & 0.1 & 0.0 & 0.9 & 1.2 \\
\hline Auxiliary nurse midwife/nurse/AWW/ASHA & 0.0 & 0.0 & 3.9 & 4.9 & 6.3 \\
\hline Plumber/electrician/driver & 1.2 & 3.5 & 0.1 & 0.0 & 0.0 \\
\hline Artist, sportsperson, fashion designer & 1.5 & 0.4 & 0.1 & 0.2 & 0.1 \\
\hline Lawyer & 0.8 & 0.2 & 0.1 & 0.1 & 0.0 \\
\hline Accounting and finance services & 1.2 & 2.1 & 0.7 & 3.3 & 0.7 \\
\hline Aviation services & 0.0 & 0.2 & 0.0 & 0.0 & 0.0 \\
\hline Government services & 2.4 & 3.8 & 0.0 & 0.8 & 0.2 \\
\hline Others & 0.7 & 0.6 & 0.0 & 0.1 & 0.0 \\
\hline Did not think about it & 35.8 & 31.0 & 44.0 & 36.2 & 48.9 \\
\hline Number of respondents & 560 & 813 & 377 & 1,690 & 2,042 \\
\hline
\end{tabular}

Notes: All Ns are unweighted. Percentages add to more than 100 because of multiple responses. ANM: auxiliary nurse midwife; AWW: anganwadi worker; ASHA: accredited social health activist.

Aspirations reported by rural and urban adolescents mirrored the pattern described above for the combined sample. Even so, younger and older boys in urban areas were more likely than their rural counterparts to report that they would like to become an engineer or a scientist (22\% versus $11-13 \%)$ and less likely to report that they wanted to become a teacher (3-4\% versus $12-14 \%$ ) or be unsure about what profession or vocation they would like to follow in the future (20-26\% versus $31-36 \%)$. Younger girls and unmarried older girls in urban areas were less likely than their rural counterparts to want to become a teacher (21-24\% versus $30-35 \%)$ or be unsure about what profession or vocation they would like to follow in the future (24-25\% versus $36-44 \%)$. At the same time, younger girls in urban areas were more likely than younger girls in rural areas to report that they would like to become a doctor (29\% versus $15 \%)$ or an engineer/a scientist (10\% versus 3\%). Unmarried older girls in urban areas additionally were more likely to wish for a career in accounting and finance services than their rural counterparts (13\% versus 3\%).

\subsection{Agency}

Drawing on conceptualisations of agency in the existing literature, we identified four components that define agency among adolescents-decision-making capacity, freedom of movement, access to money and ability to control it, and self-efficacy.

\subsubsection{Decision-making}

We asked respondents about their participation in decisions related to three specific matters. The three domains of decision-making that we probed differed for younger and older adolescents, because we sought to capture adolescents' engagement in decision-making according to age. They included, for younger adolescents, decisions about the choice of friends, going to a friend's house, and the level of schooling that the respondent should have, 
and, for older adolescents, decisions on the level of schooling that the respondent should have, major household purchases, and whether or not to engage in work. If adolescents reported that they were involved in decision-making on any issue, we asked them whether they made the decision entirely on their own or jointly with other family members.

Findings, presented in Table 7.3, reveal that irrespective of sex and of residence in rural or urban areas, younger adolescents were overwhelmingly likely to choose their friends on their own; 78 percent of boys and 62 percent of girls reported that they decided on their own who their friends would be. However, 11 percent of boys and 16 percent of girls jointly decided with others, while 11 percent of boys and 22 percent of girls did not participate at all in such decisions. Fewer younger adolescents, particularly girls, decided on their own about going to a friend's house (62\% of boys and 35\% of girls), while 21 percent of boys and 42 percent of girls decided jointly with others, and as many as 17 percent of boys and 23 percent of girls reported that such decisions were taken by other family members without any involvement from them. Even fewer younger adolescents were consulted on decisions related to the level of schooling that they should have-of those who were ever enrolled in school, 26 percent of boys and 17 percent of girls were able to or believed that they would be able to decide independently the level of schooling that they wanted for themselves, while 32 percent of boys and 35 percent of girls indicated joint decision-making, and 42 percent, and 48 percent of boys and girls, respectively, were not consulted or believed that they would not be consulted in such decisions.

With respect to the decision-making ability of older adolescents, findings show that 51 percent of boys and 25-28 percent of girls who were ever enrolled in school were able to or believed that they would be able to decide on their own the level of schooling they should have, while 28 percent of boys and 36-39 percent of girls indicated joint decision-making, and 22 percent of boys and 34-39 percent of girls did not have or believed they would not have any say in this matter. Likewise, 51 percent of boys and 6-15 percent of girls reported that they decided or believed that they would decide on their own whether to work or stay at home, while 26 percent of boys and 41-46 percent of girls reported joint decision-making, and 23 percent of boys and 45-48 percent of girls reported that they were not involved or believed that they would not be involved in such decisions. Finally, just three percent of boys and one percent of girls were able to take independent decisions on major household purchases, while 32 percent of boys and 26-38 percent of girls made joint decisions, and 66 percent of boys and 61-74 percent of girls did not have any say in such decisions.

As evident from the above, differences by sex were evident across all domains of decision-making, except for decisions related to household purchases, among both younger and older adolescents, with boys more likely than girls to have some say in these decisions. Where comparisons across age groups were possible as in decisions related to the level of schooling that respondents should have, findings show that older adolescents were more likely than younger adolescents to report independent decision making ( $51 \%$ versus $26 \%$ of boys; $25-28 \%$ versus $17 \%$ of girls). What is notable however is that unmarried and married older girls were only as likely as younger boys to make independent decisions (25-28\% versus $26 \%$ ). Among older girls, there were differences by marital status with respect to decisions related to whether to work or stay at home, with a larger proportion of unmarried than married older girls reporting independent decision-making (15\% versus $6 \%$ ). Differences by residence in rural and urban areas show that rural younger girls and unmarried older girls were less likely to make independent decisions related to the level of schooling that they should have than their counterparts from urban areas (16\% versus $30 \%$ of younger girls and $27 \%$ versus $36 \%$ of unmarried older girls). Similarly, rural unmarried older girls were less likely to make independent decisions on whether to work or stay at home compared with their urban counterparts (14\% versus $22 \%$ ). 


\section{Table 7.3: Decision-making}

Percent distribution of adolescents by participation in decision-making on selected matters, according to residence, Bihar, 2016

\begin{tabular}{|c|c|c|c|c|c|}
\hline Participation in decision-making & $\begin{array}{c}\text { Boys } \\
(10-14)\end{array}$ & $\begin{array}{c}\text { Boys } \\
(15-19)\end{array}$ & $\begin{array}{c}\text { Girls } \\
(10-14)\end{array}$ & $\begin{array}{c}\text { Girls } \\
(15-19)\end{array}$ & $\begin{array}{l}\text { Married girls } \\
\qquad(15-19)\end{array}$ \\
\hline \multicolumn{6}{|c|}{ Combined (percent) } \\
\hline \multicolumn{6}{|l|}{ Choice of friends } \\
\hline Respondent only & 77.7 & NA & 62.4 & NA & NA \\
\hline Jointly with others & 10.9 & NA & 16.0 & NA & NA \\
\hline Others only & 11.4 & NA & 21.6 & NA & NA \\
\hline \multicolumn{6}{|l|}{ Going to a friend's house } \\
\hline Respondent only & 62.2 & NA & 35.2 & NA & NA \\
\hline Jointly with others & 21.0 & NA & 42.2 & NA & NA \\
\hline Others only & 16.9 & NA & 22.6 & NA & NA \\
\hline Number of respondents & 1,012 & NA & 764 & NA & NA \\
\hline \multicolumn{6}{|l|}{ Years of schooling } \\
\hline Respondent only & 26.2 & 50.8 & 17.0 & 28.0 & 24.8 \\
\hline Jointly with others & 31.7 & 27.5 & 35.2 & 38.5 & 36.4 \\
\hline Others only & 42.1 & 21.7 & 47.7 & 33.6 & 38.7 \\
\hline Number of respondents who were ever enrolled in school & 998 & 1,764 & 730 & 3,191 & 2,361 \\
\hline \multicolumn{6}{|l|}{ Household purchases } \\
\hline Respondent only & NA & 2.6 & NA & 0.6 & 1.3 \\
\hline Jointly with others & NA & 31.5 & NA & 25.8 & 37.9 \\
\hline Others only & NA & 65.9 & NA & 73.6 & 60.8 \\
\hline \multicolumn{6}{|l|}{ Working or staying at home } \\
\hline Respondent only & NA & 50.9 & NA & 14.8 & 5.7 \\
\hline Jointly with others & NA & 26.0 & NA & 40.6 & 46.2 \\
\hline Others only & NA & 23.1 & NA & 44.6 & 48.1 \\
\hline Number of respondents & NA & 1,821 & NA & 3,428 & 3,408 \\
\hline \multicolumn{6}{|c|}{ Urban (percent) } \\
\hline \multicolumn{6}{|l|}{ Choice of friends } \\
\hline Respondent only & 74.6 & NA & 67.9 & NA & NA \\
\hline Jointly with others & 12.5 & NA & 16.8 & NA & NA \\
\hline Others only & 12.9 & NA & 15.2 & NA & NA \\
\hline \multicolumn{6}{|l|}{ Going to a friend's house } \\
\hline Respondent only & 52.0 & NA & 31.0 & NA & NA \\
\hline Jointly with others & 25.2 & NA & 47.2 & NA & NA \\
\hline Others only & 22.8 & NA & 21.8 & NA & NA \\
\hline Number of respondents & 452 & NA & 387 & NA & NA \\
\hline \multicolumn{6}{|l|}{ Years of schooling } \\
\hline Respondent only & 26.4 & 54.5 & 29.8 & 35.5 & 23.7 \\
\hline Jointly with others & 35.4 & 28.7 & 33.1 & 41.4 & 36.0 \\
\hline Others only & 38.2 & 16.8 & 37.1 & 23.1 & 40.3 \\
\hline Number of respondents who were ever enrolled in school & 444 & 972 & 372 & 1,645 & 985 \\
\hline
\end{tabular}


Table 7.3 Cont.

\begin{tabular}{|c|c|c|c|c|c|}
\hline Participation in decision-making & $\begin{array}{c}\text { Boys } \\
(10-14)\end{array}$ & $\begin{array}{c}\text { Boys } \\
(15-19)\end{array}$ & $\begin{array}{c}\text { Girls } \\
(10-14)\end{array}$ & $\begin{array}{c}\text { Girls } \\
(15-19)\end{array}$ & $\begin{array}{l}\text { Married girls } \\
\qquad(15-19)\end{array}$ \\
\hline \multicolumn{6}{|l|}{ Household purchases } \\
\hline Respondent only & NA & 3.1 & NA & 0.8 & 1.7 \\
\hline Jointly with others & NA & 35.4 & NA & 29.6 & 38.5 \\
\hline Others only & NA & 61.5 & NA & 69.6 & 59.8 \\
\hline \multicolumn{6}{|l|}{ Working or staying at home } \\
\hline Respondent only & NA & 55.6 & NA & 22.0 & 7.6 \\
\hline Jointly with others & NA & 23.3 & NA & 40.5 & 46.5 \\
\hline Others only & NA & 21.1 & NA & 37.5 & 45.9 \\
\hline Number of respondents & NA & 1,008 & NA & 1,738 & 1,366 \\
\hline \multicolumn{6}{|c|}{ Rural (percent) } \\
\hline \multicolumn{6}{|l|}{ Choice of friends } \\
\hline Respondent only & 78.1 & NA & 61.7 & NA & NA \\
\hline Jointly with others & 10.7 & NA & 15.9 & NA & NA \\
\hline Others only & 11.2 & NA & 22.4 & NA & NA \\
\hline \multicolumn{6}{|l|}{ Going to a friend's house } \\
\hline Respondent only & 63.4 & NA & 35.8 & NA & NA \\
\hline Jointly with others & 20.5 & NA & 41.6 & NA & NA \\
\hline Others only & 16.2 & NA & 22.6 & NA & NA \\
\hline Number of respondents & 560 & NA & 377 & NA & NA \\
\hline \multicolumn{6}{|l|}{ Years of schooling } \\
\hline Respondent only & 26.2 & 50.4 & 15.5 & 27.0 & 25.0 \\
\hline Jointly with others & 31.3 & 27.3 & 35.5 & 38.1 & 36.5 \\
\hline Others only & 42.5 & 22.3 & 49.0 & 34.9 & 38.5 \\
\hline Number of respondents who were ever enrolled in school & 554 & 792 & 358 & 1,546 & 1,376 \\
\hline \multicolumn{6}{|l|}{ Household purchases } \\
\hline Respondent only & NA & 2.6 & NA & 0.6 & 1.3 \\
\hline Jointly with others & NA & 31.0 & NA & 25.3 & 37.8 \\
\hline Others only & NA & 66.5 & NA & 74.1 & 60.9 \\
\hline \multicolumn{6}{|l|}{ Working or staying at home } \\
\hline Respondent only & NA & 50.3 & NA & 13.9 & 5.5 \\
\hline Jointly with others & NA & 26.3 & NA & 40.6 & 46.2 \\
\hline Others only & NA & 23.4 & NA & 45.5 & 48.3 \\
\hline Number of respondents & NA & 813 & NA & 1,690 & 2,042 \\
\hline
\end{tabular}

Notes: All Ns are unweighted. NA: not applicable.

Table 7.4 presents differentials by selected background characteristics among adolescents who independently or jointly made decisions related to all three matters-decisions on choice of friends, going to a friend's house, and the level of schooling that they choose to have (for younger adolescents), and decisions on major household purchases, engaging in work, and the level of schooling that they choose to have (for older adolescents). As mentioned earlier, the three domains of decision-making that we probed among younger and older adolescents were different for both 
groups and, therefore, comparisons between age groups may not be possible in all aspects. We also need to point out that because we posed the question related to decisions on the level of schooling that the respondent should have to only those who were ever enrolled in school, the bi-variate analyses presented in this section were restricted to those who were ever enrolled in school.

In total, 48 percent of younger boys and 40 percent of younger girls reported participation in all three decisions. While differences by residence in rural or urban areas were narrow among younger boys, they were wide among younger girls, with more urban than rural girls reporting participation in all three decisions (50\% versus 39\%). Among younger boys, participation in decision-making increased with age (41\% of those in ages $10-12$ versus $61 \%$ of those in ages 13-14), but this was unrelated with age among younger girls. Findings show that differences by religion were muted among younger girls, but wide among younger boys-Hindu boys were less likely than Muslim boys to report participation in decision-making ( $47 \%$ versus $57 \%$ ). Caste-wise differences were narrow among younger boys, but wide among younger girls, among whom those belonging to general castes were more likely than those from other castes to report participation in all three decisions (58\% versus $37-39 \%)$. Participation in decision-making increased consistently with level of education among younger boys but not among younger girls; for example, 67 percent of boys with 8-9 years of schooling reported participation in decision-making compared with 43-45 percent of boys who had completed 1-7 years of schooling. Participation in decision-making was less likely among younger boys and girls who were currently enrolled in school than the younger adolescents who were not (47\% versus $64 \%$ among boys and $47 \%$ versus $40 \%$ among girls). Among younger boys, those engaged in economic activity were more likely than those not working to have some say in all three decisions (64\% versus $47 \%$ ), but the association was reversed among younger girls (34\% versus $41 \%$ ). Among younger boys and girls, those who belonged to the richest households were somewhat more likely than those from poorer households to report participation in decision-making (56\% versus $34-51 \%$ of boys and $49 \%$ versus $34-44 \%$ of girls). Participation in decision-making also increased with mother's education among younger boys and girls. Those whose mothers had no education were less likely to participate in decisionmaking than those whose mothers had 10 or more years of education ( $46 \%$ versus $57 \%$ among boys and $40 \%$ versus $58 \%$ among girls).

Among older adolescents, 31 percent of boys and 23-30 percent of girls reported participation in all three decisions. As among younger adolescents, differences by sex were wide, and among older girls, differences by marital status show that married older girls were somewhat more likely than unmarried older girls to have participated in all three decisions (30\% versus 23\%). Participation in decision-making increased with age across all three categories (26\% of those in ages $15-17$ versus $44 \%$ of those in ages $18-19$ among boys; $21 \%$ of those in ages $15-17$ versus $30 \%$ of those in ages 18-19 among unmarried older girls; and 23\% of those in ages 15-17 versus 33\% of those in ages 18-19 among married older girls). Furthermore, differences by place of residence were apparent among boys and unmarried girls, with urban adolescents somewhat more likely than rural adolescents to report participation in decision-making (36\% versus $30 \%$ among boys and $28 \%$ versus $23 \%$ among unmarried girls).

Findings also show that differences by religion were narrow among all three categories of older adolescents. Castewise differences were narrow among older boys and married older girls, but somewhat notable among unmarried older girls, among whom a larger proportion of girls belonging to general castes than girls belonging to other castes reported participation in all three decisions (31\% versus 20-22\%). Participation in decision-making increased with level of education among older adolescents. Among boys, for example, 50 percent of those with 12 or more years of schooling reported participation in decision-making compared with just 34 percent of boys who had completed 1-4 years of schooling; the corresponding proportions among unmarried older girls were 39 percent and nine percent, and these were 42 percent and 26 percent among married older girls. Participation in decision-making was more likely among girls who were pursuing their education at the time of the interview than those who were not (24\% versus $17 \%$ among unmarried girls and $37 \%$ versus $28 \%$ among married girls), but a reverse pattern was apparent among boys (47\% versus $64 \%$ ). Economic activity status was not associated with participation in decisionmaking among older boys and unmarried older girls, but among married older girls, those who were engaged in paid work were more likely to participate in decision-making than those who were not so engaged (37\% versus $29 \%$ ). Participation of adolescents in decision-making increased with household economic status among older boys and unmarried older girls, but was unrelated to household economic status among married girls. Participation in decisionmaking increased with mother's education among girls but not among boys. 
Table 7.4: Decision-making autonomy by selected background characteristics

Percentage of adolescents who reported some say in all decisions by selected background characteristics, Bihar, 2016

\begin{tabular}{|c|c|c|c|c|c|}
\hline Background characteristics (percent) & $\begin{array}{c}\text { Boys } \\
(10-14)\end{array}$ & $\begin{array}{c}\text { Boys } \\
(15-19)\end{array}$ & $\begin{array}{c}\text { Girls } \\
(10-14)\end{array}$ & $\begin{array}{c}\text { Girls } \\
(15-19)\end{array}$ & $\begin{array}{c}\text { Married girls } \\
(15-19)\end{array}$ \\
\hline \multicolumn{6}{|l|}{ Age } \\
\hline $10-12$ & 40.6 & NA & 40.1 & NA & NA \\
\hline $13-14$ & 61.2 & NA & 40.4 & NA & NA \\
\hline $15-17$ & NA & 26.3 & NA & 21.3 & 23.0 \\
\hline $18-19$ & NA & 43.7 & NA & 29.7 & 33.0 \\
\hline \multicolumn{6}{|l|}{ Religion $^{1}$} \\
\hline Hindu & 46.6 & 30.8 & 39.8 & 22.6 & 29.4 \\
\hline Muslim & 57.2 & 31.1 & 43.0 & 27.4 & 30.6 \\
\hline \multicolumn{6}{|l|}{ Caste $^{2}$} \\
\hline SC & 48.2 & 28.6 & 39.3 & 20.4 & 29.0 \\
\hline $\mathrm{OBC}$ & 48.0 & 32.0 & 37.3 & 22.1 & 30.0 \\
\hline General $^{3}$ & 48.3 & 29.0 & 58.2 & 31.4 & 29.3 \\
\hline \multicolumn{6}{|l|}{ Completed years of schooling ${ }^{4}$} \\
\hline $1-4$ & 43.1 & 33.9 & 39.2 & 8.5 & 25.8 \\
\hline $5-7$ & 45.3 & 29.6 & 40.5 & 15.1 & 27.2 \\
\hline $8-9$ & 66.6 & 25.2 & 41.6 & 19.6 & 24.9 \\
\hline $10-11$ & NA & 35.4 & NA & 30.9 & 35.1 \\
\hline 12 and above & NA & 50.4 & NA & 39.2 & 42.1 \\
\hline \multicolumn{6}{|l|}{ Current schooling status ${ }^{5}$} \\
\hline Yes & 47.2 & 28.2 & 39.8 & 24.4 & 37.1 \\
\hline No & $(64.1)$ & 40.9 & $(47.3)$ & 17.3 & 27.8 \\
\hline \multicolumn{6}{|c|}{ Paid work in the 12 months prior to the interview } \\
\hline Yes & 64.2 & 33.4 & 33.7 & 25.7 & 36.9 \\
\hline No & 47.0 & 30.0 & 40.8 & 22.8 & 28.9 \\
\hline \multicolumn{6}{|l|}{ Wealth quintile } \\
\hline First & 33.8 & 21.5 & 35.4 & 19.4 & 29.4 \\
\hline Second & 51.3 & 26.0 & 34.5 & 16.3 & 24.1 \\
\hline Third & 47.8 & 30.6 & 34.3 & 22.4 & 24.6 \\
\hline Fourth & 45.1 & 33.1 & 44.1 & 22.0 & 36.1 \\
\hline Fifth & 56.1 & 34.0 & 49.2 & 29.1 & 30.0 \\
\hline \multicolumn{6}{|c|}{ Mother's education (in years of schooling completed) } \\
\hline None $^{6}$ & 46.1 & 30.4 & 39.9 & 21.1 & 29.6 \\
\hline $1-7$ & 53.6 & 30.5 & 36.1 & 25.1 & 26.9 \\
\hline $8-9$ & 54.5 & 32.2 & 26.3 & 25.6 & 28.5 \\
\hline 10 and above & 56.6 & 33.3 & 57.8 & 32.9 & 34.9 \\
\hline
\end{tabular}


Table 7.3 Cont.

\begin{tabular}{|c|c|c|c|c|c|}
\hline Background characteristics (percent) & $\begin{array}{c}\text { Boys } \\
(10-14)\end{array}$ & $\begin{array}{c}\text { Boys } \\
(15-19)\end{array}$ & $\begin{array}{c}\text { Girls } \\
(10-14)\end{array}$ & $\begin{array}{c}\text { Girls } \\
(15-19)\end{array}$ & $\begin{array}{l}\text { Married girls } \\
\qquad(15-19)\end{array}$ \\
\hline \multicolumn{6}{|l|}{ Place of residence } \\
\hline Urban & 50.2 & 35.8 & 49.8 & 27.8 & 28.2 \\
\hline Rural & 47.8 & 30.2 & 39.1 & 22.6 & 29.7 \\
\hline Total & 48.0 & 30.8 & 40.2 & 23.2 & 29.5 \\
\hline
\end{tabular}

Notes: ( ) Based on 25-49 unweighted cases. NA: not applicable; OBC: other backward caste; SC: scheduled caste; ST: scheduled tribe. ${ }^{1}$ Percentages not shown for those belonging to other religions as less than one percent of surveyed adolescents belonged to other religions. ${ }^{2}$ Percentages not shown for those belonging to STs as less than one percent of surveyed adolescents belonged to STs. ${ }^{3}$ Includes all those not belonging to SCs, STs, or OBCs. ${ }^{4}$ Percentages not shown for those who were illiterate or had no formal education, because the question on decision-making related to the level of education that the respondent chooses to have was posed to only those who had ever attended school. ${ }^{5}$ Percentages not shown for adolescents who were pursuing their education through distance education courses at the time of interview or those who never went to school. Respondents in ages 10-14 were asked about decisions related to years of schooling they choose to have, choice of friends, and going to a friend's house; respondents in ages 15-19 were asked about decisions related to years of schooling they choose to have, major household purchases, and whether to work or stay at home. ${ }^{6}$ Includes nonliterate and literate with no formal schooling.

\subsubsection{Freedom of movement}

We measured freedom of movement by asking a number of questions relating to whether the respondent was permitted to visit places within and outside the village (rural) or ward (urban) unescorted; whether he/she was permitted only if accompanied by someone else; and whether the respondent was not permitted at all to visit the place. These locations included a shop, a market, the home of a friend or relative within or outside the respondent's own village or ward, and a community programme (a mela, sports event, adolescent group meeting) within the respondent's own village or ward. Younger adolescents in addition were asked whether they were allowed to play in open spaces in their village or ward. Table 7.5 reports findings relating to mobility, and findings confirm that freedom of movement varied by locations, age, sex, and, among older girls, by marital status.

First, mobility within the village or ward was less restricted than mobility outside the village or ward. Thus, 94 percent of younger boys and 98 percent of older boys could go to a shop, market, or house of a friend or relative within their village or ward unescorted; in comparison, 44 percent and 89 percent of younger and older boys, respectively, were allowed to visit these locations outside their village or ward unescorted. Far fewer girls reported such mobility, and the corresponding differences among girls were much wider-84 percent of younger girls, 80 percent of unmarried older girls, and 36 percent of married girls reported the freedom to go to a shop, market, or house of a friend or relative within their village or ward unescorted, while only 23 percent, 34 percent, and 17 percent, respectively, were allowed to visit such locations outside their village or ward unescorted. Finally, among younger adolescents, 90 percent of boys and 64 percent of girls were allowed to play in open spaces of the village or ward unescorted.

Second, mobility within the village or ward also varied by the type of location, that is, locations that are part of routine village or urban life (for example, a shop, market, friend's or relative's house) compared with locations where special events took place (for example, a mela, sports event, adolescent group meeting) across all categories of adolescents, except among older boys. Only 66 percent of younger boys, for example, were allowed to attend a community programme within their village or ward unescorted, that is, considerably fewer than those who were allowed to visit a shop, market, friend's or relative's house (as seen above). The restrictions on freedom to attend such community programmes were stronger for girls than boys-only 40 percent of younger girls and unmarried older girls and 19 percent of married older girls were allowed to do so unescorted. Older boys, however, faced no such restrictions-as many as 95 percent of boys reported that they could attend such programmes unescorted.

Third, freedom to visit locations that are not part of routine village or urban life increased with age among boys; older boys reported greater mobility than younger boys (95\% versus $66 \%$ with respect to attending a community programme within the village or ward and $89 \%$ versus $44 \%$ with respect to visiting a shop, market, friend's or 
relative's house outside the village or ward). Among younger girls and unmarried older girls, the pattern was less consistent-younger girls were as likely as unmarried older girls to be allowed to visit locations within their village or ward, for example, a shop, market, or friend's or relative's house within the village or ward on their own (84\% of younger girls and $80 \%$ of unmarried older girls) and a community programme ( $40 \%$ each), but less likely to be allowed to visit a shop, market, or friend's or relative's house outside the village or ward on their own (23\% versus $34 \%$ ).

Fourth, as seen above, boys reported greater mobility than girls, regardless of the locations, age, and residence in rural or urban areas. Even younger boys had more mobility than girls, irrespective of the age of girls and, among older girls, marital status. Such differences were evident even in the freedom for younger adolescents to play in the open spaces of the village or ward-90 percent of boys compared with 64 percent of girls were allowed to do so.

Fifth, findings show that the mobility of married older girls was much more restricted than the mobility of unmarried older girls. Just 36 percent of married older girls, for example, compared with 80 percent of unmarried older girls were allowed to visit a shop, market, or friend's or relative's house within their village or ward on their own. Differences persisted with respect to attending a community programme within their village or ward and visiting a shop, market, or friend's or relative's house outside their village or ward on their own (17-19\% of married older girls reported so versus $34-40 \%$ of unmarried older girls).

Finally, differences between those from urban and those from rural areas were modest at best, except that girls in urban areas were more likely to be allowed to visit a shop, market, or friend's or relative's house outside their ward on their own than their rural counterparts (36\% versus $21 \%$ of younger girls; $53 \%$ versus $32 \%$ of unmarried older girls; and $23 \%$ versus $16 \%$ of married older girls ) and, among unmarried older girls, to attend a community programme within their village or ward (48\% versus $39 \%)$.

\section{Table 7.5: Freedom of movement}

Percent distribution of adolescents by extent of freedom to visit selected locations within or outside the village/ward, according to residence, Bihar, 2016

\begin{tabular}{|c|c|c|c|c|c|}
\hline Mobility indicators & $\begin{array}{l}\text { Boys } \\
(10-14)\end{array}$ & $\begin{array}{l}\text { Boys } \\
(15-19)\end{array}$ & $\begin{array}{c}\text { Girls } \\
(10-14)\end{array}$ & $\begin{array}{l}\text { Girls } \\
(15-19)\end{array}$ & $\begin{array}{l}\text { Married girls } \\
\quad(15-19)\end{array}$ \\
\hline \multicolumn{6}{|c|}{ Combined (percent) } \\
\hline \multicolumn{6}{|l|}{ Permitted to: } \\
\hline \multicolumn{6}{|c|}{ Visit shop/market/or a friend/relative within village/ward } \\
\hline Alone & 93.7 & 98.3 & 83.5 & 79.5 & 35.5 \\
\hline Only with someone else & 5.9 & 1.7 & 15.4 & 18.7 & 51.6 \\
\hline Not at all & 0.4 & 0.0 & 1.1 & 1.8 & 12.9 \\
\hline \multicolumn{6}{|c|}{ Visit shop/market or a friend/relative outside village/ward } \\
\hline Alone & 44.3 & 89.2 & 22.6 & 34.4 & 16.9 \\
\hline Only with someone else & 50.7 & 10.4 & 75.2 & 63.6 & 78.6 \\
\hline Not at all & 5.0 & 0.5 & 2.2 & 2.0 & 4.5 \\
\hline \multicolumn{6}{|c|}{$\begin{array}{l}\text { Attend programme (mela, sports event, adolescent group } \\
\text { meeting) within village/ward }\end{array}$} \\
\hline Alone & 66.4 & 94.6 & 40.3 & 40.1 & 19.1 \\
\hline Only with someone else & 32.2 & 5.3 & 57.7 & 56.9 & 71.2 \\
\hline Not at all & 1.4 & 0.1 & 1.9 & 3.1 & 9.7 \\
\hline \multicolumn{6}{|c|}{ Play in open spaces of the village/ward } \\
\hline Yes & 89.5 & NA & 64.3 & NA & NA \\
\hline No & 10.5 & NA & 35.7 & NA & NA \\
\hline Number of respondents & 1,012 & 1,821 & 764 & 3,428 & 3,408 \\
\hline
\end{tabular}


Table 7.5 Cont.

\begin{tabular}{|c|c|c|c|c|c|}
\hline Mobility indicators & $\begin{array}{c}\text { Boys } \\
(10-14)\end{array}$ & $\begin{array}{c}\text { Boys } \\
(15-19)\end{array}$ & $\begin{array}{l}\text { Girls } \\
(10-14)\end{array}$ & $\begin{array}{l}\text { Girls } \\
(15-19)\end{array}$ & $\begin{array}{l}\text { Married girls } \\
\qquad(15-19)\end{array}$ \\
\hline \multicolumn{6}{|c|}{ Urban (percent) } \\
\hline \multicolumn{6}{|l|}{ Permitted to: } \\
\hline \multicolumn{6}{|c|}{ Visit shop/market/or a friend/relative within ward } \\
\hline Alone & 88.7 & 98.7 & 82.2 & 82.5 & 38.1 \\
\hline Only with someone else & 9.6 & 1.0 & 17.3 & 16.3 & 51.2 \\
\hline Not at all & 1.7 & 0.2 & 0.5 & 1.2 & 10.8 \\
\hline \multicolumn{6}{|c|}{ Visit shop/market or a friend/relative outside ward } \\
\hline Alone & 41.3 & 90.8 & 35.9 & 53.0 & 23.1 \\
\hline Only with someone else & 52.5 & 8.4 & 63.9 & 46.0 & 73.6 \\
\hline Not at all & 6.2 & 0.8 & 0.2 & 1.0 & 3.3 \\
\hline \multicolumn{6}{|c|}{$\begin{array}{l}\text { Attend programme (mela, sports event, adolescent group } \\
\text { meeting) within ward }\end{array}$} \\
\hline Alone & 62.8 & 95.5 & 39.0 & 48.4 & 21.5 \\
\hline Only with someone else & 34.6 & 4.3 & 58.7 & 49.2 & 70.0 \\
\hline Not at all & 2.6 & 0.3 & 2.3 & 2.4 & 8.5 \\
\hline \multicolumn{6}{|c|}{ Play in open spaces of the ward } \\
\hline Yes & 89.8 & NA & 59.1 & NA & NA \\
\hline No & 10.2 & NA & 40.9 & NA & NA \\
\hline Number of respondents & 452 & 1,008 & 387 & 1,738 & 1,366 \\
\hline \multicolumn{6}{|c|}{ Rural (percent) } \\
\hline \multicolumn{6}{|l|}{ Permitted to: } \\
\hline \multicolumn{6}{|c|}{ Visit shop/market/or a friend/relative within village } \\
\hline Alone & 94.3 & 98.2 & 83.7 & 79.2 & 35.2 \\
\hline Only with someone else & 5.5 & 1.8 & 15.2 & 19.0 & 51.7 \\
\hline Not at all & 0.3 & 0.0 & 1.1 & 1.8 & 13.1 \\
\hline \multicolumn{6}{|c|}{ Visit shop/market or a friend/relative outside village } \\
\hline Alone & 44.7 & 89.0 & 21.0 & 32.2 & 16.2 \\
\hline Only with someone else & 50.5 & 10.6 & 76.6 & 65.7 & 79.2 \\
\hline Not at all & 4.9 & 0.4 & 2.4 & 2.1 & 4.6 \\
\hline \multicolumn{6}{|c|}{$\begin{array}{l}\text { Attend programme (mela, sports event, adolescent group } \\
\text { meeting) within village }\end{array}$} \\
\hline Alone & 66.9 & 94.5 & 40.5 & 39.1 & 18.8 \\
\hline Only with someone else & 31.9 & 5.4 & 57.6 & 57.8 & 71.4 \\
\hline Not at all & 1.2 & 0.1 & 1.9 & 3.2 & 9.9 \\
\hline \multicolumn{6}{|c|}{ Play in open spaces of the village } \\
\hline Yes & 89.4 & NA & 64.9 & NA & NA \\
\hline No & 10.6 & NA & 35.1 & NA & NA \\
\hline Number of respondents & 560 & 813 & 377 & 1,690 & 2,042 \\
\hline
\end{tabular}

Notes: All Ns are unweighted. NA: not applicable. 
A summary measure was created from the range of questions relating to freedom to visit places unescorted within and outside the village or neighbourhood-namely, the percentage who were free to visit at least two locations unescorted. Table 7.6 shows that 72 percent and 96 percent of younger and older boys, respectively, had freedom to visit at least two locations unescorted. In comparison, only 44 percent of younger girls, 47 percent of unmarried older girls, and 21 percent of married older girls had such freedom.

Table 7.6 also presents differentials in freedom of movement by selected background characteristics. Findings reveal that differentials were negligible among older boys. However, differences by age, religion, caste, educational attainment, and engagement in paid work were notable among younger boys. Findings show that among younger boys, 13-14 year olds were more likely than 10-12 year olds to report freedom of movement to visit at least two locations (83\% versus $65 \%$ ). Muslim boys were more likely than Hindu boys to report freedom of movement ( $76 \%$ versus $71 \%$ ). Boys belonging to scheduled castes were the most likely and boys belonging to general castes were the least likely to report freedom of movement ( $81 \%$ and $64 \%$, respectively). Mobility also increased with years of schooling; the proportion of boys who could visit two locations unescorted increased from 64 percent among those with 1-4 years of schooling to 85 percent among those with 8-9 years of schooling. Boys who were engaged in paid work in the year preceding the interview were more likely than those who were not to report freedom of movement ( $88 \%$ versus $70 \%$ ).

Differentials by background characteristics differed across the three categories of adolescent girls. Findings show that Hindu girls were more likely than Muslims girls to report freedom of movement (46\% versus $37 \%$ of younger girls; $47 \%$ versus $42 \%$ of unmarried older girls; and $22 \%$ versus $15 \%$ of married older girls). Differences by caste varied across the three categories of adolescent girls: among younger girls, those belonging to general castes were more likely than those belonging to other castes to report freedom of movement (57\% versus $41-49 \%$ ); among married older girls, those from general castes were less likely than those from other castes to so report (11\% versus $20-22 \%)$; and freedom of movement did not differ by caste among unmarried older girls. Freedom of movement increased with educational attainment among unmarried older girls (but not among younger girls or among married older girls); the proportion of girls who reported mobility increased from 29 percent among those with no schooling to 65 percent among those with 12 or more years of schooling. Mobility differed by current schooling status among unmarried and married older girls (but not among younger girls): those who were currently enrolled in school were more likely than those who were not to have freedom of movement to visit at least two locations (51\% versus $37 \%$ among unmarried older girls and $28 \%$ versus $20 \%$ among married older girls). Engagement in economic activity was associated with freedom of movement among married older girls but not among younger girls and unmarried older girls; among married older girls, those who were engaged in paid work were more likely than those who were not to report freedom of movement (35\% versus 19\%). Findings also show that among unmarried older girls (but not among younger girls or married older girls), a larger proportion of those belonging to the wealthiest households than those belonging to the poorest households had the freedom to visit two or more locations unescorted (55\% versus 33\%). The proportion of unmarried older girls who reported freedom of movement increased with mother's education, from 44-48 percent among those whose mother had completed less than 10 years of schooling to 62 percent among those whose mother had 10 years of schooling or above, but no such difference was observed for younger girls and married older girls. Finally, differences between those from rural and those from urban areas were apparent for unmarried and married older girls (but not for younger girls) among whom a larger proportion of urban than rural girls reported freedom to visit at least two locations unescorted (60\% versus $45 \%$ among unmarried older girls and $26 \%$ versus $20 \%$ among married girls).

Table 7.6: Freedom of movement by selected background characteristics

Percentage of adolescents who could visit at least two selected locations unescorted by selected background characteristics, Bihar, 2016

\begin{tabular}{lrrrrr}
\hline Background characteristics (percent) & $\begin{array}{c}\text { Boys } \\
(10-14)\end{array}$ & $\begin{array}{c}\text { Boys } \\
(15-19)\end{array}$ & $\begin{array}{c}\text { Girls } \\
(10-14)\end{array}$ & $\begin{array}{c}\text { Girls } \\
(15-19)\end{array}$ & $\begin{array}{c}\text { Married girls } \\
(15-19)\end{array}$ \\
\hline Age & & & & & \\
$10-12$ & 65.1 & NA & 47.1 & NA & NA \\
$13-14$ & 82.8 & NA & 40.7 & NA & NA \\
$15-17$ & NA & 95.9 & NA & 45.6 & 19.6 \\
$18-19$ & NA & 97.8 & NA & 49.5 & 21.5 \\
\hline
\end{tabular}


Table 7.6 Cont.

\begin{tabular}{|c|c|c|c|c|c|}
\hline Background characteristics (percent) & $\begin{array}{c}\text { Boys } \\
(10-14)\end{array}$ & $\begin{array}{c}\text { Boys } \\
(15-19)\end{array}$ & $\begin{array}{c}\text { Girls } \\
(10-14)\end{array}$ & $\begin{array}{c}\text { Girls } \\
(15-19)\end{array}$ & $\begin{array}{c}\text { Married girls } \\
(15-19)\end{array}$ \\
\hline \multicolumn{6}{|l|}{ Religion $^{1}$} \\
\hline Hindu & 70.6 & 96.2 & 45.9 & 47.4 & 21.7 \\
\hline Muslim & 76.4 & 97.4 & 36.6 & 42.0 & 14.7 \\
\hline \multicolumn{6}{|l|}{ Caste $^{2}$} \\
\hline SC & 80.9 & 96.4 & 48.8 & 43.8 & 20.3 \\
\hline OBC & 70.7 & 96.2 & 40.8 & 46.7 & 22.3 \\
\hline General $^{3}$ & 63.8 & 97.0 & 57.2 & 47.5 & 10.5 \\
\hline \multicolumn{6}{|l|}{ Completed years of schooling } \\
\hline None $^{4}$ & * & 94.0 & $(38.4)$ & 29.3 & 18.0 \\
\hline $1-4$ & 64.0 & 93.7 & 47.4 & 42.4 & 19.5 \\
\hline $5-7$ & 71.9 & 93.8 & 42.0 & 32.9 & 21.8 \\
\hline $8-9$ & 84.8 & 95.9 & 49.5 & 46.7 & 23.4 \\
\hline 10-11 & NA & 99.0 & NA & 54.2 & 22.2 \\
\hline 12 and above & NA & 98.9 & NA & 65.3 & 20.8 \\
\hline \multicolumn{6}{|l|}{ Current schooling status $^{5}$} \\
\hline Yes & 71.4 & 96.3 & 44.9 & 51.0 & 28.2 \\
\hline No & $(71.5)$ & 96.8 & $(41.4)$ & 37.3 & 20.1 \\
\hline \multicolumn{6}{|c|}{ Paid work in the12 months prior to the interview } \\
\hline Yes & 88.4 & 97.7 & 44.5 & 50.7 & 35.2 \\
\hline No & 70.4 & 95.9 & 44.4 & 45.6 & 19.1 \\
\hline \multicolumn{6}{|l|}{ Wealth quintile } \\
\hline First & 77.5 & 93.3 & 38.2 & 33.2 & 22.9 \\
\hline Second & 72.4 & 96.2 & 52.2 & 39.2 & 22.7 \\
\hline Third & 72.4 & 95.8 & 33.8 & 44.3 & 19.4 \\
\hline Fourth & 66.4 & 96.9 & 50.5 & 48.5 & 22.7 \\
\hline Fifth & 71.4 & 97.2 & 46.4 & 54.9 & 16.8 \\
\hline \multicolumn{6}{|c|}{ Mother's education (in years of schooling completed) } \\
\hline None $^{4}$ & 71.2 & 96.2 & 41.9 & 44.3 & 21.5 \\
\hline $1-7$ & 77.7 & 97.8 & 57.4 & 46.1 & 15.5 \\
\hline $8-9$ & 73.0 & 94.7 & 41.7 & 47.5 & 19.5 \\
\hline 10 and above & 66.5 & 98.1 & 54.1 & 61.6 & 21.0 \\
\hline \multicolumn{6}{|l|}{ Place of residence } \\
\hline Urban & 66.7 & 96.4 & 47.0 & 60.0 & 25.8 \\
\hline Rural & 72.1 & 96.4 & 44.1 & 44.9 & 20.3 \\
\hline Total & 71.5 & 96.4 & 44.4 & 46.5 & 20.9 \\
\hline
\end{tabular}

Notes: * Percentage not shown as this was based on fewer than 25 unweighted cases. () Based on 25-49 unweighted cases. NA: not applicable; OBC: other backward caste; SC: scheduled caste; ST: scheduled tribe. ${ }^{1}$ Percentages not shown for those belonging to other religions as less than one percent of surveyed adolescents belonged to other religions. ${ }^{2}$ Percentages not shown for those belonging to STs as less than one percent of surveyed adolescents belonged to STs. ${ }^{3}$ Includes all those not belonging to SCs, STs, or OBCs. ${ }^{4}$ Includes non-literate and literate with no formal schooling. ${ }^{5}$ Percentages not shown for adolescents who were pursuing their education through distance education courses at the time of interview or those who never went to school. 


\subsubsection{Access to money}

In order to understand access to financial resources among adolescents, we obtained information on whether they had any savings, whether they owned an account in a bank or a post office, and, if so, whether they operated the account themselves. Results are presented in Table 7.7.

Findings show that 34 percent of younger boys and 58 percent of older boys reported some savings, as did 41 percent of younger girls and 65-73 percent of unmarried and married older girls. As seen above, differences by age were notable, with older adolescents more likely than younger adolescents to have had some savings. Likewise, girls were somewhat more likely than boys to report some savings (41\% versus 34\% among younger adolescents and $65-73 \%$ versus 58\% among older adolescents). Moreover, a somewhat larger proportion of married older girls than unmarried older girls reported some savings (73\% versus 65\%). Finally, a larger proportion of urban than rural adolescents across all categories of adolescents, except among married older girls, reported some savings (48-67\% versus 33-57\% among boys and 57-74\% versus 39-64\% among younger girls and unmarried older girls); similar proportions of married older girls in urban and rural reported some savings (72-75\%).

Fewer adolescents reported owning a bank/post office account, either independently or jointly with someone else. Younger adolescents were less likely than older adolescents to independently or jointly own an account-29 percent of younger boys compared with 52 percent of older boys and 28 percent of younger girls compared with 34-50 percent of unmarried and married older girls. While differences by sex were muted, differences by marital status were noted among older girls-a larger proportion of unmarried than married girls reported independently or jointly owning an account (50\% versus 34\%). Differences by residence in rural or urban areas were modest, except for unmarried older girls, among whom more of those in urban than rural areas owned an account (57\% versus 49\%).

With regard to operation of the account, some differences by sex were noted among older adolescents-72 percent of boys who owned an account reported operating it themselves compared with 64-66 percent of girls. However, no such difference was observed among younger adolescents (26-29\%). No difference by marital status was observed among older girls. Differences by residence in rural or urban areas were observed among all categories of adolescents, except among younger girls, with urban adolescents more likely than rural adolescents to operate their account on their own (42\% versus $28 \%$ among younger boys; $87 \%$ versus $70 \%$ among older boys; $74 \%$ versus $65 \%$ among unmarried older girls; and $75 \%$ versus $63 \%$ among married older girls).

\section{Table 7.7 Access to money}

Percentage of adolescents who reported having any savings, owning an account in a bank or post office, and operating the account themselves, according to residence, Bihar, 2016

\begin{tabular}{|c|c|c|c|c|c|}
\hline Savings behaviour & $\begin{array}{c}\text { Boys } \\
(10-14)\end{array}$ & $\begin{array}{c}\text { Boys } \\
(15-19)\end{array}$ & $\begin{array}{c}\text { Girls } \\
(10-14)\end{array}$ & $\begin{array}{c}\text { Girls } \\
(15-19)\end{array}$ & $\begin{array}{l}\text { Married girls } \\
\text { (15-19) }\end{array}$ \\
\hline \multicolumn{6}{|c|}{ Combined (percent) } \\
\hline Has savings of any amount & 34.3 & 58.2 & 41.0 & 64.6 & 72.6 \\
\hline \multicolumn{6}{|l|}{ Ownership of a bank/post office account } \\
\hline In own (respondent's) name & 27.8 & 51.4 & 26.8 & 49.4 & 32.7 \\
\hline Jointly with someone else & 0.8 & 0.6 & 1.2 & 0.4 & 1.0 \\
\hline Both & 0.0 & 0.0 & 0.0 & 0.1 & 0.0 \\
\hline Any account & 28.7 & 52.0 & 28.0 & 49.6 & 33.6 \\
\hline Number of respondents & 1,012 & 1,821 & 764 & 3,428 & 3,408 \\
\hline Operates bank/post office account themselves & 29.0 & 72.3 & 26.1 & 66.3 & 64.2 \\
\hline Number with an account & 254 & 971 & 208 & 1,809 & 1,106 \\
\hline
\end{tabular}


Table 7.7 Cont.

\begin{tabular}{|c|c|c|c|c|c|}
\hline Savings behaviour & $\begin{array}{c}\text { Boys } \\
(10-14)\end{array}$ & $\begin{array}{c}\text { Boys } \\
(15-19)\end{array}$ & $\begin{array}{c}\text { Girls } \\
(10-14)\end{array}$ & $\begin{array}{c}\text { Girls } \\
(15-19)\end{array}$ & $\begin{array}{l}\text { Married girls } \\
\qquad(15-19)\end{array}$ \\
\hline \multicolumn{6}{|c|}{ Urban (percent) } \\
\hline Has savings of any amount & 48.2 & 67.1 & 56.8 & 73.5 & 75.4 \\
\hline \multicolumn{6}{|l|}{ Ownership of a bank/post office account } \\
\hline In own (respondent's) name & 22.8 & 54.0 & 26.3 & 56.3 & 33.3 \\
\hline Jointly with someone else & 0.8 & 1.0 & 1.1 & 1.0 & 1.3 \\
\hline Both & 0.0 & 0.0 & 0.0 & 0.0 & 0.0 \\
\hline Any account & 23.7 & 55.1 & 27.3 & 57.2 & 34.5 \\
\hline Number of respondents & 452 & 1,008 & 387 & 1,738 & 1,366 \\
\hline Operates bank/post office account themselves & 41.6 & 87.4 & 27.4 & 74.4 & 74.5 \\
\hline Number with an account & 90 & 540 & 104 & 972 & 441 \\
\hline \multicolumn{6}{|c|}{ Rural (percent) } \\
\hline Has savings of any amount & 32.7 & 57.1 & 39.0 & 63.6 & 72.3 \\
\hline \multicolumn{6}{|l|}{ Ownership of a bank/post office account } \\
\hline In own (respondent's) name & 28.4 & 51.1 & 26.9 & 48.5 & 32.6 \\
\hline Jointly with someone else & 0.8 & 0.5 & 1.2 & 0.3 & 0.9 \\
\hline Both & 0.0 & 0.0 & 0.0 & 0.1 & 0.0 \\
\hline Any account & 29.3 & 51.6 & 28.1 & 48.7 & 33.5 \\
\hline Number of respondents & 560 & 813 & 377 & 1,690 & 2,042 \\
\hline Operates bank/post office account themselves & 27.8 & 70.3 & 25.9 & 65.1 & 63.0 \\
\hline Number with an account & 164 & 431 & 104 & 837 & 665 \\
\hline
\end{tabular}

Note: All Ns are unweighted.

\subsubsection{Sense of self-efficacy}

We posed several age-appropriate questions to study participants to measure their sense of self-efficacy. We asked younger adolescents whether they were able to express their opinion to elders in their family, whether they could express disagreement if he/she disagrees with someone, whether they were able to ask questions to his/her teachers, and whether they were able speak in front of a group of their peers. We asked older adolescents whether they were able to express their opinion to elders in their family and whether they could confront a person who says or does something wrong to them. The response categories for all these questions were 'never', 'some of the time', and 'most of the time'. Findings are described in Table 7.8. Substantial proportions of adolescents, regardless of age, sex, and, among older girls, marital status, reported self-efficacy in expressing their views in public and private spaces as well as in resisting or confronting those who misbehave with them.

Among younger adolescents, 57 percent of boys and 43 percent of girls were confident about asking questions to his/her teachers most of the time and 44 percent of boys and 39 percent of girls were confident about speaking in front of a group of peers most of the time. Some 23-26 percent of younger boys and 33-34 percent of younger girls reported that they were able to express their disagreement most of the time if he/she disagrees with someone and to express their views to elders in their family most of the time.

Among older adolescents, 27 percent of boys and 17-25 percent of girls reported that they were able to express their views to elders in their family most of the time, and 39 percent of boys and unmarried girls, and 26 percent of married girls reported that they were able to confront a person who says or does something to wrong to them most of the time. 


\section{Table 7.8: Sense of self-efficacy}

Percentage of adolescents who perceived a sense of self-efficacy under selected circumstances, according to residence, Bihar, 2016

\begin{tabular}{|c|c|c|c|c|c|}
\hline Self-efficacy & $\begin{array}{c}\text { Boys } \\
(10-14)\end{array}$ & $\begin{array}{l}\text { Boys } \\
(15-19)\end{array}$ & $\begin{array}{c}\text { Girls } \\
(10-14)\end{array}$ & $\begin{array}{c}\text { Girls } \\
(15-19)\end{array}$ & $\begin{array}{l}\text { Married girls } \\
\qquad(15-19)\end{array}$ \\
\hline \multicolumn{6}{|c|}{ Combined (percent) } \\
\hline \multicolumn{6}{|c|}{ Confident about asking questions to his/her teachers } \\
\hline Never & 12.5 & NA & 13.6 & NA & NA \\
\hline Some of the time & 30.7 & NA & 43.6 & NA & NA \\
\hline Most of the time & 56.8 & NA & 42.8 & NA & NA \\
\hline \multicolumn{6}{|c|}{ Confident about speaking in front of a group of peers } \\
\hline Never & 15.6 & NA & 14.9 & NA & NA \\
\hline Some of the time & 40.4 & NA & 45.8 & NA & NA \\
\hline Most of the time & 44.0 & NA & 39.3 & NA & NA \\
\hline \multicolumn{6}{|c|}{$\begin{array}{l}\text { Able to express disagreement if he/she disagrees with } \\
\text { someone }\end{array}$} \\
\hline Never & 19.8 & NA & 14.3 & NA & NA \\
\hline Some of the time & 56.9 & NA & 52.1 & NA & NA \\
\hline Most of the time & 23.3 & NA & 33.6 & NA & NA \\
\hline \multicolumn{6}{|c|}{ Able to express own opinion to elders in the family } \\
\hline Never & 14.7 & 11.5 & 8.5 & 11.5 & 17.0 \\
\hline Some of the time & 59.3 & 61.9 & 58.7 & 63.3 & 65.8 \\
\hline Most of the time & 26.0 & 26.6 & 32.8 & 25.2 & 17.1 \\
\hline \multicolumn{6}{|c|}{$\begin{array}{l}\text { Able to confront a person who says or does something } \\
\text { wrong to the respondent }\end{array}$} \\
\hline Never & NA & 12.5 & NA & 11.7 & 19.6 \\
\hline Some of the time & NA & 48.7 & NA & 49.2 & 54.8 \\
\hline Most of the time & NA & 38.9 & NA & 39.1 & 25.6 \\
\hline Number of respondents & 1,012 & 1,821 & 764 & 3,428 & 3,408 \\
\hline \multicolumn{6}{|c|}{ Urban (percent) } \\
\hline \multicolumn{6}{|c|}{ Confident about asking questions to his/her teachers } \\
\hline Never & 9.0 & NA & 11.9 & NA & NA \\
\hline Some of the time & 24.3 & NA & 30.3 & NA & NA \\
\hline Most of the time & 66.7 & NA & 57.8 & NA & NA \\
\hline \multicolumn{6}{|c|}{ Confident about speaking in front of a group of peers } \\
\hline Never & 8.1 & NA & 11.1 & NA & NA \\
\hline Some of the time & 35.4 & NA & 33.0 & NA & NA \\
\hline Most of the time & 56.5 & NA & 56.0 & NA & NA \\
\hline \multicolumn{6}{|c|}{$\begin{array}{l}\text { Able to express disagreement if he/she disagrees with } \\
\text { someone }\end{array}$} \\
\hline Never & 16.4 & NA & 16.6 & NA & NA \\
\hline Some of the time & 57.7 & NA & 46.7 & NA & NA \\
\hline Most of the time & 25.9 & NA & 36.8 & NA & NA \\
\hline
\end{tabular}


Table 7.8 Cont.

\begin{tabular}{|c|c|c|c|c|c|}
\hline Self-efficacy & $\begin{array}{c}\text { Boys } \\
(10-14)\end{array}$ & $\begin{array}{l}\text { Boys } \\
(15-19)\end{array}$ & $\begin{array}{c}\text { Girls } \\
(10-14)\end{array}$ & $\begin{array}{c}\text { Girls } \\
(15-19)\end{array}$ & $\begin{array}{l}\text { Married girls } \\
\qquad(15-19)\end{array}$ \\
\hline \multicolumn{6}{|c|}{ Able to express own opinion to elders in the family } \\
\hline Never & 9.3 & 7.0 & 6.3 & 6.6 & 13.9 \\
\hline Some of the time & 52.4 & 56.6 & 45.4 & 58.8 & 65.2 \\
\hline Most of the time & 38.3 & 36.4 & 48.3 & 34.7 & 20.9 \\
\hline \multicolumn{6}{|c|}{$\begin{array}{l}\text { Able to confront a person who says or does something } \\
\text { wrong to the respondent }\end{array}$} \\
\hline Never & NA & 9.8 & NA & 9.3 & 17.9 \\
\hline Some of the time & NA & 47.1 & NA & 47.0 & 53.5 \\
\hline Most of the time & NA & 43.2 & NA & 43.6 & 28.6 \\
\hline Number of respondents & 452 & 1,008 & 387 & 1,738 & 1,366 \\
\hline \multicolumn{6}{|c|}{ Rural (percent) } \\
\hline \multicolumn{6}{|c|}{ Confident about asking questions to his/her teachers } \\
\hline Never & 12.9 & NA & 13.8 & NA & NA \\
\hline Some of the time & 31.5 & NA & 45.2 & NA & NA \\
\hline Most of the time & 55.6 & NA & 41.0 & NA & NA \\
\hline \multicolumn{6}{|c|}{ Confident about speaking in front of a group of peers } \\
\hline Never & 16.5 & NA & 15.4 & NA & NA \\
\hline Some of the time & 41.0 & NA & 47.3 & NA & NA \\
\hline Most of the time & 42.5 & NA & 37.3 & NA & NA \\
\hline \multicolumn{6}{|c|}{$\begin{array}{l}\text { Able to express disagreement if he/she disagrees with } \\
\text { someone }\end{array}$} \\
\hline Never & 20.2 & NA & 14.1 & NA & NA \\
\hline Some of the time & 56.9 & NA & 52.7 & NA & NA \\
\hline Most of the time & 23.0 & NA & 33.2 & NA & NA \\
\hline \multicolumn{6}{|c|}{ Able to express own opinion to elders in the family } \\
\hline Never & 15.3 & 12.1 & 8.8 & 12.1 & 17.4 \\
\hline Some of the time & 60.1 & 62.5 & 60.3 & 63.8 & 65.9 \\
\hline Most of the time & 24.5 & 25.4 & 30.9 & 24.1 & 16.7 \\
\hline \multicolumn{6}{|c|}{$\begin{array}{l}\text { Able to confront a person who says or does something } \\
\text { wrong to the respondent }\end{array}$} \\
\hline Never & NA & 12.8 & NA & 12.0 & 19.8 \\
\hline Some of the time & NA & 48.9 & NA & 49.4 & 54.9 \\
\hline Most of the time & NA & 38.3 & NA & 38.5 & 25.3 \\
\hline Number of respondents & 560 & 813 & 377 & 1,690 & 2,042 \\
\hline
\end{tabular}

Notes: All Ns are unweighted. NA: not applicable.

Differences by sex were narrow. Even so, among younger adolescents, boys were more likely than girls to report that they were confident about asking questions to their teachers most of the time (57\% versus 43\%), while they were less likely to report that they were able to express their disagreement most of the time if they disagreed with someone (23\% versus 34\%) and to express their opinion to elders in the family most of the time (26\% versus 33\%). We observed no such differences among older adolescents. Differences by marital status among older girls show 
that unmarried girls were more likely than their married counterparts to report that most of the time they were able to express their opinion to elders in the family (25\% versus $17 \%$ ) and to confront most of the time a person who said or did something wrong to them (39\% versus $26 \%$ ).

Differences between those from rural and those from urban areas were modest for the most part. However, some differences were notable. First, a larger proportion of younger adolescents in urban than rural areas were confident of their ability to ask questions to their teachers ( $67 \%$ versus $56 \%$ among boys and $58 \%$ versus $41 \%$ among girls) and to report that most of the time they were confident about speaking in front of a group of peers $(57 \%$ versus $43 \%$ among boys and $56 \%$ versus $37 \%$ among girls). Also, across all categories of adolescents, except married older girls, urban adolescents were more likely than rural adolescents to report confidence about their ability to express their opinion to elders in the family (36-38\% versus $25 \%$ among boys; $48 \%$ versus $31 \%$ among younger girls; $35 \%$ versus $24 \%$ among unmarried older girls).

\subsection{Gender role attitudes}

In order to understand gender role attitudes, the survey contained nine questions, some of which we posed exclusively to younger adolescents and some others to only older adolescents. Questions to younger adolescents probed their attitudes about the importance attached to educating boys relative to girls, the comparative performance of girls and boys in studies, and the division of household chores between girls and boys. Older adolescents answered questions on whether they perceived girls' friendship with boys as wrong, whether husband and wife should share childcare, and whether men have the right to beat their wife. Both younger and older adolescents were asked whether they think that girls like to be teased by boys, whether girls have a right to decide when they want to marry, and whether a father or husband should be the main decision-maker with regard to spending household money. What needs to be noted is that we posed six questions each to both younger and older adolescents, three of which were common to both age groups while the other three questions were different for each of the two age groups, as can be seen from Table 7.9.

Questions that were the most likely to elicit egalitarian attitudes from younger adolescents were whether girls like to be teased by boys, whether girls are as good as boys in studies, whether educating boys is more important than educating girls, and whether fathers should be the main decision-maker with regard to spending household money. On these matters, 56-82 percent of younger boys and 76-90 percent of younger girls expressed egalitarian views. Fewer boys and girls expressed egalitarian responses to such statements as 'boys should do as much housework as girls' (39\% of boys and $45 \%$ of girls) and 'girls should be allowed to decide when they want to marry' (29\% of boys and $44 \%$ of girls).

Half or more of older boys and unmarried older girls expressed egalitarian views in response to all six questions posed to them: 71-90 percent of older boys believed that girls do not like to be teased by boys, it is all right for girls to have male friends, it is not acceptable for a man to beat his wife if she does not listen to him or obey him, and the husband alone/mainly should not decide about spending household money; 53-66 percent of older boys agreed that childcare is not a woman's responsibility alone and girls should be allowed to decide when they want to marry. Among unmarried older girls, 79-95 percent agreed that it is not acceptable for a man to beat his wife if she does not listen to him or obey him, girls do not like to be teased by boys, and the husband alone/mainly should not be the one to decide about spending household money; somewhat fewer-58-61 percent-believed that it is all right for girls to have male friends, childcare is not a woman's responsibility alone, and girls should be allowed to decide when they want to marry.

Among married older girls as well, half or more expressed egalitarian views in response to all questions, except the one on sharing childcare responsibility. Indeed, 74-93 percent of married older girls perceived that girls do not like to be teased by boys, husband should not be the only one to decide or to mainly decide about spending household money, and it is not acceptable for a man to beat his wife if she does not listen to him or obey him; and 44-58 percent agreed that it is all right for girls to have male friends, childcare is not a woman's responsibility alone, and girls should be allowed to decide when they wish to marry.

Where comparisons are possible, findings show that older adolescents were more likely than younger adolescents to express gender egalitarian views, particularly among boys. Thus, 90 percent of older boys compared with 82 percent of younger boys reported that girls do not like to be teased; the corresponding percentages among girls were 93-95 percent among unmarried and married older girls and 90 percent among younger girls. Likewise, 53 percent of older 
boys compared with 29 percent of younger boys and 58-61 percent of unmarried and married older girls compared with 44 percent of younger girls reported that girls should be allowed to decide when they want to marry. Similarly, 71 percent of older boys compared with 56 percent of younger boys and 84-87 percent of unmarried and married older girls compared with 81 percent of younger girls perceived that decisions about spending household money should be jointly taken by husband and wife.

Younger boys were consistently more likely than girls to report unequal gender role attitudes in relation to all six topics posed to them, and differences were pronounced on several statements. Thus, even though large proportions of younger adolescents believed that educating boys is no more important than educating girls, a larger proportion of younger boys than younger girls expressed the traditional attitude that educating boys is more important (30\% of younger boys and $21 \%$ of younger girls). Among older adolescents, differences by sex were inconsistent: while more boys than girls expressed egalitarian views in response to such topics as it is all right for girls to have male friends ( $74 \%$ versus $55-60 \%$ agreed) and childcare is not a woman's responsibility alone (66\% versus $44-58 \%$ agreed), fewer boys than girls expressed egalitarian views in response to such statements as 'girls should be allowed to decide when they wish to marry' (53\% versus 58-61\% agreed) and 'the husband mainly should decide how to spend household money' ( $71 \%$ versus $84-87 \%$ agreed). As many boys as girls expressed egalitarian views in response to such statements as 'it is not acceptable for a man to beat his wife if she does not listen to him or obey him' and 'girls do not like to be teased by boys'.

Differences by marital status among older girls were modest at best. Even so, married girls were less likely than unmarried girls to express egalitarian views on the statement that childcare is not the sole responsibility of women (44\% versus $58 \%$ agreed), it is all right for girls to have male friends (55\% versus $60 \%$ agreed) and it is not acceptable for a man to beat his wife if she does not listen to him or obey him ( $74 \%$ versus $79 \%$ agreed). There were consistent differences by residence in rural or urban areas among all categories of adolescents; urban adolescents were more likely than rural adolescents to express egalitarian attitudes in relation to most of the statements posed to them.

\section{Table 7.9 Gender role attitudes}

Percent distribution of adolescents by attitude towards gender roles, according to residence, Bihar, 2016

\begin{tabular}{|c|c|c|c|c|c|}
\hline Gender role attitudes & $\begin{array}{l}\text { Boys } \\
(10-14)\end{array}$ & $\begin{array}{l}\text { Boys } \\
(15-19)\end{array}$ & $\begin{array}{l}\text { Girls } \\
(10-14)\end{array}$ & $\begin{array}{l}\text { Girls } \\
(15-19)\end{array}$ & $\begin{array}{l}\text { Married girls } \\
(15-19)\end{array}$ \\
\hline \multicolumn{6}{|c|}{ Combined (percent) } \\
\hline \multicolumn{6}{|c|}{ Educating boys is more important than educating girls } \\
\hline Yes & 30.0 & NA & 21.2 & NA & NA \\
\hline No & 63.7 & NA & 76.4 & NA & NA \\
\hline Unsure/cannot say & 6.3 & NA & 2.4 & NA & NA \\
\hline \multicolumn{6}{|c|}{ Girls are as good as boys in studies } \\
\hline Yes & 70.5 & NA & 86.9 & NA & NA \\
\hline No & 22.8 & NA & 10.2 & NA & NA \\
\hline Unsure/cannot say & 6.7 & NA & 2.9 & NA & NA \\
\hline \multicolumn{6}{|c|}{ Boys should do as much domestic work as girls } \\
\hline Yes & 38.6 & NA & 45.0 & NA & NA \\
\hline No & 60.1 & NA & 54.1 & NA & NA \\
\hline Unsure/cannot say & 1.3 & NA & 0.9 & NA & NA \\
\hline \multicolumn{6}{|c|}{ It is wrong for girls to have male friends } \\
\hline Yes & NA & 24.4 & NA & 37.0 & 43.5 \\
\hline No & NA & 73.6 & NA & 60.0 & 54.6 \\
\hline Unsure/cannot say & NA & 2.0 & NA & 3.0 & 1.8 \\
\hline
\end{tabular}


Table 7.9 Cont.

\begin{tabular}{l} 
Gender role attitudes \\
\hline Giving young children a bath and feeding them are only a \\
woman's responsibility
\end{tabular}

Yes

No

Unsure/cannot say

Boys

Boys

Girls

Girls

Married girls

$(10-14) \quad(15-19)$

$(10-14)$

$(15-19)$

$(15-19)$

It is all right for a husband to beat his wife if she does not listen to him or obey him

Yes

No

Unsure/cannot say

$\begin{array}{rrrrr}\text { NA } & 33.8 & \text { NA } & 41.8 & 55.5 \\ \text { NA } & 65.8 & \text { NA } & 57.5 & 44.0 \\ \text { NA } & 0.4 & \text { NA } & 0.7 & 0.5\end{array}$

Girls like to be teased by boys

Yes

No

Unsure/cannot say

$\begin{array}{rrrrr}\text { NA } & 22.9 & \text { NA } & 19.7 & 26.1 \\ \text { NA } & 75.8 & \text { NA } & 79.4 & 73.7 \\ \text { NA } & 1.3 & \text { NA } & 0.9 & 0.2\end{array}$

Girls should be allowed to decide when they want to marry

Yes

521

53.1

43.6

3.6

2.9

4.3

82.1

90.2

90.0

95.0

93.4

No

52.1

44.2

39.7

2.2

2.2

Unsure/cannot say

18.6

2.8

16.7

61.1

57.8

Father/husband alone/mainly should decide about spending household money

Yes

No

$\begin{array}{lllll}35.5 & 28.0 & 11.8 & 11.6 & 15.1\end{array}$

55.6

70.7

81.0

87.3

84.3

Unsure/cannot say

Number of respondents

\begin{tabular}{rrrrr}
8.9 & 1.3 & 7.2 & 1.1 & 0.6 \\
$\mathbf{1 , 0 1 2}$ & $\mathbf{1 , 8 2 1}$ & $\mathbf{7 6 4}$ & $\mathbf{3 , 4 2 8}$ & $\mathbf{3 , 4 0 8}$ \\
\hline
\end{tabular}

Urban (percent)

Educating boys is more important than educating girls

Yes

No

75.4

NA

12.9

NA

NA

Unsure/cannot say

6.6

NA

83.4

NA

NA

Girls are as good as boys in studies

Yes

No

76.5

19.1

$$
\text { NA }
$$

NA

NA

Unsure/cannot say

$\begin{array}{lllll}4.4 & N A & 4.0 & N A & N A\end{array}$

Boys should do as much domestic work as girls

Yes

No

$\begin{array}{rrrrr}51.0 & \text { NA } & 60.8 & \text { NA } & \text { NA } \\ 47.1 & \text { NA } & 35.7 & \text { NA } & \text { NA } \\ 1.9 & \text { NA } & 3.5 & \text { NA } & \text { NA }\end{array}$

Unsure/cannot say

1

It is wrong for girls to have male friends

Yes

\begin{tabular}{lrrrr} 
NA & 10.1 & NA & 20.8 & 31.1 \\
NA & 88.2 & NA & 76.8 & 67.3 \\
NA & 1.7 & NA & 2.5 & 1.6 \\
\hline
\end{tabular}


Table 7.9 Cont.

\begin{tabular}{|c|c|c|c|c|c|}
\hline Gender role attitudes & $\begin{array}{c}\text { Boys } \\
(10-14)\end{array}$ & $\begin{array}{l}\text { Boys } \\
(15-19)\end{array}$ & $\begin{array}{c}\text { Girls } \\
(10-14)\end{array}$ & $\begin{array}{c}\text { Girls } \\
(15-19)\end{array}$ & $\begin{array}{l}\text { Married girls } \\
\quad(15-19)\end{array}$ \\
\hline \multicolumn{6}{|c|}{$\begin{array}{l}\text { Giving young children a bath and feeding them are only a } \\
\text { woman's responsibility }\end{array}$} \\
\hline Yes & NA & 19.2 & NA & 23.3 & 44.8 \\
\hline No & NA & 80.4 & NA & 76.1 & 55.1 \\
\hline Unsure/cannot say & NA & 0.4 & NA & 0.6 & 0.1 \\
\hline \multicolumn{6}{|c|}{$\begin{array}{l}\text { It is all right for a husband to beat his wife if she does not } \\
\text { listen to him or obey him }\end{array}$} \\
\hline Yes & NA & 11.9 & NA & 8.6 & 19.7 \\
\hline No & NA & 87.3 & NA & 90.5 & 80.2 \\
\hline Unsure/cannot say & NA & 0.8 & NA & 0.9 & 0.1 \\
\hline \multicolumn{6}{|c|}{ Girls like to be teased by boys } \\
\hline Yes & 2.2 & 3.7 & 4.0 & 3.0 & 3.6 \\
\hline No & 88.3 & 91.9 & 92.0 & 95.7 & 95.1 \\
\hline Unsure/cannot say & 9.5 & 4.4 & 4.0 & 1.3 & 1.3 \\
\hline \multicolumn{6}{|c|}{ Girls should be allowed to decide when they want to marry } \\
\hline Yes & 43.4 & 63.0 & 55.2 & 76.2 & 62.4 \\
\hline No & 41.8 & 33.8 & 28.7 & 22.3 & 35.5 \\
\hline Unsure/cannot say & 14.8 & 3.2 & 16.2 & 1.5 & 2.1 \\
\hline \multicolumn{6}{|c|}{$\begin{array}{l}\text { Father/husband alone/mainly should decide about spending } \\
\text { household money }\end{array}$} \\
\hline Yes & 27.8 & 16.4 & 14.4 & 4.8 & 11.7 \\
\hline No & 68.2 & 82.7 & 79.4 & 93.8 & 87.7 \\
\hline Unsure/cannot say & 4.0 & 0.9 & 6.2 & 1.4 & 0.6 \\
\hline Number of respondents & 452 & 1,008 & 387 & 1,738 & 1,366 \\
\hline \multicolumn{6}{|c|}{ Rural (percent) } \\
\hline \multicolumn{6}{|c|}{ Educating boys is more important than educating girls } \\
\hline Yes & 31.4 & NA & 22.2 & NA & NA \\
\hline No & 62.4 & NA & 75.5 & NA & NA \\
\hline Unsure/cannot say & 6.3 & NA & 2.3 & NA & NA \\
\hline \multicolumn{6}{|c|}{ Girls are as good as boys in studies } \\
\hline Yes & 69.8 & NA & 86.7 & NA & NA \\
\hline No & 23.2 & NA & 10.5 & NA & NA \\
\hline Unsure/cannot say & 7.0 & NA & 2.8 & NA & NA \\
\hline \multicolumn{6}{|c|}{ Boys should do as much domestic work as girls } \\
\hline Yes & 37.1 & NA & 43.1 & NA & NA \\
\hline No & 61.6 & NA & 56.4 & NA & NA \\
\hline Unsure/cannot say & 1.2 & NA & 0.6 & NA & NA \\
\hline \multicolumn{6}{|c|}{ It is wrong for girls to have male friends } \\
\hline Yes & NA & 26.2 & NA & 38.9 & 45.0 \\
\hline No & NA & 71.7 & NA & 58.0 & 53.2 \\
\hline Unsure/cannot say & NA & 2.1 & NA & 3.1 & 1.8 \\
\hline
\end{tabular}


Table 7.9 Cont.

\begin{tabular}{|c|c|c|c|c|c|}
\hline Gender role attitudes & $\begin{array}{l}\text { Boys } \\
(10-14)\end{array}$ & $\begin{array}{l}\text { Boys } \\
(15-19)\end{array}$ & $\begin{array}{c}\text { Girls } \\
(\mathbf{1 0}-14)\end{array}$ & $\begin{array}{c}\text { Girls } \\
(15-19)\end{array}$ & $\begin{array}{l}\text { Married girls } \\
\quad(15-19)\end{array}$ \\
\hline \multicolumn{6}{|c|}{$\begin{array}{l}\text { Giving young children a bath and feeding them are only a } \\
\text { woman's responsibility }\end{array}$} \\
\hline Yes & NA & 35.7 & NA & 44.0 & 56.7 \\
\hline No & NA & 64.0 & NA & 55.3 & 42.8 \\
\hline Unsure/cannot say & NA & 0.4 & NA & 0.7 & 0.5 \\
\hline \multicolumn{6}{|c|}{$\begin{array}{l}\text { It is all right for a husband to beat his wife if she does not } \\
\text { listen to him or obey him }\end{array}$} \\
\hline Yes & NA & 24.3 & NA & 21.0 & 26.8 \\
\hline No & NA & 74.4 & NA & 78.1 & 73.0 \\
\hline Unsure/cannot say & NA & 1.3 & NA & 0.9 & 0.2 \\
\hline \multicolumn{6}{|c|}{ Girls like to be teased by boys } \\
\hline Yes & 2.8 & 5.3 & 3.5 & 2.8 & 4.4 \\
\hline No & 81.4 & 90.0 & 89.8 & 94.9 & 93.2 \\
\hline Unsure/cannot say & 15.8 & 4.6 & 6.7 & 2.3 & 2.3 \\
\hline \multicolumn{6}{|c|}{ Girls should be allowed to decide when they want to marry } \\
\hline Yes & 27.6 & 51.8 & 42.2 & 59.3 & 57.3 \\
\hline No & 53.4 & 45.5 & 41.0 & 37.8 & 40.8 \\
\hline Unsure/cannot say & 19.0 & 2.7 & 16.8 & 2.9 & 2.0 \\
\hline \multicolumn{6}{|c|}{$\begin{array}{l}\text { Father/husband alone/mainly should decide about spending } \\
\text { household money }\end{array}$} \\
\hline Yes & 36.5 & 29.4 & 11.5 & 12.4 & 15.5 \\
\hline No & 54.1 & 69.2 & 81.2 & 86.5 & 83.9 \\
\hline Unsure/cannot say & 9.4 & 1.4 & 7.3 & 1.1 & 0.6 \\
\hline Number of respondents & 560 & 813 & 377 & 1,690 & 2,042 \\
\hline
\end{tabular}

Notes: All Ns are unweighted. NA: not applicable.

A summary measure was created from the range of questions relating to gender role attitudes-namely, the percentage of adolescents who expressed egalitarian attitudes in four or more of the six statements posed to them. Findings, presented in Table 7.10, show considerable differences in adherence to egalitarian gender role attitudes by background characteristics. As mentioned earlier, the questions we posed to younger and older adolescents were different, and therefore, findings are not exactly comparable between younger and older adolescents.

On the whole, 47 percent of younger boys and 74 percent of older boys reported gender egalitarian attitudes, as did 77 percent of younger girls and 66-74 percent of unmarried and married older girls. The proportion who adhered to egalitarian attitudes increased with age among younger boys, but not among the other four categories of adolescents. Among younger boys, for example, the percentage of those who adhered to egalitarian attitudes rose from 40 percent among 10-12 year olds to 58 percent among $13-14$ year olds. 
Table 7.10: Adherence to egalitarian gender role attitudes by selected background characteristics

Percentage of adolescents who displayed egalitarian gender role attitudes ${ }^{1}$ by selected background characteristics, according to residence, Bihar, 2016

\begin{tabular}{|c|c|c|c|c|c|}
\hline Background characteristics (percent) & $\begin{array}{c}\text { Boys } \\
(10-14)\end{array}$ & $\begin{array}{c}\text { Boys } \\
(15-19)\end{array}$ & $\begin{array}{c}\text { Girls } \\
(10-14)\end{array}$ & $\begin{array}{c}\text { Girls } \\
(15-19)\end{array}$ & $\begin{array}{l}\text { Married girls } \\
\qquad(15-19)\end{array}$ \\
\hline \multicolumn{6}{|l|}{ Age } \\
\hline $10-12$ & 40.3 & NA & 74.9 & NA & NA \\
\hline $13-14$ & 57.8 & NA & 80.2 & NA & NA \\
\hline $15-17$ & NA & 72.7 & NA & 73.1 & 65.5 \\
\hline $18-19$ & NA & 76.2 & NA & 78.1 & 65.9 \\
\hline \multicolumn{6}{|l|}{ Religion $^{2}$} \\
\hline Hindu & 49.0 & 73.5 & 77.4 & 75.5 & 65.8 \\
\hline Muslim & 32.3 & 74.6 & 75.6 & 66.8 & 65.0 \\
\hline \multicolumn{6}{|l|}{ Caste $^{3}$} \\
\hline SC & 34.0 & 71.9 & 65.8 & 71.5 & 57.5 \\
\hline $\mathrm{OBC}$ & 48.4 & 73.3 & 79.5 & 72.0 & 67.7 \\
\hline General $^{4}$ & 56.2 & 79.0 & 83.9 & 86.9 & 77.6 \\
\hline \multicolumn{6}{|l|}{ Completed years of schooling } \\
\hline None $^{5}$ & * & 61.9 & (36.5) & 46.6 & 50.8 \\
\hline $1-4$ & 33.0 & 47.6 & 68.5 & 45.4 & 48.9 \\
\hline $5-7$ & 53.4 & 66.0 & 82.1 & 66.9 & 67.0 \\
\hline $8-9$ & 56.8 & 71.9 & 91.5 & 76.0 & 72.9 \\
\hline $10-11$ & NA & 84.2 & NA & 84.5 & 80.5 \\
\hline 12 and above & NA & 85.8 & NA & 91.3 & 84.8 \\
\hline \multicolumn{6}{|l|}{ Current schooling status ${ }^{6}$} \\
\hline Yes & 48.6 & 76.3 & 80.3 & 79.5 & 81.0 \\
\hline No & (20.0) & 64.1 & $(59.2)$ & 66.6 & 69.0 \\
\hline \multicolumn{6}{|c|}{ Paid work in the 12 months prior to the interview } \\
\hline Yes & 23.3 & 73.8 & 69.3 & 69.8 & 61.5 \\
\hline No & 48.2 & 73.6 & 77.8 & 75.1 & 66.3 \\
\hline \multicolumn{6}{|l|}{ Wealth quintile } \\
\hline First & 29.4 & 56.2 & 63.5 & 57.2 & 54.7 \\
\hline Second & 34.9 & 70.3 & 73.1 & 57.3 & 60.1 \\
\hline Third & 41.8 & 66.8 & 68.7 & 71.0 & 62.8 \\
\hline Fourth & 48.1 & 77.3 & 85.4 & 77.0 & 69.3 \\
\hline Fifth & 74.6 & 82.5 & 89.2 & 89.2 & 78.4 \\
\hline
\end{tabular}


Table 7.10 Cont.

\begin{tabular}{|c|c|c|c|c|c|}
\hline Background characteristics (percent) & $\begin{array}{c}\text { Boys } \\
(10-14)\end{array}$ & $\begin{array}{c}\text { Boys } \\
(15-19)\end{array}$ & $\begin{array}{c}\text { Girls } \\
(10-14)\end{array}$ & $\begin{array}{c}\text { Girls } \\
(15-19)\end{array}$ & $\begin{array}{c}\text { Married girls } \\
(15-19)\end{array}$ \\
\hline \multicolumn{6}{|c|}{ Mother's education (in years of schooling completed) } \\
\hline None $^{5}$ & 42.1 & 71.4 & 74.8 & 69.7 & 63.9 \\
\hline $1-7$ & 64.9 & 71.5 & 86.4 & 81.4 & 72.4 \\
\hline 8-9 & 55.4 & 84.0 & 85.9 & 82.7 & 74.3 \\
\hline 10 and above & 65.5 & 88.2 & 82.7 & 92.6 & 78.1 \\
\hline \multicolumn{6}{|l|}{ Place of residence } \\
\hline Urban & 67.4 & 88.9 & 83.4 & 89.0 & 75.0 \\
\hline Rural & 44.1 & 71.8 & 76.3 & 72.4 & 64.7 \\
\hline Total & 46.6 & 73.7 & 77.1 & 74.2 & 65.8 \\
\hline
\end{tabular}

Notes: *Percentage not shown as this was based on fewer than 25 unweighted cases. () Based on 25-49 unweighted cases. NA: not applicable; OBC: other backward caste; SC: scheduled caste; ST: scheduled tribe. ${ }^{1}$ Refers to those who displayed gender egalitarian attitude in four out of six statements posed to the respondents; these statements referred to: the importance of educating boys versus girls, comparative performance of girls versus boys in studies, and boys' sharing household chores with their sisters (for 10-14 year olds); sharing chores related to taking care of children between parents, wrong for a girl to have male friends, and men's perceived right to beat his wife if she does not listen or obey him (for 15-19 year olds); and girls' interest in being teased by boys, girls' right to be involved in decisions related to when they want to marry, and father's/husband's right to decide about spending household money (for both 10-14 year olds and 15-19 year olds). ${ }^{2}$ Percentages not shown for those belonging to other religions as less than one percent of surveyed adolescents belonged to other religions. ${ }^{3}$ Percentages not shown for those belonging to STs as less than one percent of surveyed adolescents belonged to STs. ${ }^{4}$ Includes all those not belonging to SCs, STs, or OBCs. ${ }^{5}$ ncludes non-literate and literate with no formal schooling. ${ }^{6}$ Percentages not shown for adolescents who were pursuing their education through distance education courses at the time of interview or those who never went to school.

There were differences by religion among younger boys and unmarried older girls among whom more Hindu respondents than Muslim respondents displayed egalitarian attitudes (49\% versus $32 \%$ of younger boys and $76 \%$ versus $67 \%$ of unmarried older girls). We observed caste-wise differentials among all categories of adolescents; adolescents from general castes were more likely than those from other castes to express egalitarian attitudes. Adherence to egalitarian attitudes, across all categories of adolescents, increased with the number of years of schooling they had completed. Gender egalitarian attitudes were also more likely to be expressed by those currently in school than those out of school among all categories of adolescents. Differences by engagement in paid work were marked, except among older boys; boys and married older girls; younger adolescents and unmarried older girls who were engaged in paid work were less likely than those who were not to report gender egalitarian attitudes. Adherence to egalitarian attitudes rose with household economic status and mother's education across all categories of adolescents. Finally, a larger proportion of urban than rural adolescents adhered to egalitarian attitudes. 


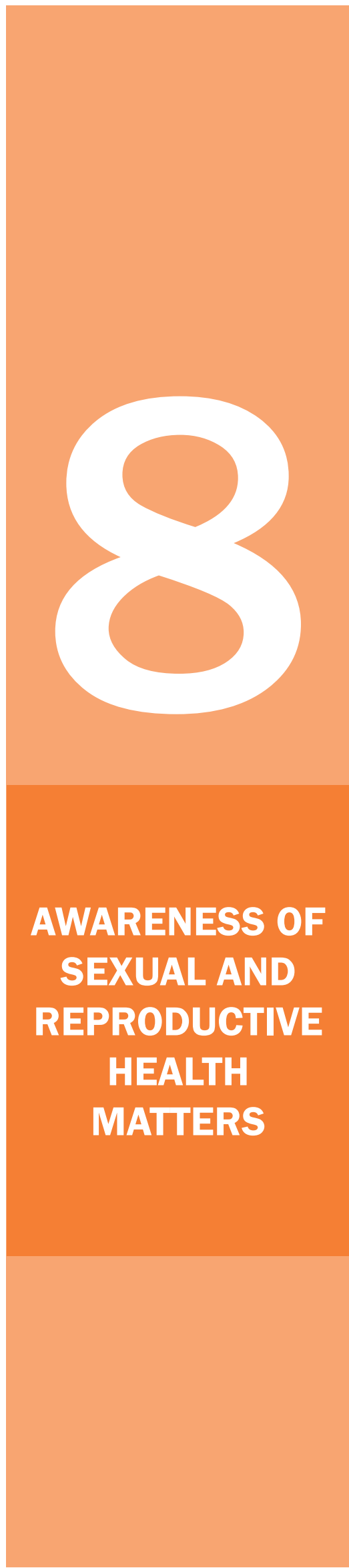

\section{A Snapshot}

Awareness of sexual and reproductive health matters is limited: ${ }^{1}$

- 9\% of younger boys (ages 13-14)

- $28 \%$ of older boys

- $10 \%$ of younger girls (ages 13-14)

- $27 \%$ of unmarried older girls

- 53\% of married older girls knew that a woman can get pregnant at first sex

\section{- $7 \%$ of older boys}

- $8 \%$ of unmarried older girls

- $18 \%$ of married older girls knew that oral contraceptive pills should be taken daily/weekly

- $11 \%$ of younger boys (ages 10-14)

- $54 \%$ of older boys

- 5\% of younger girls (ages 10-14)

- $30 \%$ of unmarried older girls

- $20 \%$ of married older girls were aware of HIV/AIDS

\section{- $30 \%$ of older boys}

- $32 \%$ of unmarried older girls

- $43 \%$ of married older girls knew that a newborn should be breastfed within an hour of birth
- $5 \%$ of older boys

- $4 \%$ of unmarried older girls

- $12 \%$ of married older girls knew that a woman is most likely to become pregnant if she engages in sexual relations mid-cycle
- $62 \%$ of older boys

- $14 \%$ of unmarried older girls

- $38 \%$ of married older girls knew that one condom can be used for one act of sexual intercourse only
- $22 \%$ of older boys
- $26 \%$ of unmarried older girls
- $28 \%$ of married older girls knew that a pregnant woman should have at least four antenatal checkups

${ }^{1}$ Only age-appropriate questions were asked on awareness of sexual and reproductive health matters. Hence, 10-12 year olds were not asked many questions, and some questions were not asked of adolescents under 15 years of age.

\section{POPULATION} COUNCIL

Ideas. Evidence. Impact.

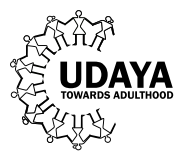




\section{A Snapshot}

Yet, availability of sex determination tests is known widely:

- $31 \%$ of younger boys

- $67 \%$ of older boys

- $39 \%$ of younger girls

- $72 \%$ of unmarried older girls

- $76 \%$ of married older girls had heard about sex determination tests
Relatively few adolescents find abortion acceptable:

- $23 \%$ of older boys

- $30 \%$ of unmarried older girls

- $36 \%$ of married older girls found it acceptable for a girl or woman to have an abortion if she does not want to continue with her pregnancy

Adolescents have few sources of information on sexual and reproductive matters and gender differences are wide:

Family members were a source of information

on sexual and reproductive matters for

- $2 \%$ of younger boys (ages 13-14)

- $10 \%$ of older boys

- $20 \%$ of younger girls (ages 13-14)

- $36 \%$ of unmarried older girls

- $58 \%$ of married older girls

- $70 \%$ of younger boys (ages 13-14)

- $25 \%$ of older boys

- $72 \%$ of younger girls (ages 13-14)

- $44 \%$ of unmarried older girls

- $30 \%$ of married older girls had never received information on sexual and reproductive matters
Friends were a source of information on sexual and reproductive matters for

- $17 \%$ of younger boys (ages 13-14)

- $59 \%$ of older boys

- $4 \%$ of younger girls (ages 13-14)

- $18 \%$ of unmarried older girls

- $17 \%$ of married older girls

Adolescents exposed to family life education are better informed about sexual and reproductive matters than those who were not

The rural disadvantage is clear-rural adolescents were less likely than urban adolescents to be informed about sexual and reproductive matters 
In India, notwithstanding commitments articulated in national policies and programmes to raise awareness of sexual and reproductive matters among adolescents and youth, the reality is that most adolescents and youth continue to lack such awareness (International Institute of Population Sciences [IIPS] and Macro International, 2007; IIPS and Population Council, 2010; Santhya and Jejeebhoy, 2014). Therefore, we sought to explore among the study participants of UDAYA the extent of their awareness of a wide range of issues relating to sex, pregnancy, prenatal sex determination tests, contraception, sexually transmitted infections (STIs), including HIV/AIDS, and maternal and newborn care practices. The survey also probed adolescents' perceptions about abortion and their knowledge of laws on the legal minimum age of marriage. Where possible, further questions were posed to assess the extent of in-depth awareness of these matters. This chapter describes adolescents' awareness of all these issues, and it also presents findings on their actual and preferred sources of information for sexual and reproductive matters and their exposure to family life education (FLE) or sex education programmes.

\subsection{Awareness of sexual and reproductive matters}

In this section, we present evidence on the extent of adolescents' awareness of various issues related to sex and pregnancy, prenatal sex determination tests, contraception, STIs and HIV/AIDS, and maternal and newborn care practices.

\subsubsection{Awareness of matters related to sex and pregnancy}

Two questions that we posed to assess awareness of sex- and pregnancy-related matters among younger adolescents (in this sub-section, younger adolescents refer to those in ages 13-14, as questions on sex and pregnancy matters were not probed among those in ages 10-12) were whether they thought a woman can get pregnant after kissing or hugging and whether they thought a woman can get pregnant at first sex. We asked older adolescents, similarly, whether they thought a woman can get pregnant at first sex and when a woman would be most likely to get pregnant during her menstrual cycle.

Findings, presented in Table 8.1 and Figure 8.1, clearly show that awareness of sex- and pregnancy-related matters was limited. Only 56 percent of younger boys and 44 percent of younger girls, for example, knew that a woman cannot become pregnant after kissing or hugging; as many as 39 percent of boys and 53 percent of girls were unsure. Awareness of the fact that a woman can get pregnant at first sex was reported by far smaller proportions- just 9-10 percent- of younger adolescents. Even among older adolescents, only 27-28 percent of boys and unmarried girls, and 53 percent of married girls knew that a woman can get pregnant at first sex (Figure 8.1). Similarly, among 15-19-year-old adolescents, just 4-5 percent of boys and unmarried girls, and 12 percent of married girls were aware that a woman is most likely to become pregnant if she engages in sexual relations mid-cycle. As seen above, more married than unmarried older girls knew about sex and pregnancy matters.

Differences in awareness of sex- and pregnancy-related matters between adolescents from rural areas and those from urban areas were modest for the most part. Even so, a larger proportion of rural younger girls in ages 13-14 were aware that a woman cannot become pregnant after kissing or hugging compared with their urban counterparts (45\% versus $38 \%)$. 
Table 8.1: Awareness of sex- and pregnancy-related matters

Percent distribution of adolescents in ages 13-19 by awareness of sex- and pregnancy-related matters and percentage reporting awareness on any and all indicators, according to residence, Bihar, 2016

\begin{tabular}{|c|c|c|c|c|c|}
\hline Awareness indicators & $\begin{array}{c}\text { Boys } \\
(13-14)\end{array}$ & $\begin{array}{c}\text { Boys } \\
(15-19)\end{array}$ & $\begin{array}{c}\text { Girls } \\
(13-14)\end{array}$ & $\begin{array}{c}\text { Girls } \\
(15-19)\end{array}$ & $\begin{array}{l}\text { Married girls } \\
\qquad(15-19)\end{array}$ \\
\hline \multicolumn{6}{|c|}{ Combined (percent) } \\
\hline \multicolumn{6}{|l|}{ A woman can get pregnant after kissing/hugging } \\
\hline Yes & 5.2 & NA & 3.7 & NA & NA \\
\hline No & 56.1 & NA & 43.8 & NA & NA \\
\hline Unsure/cannot say & 38.6 & NA & 52.5 & NA & NA \\
\hline \multicolumn{6}{|l|}{ A woman can get pregnant at first sex } \\
\hline Yes & 9.4 & 28.3 & 9.9 & 27.3 & 52.9 \\
\hline No & 15.0 & 27.2 & 7.1 & 16.7 & 28.0 \\
\hline Unsure/cannot say & 75.6 & 44.5 & 83.0 & 56.0 & 19.1 \\
\hline Number of respondents aged 13 years and above & 378 & 1,821 & 318 & 3,428 & 3,408 \\
\hline \multicolumn{6}{|c|}{$\begin{array}{l}\text { A woman is most likely to get pregnant if she has sex half-way } \\
\text { between her periods }\end{array}$} \\
\hline Yes & NA & 5.1 & NA & 3.9 & 11.6 \\
\hline No & NA & 25.7 & NA & 19.9 & 48.9 \\
\hline Unsure/cannot say & NA & 69.2 & NA & 76.2 & 39.5 \\
\hline Number of respondents aged 15 years and above & NA & 1,821 & NA & 3,428 & 3,408 \\
\hline \multicolumn{6}{|c|}{ Urban (percent) } \\
\hline \multicolumn{6}{|l|}{ A woman can get pregnant after kissing/hugging } \\
\hline Yes & 3.2 & NA & 2.6 & NA & NA \\
\hline No & 52.3 & NA & 38.1 & NA & NA \\
\hline Unsure/cannot say & 44.6 & NA & 59.2 & NA & NA \\
\hline \multicolumn{6}{|l|}{ A woman can get pregnant at first sex } \\
\hline Yes & 5.7 & 29.1 & 7.1 & 31.7 & 57.3 \\
\hline No & 14.9 & 26.5 & 7.1 & 18.2 & 24.1 \\
\hline Unsure/cannot say & 79.4 & 44.3 & 85.8 & 50.1 & 18.6 \\
\hline Number of respondents aged 13 years and above & 168 & 1,008 & 168 & 1,738 & 1,366 \\
\hline \multicolumn{6}{|c|}{$\begin{array}{l}\text { A woman is most likely to get pregnant if she has sex half-way } \\
\text { between her periods }\end{array}$} \\
\hline Yes & NA & 8.2 & NA & 7.6 & 12.8 \\
\hline No & NA & 26.9 & NA & 22.4 & 52.7 \\
\hline Unsure/cannot say & NA & 64.9 & NA & 70.0 & 34.6 \\
\hline Number of respondents aged 15 years and above & NA & 1,008 & NA & 1,738 & 1,366 \\
\hline
\end{tabular}


Table 8.1 Cont.

\begin{tabular}{|c|c|c|c|c|c|}
\hline Awareness indicators & $\begin{array}{c}\text { Boys } \\
(13-14)\end{array}$ & $\begin{array}{c}\text { Boys } \\
(15-19)\end{array}$ & $\begin{array}{c}\text { Girls } \\
(13-14)\end{array}$ & $\begin{array}{c}\text { Girls } \\
(15-19)\end{array}$ & $\begin{array}{l}\text { Married girls } \\
\qquad(15-19)\end{array}$ \\
\hline \multicolumn{6}{|c|}{ Rural (percent) } \\
\hline \multicolumn{6}{|l|}{ A woman can get pregnant after kissing/hugging } \\
\hline Yes & 5.5 & NA & 3.9 & NA & NA \\
\hline No & 56.6 & NA & 44.6 & NA & NA \\
\hline Unsure/cannot say & 37.9 & NA & 51.6 & NA & NA \\
\hline \multicolumn{6}{|l|}{ A woman can get pregnant at first sex } \\
\hline Yes & 9.8 & 28.2 & 10.3 & 26.8 & 52.4 \\
\hline No & 15.0 & 27.3 & 7.1 & 16.5 & 28.5 \\
\hline Unsure/cannot say & 75.2 & 44.5 & 82.6 & 56.7 & 19.2 \\
\hline Number of respondents aged 13 years and above & 210 & 813 & 150 & 1,690 & 2,042 \\
\hline \multicolumn{6}{|c|}{$\begin{array}{l}\text { A woman is most likely to get pregnant if she has sex half-way } \\
\text { between her periods }\end{array}$} \\
\hline Yes & NA & 4.8 & NA & 3.4 & 11.5 \\
\hline No & NA & 25.5 & NA & 19.6 & 48.5 \\
\hline Unsure/cannot say & NA & 69.7 & NA & 77.0 & 40.0 \\
\hline Number of respondents aged 15 years and above & NA & 813 & NA & 1,690 & 2,042 \\
\hline
\end{tabular}

Notes: All Ns are unweighted. NA: not applicable.

Figure 8.1: Percentage of adolescents in ages 15-19 reporting awareness of selected sex- and pregnancyrelated matters, according to residence, Bihar, 2016

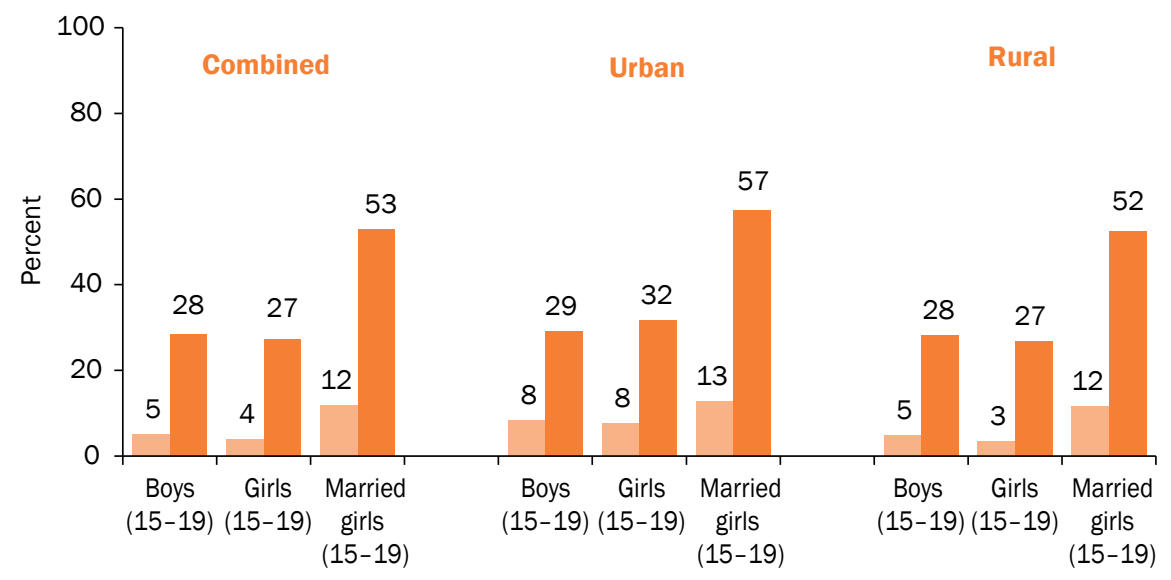

A woman is most likely to get pregnant if she has sex half-way between her periods

A woman can get pregnant at first sex

Differentials in awareness of sex- and pregnancy-related matters, measured with respect to the percentage who answered correctly any one of the two questions posed to them, are presented in Tables 8.2a and 8.2b for younger and older adolescents, respectively. It is to be noted that the questions posed to younger and older adolescents differed somewhat and, therefore, findings are not exactly comparable between younger and older adolescents. 
Table 8.2a: Awareness of sex- and pregnancy-related matters among younger adolescents by selected background characteristics

Percentage of adolescents in ages 13-14 who had correct knowledge of sex- and pregnancy-related matters in any one question posed to them by selected background characteristics, Bihar, 2016

\begin{tabular}{|c|c|c|}
\hline Background characteristics (percent) & $\begin{array}{c}\text { Boys } \\
(13-14)\end{array}$ & $\begin{array}{c}\text { Girls } \\
(13-14)\end{array}$ \\
\hline \multicolumn{3}{|l|}{ Religion ${ }^{1}$} \\
\hline Hindu & 57.2 & 45.0 \\
\hline Muslim & 65.0 & 49.9 \\
\hline \multicolumn{3}{|l|}{ Caste $^{2}$} \\
\hline SC & 74.6 & 53.7 \\
\hline OBC & 57.3 & 41.7 \\
\hline General $^{3}$ & 44.0 & 51.2 \\
\hline \multicolumn{3}{|l|}{ Completed years of schooling } \\
\hline None $^{4}$ & * & * \\
\hline $1-4$ & $(43.5)$ & $(27.9)$ \\
\hline $5-7$ & 53.9 & 44.7 \\
\hline $8-9$ & 65.8 & 52.1 \\
\hline \multicolumn{3}{|l|}{ Current schooling status ${ }^{5}$} \\
\hline Yes & 57.5 & 46.5 \\
\hline No & * & * \\
\hline \multicolumn{3}{|c|}{ Paid work in the 12 months prior to the interview } \\
\hline Yes & $(74.0)$ & $(59.0)$ \\
\hline No & 57.0 & 43.9 \\
\hline \multicolumn{3}{|l|}{ Wealth quintile } \\
\hline First & $(62.4)$ & $(32.1)$ \\
\hline Second & 67.2 & $(50.1)$ \\
\hline Third & 57.2 & 38.8 \\
\hline Fourth & 52.9 & 54.6 \\
\hline Fifth & 55.0 & 45.1 \\
\hline \multicolumn{3}{|c|}{ Mother's education (in years of schooling completed) } \\
\hline None $^{4}$ & 59.0 & 48.1 \\
\hline $1-7$ & $(58.1)$ & $(37.5)$ \\
\hline $8-9$ & $(45.2)$ & * \\
\hline 10 and above & 66.1 & $(40.6)$ \\
\hline Total & 58.5 & 45.8 \\
\hline
\end{tabular}

Notes: *Percentage not shown as this was based on fewer than 25 unweighted cases. () Based on 25-49 unweighted cases. NA: not applicable; OBC: other backward caste; SC: scheduled caste; ST: scheduled tribe. ${ }^{1}$ Percentages not shown for those belonging to other religions as less than one percent of surveyed adolescents belonged to other religions. ${ }^{2}$ Percentages not shown for those belonging to STs as less than one percent of surveyed adolescents belonged to STs. ${ }^{3}$ Includes all those not belonging to SCs, STs, or OBCs. ${ }^{4}$ Includes non-literate and literate with no formal schooling. ${ }^{5}$ Percentages not shown for adolescents who were pursuing their education through distance education courses at the time of interview or those who never went to school. 
Table 8.2a shows that, on the whole, 59 percent of younger boys and 46 percent of younger girls responded correctly to any one of the two questions posed to them. Differences in awareness by religion show that more Muslim than Hindu boys and girls knew about sex- and pregnancy-related matters (65\% versus $57 \%$ among boys and $50 \%$ versus $45 \%$ among girls). Caste-wise awareness levels differed between boys and girls. Among boys, respondents from scheduled castes were the most likely to report awareness of these matters, while those from general castes were the least likely to do so (75\% versus $44 \%$ ); in contrast, more girls from scheduled and general castes (51-54\%) than other backward castes (42\%) reported awareness. Levels of awareness increased with education among both boys and girls (44\% among boys with 1-4 years of schooling to $66 \%$ among those with 8-9 years of schooling, and the corresponding increase among girls was from $28 \%$ to $52 \%$ ). Awareness was positively associated with engagement in paid work in the 12 months prior to the interview among both boys and girls ( $74 \%$ of boys who were engaged in paid work versus $57 \%$ of boys who were not, and the corresponding proportions among girls were $59 \%$ versus $44 \%$ ). The association between awareness and household economic status was erratic among both boys and girls, as was the association between awareness and level of mother's education.

Among older adolescents, 31 percent of boys, 29 percent of unmarried girls, and 57 percent of married girls answered any one of the two questions posed to them correctly (Table 8.2b). Levels of awareness increased consistently with age among them. Differences in awareness by religion were narrow, but differences by caste were wide. Respondents from scheduled castes were the least likely to report awareness of these matters, while those from general castes were the most likely to do so across all three categories of older adolescents (29\% versus $38 \%$ among boys; $27 \%$ versus $36 \%$ among unmarried girls; and $51 \%$ versus $59 \%$ among married girls). Levels of awareness increased by and large with education except among married girls among whom the association was erratic. Differences by current schooling status were narrow among boys and unmarried girls; however, among married girls, more of those out-of-school than in-school reported awareness. Differences by engagement in paid work in the 12 months prior to the interview were narrow across all categories of adolescents. However, awareness increased with household economic status (from 21\% among boys who belonged to poorest households to $36 \%$ among boys who belonged to wealthiest households; the corresponding increase among unmarried older girls was from $19 \%$ to $36 \%$; and for married older girls, it was from $51 \%$ to $61 \%$ ) and with mother's education (from $30 \%$ among boys whose mother had no schooling to $36 \%$ among those whose mother had 10 or more years of schooling; the corresponding increase among unmarried older girls was from $27 \%$ to $42 \%$; and for married older girls, it was from $57 \%$ to $66 \%)$.

\section{Table 8.2b: Awareness of sex- and pregnancy-related matters among older adolescents by selected background characteristics}

Percentage of adolescents in ages 15-19 who had correct knowledge of sex- and pregnancy-related matters in any one question posed to them by selected background characteristics, Bihar, 2016

\begin{tabular}{lccc}
\hline Background characteristics (percent) & $\begin{array}{c}\text { Boys } \\
(15-19)\end{array}$ & $\begin{array}{c}\text { Girls } \\
(15-19)\end{array}$ & $\begin{array}{c}\text { Married girls } \\
(15-19)\end{array}$ \\
\hline Age & & & \\
$15-17$ & 27.6 & 26.3 & 48.5 \\
$18-19$ & 39.7 & 36.4 & 61.6 \\
Religion ${ }^{1}$ & & & \\
Hindu & 30.3 & 28.8 & 56.8 \\
Muslim & 33.3 & 27.2 & 59.4 \\
Caste $^{2}$ & & & \\
SC & 31.4 \\
OBC $^{\text {General }}{ }^{3}$ & 29.0 & 26.9 & 51.4 \\
& 30.3 & 27.4 & 59.2 \\
\hline
\end{tabular}


Table $8.2 b$ Cont.

\begin{tabular}{|c|c|c|c|}
\hline Background characteristics (percent) & $\begin{array}{c}\text { Boys } \\
(15-19)\end{array}$ & $\begin{array}{c}\text { Girls } \\
(15-19)\end{array}$ & $\begin{array}{l}\text { Married girls } \\
\qquad(15-19)\end{array}$ \\
\hline \multicolumn{4}{|l|}{ Completed years of schooling } \\
\hline None $^{4}$ & 19.2 & 21.2 & 49.5 \\
\hline $1-4$ & 24.6 & 26.0 & 53.2 \\
\hline $5-7$ & 21.1 & 20.7 & 65.7 \\
\hline $8-9$ & 29.7 & 29.0 & 55.8 \\
\hline $10-11$ & 35.0 & 28.8 & 63.8 \\
\hline 12 and above & 48.5 & 45.0 & 63.5 \\
\hline \multicolumn{4}{|l|}{ Current schooling status $^{5}$} \\
\hline Yes & 32.0 & 29.7 & 56.1 \\
\hline No & 27.9 & 25.7 & 62.2 \\
\hline \multicolumn{4}{|c|}{ Paid work in the 12 months prior to the interview } \\
\hline Yes & 28.3 & 29.0 & 54.4 \\
\hline No & 31.6 & 28.4 & 57.5 \\
\hline \multicolumn{4}{|l|}{ Wealth quintile } \\
\hline First & 21.1 & 18.8 & 51.4 \\
\hline Second & 24.2 & 24.4 & 54.5 \\
\hline Third & 34.2 & 24.7 & 55.8 \\
\hline Fourth & 30.5 & 29.2 & 60.9 \\
\hline Fifth & 35.5 & 36.3 & 60.6 \\
\hline \multicolumn{4}{|c|}{ Mother's education (in years of schooling completed) } \\
\hline None $^{4}$ & 30.0 & 26.5 & 57.4 \\
\hline $1-7$ & 30.8 & 29.9 & 51.8 \\
\hline $8-9$ & 32.8 & 28.6 & 55.4 \\
\hline 10 and above & 36.2 & 42.0 & 66.0 \\
\hline Total & 30.8 & 28.5 & 57.2 \\
\hline
\end{tabular}

Notes: NA: not applicable; OBC: other backward caste; SC: scheduled caste; ST: scheduled tribe. ${ }^{1}$ Percentages not shown for those belonging to other religions as less than one percent of surveyed adolescents belonged to other religions. ${ }^{2}$ Percentages not shown for those belonging to STs as less than one percent of surveyed adolescents belonged to STs. ${ }^{3}$ Includes all those not belonging to SCs, STs, or OBCs. ${ }^{4}$ Includes non-literate and literate with no formal schooling. ${ }^{5}$ Percentages not shown for adolescents who were pursuing their education through distance education courses at the time of interview or those who never went to school.

\subsubsection{Awareness of prenatal sex determination tests}

Given the prevalence of sex-selective abortions in the country (Bhat and Zavier, 2007; Dagar, 2007), we asked adolescents whether they were aware of any tests that could determine the sex of the foetus. As many as 31 percent of younger boys and 67 percent of older boys were aware of the availability of tests to determine the sex of the foetus as were 39 percent of younger girls and 72-76 percent of unmarried and married older girls (Table 8.3; in this sub-section, younger adolescents refer to those in age group 10-14). As seen above, more girls than boys reported awareness of sex determination tests. Differences by residence in rural or urban areas show that more of urban younger and older boys and younger girls reported awareness of prenatal sex determination tests, compared with their rural counterparts; however, differences were narrow among unmarried and married older girls. 
Table 8.3: Awareness of prenatal sex determination tests

Percent distribution of adolescents by awareness of prenatal sex determination tests, according to residence, Bihar, 2016

\begin{tabular}{|c|c|c|c|c|c|}
\hline $\begin{array}{l}\text { Awareness of any tests that could determine the sex } \\
\text { of the foetus }\end{array}$ & $\begin{array}{l}\text { Boys } \\
(10-14)\end{array}$ & $\begin{array}{c}\text { Boys } \\
(15-19)\end{array}$ & $\begin{array}{c}\text { Girls } \\
(10-14)\end{array}$ & $\begin{array}{c}\text { Girls } \\
(15-19)\end{array}$ & $\begin{array}{l}\text { Married girls } \\
\qquad(15-19)\end{array}$ \\
\hline \multicolumn{6}{|c|}{ Combined (percent) } \\
\hline Yes & 31.3 & 66.6 & 39.2 & 72.0 & 75.9 \\
\hline No & 25.2 & 22.4 & 12.5 & 18.1 & 19.2 \\
\hline Do not know/cannot say & 43.5 & 11.0 & 48.4 & 10.0 & 4.9 \\
\hline Number of respondents & 1,012 & 1,821 & 764 & 3,428 & 3,408 \\
\hline \multicolumn{6}{|c|}{ Urban (percent) } \\
\hline Yes & 35.8 & 71.1 & 46.8 & 74.3 & 74.0 \\
\hline No & 17.4 & 19.0 & 11.7 & 16.7 & 21.4 \\
\hline Do not know/cannot say & 46.8 & 9.9 & 41.4 & 9.0 & 4.5 \\
\hline Number of respondents & 452 & 1,008 & 387 & 1,738 & 1,366 \\
\hline \multicolumn{6}{|c|}{ Rural (percent) } \\
\hline Yes & 30.7 & 66.0 & 38.2 & 71.7 & 76.1 \\
\hline No & 26.1 & 22.8 & 12.6 & 18.2 & 19.0 \\
\hline Do not know/cannot say & 43.1 & 11.2 & 49.2 & 10.1 & 5.0 \\
\hline Number of respondents & 560 & 813 & 377 & 1,690 & 2,042 \\
\hline
\end{tabular}

Note: All Ns are unweighted.

\subsubsection{Awareness of contraceptive methods}

The survey explored older adolescents' awareness of selected modern contraceptive methods that are suitable for adolescents, namely, oral pills, emergency contraceptive pills, and condoms. Moreover, we sought to elicit information on specific knowledge of the use of each of these methods from respondents who were aware of these methods. Table 8.4 presents percentages of adolescents reporting awareness and specific knowledge of these methods.

Findings show that the majority of older adolescents reported awareness of at least one modern method of contraception that the study had probed, although fewer unmarried girls than boys and married girls reported so-84 percent of boys, 65 percent of unmarried girls, and 86 percent of married girls. Specifically, 82 percent of boys, 38 percent of unmarried girls, and 66 percent of married girls had heard about condoms. Fewer boys had heard about pills (43\%), while more unmarried girls and married girls had heard about oral pills-58 percent and 80 percent, respectively. Even fewer adolescents across all categories of older adolescents reported awareness of emergency contraceptive pills-20 percent of boys and 9-12 percent of unmarried and married girls.

Differences in awareness between adolescents from rural areas and those from urban areas were wide, with more of urban than rural adolescents across all three categories reporting awareness of at least one modern method of contraception (93\% versus $82 \%$ among boys; $77 \%$ versus $64 \%$ among unmarried girls; and $93 \%$ versus $85 \%$ among married girls) and each of the three methods probed in the study-pills (56\% versus $41 \%$ among boys and $71-87 \%$ versus $57-80 \%$ among girls), emergency contraceptive pills (34\% versus $18 \%$ among boys and $19-20 \%$ versus $8-11 \%$ among girls) and condoms (92\% versus $80 \%$ among boys and $59-78 \%$ versus $36-64 \%$ among girls). 
Table 8.4 Awareness of selected modern contraceptive methods

Percentage of adolescents in ages 15-19 who reported awareness and specific knowledge of selected modern contraceptive methods, according to residence, Bihar, 2016

\begin{tabular}{|c|c|c|c|c|c|c|c|c|c|}
\hline Awareness indicators & $\begin{array}{l}\text { Boys } \\
(15-19)\end{array}$ & $\begin{array}{l}\text { Girls } \\
(15-19)\end{array}$ & $\begin{array}{l}\text { Married } \\
\text { girls } \\
(15-19)\end{array}$ & $\begin{array}{l}\text { Boys } \\
(15-19)\end{array}$ & $\begin{array}{l}\text { Girls } \\
(15-19)\end{array}$ & $\begin{array}{c}\text { Married } \\
\text { girls } \\
\text { (15-19) }\end{array}$ & $\begin{array}{l}\text { Boys } \\
(15-19)\end{array}$ & $\begin{array}{l}\text { Girls } \\
(15-19)\end{array}$ & $\begin{array}{c}\text { Married } \\
\text { girls } \\
\text { (15-19) }\end{array}$ \\
\hline & \multicolumn{3}{|c|}{ Combined (percent) } & \multicolumn{3}{|c|}{ Urban (percent) } & \multicolumn{3}{|c|}{ Rural (percent) } \\
\hline \multicolumn{10}{|c|}{ A. Awareness } \\
\hline Oral pills & 42.8 & 58.2 & 80.4 & 55.8 & 71.0 & 87.1 & 41.2 & 56.6 & 79.6 \\
\hline $\begin{array}{l}\text { Emergency contraceptive } \\
\text { pills }\end{array}$ & 19.5 & 8.9 & 11.5 & 34.1 & 20.1 & 18.6 & 17.7 & 7.5 & 10.7 \\
\hline Condoms & 81.7 & 38.1 & 65.8 & 92.1 & 58.5 & 78.3 & 80.3 & 35.6 & 64.4 \\
\hline Any of the above & 83.4 & 65.0 & 85.8 & 93.1 & 77.3 & 92.9 & 82.2 & 63.5 & 85.0 \\
\hline \multicolumn{10}{|c|}{ B. Specific knowledge ${ }^{1}$} \\
\hline Oral pills & 7.3 & 7.6 & 17.6 & 11.8 & 15.6 & 24.4 & 6.7 & 6.7 & 16.8 \\
\hline Emergency contraceptive pills & 4.1 & 1.6 & 2.3 & 12.9 & 5.0 & 4.4 & 3.1 & 1.1 & 2.1 \\
\hline Condoms & 62.3 & 13.5 & 37.9 & 75.1 & 26.7 & 51.4 & 60.7 & 11.9 & 36.3 \\
\hline $\begin{array}{l}\text { At least one modern } \\
\text { method }\end{array}$ & 63.0 & 17.6 & 43.3 & 75.4 & 33.6 & 56.4 & 61.5 & 15.7 & 41.8 \\
\hline Number of respondents & 1,821 & 3,428 & 3,408 & 1,008 & 1,738 & 1,366 & 813 & 1,690 & 2,042 \\
\hline
\end{tabular}

Notes: All Ns are unweighted. ${ }^{1}$ The following questions were asked to assess specific knowledge of methods (correct answers in brackets)-Oral pills: How often should a woman take pills? [Daily/Weekly]; Emergency contraceptive pills: How soon after sexual intercourse should these pills be taken? [Within 72 hours]; Condoms: For how many acts of sexual intercourse can one condom be used? [One].

In order to assess the extent of older adolescents' specific knowledge of modern contraceptive methods as opposed to a general awareness where they had just heard of various methods, we inquired whether adolescents were aware of the prescribed frequency for taking oral contraceptives (should be daily or weekly); the number of sex acts for which one (male) condom could be used (should be used once); and the number of hours following sex that emergency contraceptive pills must be taken (should be within 72 hours). Table 8.4 and Figure 8.2 present percentages of adolescents reporting specific knowledge of these methods. Findings show that specific knowledge of even one modern method of contraception was limited. More boys than girls reported specific knowledge of at least one of the three methods of contraception $(63 \%, 18 \%$, and $43 \%$, respectively, of boys, unmarried girls, and married girls). Urban respondents were more likely than the rural ones to report specific knowledge of at least one method of contraception across all categories of older adolescents ( $75 \%$ versus $62 \%$ of boys; $34 \%$ versus $16 \%$ of unmarried girls; and $56 \%$ versus $42 \%$ of married girls).

Findings also show that more married girls reported specific knowledge of oral contraceptives than boys and unmarried girls ( $18 \%$ of married girls compared with $7-8 \%$ of boys and unmarried girls). Conversely, more boys than girls reported specific knowledge of condoms (62\% of boys compared with $14 \%$ and $38 \%$ of unmarried girls and married girls, respectively). Differences by sex in the proportion of adolescents reporting specific knowledge of emergency contraception pills were negligible (2-4\%). As seen above, differences by marital status among girls were apparent, with the married typically more likely than the unmarried to report specific knowledge of oral pills and condoms.

We observed differences by residence in rural or urban areas, with urban respondents more likely than rural respondents to report specific knowledge of contraceptive methods. Thus, unmarried and married urban girls were more likely than their rural counterparts to report specific knowledge of oral pills(16-24\% versus $7-17 \%)$, as were urban boys compared with rural boys with respect to emergency contraceptive pills (13\% versus $3 \%$ ). Urban adolescents were more likely than rural adolescents to report specific knowledge of condoms among all three categories of adolescents ( $75 \%$ versus $61 \%$ of boys; $27 \%$ versus $12 \%$ of unmarried girls; and $51 \%$ versus $36 \%$ of married girls). 
Figure 8.2: Percentage of adolescents in ages 15-19 who reported correct specific knowledge of selected modern contraceptive methods, according to residence, Bihar, 2016

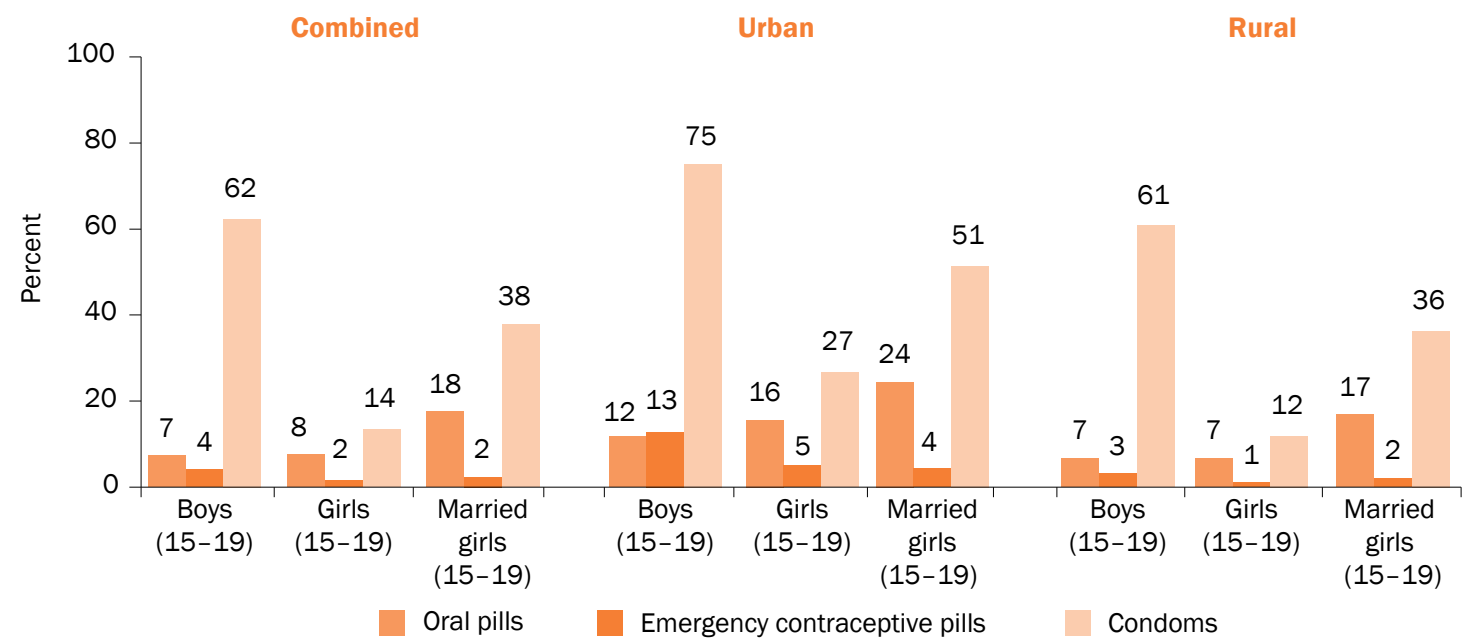

Differentials in specific knowledge of at least one modern method of contraception by selected background characteristics among older adolescents are presented in Table 8.5. Findings show that specific knowledge of modern methods of contraception increased with age-15-17-year-old adolescents were less likely than 18-19-yearold adolescents to report specific knowledge of modern methods of contraception (59\% versus 74\% among boys; $15 \%$ versus $28 \%$ among unmarried girls; and 33\% versus $49 \%$ among married girls). While differences by religion were narrow among girls, more of Hindu than Muslim boys had specific knowledge of at least one method of contraception (64\% versus 56\%). While caste-wise differences were erratic among boys, unmarried and married girls who belonged to scheduled castes were the least likely to report specific knowledge of at least one modern method of contraception, while unmarried and married girls who belonged to general castes were the most likely to do so ( $12 \%$ versus $32 \%$ of unmarried girls and $40 \%$ versus $50 \%$ of married girls). A positive association between specific knowledge of at least one contraceptive method and educational attainment, household wealth status, and mother's education was observed across all categories of adolescents. Moreover, those currently in school were more likely than those out of school to report specific knowledge of at least one contraceptive method (64\% versus $58 \%$ among boys; $22 \%$ versus $8 \%$ among unmarried girls; and $56 \%$ versus $48 \%$ among married girls). No such association was observed with respect to engagement in paid work in the 12 months prior to the interview, except for married girls, among whom fewer of those who were engaged in paid work had specific knowledge of at least one contraceptive method compared with those who were not engaged in paid work.

Table 8.5: Specific knowledge of at least one modern contraceptive method

Percentage of adolescents in ages 15-19 who had specific knowledge of at least one modern contraceptive method by selected background characteristics, Bihar, 2016

\begin{tabular}{|c|c|c|c|}
\hline $\begin{array}{l}\text { Background characteristics } \\
\text { (percent) }\end{array}$ & $\begin{array}{c}\text { Boys } \\
(15-19)\end{array}$ & $\begin{array}{c}\text { Girls } \\
(15-19)\end{array}$ & $\begin{array}{l}\text { Married girls } \\
\qquad(15-19)\end{array}$ \\
\hline \multicolumn{4}{|l|}{ Age } \\
\hline $15-17$ & 58.9 & 14.7 & 32.8 \\
\hline $18-19$ & 74.4 & 28.1 & 48.6 \\
\hline \multicolumn{4}{|l|}{ Religion ${ }^{1}$} \\
\hline Hindu & 64.2 & 17.7 & 43.2 \\
\hline Muslim & 55.9 & 17.6 & 43.7 \\
\hline \multicolumn{4}{|l|}{ Caste $^{2}$} \\
\hline SC & 57.4 & 12.1 & 39.5 \\
\hline $\mathrm{OBC}$ & 64.2 & 16.1 & 43.9 \\
\hline General $^{3}$ & 55.9 & 31.5 & 50.1 \\
\hline
\end{tabular}


Table 8.5 Cont.

\begin{tabular}{|c|c|c|c|}
\hline $\begin{array}{l}\text { Background characteristics } \\
\text { (percent) }\end{array}$ & $\begin{array}{c}\text { Boys } \\
(15-19)\end{array}$ & $\begin{array}{c}\text { Girls } \\
(15-19)\end{array}$ & $\begin{array}{l}\text { Married girls } \\
\qquad(15-19)\end{array}$ \\
\hline \multicolumn{4}{|l|}{ Completed years of schooling } \\
\hline None $^{4}$ & 50.3 & 4.6 & 26.2 \\
\hline $1-4$ & 37.0 & 2.9 & 34.4 \\
\hline $5-7$ & 45.7 & 8.0 & 40.0 \\
\hline $8-9$ & 59.7 & 14.7 & 45.9 \\
\hline $10-11$ & 79.8 & 25.3 & 67.1 \\
\hline 12 and above & 85.0 & 44.9 & 71.8 \\
\hline \multicolumn{4}{|l|}{ Current schooling status ${ }^{5}$} \\
\hline Yes & 64.4 & 21.5 & 56.4 \\
\hline No & 57.8 & 7.7 & 48.0 \\
\hline \multicolumn{4}{|c|}{ Paid work in the 12 months prior to the interview } \\
\hline Yes & 62.5 & 17.0 & 34.6 \\
\hline No & 63.2 & 17.8 & 44.3 \\
\hline \multicolumn{4}{|l|}{ Wealth quintile } \\
\hline First & 39.0 & 3.5 & 26.5 \\
\hline Second & 62.8 & 6.9 & 29.8 \\
\hline Third & 63.0 & 12.1 & 35.7 \\
\hline Fourth & 61.4 & 18.3 & 54.4 \\
\hline Fifth & 71.7 & 31.9 & 63.0 \\
\hline \multicolumn{4}{|c|}{ Mother's education (in years of schooling completed) } \\
\hline None $^{4}$ & 60.3 & 12.6 & 42.2 \\
\hline $1-7$ & 67.1 & 26.7 & 43.7 \\
\hline $8-9$ & 72.0 & 19.6 & 44.5 \\
\hline 10 and above & 77.2 & 43.8 & 61.1 \\
\hline Total & 63.0 & 17.6 & 43.3 \\
\hline
\end{tabular}

Notes: OBC: other backward caste; SC: scheduled caste; ST: scheduled tribe. ${ }^{1}$ Percentages not shown for those belonging to other religions as less than one percent of surveyed adolescents belonged to other religions. ${ }^{2}$ Percentages not shown for those belonging to STs as less than one percent of surveyed adolescents belonged to STs. ${ }^{3}$ Includes all those not belonging to SCs, STs, or OBCs. ${ }^{4}$ Includes non-literate and literate with no formal schooling. ${ }^{5}$ Percentages not shown for adolescents who were pursuing their education through distance education courses at the time of interview or those who never went to school.

\subsubsection{Awareness of HIV/AIDS and other sexually transmitted infections (STIs)}

An important area covered by the survey was one that explored adolescents' awareness of infections that were transmitted through sexual contact. They were asked whether they had heard about HIV/AIDS as well as other sexually transmitted infections (STIS). Questions that explored adolescents' awareness of HIV/AIDS were adapted from those used in the National Family Health Survey. The study also assessed comprehensive awareness of HIV/AIDS. Since we did not enquire about younger adolescents' awareness of single partner sexual relationships and consistent condom use as preventive measures against HIV/AIDS, we defined comprehensive awareness of HIV/AIDS differently for younger and older adolescents. It was defined in terms of the percentage of adolescents who gave correct responses to all questions posed to each age group-we posed four questions related to misconceptions to younger adolescents and two additional ones related to prevention to older adolescents. The questions on misconceptions were whether HIV can be transmitted through mosquito bites, sharing food, or hugging and whether one can tell by looking at a person whether he or she has HIV. The questions related to HIV prevention sought to find out from older adolescents whether they were aware that HIV can be prevented by consistent condom use and single partner relations. 
Findings, presented in Table 8.6, show that awareness of HIV/AIDS was limited and that awareness varied by age, sex, residence, and, among older girls, by marital status. Younger adolescents (in ages 10-14) were less likely than older adolescents to have heard about HIV/AIDS (11\% versus $54 \%$ among boys and $5 \%$ versus $20-30 \%$ among girls). Differences by sex were narrow among younger adolescents but were wide for older adolescents, among whom boys were more likely than girls to have heard of HIV/AIDS (54\% of older boys versus $20-30 \%$ of unmarried and married older girls). Among older girls, somewhat more unmarried than married girls reported awareness of HIV/AIDS-30 percent and 20 percent, respectively-and these differences were particularly marked in urban areas than in rural areas ( $57 \%$ versus $32 \%$ and $27 \%$ versus $19 \%$, respectively). Urban adolescents were more likely than their rural counterparts to report awareness of HIV/AIDS.

\section{Table 8.6: Awareness of HIV/AIDS}

Percentage of adolescents who had heard of and had comprehensive awareness of HIV/AIDS, according to residence, Bihar, 2016

\begin{tabular}{|c|c|c|c|c|c|}
\hline Awareness indicators & $\begin{array}{c}\text { Boys } \\
(10-14)\end{array}$ & $\begin{array}{l}\text { Boys } \\
(15-19)\end{array}$ & $\begin{array}{c}\text { Girls } \\
(10-14)\end{array}$ & $\begin{array}{c}\text { Girls } \\
(15-19)\end{array}$ & $\begin{array}{l}\text { Married girls } \\
\qquad(15-19)\end{array}$ \\
\hline \multicolumn{6}{|c|}{ Combined (percent) } \\
\hline Heard about HIV/AIDS & 10.7 & 53.5 & 5.3 & 30.4 & 20.3 \\
\hline Number of respondents & 1,012 & 1,821 & 764 & 3,428 & 3,408 \\
\hline \multicolumn{6}{|l|}{ Respondents who had heard about HIV/AIDS reporting that: } \\
\hline $\begin{array}{l}\text { One can reduce one's chances of getting HIV by having a } \\
\text { single sexual partner }\end{array}$ & NA & 76.6 & NA & 51.5 & 61.3 \\
\hline $\begin{array}{l}\text { One can reduce one's chances of getting HIV by consistent } \\
\text { use of condoms }\end{array}$ & NA & 80.1 & NA & 38.5 & 45.0 \\
\hline One cannot get HIV through mosquito bites & 48.8 & 59.3 & 49.2 & 52.6 & 46.3 \\
\hline One cannot get HIV by sharing food with an HIV-positive person & 29.6 & 47.6 & 37.4 & 48.3 & 46.9 \\
\hline One cannot get HIV by hugging an HIV-positive person & 49.0 & 62.4 & 53.8 & 58.7 & 55.4 \\
\hline One cannot tell if a person is HIV-positive by just looking at him/her & 77.7 & 79.4 & 76.7 & 82.9 & 82.4 \\
\hline Number who had heard about HIV/AIDS & 134 & 1,185 & 70 & 1,435 & 759 \\
\hline Comprehensive awareness of HIV/AIDs ${ }^{1}$ & 2.1 & 12.3 & 1.0 & 4.0 & 2.9 \\
\hline Number of respondents & 1,012 & 1,821 & 764 & 3,428 & 3,408 \\
\hline \multicolumn{6}{|c|}{ Urban (percent) } \\
\hline Heard about HIV/AIDS & 17.9 & 74.3 & 14.4 & 56.5 & 32.0 \\
\hline Number of respondents & 452 & 1,008 & 387 & 1,738 & 1,366 \\
\hline \multicolumn{6}{|l|}{ Respondents who had heard about HIV/AIDS reporting that: } \\
\hline $\begin{array}{l}\text { One can reduce one's chances of getting HIV by having a } \\
\text { single sexual partner }\end{array}$ & NA & 80.7 & NA & 56.0 & 66.5 \\
\hline $\begin{array}{l}\text { One can reduce one's chances of getting HIV by consistent } \\
\text { use of condoms }\end{array}$ & NA & 83.1 & NA & 49.4 & 55.2 \\
\hline One cannot get HIV through mosquito bites & 60.9 & 65.1 & 64.7 & 62.6 & 50.3 \\
\hline One cannot get HIV by sharing food with an HIV-positive person & 39.5 & 64.2 & 33.1 & 60.6 & 52.6 \\
\hline One cannot get HIV by hugging an HIV-positive person & 59.5 & 75.6 & 62.8 & 67.7 & 60.1 \\
\hline One cannot tell if a person is HIV-positive by just looking at him/her & 86.6 & 88.5 & 88.5 & 87.2 & 85.6 \\
\hline Number who had heard about HIV/AIDS & 78 & 754 & 53 & 966 & 390 \\
\hline Comprehensive awareness of HIV/AIDs ${ }^{1}$ & 4.3 & 24.9 & 3.2 & 12.9 & 8.1 \\
\hline Number of respondents & 452 & 1,008 & 387 & 1,738 & 1,366 \\
\hline
\end{tabular}


Table 8.6 Cont.

\begin{tabular}{|c|c|c|c|c|c|}
\hline Awareness indicators & $\begin{array}{l}\text { Boys } \\
(10-14)\end{array}$ & $\begin{array}{l}\text { Boys } \\
(15-19)\end{array}$ & $\begin{array}{c}\text { Girls } \\
(10-14)\end{array}$ & $\begin{array}{l}\text { Girls } \\
(15-19)\end{array}$ & $\begin{array}{l}\text { Married girls } \\
\qquad(15-19)\end{array}$ \\
\hline \multicolumn{6}{|c|}{ Rural (percent) } \\
\hline Heard about HIV/AIDS & 9.9 & 50.9 & 4.2 & 27.3 & 19.0 \\
\hline Number of respondents & 560 & 813 & 377 & 1,690 & 2,042 \\
\hline \multicolumn{6}{|l|}{ Respondents who had heard about HIV/AIDS reporting that: } \\
\hline $\begin{array}{l}\text { One can reduce one's chances of getting HIV by having a } \\
\text { single sexual partner }\end{array}$ & NA & 75.9 & NA & 50.3 & 60.3 \\
\hline $\begin{array}{l}\text { One can reduce one's chances of getting HIV by consistent } \\
\text { use of condoms }\end{array}$ & NA & 79.6 & NA & 35.8 & 43.1 \\
\hline One cannot get HIV through mosquito bites & 46.2 & 58.3 & * & 50.1 & 45.6 \\
\hline One cannot get HIV by sharing food with an HIV-positive person & 27.5 & 44.6 & * & 45.3 & 45.8 \\
\hline One cannot get HIV by hugging an HIV-positive person & 46.7 & 60.0 & * & 56.4 & 54.5 \\
\hline One cannot tell if a person is HIV-positive by just looking at him/her & 75.8 & 77.8 & * & 81.9 & 81.8 \\
\hline Number who had heard about HIV/AIDS & 56 & 431 & 17 & 469 & 369 \\
\hline Comprehensive awareness of HIV/AIDs ${ }^{1}$ & 1.9 & 10.8 & 0.7 & 3.0 & 2.3 \\
\hline Number of respondents & 560 & 813 & 377 & 1,690 & 2,042 \\
\hline
\end{tabular}

Notes: All Ns are unweighted. * Percentage not shown as this was based on fewer than 25 unweighted cases. NA: not applicable. ${ }^{1}$ Comprehensive awareness of HIV/AIDS for 15-19-year-old adolescents includes: (1) identifying two major ways of preventing HIV (using condoms always and limiting sex to one partner); (2) rejecting three common misconceptions about HIV transmission (that HIV can be transmitted through mosquito bites, sharing food with a person who has HIV, and hugging someone who has HIV); and (3) knowing that a healthy-looking person can be HIV-positive. Comprehensive awareness of HIV/AIDS for 10-14-year-old adolescents includes: (1) rejecting three common misconceptions about HIV transmission (that HIV can be transmitted through mosquito bites, sharing food with a person who has HIV, and hugging someone who has HIV); and (2) knowing that a healthy-looking person can be HIV-positive.

Among those who reported awareness of HIV/AIDS, knowledge of specific aspects of the disease was by no means complete, and differences by sex were notable. Thus, 77 percent of older boys who had heard of HIV/AIDS were aware that one can reduce the chances of getting HIV by being faithful to a single partner as were 52 percent of unmarried older girls and 61 percent of married older girls. Awareness that one can reduce the chances of contracting HIV by using a condom every time one has sex was reported by 80 percent of older boys and 39-45 percent of unmarried and married older girls. Differences by marital status among older girls were also marked; married girls were more likely than their unmarried counterparts to report that they were aware that the chances of contracting HIV could be reduced by restricting sexual relationships to a single partner ( $61 \%$ versus $52 \%)$ and by consistent condom use (45\% versus 39\%). Differences between those from rural and those from urban areas were narrow for the most part; even so, unmarried and married older girls in urban areas were more likely than their rural counterparts to report awareness of consistent condom use as a preventive measure (49\% versus $36 \%$ of unmarried older girls and $55 \%$ versus $43 \%$ of married older girls).

Reflecting their limited in-depth awareness of HIV/AIDS, adolescents' rejection of common misconceptions was also limited among those who had heard of HIV/AIDS. Specifically, 49 percent of younger boys, 59 percent of older boys, and 46-53 percent of all three groups of girls were aware that HIV cannot be transmitted through mosquito bites. Similarly, 30 percent of younger boys and 48 percent of older boys knew that one cannot acquire HIV by sharing food with an HIV-infected person, while the proportions among girls who correctly reported this fact were 37 percent of younger girls and 47-48 percent of unmarried and married older girls. Furthermore, 49 percent of younger boys and 62 percent of older boys were aware that one cannot get HIV by hugging an HIV-positive person as were 54-59 percent of girls. Finally, 78-79 percent of boys and 77-83 percent of girls reported that one cannot tell if a person is HIV-positive by looking at him/her. By and large, differences by marital status among older girls were narrow; however, unmarried girls were more likely than their married counterparts to be aware that HIV cannot be transmitted through mosquito bites (53\% versus $46 \%$ ). Differences by residence in rural or urban areas suggest, for the most part, that more urban than rural adolescents had rejected these misconceptions. 
Findings show that just 1-2 percent of younger adolescents reported comprehensive awareness of HIV/AIDS. Among older adolescents, 12 percent of boys compared with 3-4 percent of girls reported comprehensive awareness of HIV/ AIDS. Differences by residence in rural or urban areas show that older adolescents in urban areas were more likely than their rural counterparts to report comprehensive awareness of HIV/AIDS. (25\% versus $11 \%$ among boys; $13 \%$ versus $3 \%$ among unmarried girls; and $8 \%$ versus $2 \%$ among married girls), but no such differences were observed among younger adolescents.

Differentials in comprehensive awareness of HIV/AIDS among older adolescents ${ }^{1}$ by selected background characteristics are presented in Table 8.7. Comprehensive awareness of HIV/AIDS increased with age, particularly among boys. Though comprehensive awareness did not differ by religion, it was somewhat greater among boys and unmarried girls who belonged to general castes than those who were from scheduled castes (18\% versus $11 \%$ of boys and $8 \%$ versus $1 \%$ of unmarried girls; differences remained mild among married girls). It was also greater among adolescents who were better educated. As shown also in Figure 8.3a, just four percent of boys with no formal education displayed comprehensive HIV/AIDS awareness compared with 38 percent of those with 12 or more years of education; the corresponding proportions among girls were less than one percent and 13-18 percent. No association was observed between comprehensive awareness and current schooling status and engagement in paid work in the year preceding the interview across all groups of adolescents. As shown also in Figure 8.3b, comprehensive awareness increased with household wealth status, from three percent among boys in the poorest (first) wealth quintile to 17 percent among those in the wealthiest (fifth) quintile and, correspondingly, from one percent or less to 9-10 percent among girls. Finally, it increased with mother's education, from 10 percent among boys whose mother had no formal education to 26 percent among boys whose mother had completed 10 or more years of schooling, and the corresponding increase among girls was from two percent to 16-19 percent.

\section{Table 8.7: Comprehensive awareness of HIV/AIDS}

Percentage of adolescents in ages 15-19 who had comprehensive awareness of HIV/AIDS by selected background characteristics, Bihar, 2016

\begin{tabular}{lccc}
\hline Background characteristics (percent) & $\begin{array}{c}\text { Boys } \\
(15-19)\end{array}$ & $\begin{array}{c}\text { Girls } \\
(15-19)\end{array}$ & $\begin{array}{c}\text { Married girls } \\
(15-19)\end{array}$ \\
\hline Age & & & 1.7 \\
$15-17$ & 9.9 & 3.8 & 3.5 \\
$18-19$ & 19.0 & & 2.9 \\
Religion $^{1}$ & & 4.3 & 2.6 \\
Hindu & 12.8 & 3.0 & \\
Muslim & 9.5 & & 2.7 \\
Caste $^{2}$ & & 1.1 & 2.5 \\
SC & 11.0 & 4.0 & 6.7 \\
OBC & 11.3 & 8.2 & \\
General & & & \\
Completed years of schooling $^{3}$ & 18.3 & & 0.1 \\
None & & & 1.0 \\
$1-4$ & 3.9 & 0.0 & 0.8 \\
$5-7$ & 4.9 & 0.0 & 1.7 \\
$8-9$ & 3.0 & 0.2 & 8.6 \\
$10-11$ & 8.9 & 2.9 & 13.4 \\
12 and above & 18.0 & 4.8 & Cont. \\
\hline
\end{tabular}

\footnotetext{
${ }^{1}$ Differentials in comprehensive awareness of HIV/AIDS were not presented for younger adolescents because of the small proportion of younger adolescents who had displayed such awareness.
} 
Table 8.7 Cont.

\begin{tabular}{|c|c|c|c|}
\hline Background characteristics (percent) & $\begin{array}{c}\text { Boys } \\
(15-19)\end{array}$ & $\begin{array}{c}\text { Girls } \\
(15-19)\end{array}$ & $\begin{array}{c}\text { Married girls } \\
(15-19)\end{array}$ \\
\hline \multicolumn{4}{|l|}{ Current schooling status $^{5}$} \\
\hline Yes & 12.7 & 5.0 & 7.4 \\
\hline No & 10.7 & 1.0 & 2.6 \\
\hline \multicolumn{4}{|c|}{ Paid work in the 12 months prior to the interview } \\
\hline Yes & 11.6 & 4.2 & 0.9 \\
\hline No & 12.6 & 4.0 & 3.2 \\
\hline \multicolumn{4}{|l|}{ Wealth quintile } \\
\hline First & 3.1 & 0.0 & 0.8 \\
\hline Second & 11.8 & 0.7 & 1.3 \\
\hline Third & 10.0 & 1.4 & 1.4 \\
\hline Fourth & 12.4 & 3.2 & 2.4 \\
\hline Fifth & 17.1 & 10.0 & 8.8 \\
\hline \multicolumn{4}{|c|}{ Mother's education (in years of schooling completed) } \\
\hline None $^{4}$ & 10.1 & 1.7 & 1.7 \\
\hline $1-7$ & 11.2 & 6.8 & 2.4 \\
\hline $8-9$ & 22.0 & 6.2 & 10.8 \\
\hline 10 and above & 26.3 & 16.3 & 18.6 \\
\hline Total & 12.3 & 4.0 & 2.9 \\
\hline
\end{tabular}

Notes: OBC: other backward caste; SC: scheduled caste; ST: scheduled tribe. ${ }^{1}$ Percentages not shown for those belonging to other religions as less than one percent of surveyed adolescents belonged to other religions. ${ }^{2}$ Percentages not shown for those belonging to STs as less than one percent of surveyed adolescents belonged to STs. ${ }^{3}$ Includes all those not belonging to SCs, STs, or OBCs. ${ }^{4}$ Includes non-literate and literate with no formal schooling. ${ }^{5}$ Percentages not shown for adolescents who were pursuing their education through distance education courses at the time of interview or those who never went to school.

Figure 8.3a: Percentage of adolescents in ages 15-19 reporting comprehensive awareness of HIV/AIDS by educational level, Bihar, 2016

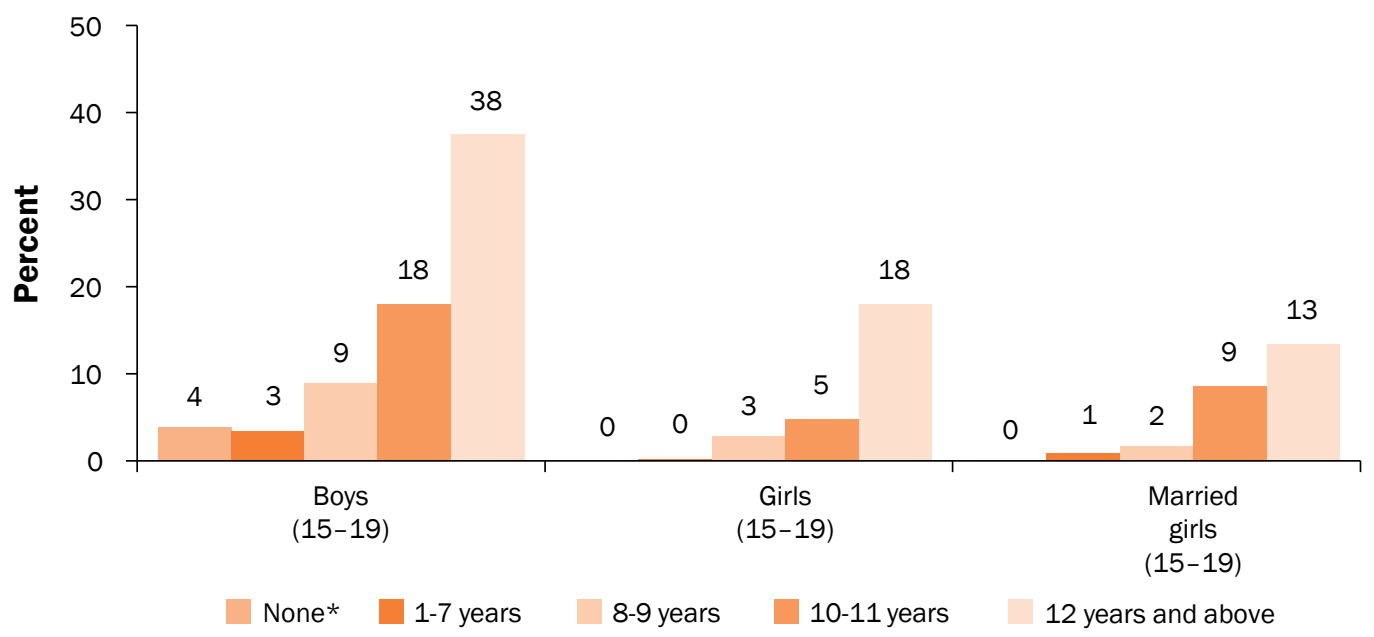

Note: *Includes non-literate and literate with no formal schooling 
Figure 8.3b: Percentage of adolescents in ages 15-19 reporting comprehensive awareness of HIV/AIDS by wealth quintile, Bihar, 2016

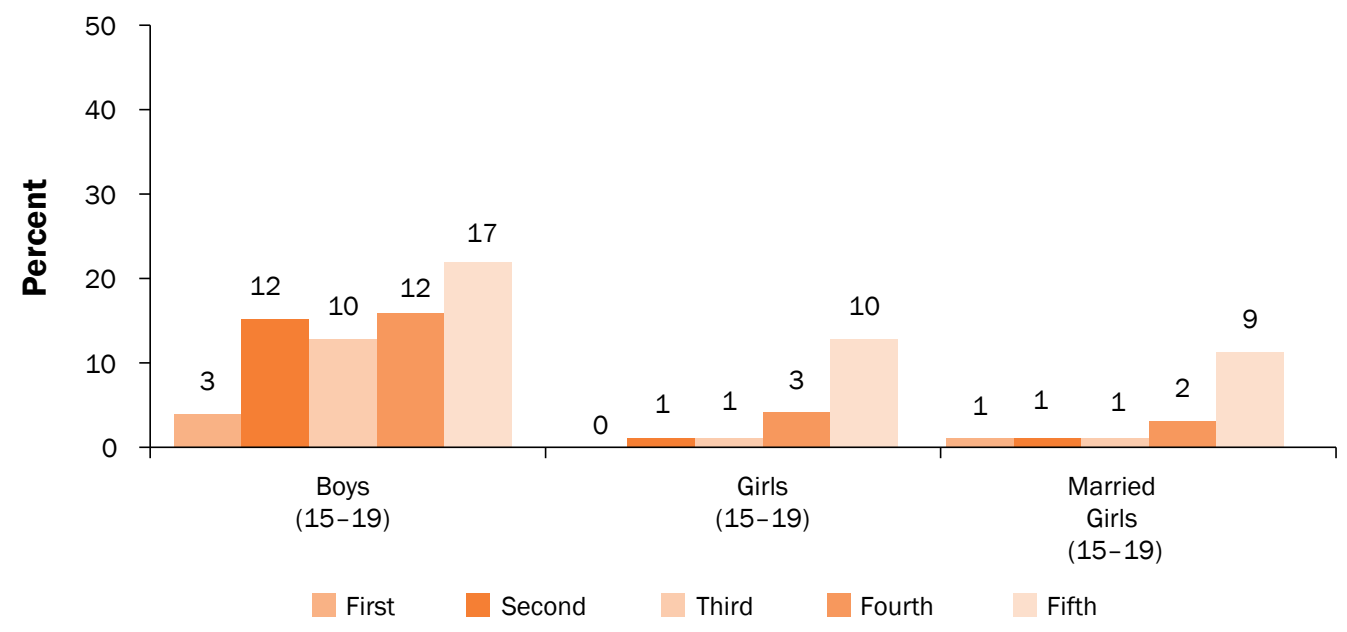

Findings, presented in Table 8.8, suggest that, among older adolescents (questions on STIs were not posed to younger adolescents), awareness of STIs other than HIV/AIDS was limited. Indeed, just 11 percent of boys and 15 percent and 21 percent of unmarried girls and married girls, respectively, reported awareness of STIs. Differences by residence in rural or urban areas show that somewhat more urban than rural adolescents had heard about STIs (18\% versus $10 \%$ among boys and $20-25 \%$ versus $14-20 \%$ among girls).

\section{Table 8.8: Awareness of STIs other than HIV/AIDS}

Percent distribution of adolescents in ages 15-19 who had heard of and had specific knowledge about STIs other than HIV/AIDS, according to residence, Bihar, 2016

\begin{tabular}{|c|c|c|c|}
\hline Awareness indicators & $\begin{array}{c}\text { Boys } \\
(15-19)\end{array}$ & $\begin{array}{c}\text { Girls } \\
(15-19)\end{array}$ & $\begin{array}{l}\text { Married girls } \\
\qquad(15-19)\end{array}$ \\
\hline \multicolumn{4}{|l|}{ Combined (percent) } \\
\hline Heard about STIs other than HIV/AIDS & 11.3 & 14.6 & 20.7 \\
\hline Number of respondents & 1,821 & 3,428 & 3,408 \\
\hline \multicolumn{4}{|l|}{ Awareness about symptoms of STIs } \\
\hline Ulcers/sore in private parts & 12.9 & 7.7 & 11.4 \\
\hline Genital discharge & 12.5 & 15.4 & 25.7 \\
\hline Itching in private parts & 16.2 & 12.4 & 19.3 \\
\hline Lower abdominal tenderness/pain & 3.3 & 9.2 & 11.9 \\
\hline Warts or growths on private parts & 1.2 & 1.4 & 2.7 \\
\hline Burning sensation or pain on urination & 12.8 & 12.0 & 15.9 \\
\hline Infertility and related symptoms & 0.0 & 0.0 & 0.0 \\
\hline Fever and weakness & 0.0 & 2.1 & 1.3 \\
\hline Asymptomatic & 1.6 & 2.4 & 3.4 \\
\hline Aware of at least one symptom of STIs or that STIs can be asymptomatic ${ }^{1}$ & 36.8 & 37.4 & 52.4 \\
\hline Number who had heard about STls & 268 & 593 & 738 \\
\hline
\end{tabular}


Table 8.8 Cont.

\begin{tabular}{|c|c|c|c|}
\hline Awareness indicators & $\begin{array}{c}\text { Boys } \\
(15-19)\end{array}$ & $\begin{array}{c}\text { Girls } \\
(15-19)\end{array}$ & $\begin{array}{l}\text { Married girls } \\
\qquad(15-19)\end{array}$ \\
\hline \multicolumn{4}{|l|}{ Urban (percent) } \\
\hline Heard about STIs other than HIV/AIDS & 17.8 & 20.0 & 24.5 \\
\hline Number of respondents & 1,008 & 1,738 & 1,366 \\
\hline \multicolumn{4}{|l|}{ Awareness about symptoms of STIs } \\
\hline Ulcers/sore in private parts & 20.5 & 14.1 & 9.4 \\
\hline Genital discharge & 24.0 & 19.6 & 28.7 \\
\hline Itching in private parts & 19.5 & 17.1 & 22.9 \\
\hline Lower abdominal tenderness/pain & 3.2 & 11.4 & 13.3 \\
\hline Warts or growths on private parts & 1.2 & 5.2 & 3.3 \\
\hline Burning sensation or pain on urination & 12.4 & 16.1 & 20.7 \\
\hline Infertility and related symptoms & 0.0 & 0.0 & 0.0 \\
\hline Fever and weakness & 0.0 & 1.2 & 1.1 \\
\hline Asymptomatic & 1.5 & 5.3 & 3.7 \\
\hline Aware of at least one symptom of STIs or that STIs can be asymptomatic ${ }^{1}$ & 50.4 & 46.9 & 59.2 \\
\hline Number who had heard about STIs & 181 & 347 & 330 \\
\hline \multicolumn{4}{|l|}{ Rural (percent) } \\
\hline Heard about STIs other than HIV/AIDS & 10.4 & 13.9 & 20.3 \\
\hline Number of respondents & 813 & 1,690 & 2,042 \\
\hline \multicolumn{4}{|l|}{ Awareness about symptoms of STIs } \\
\hline Ulcers/sore in private parts & 11.3 & 6.6 & 11.7 \\
\hline Genital discharge & 10.0 & 14.6 & 25.3 \\
\hline Itching in private parts & 15.5 & 11.6 & 18.8 \\
\hline Lower abdominal tenderness/pain & 3.3 & 8.9 & 11.8 \\
\hline Warts or growths on private parts & 1.2 & 0.7 & 2.6 \\
\hline Burning sensation or pain on urination & 12.9 & 11.3 & 15.2 \\
\hline Infertility and related symptoms & 0.0 & 0.0 & 0.0 \\
\hline Fever and weakness & 0.0 & 2.2 & 1.3 \\
\hline Asymptomatic & 1.7 & 1.9 & 3.4 \\
\hline Aware of at least one symptom of STIs or that STIs can be asymptomatic ${ }^{1}$ & 33.8 & 35.7 & 51.5 \\
\hline Number who had heard about STls & 87 & 246 & 408 \\
\hline
\end{tabular}

Notes: All Ns are unweighted. Column totals may exceed $100 \%$ owing to multiple responses. ${ }^{1}$ Symptoms of STIs considered in the summary measure include ulcers/sore in private parts, genital discharge, itching in private parts, lower abdominal tenderness/pain, warts or growths on private parts, and burning sensation or pain on urination.

Among older adolescents who were aware of STIs other than HIV/AIDS, 37 percent each of boys and unmarried girls and 52 percent of married girls were aware of at least one symptom of infection or that STIs can be asymptomatic. Differences by residence in rural or urban areas show that more urban than rural older adolescents, particularly boys and unmarried girls, could identify a symptom of infection (50\% versus 34\% among boys; $47 \%$ versus $36 \%$ among unmarried girls; and $59 \%$ versus $52 \%$ among married girls). The symptoms that were most frequently identified by boys and girls were similar, although the proportions reporting each of the symptoms differed across boys, unmarried girls, and married girls-genital itching (identified by $16 \%$ of boys; $12 \%$ of unmarried girls; and 19\% of married girls), genital ulcers or sores (identified by $13 \%, 8 \%$, and $11 \%$, respectively), genital discharge (identified by $13 \%, 15 \%$, and 
$26 \%$, respectively) and burning sensation or pain during urination (identified by $13 \%, 12 \%$, and $16 \%$, respectively). Girls in addition listed lower abdominal pain (9-12\%).

A comparison of awareness of HIV/AIDS and other STIs among older adolescents, presented in Figure 8.4, shows that, among boys and unmarried girls, awareness of STIs other than HIV/AIDS was more limited than awareness of HIV/AIDS. However, among married girls, similar proportions had heard about both HIV/AIDS and STIs.

\section{Figure 8.4: Percentage of adolescents in ages 15-19 by awareness of HIV/AIDS, comprehensive knowledge about HIV/AIDS, and awareness of STIs, Bihar, 2016}

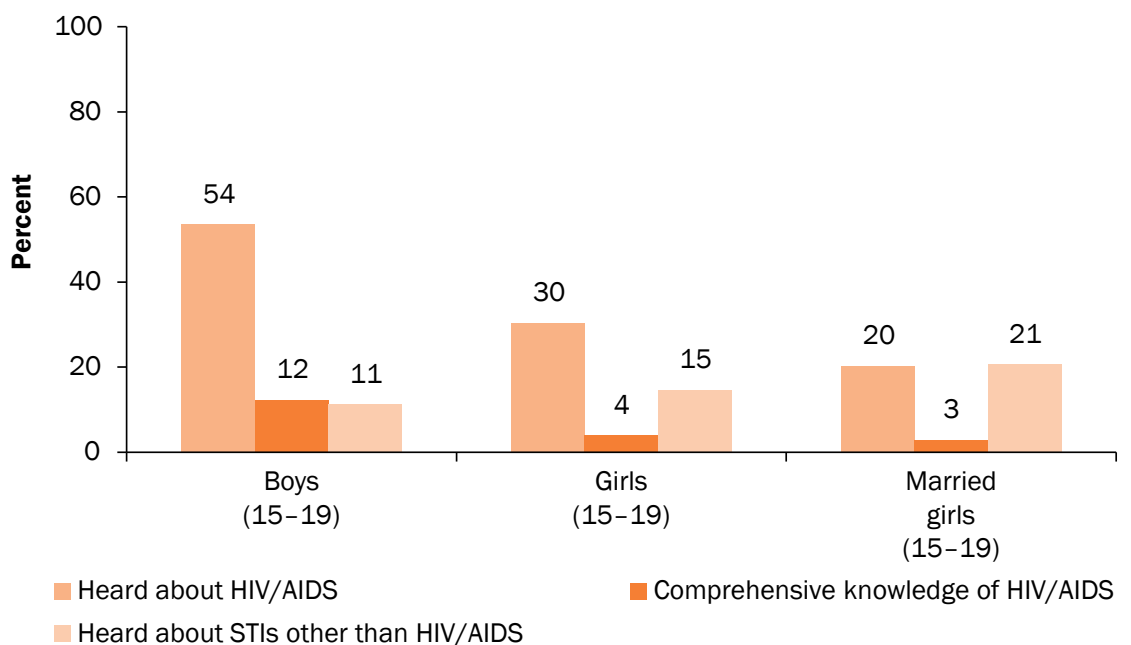

\subsection{5: Awareness of maternal and newborn care practices}

We assessed the awareness of only older adolescents regarding maternal and newborn care practices. As mentioned in Chapter 1, we made the survey questions age-appropriate, and, hence, we did not include younger adolescents in this assessment. Specifically, we asked older adolescents whether they were aware of the minimum number of antenatal check-ups a pregnant woman should have and the need for a woman to have a post-partum check-up even if she feels well following childbirth. We also asked whether they were aware of the importance of breastfeeding a newborn within an hour of birth, feeding colostrum, breastfeeding exclusively for six months, and avoiding bathing the newborn on the first day of birth. Findings are summarised in Table 8.9.

Findings highlight the limited awareness of maternal care practices among older adolescents, including among married girls. Just 22 percent of boys and 26-28 percent of unmarried and married girls knew, for example, that a pregnant woman should have at least four antenatal check-ups. Some $44 \%$ of boys and $52 \%$ and $63 \%$ of unmarried girls and married girls, respectively, believed that a pregnant woman should have three or more antenatal checkups (not shown in table). In contrast, larger proportions-68-71 percent of boys and girls-reported that a woman should have post-partum check-ups even if she is feeling well following childbirth. As seen above, differences by sex and, among girls, by marital status were narrow. Differences by residence in rural or urban areas show that more of urban than rural adolescents across all three categories reported that a pregnant woman should have at least four antenatal check-ups and that a woman should have post-partum checks-up even if she is feeling well following childbirth.

Compared to awareness of maternal care practices, a somewhat larger proportion of married girls than boys and unmarried girls were informed about most newborn care practices explored in the study. Specifically, 43 percent of married girls compared with 30-32 percent of boys and unmarried girls knew that a newborn should be breastfed immediately, that is, within an hour of birth. Half of married girls knew that colostrum should be fed to the newborn-50 percent-compared with 39-43 percent of boys and unmarried girls. Awareness that an infant should be breastfed exclusively for six months was reported by 48 percent of married girls compared with 28 percent of boys and 41 percent of unmarried girls. However, more boys than girls knew that a newborn should not be bathed immediately, that is, on the first day of birth ( $62 \%$ of boys versus $34-39 \%$ of girls). Differentials between those 
from rural and those from urban areas show that more urban than rural adolescents were aware of breastfeeding practices. However, we observed no such differences with regard to awareness about refraining from bathing the newborn on the first day of birth.

A summary measure has been created from the range of questions relating to maternal and newborn care practices, namely, the percentage who were aware of three or more of the six practices probed. Table 8.9 shows that $46-47$ percent of boys and unmarried girls and 55 percent of married girls were aware of three or more practices; more of urban than rural adolescents so reported (63-68\% versus $44-53 \%)$.

\section{Table 8.9: Awareness of maternal and newborn care practices}

Percentage of adolescents in ages 15-19 reporting awareness of maternal and newborn care practices, according to residence, Bihar, 2016

\begin{tabular}{|c|c|c|c|}
\hline Awareness indicators & $\begin{array}{c}\text { Boys } \\
(15-19)\end{array}$ & $\begin{array}{c}\text { Girls } \\
(15-19)\end{array}$ & $\begin{array}{l}\text { Married girls } \\
(15-19)\end{array}$ \\
\hline \multicolumn{4}{|l|}{ Combined (percent) } \\
\hline Knew that a pregnant woman should have at least four antenatal checkups & 21.6 & 26.3 & 27.7 \\
\hline Knew that a woman needs to go for check-ups following childbirth even if she feels well & 68.4 & 70.9 & 69.8 \\
\hline Knew that a newborn should be breastfed immediately after birth (within an hour) & 29.6 & 31.8 & 42.8 \\
\hline Knew that a newborn should be fed colostrum & 42.6 & 38.6 & 50.3 \\
\hline Knew that a newborn should be exclusively breastfed for six months & 27.7 & 41.1 & 48.2 \\
\hline Knew that a newborn should not be bathed immediately (on the first day of birth) & 62.1 & 39.4 & 33.7 \\
\hline Knew at least three of the above & 46.9 & 46.1 & 54.5 \\
\hline Number of respondents & 1,821 & 3,428 & 3,408 \\
\hline \multicolumn{4}{|l|}{ Urban (percent) } \\
\hline Knew that a pregnant woman should have at least four antenatal checkups & 28.4 & 32.7 & 38.9 \\
\hline Knew that a woman needs to go for check-ups following childbirth even if she feels well & 76.1 & 76.0 & 73.2 \\
\hline Knew that a newborn should be breastfed immediately after birth (within an hour) & 76.1 & 76.0 & 73.2 \\
\hline Knew that a newborn should be fed colostrum & 62.0 & 59.3 & 59.7 \\
\hline Knew that a newborn should be exclusively breastfed for six months & 38.7 & 53.0 & 59.1 \\
\hline Knew that a newborn should not be bathed immediately (on the first day of birth) & 67.2 & 40.2 & 35.9 \\
\hline Knew at least three of the above & 64.0 & 63.3 & 67.7 \\
\hline Number of respondents & 1,008 & 1,738 & 1,366 \\
\hline \multicolumn{4}{|l|}{ Rural (percent) } \\
\hline Knew that a pregnant woman should have at least four antenatal checkups & 20.7 & 25.5 & 26.5 \\
\hline Knew that a woman needs to go for check-ups following childbirth even if she feels well & 67.4 & 70.3 & 69.4 \\
\hline Knew that a newborn should be breastfed immediately after birth (within an hour) & 28.8 & 30.8 & 42.1 \\
\hline Knew that a newborn should be fed colostrum & 40.2 & 36.2 & 49.3 \\
\hline Knew that a newborn should be exclusively breastfed for six months & 26.4 & 39.6 & 46.9 \\
\hline Knew that a newborn should not be bathed immediately (on the first day of birth) & 61.4 & 39.3 & 33.5 \\
\hline Knew at least three of the above & 44.8 & 44.0 & 53.1 \\
\hline Number of respondents & 813 & 1,690 & 2,042 \\
\hline
\end{tabular}

Note: All Ns are unweighted. 
Table 8.10 describes the differentials in awareness of maternal and newborn care practices by selected background characteristics of older adolescents. Findings show that awareness increased with age across all three categories of older adolescents. Religious differentials were observed among boys but not among girls, with a larger proportion of Hindu than Muslim boys reporting awareness of maternal and newborn care practices (49\% versus 37\%). Caste-wise differentials were observed among all three categories of adolescents; respondents belonging to general castes were more likely than those from other castes to report awareness of maternal and newborn care practices (54\% versus $46 \%$ among boys; $65 \%$ versus $39-44 \%$ among unmarried girls; and $65 \%$ versus $48-56 \%$ among married girls). A positive association was found between awareness of maternal and newborn care practices and educational level, household wealth status, and mother's education. It was greater among those who were pursuing their education than those who were not (except among married girls). However, awareness of maternal and newborn care practices was lower among those who were engaged in paid work in the year preceding the interview than those who were not engaged in paid work.

Table 8.10: Awareness of maternal and newborn care practices by selected background characteristics

Percentage of adolescents in ages 15-19 who had knowledge of maternal and newborn care practices by selected background characteristics, Bihar, 2016

\begin{tabular}{|c|c|c|c|}
\hline Background characteristics (percent) & $\begin{array}{c}\text { Boys } \\
(15-19)\end{array}$ & $\begin{array}{c}\text { Girls } \\
(15-19)\end{array}$ & $\begin{array}{c}\text { Married girls } \\
(15-19)\end{array}$ \\
\hline \multicolumn{4}{|l|}{ Age } \\
\hline $15-17$ & 43.4 & 42.3 & 45.2 \\
\hline $18-19$ & 56.6 & 59.4 & 59.3 \\
\hline \multicolumn{4}{|l|}{ Religion $^{1}$} \\
\hline Hindu & 48.6 & 46.4 & 55.0 \\
\hline Muslim & 36.5 & 43.4 & 52.1 \\
\hline \multicolumn{4}{|l|}{ Caste $^{2}$} \\
\hline SC & 45.7 & 38.6 & 47.5 \\
\hline OBC & 46.0 & 43.7 & 56.2 \\
\hline General $^{3}$ & 53.6 & 65.2 & 64.8 \\
\hline \multicolumn{4}{|l|}{ Completed years of schooling } \\
\hline None $^{4}$ & 12.0 & 21.6 & 38.9 \\
\hline $1-4$ & 22.9 & 12.9 & 44.9 \\
\hline $5-7$ & 32.5 & 35.3 & 57.8 \\
\hline $8-9$ & 46.1 & 44.3 & 57.9 \\
\hline $10-11$ & 60.1 & 58.9 & 69.5 \\
\hline 12 and above & 65.8 & 76.7 & 77.0 \\
\hline \multicolumn{4}{|l|}{ Current schooling status ${ }^{5}$} \\
\hline Yes & 50.4 & 50.4 & 60.6 \\
\hline No & 39.1 & 40.2 & 60.4 \\
\hline \multicolumn{4}{|c|}{ Paid work in the 12 months prior to the interview } \\
\hline Yes & 39.6 & 39.5 & 49.9 \\
\hline No & 49.4 & 47.4 & 55.1 \\
\hline
\end{tabular}


Table 8.10 Cont.

\begin{tabular}{|c|c|c|c|}
\hline Background characteristics (percent) & $\begin{array}{c}\text { Boys } \\
(15-19)\end{array}$ & $\begin{array}{c}\text { Girls } \\
(15-19)\end{array}$ & $\begin{array}{l}\text { Married girls } \\
(15-19)\end{array}$ \\
\hline \multicolumn{4}{|l|}{ Wealth quintile } \\
\hline First & 32.6 & 29.2 & 46.3 \\
\hline Second & 40.8 & 37.2 & 46.6 \\
\hline Third & 40.6 & 38.6 & 51.1 \\
\hline Fourth & 48.8 & 43.4 & 56.8 \\
\hline Fifth & 58.2 & 64.8 & 69.9 \\
\hline \multicolumn{4}{|c|}{ Mother's education (in years of schooling completed) } \\
\hline None $^{4}$ & 43.4 & 39.7 & 52.7 \\
\hline $1-7$ & 54.1 & 57.1 & 56.1 \\
\hline $8-9$ & 52.9 & 59.4 & 66.0 \\
\hline 10 and above & 67.1 & 70.8 & 74.7 \\
\hline Total & 46.9 & 46.1 & 54.5 \\
\hline
\end{tabular}

Notes: OBC: other backward caste; SC: scheduled caste; ST: scheduled tribe. ${ }^{1}$ Percentages not shown for those belonging to other religions as less than one percent of surveyed adolescents belonged to other religions. ${ }^{2}$ Percentages not shown for those belonging to STs as less than one percent of surveyed adolescents belonged to STs. ${ }^{3}$ Includes all those not belonging to SCs, STs, or OBCs. ${ }^{4}$ Includes non-literate and literate with no formal schooling. ${ }^{5}$ Percentages not shown for adolescents who were pursuing their education through distance education courses at the time of interview or those who never went to school.

\subsection{Perceptions about abortion}

We addressed two questions regarding perceptions about abortion to older adolescents. We decided against asking them if they knew whether abortion is legally permitted in India, as our pre-test revealed that adolescents tended to provide normative responses, and, when we sought more details, they appeared to be unaware of the legal status of pregnancy termination. Hence, we chose to probe (1) their attitude about abortion, and (2) an indirect assessment of legality, that is, whether they were aware that abortions were provided by government and private physicians. Specifically, we asked older adolescents whether they considered abortion to be an acceptable choice for a pregnant girl or woman if she does not want to continue with the pregnancy. Respondents who were aware of induced abortion were further asked about the facility to which they would direct a friend or relative who wanted to terminate her pregnancy. Findings are presented in Table 8.11.

Relatively few older adolescents perceived that it is acceptable for a girl or woman to have an abortion if she does not want to continue with her pregnancy; only 23 percent of boys, 30 percent of unmarried older girls, and 36 percent of married girls reported that they found termination of unwanted pregnancies acceptable, and another 19 percent, 11 percent, and four percent, respectively, were either unsure or unaware about abortion. Indeed, as many as 58-61 percent of boys and girls believed that it is not acceptable to terminate a pregnancy. Differences by residence in rural or urban areas were mild with regard to acceptability of abortion.

Among the older adolescents who were aware of abortion, considerable proportions-64 percent of boys and 53-58 percent of girls - reported that they would direct a friend or relative in need of abortion services to facilities or providers likely to be certified or registered to provide these services-a government facility/doctor or a private facility/ doctor-which indicates some indirect understanding that abortion is legally available. Only very small proportions of adolescents reported that they would suggest a facility or provider not authorised to provide abortion services $(2-4 \%)$. It is notable that 12 percent of boys and 25-31 percent of girls reported that they would advise their friend or relative in need of an abortion service against termination of the pregnancy. Finally, 23 percent of boys and 11-22 percent of girls reported that they did not know of facilities that offer abortion services.

Differences were evident in comparisons between boys and unmarried girls. Boys were more likely than unmarried girls to suggest a provider or facility that was likely to be legal (64\% versus $53 \%$ ), but less likely to advise against terminating the pregnancy ( $12 \%$ versus $25 \%)$. Among girls, differences by marital status were evident-married girls 
were somewhat more likely than the unmarried to suggest a likely trained provider or facility (58\% versus $53 \%$ ). They were also somewhat more likely to advise against terminating the pregnancy ( $31 \%$ versus $25 \%$ ), but less likely to report that they did not know of facilities that offer abortion services (11\% versus $22 \%)$. Differences by residence in rural or urban areas were narrow, although urban boys and unmarried girls were less likely than their rural counterparts to report that they did not know of facilities that offer abortion services (16\% each versus $23-24 \%$ ).

We note that though a number of adolescents were aware of abortion, the vast majority of them neither had experienced one nor would have known someone who had undergone one, and, therefore, responses do not necessarily reflect the reality of adolescents who are seeking abortions.

\section{Table 8.11: Perceptions about abortion}

Percent distribution of adolescents in ages $15-19$ by perceptions about abortion and percentage of adolescents aware of abortion by type of facility they would recommend for undergoing abortion, according to residence, Bihar, 2016

\begin{tabular}{|c|c|c|c|}
\hline Perceptions & $\begin{array}{l}\text { Boys } \\
(15-19)\end{array}$ & $\begin{array}{c}\text { Girls } \\
(15-19)\end{array}$ & $\begin{array}{l}\text { Married girls } \\
\qquad(15-19)\end{array}$ \\
\hline \multicolumn{4}{|c|}{ Combined (percent) } \\
\hline \multicolumn{4}{|c|}{$\begin{array}{l}\text { It is acceptable for a girl/woman to have an abortion if she does not want to } \\
\text { continue her pregnancy }\end{array}$} \\
\hline Yes & 23.1 & 29.9 & 35.5 \\
\hline No & 57.6 & 59.4 & 60.6 \\
\hline Cannot say & 13.8 & 7.6 & 1.1 \\
\hline Does not know about abortion & 5.5 & 3.0 & 2.9 \\
\hline Number of respondents & 1,821 & 3,428 & 3,408 \\
\hline \multicolumn{4}{|l|}{ Facility respondent would recommend for abortion } \\
\hline A likely legal facility/provider ${ }^{1}$ & 63.5 & 53.3 & 58.0 \\
\hline A facility/provider not authorised to provide abortion service ${ }^{2}$ & 2.9 & 1.6 & 4.0 \\
\hline Advise her not to abort & 11.9 & 25.1 & 31.0 \\
\hline Does not know where to refer & 22.7 & 22.1 & 11.0 \\
\hline Number aware of abortion & 1,713 & 3,324 & 3,377 \\
\hline \multicolumn{4}{|c|}{ Urban (percent) } \\
\hline \multicolumn{4}{|c|}{$\begin{array}{l}\text { It is acceptable for a girl/woman to have an abortion if she does not want to } \\
\text { continue her pregnancy }\end{array}$} \\
\hline Yes & 21.0 & 31.2 & 37.3 \\
\hline No & 63.7 & 56.8 & 59.2 \\
\hline Cannot say & 9.3 & 8.2 & 3.0 \\
\hline Does not know about abortion & 6.0 & 3.7 & 0.5 \\
\hline Number of respondents & 1,008 & 1,738 & 1,366 \\
\hline \multicolumn{4}{|l|}{ Facility respondent would recommend for abortion } \\
\hline A likely legal facility/provider ${ }^{1}$ & 67.6 & 55.4 & 59.3 \\
\hline A facility/provider not authorised to provide abortion service ${ }^{2}$ & 1.9 & 2.0 & 3.5 \\
\hline Advise her not to abort & 15.6 & 28.7 & 32.0 \\
\hline Does not know where to refer & 16.0 & 16.0 & 8.8 \\
\hline Number aware of abortion & 944 & 1,681 & 1,359 \\
\hline
\end{tabular}


Table 8.11 Cont.

\begin{tabular}{|c|c|c|c|}
\hline Perceptions & $\begin{array}{c}\text { Boys } \\
(15-19)\end{array}$ & $\begin{array}{c}\text { Girls } \\
(15-19)\end{array}$ & $\begin{array}{c}\text { Married girls } \\
(15-19)\end{array}$ \\
\hline \multicolumn{4}{|c|}{ Rural (percent) } \\
\hline \multicolumn{4}{|c|}{$\begin{array}{l}\text { It is acceptable for a girl/woman to have an abortion if she does not want to } \\
\text { continue her pregnancy }\end{array}$} \\
\hline Yes & 23.4 & 29.8 & 35.3 \\
\hline No & 56.8 & 59.7 & 60.7 \\
\hline Cannot say & 14.3 & 7.5 & 2.8 \\
\hline Does not know about abortion & 5.4 & 3.0 & 1.2 \\
\hline Number of respondents & 813 & 1,690 & 2,042 \\
\hline \multicolumn{4}{|l|}{ Facility respondent would recommend for abortion } \\
\hline A likely legal facility/provider ${ }^{1}$ & 63.0 & 53.0 & 57.8 \\
\hline A facility/provider not authorised to provide abortion service ${ }^{2}$ & 3.0 & 1.5 & 4.1 \\
\hline Advise her not to abort & 11.4 & 24.7 & 30.9 \\
\hline Does not know where to refer & 23.6 & 22.9 & 11.2 \\
\hline Number aware of abortion & 769 & 1,643 & 2,018 \\
\hline
\end{tabular}

Notes: All Ns are unweighted. ${ }^{1}$ A government facility/doctor or a private facility or provider. ${ }^{2}$ Unqualified medical practitioners, traditional healers, home remedies, medical shop/chemist, ANM or ASHA.

\subsection{Knowledge of law on minimum age of marriage}

In this section, we present findings on the extent of adolescents' awareness of the law on age of marriage. Interviewers collected information on whether adolescents were aware that a law exists that stipulates a legal minimum age of marriage for males and females in India and whether they knew the correct legal minimum age of marriage for males and females. Table 8.12 shows percentages of adolescents who were aware that there is a law on the legal minimum age of marriage for males and females and could identify the correct legal minimum age of marriage for males and females.

Awareness that there is a law on the minimum age of marriage was far from universal; moreover, it differed by age and sex of the respondent. Younger adolescents were less likely than older adolescents to report that there is a legal minimum age of marriage for males and females in India ( $55 \%$ versus $86 \%$ among boys and $47 \%$ versus $78-82 \%$ among girls). A somewhat larger proportion of boys than girls so reported (55\% versus $47 \%$ among younger adolescents and $86 \%$ versus $78-82 \%$ among older adolescents). We observed no differences by marital status among older girls. Differences by residence in rural and urban areas indicate that more urban than rural respondents were aware of the law related to minimum age of marriage (58-62\% versus $46-54 \%$ of younger adolescents and $82-92 \%$ versus $77-85 \%$ of older adolescents).

Fewer were aware of the correct legal minimum age of marriage for females and, particularly, for males. Younger adolescents were less likely than older adolescents to be aware of the correct legal minimum age of marriage. Thus, 35 percent of younger boys compared with 68 percent of older boys correctly reported that 18 years is the legal minimum age of marriage for females as did 36 percent of younger girls compared with 64-71 percent of unmarried and married older girls. Far fewer-15 percent each of younger boys and girls, 36 percent of older boys, and 32-44 percent of unmarried and married older girls-reported that 21 is the legal minimum age of marriage for males. Differences by sex were narrow, except that more unmarried older girls than older boys correctly reported that 21 is the legal minimum age of marriage for males (44\% versus $36 \%$ ). Among older girls, differences by marital status were wide, and more unmarried than married girls correctly reported the legal minimum age for males (44\% versus $32 \%$ ) and females (71\% versus $64 \%$ ). Differences between those from rural and those from urban areas show that more urban than rural adolescents knew about the legal minimum age for males and females. 


\section{Table 8.12: Knowledge of the legal minimum age of marriage}

Percentage of adolescents who had correct knowledge of the legal minimum age of marriage in India, according to residence, Bihar, 2016

\begin{tabular}{|c|c|c|c|c|c|}
\hline Awareness indicators & $\begin{array}{c}\text { Boys } \\
(10-14)\end{array}$ & $\begin{array}{c}\text { Boys } \\
(15-19)\end{array}$ & $\begin{array}{c}\text { Girls } \\
(10-14)\end{array}$ & $\begin{array}{c}\text { Girls } \\
(15-19)\end{array}$ & $\begin{array}{l}\text { Married girls } \\
(15-19)\end{array}$ \\
\hline \multicolumn{6}{|c|}{ Combined (percent) } \\
\hline $\begin{array}{l}\text { Aware that there is a legal minimum age of marriage for boys and } \\
\text { girls in India }\end{array}$ & 55.1 & 86.1 & 46.9 & 82.3 & 77.7 \\
\hline Knew that 21 is the legal minimum age of marriage for boys in India & 15.2 & 35.5 & 15.4 & 43.7 & 32.2 \\
\hline Knew that 18 is the legal minimum age of marriage for girls in India & 35.3 & 68.2 & 35.6 & 70.9 & 63.7 \\
\hline Number of respondents & 1,012 & 1,821 & 764 & 3,428 & 3,408 \\
\hline \multicolumn{6}{|c|}{ Urban (percent) } \\
\hline $\begin{array}{l}\text { Aware that there is a legal minimum age of marriage for boys and } \\
\text { girls in India }\end{array}$ & 61.5 & 92.3 & 57.6 & 90.5 & 81.6 \\
\hline Knew that 21 is the legal minimum age of marriage for boys in India & 21.6 & 47.4 & 23.3 & 52.8 & 40.0 \\
\hline Knew that 18 is the legal minimum age of marriage for girls in India & 42.4 & 74.2 & 39.0 & 78.2 & 69.4 \\
\hline Number of respondents & 452 & 1,008 & 387 & 1,738 & 1,366 \\
\hline \multicolumn{6}{|c|}{ Rural (percent) } \\
\hline $\begin{array}{l}\text { Aware that there is a legal minimum age of marriage for boys and } \\
\text { girls in India }\end{array}$ & 54.4 & 85.3 & 45.6 & 81.3 & 77.3 \\
\hline Knew that 21 is the legal minimum age of marriage for boys in India & 14.4 & 34.0 & 14.5 & 42.6 & 31.3 \\
\hline Knew that 18 is the legal minimum age of marriage for girls in India & 34.4 & 67.4 & 35.2 & 70.0 & 63.1 \\
\hline Number of respondents & 560 & 813 & 377 & 1,690 & 2,042 \\
\hline
\end{tabular}

Note: All Ns are unweighted.

\subsection{Sources of information on sexual and reproductive matters and access to family life education or sex education}

This section presents data on sources of information on sexual and reproductive matters among study participants and also on the extent of their access to family life education (FLE) or sex education.

\subsubsection{Sources of information on puberty and sexual and reproductive matters}

In order to better understand adolescents' sources of information on puberty and sexual and reproductive matters, we asked younger adolescents to list the three most important sources from whom (family members, friends, etc.) or from which (the media) they had received and would like to receive information about physical changes that take place during adolescence. In a similar way, we also asked respondents aged 13 and above to list the three most important sources from whom or which they had received and they would like to receive information about sexual matters, such as how pregnancy occurs and how it can be prevented. Findings pertaining to sources from which adolescents had received information are presented in Table 8.13.

With regard to information on puberty, findings among younger adolescents (in ages 10-14) show that large proportions of boys and girls had never received any information about puberty ( $57 \%$ and $53 \%$, respectively). Leading sources listed by adolescents were a family member ( $15 \%$ of boys and $38 \%$ of girls), particularly parents, followed by friends ( $12 \%$ of boys and $6 \%$ of girls) and influential adults in the community ( $9 \%$ of boys and $7 \%$ of girls), particularly teachers. Hardly any of the younger adolescents listed healthcare providers (less than 1\%) or the mass media (1-2\%) as their major sources of information. Some seven percent of boys and one percent of girls reported that they had 
Table 8.13: Sources of information on puberty and sexual and reproductive matters

Percentage of adolescents by sources of information on puberty and sexual and reproductive matters, according to residence, Bihar, 2016

\begin{tabular}{|c|c|c|c|c|c|c|c|}
\hline \multirow[t]{2}{*}{ Sources of information } & $\begin{array}{c}\text { Boys } \\
(10-14) \\
\end{array}$ & $\begin{array}{c}\text { Girls } \\
(10-14)\end{array}$ & $\begin{array}{c}\text { Boys } \\
(13-14)\end{array}$ & $\begin{array}{c}\text { Boys } \\
(15-19)\end{array}$ & $\begin{array}{c}\text { Girls } \\
(13-14)\end{array}$ & $\begin{array}{c}\text { Girls } \\
(15-19)\end{array}$ & $\begin{array}{c}\text { Married girls } \\
\text { (15-19) }\end{array}$ \\
\hline & \multicolumn{2}{|c|}{ A. Puberty } & \multicolumn{5}{|c|}{ B. Sexual and reproductive matters } \\
\hline \multicolumn{8}{|c|}{ Combined (percent) } \\
\hline Parents & 13.1 & 31.1 & 1.0 & 3.2 & 10.6 & 11.2 & 13.7 \\
\hline Siblings & 2.8 & 11.2 & 0.2 & 1.1 & 5.0 & 5.9 & 5.2 \\
\hline Spouse/partner & NA & NA & 0.1 & 1.0 & 0.0 & 0.2 & 11.1 \\
\hline Siblings-in-law & 0.4 & 3.1 & 0.0 & 2.9 & 4.5 & 10.7 & 19.7 \\
\hline Other female family members & 0.6 & 5.5 & 0.3 & 1.7 & 5.2 & 17.6 & 28.7 \\
\hline Other male family members & 1.1 & 0.6 & 0.4 & 1.8 & 0.0 & 0.5 & 0.9 \\
\hline Any family member & 15.1 & 38.1 & 1.9 & 10.3 & 19.9 & 35.7 & 58.4 \\
\hline Female friends/neighbours & 0.3 & 6.0 & 0.7 & 2.5 & 4.1 & 17.8 & 17.0 \\
\hline Male friends/neighbours & 11.9 & 0.0 & 17.0 & 58.4 & 0.0 & 0.6 & 0.3 \\
\hline Any friend & 12.2 & 6.1 & 17.3 & 59.3 & 4.1 & 18.1 & 17.3 \\
\hline Teachers/school & 8.8 & 7.0 & 10.0 & 12.6 & 5.3 & 8.9 & 4.1 \\
\hline Healthcare providers & 0.3 & 0.2 & 0.7 & 2.4 & 0.1 & 0.8 & 5.0 \\
\hline Youth/mahila mandal/NGO workers & 0.0 & 0.0 & 0.3 & 0.1 & 0.0 & 0.2 & 0.3 \\
\hline Any influential adult in the community & 9.0 & 7.3 & 10.6 & 14.5 & 5.4 & 9.6 & 8.4 \\
\hline Newspapers/books/magazines & 1.9 & 0.6 & 2.5 & 14.8 & 1.3 & 10.8 & 4.4 \\
\hline Radio/TV/internet & 0.3 & 0.3 & 0.2 & 4.9 & 0.3 & 4.2 & 2.0 \\
\hline Posters/billboards & 0.0 & 0.0 & 0.0 & 0.8 & 0.0 & 0.0 & 0.0 \\
\hline Any media & 2.2 & 0.9 & 2.6 & 18.3 & 1.5 & 13.7 & 5.8 \\
\hline Learned on his/her own as he/she grew up & 7.2 & 0.6 & NA & NA & NA & NA & NA \\
\hline Never received & 56.9 & 52.5 & 69.7 & 24.6 & 71.7 & 44.3 & 29.8 \\
\hline Does not remember/cannot say & 2.8 & 2.6 & 1.5 & 0.4 & 0.1 & 0.5 & 0.5 \\
\hline Number of respondents & 1,012 & 764 & 378 & 1,821 & 318 & 3,428 & 3,408 \\
\hline \multicolumn{8}{|c|}{ Urban (percent) } \\
\hline Parents & 17.9 & 41.6 & 3.7 & 3.0 & 11.7 & 14.0 & 19.6 \\
\hline Siblings & 3.7 & 10.9 & 2.1 & 0.8 & 4.0 & 6.9 & 7.1 \\
\hline Spouse/partner & NA & NA & 0.5 & 0.2 & 0.0 & 0.1 & 16.4 \\
\hline Siblings-in-law & 0.4 & 0.9 & 0.0 & 1.2 & 1.7 & 7.2 & 18.7 \\
\hline Other female family members & 0.1 & 6.0 & 1.0 & 0.8 & 4.4 & 12.7 & 25.8 \\
\hline Other male family members & 1.0 & 0.5 & 0.6 & 1.0 & 0.0 & 0.2 & 0.3 \\
\hline Any family member & 20.1 & 49.5 & 7.1 & 6.4 & 19.9 & 34.5 & 66.0 \\
\hline Female friends/neighbours & 0.0 & 1.6 & 0.5 & 1.6 & 2.5 & 18.6 & 16.0 \\
\hline Male friends/neighbours & 14.3 & 0.3 & 11.6 & 56.9 & 0.0 & 0.7 & 0.2 \\
\hline Any friend & 14.3 & 1.7 & 12.2 & 57.5 & 2.5 & 19.0 & 16.3 \\
\hline Teachers/school & 11.7 & 5.3 & 9.7 & 14.2 & 0.7 & 12.6 & 3.4 \\
\hline Healthcare providers & 1.0 & 0.0 & 1.3 & 3.3 & 1.1 & 1.3 & 6.3 \\
\hline Youth/mahila mandal/NGO workers & 0.0 & 0.0 & 0.0 & 0.2 & 0.0 & 0.3 & 0.1 \\
\hline Any influential adult in the community & 12.1 & 5.3 & 10.7 & 17.0 & 1.5 & 13.9 & 9.5 \\
\hline
\end{tabular}


Table 8.13 Cont.

\begin{tabular}{|c|c|c|c|c|c|c|c|}
\hline \multirow{2}{*}{ Sources of information } & $\begin{array}{c}\text { Boys } \\
(10-14)\end{array}$ & $\begin{array}{c}\text { Girls } \\
(10-14)\end{array}$ & $\begin{array}{c}\text { Boys } \\
(13-14)\end{array}$ & $\begin{array}{c}\text { Boys } \\
(15-19)\end{array}$ & $\begin{array}{c}\text { Girls } \\
(13-14)\end{array}$ & $\begin{array}{c}\text { Girls } \\
(15-19)\end{array}$ & $\begin{array}{c}\text { Married girls } \\
(15-19)\end{array}$ \\
\hline & \multicolumn{2}{|c|}{ A. Puberty } & \multicolumn{5}{|c|}{ B. Sexual and reproductive matters } \\
\hline Newspapers/books/magazines & 5.3 & 3.1 & 7.5 & 24.2 & 4.2 & 21.4 & 6.3 \\
\hline Radio/TV/internet & 1.3 & 2.7 & 1.5 & 13.7 & 2.3 & 15.5 & 6.2 \\
\hline Posters/billboards & 0.0 & 0.0 & 0.0 & 0.8 & 0.0 & 0.1 & 0.1 \\
\hline Any media & 6.4 & 5.4 & 9.0 & 32.2 & 5.9 & 30.4 & 10.7 \\
\hline Learned on his/her own as he/she grew up & 7.8 & 1.1 & NA & NA & NA & NA & NA \\
\hline Never received & 45.3 & 42.6 & 67.0 & 20.4 & 73.0 & 33.9 & 21.0 \\
\hline Does not remember/cannot say & 4.8 & 1.3 & 4.5 & 0.6 & 0.8 & 0.6 & 0.2 \\
\hline Number of respondents & 452 & 387 & 168 & 1,008 & 168 & 1,738 & 1,366 \\
\hline \multicolumn{8}{|c|}{ Rural (percent) } \\
\hline Parents & 12.5 & 29.8 & 0.7 & 3.2 & 10.5 & 10.9 & 13.1 \\
\hline Siblings & 2.7 & 11.2 & 0.0 & 1.1 & 5.1 & 5.8 & 4.9 \\
\hline Spouse/partner & NA & NA & 0.0 & 1.1 & 0.0 & 0.2 & 10.5 \\
\hline Siblings-in-law & 0.4 & 3.3 & 0.0 & 3.1 & 4.9 & 11.1 & 19.8 \\
\hline Other female family members & 0.6 & 5.5 & 0.2 & 1.9 & 5.3 & 18.2 & 29.0 \\
\hline Other male family members & 1.1 & 0.6 & 0.3 & 1.9 & 0.0 & 0.6 & 1.0 \\
\hline Any family member & 14.5 & 36.7 & 1.3 & 10.8 & 19.9 & 35.9 & 57.5 \\
\hline Female friends/neighbours & 0.3 & 6.6 & 0.7 & 2.6 & 4.3 & 17.7 & 17.2 \\
\hline Male friends/neighbours & 11.6 & 0.0 & 17.6 & 58.6 & 0.0 & 0.5 & 0.3 \\
\hline Any friend & 11.9 & 6.6 & 17.9 & 59.5 & 4.3 & 18.0 & 17.5 \\
\hline Teachers/school & 8.4 & 7.2 & 10.1 & 12.4 & 5.9 & 8.4 & 4.2 \\
\hline Healthcare providers & 0.2 & 0.3 & 0.6 & 2.3 & 0.0 & 0.7 & 4.9 \\
\hline Youth/mahila mandal/NGO workers & 0.0 & 0.0 & 0.3 & 0.1 & 0.0 & 0.2 & 0.3 \\
\hline Any influential adult in the community & 8.7 & 7.5 & 10.6 & 14.2 & 5.9 & 9.1 & 8.2 \\
\hline Newspapers/books/magazines & 1.5 & 0.3 & 1.9 & 13.7 & 0.9 & 9.5 & 4.1 \\
\hline Radio/TV/internet & 0.2 & 0.0 & 0.0 & 3.8 & 0.0 & 2.8 & 1.5 \\
\hline Posters/billboards & 0.0 & 0.0 & 0.0 & 0.8 & 0.0 & 0.0 & 0.0 \\
\hline Any media & 1.7 & 0.3 & 1.9 & 16.5 & 0.9 & 11.6 & 5.2 \\
\hline Learned on his/her own as he/she grew up & 7.2 & 0.6 & NA & NA & NA & NA & NA \\
\hline Never received & 58.2 & 53.7 & 70.0 & 25.1 & 71.5 & 45.5 & 30.8 \\
\hline Does not remember/cannot say & 2.5 & 2.8 & 1.1 & 0.4 & 0.0 & 0.5 & 0.6 \\
\hline Number of respondents & 560 & 377 & 210 & 813 & 150 & 1,690 & 2,042 \\
\hline
\end{tabular}

Notes: All Ns are unweighted. NA: not applicable.

learned on their own as they grew up. As seen above, differences by sex in leading sources of information on puberty were similar generally, but differed in one notable respect-boys were less likely than girls to list family members. Differences by residence in rural and urban areas were muted.

With regard to information on sexual and reproductive matters among adolescents aged 13 and above, findings show that large proportions of adolescents, particularly adolescents in ages 13-14 and unmarried older girls, that is, those in ages $15-19$, had never received information on sexual and reproductive matters $(70 \%$ and $72 \%$ of boys and girls of ages $13-14$, respectively; $25 \%, 44 \%$, and $30 \%$ of boys, unmarried girls, and married girls of ages $15-19$, respectively). 
Leading sources of information on sexual and reproductive matters differed between younger and older adolescents, between boys and girls, and, among older girls, between the unmarried and the married. Although friends constituted the leading sources for both younger and older boys, a larger proportion of 15-19-year-old boys than 13-14-year-old boys so reported ( $59 \%$ versus $17 \%$ ). They were also more likely to list the mass media ( $18 \%$ versus $3 \%$ ) and family members (10\% versus $2 \%$ ), while they were as likely as boys in ages $13-14$ to mention influential adults in the community ( $15 \%$ and $11 \%$, respectively) as important sources of information.

Among girls, while family members constituted the leading sources for both younger (13-14-year-old girls) and older girls, a larger proportion of unmarried and married older girls than younger girls so reported (36-58\% versus 20\%); they were also more likely to identify friends as an important source of information (17-18\% versus $4 \%$ ). More of unmarried older girls than younger girls and married older girls identified media as a source of information (14\% versus $2-6 \%$ ), and more of unmarried older girls than younger girls identified influential adults in the community $(10 \%$ versus $5 \%)$ as sources of information. Differences by sex were evident-boys, both younger and older, were more likely than girls to list friends. In contrast, girls were more likely than boys to list family members as a leading source. Among older girls, differences by marital status were evident; the married were more likely than the unmarried to mention family members, but less likely to list the mass media. Differences by residence in rural and urban areas were muted for the most part. Even so, more urban than rural married older girls identified family members, and more urban than rural adolescents mentioned any media as an important source of information.

Findings related to sources from whom or which adolescents would like to receive information are presented in Table 8.14. Younger adolescents (in ages 10-14) wanted to receive information on puberty from a family member (37\% of boys and $74 \%$ of girls), particularly parents (36\% of boys and $65 \%$ of girls), followed by influential adults in the community ( $32 \%$ of boys and $10 \%$ of girls), particularly teachers (30\% of boys and $10 \%$ of girls), and friends ( $17 \%$ of boys and $10 \%$ of girls). As with actual sources of information, fewer boys than girls wished to receive information from a family member, and more boys than girls preferred to receive such information from influential adults in the community and friends. Finally, as many as 16-22 percent of boys and girls reported that they did not want to receive such information. Differences by residence in rural or urban areas were narrow.

Adolescents aged 13 and above preferred to receive information on sexual and reproductive matters from an expanded list of sources and, as with actual sources of information, preferred channels also differed by age, sex, residence in rural or urban areas, and, among older girls, by marital status. Friends and influential adults in the community, mainly teachers and healthcare providers, constituted the most preferred channels to receive such information for both younger (in ages 13-14) and older boys, although the percentages who preferred to receive information from these channels varied. Thus, 26 percent of younger boys (in ages 13-14) and 53 percent of older boys preferred friends, and 36 percent and 39 percent, respectively, preferred influential adults in the community. Also preferred by considerable proportions of boys were family members and the media. Younger boys in ages 13-14 and older boys who preferred family members constituted 19 percent each and those who preferred the mass media constituted 8-15 percent. Substantial proportions of boys-22 percent and 12 percent of 13-14-year-old boys and older boys, respectively-reported that they did not want to receive such information.

Family members and friends constituted the most preferred channels to receive sexual and reproductive information for both younger girls (in ages 13-14) and unmarried and married older girls; 60 percent of 13-14-year-old girls, 67 percent of unmarried older girls, and 81 percent of married older girls preferred family members and 12 percent, 21 percent, and 15 percent, respectively, preferred friends. Some nine percent of 13-14-year-old girls and 16-17 percent of unmarried and married older girls preferred influential adults in the community, mainly healthcare providers. Hardly any 13-14-year-old girls or married older girls indicated a preference to receive such information from the mass media; however, nine percent of unmarried older girls identified media as a preferred source. As many as 28 percent of 13-14-year-old girls, 10 percent of unmarried older girls, and five percent of married older girls preferred not to receive information on sexual and reproductive matters.

Differences by sex were evident: while just one in five boys preferred family members, girls overwhelmingly preferred them; larger proportions of boys than girls preferred friends, influential adults in the community, and the media. Differences by marital status were modest among older girls for the most part. Even so, more married than unmarried older girls preferred family members ( $81 \%$ versus $67 \%$ ), while more unmarried than married older girls preferred to receive information on sexual and reproductive matters from friends (21\% versus $15 \%)$. Sources preferred by rural and urban adolescents largely mirrored the patterns described above for the combined sample. Even so, some 
differences were noted among older boys and unmarried older girls: fewer urban boys and unmarried older girls than their rural counterparts preferred family members, but more of them preferred media. Fewer urban boys (in ages 13-19), moreover, preferred friends.

\section{Table 8.14: Preferred sources of information on puberty and sexual and reproductive matters}

Percentage of adolescents by preferred sources of information on puberty and sexual and reproductive matters, according to residence, Bihar, 2016

\begin{tabular}{|c|c|c|c|c|c|c|c|}
\hline \multirow[t]{2}{*}{ Preferred sources of information } & $\begin{array}{c}\text { Boys } \\
(10-14)\end{array}$ & $\begin{array}{c}\text { Girls } \\
(10-14)\end{array}$ & $\begin{array}{c}\text { Boys } \\
\text { (13-14) }\end{array}$ & $\begin{array}{c}\text { Boys } \\
(15-19)\end{array}$ & $\begin{array}{c}\text { Girls } \\
(13-14)\end{array}$ & $\begin{array}{c}\text { Girls } \\
(15-19)\end{array}$ & $\begin{array}{l}\text { Married girls } \\
\qquad(15-19)\end{array}$ \\
\hline & \multicolumn{3}{|c|}{ A. Puberty } & \multicolumn{4}{|c|}{ B. Sexual and reproductive matters } \\
\hline \multicolumn{8}{|c|}{ Combined (percent) } \\
\hline Parents & 35.5 & 64.8 & 14.2 & 8.2 & 41.3 & 35.3 & 24.9 \\
\hline Siblings & 7.3 & 14.5 & 2.4 & 1.9 & 10.3 & 15.8 & 8.5 \\
\hline Spouse/partner & NA & NA & 0.5 & 2.5 & 0.6 & 3.1 & 27.3 \\
\hline Siblings-in-law & 0.8 & 4.7 & 3.3 & 6.7 & 12.1 & 22.1 & 25.1 \\
\hline Other female family members & 0.4 & 6.4 & 0.2 & 0.8 & 9.7 & 12.6 & 27.5 \\
\hline Other male family members & 0.8 & 0.0 & 0.6 & 0.9 & 0.0 & 0.1 & 0.6 \\
\hline Any family member & 37.3 & 74.4 & 19.3 & 19.0 & 59.9 & 66.8 & 81.4 \\
\hline Female friends/neighbours & 0.1 & 9.2 & 0.0 & 3.4 & 11.7 & 20.5 & 14.3 \\
\hline Male friends/neighbours & 17.3 & 0.2 & 25.5 & 51.1 & 0.6 & 0.4 & 0.1 \\
\hline Any friend & 17.4 & 9.5 & 25.5 & 53.4 & 12.3 & 20.8 & 14.5 \\
\hline Teachers/school & 29.9 & 9.8 & 29.5 & 22.7 & 6.8 & 8.3 & 1.9 \\
\hline Healthcare providers & 4.3 & 0.7 & 10.7 & 25.3 & 1.9 & 10.2 & 15.1 \\
\hline Youth/mahila mandal/NGO workers & 0.0 & 0.0 & 0.3 & 0.0 & 0.0 & 0.1 & 0.3 \\
\hline Any influential adult in the community & 32.1 & 10.0 & 35.5 & 38.6 & 8.7 & 17.4 & 16.3 \\
\hline Newspapers/books/magazines & 2.8 & 0.6 & 6.3 & 11.3 & 1.5 & 7.9 & 2.4 \\
\hline Radio/TV/internet & 1.6 & 0.1 & 3.0 & 5.3 & 0.2 & 1.9 & 1.0 \\
\hline Posters/billboards & 0.0 & 0.0 & 0.0 & 0.1 & 0.0 & 0.0 & 0.0 \\
\hline Any media & 4.2 & 0.7 & 7.6 & 15.3 & 1.6 & 9.2 & 3.1 \\
\hline Do not want to receive & 22.3 & 16.4 & 21.8 & 11.8 & 28.1 & 10.1 & 5.3 \\
\hline Cannot say & 9.6 & 1.8 & 10.6 & 4.0 & 4.9 & 1.7 & 1.0 \\
\hline Number of respondents & 1,012 & 764 & 378 & 1,821 & 318 & $\mathbf{3 , 4 2 8}$ & 3,408 \\
\hline \multicolumn{8}{|c|}{ Urban (percent) } \\
\hline Parents & 36.6 & 65.7 & 16.3 & 5.7 & 46.6 & 37.5 & 24.9 \\
\hline Siblings & 7.5 & 15.0 & 1.1 & 2.7 & 12.9 & 14.4 & 8.4 \\
\hline Spouse/partner & NA & NA & 0.0 & 1.5 & 1.0 & 2.3 & 30.7 \\
\hline Siblings-in-law & 0.5 & 2.1 & 0.0 & 2.5 & 3.2 & 11.9 & 22.0 \\
\hline Other female family members & 0.4 & 3.9 & 0.0 & 0.5 & 5.4 & 9.7 & 23.2 \\
\hline Other male family members & 0.8 & 0.2 & 1.2 & 0.8 & 0.0 & 0.4 & 0.3 \\
\hline Any family member & 40.0 & 77.2 & 17.5 & 11.6 & 61.6 & 59.6 & 80.1 \\
\hline
\end{tabular}


Table 8.14 Cont.

\begin{tabular}{|c|c|c|c|c|c|c|c|}
\hline \multirow[t]{2}{*}{ Preferred sources of information } & $\begin{array}{c}\text { Boys } \\
(10-14)\end{array}$ & $\begin{array}{c}\text { Girls } \\
(10-14)\end{array}$ & $\begin{array}{c}\text { Boys } \\
(13-14)\end{array}$ & $\begin{array}{c}\text { Boys } \\
(15-19)\end{array}$ & $\begin{array}{c}\text { Girls } \\
(13-14)\end{array}$ & $\begin{array}{c}\text { Girls } \\
(15-19)\end{array}$ & $\begin{array}{c}\text { Married girls } \\
(15-19)\end{array}$ \\
\hline & \multicolumn{3}{|c|}{ A. Puberty } & \multicolumn{4}{|c|}{ B. Sexual and reproductive matters } \\
\hline \multicolumn{8}{|c|}{ Urban (percent) } \\
\hline Female friends/neighbours & 1.1 & 5.6 & 0.4 & 1.2 & 5.3 & 17.7 & 11.0 \\
\hline Male friends/neighbours & 17.2 & 0.6 & 20.9 & 44.1 & 1.2 & 0.7 & 0.1 \\
\hline Any friend & 18.0 & 6.0 & 20.9 & 44.3 & 6.5 & 18.3 & 11.1 \\
\hline Teachers/school & 29.5 & 8.3 & 23.2 & 23.7 & 7.6 & 9.4 & 1.6 \\
\hline Healthcare providers & 6.0 & 2.0 & 9.0 & 26.5 & 5.8 & 13.4 & 17.5 \\
\hline Youth/mahila mandal/NGO workers & 0.0 & 0.0 & 0.0 & 0.4 & 0.0 & 0.2 & 0.3 \\
\hline Any influential adult in the community & 32.9 & 10.0 & 30.2 & 40.0 & 12.6 & 21.3 & 18.7 \\
\hline Newspapers/books/magazines & 7.3 & 3.1 & 8.8 & 14.9 & 4.7 & 12.7 & 3.6 \\
\hline Radio/TV/internet & 3.1 & 0.9 & 6.4 & 16.9 & 1.8 & 8.0 & 2.8 \\
\hline Posters/billboards & 0.1 & 0.0 & 0.0 & 0.2 & 0.0 & 0.0 & 0.0 \\
\hline Any media & 9.3 & 4.0 & 11.4 & 26.1 & 5.4 & 17.7 & 5.4 \\
\hline Do not want to receive & 21.3 & 14.8 & 21.3 & 16.0 & 24.0 & 9.1 & 3.6 \\
\hline Cannot say & 8.3 & 0.8 & 14.6 & 3.2 & 4.2 & 2.3 & 0.5 \\
\hline Number of respondents & 452 & 387 & 168 & 1,008 & 168 & 1,738 & 1,366 \\
\hline \multicolumn{8}{|c|}{ Rural (percent) } \\
\hline Parents & 35.3 & 64.7 & 14.0 & 8.5 & 40.6 & 35.1 & 24.9 \\
\hline Siblings & 7.2 & 14.4 & 2.5 & 1.8 & 9.9 & 16.0 & 8.5 \\
\hline Spouse/partner & NA & NA & 0.6 & 2.7 & 0.6 & 3.2 & 26.9 \\
\hline Siblings-in-law & 0.8 & 5.0 & 3.7 & 7.2 & 13.3 & 23.3 & 25.5 \\
\hline Other female family members & 0.4 & 6.7 & 0.2 & 0.8 & 10.3 & 13.0 & 28.0 \\
\hline Other male family members & 0.8 & 0.0 & 0.5 & 1.0 & 0.0 & 0.1 & 0.7 \\
\hline Any family member & 37.0 & 74.1 & 19.6 & 20.0 & 59.7 & 67.7 & 81.5 \\
\hline Female friends/neighbours & 0.0 & 9.7 & 0.0 & 3.7 & 12.6 & 20.8 & 14.7 \\
\hline Male friends/neighbours & 17.3 & 0.2 & 26.1 & 52.0 & 0.5 & 0.4 & 0.2 \\
\hline Any friend & 17.3 & 9.9 & 26.1 & 54.5 & 13.1 & 21.1 & 14.9 \\
\hline Teachers/school & 30.0 & 10.0 & 30.3 & 22.5 & 6.7 & 8.2 & 1.9 \\
\hline Healthcare providers & 4.1 & 0.6 & 10.9 & 25.2 & 1.4 & 9.8 & 14.8 \\
\hline Youth/mahila mandal/NGO workers & 0.0 & 0.0 & 0.3 & 0.0 & 0.0 & 0.1 & 0.4 \\
\hline Any influential adult in the community & 32.0 & 10.0 & 36.1 & 38.5 & 8.2 & 16.9 & 16.0 \\
\hline Newspapers/books/magazines & 2.3 & 0.3 & 6.0 & 10.8 & 1.1 & 7.3 & 2.3 \\
\hline Radio/TV/internet & 1.4 & 0.0 & 2.7 & 3.8 & 0.0 & 1.2 & 0.8 \\
\hline Posters/billboards & 0.0 & 0.0 & 0.0 & 0.1 & 0.0 & 0.0 & 0.0 \\
\hline Any media & 3.6 & 0.3 & 7.1 & 14.0 & 1.1 & 8.2 & 2.8 \\
\hline Do not want to receive & 22.4 & 16.6 & 21.9 & 11.3 & 28.7 & 10.3 & 5.5 \\
\hline Cannot say & 9.8 & 1.9 & 10.1 & 4.1 & 5.0 & 1.6 & 1.0 \\
\hline Number of respondents & 560 & 377 & 210 & 813 & 150 & 1,690 & 2,042 \\
\hline
\end{tabular}

Notes: All Ns are unweighted. NA: not applicable. 


\subsubsection{Access to family life education or sex education}

We gauged the extent of family life education or sex education of respondents aged 13 and above by asking whether they had received formal family life or sex education and, if so, the source of this education, the age at which they received such education, and the topics covered. Findings presented in Figure 8.5 show that only few adolescents-3-5 percent of boys and 11-22 percent of girls-had received family life or sex education in school or through special programmes sponsored by the government or NGOs. Girls were somewhat more likely than boys to have received such education. Marital status differences among older girls indicate that the unmarried were more likely than the married to have received such education (22\% versus $11 \%$ ). Differentials based on residence in rural or urban areas were narrow across all categories of adolescents, except for unmarried older girls, among whom more of urban than rural girls had received such education (33\% versus $21 \%)$.

Figure 8.5: Percentage of adolescents in ages 13-19 who had received family life or sex education, according to residence, Bihar, 2016

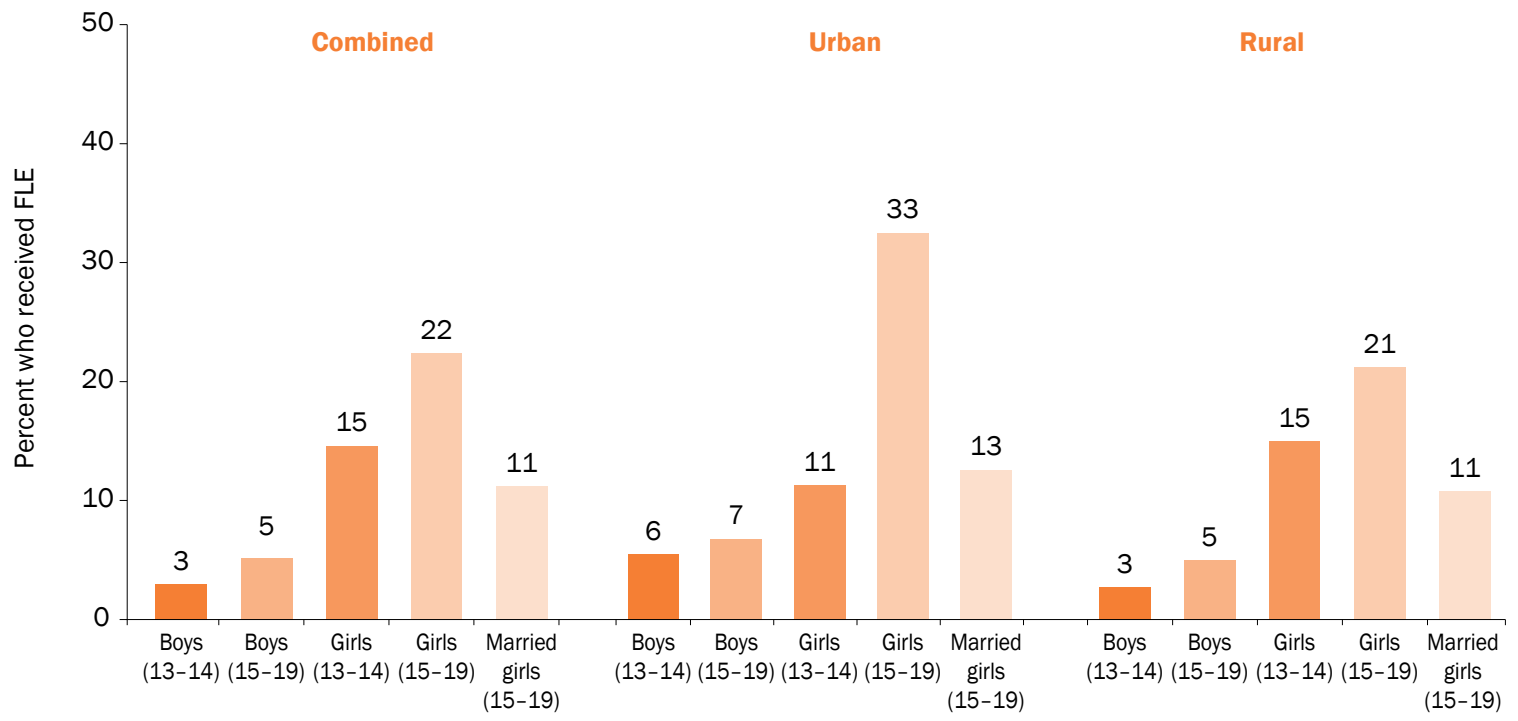

Table 8.15 presents findings, for older adolescents (in ages 15-19), on the sources of family life or sex education, the age at which the respondent first received such education, and the topics covered. ${ }^{2}$ Almost all adolescents who had received family life or sex education had received it in school or college (94\% of boys and $89-91 \%$ of girls). Differences by residence in rural or urban areas were evident among boys and unmarried girls; while fewer urban than rural boys had received family life or sex education in school or college (89\% versus $95 \%$ ), more urban than rural girls had received it in school or college (96\% versus $90 \%)$.

Among the older adolescents who reported their having received formal family life or sex education, the majority (44-49\%) had first received such education at ages 13-14 or at ages 15-17 (43-50\%), with a mean age of 14.314.6 years. Differences by sex show that girls were more likely than boys to have received such education before age 15 (55-56\% versus 48\%). Among girls, differences by marital status were muted. Differences by residence in rural or urban areas were also narrow.

The topics covered in the family life or sex education as recalled, on probing selected topics, by older adolescents who had received such education differed by sex of the respondent. The majority of boys who had received such education reported that it covered modes of HIV transmission and its prevention (93\%), while somewhat fewer girls so recalled ( $71 \%$ of unmarried girls and $65 \%$ of married girls). The topic that was reported by the largest proportion of girls was that on menstruation-reported by 87 percent of unmarried girls and 91 percent of married girls; in contrast, just 22 percent of boys reported exposure to any session on nocturnal emission. Some 50 percent of boys, 29 percent of unmarried girls, and 34 percent of married girls had attended sessions on pregnancy, and 58 percent of boys and

\footnotetext{
${ }^{2}$ Findings are not presented for younger adolescents because of the small number of younger adolescents who had received family life or sex
} education. 
35-36 percent of girls had attended sessions on relationships between boys and girls. Differences by residence in rural or urban areas show that urban boys were less likely than rural boys to have been exposed to sessions on pregnancy (36\% versus 53\%) and relationships between boys and girls (41\% versus $61 \%)$. In contrast, urban unmarried girls were more likely than rural unmarried girls to report sessions on HIV transmission and prevention (77\% versus $70 \%$ ), pregnancy (34\% versus 28\%), and relationships between boys and girls (43\% versus 35\%). Among married girls, differences were modest, except that fewer urban than rural girls had attended sessions on pregnancy (26\% versus $35 \%)$.

\section{Table 8.15: Access to family life or sex education}

Percentage of adolescents in ages 15-19 who had received formal family life or sex education reporting experiences related to the education received, according to residence, Bihar, 2016

\begin{tabular}{|c|c|c|c|}
\hline Exposure indicators & $\begin{array}{c}\text { Boys } \\
(15-19)\end{array}$ & $\begin{array}{c}\text { Girls } \\
(15-19)\end{array}$ & $\begin{array}{l}\text { Married girls } \\
\qquad(15-19)\end{array}$ \\
\hline \multicolumn{4}{|l|}{ Combined (percent) } \\
\hline \multicolumn{4}{|l|}{ Source of family life or sex education } \\
\hline NGO programme/camp & 1.2 & 4.0 & 2.9 \\
\hline Government programme/camp & 4.7 & 5.6 & 8.6 \\
\hline School/college & 94.1 & 90.6 & 88.9 \\
\hline \multicolumn{4}{|l|}{ Age when the respondent received family life or sex education for the first time } \\
\hline $11-12$ & 0.8 & 5.9 & 12.4 \\
\hline $13-14$ & 47.2 & 48.6 & 43.8 \\
\hline $15-17$ & 50.0 & 45.0 & 42.5 \\
\hline $18-19$ & 2.0 & 0.5 & 1.4 \\
\hline Mean age at which the respondent first received family life/sex education & 14.6 & 14.3 & 14.3 \\
\hline \multicolumn{4}{|l|}{ Topics covered } \\
\hline Modes of HIV transmission or ways of preventing HIV infection & 92.7 & 71.2 & 64.6 \\
\hline Menstruation/nocturnal emission & 21.8 & 86.6 & 90.5 \\
\hline Pregnancy & 50.3 & 28.6 & 34.0 \\
\hline Relationship between boys and girls & 58.0 & 36.3 & 35.2 \\
\hline Respondents who had received family life or sex education & 109 & 883 & 372 \\
\hline \multicolumn{4}{|l|}{ Urban (percent) } \\
\hline \multicolumn{4}{|l|}{ Source of family life or sex education } \\
\hline NGO programme/camp & 8.2 & 2.9 & 0.3 \\
\hline Government programme/camp & 2.5 & 2.6 & 7.7 \\
\hline School/college & 89.2 & 95.5 & 92.4 \\
\hline \multicolumn{4}{|l|}{ Age at which the respondent first received family life or sex education } \\
\hline $11-12$ & 5.7 & 6.7 & 10.5 \\
\hline $13-14$ & 43.2 & 52.0 & 43.2 \\
\hline $15-17$ & 51.1 & 40.5 & 46.3 \\
\hline $18-19$ & 0.0 & 0.8 & 0.0 \\
\hline Mean age at which the respondent first received family life or sex education & 14.5 & 14.2 & 14.3 \\
\hline
\end{tabular}


Table 8.15 Cont.

\begin{tabular}{|c|c|c|c|}
\hline Exposure indicators & $\begin{array}{c}\text { Boys } \\
(15-19)\end{array}$ & $\begin{array}{c}\text { Girls } \\
(15-19)\end{array}$ & $\begin{array}{c}\text { Married girls } \\
\text { (15-19) }\end{array}$ \\
\hline \multicolumn{4}{|l|}{ Topics covered } \\
\hline Modes of HIV transmission or ways of preventing HIV infection & 88.8 & 76.9 & 63.2 \\
\hline Menstruation/nocturnal emission & 19.0 & 89.8 & 86.1 \\
\hline Pregnancy & 36.0 & 34.1 & 26.0 \\
\hline Relationship between boys and girls & 40.7 & 43.1 & 35.8 \\
\hline Respondents who had received family life or sex education & 74 & 528 & 153 \\
\hline \multicolumn{4}{|l|}{ Rural (percent) } \\
\hline \multicolumn{4}{|l|}{ Source of family life or sex education } \\
\hline NGO programme/camp & $(0.0)$ & 4.2 & 3.3 \\
\hline Government programme/camp & $(5.1)$ & 6.1 & 8.7 \\
\hline School/college & (94.9) & 89.7 & 88.5 \\
\hline \multicolumn{4}{|l|}{ Age at which the respondent first received family life or sex education } \\
\hline $11-12$ & $(0.0)$ & 5.7 & 12.6 \\
\hline $13-14$ & $(47.9)$ & 47.9 & 43.8 \\
\hline $15-17$ & $(49.8)$ & 45.9 & 42.0 \\
\hline $18-19$ & $(2.3)$ & 0.4 & 1.5 \\
\hline Mean age at which the respondent first received family life or sex education & (14.7) & 14.3 & 14.3 \\
\hline \multicolumn{4}{|l|}{ Topics covered } \\
\hline Modes of HIV transmission or ways of preventing HIV infection & $(93.4)$ & 69.8 & 64.9 \\
\hline Menstruation/nocturnal emission & $(22.3)$ & 86.0 & 91.1 \\
\hline Pregnancy & $(52.8)$ & 27.7 & 35.1 \\
\hline Relationship between boys and girls & $(61.0)$ & 35.1 & 35.1 \\
\hline Respondents who had received family life or sex education & 35 & 355 & 219 \\
\hline
\end{tabular}

Notes: All Ns are unweighted. () Based on 25-49 unweighted cases.

Table 8.16 presents differentials in exposure to family life or sex education by selected background characteristics among adolescents aged 13 and above. Findings show that differences by age (among adolescents in ages 15-19) were narrow in the proportions of adolescents who had received family life or sex education. Differences by religion were narrow among boys; among older girls, however, Hindu girls were more likely than Muslim girls to have received such education ( $24 \%$ versus $15 \%$ among the unmarried, $12 \%$ versus $7 \%$ among the married). Caste-wise differentials show that adolescents belonging to general castes were more likely than those belonging to other castes to have received such education across all categories of adolescents, except for younger girls in ages 13-14. Not surprisingly, exposure to family life education increased among the better educated, those who were enrolled in school/college at the time of the interview, and those belonging to economically better-off households. Finally, it was by and large greater among adolescents whose mother had completed 10 or more years than those whose mother had not, except for adolescents in ages 13-14. 
Table 8.16: Exposure to family life or sex education by selected background characteristics

Percentage of adolescents in ages 13-19 who had received formal family life or sex education by selected background characteristics, Bihar, 2016

\begin{tabular}{|c|c|c|c|c|c|}
\hline Background characteristics (percent) & $\begin{array}{c}\text { Boys } \\
(13-14)\end{array}$ & $\begin{array}{c}\text { Boys } \\
(15-19)\end{array}$ & $\begin{array}{c}\text { Girls } \\
(13-14)\end{array}$ & $\begin{array}{c}\text { Girls } \\
(15-19)\end{array}$ & $\begin{array}{c}\text { Married girls } \\
(15-19)\end{array}$ \\
\hline \multicolumn{6}{|l|}{ Age } \\
\hline $13-14$ & 3.0 & NA & 14.6 & NA & NA \\
\hline $15-17$ & NA & 5.1 & NA & 22.0 & 11.2 \\
\hline $18-19$ & NA & 5.4 & NA & 23.8 & 10.9 \\
\hline \multicolumn{6}{|l|}{ Religion $^{1}$} \\
\hline Hindu & 3.2 & 4.6 & 13.9 & 23.6 & 11.5 \\
\hline Muslim & 1.8 & 8.9 & 18.3 & 14.8 & 7.0 \\
\hline \multicolumn{6}{|l|}{ Caste $^{2}$} \\
\hline SC & 0.2 & 1.4 & 14.8 & 20.9 & 8.9 \\
\hline OBC & 2.1 & 6.1 & 14.0 & 20.8 & 11.3 \\
\hline General $^{3}$ & 9.9 & 6.7 & 18.1 & 31.5 & 15.7 \\
\hline \multicolumn{6}{|l|}{ Years of schooling completed } \\
\hline None $^{4}$ & * & 0.0 & * & 0.0 & 0.1 \\
\hline $1-4$ & $(0.0)$ & 0.0 & $(0.4)$ & 0.0 & 2.0 \\
\hline $5-7$ & 3.4 & 0.0 & 10.3 & 12.6 & 3.1 \\
\hline $8-9$ & 3.2 & 6.1 & 28.4 & 23.1 & 18.1 \\
\hline $10-11$ & NA & 6.9 & NA & 33.4 & 24.2 \\
\hline 12 and above & NA & 8.1 & NA & 39.1 & 30.9 \\
\hline \multicolumn{6}{|l|}{ Current schooling status ${ }^{5}$} \\
\hline Yes & 3.3 & 6.3 & 16.2 & 28.9 & 29.2 \\
\hline No & * & 0.7 & * & 9.9 & 10.2 \\
\hline \multicolumn{6}{|c|}{ Paid work in the 12 months prior to the interview } \\
\hline Yes & $(0.0)$ & 1.9 & $(0.6)$ & 20.0 & 7.5 \\
\hline No & 3.3 & 6.3 & 16.5 & 22.9 & 11.4 \\
\hline \multicolumn{6}{|l|}{ Wealth quintile } \\
\hline First & $(0.0)$ & 1.2 & $(9.3)$ & 7.2 & 4.0 \\
\hline Second & 0.0 & 5.1 & $(6.2)$ & 16.9 & 8.4 \\
\hline Third & 0.0 & 5.3 & 10.5 & 18.7 & 9.0 \\
\hline Fourth & 1.2 & 4.2 & 22.5 & 19.7 & 12.6 \\
\hline Fifth & 11.5 & 7.3 & 18.1 & 36.1 & 19.1 \\
\hline \multicolumn{6}{|c|}{ Mother's education (in years of schooling completed) } \\
\hline None $^{4}$ & 1.0 & 3.9 & 15.9 & 17.5 & 9.4 \\
\hline $1-7$ & $(11.4)$ & 9.1 & (7.1) & 32.7 & 12.3 \\
\hline $8-9$ & $(2.8)$ & 7.1 & * & 35.7 & 22.7 \\
\hline 10 and above & 9.8 & 11.1 & $(17.7)$ & 37.2 & 25.8 \\
\hline Total & 3.0 & 5.2 & 14.6 & 22.4 & 11.0 \\
\hline
\end{tabular}

Notes: *Percentage not shown as this was based on fewer than 25 unweighted cases. () Based on 25-49 unweighted cases. NA; not applicable; OBC: other backward caste; SC: scheduled caste; ST: scheduled tribe. ${ }^{1}$ Percentages not shown for those belonging to other religions as less than one percent of surveyed adolescents belonged to other religions. ${ }^{2}$ Percentages not shown for those belonging to STs as less than one percent of surveyed adolescents belonged to STs. ${ }^{3}$ Includes all those not belonging to SCs, STs, or OBCs. ${ }^{4}$ Includes non-literate and literate with no formal schooling. ${ }^{5}$ Percentages not shown for adolescents who were pursuing their education through distance education courses at the time of interview or those who never went to school. 
Figure 8.6 compares the extent to which older adolescents who had received family life or sex education differed with regard to in-depth knowledge of selected sexual and reproductive health matters from those who had not (see Sections 8.1.1, 8.1.3, 8.1.4, and 8.1.5 for details of items considered in each summary measure).

Figure 8.6: Percentage of adolescents in ages 15-19 reporting knowledge of selected sexual and reproductive matters according to whether they had or had not received family life or sex education, Bihar, 2016

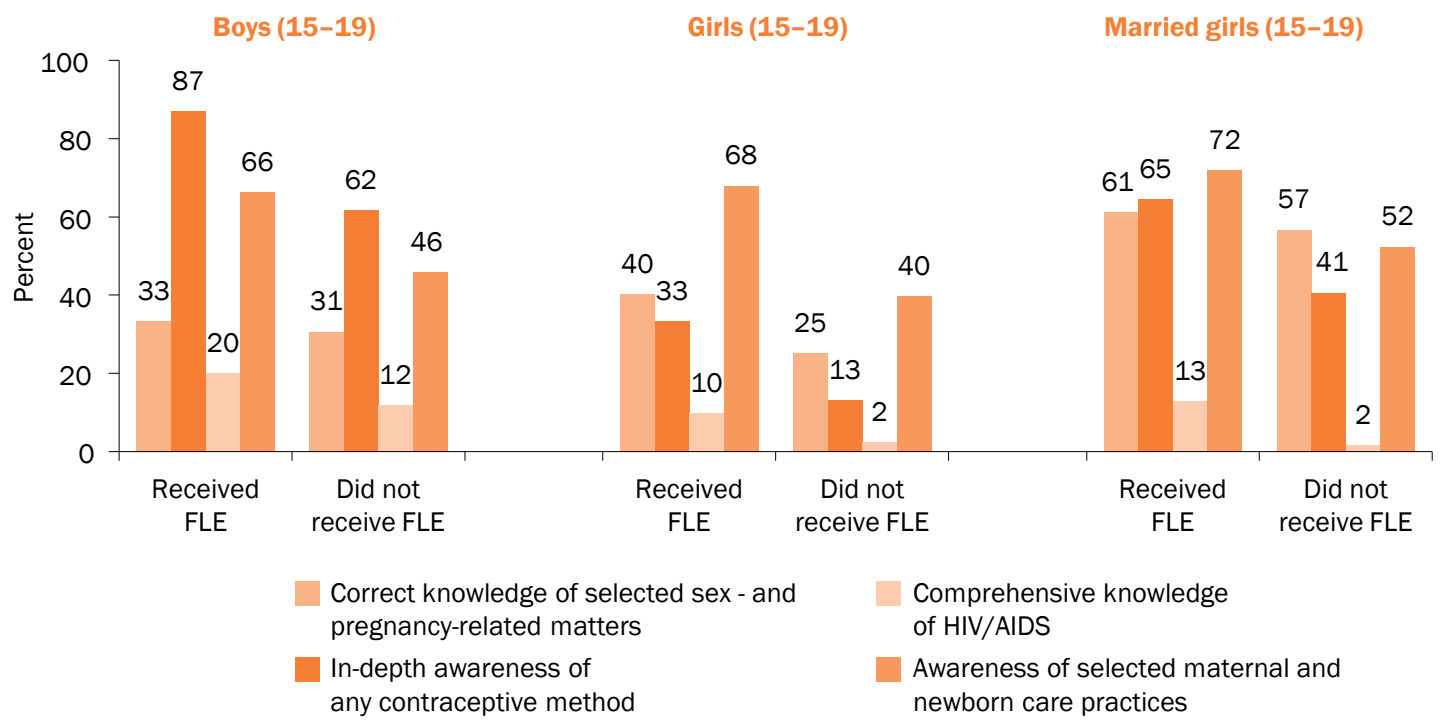

Findings show that adolescents who had received family life or sex education were more likely than those who had not to report in-depth awareness of sex and pregnancy matters, contraception, comprehensive awareness of HIV/AIDS, and maternal and newborn care practices, although the differences were narrow among boys and married girls with respect to awareness of sex and pregnancy matters. 



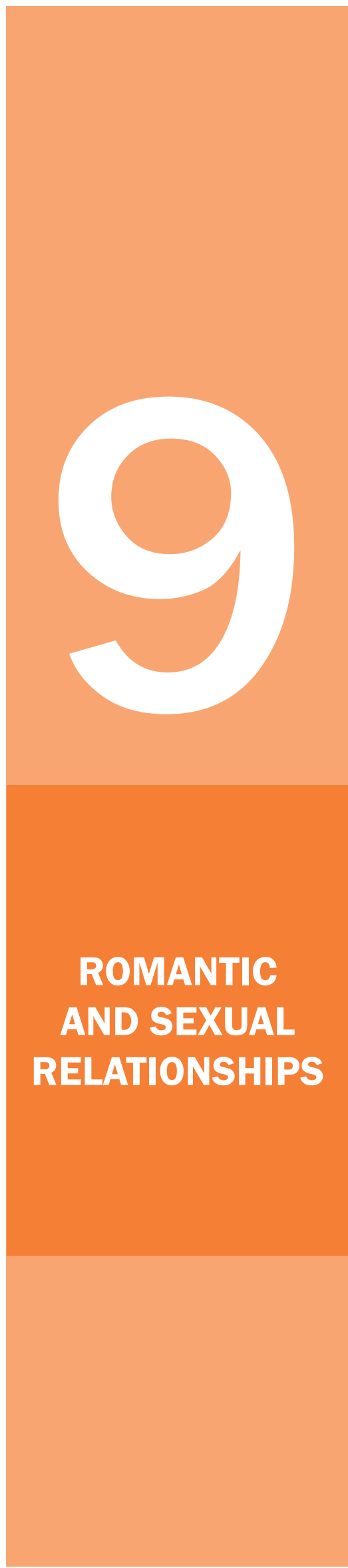

\section{A Snapshot}

Despite strict norms, opportunities exist for adolescents to form romantic

relationships and to engage in premarital sexual relationships: ${ }^{1}$

- $19 \%$ of older boys

- $14 \%$ of unmarried older girls, and

- $13 \%$ of married older girls reported a romantic relationship
- $14 \%$ of older boys and

- $6 \%$ each of unmarried and married older girls reported a premarital sexual experience ${ }^{2}$

Sexual experiences before marriage are characterised by risky practices:

- $22 \%$ of older boys

- $29 \%$ of unmarried older girls, and

- $28 \%$ of married older girls who had engaged in premarital sex had engaged in sex before age 15

- $20 \%$ of older boys

- $8 \%$ of unmarried older girls, and

- $1 \%$ of married older girls who had engaged in premarital sex reported consistent condom use
- $30 \%$ of older boys

- $5 \%$ of unmarried older girls, and

- $27 \%$ of married older girls who had engaged in premarital sex had engaged in sex with multiple partners

- $2 \%$ of older boys

- $7 \%$ of unmarried older girls, and

- $14 \%$ of married older girls who had engaged in premarital sex reported a premarital pregnancy

A significant number of adolescents had experienced non-consensual sexual experiences:

- $1 \%$ of younger boys

- $2 \%$ of older boys

- $7 \%$ of younger girls

- $11 \%$ of unmarried older girls, and

- $8 \%$ of married older girls had experienced non-consensual sexual touch

A significant number of adolescents had experienced non-consensual sexual experiences:

- $3 \%$ of younger boys and

- $19 \%$ of older boys had verbally harassed a girl in a sexual way
- $4 \%$ of unmarried older girls and

- $3 \%$ of married older girls had experienced forced sex

$5 \%$ of older boys had perpetrated forced sex on a girl

Differences between rural and urban adolescents were narrow for most indicators, except that more rural than urban boys had experienced sex

${ }^{1}$ Only older adolescents were asked about romantic and sexual experiences, while both younger and older adolescents were asked about non-consensual sexual experiences.

${ }^{2}$ Reported in the course of face-to-face interview or anonymously via a sealed envelope method

- $1 \%$ of younger boys and

- $3 \%$ of older boys had perpetrated non-consensual sexual touch on a girl

\section{POPULATION
$\begin{aligned} & \text { COUNCIL } \\ & \text { Ideas. Evidence. Impact. }\end{aligned}$ \\ POPULATION
$\begin{aligned} & \text { COUNCIL } \\ & \text { Ideas. Evidence. Impact. }\end{aligned}$

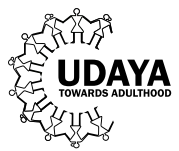


As part of its survey of young people, the Youth in India: Situation and Needs 2006-07 study sought information on the sexual experiences of youth who were in the ages 15-24. Its findings presented for the first time (at subnational level) the extent of premarital sexual relationships among adolescents. Findings showed that some 15 percent of boys and four percent of girls had experienced premarital sex (IIPS and Population Council, 2010) and that considerable premarital interaction and romantic relations existed between boys and girls. In 2012, in Rajasthan, a cross-sectional study of unmarried adolescents in ages 15-19 in the same sampling clusters covered in the 2006-07 Youth Study revealed a considerable increase in the percentage of boys and girls who had experienced romantic and sexual relationships (Jejeebhoy and Acharya, 2014). Findings from these studies and others highlight that despite socio-cultural taboos, adolescents and youth in India do find opportunities to socialise and form romantic relationships and also to engage in premarital sex with a range of partners and in a variety of situations (Abraham, 2002; Abraham and Kumar, 1999; Alexander et al., 2006a; 2006b; Awasthi, Nichter, and Pande, 2000). This survey under UDAYA probed, in a largely similar way as in 2007 and 2012, the extent of romantic and sexual experiences, including those in the context of romantic partnerships and in other contexts, among adolescents. This chapter describes findings relating to the romantic and sexual relationships of the surveyed adolescents.

\subsection{Questionnaire module on romantic and sexual relationships}

We used the module on premarital romantic and sexual relationships that was developed for the 2007 Youth Study (IIPS and Population Council, 2010) for this survey, but with a few modifications. It needs to be mentioned that this module was administered to only older adolescents and that married girls were asked about romantic and sexual relationships that they may have had before their marriage. To assess experiences in early adolescence, we probed respondents about the age at which they had initiated various activities.

In order to explore the extent of opposite-sex romantic relationships, adolescents were asked a single question, which was whether or not they had ever had a boyfriend or girlfriend. All respondents who had reported a romantic partner were then asked questions regarding the nature of the relationship and the extent of physical contact experienced in the relationship. We posed questions relating to physical intimacy in the form of a continuum, which started with questions on hugging and extended to questions on sexual relations. Thus, the instrument sought to ask potentially sensitive or embarrassing questions in a graded way, which thereby also enabled the interviewer to build a rapport with the respondent. The interviewer asked detailed questions concerning the nature of the relationship with the first romantic sexual partner as well as the most recent, if they had reported more than one partner. Interviewers asked questions about the age at initiation of their first romantic sexual experience; contraceptive use at first sex and later sexual encounters as well as the contraceptive method used; and the extent to which sex was consensual at first sex and in later sexual encounters. For those who reported more than one romantic sexual partner, questions on contraceptive use and consensual sex were repeated with respect to the last romantic sexual partner.

Interviewers sought to elicit information on sexual relations in other situations and with other partners, including with sex workers and older married girls or women (for boys), casual sex, forced sex (experienced by both boys and girls and perpetrated by boys), and exchange sex. In each case, interviewers asked those who reported such relationships to indicate their age when such a relationship was experienced for the first time, condom use at last sex and in all sexual encounters with the partner, and sexual encounters in the year preceding the interview in such relationships.

Additionally, recognising the reluctance of adolescents to disclose sexual experiences in a face-to-face interview, at the conclusion of this interview, we gave all respondents two blank cards to indicate their answers to questions on any sexual experience with an opposite-sex person and questions on forced sex that they had experienced with (for girls) or perpetrated on (for boys) an opposite-sex person. Both girls and boys were asked, 'Have you ever had sex with anyone?', while married girls were asked, 'Did you ever have sex before marriage?'. In addition, girls were asked, 'Has anybody ever forced you to have sex?', while married girls were asked, 'Did anybody force you to have sex before marriage?'. Correspondingly, boys were asked, 'Have you ever forced anyone to have sex with you?'. All respondents were instructed to mark the card with a ' $\sqrt{ }$ ' or a ' $x$ ' representing 'Yes' or 'No', according to their experience, place the cards in an envelope, seal it, and return it to the interviewer. Interviewers informed respondents that the envelope would not be opened in the field and that only the principal investigators would be able to link the information provided in the envelope with the information in the main body of the questionnaire. 
In order to capture same-sex relationships among older adolescents, we asked boys whether they ever had been romantically or sexually attracted to other boys and whether they ever had been in an intimate relationship with other boys, that is, kissing on the lips, touching private parts, and engaging in sexual intercourse. Girls were similarly asked whether they ever had been romantically or sexually attracted to other girls and whether they ever had been in an intimate relationship with other girls, that is, kissing on the lips and touching private parts.

In addition, efforts were made to ensure that adolescents were comfortable revealing sensitive behaviours. The interviewers were young, and they were trained to build rapport, discuss sensitive experiences in empathetic and matter-of-fact ways, and generally make the respondents feel comfortable about the topics to be discussed during the interview. As far as possible, interviews were held at times and places that assured the respondent maximum confidentiality. In cases in which family members attempted to participate in or overhear the interview, another interviewer was called upon to conduct an informal discussion or interview with the other family members so as to ensure privacy for the respondent's interview. Nevertheless, we acknowledge that ensuring privacy may have been a problem, especially in low-income urban settings characterised by cramped housing conditions and that some adolescents may not have felt entirely at ease despite the extensive efforts made to ensure confidentiality. We therefore acknowledge that romantic and sexual experiences, notably among unmarried older girls, and nonconsensual sexual experiences among younger and older adolescents, particularly among younger boys, may have been under-reported in the survey, and that the percentages presented here may be interpreted as conservative estimates.

\subsection{Romantic relationships among older adolescents}

In this section, we present findings on the prevalence of opposite-sex romantic relationships among older adolescents and a profile of those who engaged in such relationships. The section also describes the extent of physical contact experienced and characteristics of sexual experiences in these relationships.

\subsubsection{Prevalence of romantic relationships}

Findings for older adolescents, presented in Table 9.1, show that opportunities to form romantic relationships did exist (for some adolescents) irrespective of sex and residence in rural or urban areas. Some 19 percent of boys and 13-14 percent of girls reported a romantic relationship. Furthermore, four percent of boys and less than one percent of girls reported more than one romantic partner. Differences in the prevalence of romantic relationships by residence in rural or urban areas were negligible, although married girls in urban areas were slightly more likely than rural girls to report premarital romantic relationships (17\% versus $12 \%$ ).

\section{Table 9.1: Premarital romantic relationships of older adolescents}

Percentage of adolescents in ages 15-19 reporting a premarital romantic relationship, according to residence, Bihar, 2016

\begin{tabular}{|c|c|c|c|}
\hline Premarital romantic relationships & $\begin{array}{c}\text { Boys } \\
(15-19)\end{array}$ & $\begin{array}{c}\text { Girls } \\
(15-19)\end{array}$ & $\begin{array}{l}\text { Married girls } \\
\qquad(15-19)\end{array}$ \\
\hline \multicolumn{4}{|c|}{ Combined (percent) } \\
\hline Reported a romantic partner & 19.3 & 13.6 & 12.5 \\
\hline Reported more than one romantic partner & 3.6 & 0.4 & 0.5 \\
\hline Number of respondents & 1,821 & 3,428 & 3,408 \\
\hline \multicolumn{4}{|c|}{ Urban (percent) } \\
\hline Reported a romantic partner & 19.2 & 15.7 & 16.8 \\
\hline Reported more than one romantic partner & 4.6 & 0.7 & 0.6 \\
\hline Number of respondents & 1,008 & 1,738 & 1,366 \\
\hline
\end{tabular}


Table 9.1 Cont.

\begin{tabular}{|c|c|c|c|}
\hline Premarital romantic relationships & $\begin{array}{c}\text { Boys } \\
(15-19)\end{array}$ & $\begin{array}{c}\text { Girls } \\
(15-19)\end{array}$ & $\begin{array}{l}\text { Married girls } \\
\text { (15-19) }\end{array}$ \\
\hline \multicolumn{4}{|c|}{ Rural (percent) } \\
\hline Reported a romantic partner & 19.3 & 13.4 & 12.0 \\
\hline Reported more than one romantic partner & 3.5 & 0.3 & 0.5 \\
\hline Number of respondents & 813 & 1,690 & 2,042 \\
\hline
\end{tabular}

Note: All Ns are unweighted.

Table 9.2 presents the percentage of surveyed older adolescents reporting romantic relationships by background characteristics. It should be noted that such characteristics as age, educational level achieved, schooling status, work status, and household economic status reflect the situation of adolescents at the time of the interview and not necessarily at the time when romantic relationships were formed. As seen in Table 9.2, age profiles indicate a positive association between age and the formation of romantic relationships among boys, but not among girls-the percentage of boys who reported a romantic relationship increased from 15 percent among those in ages 15-17 to 31 percent among those in ages 18-19. Differentials by religion were negligible among boys and unmarried girls; however, somewhat more Muslim married girls compared with Hindu married girls reported a romantic partner (17\% versus $12 \%)$. Differentials by caste were narrow across all three categories of older adolescents. The association between educational level and reporting of a romantic relationship was generally positive except for a decline among married girls who had completed Classes 12 and above. However, no association was observed with current enrolment status across all three categories of older adolescents. We also observed that boys and unmarried girls who were engaged in paid work in the year preceding the interview were more likely than those who were not to report involvement in a romantic relationship; no such association was observed among married girls. Differentials by household economic status were erratic, except for, married girls among whom the proportion reporting a premarital romantic relationship increased with household economic status. Finally, differentials by mother's education were inconsistent.

\section{Table 9.2: Prevalence of premarital romantic relationships among older adolescents by selected background} characteristics

Percentage of adolescents in ages 15-19 reporting a premarital romantic relationship by selected background characteristics, Bihar, 2016

\begin{tabular}{lccc}
\hline Background characteristics (percent) & $\begin{array}{c}\text { Boys } \\
(15-19)\end{array}$ & $\begin{array}{c}\text { Girls } \\
(15-19)\end{array}$ & $\begin{array}{c}\text { Married girls } \\
(15-19)\end{array}$ \\
\hline Age & & & 12.3 \\
$15-17$ & 15.1 & 12.7 & 12.6 \\
$18-19$ & 30.8 & 17.0 & \\
Religion $^{1}$ & & & 11.8 \\
Hindu & 19.4 & 13.4 & 17.2 \\
Muslim & 18.6 & 15.2 & 13.7 \\
Caste $^{2}$ & & & 11.6 \\
SC & 19.2 & 16.0 & 13.4 \\
OBC & 18.7 & 12.8 & Cont. \\
General & 3
\end{tabular}


Table 9.2 Cont.

\begin{tabular}{|c|c|c|c|}
\hline Background characteristics (percent) & $\begin{array}{c}\text { Boys } \\
(15-19)\end{array}$ & $\begin{array}{c}\text { Girls } \\
(15-19)\end{array}$ & $\begin{array}{c}\text { Married girls } \\
(15-19)\end{array}$ \\
\hline \multicolumn{4}{|l|}{ Completed years of schooling } \\
\hline None $^{4}$ & 9.4 & 9.8 & 10.5 \\
\hline $1-4$ & 8.9 & 11.2 & 10.1 \\
\hline $5-7$ & 12.5 & 10.7 & 9.5 \\
\hline $8-9$ & 17.8 & 12.9 & 13.3 \\
\hline $10-11$ & 23.8 & 17.1 & 19.5 \\
\hline 12 and above & 34.9 & 17.5 & 14.3 \\
\hline \multicolumn{4}{|l|}{ Current schooling status ${ }^{5}$} \\
\hline Yes & 19.3 & 13.4 & 13.7 \\
\hline No & 19.7 & 14.4 & 13.0 \\
\hline \multicolumn{4}{|c|}{ Paid work in the 12 months prior to the interview } \\
\hline Yes & 25.8 & 17.6 & 15.0 \\
\hline No & 17.0 & 12.8 & 12.1 \\
\hline \multicolumn{4}{|l|}{ Wealth quintile } \\
\hline First & 11.5 & 13.6 & 9.4 \\
\hline Second & 19.7 & 13.0 & 11.8 \\
\hline Third & 22.5 & 12.2 & 10.4 \\
\hline Fourth & 18.2 & 14.2 & 13.8 \\
\hline Fifth & 19.6 & 14.5 & 16.1 \\
\hline \multicolumn{4}{|c|}{ Mother's education (in years of schooling completed) } \\
\hline None $^{4}$ & 18.8 & 14.1 & 12.0 \\
\hline $1-7$ & 26.5 & 15.0 & 14.5 \\
\hline $8-9$ & 14.8 & 8.0 & 14.0 \\
\hline 10 and above & 20.1 & 14.0 & 14.5 \\
\hline Total & 19.3 & 13.6 & 12.5 \\
\hline
\end{tabular}

Notes: OBC: other backward caste; SC: scheduled caste; ST: scheduled tribe. ${ }^{1}$ Percentages not shown for those belonging to other religions as less than one percent of surveyed adolescents belonged to other religions. ${ }^{2}$ Percentages not shown for those belonging to STs as less than one percent of surveyed adolescents belonged to STs. ${ }^{3}$ Includes all those not belonging to SCs, STs, or OBCs. ${ }^{4}$ Includes non-literate and literate with no formal schooling. ${ }^{5}$ Percentages not shown for adolescents who were pursuing their education through distance education courses at the time of interview or those who never went to school.

\subsubsection{Physical intimacy and sex with a romantic partner}

Older adolescents who reported a romantic relationship were asked whether they had engaged in intimate behaviours with their romantic partner. These ranged from behaviours reflecting minimal physical intimacy (hugging) to those reflecting increased physical intimacy (kissing on the lips) and, lastly, engaging in sexual relations. Findings, presented in Figure 9.1, refer to older adolescents' experiences of physical intimacy with any of their romantic partners.

While the majority of older adolescents had hugged their romantic partner ( $74 \%$ of boys and $52-55 \%$ of girls), progressively fewer reported more intimate behaviours, such as kissing their romantic partner on the lips (64\% of boys and $43-47 \%$ of girls) and engaging in sexual relations with their partner (41\% of boys and $17-18 \%$ of girls). As seen above, differences by sex in physical intimacy were evident. Among girls, differences by marital status were narrow. 
Differences in reporting of physical intimacy by residence in rural or urban areas were notable with regard to boys, among whom more rural than urban respondents reported each of the behaviours. Thus, 76 percent of rural boys reported having hugged their girlfriend as compared to 60 percent of urban boys and 43 percent of rural boys had sex with their romantic partner compared with 21 percent of their urban counterparts. Differences were, in contrast, mild among girls, except that unmarried girls in rural areas were more likely than their urban counterparts to have hugged their boyfriend (44\% versus $37 \%$ ) and both unmarried and married girls in rural areas were more likely than urban girls to report sex with their romantic partner (18-19\% versus $11-12 \%)$.

Figure 9.1: Percentage of adolescents in ages 15-19 reporting a premarital romantic relationship by experiences of physical intimacy and sex with their romantic partner, according to residence, Bihar, 2016

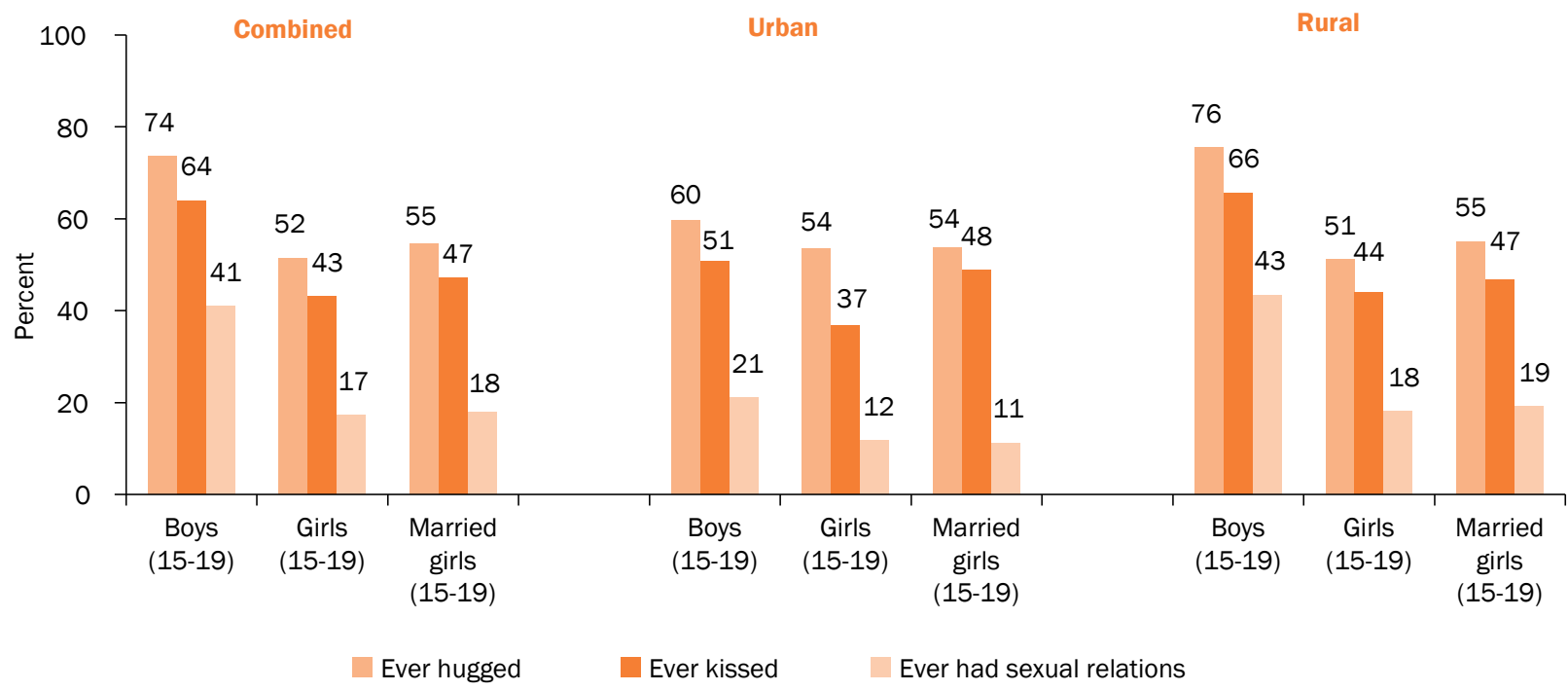

We note that seven percent of boys, and none of the unmarried and married girls who reported a romantic relationship reported sex with more than one romantic partner (not shown in figure).

\subsubsection{Characteristics of sexual experiences within premarital romantic relationships}

We asked all older respondents reporting sex with a romantic partner their age at first sex with the romantic partner and contraceptive use in general and condom use in particular at first and subsequent sexual encounters with a romantic partner. Findings are presented in Table 9.3. It needs to be noted that the number of older adolescents who had sex before marriage with a romantic partner was small in urban areas, and therefore, differences by residence in rural or urban areas are not presented.

As seen in Table 9.3, the average age of first sex with a romantic partner was 16 years among boys and 15 years among girls.

Contraceptive use within romantic relationships was limited among adolescents- just 31 percent of boys and 17 percent of girls who reported premarital sexual experience with a romantic partner had used a contraceptive method at first sex. Consistent contraceptive use was even more limited-just 28 percent of boys and 7-11 percent of girls reported that they had practised contraception in all sexual encounters with their first romantic sexual partner and the last romantic sexual partner (if the respondent reported more than one romantic sexual partner). As seen above, boys were more likely than girls to report contraceptive use within premarital romantic relationships. Among girls, differences by marital status were narrow.

Condom use was correspondingly limited; just 23 percent of boys and 10-13 percent of girls reported condom use during their first sexual encounter with a romantic partner. It is clear that the majority of those who practised contraception at first sex used a condom ( $75 \%$ of boys and $60-78 \%$ of girls, not shown in the table). A larger proportion of unmarried than married girls who practised contraception at first sex reported condom use ( $78 \%$ versus $60 \%$, not shown in the table). 
Consistent condom use in all sexual encounters with the first romantic sexual partner and the last, if more than one romantic sexual partner was reported, was far more limited-23 percent of boys, nine percent of unmarried girls and less than one percent of married girls reported consistent condom use.

Table 9.3: Characteristics of sexual experiences of older adolescents within premarital romantic relationships

Percentage of adolescents in ages 15-19 reporting premarital sexual experiences with an opposite-sex romantic partner by selected characteristics of their first and subsequent sexual encounters with the romantic partner(s), Bihar, 2016

\begin{tabular}{|c|c|c|c|}
\hline Characteristics & $\begin{array}{c}\text { Boys } \\
(15-19)\end{array}$ & $\begin{array}{l}\text { Girls } \\
(15-19)\end{array}$ & $\begin{array}{l}\text { Married girls } \\
\qquad(15-19)\end{array}$ \\
\hline Age at first sex (Mean) & 15.8 & 15.4 & 15.1 \\
\hline \multicolumn{4}{|l|}{ Contraceptive use } \\
\hline Practised contraception at first sex & 31.0 & 17.2 & 17.1 \\
\hline $\begin{array}{l}\text { Practised contraception in all sexual encounters with first and last romantic sexual } \\
\text { partner }^{1}\end{array}$ & 27.9 & 11.1 & 6.6 \\
\hline \multicolumn{4}{|l|}{ Condom use } \\
\hline Used a condom at first sex & 23.2 & 13.4 & 10.2 \\
\hline Used condoms in all sexual encounters with first and last romantic sexual partner ${ }^{1}$ & 23.1 & 9.4 & 0.3 \\
\hline Number reporting premarital sex with an opposite-sex romantic partner & 104 & 82 & 76 \\
\hline
\end{tabular}

Notes: All Ns are unweighted. ${ }^{1}$ In-depth probing of sexual experiences was restricted to respondent's first romantic sexual partner, and if they reported more than one romantic sexual partner, the last romantic sexual partner as well.

\subsection{Non-consensual sexual experiences}

The survey also probed the extent to which adolescents had ever experienced such non-consensual sexual acts as verbal harassment of a sexual nature, non-consensual sexual touch, or forced sex. It is to be noted that for married older girls, our measure of non-consensual sexual experiences refers to experiences before marriage.

Recognising that exploring sensitive issues with young adolescents has the potential to cause harm to them, we ensured that our survey instruments included only age-appropriate questions related to non-consensual sexual experiences. Therefore, we asked younger girls whether they had ever experienced verbal or other such harassment of a sexual nature (for example, dirty comments or gestures made by a boy/man); and younger girls and boys about non-consensual sexual touch (for example, we asked girls whether they had been touched in a bad way, such as on their private parts, when they did not want to be touched by a boy/man, and we asked boys whether they had experienced this from boy/man/girl/woman).

Experiences of non-consensual sexual touch among unmarried and married older girls were captured by asking them (1) whether any boy/man had ever forcibly hugged or kissed them, or had touched them on their private parts, including brushing past them, pinching their private parts, or had forced them to touch his private parts; and (2) whether any boy/man other than their romantic partner, if any, had ever attempted to force sex on them. Non-consensual sexual touch among older boys was similarly measured by asking them (1) whether a boy/man/ girl/woman had ever touched them in a bad way, for example, on their private parts, when they did not want to be touched; and (2) whether a boy/man/girl/woman had ever attempted to force sex on them.

We also sought to elicit information on forced sexual experiences among older adolescents. Unmarried and married older girls were asked (1) whether their first romantic sexual partner had forced them to engage in sex at their first sexual encounter and subsequent sexual encounters; (2) whether their most recent romantic partner, if more than one romantic sexual partner was reported, had forced them to engage in sex; and (3) whether any boy/man other than their romantic partner/s had ever forced them to engage in sex. Older boys were asked whether a boy/man/girl/ woman had ever forced them to engage in sex. 
We acknowledge that forced sex is an extremely sensitive issue and, hence, very likely to have been under-reported. As such, we supplemented questions on forced sex in the face-to-face format with a single question using the anonymous format, that is, via a sealed envelope for girls. They were asked whether they had ever experienced forced sex, and married girls were asked whether they had experienced this before their marriage.

Perpetration of non-consensual sexual acts by younger and older boys was also assessed. We asked younger and older boys whether they had ever verbally or in other ways harassed a girl (for example, passed comments, said bad words to or made dirty gestures at them, sang songs in a teasing way when a girl was walking to school or to a shop), and whether they had ever perpetrated non-consensual sexual touch on a girl/woman (for example, younger boys were asked whether they had touched a girl in a bad way when she did not want to be touched, while older boys were asked whether they had forcibly hugged or kissed a girl/woman, touched her private parts without her consent, deliberately brushed past her, pinched her private parts, or forced a girl/woman to touch his private parts). Older boys additionally were asked about the perpetration of forced sex. Specifically, they were asked whether they had forced their first romantic sexual partner, if any, to engage in sex the first time and in subsequent sexual encounters with her, and likewise with the last romantic sexual partner, if more than one romantic partner was reported. They were also asked whether they had ever forcibly attempted to have sex with a girl/woman other than their romantic partner/s. As with older girls, acknowledging that boys are likely to under-report perpetration of forced sex in the face-to-face format, we supplemented questions on perpetration of forced sex with a single question using the anonymous format, that is, via a sealed envelope, in which boys were asked whether they had ever forced a girl or woman to engage in sex with them.

Findings pertaining to younger adolescents' experience of non-consensual sexual acts and younger boys' perpetration of such acts are presented in Table 9.4. Verbal harassment of a sexual nature was experienced by 22 percent of younger girls, with no variation by residence in rural or urban areas. While seven percent of younger girls had ever experienced non-consensual sexual touch, among younger boys, one percent had ever experienced non-consensual sexual touch from a boy/man.

Some three percent of younger boys admitted that they had verbally harassed a girl in a sexual way (4\% and $3 \%$ in urban and rural areas, respectively) and less than one percent reported that they had touched a girl in inappropriate ways.

Table 9.4: Non-consensual sexual experiences among younger adolescents

Percentage of adolescents in ages 10-14 reporting experience (boys and girls)/perpetration (boys) of various forms of non-consensual sexual acts, according to residence, Bihar, 2016

\begin{tabular}{|c|c|c|c|c|c|c|}
\hline \multirow{2}{*}{ Non-consensual sexual experiences } & $\begin{array}{c}\text { Boys } \\
(10-14)\end{array}$ & $\begin{array}{c}\text { Girls } \\
(10-14)\end{array}$ & $\begin{array}{c}\text { Boys } \\
(10-14)\end{array}$ & $\begin{array}{c}\text { Girls } \\
(10-14)\end{array}$ & $\begin{array}{c}\text { Boys } \\
(10-14)\end{array}$ & $\begin{array}{c}\text { Girls } \\
(10-14)\end{array}$ \\
\hline & \multicolumn{2}{|c|}{ Combined (percent) } & \multicolumn{2}{|c|}{ Urban (percent) } & \multicolumn{2}{|c|}{ Rural (percent) } \\
\hline Ever experienced verbal sexual harassment & NA & 22.3 & NA & 21.5 & NA & 22.4 \\
\hline \multicolumn{7}{|l|}{ Non-consensual sexual touch } \\
\hline Ever experienced non-consensual sexual touch & 1.1 & 7.2 & 1.0 & 4.6 & 1.1 & 7.6 \\
\hline \multicolumn{7}{|l|}{ Perpetrated by: } \\
\hline Opposite-sex person & 0.2 & 7.2 & 0.2 & 4.6 & 0.2 & 7.6 \\
\hline Same-sex person & 0.9 & 0.0 & 0.8 & 0.0 & 0.9 & 0.0 \\
\hline \multicolumn{7}{|l|}{ Perpetration of non-consensual sexual acts } \\
\hline Ever verbally harassed a girl in a sexual way & 3.4 & NA & 3.5 & NA & 3.4 & NA \\
\hline $\begin{array}{l}\text { Ever perpetrated non-consensual sexual touch on } \\
\text { a girl }\end{array}$ & 0.7 & NA & 0.0 & NA & 0.8 & NA \\
\hline Number of respondents & 1,012 & 764 & 452 & 387 & 560 & 377 \\
\hline
\end{tabular}

Notes: All Ns are unweighted. NA: not applicable.

Table 9.5 shows that two percent of older boys had ever experienced non-consensual sexual touch, including attempted forced sex (1.1\% reported that non-consensual touch was perpetrated by an opposite-sex person and $0.6 \%$ 
reported such experience from a same-sex person); correspondingly, 11 percent of unmarried older girls reported ever experiencing non-consensual sexual touch, including attempts to force sex on them, and eight percent of married girls reported such experience before their marriage. One percent of older boys and five percent of unmarried older girls reported the experience of unwanted sexual touch in the year preceding the interview. Differences by residence in rural or urban areas in this respect were muted.

As far as experience of forced sex is concerned, findings show that in response to questions posed in the face-to-face interview, two percent of unmarried older girls and one percent of married older girls reported such an experience ever in life (married older girls were asked to report such experience if it had occurred before their marriage). Differences by residence in rural or urban areas were negligible. Giving adolescents the opportunity to report forced sex anonymously did indeed result in more girls' reporting the experience of forced sex and more boys' reporting its perpetration as compared with face-to-face responses. Indeed, three percent each of unmarried older girls and married older girls reported in the anonymous format that they had experienced forced sex ever in life, including forced sex perpetrated by their romantic partner/s, compared with two percent and one percent, respectively, in the face-to-face interview (married older girls were asked to report such experience if it had occurred before their marriage). On the whole, four percent of unmarried older girls and three percent of married older girls (experience before marriage) reported a forced sexual encounter ever in life. Differences by residence in rural or urban areas were muted.

Findings presented in Table 9.5 also reveal that as many as 19 percent of older boys had ever verbally harassed a girl in sexual way, with modest differences with regard to verbal harassment between those from urban and those from rural areas ( $16 \%$ and $20 \%$, respectively). Far fewer-three percent and one percent- admitted perpetrating nonconsensual sexual touch on a girl ever in their life and in the 12 months prior to the interview, respectively.

As many as two percent of boys admitted in the face-to-face interview to their ever forcing sex on a girl, including their romantic partner/s, and three percent admitted this in the anonymous format. On the whole, as many as five percent of boys reported the perpetration of forced sex ( $2 \%$ and $5 \%$, respectively, in urban and rural areas).

\section{Table 9.5: Non-consensual sexual experiences among older adolescents}

Percentage of adolescents in ages 15-19 reporting experience (boys and girls)/perpetration (boys) of various forms of non-consensual sexual acts, according to residence, Bihar, 2016

\begin{tabular}{|c|c|c|c|c|c|c|c|c|c|}
\hline $\begin{array}{l}\text { Non-consensual sexual } \\
\text { experiences }\end{array}$ & $\begin{array}{c}\text { Boys } \\
(15-19)\end{array}$ & $\begin{array}{c}\text { Girls } \\
(15-19)\end{array}$ & $\begin{array}{l}\text { Married } \\
\text { girls } \\
(15-19)\end{array}$ & $\begin{array}{c}\text { Boys } \\
(15-19)\end{array}$ & $\begin{array}{c}\text { Girls } \\
(15-19)\end{array}$ & $\begin{array}{c}\text { Married } \\
\text { girls } \\
(15-19)\end{array}$ & $\begin{array}{c}\text { Boys } \\
(15-19)\end{array}$ & $\begin{array}{c}\text { Girls } \\
(15-19)\end{array}$ & $\begin{array}{c}\text { Married } \\
\text { girls } \\
(15-19)\end{array}$ \\
\hline
\end{tabular}

\section{Non-consensual sexual touch}

Ever experienced nonconsensual sexual touch, including attempted forced sex

$\begin{array}{ccccccccc}1.7 & 11.2 & 7.9 & 0.8 & 12.7 & 8.6 & 1.8 & 11.0 & 7.9 \\ 1.1 & 11.2 & 7.9 & 0.3 & 12.7 & 8.6 & 1.3 & 11.0 & 7.9 \\ 0.6 & \text { NA } & \text { NA } & 0.5 & \text { NA } & \text { NA } & 0.6 & \text { NA } & \text { NA }\end{array}$

\section{Perpetrated by:} Opposite-sex person

Same-sex person

Experienced nonconsensual sexual touch in the 12 months prior to the interview

NA

0.1

6.1

NA

0.8

5.3

NA 
Table 9.5 Cont.

\begin{tabular}{|c|c|c|c|c|c|c|c|c|c|}
\hline $\begin{array}{l}\text { Non-consensual sexual } \\
\text { experiences }\end{array}$ & $\begin{array}{l}\text { Boys } \\
(15-19)\end{array}$ & $\begin{array}{l}\text { Girls } \\
(15-19)\end{array}$ & $\begin{array}{l}\text { Married } \\
\text { girls } \\
(15-19) \\
\end{array}$ & $\begin{array}{c}\text { Boys } \\
(15-19)\end{array}$ & $\begin{array}{l}\text { Girls } \\
(15-19)\end{array}$ & $\begin{array}{l}\text { Married } \\
\text { girls } \\
(15-19) \\
\end{array}$ & $\begin{array}{c}\text { Boys } \\
(15-19)\end{array}$ & $\begin{array}{c}\text { Girls } \\
(15-19)\end{array}$ & $\begin{array}{c}\text { Married } \\
\text { girls } \\
(15-19)\end{array}$ \\
\hline & \multicolumn{3}{|c|}{ Combined (percent) } & \multicolumn{3}{|c|}{ Urban (percent) } & \multicolumn{3}{|c|}{ Rural (percent) } \\
\hline \multicolumn{10}{|c|}{ Ever experienced forced sex as reported in: } \\
\hline Face-to-face interview & NA & 1.8 & 1.2 & NA & 1.3 & 1.1 & NA & 1.8 & 1.2 \\
\hline $\begin{array}{l}\text { Anonymous format } \\
\text { (sealed envelope) }\end{array}$ & NA & 2.9 & 2.7 & NA & 2.9 & 1.6 & NA & 2.9 & 2.8 \\
\hline $\begin{array}{l}\text { Face-to-face interview } \\
\text { or anonymous format } \\
\text { (sealed envelope) }\end{array}$ & NA & 4.0 & 3.4 & NA & 3.5 & 2.4 & NA & 4.0 & 3.5 \\
\hline \multicolumn{10}{|c|}{ Perpetration of non-consensual sexual acts } \\
\hline $\begin{array}{l}\text { Ever verbally harassed a } \\
\text { girl in a sexual way }\end{array}$ & 19.4 & NA & NA & 15.7 & NA & NA & 19.9 & NA & NA \\
\hline $\begin{array}{l}\text { Ever perpetrated non- } \\
\text { consensual sexual touch } \\
\text { on a girl }\end{array}$ & 2.9 & NA & NA & 1.4 & NA & NA & 3.1 & NA & NA \\
\hline $\begin{array}{l}\text { Perpetrated non- } \\
\text { consensual sexual } \\
\text { touch on a girl in the } \\
12 \text { months prior to the } \\
\text { interview }\end{array}$ & 1.3 & NA & NA & 0.4 & NA & NA & 1.4 & NA & NA \\
\hline \multicolumn{10}{|c|}{ Ever forced sex on a girl as reported in: } \\
\hline Face-to-face interview & 1.8 & NA & NA & 0.9 & NA & NA & 1.9 & NA & NA \\
\hline $\begin{array}{l}\text { Anonymous format } \\
\text { (sealed envelope) }\end{array}$ & 3.2 & NA & NA & 1.0 & NA & NA & 3.5 & NA & NA \\
\hline $\begin{array}{l}\text { Face-to-face interview } \\
\text { or anonymous format } \\
\text { (sealed envelope) }\end{array}$ & 4.5 & NA & NA & 1.6 & NA & NA & 4.9 & NA & NA \\
\hline Number of respondents & 1,821 & 3,428 & 3,408 & 1,008 & 1,738 & 1,366 & 813 & 1,690 & 2,042 \\
\hline
\end{tabular}

Notes: All Ns are unweighted. NA: not applicable.

\subsection{Sexual experiences within romantic and other relationships among older}

\section{adolescents}

Aside from the romantic and forced sexual relationships among older adolescents discussed in the previous sections, the survey also probed their experiences of sex with other partners, including casual partners, and in situations characterised by exchange of gifts or favours. In addition, boys were asked about their sexual relationships with sex workers and married girls/women, and married girls were asked about sexual relations with their husband before marriage.

In this and subsequent sections of this chapter, we present findings on the prevalence of sexual experiences (irrespective of whether such experiences took place within romantic or other partnerships or in forced or consensual relationships) among all older adolescents in the sample.

\subsubsection{Extent of sexual experiences}

Table 9.6 reports percentages of older adolescents reporting sex in any of the situations described above. Findings from face-to-face interviews indicate that for eight percent of boys and two percent of girls, sexual relations occurred in a romantic relationship with a person of the opposite sex. Also notable are findings relating to forced sex-as many as two percent of unmarried older girls and one percent of married older girls reported the experience of forced sex in the face-to-face format, and two percent of boys reported the perpetration of forced sex. 
Sex in exchange for money or favours was rarely reported (0.0-0.1\%). Casual sex was reported by two percent of boys, but by hardly any girls. In addition, less than one percent of boys reported sex with a sex worker or a married woman. Among married girls, less than one percent reported sex with their husband before marriage.

Thus, in all, 10 percent of boys, and three percent each of unmarried girls and married girls reported premarital sexual relations in the course of face-to-face interviews. Differences by residence in rural or urban areas were evident, particularly among boys; rural boys were twice as likely as their urban counterparts to report premarital sexual experiences (10\% versus $5 \%)$.

\section{Table 9.6: Overall premarital sexual experiences of older adolescents with opposite-sex partners}

Percentage of adolescents in ages 15-19 reporting premarital sexual experiences with opposite-sex partners and via different reporting methods, according to residence, Bihar, 2016

\begin{tabular}{|c|c|c|c|}
\hline Premarital sexual experiences and reporting methods & $\begin{array}{c}\text { Boys } \\
(15-19)\end{array}$ & $\begin{array}{c}\text { Girls } \\
(15-19)\end{array}$ & $\begin{array}{l}\text { Married girls } \\
\text { (15-19) }\end{array}$ \\
\hline \multicolumn{4}{|c|}{ Combined (percent) } \\
\hline \multicolumn{4}{|l|}{ Reported premarital sex partners } \\
\hline Opposite-sex romantic partner & 7.9 & 2.4 & 2.2 \\
\hline Someone who forced respondent to have sex ${ }^{1}$ & 0.0 & 1.8 & 1.2 \\
\hline Girl/s whom respondent forced ${ }^{1}$ & 1.8 & NA & NA \\
\hline Someone in exchange for money/favours & 0.1 & 0.1 & 0.1 \\
\hline Sex worker & 0.1 & NA & NA \\
\hline Married woman & 0.9 & NA & NA \\
\hline Casual partner & 2.0 & 0.2 & 0.1 \\
\hline Husband before marriage & NA & NA & 0.8 \\
\hline \multicolumn{4}{|l|}{ Reporting methods } \\
\hline Face-to-face interview & 10.1 & 2.7 & 2.7 \\
\hline Anonymous format (sealed envelope) & 11.7 & 5.3 & 4.9 \\
\hline Face-to-face interview or anonymous format (sealed envelope) & 14.1 & 6.3 & 5.8 \\
\hline Number of respondents & 1,821 & 3,428 & 3,408 \\
\hline \multicolumn{4}{|c|}{ Urban (percent) } \\
\hline \multicolumn{4}{|l|}{ Reported premarital sex partners } \\
\hline Opposite-sex romantic partner & 4.0 & 1.8 & 1.9 \\
\hline Someone who forced respondent to have sex ${ }^{1}$ & 0.0 & 1.3 & 1.1 \\
\hline Girl/s whom respondent forced ${ }^{1}$ & 0.9 & NA & NA \\
\hline Someone in exchange for money/favours & 0.0 & 0.0 & 0.0 \\
\hline Sex worker & 0.2 & NA & NA \\
\hline Married woman & 0.2 & NA & NA \\
\hline Casual partner & 0.3 & 0.1 & 0.0 \\
\hline Husband before marriage & NA & NA & 1.3 \\
\hline \multicolumn{4}{|l|}{ Reporting methods } \\
\hline Face-to-face interview & 4.6 & 2.1 & 2.6 \\
\hline Anonymous format (sealed envelope) & 6.2 & 4.5 & 4.2 \\
\hline Face-to-face interview or anonymous format (sealed envelope) & 7.7 & 5.0 & 5.3 \\
\hline Number of respondents & 1,008 & 1,738 & 1,366 \\
\hline
\end{tabular}


Table 9.6 Cont.

\begin{tabular}{|c|c|c|c|}
\hline Premarital sexual experiences and reporting methods & $\begin{array}{c}\text { Boys } \\
(15-19)\end{array}$ & $\begin{array}{c}\text { Girls } \\
(15-19)\end{array}$ & $\begin{array}{c}\text { Married girls } \\
(15-19)\end{array}$ \\
\hline \multicolumn{4}{|c|}{ Rural (percent) } \\
\hline \multicolumn{4}{|l|}{ Reported premarital sex partners } \\
\hline Opposite-sex romantic partner & 8.4 & 2.4 & 2.3 \\
\hline Someone who forced respondent to have sex1 & 0.0 & 1.8 & 1.2 \\
\hline Girl/s whom respondent forced1 & 1.9 & NA & NA \\
\hline Someone in exchange for money/favours & 0.1 & 0.1 & 0.1 \\
\hline Sex worker & 0.1 & NA & NA \\
\hline Married woman & 1.0 & NA & NA \\
\hline Casual partner & 2.2 & 0.2 & 0.1 \\
\hline Husband before marriage & NA & NA & 0.7 \\
\hline \multicolumn{4}{|l|}{ Reporting methods } \\
\hline Face-to-face interview & 10.0 & 2.8 & 2.7 \\
\hline Anonymous format (sealed envelope) & 12.3 & 5.4 & 5.0 \\
\hline Face-to-face interview or anonymous format (sealed envelope) & 14.9 & 6.5 & 5.8 \\
\hline Number of respondents & 813 & 1,690 & 2,042 \\
\hline
\end{tabular}

Notes: All Ns are unweighted. NA: not applicable. 1Includes forced sex within romantic relationship.

As mentioned earlier, we also inquired about sexual experiences through anonymous reporting via a sealed envelope method. Several adolescents, particularly girls, who had not admitted their sexual experience in the faceto-face format did so in the anonymous format (sealed envelope). Thus, 12 percent of boys and five percent of girls acknowledged that they had engaged in premarital sex in the anonymous format. Percentages reporting premarital sexual experiences in either format ranged from 14 percent among boys to six percent each among unmarried girls and married girls. Differences by residence in rural or urban areas were evident for boys. Rural boys were more likely than urban boys to report premarital sex (15\% versus 8\%) (Table 9.6 and Figure 9.2).

Figure 9.2: Percentage of adolescents in ages 15-19 reporting any premarital sexual experiences (in face-toface interview or anonymous format), according to residence, Bihar, 2016

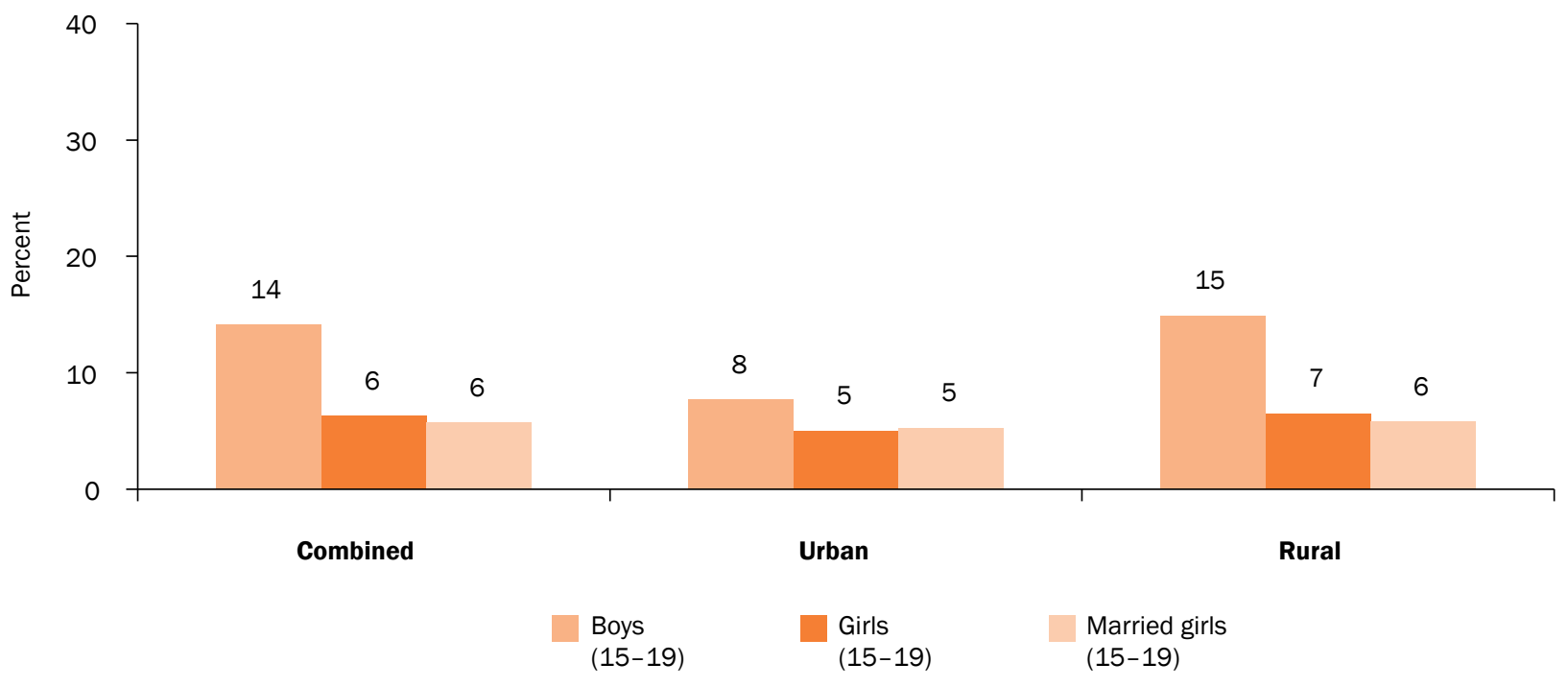


Table 9.7 presents the percentages of older adolescents who had reported any premarital sexual experience by selected socio-demographic characteristics. As indicated earlier, many of these background characteristics reflect the situation of adolescents at the time of interview and not necessarily at the time of sexual experiences.

Age profiles suggest a positive association between age and sexual experiences among boys, with those in ages 1819 more likely than those in ages $15-17$ to report sexual experiences (20\% versus $12 \%)$; in contrast, little differences were observed among girls, irrespective of their marital status.

Differentials by religion were mild among both boys and girls. Caste-wise differences were noted among boys, but not so much among girls: those from general castes were the least likely to report sexual experiences, and those from scheduled castes were the most likely to report sexual experiences. Thus, 11 percent of boys belonging to general castes reported premarital sexual experience compared with 16 percent of boys belonging to scheduled castes.

The association between premarital sexual experiences and educational attainment was positive among boys, but erratic among girls. Moreover, sexual experience was not correlated with the current enrolment status or the household economic status of adolescents.

Older adolescents, particularly boys who were working for pay in the year preceding the interview were more likely than their non-working counterparts to report sexual experience (19\% versus $13 \%$ of boys), a finding that may be attributed to the greater mobility and relative freedom from parental supervision experienced by working adolescents as compared with non-working adolescents.

\section{Table 9.7: Overall premarital sexual experiences of older adolescents with opposite-sex partners by selected background characteristics}

Percentage of adolescents in ages 15-19 r eporting any premarital sexual experiences with opposite-sex partners by selected background characteristics, Bihar, 2016

\begin{tabular}{|c|c|c|c|}
\hline Background characteristics (percent) & $\begin{array}{c}\text { Boys } \\
(15-19)\end{array}$ & $\begin{array}{c}\text { Girls } \\
(15-19)\end{array}$ & $\begin{array}{c}\text { Married girls } \\
\quad(15-19)\end{array}$ \\
\hline \multicolumn{4}{|l|}{ Age } \\
\hline $15-17$ & 11.9 & 6.5 & 6.8 \\
\hline $18-19$ & 20.3 & 5.8 & 5.3 \\
\hline \multicolumn{4}{|l|}{ Religion ${ }^{1}$} \\
\hline Hindu & 14.4 & 6.3 & 6.0 \\
\hline Muslim & 12.4 & 6.0 & 4.1 \\
\hline \multicolumn{4}{|l|}{ Caste $^{2}$} \\
\hline SC & 16.1 & 9.0 & 7.1 \\
\hline OBC & 14.2 & 5.7 & 5.2 \\
\hline General $^{3}$ & 10.9 & 4.7 & 4.4 \\
\hline \multicolumn{4}{|l|}{ Completed years of schooling } \\
\hline None $^{4}$ & 10.7 & 5.7 & 5.8 \\
\hline $1-4$ & 9.6 & 4.1 & 5.6 \\
\hline $5-7$ & 10.5 & 9.5 & 2.7 \\
\hline $8-9$ & 14.6 & 7.0 & 6.8 \\
\hline $10-11$ & 13.9 & 4.5 & 9.4 \\
\hline 12 and above & 20.3 & 4.6 & 3.4 \\
\hline \multicolumn{4}{|l|}{ Current schooling status ${ }^{5}$} \\
\hline Yes & 13.9 & 6.4 & 8.5 \\
\hline No & 15.6 & 6.7 & 5.5 \\
\hline
\end{tabular}


Table 9.7 Cont.

\section{Paid work in the $\mathbf{1 2}$ months prior to the interview}

Yes

No

Wealth quintile

First

Second

Third

Fourth

Fifth

Mother's education (in years of schooling completed)

None $^{4}$

1-7

8-9

10 and above

Total

$\begin{array}{rrr}19.0 & 9.6 & 8.0 \\ 12.5 & 5.7 & 5.5 \\ 7.4 & 6.7 & 7.0 \\ 15.8 & 8.3 & 5.5 \\ 19.6 & 7.2 & 4.9 \\ 12.9 & 5.2 & 5.0 \\ 11.5 & 5.5 & 7.5 \\ & & \\ 14.9 & 7.5 & 5.9 \\ 15.9 & 4.9 & 5.4 \\ 7.2 & 2.7 & 5.6 \\ 10.4 & 2.5 & 5.7 \\ 14.1 & 6.3 & 5.8\end{array}$

Notes:OBC: other backward caste; SC: scheduled caste; ST: scheduled tribe. ${ }^{1}$ Percentages not shown for those belonging to other religions as less than one percent of surveyed adolescents belonged to other religions. ${ }^{2}$ Percentages not shown for those belonging to STs as less than one percent of surveyed adolescents belonged to STs. ${ }^{3}$ Includes all those not belonging to SCs, STs, or OBCs. ${ }^{4}$ Includes non-literate and literate with no formal schooling. ${ }^{5}$ Percentages not shown for adolescents who were pursuing their education through distance education courses at the time of interview or those who never went to school.

Finally, a negative association between mother's education and reports of premarital sex was apparent among unmarried girls, while no such association was apparent among boys or married girls; the percentage of unmarried older girls who reported premarital sex declined from eight percent among those whose mother was illiterate to three percent among those whose mother had 10 or more years of education.

\subsubsection{Sexual risk behaviours in premarital relationships}

Interviewers asked older adolescents who had reported any premarital sexual experience in the course of the face-toface interview about the number of partners with whom they had ever had physical relations and also about condom use. Boys and unmarried girls were additionally asked about the number of partners with whom they had engaged in physical relations in the year preceding the interview. It needs to be noted that the number of older adolescents who had sex before marriage was small in urban areas, and therefore, differences by residence in rural or urban areas are not described in this section. Findings confirm that where adolescents had engaged in sexual relations, they had generally followed unsafe practices (Figure 9.3).

One-fifth (22\%) of boys and a little over one-quarter of girls (28-29\%) who had sexual experiences reported that they had engaged in sex before age 15.

One-third (30\%) of boys who had sexual experiences reported that they had engaged in sex with more than one partner; likewise, one-quarter (27\%) of married girls who reported premarital sex reported that they had engaged in sex with more than one partner before marriage. In contrast, fewer unmarried girls reported multiple partner relations-five percent. Findings suggest that among adolescents who reported premarital sexual experiences in the face-to-face interview, those reporting consistent condom use were few-only 20 percent of boys and 1-8 percent of girls reported that they/their partner had always used a condom. 


\section{Figure 9.3: Premarital sexual risk behaviours of older adolescents}

Percentage of adolescents in ages 15-19 with any sexual experience with opposite-sex partners by age at first premarital sex, number of partners, and condom use ${ }^{1}$, Bihar, 2016

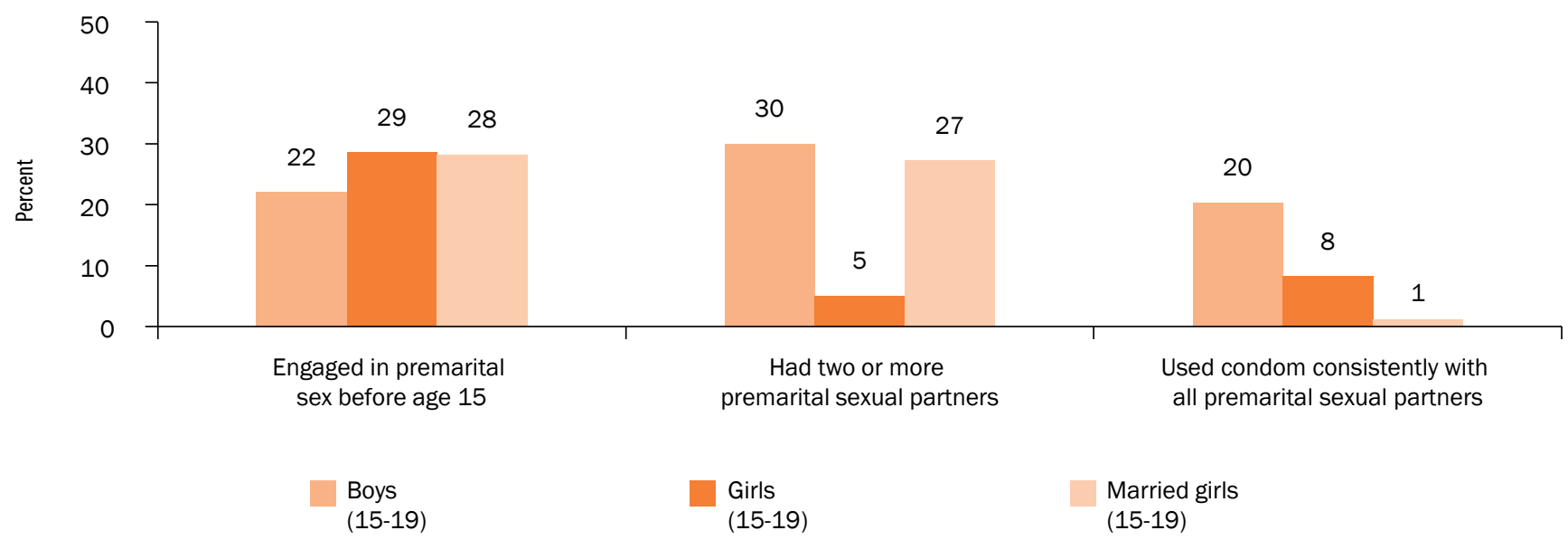

Note: ${ }^{1}$ Questions on consistent condom use were asked only with regard to sexual relationships with first and/or most recent romantic partner, exchange sex partner, sex worker, married woman, casual partner, spouse before marriage, and it excluded experiences with romantic partners other than first or most recent romantic partner and experiences of forced sex.

Among boys and unmarried girls who had ever engaged in sex with an opposite-sex partner, 77 percent and 73 percent, respectively, had engaged in sexual relationships in the 12 months preceding the interview (not shown in table or figure). Of those who had engaged in sexual relationships in the 12 months preceding the interview, 19 percent of boys and hardly any unmarried girls reported sex with multiple partners, and 25 percent of boys and 10 percent of unmarried girls reported condom use in all sexual encounters during the 12 months prior to the survey.

\subsubsection{Premarital pregnancy}

The survey included questions to elicit information on premarital pregnancy. Boys were asked whether their girlfriend or any other sexual partner had become pregnant, and girls reporting sexual experience, similarly, were asked whether they had experienced a premarital pregnancy. Findings, presented in Table 9.8, reveal that two percent of boys and 7-14 percent of girls who had reported a premarital sexual relationship in the face-to-face interview reported a premarital pregnancy.

\section{Table 9.8: Premarital pregnancy among older adolescents}

Percentage of adolescents in ages 15-19 who had sexual experience before marriage reporting a premarital pregnancy, Bihar, 2016

\begin{tabular}{lrrr}
\hline Premarital pregnancy & $\begin{array}{c}\text { Boys } \\
(15-19)\end{array}$ & $\begin{array}{c}\text { Girls } \\
(15-19)\end{array}$ & $\begin{array}{c}\text { Married girls } \\
(\mathbf{1 5}-19)\end{array}$ \\
\hline Had a premarital pregnancy $^{1}$ & 1.7 & 6.7 & 14.3 \\
Number reporting a premarital sexual relationship in face-to-face interview & $\mathbf{1 3 0}$ & $\mathbf{9 6}$ & $\mathbf{9 2}$ \\
\hline
\end{tabular}

Notes: All Ns are unweighted. ${ }^{1}$ Adolescent boys in ages 15-19 years who reported premarital sex were asked if their girlfriend or other sexual partner had become pregnant. 


\subsection{Same-sex relationship among older adolescents}

The survey also sought to elicit information on same-sex attraction and intimate relationships (kissing on the lips, touching private parts, and, for boys, having sexual intercourse as well) among older adolescents. Findings presented in Table 9.9 show that hardly any boys and girls were ever romantically/sexually attracted to a person of the same sex or had experienced an intimate relationship with a same sex partner.

\section{Table 9.9: Same-sex relationship among older adolescents}

Percentage of adolescents in ages 15-19 reporting attraction and intimate relationship with a same-sex partner, according to residence, Bihar, 2016

\begin{tabular}{|c|c|c|c|}
\hline Same-sex sexual experiences & $\begin{array}{c}\text { Boys } \\
(15-19)\end{array}$ & $\begin{array}{c}\text { Girls } \\
(15-19)\end{array}$ & $\begin{array}{c}\text { Married girls } \\
(15-19)\end{array}$ \\
\hline \multicolumn{4}{|c|}{ Combined (percent) } \\
\hline Romantically/sexually attracted & 0.4 & 0.2 & 0.4 \\
\hline Had intimate relationship with a same-sex partner ${ }^{1}$ & 0.4 & 0.2 & 0.1 \\
\hline Number of respondents & 1,821 & 3,428 & 3,408 \\
\hline \multicolumn{4}{|c|}{ Urban (percent) } \\
\hline Romantically/sexually attracted & 0.4 & 0.1 & 0.3 \\
\hline Had intimate relationship with a same-sex partner ${ }^{1}$ & 0.5 & 0.1 & 0.5 \\
\hline Number of respondents & 1,008 & 1,738 & 1,366 \\
\hline \multicolumn{4}{|c|}{ Rural (percent) } \\
\hline Romantically/sexually attracted & 0.4 & 0.2 & 0.4 \\
\hline Had intimate relationship with a same-sex partner ${ }^{1}$ & 0.4 & 0.2 & 0.1 \\
\hline Number of respondents & 813 & 1,690 & 2,042 \\
\hline
\end{tabular}

Notes: All Ns are unweighted. Includes kissing on the lips or touching private parts for female respondents and engaging in sexual intercourse as well for male respondents. 


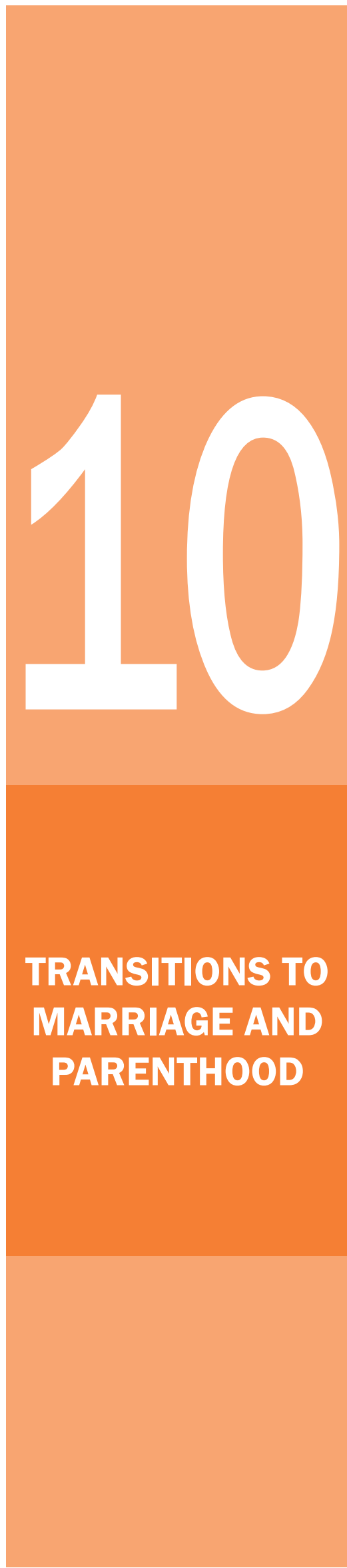

\section{A Snapshot}

Few adolescents prefer to marry before the legal minimum age of marriage or in adolescence:

- $2 \%$ of unmarried older girls preferred to marry before age 18 , the legal minimum age of marriage for females

- $5 \%$ of older boys preferred to marry before age 21 , the legal minimum age of marriage for males

- $2 \%$ of older boys

- $13 \%$ of unmarried older girls preferred to marry before age 20
- $51 \%$ of older boys

- $50 \%$ of unmarried older girls had not thought about the age at which they would like to get married

Adolescents' exercise of choice in marriage-related decisions is limited:

- $46 \%$ of married girls had been consulted on the age they want to marry

- $34 \%$ of married girls had been consulted in choosing their husband

- $77 \%$ of married girls had met their husband for the first time on the wedding day

Child marriage is common:

- $7 \%$ of 15-19-year-old girls were married before age 15

- $44 \%$ of 18-19-year-old girls were married before age 18

Payment of dowry and dowry-related harassment are widespread:

- $91 \%$ of married girls reported that their family paid a dowry

- $31 \%$ of married girls experienced dowry-related harassment

Married life is characterised by violence, limited spousal communication, and pressure to prove fertility:

- $34 \%$ of married girls had ever experienced emotional violence

- $28 \%$ of married girls had ever experienced physical violence

- $37 \%$ of married girls had ever experienced sexual violence

- $54 \%$ of married girls had ever discussed with their husband about the number of children to have

- $33 \%$ of married girls felt pressurised to prove their fertility

POPULATION COUNCIL

Ideas. Evidence. Impact.

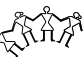

UDAYA 


\section{A Snapshot}

Several girls are not able to realise their fertility intentions:

- $42 \%$ of married girls wanted to delay their first birth by two or more years after marriage

- $9 \%$ of married girls had practised contraception in the first two years of marriage

- $32 \%$ of married girls who had wanted to delay the first birth but did not practise contraception

had experienced husband's or other family member's objections to family planning

- $45 \%$ of married girls had an unmet need for spacing

- $42 \%$ of married girls reported that their last pregnancy was mistimed or unwanted

Childbearing in adolescence is common:

- $13 \%$ of all girls ${ }^{1}$ (ages 15-19) had a child or were pregnant with their first child at the time of the interview

- 51\% of married girls (ages 15-19) had a child or were pregnant with their first child at the time of the interview

- $25 \%$ of all girls ${ }^{2}$ (ages 18-19) had their first birth before age 18

Pregnancy loss and infant mortality are considerable:

- $9 \%$ of married girls experienced a pregnancy loss

- Neonatal mortality rate stood at 48 deaths per 1,000 live births

- Post-neonatal mortality rate was 15 deaths per 1,000 live births

- Infant mortality rate stood at 63 deaths per 1,000 live births

Continuum of care eludes many even for the first birth:

- $98 \%$ of girls with at least one live birth had received at least one antenatal check-up for the first birth

- 95\% had received at least one tetanus toxoid injection

- $47 \%$ had their first check-up in the first trimester

- 36\% had received four or more antenatal check-ups

- $6 \%$ had taken iron and folic acid tablets for 100 days

- $79 \%$ had delivered their child in a health facility

- $84 \%$ had received skilled attendance at birth

- 39\% had at least one post-partum check-up following the first birth

- $47 \%$ had initiated breastfeeding of their first child within an hour of delivery 


\section{A Snapshot}

Programmes to promote maternal, newborn, and child health are not reaching married girls sufficiently:

- $72 \%$ of married girls who had delivered in a public health facility had received Janani Suraksha Yojana (JSY) benefits

- $48 \%$ of girls who delivered in a public or private health facility had received Janani-Shishu Suraksha Karyakram (JSSK) benefits

- $36 \%$ of girls had received food supplementation from the ICDS programme during their first pregnancy or during the lactation period following the birth of their first child

- $67 \%$ of girls had received services for their first child under six years of age from the ICDS programme

The rural disadvantage is manifested on many indicators-rural girls are less likely than urban girls to exercise choice in marriage-related decisions, more likely to be married and become mothers in childhood, more likely to experience sexual violence within marriage, less likely to receive timely and adequate pregnancy care, and more likely to experience neonatal, postneonatal, and infant mortality

Rural girls were more likely than urban girls to have benefited from government programmes to promote maternal, newborn, and child health 
Although child marriage is declining in India, the transition to marriage occurs early for notable proportions of girls and boys. Data from the most recent National Family Health Survey show that as many as 39 percent of women in ages 20-24 years were married before age 18 (IIPS, 2017b). While marriage occurs early, marriage-related planning occurs even earlier, which can occur as soon as a girl reaches menarche or even before the girl reaches menarche, and is often done without consulting her. Moreover, while consummation of marriage occurs following menarche, early married life tends to be isolating and frightening for many adolescent girls and young women. This chapter captures some of these experiences, including unmarried adolescents' preferences regarding the age for their marriage, and adolescents' participation in marriage preparation and planning. It also explores married girls' experiences in early married life and their fertility and contraceptive behaviours.

\subsection{Preferences regarding marriage age}

The module on marriage sought information on unmarried adolescents' preference for the age at which they would like to marry and their perceptions about their parents' preferred age for them to marry. Since as many as 72 percent of younger boys and 81 percent of younger girls reported that they had not thought about the age at which they would like to get married, findings are presented for only older boys and unmarried older girls. Several findings are notable (Table 10.1). First, just two percent of unmarried older girls (and hardly any older boys) preferred to marry below age 18 , that is, the legal minimum age of marriage for females, regardless of residence in rural or urban areas. Second, a significant minority of older boys (5\%) preferred to marry before age 21 , that is, the legal minimum age of marriage for males; this compares with 25 percent of unmarried older girls who preferred to marry before age 21 . Rural girls were somewhat more likely than urban girls to express such preference ( $26 \%$ versus $16 \%)$. Third, notable proportions of older boys preferred to marry at age 25 or later (29\%) compared with seven percent of unmarried older girls. Differences by residence in rural or urban areas in preferences to marry late were narrow, except for unmarried older girls, among whom more urban than rural respondents preferred to marry late ( $17 \%$ versus $6 \%$ preferred to marry after age 25). Finally, it is notable that half of older boys and unmarried older girls reported that they had not thought about the age at which they would like to get married.

\section{Table 10.1 Preferred age for marriage}

Percent distribution of unmarried adolescents in ages 15-19 by preferred age for marriage, according to residence, Bihar, 2016

\begin{tabular}{|c|c|c|c|c|c|c|}
\hline \multirow[t]{2}{*}{$\begin{array}{l}\text { Age at which respondent prefers to } \\
\text { marry }\end{array}$} & $\begin{array}{l}\text { Boys } \\
(15-19)\end{array}$ & $\begin{array}{c}\text { Girls } \\
(15-19)\end{array}$ & $\begin{array}{l}\text { Boys } \\
(15-19)\end{array}$ & $\begin{array}{c}\text { Girls } \\
(15-19)\end{array}$ & $\begin{array}{c}\text { Boys } \\
(15-19)\end{array}$ & $\begin{array}{l}\text { Girls } \\
(15-19)\end{array}$ \\
\hline & \multicolumn{2}{|c|}{ Combined (percent) } & \multicolumn{2}{|c|}{ Urban (percent) } & \multicolumn{2}{|c|}{ Rural (percent) } \\
\hline 17 or below & 0.2 & 1.5 & 0.1 & 0.9 & 0.3 & 1.6 \\
\hline 18 & 0.8 & 7.4 & 0.4 & 4.5 & 0.9 & 7.8 \\
\hline 19 & 0.5 & 3.8 & 0.2 & 2.8 & 0.5 & 3.9 \\
\hline 20 & 3.6 & 12.4 & 2.3 & 7.4 & 3.8 & 13.0 \\
\hline 21 & 2.9 & 6.5 & 1.7 & 4.5 & 3.0 & 6.7 \\
\hline 22 & 6.9 & 5.9 & 3.2 & 5.2 & 7.3 & 6.0 \\
\hline 23 & 3.0 & 2.5 & 2.4 & 2.8 & 3.1 & 2.4 \\
\hline 24 & 2.8 & 1.6 & 2.4 & 2.9 & 2.8 & 1.4 \\
\hline 25 or above & 28.5 & 7.0 & 32.4 & 16.6 & 28.0 & 5.8 \\
\hline $\begin{array}{l}\text { Did not think about the age at which } \\
\text { to marry }\end{array}$ & 50.6 & 50.3 & 54.2 & 51.3 & 50.1 & 50.2 \\
\hline Preferred not to marry & 0.2 & 1.1 & 0.8 & 0.9 & 0.1 & 1.2 \\
\hline Number of respondents & 1,821 & 3,428 & 1,008 & 1,738 & 813 & 1,690 \\
\hline
\end{tabular}

Note: All Ns are unweighted. 
Table 10.2 describes perceptions of older boys and unmarried older girls about their parents' preferred age for them to marry. First and foremost, findings show that the large majority of older adolescents reported that they did not know their parents' preference, which is perhaps a reflection of the limited communication between adolescents and parents on these matters and the exclusion of adolescents from marriage-related decisions ( $84 \%$ of boys and $62 \%$ of girls). As such, the preferred age reported by study participants should be interpreted with caution. Only a negligible minority of boys (1\%) and as many as 10 percent of girls thought that their parents preferred marriage before age 18 for them, and somewhat more rural girls than urban girls reported so (11\% versus $6 \%$ ). Some six percent of older boys and 32 percent of unmarried older girls reported that their parents would prefer marriage before age 21 for them; again, more rural than urban girls perceived that their parents would like them to marry before age 21 (34\% versus $21 \%$ ). Finally, a small proportion of older adolescents-seven percent of older boys and two percent of unmarried older girls-thought that their parents would prefer late marriage, that is, at age 25 or later.

\section{Table 10.2 Perceptions of parental preferences for age of marriage for respondents}

Percent distribution of unmarried adolescents in ages 15-19 by their perceptions of parental preferences for age of marriage for them, according to residence, Bihar, 2016

\begin{tabular}{|c|c|c|c|c|c|c|}
\hline \multirow[t]{2}{*}{$\begin{array}{l}\text { Age at which parents preferred } \\
\text { that respondent should marry }\end{array}$} & $\begin{array}{l}\text { Boys } \\
(15-19)\end{array}$ & $\begin{array}{l}\text { Girls } \\
(15-19)\end{array}$ & $\begin{array}{l}\text { Boys } \\
(15-19)\end{array}$ & $\begin{array}{c}\text { Girls } \\
(15-19)\end{array}$ & $\begin{array}{l}\text { Boys } \\
(15-19)\end{array}$ & $\begin{array}{l}\text { Girls } \\
(15-19)\end{array}$ \\
\hline & \multicolumn{2}{|c|}{ Combined (percent) } & \multicolumn{2}{|c|}{ Urban (percent) } & \multicolumn{2}{|c|}{ Rural (percent) } \\
\hline 17 or below & 1.1 & 10.3 & 0.1 & 5.5 & 1.2 & 10.9 \\
\hline 18 & 1.0 & 11.7 & 0.6 & 7.6 & 1.0 & 12.2 \\
\hline 19 & 0.8 & 4.4 & 0.8 & 3.2 & 0.8 & 4.6 \\
\hline 20 & 2.8 & 5.8 & 1.5 & 4.8 & 2.9 & 5.9 \\
\hline 21 & 0.6 & 1.8 & 0.7 & 2.0 & 0.5 & 1.8 \\
\hline 22 & 1.5 & 1.8 & 1.3 & 2.3 & 1.5 & 1.7 \\
\hline 23 & 0.8 & 0.8 & 0.6 & 1.3 & 0.8 & 0.7 \\
\hline 24 & 0.7 & 0.3 & 1.2 & 0.9 & 0.6 & 0.3 \\
\hline 25 or above & 7.3 & 1.6 & 8.1 & 5.3 & 7.2 & 1.2 \\
\hline Does not know & 83.6 & 61.5 & 85.2 & 67.1 & 83.4 & 60.8 \\
\hline Number of respondents & 1,821 & 3,428 & 1,008 & 1,738 & 813 & 1,690 \\
\hline
\end{tabular}

Note: All Ns are unweighted.

Among adolescents for whom data were available for both their own and the perceived preference of their parents for their age of marriage, we compared the age at which respondents preferred to marry and the age at which respondents perceived that their parents would want them to marry. As mentioned earlier, a large majority of adolescents were not aware of their parents' preferences and, as such, these comparisons should not be generalised for adolescents in the state. Findings are summarised in Table 10.3. The majority of older boys reported that the age at which they would like to marry coincided with the age at which they thought that their parents would want them to marry (64\%), which, however, somewhat fewer unmarried older girls reported (37\%). Indeed, the majority of unmarried older girls reported that they preferred to marry at a later age than the age they considered their parents would want (61\%), which fewer older boys reported (30\%). Only a small minority of older adolescents preferred to marry earlier than the age their parents preferred as perceived by them (2-6\%). Differences by residence in rural or urban areas with regard to preferences were marked. Congruence of adolescents' preferences with their perceived parental preferences was more likely to be observed in the reports of rural than urban boys (64\% versus $58 \%$ ), while a reverse pattern was observed in the reports of girls (36\% versus $44 \%$ ). Moreover, more rural than urban girls were likely to report that they preferred to marry at a later age than the age they considered their parents would want (62\% versus 54\%). We observed that congruence of adolescents' preferences with their perceived parental preferences was more likely when they thought that parents preferred a later marriage for them than an earlier one-for example, while the extent of congruence was 38 percent for preferred marriage age of below 20 years, it was as high as 88 percent for preferred marriage age of 20-24 years and 97 percent for preferred marriage age of 25 years and above 
in older boys' reports of their preferences and what they perceived as their parents' preferences. The corresponding proportions for unmarried older girls were 42 percent, 87 percent, and 99 percent (not shown in tables or figures).

Table 10.3: Congruence and dissonance of adolescents' preferences with perceived parental preferences for age of marriage for adolescents

Percent distribution of unmarried adolescents in ages 15-19 by congruence and dissonance of adolescents' preferences with perceived parental preferences for age of marriage for respondents, according to residence, Bihar, 2016

\begin{tabular}{|c|c|c|c|c|c|c|}
\hline \multirow{2}{*}{$\begin{array}{l}\text { Congruence/dissonance in preferred age of } \\
\text { marriage }\end{array}$} & $\begin{array}{l}\text { Boys } \\
(15-19)\end{array}$ & $\begin{array}{c}\text { Girls } \\
(15-19)\end{array}$ & $\begin{array}{l}\text { Boys } \\
(15-19)\end{array}$ & $\begin{array}{c}\text { Girls } \\
(15-19)\end{array}$ & $\begin{array}{l}\text { Boys } \\
(15-19)\end{array}$ & $\begin{array}{c}\text { Girls } \\
(15-19)\end{array}$ \\
\hline & \multicolumn{2}{|c|}{ Combined (percent) } & \multicolumn{2}{|c|}{ Urban (percent) } & \multicolumn{2}{|c|}{ Rural (percent) } \\
\hline $\begin{array}{l}\text { Respondent preferred to marry at ages earlier } \\
\text { than ages perceived as preferred by parents }\end{array}$ & 6.1 & 2.2 & 10.9 & 1.4 & 5.6 & 2.2 \\
\hline No differences in preferences & 63.8 & 36.7 & 58.4 & 44.2 & 64.4 & 36.0 \\
\hline \multicolumn{7}{|l|}{$\begin{array}{l}\text { Respondent preferred to marry at ages later } \\
\text { than ages perceived as preferred by parents }\end{array}$} \\
\hline 1 year & 6.3 & 9.4 & 6.7 & 9.7 & 6.2 & 9.4 \\
\hline 2 years & 9.0 & 20.2 & 5.1 & 15.1 & 9.5 & 20.7 \\
\hline 3 years & 4.1 & 12.5 & 5.3 & 10.5 & 4.0 & 12.7 \\
\hline 4 years & 5.5 & 8.2 & 4.7 & 8.0 & 5.6 & 8.2 \\
\hline 5 or more years & 5.2 & 10.8 & 8.9 & 11.1 & 4.7 & 10.7 \\
\hline $\begin{array}{l}\text { Number of respondents for whom their } \\
\text { preferences and their perceived parental } \\
\text { preferences for age at marriage were known }\end{array}$ & 274 & 1,016 & 140 & 471 & 134 & 545 \\
\hline
\end{tabular}

Note: All Ns are unweighted.

\subsection{Marriage planning and extent of adolescents' participation in it}

We probed the process of marriage planning as well as the participation of both younger and older adolescents in this process. We asked all respondents whether their parents or guardians had sought their opinion about the age at which they wished to marry and, if so, about their age at that time.

Figure 10.1: Percentage of adolescents in ages 10-19 reporting that their parents had sought their opinion about marriage age, according to residence, Bihar, 2016

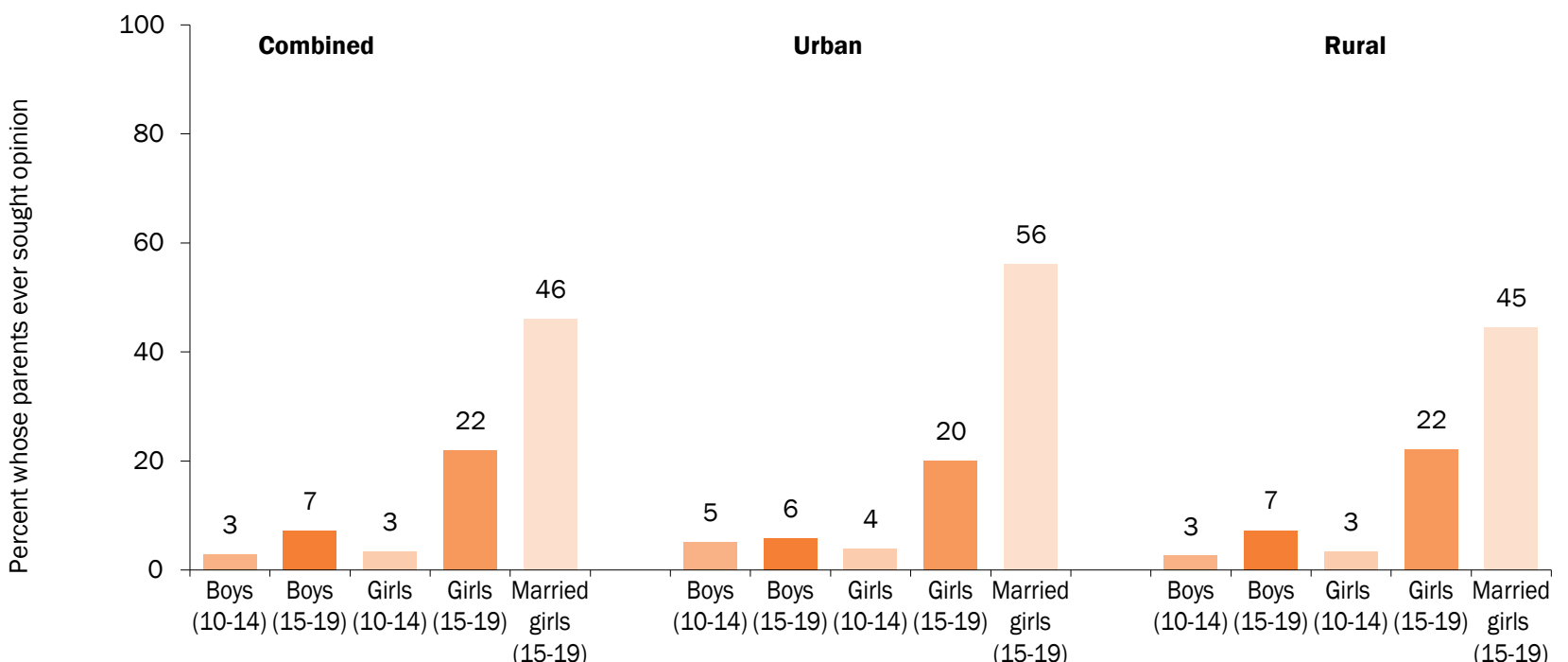


Some three percent of younger adolescents and 7-22 percent of older boys and unmarried older girls reported that their parents had sought their opinion on when they would like to marry (Figure 10.1). Among married older girls, 46 percent reported that they had been consulted by their parents, while as many as 54 percent of married older girls reported that they had not been consulted at all on the age at which they wished to marry. Differences in the extent of participation in such decisions between adolescents from rural and those from urban areas were wide among married older girls; more urban than rural married older girls reported that their parents had sought their opinion about when they would like to marry (56\% versus $45 \%$ ).

Findings presented in Table 10.4 show that among older adolescents whose parents had sought their opinion about when they should marry, less than one percent of boys and five percent of unmarried girls reported that marriagerelated discussions were initiated before age 15 . Among married girls, such discussion took place before age 15 for as many as 29 percent. Differences by residence in rural or urban areas were narrow among unmarried girls, but more of urban than rural boys and less of urban than rural married girls reported that such discussion occurred in early adolescence ( $6 \%$ versus none among boys and $24 \%$ versus $30 \%$ ). The median age at initiation of marriagerelated discussion was 17 years for boys, 16 years for unmarried girls, and 15 years for married girls among those who were able to recall their age at the initiation of such discussion. Age at initiation of such discussion was a year later for urban than rural adolescents.

\section{Table 10.4: Age at initiation of marriage-related discussion}

Percentage of adolescents in ages 15-19 whose opinion had been sought on when to marry reporting initiation of marriage-related discussions in early adolescence and the median age at initiation of discussion, according to residence, Bihar, 2016

\begin{tabular}{|c|c|c|c|}
\hline Marriage discussion & $\begin{array}{c}\text { Boys } \\
(15-19)\end{array}$ & $\begin{array}{c}\text { Girls } \\
(15-19)\end{array}$ & $\begin{array}{l}\text { Married girls } \\
(15-19)\end{array}$ \\
\hline \multicolumn{4}{|c|}{ Combined (percent) } \\
\hline Discussion on marriage initiated before age 15 & 0.5 & 5.3 & 29.4 \\
\hline Median age at discussion & 17 & 16 & 15 \\
\hline Number whose parents had initiated discussion on when to marry & 125 & 763 & 1,644 \\
\hline \multicolumn{4}{|c|}{ Urban (percent) } \\
\hline Discussion on marriage initiated before age 15 & 5.7 & 4.7 & 24.0 \\
\hline Median age at discussion & 18 & 17 & 16 \\
\hline Number whose parents had initiated discussion on when to marry & 61 & 365 & 762 \\
\hline \multicolumn{4}{|c|}{ Rural (percent) } \\
\hline Discussion on marriage initiated before age 15 & 0.0 & 5.3 & 30.2 \\
\hline Median age at discussion & 17 & 16 & 15 \\
\hline Number whose parents had initiated discussion on when to marry & 64 & 398 & 882 \\
\hline
\end{tabular}

Notes: All Ns are unweighted. ${ }^{1}$ We excluded 51 boys, 57 unmarried older girls, and 165 married older girls who had reported that they did not remember the age at initiation of marriage-related discussion.

\subsection{Marriage preparedness}

Several questions were put to married older girls to understand their preparedness for marriage. Questions ranged from whether their husband had been chosen by the girl or by her parents; whether the girl's approval of the husband had been sought, if chosen by the parents; and how much contact the girl had with her prospective husband prior to marriage.

Table 10.5 describes marriage-related preparedness. An overwhelming proportion (94\%) of girls had married a partner chosen by their parents. Only 34 percent of girls reported that their parents had sought their approval while choosing their marriage partner, although 46 percent had been consulted on the age at which they wished to marry 
(see Figure 10.1). As many as 61 percent of girls reported that their parents had not sought their approval at all; more rural than urban girls so reported (62\% versus $44 \%$ ). Just six percent of girls reported that they had chosen their marriage partner on their own, and more urban girls than their rural counterparts so reported (12\% versus $5 \%$ ).

Premarital acquaintance was limited-just 23 percent of girls reported a chance ever to meet and interact alone with their husband-to-be prior to marriage, and more urban than rural girls so reported (34\% versus $22 \%$ ). Moreover, 77 percent of girls reported that they had met their husband for the first time on the wedding day, and 15 percent reported that they knew their husband somewhat before marriage. Just eight percent reported that they knew their husband well prior to marriage. Differences between those from rural and those from urban areas indicate that urban girls were more likely than rural girls to report that they knew their husband well prior to marriage (15\% versus $7 \%$ ) and less likely to report that they had met him on their wedding day (67\% versus $78 \%)$. In short, findings underscore the extent to which girls were excluded from marriage-related decision-making and the extent to which girls were married to relative strangers.

\section{Table 10.5: Marriage preparedness}

Percent distribution of married girls in ages 15-19 by type of marriage and degree of acquaintance with husbands before marriage and percentage reporting ever interacting with fiancé, according to residence, Bihar, 2016

\begin{tabular}{lccc}
\hline Marriage indicators & $\begin{array}{c}\text { Combined } \\
\text { (percent) }\end{array}$ & $\begin{array}{c}\text { Urban } \\
\text { (percent) }\end{array}$ & $\begin{array}{c}\text { Rural } \\
\text { (percent) }\end{array}$ \\
\hline Type of marriage & 5.9 & 11.5 & 5.3 \\
Marriage fixed by respondent herself (love marriage) & & & 32.4 \\
Marriage arranged by parents with respondent's approval of choice of & 33.6 & 44.4 & 62.4 \\
husband & 60.5 & 44.1 & 22.2 \\
Marriage fixed by parents without seeking respondent's approval & 23.4 & 33.9 & 77.9 \\
Ever had a chance to meet/talk with fiancé alone & & & 14.9 \\
Acquaintance with husband before marriage & 76.8 & 66.7 & 7.2 \\
Met on wedding day & 15.2 & 18.6 & $\mathbf{2 , 0 4 2}$ \\
Knew somewhat & 8.0 & $\mathbf{1 4 . 7}$ & $\mathbf{1 , 3 6 6}$ \\
Knew very well & $\mathbf{3 , 4 0 8}$ & & $\mathbf{2 0 4}$ \\
Number of respondents & & & \\
\hline
\end{tabular}

Note: All Ns are unweighted.

\subsection{Age at marriage and cohabitation}

Findings confirm the prevalence of child marriage among girls, although marriages in early adolescence, that is, before age 15, were somewhat rare (Table 10.6). Findings show that among girls in ages 15-19, seven percent were married before age 15, with a slight difference in this regard between those from rural and those from urban areas ( $7 \%$ in rural areas versus $3 \%$ in urban areas). However, among girls in ages $18-19$, as many as 44 percent were married before age 18. Although not exactly comparable, our findings concur with evidence from the National Family Health Survey 2015-16, which reported that 39 percent of 20-24-year-old women were married before age 18 (IIPS, 2017a). In rural areas, as many as 46 percent of 18-19-year-old girls were married before age 18; the corresponding proportion in urban areas was 27 percent. In total, among 15-19-year-old girls, 74 percent were never married, and 83 percent of girls in urban areas and 73 percent of girls in rural areas were not married. The median age at both marriage and cohabitation among the married was 16 years in the combined sample. Neither median age at marriage nor median age at cohabitation differed between rural and urban areas. 


\section{Table 10.6: Age at marriage and cohabitation}

Percentage of adolescent girls in ages 15-19 who were married before selected ages, percentage never married, and median age at marriage and cohabitation among those married, according to residence, Bihar, 2016

\begin{tabular}{|c|c|c|c|}
\hline Indicators of age at marriage & $\begin{array}{c}\text { Combined } \\
\text { (percent) }\end{array}$ & $\begin{array}{c}\text { Urban } \\
\text { (percent) }\end{array}$ & $\begin{array}{c}\text { Rural } \\
\text { (percent) }\end{array}$ \\
\hline \multicolumn{4}{|l|}{ Age at marriage } \\
\hline Married by age 15 & 6.8 & 3.4 & 7.2 \\
\hline Number of girls in ages 15-19 & 6,836 & 3,104 & 3,732 \\
\hline Married by age 18 & 43.7 & 27.3 & 45.8 \\
\hline Number of girls in ages 18-19 & 3,187 & 1,503 & 1,684 \\
\hline Girls never married & 73.9 & 83.4 & 72.8 \\
\hline Number of girls in ages 15-19 & 6,836 & 3,104 & 3,732 \\
\hline Median age at marriage & 16 & 16 & 16 \\
\hline Median age at cohabitation & 16 & 16 & 16 \\
\hline Number of married girls in ages 15-19 & 3,408 & 1,366 & 2,042 \\
\hline
\end{tabular}

Note: All Ns are unweighted.

Table 10.7 presents the percentage of girls in ages 18-19 who were married before age 18 by selected background characteristics. Findings show that Hindu girls were somewhat more likely than Muslim girls to marry before age 18 (45\% versus 36\%). Caste-wise differences indicate that girls who belonged to general castes were considerably less likely than girls from other castes to marry before age 18 (21\% versus $45-56 \%)$. The percentage of girls' marrying before age 18 decreased consistently with years of schooling-for example, the proportion of girls' marrying before age 18 declined from 74 percent among those with no formal education to 16 percent among those who had completed 12 or more years of schooling. Girls who were not enrolled in school/college at the time of the interview were more likely than those who were currently enrolled to marry before age 18 (59\% versus $12 \%)$. A larger proportion of girls who were not engaged in paid work in the year preceding the interview married before age 18 compared with those who were working (46\% versus 33\%). The proportion of girls' marrying before age 18 decreased by household wealth status-from 67 percent among girls in the poorest (first) quintile to 27 percent among those in the wealthiest (fifth) quintile. Finally, marriages before age 18 declined by mother's education-from 50 percent among girls whose mother had no formal education to 17 percent among girls whose mother had completed 10 or more years of schooling.

\section{Table 10.7: Age at marriage by selected background characteristics}

Percentage of adolescent girls in ages 18-19 who were married by age 18 by selected background characteristics, Bihar, 2016

Background characteristics (percent)

$\begin{array}{lr}\text { Religion }^{1} & \\ \text { Hindu } & 45.0 \\ \text { Muslim } & 36.3 \\ \text { Caste }^{2} & 56.4 \\ \text { SC } & 44.9 \\ \text { OBC } & 21.3 \\ \text { General }^{3} & \text { Cont. }\end{array}$


Table 10.7 Cont.

Background characteristics (percent)

\section{Completed years of schooling}

None $^{4}$

1-4

65.2

5-7

68.2

8-9

45.8

10-11

12 and above

\section{Current schooling status ${ }^{5}$}

Yes

No

Paid work in the 12 months prior to the interview

Yes

No

Wealth quintile

First

Second

Third

Fourth

Fifth

Mother's education (in years of schooling completed)

None $^{4}$

Notes:OBC: other backward caste; SC: scheduled caste; ST: scheduled tribe. ${ }^{1}$ Percentages not shown for those belonging to other religions as less than one percent of surveyed adolescents belo nged to other religions. ${ }^{2}$ Percentages not shown for those belonging to STs as less than one percent of surveyed adolescents belonged to STs. ${ }^{3}$ Includes all those not belonging to SCs, STs, or OBCs. ${ }^{4}$ Includes non-literate and literate with no formal schooling. ${ }^{5}$ Percentages not shown for adolescents who were pursuing their education through distance education courses at the time of interview or those who never went to school.

\subsection{Payment of dowry}

Despite the existence of laws against dowry, our findings confirm that the practice of dowry was widespread. Indeed, 91 percent of married older girls reported that they had brought a dowry to their marital family, with little difference between rural and urban girls in this regard. Findings also show that a notable proportion of married girls acknowledged that they had experienced dowry-related harassment. Specifically, 29 percent of girls noted that their husband's family members had commented that the dowry that they brought was too little and 19 percent reported that their husband's family members had asked them to bring more dowry. On the whole, 31 percent of married girls had experienced at least one of these forms of dowry-related harassment, with hardly any differences between those from rural and those from urban areas. 


\section{Table 10.8: Dowry practices}

Percentage of married girls in ages 15-19 reporting dowry practices and experience of dowry-related harassment, according to residence, Bihar, 2016

\begin{tabular}{lccc}
\hline Indicators of dowry payment & $\begin{array}{c}\text { Combined } \\
\text { (percent) }\end{array}$ & $\begin{array}{c}\text { Urban } \\
\text { (percent) }\end{array}$ & $\begin{array}{c}\text { Rural } \\
\text { (percent) }\end{array}$ \\
\hline Brought dowry & 91.0 & 88.0 & 91.4 \\
$\begin{array}{l}\text { Dowry-related harassment } \\
\text { A. Husband's family ever commented that the } \\
\text { dowry/gift/cash brought was too little }\end{array}$ & & & \\
Yes & 28.8 & 26.2 & 29.1 \\
No & 70.0 & 72.0 & 69.7 \\
B. Husband's family ever asked for more & & & \\
dowry/gift/cash from respondent's parents & & & \\
Yes & 19.2 & 16.2 & 19.5 \\
No & 80.8 & 83.8 & 80.5 \\
Any of the above dowry-harassment situations & 30.7 & 27.9 & 31.0 \\
Number of respondents & $\mathbf{3 , 4 0 8}$ & $\mathbf{1 , 3 6 6}$ & $\mathbf{2 , 0 4 2}$ \\
\hline
\end{tabular}

Note: All Ns are unweighted.

\subsection{Experience of domestic violence within marriage}

An assessment of domestic violence experienced by married older girls surveyed in UDAYA entailed eliciting detailed information on emotional violence, physical violence, and sexual violence that husbands had perpetrated. Table 10.9 and Figure 10.2 show that 34 percent of married girls had experienced emotional violence ever in married life, that is, their husband had either verbally humiliated them in the presence of others or threatened to hurt or harm someone close to them. Differences by residence in rural or urban areas with regard to emotional violence were narrow.

A somewhat smaller proportion reported the experience of some form of physical violence ever in married life (28\%), with negligible differences between those from rural and those from urban areas. Slapping was the most commonly reported form of physical violence experienced by almost all those reporting any form of violence (27\%). Some 9-11 percent of girls reported that their husband had either twisted their arm or pulled their hair, had pushed or shaken them, had thrown something at them, or had punched, kicked, dragged, or beaten them. Other forms of violence, including choking or burning on purpose and threatening or attacking with a knife or gun, were reported by 1-2 percent of girls.

Over the course of their married life, more girls acknowledged the experience of forced sex within marriage-37 percent of girls reported that they had ever experienced forced sex within marriage; fewer urban than rural girls so reported (33\% of urban girls versus $38 \%$ of rural girls). 


\section{Table 10.9: Domestic violence within marriage}

Percentage of married girls in ages 15-19 reporting experience of emotional, physical, and sexual violence perpetrated by their husband, according to residence, Bihar, 2016

\begin{tabular}{|c|c|c|c|}
\hline Types of violence & $\begin{array}{l}\text { Combined } \\
\text { (percent) }\end{array}$ & $\begin{array}{c}\text { Urban } \\
\text { (percent) }\end{array}$ & $\begin{array}{c}\text { Rural } \\
\text { (percent) }\end{array}$ \\
\hline \multicolumn{4}{|l|}{ Emotional violence (ever) } \\
\hline $\begin{array}{l}\text { Verbally abused respondent in the presence of others or threatened to hurt } \\
\text { or harm someone close to respondent }\end{array}$ & 33.9 & 32.1 & 34.1 \\
\hline \multicolumn{4}{|l|}{ Physical violence (ever) } \\
\hline Slapped & 27.0 & 26.6 & 27.0 \\
\hline Twisted arm or pulled hair & 11.3 & 10.6 & 11.3 \\
\hline Pushed/shook or threw something at respondent & 9.1 & 8.0 & 9.2 \\
\hline Punched, kicked, dragged, or beaten & 9.0 & 8.4 & 9.0 \\
\hline Choked or burnt on purpose & 1.8 & 1.7 & 1.8 \\
\hline Threatened or attacked with knife/gun & 0.6 & 0.6 & 0.6 \\
\hline At least one of the above & 27.5 & 26.9 & 27.5 \\
\hline \multicolumn{4}{|l|}{ Sexual violence (ever) } \\
\hline Ever forced respondent to engage in sex & 37.4 & 32.9 & 37.9 \\
\hline Number who had begun cohabiting & 3,182 & 1,311 & 1,871 \\
\hline \multicolumn{4}{|l|}{ Frequency of physical violence in the year preceding the interview } \\
\hline \multicolumn{4}{|l|}{ A. Slapped } \\
\hline Never & 72.3 & 71.8 & 72.4 \\
\hline Sometimes & 25.6 & 25.0 & 25.6 \\
\hline Often & 2.1 & 3.2 & 2.0 \\
\hline \multicolumn{4}{|l|}{ B. Twisted arm or pulled hair } \\
\hline Never & 87.7 & 87.9 & 87.7 \\
\hline Sometimes & 11.4 & 10.8 & 11.4 \\
\hline Often & 0.9 & 1.3 & 0.9 \\
\hline \multicolumn{4}{|l|}{ C. Pushed/shook or threw something at respondent } \\
\hline Never & 89.8 & 90.4 & 89.7 \\
\hline Sometimes & 9.6 & 8.3 & 9.8 \\
\hline Often & 0.6 & 1.3 & 0.5 \\
\hline \multicolumn{4}{|l|}{ D. Punched, Kicked, dragged, or beaten } \\
\hline Never & 90.3 & 89.9 & 90.4 \\
\hline Sometimes & 9.0 & 8.9 & 9.0 \\
\hline Often & 0.7 & 1.2 & 0.7 \\
\hline \multicolumn{4}{|l|}{ E. Choked or burnt on purpose } \\
\hline Never & 98.5 & 98.4 & 98.5 \\
\hline Sometimes & 1.3 & 1.2 & 1.3 \\
\hline Often & 0.3 & 0.4 & 0.2 \\
\hline \multicolumn{4}{|l|}{ F. Threatened or attacked with knife/gun } \\
\hline Never & 99.6 & 99.7 & 99.6 \\
\hline Sometimes & 0.3 & 0.2 & 0.3 \\
\hline Often & 0.1 & 0.1 & 0.1 \\
\hline At least one of the above & 28.6 & 28.7 & 28.5 \\
\hline
\end{tabular}


Table 10.9 Cont.

\begin{tabular}{|c|c|c|c|}
\hline Types of violence & $\begin{array}{c}\text { Combined } \\
\text { (percent) }\end{array}$ & $\begin{array}{c}\text { Urban } \\
\text { (percent) }\end{array}$ & $\begin{array}{c}\text { Rural } \\
\text { (percent) }\end{array}$ \\
\hline \multicolumn{4}{|l|}{ When first experience of physical violence within marriage occurred } \\
\hline First experienced violence within 12 months of marriage & 21.8 & 21.6 & 21.8 \\
\hline \multicolumn{4}{|l|}{ Sexual violence in the year preceding the interview } \\
\hline Forced respondent to engage in sex in the year preceding the interview & 28.9 & 28.6 & 28.9 \\
\hline $\begin{array}{l}\text { Experience of physical or sexual violence in the year preceding the } \\
\text { interview }\end{array}$ & 41.3 & 41.9 & 41.2 \\
\hline Number who had cohabited for at least 12 months & 2,580 & 1,056 & 1,524 \\
\hline
\end{tabular}

Note: All Ns are unweighted.

Experience of any form of physical violence within marriage in the 12 months preceding the interview was reported by 29 percent of girls who had cohabited for at least one year. As earlier, slapping was the most commonly reported form of violence; 28 percent of girls reported that they were slapped by their husband in the 12 months preceding the interview. Findings on the occurrence of physical violence within the first year of marriage (among those who had cohabited for at least one year) indicate that 22 percent of girls reported experience of physical violence within a year of marriage, with no variation between those from rural and those from urban areas. Recent experience of sexual violence, that is, in the 12 months preceding the interview, was reported by 29 percent of girls who had cohabited for at least one year, with little difference between rural and urban married girls in this regard. On the whole, 41 percent of girls who had cohabited for at least one year had experienced physical or sexual violence in the year preceding the interview.

Figure 10.2: Percentage of married girls in ages 15-19 reporting ever experience of emotional, physical, and sexual violence perpetrated by their husband, according to residence, Bihar, 2016

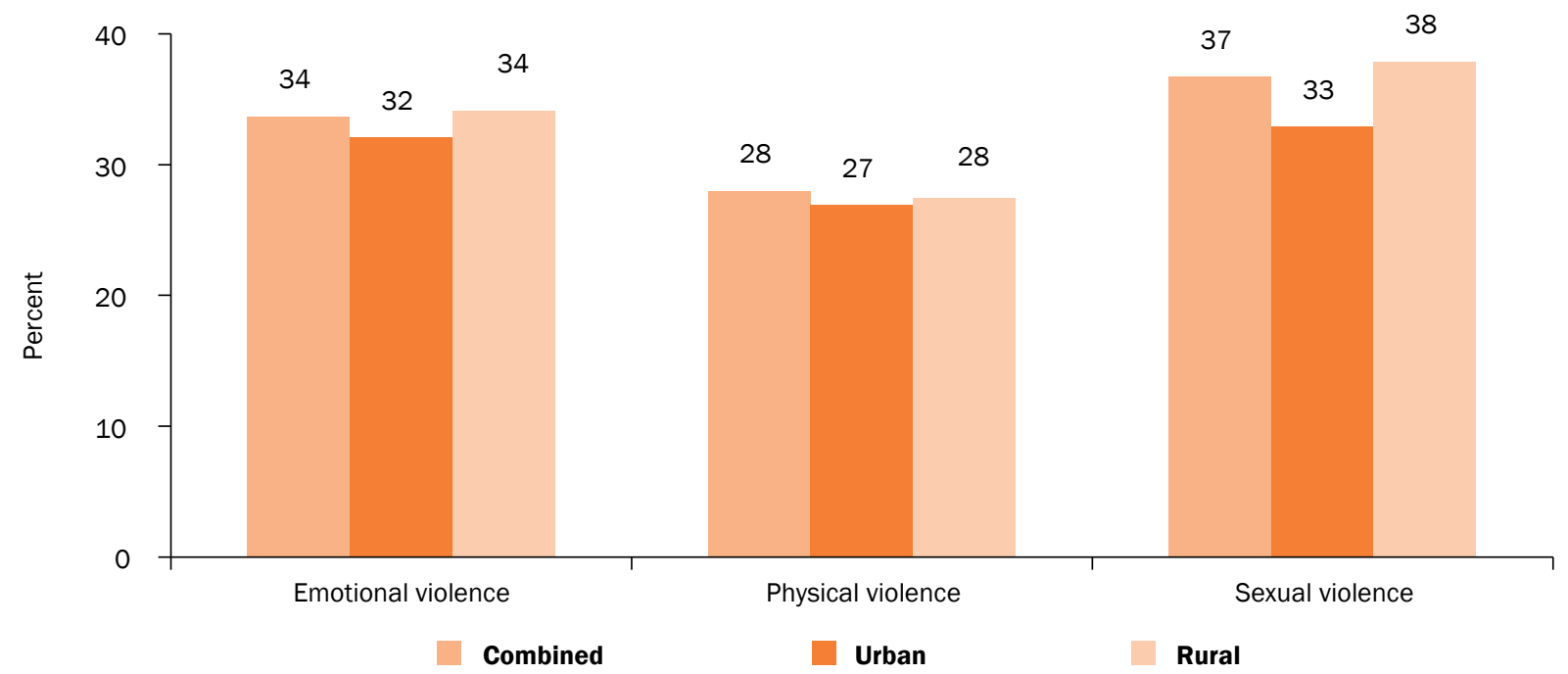

Table 10.10 presents differentials in girls' experience of physical or sexual violence within marriage in the 12 months preceding the interview among girls who had cohabited for at least a year by selected background characteristics. Findings show that recent experience of violence did not differ by age or religion. However, it differed by caste, education, current enrolment status, engagement in paid work, household wealth status, mother's education, and the number of surviving children the girl had. Caste-wise differences were marked-girls from scheduled castes were more likely than girls from other castes to report recent experience of marital violence (48\% versus 35-39\%). Recent experience of marital violence declined steadily with years of schooling completed-from 47 percent among girls with no formal education or 1-4 years of schooling to 25 percent among girls who had completed 12 or more years of schooling. A smaller proportion of girls who were currently enrolled in school/college reported marital violence experience than those who were not enrolled (30\% versus 40\%). Girls who were engaged in paid work were more 
likely than those who were not engaged to have experienced marital violence in the recent past (54\% versus $40 \%$ ). Findings also show that violence declined with household wealth status (from $48 \%$ among girls belonging to the poorest households to $33 \%$ among girls belonging to the richest households) and with mother's education (from $42-48 \%$ among girls whose mother had no formal education or 1-7 years of schooling to $23 \%$ among girls whose mother had completed 10 or more years of schooling). It also increased with the number of surviving children the girl had-from 38-42 percent among girls with no children or one surviving child to 55 percent among those with two or more children.

\section{Table 10.10: Domestic violence within marriage by background characteristics}

Percentage of married girls in ages 15-19 who had cohabited for at least a year reporting the experience of physical or sexual violence perpetrated by their husband in the 12 months prior to the interview by selected background characteristics, Bihar, 2016

Background characteristics (percent)

Age

15-17

42.3

18-19

40.9

Religion $^{1}$

Hindu

41.4

Muslim

Caste $^{2}$

$\mathrm{SC}$

OBC

General $^{3}$

Completed years of schooling

None $^{4}$

46.5

1-4

47.2

$5-7$

41.6

8-9

41.1

10-11

12 and above

Current schooling status ${ }^{5}$

Yes

No

Paid work in the $\mathbf{1 2}$ months prior to the interview

Yes

No

Wealth quintile

First

Second

Third

Fourth

Fifth

Mother's education (in years of schooling completed)

None $^{4}$

8-9 
Table 10.10 Cont.

\begin{tabular}{|c|c|}
\hline \multicolumn{2}{|c|}{ Background characteristics (percent) } \\
\hline \multicolumn{2}{|c|}{ Number of surviving children } \\
\hline None & 37.8 \\
\hline 1 & 41.8 \\
\hline 2 or more & 54.9 \\
\hline Total & 41.3 \\
\hline
\end{tabular}

\subsection{Extent of extramarital sexual experiences}

To capture the extent of extramarital sexual experiences, we asked married girls about their sexual experiences following marriage with other partners, such as romantic partners and casual partners, and in situations of forced and exchange sex. Findings show that hardly any girls reported an extramarital sexual encounter ever in their married life and in the year preceding the interview (1\%, not shown in table).

\subsection{Discussion about childbearing and pressure to bear children}

To better understand married older girls' reproductive intentions, we asked them whether they had discussed childbearing with their husband and others and whether they had experienced any pressure to bear children soon after marriage. We also asked them when they would like to have their first birth.

\subsubsection{Discussion about childbearing with husband and others}

The survey sought to ascertain from all married girls whether someone had talked to them about the importance of delaying the first pregnancy about the time of their marriage and whether they had discussed with their husband the number of children they planned to have and the use of contraception to delay the first pregnancy. Findings show that just 15 percent of girls were advised to delay the first pregnancy about the time of their marriage (Table 10.11). Communication with husband on reproductive matters was far from universal. Just 54 percent of girls reported that they had communicated with their husband on how many children they wanted. Far fewer reported that they had discussed with their husband the subject of contraceptive use to delay the first pregnancy (20\%). Differences in reports of married girls between those from rural and those from urban areas were muted on all these indicators.

\section{Table 10.11: Discussion about child bearing with husband and others}

Percentage of married girls in ages 15-19 reporting discussion about childbearing with their husband and others, according to residence, Bihar, 2016

\begin{tabular}{lrr}
\hline Indicators of communication & $\begin{array}{c}\text { Combined } \\
\text { (percent) }\end{array}$ & $\begin{array}{c}\text { Urban } \\
\text { (percent) }\end{array}$ \\
\hline $\begin{array}{l}\text { Someone talked to the respondent about the importance of delaying } \\
\text { first pregnancy about the time of respondent's marriage }\end{array}$ & 14.6 & 17.1 \\
Number of respondents & $\mathbf{3 , 4 0 8}$ & $\mathbf{1 , 3 6 6}$ \\
Ever communicated with husband on: & 54.1 & 57.9 \\
Number of children to have & 20.3 & 22.6 \\
Using contraception to delay first pregnancy & $\mathbf{2 , 1 8 2}$ & $\mathbf{1 , 3 1 1}$ \\
Number who had begun cohabiting & & $\mathbf{1 , 8 7 1}$ \\
\hline
\end{tabular}

Note: All Ns are unweighted. 


\subsubsection{Pressure to bear a child soon after marriage}

We addressed two questions to married girls who had begun cohabiting with their husband to assess whether they had felt compelled to bear a child soon after marriage. The first sought to determine whether family members had pressurised the respondent to have a child soon after marriage, and the second sought to ascertain whether the respondent feared that her in-laws and others would call her barren if she did not bear a child soon after marriage. Findings presented in Table 10.12 indicate that 25 percent of girls who had begun cohabiting with their husband were pressurised by their family members to bear a child immediately after marriage, with somewhat more of rural than urban girls reporting so (25\% versus $19 \%)$. A similar proportion also reported that they feared their in-laws and others would call her barren if she did not bear a child soon after marriage (24\%), and, again, somewhat more girls in rural than urban areas so reported (25\% versus $18 \%$ ). As many as 33 percent of girls responded affirmatively to one of these questions, which, again, more rural girls reported than urban girls (33\% versus $27 \%$ ).

\section{Table 10.12: Pressure to bear a child soon after marriage}

Percentage of married girls in ages 15-19 reporting that they had experienced pressure to bear a child soon after marriage, according to residence, Bihar, 2016

\begin{tabular}{lcc}
\hline Indicators of compulsion to bear children & $\begin{array}{c}\text { Combined } \\
\text { (percent) }\end{array}$ & $\begin{array}{c}\text { Urban } \\
\text { (percent) }\end{array}$ \\
\hline $\begin{array}{l}\text { Family members pressurised respondent to bear a child } \\
\text { immediately after marriage }\end{array}$ & 24.7 & 19.3 \\
$\begin{array}{l}\text { Respondent felt afraid that in-laws and others would call her } \\
\text { barren if she did not bear a child soon after marriage }\end{array}$ & 24.3 & 17.6 \\
Any of the above & 32.6 & 26.6 \\
Number who had begun cohabiting & $\mathbf{3 , 1 8 2}$ & $\mathbf{1 , 3 1 1}$ \\
\hline
\end{tabular}

Note: All Ns are unweighted.

\subsubsection{Preferred interval for first birth}

Findings presented in Table 10.13 show that 43 percent of girls who had begun cohabiting had wanted to have their first birth within the first year of marriage or a year after marriage, with little difference between rural and urban girls in this respect. Indeed, some 42 percent of girls desired to delay their first birth for two years after marriage.

\section{Table 10.13: Preferred interval for first birth}

Percent distribution of married girls in ages 15-19 by preferred interval for first birth, according to residence, Bihar, 2016

\begin{tabular}{|c|c|c|c|}
\hline Preferred interval for first birth & $\begin{array}{l}\text { Combined } \\
\text { (percent) }\end{array}$ & $\begin{array}{c}\text { Urban } \\
\text { (percent) }\end{array}$ & $\begin{array}{c}\text { Rural } \\
\text { (percent) }\end{array}$ \\
\hline Within the first year of or a year after marriage & 42.6 & 45.5 & 42.2 \\
\hline Two or more years after marriage & 41.6 & 40.7 & 41.8 \\
\hline Did not want any child or had not thought about when to have the first birth & 15.8 & 13.8 & 16.0 \\
\hline Number who had begun cohabiting & 3,182 & 1,311 & 1,871 \\
\hline
\end{tabular}

Note: All Ns are unweighted.

\subsection{Contraceptive practices within marriage}

The survey probed contraception practices among married older girls with respect to their lifetime and current contraceptive use as well as their use of contraception to delay the first birth. We asked those who had not practised contraception before the first birth their reasons for this. We also included questions that allowed us to estimate unmet need for contraception and questions to help assess their future intentions to use contraception. 


\subsubsection{Ever and current use of contraceptive methods}

The practice of contraception at any time during married life was limited-only 11 percent of married girls reported contraceptive use (see Table 10.14). A smaller proportion reported the use of modern contraceptive methods (5\%). The modern method most likely to have been used was the condom (reported by 4\%), while oral pills, IUD, and other modern methods were used by less than one percent for each method. The use of traditional contraceptive methods was reported by six percent of girls-these included rhythm (5\%) and withdrawal (2\%). At the time of the interview, seven percent were practising contraception, with two percent reporting condom use and three percent relying on rhythm. Differences by residence in rural or urban areas were narrow on all these indicators.

\section{Table 10.14: Contraceptive use within marriage}

Percentage of married girls in ages 15-19 by ever and current contraceptive use, according to residence, Bihar, 2016

\begin{tabular}{|c|c|c|c|}
\hline Contraceptive use & $\begin{array}{l}\text { Combined } \\
\text { (percent) }\end{array}$ & $\begin{array}{c}\text { Urban } \\
\text { (percent) }\end{array}$ & $\begin{array}{c}\text { Rural } \\
\text { (percent) }\end{array}$ \\
\hline \multicolumn{4}{|c|}{ Ever use of contraception } \\
\hline Any method & 11.2 & 15.2 & 10.7 \\
\hline Any modern method & 5.4 & 9.1 & 4.9 \\
\hline Oral pills & 0.9 & 1.4 & 0.8 \\
\hline IUD & 0.3 & 0.3 & 0.4 \\
\hline Condom & 3.9 & 6.7 & 3.5 \\
\hline Other & 0.7 & 1.0 & 0.7 \\
\hline Any traditional method & 6.4 & 7.2 & 6.3 \\
\hline Rhythm & 5.2 & 6.2 & 5.1 \\
\hline Withdrawal & 2.0 & 1.6 & 2.0 \\
\hline Number who had begun cohabiting & 3,182 & 1,311 & 1,871 \\
\hline \multicolumn{4}{|c|}{ Current use of contraception } \\
\hline Any method & 6.9 & 10.0 & 6.5 \\
\hline Any modern method & 3.4 & 6.0 & 3.0 \\
\hline Oral pills & 0.3 & 0.8 & 0.2 \\
\hline IUD & 0.3 & 0.3 & 0.3 \\
\hline Condom & 2.1 & 4.1 & 1.9 \\
\hline Other & 0.8 & 0.9 & 0.8 \\
\hline Any traditional method & 4.0 & 4.6 & 3.9 \\
\hline Rhythm & 2.9 & 3.4 & 2.9 \\
\hline Withdrawal & 1.4 & 1.0 & 1.4 \\
\hline Number who had begun cohabiting & 3,182 & 1,311 & 1,871 \\
\hline
\end{tabular}

Note: All Ns are unweighted.

Table 10.15 describes differentials in current use of any method and any modern method of contraception by selected background characteristics among married older girls. Findings show that current use of any method and any modern method did not differ substantially by age, religion, caste, or engagement in paid work in the year preceding the interview. However, both increased with level of education-for example, current use of any method increased from five percent among those with no formal education to 14 percent among those who had completed 12 or more years of schooling. Current use of any modern method also increased correspondingly from two percent to eight percent. Current use of any method was higher among those who were currently enrolled in school/college than those who were not enrolled ( $13 \%$ versus $7 \%$ ), but no such association was observed in current use of modern 
methods. Contraceptive use increased with household wealth status-from five percent among those who were from the poorest households to 14 percent among those who belonged to the richest households for current use of any method, and from two percent to nine percent with regard to current use of any modern method. A positive association was also observed with mother's education, with the proportion increasing from six percent among girls whose mother had no formal schooling to 17 percent among girls whose mother had 10 or more years of schooling with regard to current use of any method of contraception; the corresponding increase with regard to current use of any modern method of contraception was from three percent to 14 percent. Finally, current use of any method of contraception increased with the number of surviving children, from six percent among those with no surviving children to 12 percent among those with two or more surviving children; current use of a modern method increased, correspondingly from three percent to 10 percent.

\section{Table 10.15: Current contraceptive use within marriage by background characteristics}

Percentage of married girls in ages 15-19 reporting current contraceptive use by selected background characteristics, Bihar, 2016

\begin{tabular}{|c|c|c|}
\hline Background characteristics (percent) & Any method & Any modern method \\
\hline \multicolumn{3}{|l|}{ Age } \\
\hline $15-17$ & 6.4 & 2.0 \\
\hline $18-19$ & 7.1 & 4.0 \\
\hline \multicolumn{3}{|l|}{ Religion $^{1}$} \\
\hline Hindu & 7.2 & 3.3 \\
\hline Muslim & 4.8 & 3.8 \\
\hline \multicolumn{3}{|l|}{ Caste $^{2}$} \\
\hline SC & 7.1 & 2.8 \\
\hline $\mathrm{OBC}$ & 6.8 & 3.3 \\
\hline General $^{3}$ & 8.0 & 6.2 \\
\hline \multicolumn{3}{|l|}{ Completed years of schooling } \\
\hline None $^{4}$ & 4.7 & 2.3 \\
\hline $1-4$ & 6.6 & 2.1 \\
\hline $5-7$ & 3.3 & 1.0 \\
\hline $8-9$ & 7.7 & 4.5 \\
\hline $10-11$ & 10.8 & 4.9 \\
\hline 12 and above & 14.0 & 7.6 \\
\hline \multicolumn{3}{|l|}{ Current schooling status $^{5}$} \\
\hline Yes & 12.7 & 5.8 \\
\hline No & 6.5 & 3.1 \\
\hline \multicolumn{3}{|c|}{ Paid work in the 12 months prior to the interview } \\
\hline Yes & 4.7 & 2.3 \\
\hline No & 7.2 & 3.5 \\
\hline \multicolumn{3}{|l|}{ Wealth quintile } \\
\hline First & 4.5 & 2.3 \\
\hline Second & 4.5 & 1.1 \\
\hline Third & 3.8 & 1.3 \\
\hline Fourth & 7.3 & 3.7 \\
\hline Fifth & 14.3 & 8.6 \\
\hline
\end{tabular}


Table 10.15 Cont.

\begin{tabular}{lcc}
\hline Background characteristics (percent) & Any method & Any modern method \\
\hline Mother's education (in years of schooling completed) & & 2.9 \\
None $^{4}$ & 6.4 & 2.8 \\
$1-7$ & 4.6 & 4.2 \\
$8-9$ & 11.5 & 13.6 \\
10 and above & 17.0 & 2.6 \\
Number of surviving children & & 3.3 \\
None & 6.0 & 9.5 \\
1 & 7.2 & $\mathbf{3 . 4}$ \\
2 or more & 12.1 & $\mathbf{6 . 9}$ \\
\hline
\end{tabular}

Notes:OBC: other backward caste; SC: scheduled caste; ST: scheduled tribe. ${ }^{1}$ Percentages not shown for those belonging to other religions as less than one percent of surveyed adolescents belonged to other religions. ${ }^{2}$ Percentages not shown for those belonging to STs as less than one percent of surveyed adolescents belonged to STs. ${ }^{3}$ Includes all those not belonging to SCs, STs, or OBCs. ${ }^{4}$ Includes non-literate and literate with no formal schooling. ${ }^{5}$ Percentages not shown for adolescents who were pursuing their education through distance education courses at the time of interview or those who never went to school.

\subsubsection{Length of interval between cohabitation and initiation of contraceptive use}

The module on contraceptive practices also included a look at the length of interval between cohabitation and first use of contraception and the use of contraception to delay the first birth. Findings presented in Table 10.16 show that despite the desire to delay the first birth, very few of the married older girls reported that they had practised contraception early within marriage, that is, in the first six months of cohabitation (8\%). Indeed, just nine percent had practised contraception in the first two years of marriage. Differences between girls from rural and those from urban areas were marginal with regard to contraceptive use soon after marriage. Despite these small proportions, the findings imply that among those who reported ever having practised contraception, two out of three girls reported initiation of contraceptive use within the first six months following marriage.

\section{Table 10.16: Length of interval between cohabitation and initiation of contraceptive use}

Percent distribution of married girls in ages 15-19 by initiation of contraceptive use and percentage who used contraception to delay the first birth by contraceptive method, according to residence, Bihar, 2016

\begin{tabular}{|c|c|c|c|}
\hline Initiation of contraceptive use & $\begin{array}{l}\text { Combined } \\
\text { (percent) }\end{array}$ & $\begin{array}{l}\text { Urban } \\
\text { (percent) }\end{array}$ & $\begin{array}{c}\text { Rural } \\
\text { (percent) }\end{array}$ \\
\hline \multicolumn{4}{|c|}{$\begin{array}{l}\text { Length of interval between cohabitation and first use of } \\
\text { contraception }\end{array}$} \\
\hline Less than 6 months & 7.6 & 10.2 & 7.3 \\
\hline 6-11 months & 0.5 & 0.6 & 0.5 \\
\hline $12-23$ months & 1.2 & 2.1 & 1.1 \\
\hline More than 2 years & 1.1 & 1.3 & 1.1 \\
\hline Do not know/do not remember & 0.8 & 1.1 & 0.7 \\
\hline Never used contraception & 88.8 & 84.8 & 89.3 \\
\hline \multicolumn{4}{|c|}{ Use of contraception to delay the first birth } \\
\hline Any method & 8.2 & 10.2 & 8.0 \\
\hline Any modern method & 3.3 & 6.1 & 2.9 \\
\hline Oral pills & 0.3 & 0.9 & 0.2 \\
\hline Condom & 3.0 & 5.1 & 2.7 \\
\hline Other & 0.0 & 0.2 & 0.0 \\
\hline
\end{tabular}


Table 10.16 Cont.

\begin{tabular}{lcrr}
\hline Initiation of contraceptive use & $\begin{array}{c}\text { Combined } \\
\text { (percent) }\end{array}$ & $\begin{array}{c}\text { Urban } \\
\text { (percent) }\end{array}$ & $\begin{array}{c}\text { Rural } \\
\text { (percent) }\end{array}$ \\
\hline Any traditional method & $\mathbf{5 . 4}$ & $\mathbf{4 . 5}$ & $\mathbf{5 . 5}$ \\
Rhythm & 4.2 & 3.6 & 1.3 \\
Withdrawal & 1.7 & $\mathbf{1 . 3}$ & $\mathbf{1 , 3 1 1}$ \\
Number who had begun cohabiting & $\mathbf{3 , 1 8 2}$ & $\mathbf{1 , 8 7 1}$ \\
\hline
\end{tabular}

Note: All Ns are unweighted.

Only eight percent of girls reported contraception to delay the first birth. This implies that almost three-quarters of ever users had done so to delay the first birth. Again, the methods most likely to have been used were condoms (3\%) and rhythm (4\%). Differences by residence in rural or urban areas were negligible with regard to contraceptive use to delay the first birth.

Girls who did not practise contraception to delay the first birth despite a desire to delay their first birth by at least two years were asked their reasons for their not using contraception. Findings are presented in Table 10.17. The leading reason reported by girls for their not using contraception despite a desire to delay their first birth was objections to family planning, particularly from their husband or other family members (32\% reported this reason). Specifically, 20 percent of girls reported that their husband had objected and 16 percent reported that other family members had objected. Some 23 percent of girls cited lack of awareness about methods or sources for methods and eight percent mentioned issues related to access. Some 10 percent of girls mentioned method-related concerns, including fear of side effects. Infrequent sex, including a husband living away, was cited by 22 percent of girls. The reasons mentioned by girls in rural and urban areas mirrored more or less the pattern described above for the combined sample, except that more rural than urban girls reported lack of awareness about contraceptive methods and sources of contraceptive supplies (24\% versus $17 \%$ ).

\section{Table 10.17: Reasons for not using contraception to delay the first birth}

Percentage of married girls in ages 15-19 who wanted to delay the first birth by reasons for not practising contraception to delay the first birth, according to residence, Bihar, 2016

\begin{tabular}{|c|c|c|c|}
\hline Reasons for not using contraception to delay the first birth & $\begin{array}{c}\text { Combined } \\
\text { (percent) }\end{array}$ & $\begin{array}{c}\text { Urban } \\
\text { (percent) }\end{array}$ & $\begin{array}{c}\text { Rural } \\
\text { (percent) }\end{array}$ \\
\hline \multicolumn{4}{|l|}{ Objections to family planning } \\
\hline Respondent's objection to family planning & 3.5 & 1.2 & 3.7 \\
\hline Husband's objection to family planning & 19.7 & 20.9 & 19.6 \\
\hline Other family members' objection to family planning & 15.5 & 14.6 & 15.6 \\
\hline Any of the above & 31.9 & 33.1 & 31.7 \\
\hline \multicolumn{4}{|l|}{ Lack of awareness } \\
\hline Lack of awareness about contraceptive methods & 20.5 & 16.2 & 20.9 \\
\hline Lack of awareness about sources for contraceptives methods & 4.0 & 3.0 & 4.1 \\
\hline Any of the above & 23.3 & 17.4 & 24.0 \\
\hline \multicolumn{4}{|l|}{ Limited access } \\
\hline $\begin{array}{l}\text { Limited access to contraceptive methods (hard to get method/provider } \\
\text { too far away/restricted clinic hours) }\end{array}$ & 2.6 & 2.6 & 2.6 \\
\hline Embarrassed to procure methods & 5.7 & 9.6 & 5.2 \\
\hline Any of the above & 8.1 & 12.2 & 7.7 \\
\hline
\end{tabular}


Table 10.17 Cont.

\begin{tabular}{|c|c|c|c|}
\hline Reasons for not using contraception to delay the first birth & $\begin{array}{c}\text { Combined } \\
\text { (percent) }\end{array}$ & $\begin{array}{c}\text { Urban } \\
\text { (percent) }\end{array}$ & $\begin{array}{c}\text { Rural } \\
\text { (percent) }\end{array}$ \\
\hline \multicolumn{4}{|l|}{ Method-related concerns } \\
\hline Fear of side effects or health concerns & 6.8 & 6.2 & 6.9 \\
\hline Fear of procedure & 0.9 & 1.6 & 0.9 \\
\hline Perceptions that available methods are not effective & 0.1 & 0.0 & 0.1 \\
\hline Available methods are inconvenient to use & 1.9 & 3.4 & 1.7 \\
\hline Dislike for available methods & 1.1 & 2.5 & 1.0 \\
\hline Any of the above & 9.6 & 11.7 & 9.4 \\
\hline \multicolumn{4}{|l|}{ Other issues } \\
\hline Not having sex/infrequent sex/husband away & 21.9 & 15.8 & 22.5 \\
\hline Recently got married/got pregnant too quickly after marriage & 0.8 & 0.8 & 0.8 \\
\hline No reason & 13.8 & 16.6 & 13.5 \\
\hline $\begin{array}{l}\text { Number who wanted to delay the first birth for at least two years after } \\
\text { marriage and did not use a method to do so }\end{array}$ & 1,130 & 451 & 679 \\
\hline
\end{tabular}

Note: All Ns are unweighted.

\subsubsection{Unmet need}

Table 10.18 describes unmet need for contraception among married older girls. Currently married girls who were not using any method of contraception but who did not want any more children were defined as having an unmet need for limiting childbearing. Those who were not using contraception but wanted to wait for two or more years before having a child/another child were defined as having an unmet need for spacing. Going by this definition, we found that a substantial proportion of married girls had an unmet need-45 percent had an unmet need for spacing and six percent had an unmet need for limiting childbearing. On the whole, 51 percent of married girls had an unmet need for contraception, which was considerably greater than that observed for married girls in the National Family Health Survey in 2005-06 (36\%). Differences between married girls from rural and those from urban areas were narrow. Current contraceptive users were said to have a met demand; as such, five percent of married girls had a met demand for spacing and two percent had a met demand for limiting childbearing. The sum of unmet and met need constituted the total demand for contraception. Findings show that 58 percent of married girls had a demand for contraception-51 percent for spacing and eight percent for limiting. Finally, just 12 percent of the total demand for contraception was satisfied. Differences by residence in rural or urban areas were negligible, except that the demand for contraception was more likely to have been satisfied by urban than rural girls (16\% versus 11\%).

\section{Table 10.18: Unmet need for contraception}

Percentage of married girls in ages 15-19 by unmet need, met need, and total demand for contraception, according to residence, Bihar, 2016

\begin{tabular}{|c|c|c|c|}
\hline Unmet/met need for contraception & $\begin{array}{l}\text { Combined } \\
\text { (percent) }\end{array}$ & $\begin{array}{c}\text { Urban } \\
\text { (percent) }\end{array}$ & $\begin{array}{c}\text { Rural } \\
\text { (percent) }\end{array}$ \\
\hline Unmet need for spacing & 45.2 & 45.9 & 45.1 \\
\hline Unmet need for limiting & 6.1 & 5.7 & 6.1 \\
\hline Total unmet need for contraception ${ }^{1}$ & 51.3 & 51.6 & 51.2 \\
\hline Met demand for spacing & 5.4 & 8.4 & 5.0 \\
\hline Met demand for limiting & 1.5 & 1.6 & 1.5 \\
\hline Total met demand for contraception ${ }^{2}$ & 6.9 & 10.0 & 6.5 \\
\hline
\end{tabular}




\begin{tabular}{lrr}
\hline Unmet/met need for contraception & $\begin{array}{c}\text { Combined } \\
\text { (percent) }\end{array}$ & $\begin{array}{c}\text { Urban } \\
\text { (percent) }\end{array}$ \\
\hline Total demand for spacing & 50.6 & 54.4 \\
(percent)
\end{tabular}

Notes:All Ns are unweighted. ${ }^{1}$ Unmet need for spacing includes pregnant women whose pregnancy was mistimed; amenorrhoeic women who are not using family planning and whose last birth was mistimed or whose last birth was unwanted but now say they want more children; and fecund women who are neither pregnant nor amenorrhoeic and who are not using any method of family planning and say they want to wait two or more years for their next birth. Also included in unmet need for spacing are fecund women who are not using any method of family planning and say they are unsure whether they want another child or who want another child but are unsure when to have one. Unmet need for limiting refers to pregnant women whose pregnancy was unwanted; amenorrhoeic women who are not using family planning, whose last child was unwanted and who do not want any more children; and fecund women who are neither pregnant nor amenorrhoeic, who are not using any method of family planning and who want no more children. Excluded from the unmet need category are pregnant and amenorrhoeic women who became pregnant while using a method (these women are in need of a better method of contraception). ${ }^{2}$ Using for spacing is defined as women who are using some method of family planning and say they want to have another child or are undecided whether to have another. Using for limiting is defined as women who are using and who want no more children. Note that the specific methods used are not taken into account here. ${ }^{3}$ Non-users who are pregnant or amenorrhoeic whose pregnancy was the result of a contraceptive failure are not included in the category of unmet need, but are included in total demand for contraception (since they would have been using had their method not failed).

Table 10.19 describes the differentials in unmet need for contraception by selected background characteristics. Findings show that unmet need for contraception did not differ by religion, current enrolment status, and engagement in paid work, and the association with household wealth status and mother's education was erratic. However, unmet need was higher among girls in ages 15-17 compared with those in ages 18-19 (59\% versus 48\%). It was somewhat lower among girls belonging to general castes compared with girls belonging to other castes (46\% versus $50-53 \%$ ). It was higher among better educated girls than less educated girls (56-60\% among girls with 10 or more years of schooling versus $40-48 \%$ among girls with no education or 1-4 years of schooling).

\section{Table 10.19: Unmet need for contraception by background characteristics}

Percentage of married girls in ages $15-19$ by unmet need for contraception by selected background characteristics, Bihar, 2016

\begin{tabular}{lc}
\hline Background characteristics (percent) & Unmet need for contraception \\
\hline Age & \\
$15-17$ & 58.6 \\
$18-19$ & 48.0 \\
Religion $^{1}$ & \\
Hindu & 51.1 \\
Muslim & 53.0 \\
Caste $^{2}$ & \\
SC & 49.8 \\
OBC & 52.5 \\
General & \\
Completed years of schooling $^{3}$ & 46.0 \\
None & \\
$1-4$ & \\
$5-7$ & 48.4 \\
$8-9$ & 40.4 \\
$10-11$ & 50.7 \\
12 and above & 52.5 \\
\hline
\end{tabular}


Table 10.19 Cont.

\begin{tabular}{|c|c|}
\hline Background characteristics (percent) & Unmet need for contraception \\
\hline \multicolumn{2}{|l|}{ Current schooling status ${ }^{5}$} \\
\hline Yes & 55.0 \\
\hline No & 51.0 \\
\hline \multicolumn{2}{|c|}{ Paid work in the 12 months prior to the interview } \\
\hline Yes & 52.0 \\
\hline No & 51.2 \\
\hline \multicolumn{2}{|l|}{ Wealth quintile } \\
\hline First & 47.3 \\
\hline Second & 53.0 \\
\hline Third & 55.9 \\
\hline Fourth & 51.1 \\
\hline Fifth & 47.1 \\
\hline \multicolumn{2}{|c|}{ Mother's education (in years of schooling completed) } \\
\hline None $^{4}$ & 50.2 \\
\hline $1-7$ & 60.1 \\
\hline $8-9$ & 57.8 \\
\hline 10 and above & 46.5 \\
\hline Total & 51.3 \\
\hline
\end{tabular}

Notes:OBC: other backward caste; SC: scheduled caste; ST: scheduled tribe. ${ }^{1}$ Percentages not shown for those belonging to other religions as less than one percent of surveyed adolescents belonged to other religions. ${ }^{2}$ Percentages not shown for those belonging to STs as less than one percent of surveyed adolescents belonged to STs. ${ }^{3}$ Includes all those not belonging to SCs, STs, or OBCs. ${ }^{4}$ Includes non-literate and literate with no formal schooling. ${ }^{5}$ Percentages not shown for adolescents who were pursuing their education through distance education courses at the time of interview or those who never went to school.

\subsubsection{Future intention to use contraception}

Non-pregnant married older girls who were not using contraception at the time of the interview were asked about their intention to use a family planning method in the next 12 months. Girls who did not intend to use contraception in the next 12 months were further asked whether they intended to use contraception at any time or later. Some 40 percent of girls reported that they would use a contraceptive method in the next 12 months, with more urban than rural girls reporting so (47\% versus 39\%) (Table 10.20). Another 41 percent reported that they would use contraception sometime in the future and more rural than urban girls so reported (41\% versus 35\%). Even so, one in six girls reported that they did not intend to use contraception (17\%), with similar proportions of rural and urban girls so reporting (16-17\%).

\section{Table 10.20: Future intention to use contraception}

Percent distribution of non-pregnant currently married girls in ages 15-19 who were not using a contraceptive method by intention to use in future, according to residence, Bihar, 2016

\begin{tabular}{|c|c|c|c|}
\hline Indicators of intended use & $\begin{array}{c}\text { Combined } \\
\text { (percent) }\end{array}$ & $\begin{array}{c}\text { Urban } \\
\text { (percent) }\end{array}$ & $\begin{array}{c}\text { Rural } \\
\text { (percent) }\end{array}$ \\
\hline Intends to use in the next 12 months & 40.1 & 46.9 & 39.4 \\
\hline Intends to use later & 40.6 & 34.7 & 41.3 \\
\hline Does not intend to use & 17.3 & 16.3 & 17.4 \\
\hline Unsure & 2.0 & 2.2 & 2.0 \\
\hline $\begin{array}{l}\text { Number of respondents who are non-pregnant and not currently } \\
\text { using a contraception method }\end{array}$ & 2,262 & 892 & 1,370 \\
\hline
\end{tabular}

Note: All Ns are unweighted. 


\subsection{Transition to motherhood}

This section begins with a discussion of childbearing in adolescence, calculated for all girls in ages 15-19, and the characteristics of those who had begun childbearing in adolescence. It then describes the reproductive history of married older girls, neonatal and infant mortality rates for the five years preceding the interview, and unintended pregnancy experienced by married older girls. It also explores maternal and newborn care practices with respect to the first birth reported by married older girls who had at least one live birth.

\subsubsection{Teenage pregnancy and motherhood}

Findings, presented in Table 10.21, show that, in total, some 13 percent of all girls in ages 15-19 had begun childbearing, that is, they already had a child (11\%) or were pregnant with their first child (2\%). ${ }^{1}$ The proportion of girls who had initiated childbearing increased from 1-3 percent among those in ages 15-16 years to 23 percent among 18-year-old girls and to 41 percent among 19-year-old girls. Differences between those from rural and those from urban areas were narrow as were differences by religion. Girls who belonged to scheduled castes were the most likely to have begun childbearing and those who belonged to general castes were the least likely to have done so (17\% versus $7 \%)$. Teenage motherhood was greater among girls with no formal education than girls with some education (32\% versus $8-17 \%)$, those who were not currently enrolled in school compared with those who were enrolled (26\% versus $2 \%$ ), and those who were not engaged in paid work compared with those who were engaged (14\% versus $9 \%$ ). Finally, the proportion of girls who had begun childbearing declined with household wealth index-from 18 percent among those from households in the poorest quintile (first) to nine percent among those from households in the wealthiest (fifth) quintile-and with mother's education (from 15\% among girls whose mother had no formal education to $6 \%$ among girls whose mother had completed 10 or more years of schooling).

\section{Table 10.21: Teenage pregnancy and motherhood}

Percentage of adolescent girls in ages 15-19 who had experienced a live birth, who were pregnant with their first child at the time of the interview, and who had begun childbearing by selected background characteristics, Bihar, 2016

\begin{tabular}{|c|c|c|c|}
\hline Background characteristics (percent) $)^{1}$ & Had a live birth & $\begin{array}{l}\text { Are pregnant with } \\
\text { first child }\end{array}$ & $\begin{array}{c}\text { Begun } \\
\text { childbearing }\end{array}$ \\
\hline \multicolumn{4}{|l|}{ Age } \\
\hline 15 & 0.4 & 0.2 & 0.6 \\
\hline 16 & 2.4 & 1.0 & 3.4 \\
\hline 17 & 8.8 & 2.0 & 10.7 \\
\hline 18 & 18.5 & 4.1 & 22.6 \\
\hline 19 & 37.3 & 3.6 & 40.9 \\
\hline \multicolumn{4}{|l|}{ Religion $^{2}$} \\
\hline Hindu & 11.6 & 2.0 & 13.7 \\
\hline Muslim & 9.7 & 1.2 & 10.8 \\
\hline \multicolumn{4}{|l|}{ Caste $^{3}$} \\
\hline SC & 15.4 & 2.0 & 17.4 \\
\hline $\mathrm{OBC}$ & 11.0 & 2.0 & 13.0 \\
\hline General $^{4}$ & 6.0 & 1.3 & 7.3 \\
\hline
\end{tabular}

\footnotetext{
${ }^{1}$ The denominator includes all married and unmarried girls in ages 15-19; the percentage excludes girls who had ever been pregnant, but had not delivered a live birth or were not pregnant at the time of the interview.
} 
Table 10.21 Cont.

\begin{tabular}{|c|c|c|c|}
\hline Background characteristics (percent) ${ }^{1}$ & Had a live birth & $\begin{array}{l}\text { Are pregnant with } \\
\text { first child }\end{array}$ & $\begin{array}{c}\text { Begun } \\
\text { childbearing }\end{array}$ \\
\hline \multicolumn{4}{|l|}{ Completed years of schooling } \\
\hline None $^{5}$ & 28.3 & 3.2 & 31.5 \\
\hline $1-4$ & 15.8 & 1.6 & 17.4 \\
\hline $5-7$ & 11.6 & 1.7 & 13.2 \\
\hline $8-9$ & 6.4 & 1.6 & 8.0 \\
\hline $10-11$ & 7.7 & 1.7 & 9.4 \\
\hline 12 and above & 9.8 & 2.4 & 12.2 \\
\hline \multicolumn{4}{|l|}{ Current schooling status ${ }^{6}$} \\
\hline Yes & 1.4 & 0.6 & 2.0 \\
\hline No & 21.8 & 3.9 & 25.7 \\
\hline \multicolumn{4}{|c|}{ Paid work in the 12 months prior to the interview } \\
\hline Yes & 7.6 & 1.7 & 9.3 \\
\hline No & 12.0 & 2.0 & 13.9 \\
\hline \multicolumn{4}{|l|}{ Wealth quintile } \\
\hline First & 15.9 & 2.2 & 18.1 \\
\hline Second & 13.8 & 2.1 & 15.8 \\
\hline Third & 12.6 & 2.1 & 14.7 \\
\hline Fourth & 10.6 & 2.1 & 12.7 \\
\hline Fifth & 7.5 & 1.4 & 8.9 \\
\hline \multicolumn{4}{|c|}{ Mother's education (in years of schooling completed) } \\
\hline None $^{5}$ & 12.8 & 2.1 & 14.9 \\
\hline $1-7$ & 9.7 & 2.2 & 11.9 \\
\hline $8-9$ & 5.5 & 1.0 & 6.6 \\
\hline 10 and above & 5.1 & 0.6 & 5.7 \\
\hline \multicolumn{4}{|l|}{ Residence } \\
\hline Urban & 8.1 & 1.6 & 9.7 \\
\hline Rural & 11.7 & 2.0 & 13.6 \\
\hline Total & 11.3 & 1.9 & 13.2 \\
\hline
\end{tabular}

Notes:OBC: Other backward caste; SC: Scheduled caste; ST: Scheduled tribe. ${ }^{1}$ Four unmarried older girls and seven married older girls reported

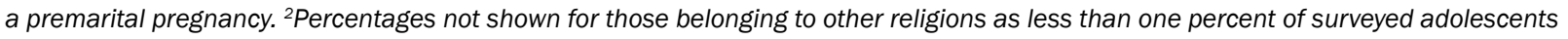
belonged to other religions. ${ }^{3}$ Percentages not shown for those belonging to STs as less than one percent of surveyed adolescents belonged to STs. ${ }^{4}$ Includes all those not belonging to SCs, STs, or OBCs. ${ }^{5}$ Includes non-literate and literate with no formal schooling. ${ }^{6}$ Percentages not shown for adolescents who were pursuing their education through distance education courses at the time of interview or those who never went to school.

Findings related to age at first birth, presented in Table 10.22, show that, as with marriages, childbearing in early adolescence was rare in the state-among all girls in ages 15-19, two percent had their first child before age 15. However, as many as 25 percent of girls in ages 18-19 had their first birth before age 18, that is, in childhood. More rural than urban girls in ages 18-19 had their first birth before age 18 (26\% versus $18 \%$ ). 


\section{Table 10.22: Age at first birth}

Percentage of girls in ages $15-19^{1}$ who had given birth before age 15 and 18 by current age and place of residence, Bihar, 2016

\begin{tabular}{|c|c|c|c|}
\hline \multirow{2}{*}{ Current age } & \multicolumn{2}{|c|}{ Percentage who gave birth before age: } & \multirow{2}{*}{$\begin{array}{c}\text { Number of } \\
\text { girls }\end{array}$} \\
\hline & 15 & 18 & \\
\hline \multicolumn{4}{|c|}{ Combined (percent) } \\
\hline 15-19 & 2.2 & NA & 6,836 \\
\hline 18-19 & 3.7 & 25.2 & 3,187 \\
\hline \multicolumn{4}{|c|}{ Urban (percent) } \\
\hline 15-19 & 1.4 & NA & 3,104 \\
\hline 18-19 & 2.5 & 17.7 & 1,503 \\
\hline \multicolumn{4}{|c|}{ Rural (percent) } \\
\hline 15-19 & 2.3 & NA & 3,732 \\
\hline 18-19 & 3.8 & 26.2 & 1,684 \\
\hline
\end{tabular}

Notes: All Ns are unweighted. NA: Not applicable. ${ }^{1}$ The denominator includes all married and unmarried girls in ages 15-19.

\subsubsection{Reproductive history of married older girls}

The reproductive history of married girls who had begun cohabiting show that 64 percent of girls had ever been pregnant, with somewhat more urban than rural girls reporting a pregnancy (69\% versus $63 \%$; Table 10.23 ). Some eight percent of married girls were pregnant for the first time at the time of the interview. Girls had experienced an average of 0.9 pregnancies. Almost half of married girls reported at least one live birth (47\%), with little difference between those from rural and those from urban areas (51\% in urban areas and $47 \%$ in rural areas). As many as 51 percent of married girls had a child or were pregnant with their first child (not shown in table). ${ }^{2}$ Some nine percent of girls reported two or more live births, and there was little difference by residence in rural or urban areas with regard to reports of two or more live births $(9-10 \%)$.

\section{Table 10.23: Reproductive history}

Percentage of married girls in ages 15-19 who had experienced at least one pregnancy, percent distribution by children ever born and children surviving, and percentage who had experienced pregnancy loss, according to residence, Bihar, 2016

\begin{tabular}{lrrr}
\hline Pregnancy experiences and outcomes & $\begin{array}{c}\text { Combined } \\
\text { (percent) }\end{array}$ & $\begin{array}{c}\text { Urban } \\
\text { (percent) }\end{array}$ & $\begin{array}{c}\text { Rural } \\
\text { (percent) }\end{array}$ \\
\hline Ever been pregnant & 63.8 & 69.0 & 63.2 \\
Currently pregnant for the first time & 8.2 & 10.0 & 7.9 \\
Mean number of lifetime pregnancies & 0.9 & 0.9 & 0.9 \\
Number of children ever born & & & \\
0 & 52.7 & 49.5 & 53.1 \\
1 & 38.1 & 40.8 & 37.8 \\
2 or more & 9.2 & 9.7 & 9.1 \\
\hline
\end{tabular}

\footnotetext{
${ }^{2}$ The percentage excludes girls who had ever been pregnant but had not delivered a live birth or were not pregnant at the time of the interview.
} 
Table 10.23 Cont.

\begin{tabular}{lrrr}
\hline Pregnancy experiences and outcomes & $\begin{array}{c}\text { Combined } \\
\text { (percent) }\end{array}$ & $\begin{array}{c}\text { Urban } \\
\text { (percent) }\end{array}$ & $\begin{array}{c}\text { Rural } \\
\text { (percent) }\end{array}$ \\
\hline Number of children surviving & & & 54.8 \\
0 & 54.5 & 51.4 & 37.5 \\
1 & 37.8 & 39.9 & 7.6 \\
2 or more & 7.8 & 8.7 & 1.8 \\
Reported one or more stillbirths & 1.8 & 1.6 & 6.7 \\
Reported one or more miscarriages & 6.6 & 5.9 & 0.3 \\
Reported one or more induced abortions & 0.3 & 0.7 & 8.7 \\
Reported at least one pregnancy loss & 8.7 & 7.7 & 3.1 \\
Reported at least one infant death & 3.1 & 2.8 & $\mathbf{1 , 8 7 1}$ \\
Number who had begun cohabiting & $\mathbf{3 , 1 8 2}$ & $\mathbf{1 , 3 1 1}$ & \\
\hline
\end{tabular}

Note: All Ns are unweighted.

Figure 10.3 depicts the length of interval between cohabitation and first birth among girls who had cohabited for at least two years. Findings show that among these girls, 65 percent of girls had their first child within two years of cohabitation and five percent had their first child after two years of cohabitation; some 29 percent of girls were yet to have their first child at the time of the interview. Urban girls were more likely than rural girls to have had their first child within two years of cohabitation ( $76 \%$ versus $64 \%)$.

Figure 10.3: Percent distribution of married girls in ages 15-19 who had cohabited for at least two years by length of interval between cohabitation and first birth, according to residence, Bihar, 2016

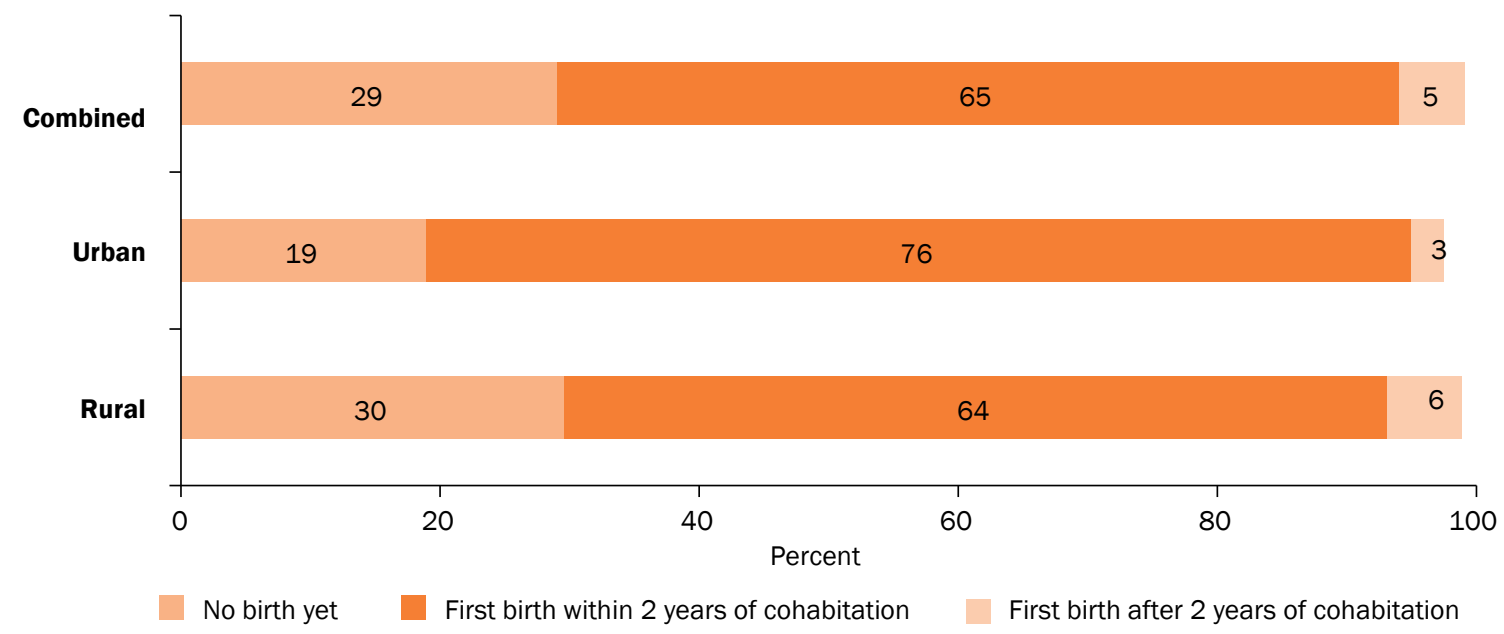

\subsubsection{Pregnancy loss and infant and child death}

Although the distribution of respondents by number of surviving children resembled that of children ever born, few married girls reported an infant death (3\%; Table 10.23). As many as nine percent of married girls had experienced pregnancy loss. Two percent of married girls, for example, reported that their pregnancy had ended in a stillbirth, seven percent reported miscarriage, and less than one percent reported an induced abortion. Differences by residence in rural or urban areas were negligible on all these indicators.

Table 10.24 presents findings related to neonatal, post-neonatal, and infant mortality rates for the five-year period preceding the survey. As in the National Family Health Survey, we asked all married older girls who had begun cohabiting with their husband to provide a complete history of the births of their children. For each live birth, we asked about the month and year of birth, sex of child, survival status, and age at the time of the survey or age at death, if death had occurred. Age at death was recorded in days for children dying in the first month of life, in months 
for children dying before their second birthday, and in years for children dying at later ages. This information was used to calculate neonatal mortality, that is, the probability of dying in the first month of life; post-neonatal mortality, that is, the probability of dying after the first month of life but before the first birthday; and infant mortality, that is, the probability of dying before the first birthday.

The neonatal mortality rate stood at 48 deaths per 1,000 live births and the post-neonatal mortality rate was 15 deaths per 1,000 live births. Differences in these rates were wide between rural and urban areas, with the rate being greater in rural than urban areas (49 versus 41 deaths per 1,000 live births with regard to neonatal mortality and 16 versus 10 deaths per 1,000 live births with regard to post-neonatal mortality). On the whole, the infant mortality rate stood at 63 deaths per I,000 live births; again, the rate was greater in rural than urban areas (65 versus 51 deaths per 1,000 live births).

\section{Table 10.24: Infant mortality}

Neonatal, post-neonatal, and infant mortality rates for the five years preceding the interview for mothers in ages 15-19, according to residence, Bihar, 2016

\begin{tabular}{lccc}
\hline Infant mortality rates & $\begin{array}{c}\text { Combined } \\
\text { (percent) }\end{array}$ & $\begin{array}{c}\text { Urban } \\
\text { (percent) }\end{array}$ & $\begin{array}{c}\text { Rural } \\
\text { (percent) }\end{array}$ \\
\hline Neonatal mortality & 48.0 & 40.8 & 48.9 \\
Post-neonatal mortality & 15.3 & 10.1 & 16.0 \\
Infant mortality & 63.3 & 50.9 & 64.9 \\
\hline
\end{tabular}

\subsubsection{Wantedness of recent pregnancies}

All married girls who reported one or more pregnancies were asked about the wantedness of their last pregnancy or, if pregnant at the time when the interview was conducted, of their current pregnancy. Findings, presented in Table 10.25, suggest high levels of unplanned pregnancy. Among married girls who were not pregnant at the time of interview, for example, 42 percent reported that their last pregnancy was mistimed or unwanted. Differences between those from rural and those from urban areas were narrow. A similar pattern emerged with regard to the wantedness of the current pregnancy-46 percent of married girls who were pregnant at the time of interview reported that the pregnancy was either unwanted or wanted at a later time, with more of urban than rural girls reporting mistimed or unwanted current pregnancy (52\% versus $45 \%$ ).

\section{Table 10.25: Wantedness of most recent pregnancy}

Percentage of married girls in ages $15-19$ by wantedness of the most recent pregnancy, according to residence, Bihar, 2016

\begin{tabular}{|c|c|c|c|}
\hline Wantedness Status & $\begin{array}{c}\text { Combined } \\
\text { (percent) }\end{array}$ & $\begin{array}{c}\text { Urban } \\
\text { (percent) }\end{array}$ & $\begin{array}{c}\text { Rural } \\
\text { (percent) }\end{array}$ \\
\hline \multicolumn{4}{|l|}{ Wantedness status of last pregnancy } \\
\hline Wanted then & 58.5 & 58.7 & 58.5 \\
\hline Wanted later & 40.0 & 39.2 & 40.1 \\
\hline Wanted not at all & 1.5 & 2.1 & 1.4 \\
\hline $\begin{array}{l}\text { Number who had experienced at least one pregnancy and } \\
\text { were not pregnant at the time of the interview }\end{array}$ & 1,701 & 699 & 1,002 \\
\hline \multicolumn{4}{|l|}{ Wantedness status of current pregnancy } \\
\hline Wanted then & 53.8 & 48.0 & 54.6 \\
\hline Wanted later & 43.6 & 49.3 & 42.8 \\
\hline Wanted not at all & 2.6 & 2.7 & 2.6 \\
\hline Number currently pregnant & 683 & 303 & 380 \\
\hline
\end{tabular}

Note: All Ns are unweighted. 


\subsubsection{Maternal healthcare practices for the first birth}

All married older girls who had at least one live birth were asked about their healthcare practices during pregnancy, delivery, and the post-partum period with respect to the first birth. Findings are presented below.

\subsubsection{Antenatal care}

Table 10.26 describes antenatal care practices for the first birth. Findings show that almost all married girls had received at least one antenatal check-up (98\%). However, fewer girls had their first check-up in the first trimester (47\%). Even fewer had received four or more antenatal check-ups (36\%). Although 44 percent of girls had taken iron and folic acid tablets, only six percent had taken it for 100 days. As many as 89 percent of girls had received two or more tetanus toxoid injections and 95 percent had received at least one. Finally, the proportion of married girls who had received full antenatal care, that is, first antenatal check-up in the first trimester, four or more antenatal checkups, at least one tetanus toxoid injection, and consumption of iron and folic acid tablets for 100 days, was negligible (3\%). Differences in antenatal care practices between those from rural and those from urban areas were negligible with regard to most practices; however, urban girls were more likely than rural girls to have received an antenatal check-up in the first trimester (57\% versus $46 \%$ ) and four or more such check-ups ( $47 \%$ versus $34 \%$ ).

\section{Table 10.26: Antenatal care}

Percentage of married girls in ages 15-19 who had received antenatal care for the first birth, according to residence, Bihar, 2016

\begin{tabular}{|c|c|c|c|}
\hline Indicators of antenatal care & $\begin{array}{c}\text { Combined } \\
\text { (percent) }\end{array}$ & $\begin{array}{c}\text { Urban } \\
\text { (percent) }\end{array}$ & $\begin{array}{c}\text { Rural } \\
\text { (percent) }\end{array}$ \\
\hline Received any antenatal care & 97.6 & 98.5 & 97.5 \\
\hline Received antenatal check-up in the first trimester & 47.3 & 56.7 & 46.0 \\
\hline \multicolumn{4}{|l|}{ Number of antenatal check-ups received } \\
\hline No antenatal check-up & 2.4 & 1.5 & 2.5 \\
\hline 1 & 5.7 & 4.8 & 5.8 \\
\hline 2 & 23.8 & 16.9 & 24.7 \\
\hline 3 & 27.6 & 24.9 & 28.0 \\
\hline 4 or above & 35.5 & 46.8 & 34.0 \\
\hline Do not remember number & 5.0 & 5.1 & 4.9 \\
\hline Took iron and folic acid tablets & 44.4 & 48.4 & 43.8 \\
\hline Took iron and folic acid tablets for 100 days & 6.1 & 10.4 & 5.6 \\
\hline Received two tetanus toxoid injections & 88.5 & 91.2 & 88.1 \\
\hline Received at least one tetanus toxoid injections & 95.1 & 97.5 & 94.8 \\
\hline Received full antenatal care ${ }^{1}$ & 2.7 & 5.0 & 2.4 \\
\hline Number who had at least one live birth & 1,593 & 667 & 926 \\
\hline
\end{tabular}

Notes:All Ns are unweighted. ${ }^{1}$ Includes minimum four antenatal care visits during pregnancy with first one within first trimester, receiving at least one tetanus toxoid injection, and taking iron and folic acid tablets for a minimum of 100 days.

Table 10.27 describes the percentages of married girls, by selected background characteristics, who had four or more antenatal check-ups, had the first antenatal check-up in the first trimester of pregnancy, had taken at least one tetanus toxoid injection, and had consumed iron and folic acid tablets for 100 days. Married girls who had their first birth at ages below 18 years were less likely than those who gave birth at ages 18-19 to have received four or more antenatal check-ups for the first birth (34\% versus 40\%). Differences by religion as well as engagement in paid work were narrow across all indicators of antenatal care. Married girls belonging to scheduled castes were less likely than those from other castes to have received four or more antenatal check-ups (25\% versus $39-49 \%$ ), the first antenatal check-up in the first trimester of pregnancy ( $42 \%$ versus $46-50 \%)$, and to have consumed iron and folic acid 
tablets for 100 days (5\% versus $6-13 \%)$. There was a generally positive trend associated with increasing education, household wealth index, mother's education, and husband's education in receiving four or more check-ups, having the first check-up in the first trimester, having at least one tetanus toxoid injection and consuming iron and folic acid tablets for 100 days. Differences by current enrolment status show that those who were currently pursuing their studies were more likely than those who were not to have received four or more check-ups and to have consumed iron and folic acid tablets for 100 days.

\section{Table 10.27: Antenatal care by selected background characteristics}

Percentage of married girls in ages 15-19 with at least one child who received selected components of antenatal care for the first birth by selected background characteristics, Bihar, 2016

\begin{tabular}{|c|c|c|c|c|}
\hline $\begin{array}{l}\text { Background characteristics } \\
\text { (percent) }\end{array}$ & $\begin{array}{c}\text { Four or more } \\
\text { antenatal check- } \\
\text { ups }\end{array}$ & $\begin{array}{l}\text { First antenatal check- } \\
\text { up in the first trimester } \\
\text { of pregnancy }\end{array}$ & $\begin{array}{l}\text { At least one } \\
\text { tetanus toxoid } \\
\text { injection }\end{array}$ & $\begin{array}{c}\text { Took iron and folic } \\
\text { acid tablets for } 100 \\
\text { days }\end{array}$ \\
\hline \multicolumn{5}{|l|}{ Age at first birth } \\
\hline$<18$ & 33.8 & 46.9 & 95.0 & 5.7 \\
\hline $18-19$ & 40.4 & 48.2 & 95.3 & 7.4 \\
\hline \multicolumn{5}{|l|}{ Religion $^{1}$} \\
\hline Hindu & 35.2 & 46.9 & 95.4 & 6.2 \\
\hline Muslim & 37.3 & 50.2 & 93.4 & 5.4 \\
\hline \multicolumn{5}{|l|}{ Caste $^{2}$} \\
\hline SC & 25.4 & 42.2 & 94.9 & 4.6 \\
\hline OBC & 38.8 & 49.9 & 94.9 & 6.1 \\
\hline General $^{3}$ & 48.7 & 46.1 & 97.6 & 13.1 \\
\hline \multicolumn{5}{|l|}{ Completed years of schooling } \\
\hline None $^{4}$ & 25.8 & 40.0 & 92.1 & 3.4 \\
\hline $1-4$ & 19.5 & 38.4 & 93.0 & 7.4 \\
\hline $5-7$ & 42.7 & 50.7 & 96.1 & 7.6 \\
\hline $8-9$ & 40.2 & 51.9 & 97.3 & 4.9 \\
\hline $10-11$ & 45.7 & 52.2 & 99.3 & 8.1 \\
\hline 12 and above & 46.4 & 58.3 & 95.2 & 13.5 \\
\hline \multicolumn{5}{|l|}{ Current schooling status $^{5}$} \\
\hline Yes & 47.9 & 43.6 & 97.9 & 11.7 \\
\hline No & 39.7 & 51.6 & 96.4 & 6.6 \\
\hline \multicolumn{5}{|c|}{ Paid work in the 12 months prior to the interview } \\
\hline Yes & 31.5 & 48.3 & 98.1 & 7.2 \\
\hline No & 35.9 & 47.1 & 94.8 & 6.0 \\
\hline \multicolumn{5}{|l|}{ Wealth quintile } \\
\hline First & 23.9 & 40.6 & 93.6 & 3.4 \\
\hline Second & 26.8 & 43.1 & 91.9 & 3.3 \\
\hline Third & 37.6 & 44.4 & 94.6 & 4.4 \\
\hline Fourth & 37.6 & 49.0 & 96.4 & 6.6 \\
\hline Fifth & 48.5 & 58.3 & 98.6 & 13.0 \\
\hline
\end{tabular}


Table 10.27 Cont.

\begin{tabular}{|c|c|c|c|c|}
\hline $\begin{array}{l}\text { Background characteristics } \\
\text { (percent) }\end{array}$ & $\begin{array}{c}\text { Four or more } \\
\text { antenatal check- } \\
\text { ups }\end{array}$ & $\begin{array}{c}\text { First antenatal check- } \\
\text { up in the first trimester } \\
\text { of pregnancy }\end{array}$ & $\begin{array}{l}\text { At least one } \\
\text { tetanus toxoid } \\
\text { injection }\end{array}$ & $\begin{array}{c}\text { Took iron and folic } \\
\text { acid tablets for } 100 \\
\text { days }\end{array}$ \\
\hline \multicolumn{5}{|c|}{ Mother's education (in years of schooling completed) } \\
\hline None $^{4}$ & 31.9 & 46.2 & 94.6 & 4.8 \\
\hline $1-7$ & 48.2 & 53.6 & 95.9 & 8.5 \\
\hline $8-9$ & 63.5 & 51.8 & 100.0 & 13.6 \\
\hline 10 and above & 59.7 & 53.9 & 100.0 & 22.7 \\
\hline \multicolumn{5}{|c|}{ Husband's education (in years of schooling completed) } \\
\hline None $^{4}$ & 24.3 & 41.7 & 91.4 & 3.1 \\
\hline $1-7$ & 33.3 & 45.1 & 95.2 & 3.9 \\
\hline $8-9$ & 43.0 & 49.6 & 97.9 & 6.6 \\
\hline 10 and above & 45.6 & 54.2 & 97.6 & 11.3 \\
\hline Total & 35.5 & 47.3 & 95.1 & 6.1 \\
\hline
\end{tabular}

Notes:All Ns are unweighted. OBC: other backward caste; SC: scheduled caste; ST: scheduled tribe. ${ }^{1}$ Percentages not shown for those belonging to other religions as less than one percent of surveyed adolescents belonged to other religions. ${ }^{2}$ Percentages not shown for those belonging to STs as less than one percent of surveyed adolescents belonged to STs. ${ }^{3}$ Includes all those not belonging to SCs, STs, or OBCs. ${ }^{4}$ Includes nonliterate and literate with no formal schooling. ${ }^{5}$ Percentages not shown for adolescents who were pursuing their education through distance education courses at the time of interview or those who never went to school.

\subsubsection{Delivery care}

Institutional delivery was far from universal for the first-and most risky-delivery. Indeed, 79 percent of married older girls reported that their first child was delivered in a health facility (Table 10.28). We observed slight differences with respect to institutional deliveries between rural and urban areas; more girls in urban than rural areas reported that the first delivery took place in a health facility (83\% versus $79 \%$ ). While reliance on public sector facilities was higher in rural than urban areas, reliance on private sector facilities was lower in rural than urban areas. Thus, 59 percent of rural girls compared with 47 percent of urban girls had delivered in a public sector health facility, and, conversely, 19 percent of girls in rural areas compared with 37 percent of those in urban areas had delivered in a private sector health facility.

\section{Table 10.28: Delivery care}

Percentage of married girls in ages 15-19 by place of first delivery and type of attendance at first delivery, according to residence, Bihar, 2016

\begin{tabular}{lccc}
\hline Indicators of delivery care & $\begin{array}{c}\text { Combined } \\
\text { (percent) }\end{array}$ & $\begin{array}{c}\text { Urban } \\
\text { (percent) }\end{array}$ & $\begin{array}{c}\text { Rural } \\
\text { (percent) }\end{array}$ \\
\hline Place of first delivery & & & 21.4 \\
Home & 20.8 & 16.4 & 59.4 \\
Public institution & 57.9 & 46.8 & 19.2 \\
Private institution & 21.2 & 36.6 & 0.1 \\
In transit & 0.1 & 0.2 & \\
Type of attendance at first delivery & & & 81.2 \\
Doctor/ANM/nurse/LHV & 81.8 & 86.1 & 2.6 \\
Midwife (trained)/other health personnel & 2.6 & 2.8 & 13.9 \\
Dai/traditional birth attendant & 13.5 & 9.9 & 2.2 \\
Friends/relatives & 2.0 & 0.8 & 0.1 \\
No assistance & 0.1 & 0.3 & $\mathbf{9 2 6}$ \\
Number who had at least one live birth & $\mathbf{1 , 5 9 3}$ & $\mathbf{6 6 7}$ & \\
\hline
\end{tabular}

Notes: All Ns are unweighted. Column totals may not equal 100\% owing to multiple responses. ANM: auxiliary nurse midwife; LHV: lady health visitor. 
Skilled attendance at first delivery was also far from universal-82 percent of married girls reported that their first birth was attended by a doctor, nurse, auxiliary nurse midwife (ANM), or lady health visitor (LHV), and three percent reported they were attended by a trained midwife or other health personnel. Differences between rural and urban areas were modest-89 percent of urban married girls compared with 84 percent of rural married girls reported skilled attendance at delivery. The fact that skilled attendance at birth exceeded institutional delivery may reflect the practice of home deliveries conducted by ANMs and LHVs, on the one hand, and by untrained providers - registered medical practitioners (RMPs)-who may have been misperceived as doctors, on the other (as observed in other settings, see for example, Barnes, 2007).

Table 10.29 describes the differentials in institutional delivery and skilled attendance in respect of first birth by selected background characteristics. Findings show that institutional delivery and skilled attendance were slightly higher among married girls who had their first birth at ages 18-19 years compared with those who had their first birth before age 18 (84\% versus $78 \%$ with respect to institutional delivery and $88 \%$ versus $83 \%$ with respect to skilled attendance). Hindu girls were more likely than Muslim girls to report institutional delivery ( $80 \%$ versus $73 \%$ ) and skilled attendance ( $85 \%$ versus $81 \%$ ) as were girls belonging to general castes compared with those belonging to scheduled castes ( $89 \%$ versus $73 \%$ and $91 \%$ versus $79 \%$, for institutional delivery and skilled attendance, respectively).

Institutional delivery and skilled attendance at delivery increased with the girl's education, household wealth status, mother's education, and husband's education. Thus, 71 percent of married girls from the poorest households compared with 86 percent of married girls from the richest households reported institutional delivery. Both institutional delivery and skilled attendance increased with the number of antenatal check-ups received-from 58-59 percent among those who had no check-ups or just one check-up to 87 percent among those who had four or more check-ups with regard to institutional births; and from 65-69 percent among those who had no check-ups or just one check-up to 91 percent among those who had four or more check-ups with regard to skilled attendance. Finally, only 26 percent of girls who had delivered at home reported skilled attendance.

Table 10.29: Institutional delivery and skilled attendance for first birth by selected background characteristics

Percentage of married girls in ages 15-19 whose first delivery took place in a health facility or was attended by a healthcare professional by selected background characteristics, Bihar, 2016

\begin{tabular}{lcc}
\hline Background characteristics (percent) & Institutional birth & Skilled attendance \\
\hline Age at first birth & & 83.2 \\
$<18$ & 77.5 & 88.1 \\
$18-19$ & 83.6 & 84.9 \\
Religion $^{1}$ & & 81.1 \\
Hindu & 80.0 & \\
Muslim & 72.6 & 79.1 \\
Caste $^{2}$ & & 86.1 \\
SC & 72.5 & 90.8 \\
OBC & 80.8 & \\
General & 3 \\
Completed years of schooling & 88.7 & 73.0 \\
None & & \\
$1-4$ & & 83.9 \\
$5-7$ & 66.9 & 89.7 \\
$8-9$ & 76.6 & 91.8 \\
$10-11$ & 86.0 & 93.9 \\
12 and above & 85.4 & 88.1 \\
\hline
\end{tabular}




\section{Current schooling status ${ }^{5}$}

Yes

$\begin{array}{ll}86.0 & 89.0 \\ 85.4 & 90.6\end{array}$

Paid work in the 12 months prior to the interview

Yes

No

\section{Wealth quintile}

First

Second

Third

80.6

83.3

Fourth

80.6

86.0

Fifth

Number of antenatal check-ups at health facility

No antenatal check-up

1

58.4

69.2

2

80.8

3

79.2

84.4

4 or above

86.7

90.7

Do not remember

\section{Place of first delivery}

Home

Public institution

Private institution

Mother's education (in years of schooling completed)

None $^{4}$

77.7

1-7

82.8

90.5

8-9

87.8

94.5

10 and above

92.3

95.8

Husband's education (in years of schooling completed)

None ${ }^{4}$

77.9

1-7

80.2

87.5

8-9

80.8

86.7

10 and above

83.8

88.3

Total

79.1

84.4

Notes:All Ns are unweighted. () Based on 25-49 unweighted cases. OBC: other backward caste; SC: scheduled caste; ST: scheduled tribe. ${ }^{1}$ Percentages not shown for those belonging to other religions as less than one percent of surveyed adolescents belonged to other religions. ${ }^{2}$ Percentages not shown for those belonging to STs as less than one percent of surveyed adolescents belonged to STs. ${ }^{3} / n c l u d e s$ all those not belonging to SCs, STs, or OBCs. ${ }^{4}$ Includes non-literate and literate with no formal schooling. ${ }^{5}$ Percentages not shown for adolescents who were pursuing their education through distance education courses at the time of interview or those who never went to school. 


\subsubsection{Postnatal care}

Findings show that the percentage of married older girls who had received a post-partum check-up following the first birth was limited-just 39 percent of married girls reported at least one check-up, with little difference between urban and rural girls in the receipt of post-partum check-ups (Table 10.30). Some 36 percent of married girls had their first post-partum check-up within two days of delivery, with little difference between those from rural and those from urban areas in this regard. Almost all married girls who had received a post-partum check-up had received it from a healthcare professional. Only nine percent of married girls had received the recommended number of check-ups, that is, three or more check-ups within six weeks of delivery, with no difference in the reports of rural and urban married girls.

\section{Table 10.30: Postnatal care}

Percentage of married girls in ages 15-19 who had received a post-partum check-up for the first birth, according to residence, Bihar, 2016

\begin{tabular}{lcrr}
\hline Indicators of postnatal care & $\begin{array}{c}\text { Combined } \\
\text { (percent) }\end{array}$ & $\begin{array}{c}\text { Urban } \\
\text { (percent) }\end{array}$ & $\begin{array}{c}\text { Rural } \\
\text { (percent) }\end{array}$ \\
\hline Post-partum check-up & $\mathbf{3 8 . 5}$ & $\mathbf{4 1 . 6}$ & $\mathbf{3 8 . 1}$ \\
Received in less than 4 hours & 30.5 & 33.6 & 30.1 \\
Received in 4-23 hours & 4.4 & 3.4 & 4.5 \\
Received in 1-2 days & 1.1 & 2.2 & 1.0 \\
Received in 3 days to 6 weeks & 1.3 & 1.1 & 1.4 \\
Received in more than 6 weeks & 0.1 & 0.1 & 0.1 \\
Do not remember & 1.1 & 1.1 & 1.1 \\
No post-partum check-up & 61.5 & 58.4 & 61.9 \\
Healthcare provider who conducted the check-up & & & 20.3 \\
Doctor & 21.1 & 27.0 & 17.2 \\
ANM/nurse/LHV/midwife (trained) & 16.8 & 13.8 & 0.4 \\
ASHA/AWW & 0.4 & 0.4 & 0.2 \\
Dai/traditional birth attendant & 0.2 & 0.3 & 61.9 \\
No post-partum check-up & 61.5 & 58.4 & 19.6 \\
Number of check-ups within six weeks of delivery & & & 8.0 \\
1 & 19.5 & 18.5 & 8.9 \\
2 S & 8.2 & 10.1 & 1.6 \\
3 or more & 8.9 & 9.2 & 61.9 \\
Do not remember & 1.9 & 3.8 & $\mathbf{9 2 6}$ \\
No post-partum check-up & 61.5 & 58.4 & $\mathbf{6 6 7}$ \\
Number who had at least one live birth & $\mathbf{1 , 5 9 3}$ & & \\
\hline
\end{tabular}

Notes:All Ns are unweighted. ANM: auxiliary nurse midwife; LHV: lady health visitor; AWW: anganwadi worker.

Table 10.31 describes the differentials in the percentages of married older girls who had received a post-partum check-up by selected background characteristics. Findings show that married girls who gave birth at ages 18-19 were somewhat more likely than those who gave birth before age 18 to have received at least one post-partum checkup for the first birth (42\% versus 37\%). No association was observed between religion or engagement in paid work and receipt of post-partum check-ups. Caste-wise differences show that married girls belonging to scheduled castes were less likely than those from other castes to have received a post-partum check-up (29\% versus 36-43\%). Married girls with no formal education or with less than eight years of schooling were less likely than married girls with more education to have received a post-partum check-up (30-34\% versus $42-58 \%)$ as were girls who were not enrolled 
in school at the time of the interview compared with those who were enrolled (41\% versus $50 \%)$. Post-partum checkups following the first birth increased with household wealth status and husband's education, but the association between post-partum check-ups and mother's education was erratic.

Findings also show that the percentage of married girls reporting a post-partum check-up was far from universal even among girls who had an institutional delivery; for example, only 42 percent and 57 percent of married girls who had delivered in a public and private health facility, respectively, had received at least one post-partum check-up. Among married girls who had delivered at home, just 11 percent had received a post-partum check-up.

\section{Table 10.31: Postnatal care by background characteristics}

Percentage of married girls in ages 15-19 who had received at least one post-partum check-up following the first birth by selected background characteristics, Bihar, 2016

Background characteristics (percent)

\section{Age at first birth}

$<18$

18-19

Religion ${ }^{1}$

Hindu

38.8

Muslim

Caste $^{2}$

$\mathrm{SC}$

$\mathrm{OBC}$

General $^{3}$

Completed years of schooling

None $^{4}$

1-4

33.2

5-7

33.9

8-9

42.4

10-11

57.8

12 and above

Current schooling status ${ }^{5}$

Yes

49.9

No

Paid work in the 12 months prior to the interview

Yes

40.4

No

Wealth quintile

First

Second

35.2

Third

36.1

Fourth

41.2

Fifth 
Table 10.31 Cont.

Background characteristics (percent)

\section{Place of first delivery}

Home

Public institution

Private institution

Mother's education (in years of schooling completed)

None $^{4}$

1-7

8-9

10 and above

Husband's education (in years of schooling completed)

None $^{4}$

1-7

Notes:All Ns are unweighted. OBC: other backward caste; SC: scheduled caste; ST: scheduled tribe. ${ }^{1}$ Percentages not shown for those belonging to other religions as less than one percent of surveyed adolescents belonged to other religions. ${ }^{2}$ Percentages not shown for those belonging to STs as less than one percent of surveyed adolescents belonged to STs. ${ }^{3}$ Includes all those not belonging to SCs, STs, or OBCs. ${ }^{4}$ Includes nonliterate and literate with no formal schooling. ${ }^{5}$ Percentages not shown for adolescents who were pursuing their education through distance education courses at the time of interview or those who never went to school.

\subsubsection{Newborn care practices}

We also sought to determine newborn care practices among married girls with at least one live birth from their breastfeeding practices and the immunisation status of their first child.

\subsubsection{Breastfeeding practices}

Findings show that breastfeeding is nearly universal; 96 percent of married girls with at least one live birth reported that they had breastfed their first child. Differences in reports of breastfeeding between rural and urban areas among adolescent mothers were not observed (Figure 10.4). Only a small proportion of married girls, however, had initiated breastfeeding of their first child within an hour of delivery (47\%); rural girls were somewhat more likely than urban girls to report initiation of breastfeeding within an hour of birth (48\% versus 41\%). As many as 80 percent of married girls reported that they had initiated breastfeeding for their first child within the first day of birth; the difference between rural and urban married girls in initiation of breastfeeding within the first day of birth was narrow. Some 82 percent of married girls reported that they had breastfed their first child day and night on demand in the first six months of birth, and differences were muted in reports between rural and urban girls in this respect. 
Figure 10.4: Percentage of married girls in ages 15-19 reporting breastfeeding practices for their first child, according to residence, Bihar, 2016

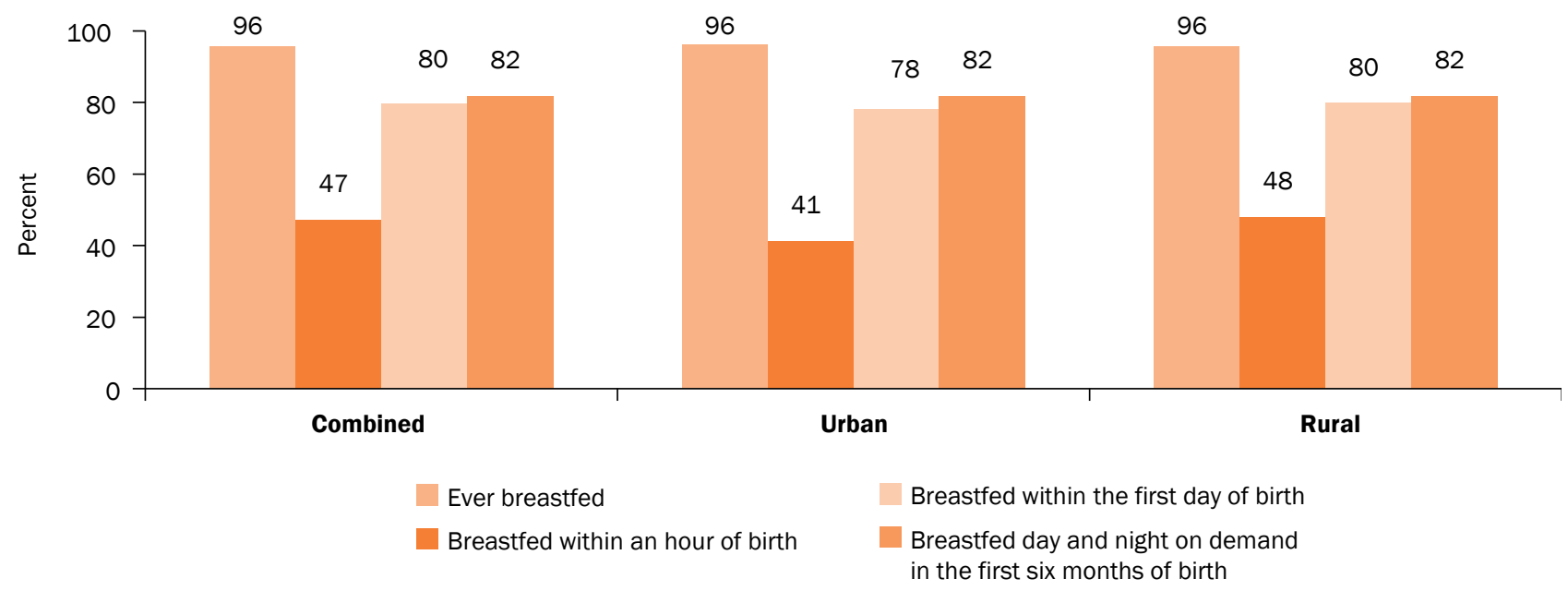

Table 10.32 shows the breastfeeding status of first-born children aged less than one year. Findings show that 91 percent of children under two months of age were exclusively breastfed. Exclusive breastfeeding dropped to 80 percent at 2-3 months of age and to 48 percent at 4-5 months of age. On the whole, 70 percent of children under six months of age were exclusively breastfed.

Table 10.32 Breastfeeding status of first-born children by age

Percentage of first-born children under one year by breastfeeding status, Bihar, 2016

\begin{tabular}{lccc}
\hline Age in months & Currently breastfeeding & Exclusively breastfed & Number of children \\
\hline$<2$ & 93.7 & 91.4 & 73 \\
$2-3$ & 94.9 & 80.4 & 109 \\
$4-5$ & 88.6 & 47.8 & 136 \\
$6-8$ & 88.5 & 26.0 & 209 \\
$9-11$ & 85.6 & 0.0 & 142 \\
$<4$ & 94.5 & 84.7 & 182 \\
$<6$ & 92.1 & 69.8 & 318 \\
$6-9$ & 88.9 & 20.0 & 260 \\
\hline
\end{tabular}

Note: All Ns are unweighted; values separately for rural and urban areas were not shown because of the small number of first-born children under one year.

\subsubsection{Immunisation}

The survey collected limited information about the immunisation status of the first child. Specifically, it asked all mothers whose first child had survived the first month of life about vaccines given in the first month of birth, namely, BCG, polio, and hepatitis B, which are all recommended to be administered during this period. Findings are presented in Table 10.33 and show that vaccination in the first month of birth was almost universal. Thus, 96 percent and 98 percent of mothers reported that their first-born child had received a BCG vaccine and an oral polio vaccine, respectively, in the first month following birth. Somewhat fewer mothers reported that their child had received a hepatitis B vaccine (80\%). Differences between rural and urban areas with regard to immunisation in the first month of birth were muted. 
Table 10.33: Immunisation status of the newborn

Percent distribution of married girls in ages 15-19 whose first child survived at least one month by the newborn's immunisation status in the first month, according to residence, Bihar, 2016

\begin{tabular}{lrrr}
\hline Type of vaccine & $\begin{array}{c}\text { Combined } \\
\text { (percent) }\end{array}$ & $\begin{array}{c}\text { Urban } \\
\text { (percent) }\end{array}$ & $\begin{array}{c}\text { Rural } \\
\text { (percent) }\end{array}$ \\
\hline BCG vaccine & & & 95.5 \\
Yes & 95.7 & 96.9 & 4.0 \\
No & 3.9 & 3.0 & 0.5 \\
Do not know & 0.4 & 0.1 & \\
Oral polio vaccine & & & 97.9 \\
Yes & 97.9 & 97.9 & 1.8 \\
No & 1.8 & 1.8 & 0.3 \\
Do not know & 0.3 & 0.3 & 79.7 \\
Hepatitis B vaccine & & & 16.0 \\
Yes & 80.2 & 84.1 & 4.3 \\
No & 15.6 & 12.7 & 3.2 \\
Do not know & 4.2 & & $\mathbf{8 3 2}$ \\
Number whose first child was at least one month old at the time of & $\mathbf{1 . 4 3 8}$ & $\mathbf{6 0 6}$ & \\
the interview or survived for at least one month & & & \\
\hline
\end{tabular}

Note: All Ns are unweighted.

\subsection{Reach of programmes to promote maternal, newborn, and child health}

The module on the extent of maternal healthcare and newborn care practices among married girls in ages 15-19 included an assessment of the reach of programmes to promote maternal, newborn, and child health. Specifically, we assessed the reach of benefits under the Janani Suraksha Yojana (JSY) and the Janani-Shishu Suraksha Karyakram. We also assessed the extent of food supplementation given to the mother during pregnancy and lactation, the extent of health and nutrition education imparted to mothers, and the extent of services given to children under six years of age through the Integrated Child Development Services (ICDS) programme. Findings are summarised in Table 10.34.

With regard to the reach of the JSY, findings show that just 43 percent of married girls with at least one live birth had received JSY cash benefits for their first birth. More rural than urban girls had received it (44\% versus $32 \%$ ). Even among those who had given birth in a public sector facility, only 72 percent had received the cash benefits. About eight percent of married girls who had given birth in a public sector facility reported that they were waiting for the cash at the time of the interview.

Among the married girls whose first birth took place in a public or a private health facility, 48 percent reported their having received at least one benefit dispensed under the Janani-Shishu Suraksha Karyakram. More girls in rural than urban areas so reported (50\% versus 38\%). The benefits that the largest proportion received were free drugs and other supplies, and free diet (reported by $29 \%$ and $27 \%$, respectively), followed by free transport to the facility (reported by 19\%). Some 6-7 percent of girls reported that they had received free diagnostic services and free treatment for the newborn. Rural married girls were more likely than urban counterparts to report that they had received free diet (28\% versus $17 \%$ ) and free transport ( $20 \%$ versus $10 \%)$. 
Table 10.34: Benefits received from schemes to promote maternal, newborn, and chill health

Percent distribution of married girls in ages 15-19 who had received benefits from schemes to promote maternal, newborn, and child health, according to residence, Bihar, 2016

\begin{tabular}{|c|c|c|c|}
\hline Benefits received from public schemes & $\begin{array}{c}\text { Combined } \\
\text { (percent) }\end{array}$ & $\begin{array}{c}\text { Urban } \\
\text { (percent) }\end{array}$ & $\begin{array}{c}\text { Rural } \\
\text { (percent) }\end{array}$ \\
\hline \multicolumn{4}{|l|}{ Received cash assistance under Janani Suraksha Yojana } \\
\hline Yes & 43.0 & 32.1 & 44.4 \\
\hline No & 52.3 & 64.6 & 50.7 \\
\hline Waiting for money & 4.7 & 3.4 & 4.9 \\
\hline Number who had at least one live birth & 1,593 & 667 & 926 \\
\hline \multicolumn{4}{|l|}{ Received cash assistance when delivered in public facility } \\
\hline Yes & 71.5 & 65.4 & 72.2 \\
\hline No & 20.4 & 27.9 & 19.7 \\
\hline Waiting for money & 8.0 & 6.7 & 8.2 \\
\hline Number whose first delivery took place in a public health facility & 851 & 309 & 542 \\
\hline \multicolumn{4}{|l|}{ Received benefits given below under JSSK scheme } \\
\hline \multicolumn{4}{|l|}{ Free drug and other supplies } \\
\hline Yes & 29.0 & 28.0 & 29.1 \\
\hline No & 67.3 & 70.6 & 66.9 \\
\hline Not required & 3.7 & 1.5 & 4.0 \\
\hline \multicolumn{4}{|l|}{ Free diet during delivery } \\
\hline Yes & 26.7 & 17.4 & 28.0 \\
\hline No & 71.6 & 80.0 & 70.4 \\
\hline Not required & 1.7 & 2.6 & 1.6 \\
\hline \multicolumn{4}{|l|}{ Free diagnostic services } \\
\hline Yes & 7.1 & 9.1 & 6.8 \\
\hline No & 64.9 & 69.0 & 64.3 \\
\hline Not required & 28.0 & 21.8 & 28.9 \\
\hline \multicolumn{4}{|l|}{ Free blood transfusion } \\
\hline Yes & 7.1 & 0.2 & 0.1 \\
\hline No & 64.9 & 33.3 & 29.0 \\
\hline Not required & 28.0 & 66.5 & 70.9 \\
\hline \multicolumn{4}{|l|}{ Free transport to the facility } \\
\hline Yes & 19.0 & 9.6 & 20.3 \\
\hline No & 76.1 & 85.9 & 74.8 \\
\hline Not required & 4.8 & 4.5 & 4.9 \\
\hline \multicolumn{4}{|l|}{ Free treatment for the newborn (up to 1 month after birth) } \\
\hline Yes & 6.2 & 5.1 & 6.4 \\
\hline No & 68.1 & 72.1 & 67.6 \\
\hline Not required & 25.6 & 22.7 & 26.0 \\
\hline Any of the above JSSK benefits received at health institution & 48.2 & 38.1 & 49.6 \\
\hline $\begin{array}{l}\text { Number whose first delivery took place in a public/private health } \\
\text { facility }\end{array}$ & 1,253 & 541 & 712 \\
\hline
\end{tabular}


Table 10.34 Cont.

\begin{tabular}{|c|c|c|c|}
\hline Benefits received from public schemes & $\begin{array}{c}\text { Combined } \\
\text { (percent) }\end{array}$ & $\begin{array}{c}\text { Urban } \\
\text { (percent) }\end{array}$ & $\begin{array}{c}\text { Rural } \\
\text { (percent) }\end{array}$ \\
\hline \multicolumn{4}{|c|}{$\begin{array}{l}\text { Received supplementary food from the ICDS programme when } \\
\text { respondent was carrying her first child or breastfeeding her first } \\
\text { child }\end{array}$} \\
\hline Yes & 36.0 & 36.2 & 36.0 \\
\hline No & 64.0 & 63.8 & 64.0 \\
\hline \multicolumn{4}{|c|}{ Received health and nutrition education from the ICDS programme } \\
\hline Yes, health education & 5.2 & 5.4 & 5.2 \\
\hline Yes, nutrition education & 5.2 & 7.7 & 4.9 \\
\hline Yes, both & 17.4 & 14.6 & 17.7 \\
\hline Neither & 72.2 & 72.3 & 72.2 \\
\hline \multicolumn{4}{|l|}{ Received benefits for the child from ICDS centre } \\
\hline Supplementary food & 29.2 & 30.5 & 29.1 \\
\hline Growth monitoring & 11.9 & 8.7 & 12.3 \\
\hline Immunisation & 60.8 & 51.0 & 62.1 \\
\hline Early childhood/preschool education & 1.3 & 1.5 & 1.3 \\
\hline ORS/other medicine (Vitamin A syrup, deworming syrup) & 4.5 & 1.6 & 4.9 \\
\hline Died before getting service & 4.5 & 3.8 & 4.6 \\
\hline Any benefits received & 66.7 & 57.4 & 67.9 \\
\hline Number who had at least one live birth & 1,593 & 667 & 926 \\
\hline
\end{tabular}

Notes: All Ns are unweighted. JSSK: Janani-Shishu Suraksha Karyakram; ICDS: Integrated Child Development Services.

The reach of services extended through the ICDS programme was even more limited. Just 36 percent of married girls reported that they had received food supplementation during their first pregnancy or during the lactation period following the birth of their first child, and difference by residence in rural or urban areas was muted. Fewer married girls who had at least one birth reported that they had received health and/or nutrition education (28\%) imparted under the ICDS programme. Far more girls (67\%), however, reported that they had received various services for their first child under six years of age. The services that the largest proportion of married girls reported their having received were immunisation of their first child, which was received by 61 percent, followed by food supplementation for and growth monitoring of their first child, which were received by 29 percent and 12 percent, respectively, of girls. Rural married girls were more likely than their urban counterparts to have received any of these services (68\% versus $57 \%)$. 


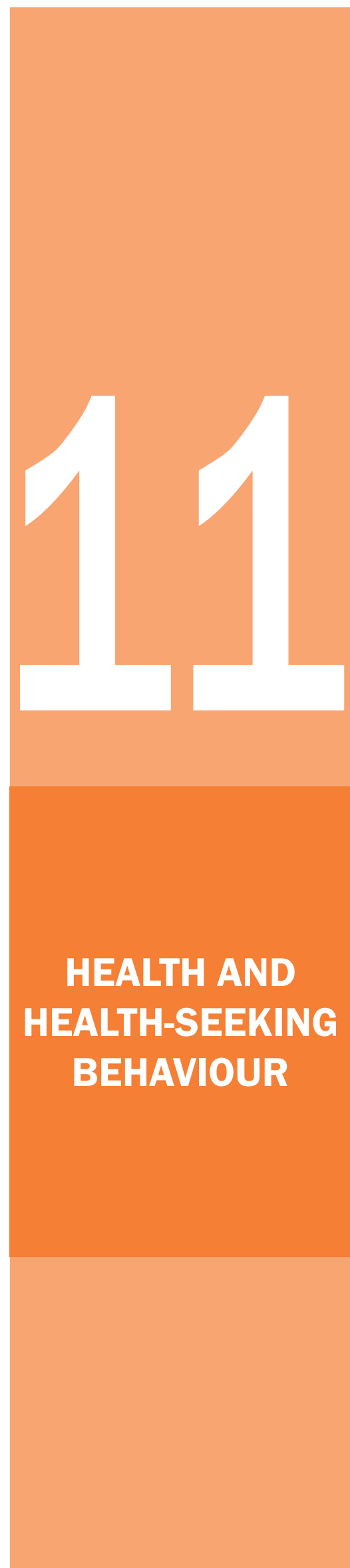

\section{A Snapshot}

Although adolescence is generally a healthy period of life, several health concerns affect their well-being:

- $14 \%$ of younger boys

- $26 \%$ of older boys

- $7 \%$ of younger girls
- $17 \%$ of unmarried older girls

- $26 \%$ of married older girls experienced symptoms suggestive of genital infection in the three months preceding the interview

- $4 \%$ of younger girls

- $10 \%$ each of unmarried and married older girls experienced menstrual problems in the three months preceding the interview

- None of the younger boys

- $1 \%$ of older boys

- $1 \%$ of younger girls

- $5 \%$ of unmarried older girls

- $7 \%$ of married older girls displayed symptoms of moderate to severe depression in the two weeks prior to the interview

- $9 \%$ of younger boys

- $11 \%$ of older boys

- 3\% each of younger girls and unmarried older girls, and

- $2 \%$ of married older girls had been injured in a road accident in the three months preceding the interview

- $2 \%$ of younger boys

- $8 \%$ of older boys

- None of the younger girls

- Less than 1\% of unmarried and married older girls had ever consumed alcohol
- $0.2 \%$ of younger boys (ages 13-14)

- $2 \%$ of older boys

- $0.3 \%$ of younger girls (ages 13-14)

- $3 \%$ of unmarried older girls

- $7 \%$ of married older girls had seriously contemplated committing suicide in the year preceding the interview

- $5 \%$ of younger boys

- $20 \%$ of older boys

- $1 \%$ of younger girls

- $2 \%$ each of unmarried and married older girls had ever consumed tobacco products

- $95 \%$ of younger boys

- $86 \%$ of older boys

- $81 \%$ of younger girls

- $51 \%$ of unmarried older girls

- $17 \%$ of married girls were usually engaged in sports and games or other physical activities

\section{POPULATION} COUNCIL

Ideas. Evidence. Impact.

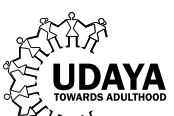




\section{A Snapshot}

Menstrual hygiene practices are unsatisfactory:

- $28 \%$ each of younger girls and unmarried older girls

- $20 \%$ of married older girls who had begun menstruating always used sanitary napkins

- $20 \%$ of younger girls

- $27 \%$ each of unmarried and married older girls used sanitary napkins intermittently

Lack of affordability of sanitary napkins is a major barrier to use of sanitary napkins

Many hesitate to seek sexual and reproductive health services:

Of those who reported symptoms suggestive

of genital infections:

- $59 \%$ of younger boys

- $64 \%$ of older boys

- $15 \%$ of younger girls

- $20 \%$ of unmarried older girls

- $32 \%$ of married older girls had sought

treatment for symptoms of genital

infection
- $36 \%$ each of older boys

- 36\% unmarried older girls

- $46 \%$ of married older girls

felt shy to approach healthcare providers for contraceptives

Awareness and reach of government programmes to promote adolescent health is limited:

- $31 \%$ of younger boys

- $18 \%$ of older boys

- $32 \%$ of younger girls

- $19 \%$ of unmarried older girls

- $15 \%$ of married older girls who were enrolled in school/college at the time of the interview had received health-related information or services from a healthcare provider in their school/ college in the year preceding the interview

- $93 \%$ of younger boys

- $96 \%$ of older boys

- $\quad 97 \%$ each of younger girls and unmarried older girls

- $96 \%$ of married older girls were aware of anganwadi workers
- $58 \%$ of younger boys

- $80 \%$ of older boys

- $77 \%$ of younger girls

- $93 \%$ of unmarried older girls

- $92 \%$ of married older girls were aware of ASHAs 


\section{A Snapshot}

Awareness and reach of government programmes to promote adolescent health is limited:

- $11 \%$ of younger boys

- $8 \%$ of older boys

- $17 \%$ of younger girls

- $16 \%$ of unmarried older girls

- $40 \%$ of married older girls had interacted with anganwadi workers or ASHAs in the year preceding the interview

- $52 \%$ of younger girls

- $21 \%$ of younger girls

- $51 \%$ of unmarried older girls

- $13 \%$ of unmarried older girls

- 38\% of married older girls who had begun

- $4 \%$ of married older girls who had begun menstruating were aware of the sanitary napkin distribution scheme menstruating had received sanitary napkins through the sanitary napkin distribution scheme

- $31 \%$ of younger boys

- $47 \%$ of older boys

- $26 \%$ of younger girls

- $37 \%$ of unmarried older girls

- $42 \%$ of married older girls in rural areas were aware of Village Health and Nutrition Days
- None of the younger boys

- $1 \%$ of older boys

- $4 \%$ of younger girls

- $2 \%$ of unmarried older girls

- $8 \%$ of married older girls in rural areas had attended a Village Health and Nutrition Day in the year preceding the interview

Differences between rural and urban adolescents were narrow on most indicators 
The Rashtriya Kishor Swasthya Karyakram programme by the Government of India was launched with a view to improve the nutrition, sexual and reproductive health, and mental health of adolescents; to prevent injuries, violence, and substance misuse among them; and to address conditions among them that could lead to non-communicable diseases in adulthood (Ministry of Health and Family Welfare, 2014a). UDAYA sought to generate evidence on these topics, and this chapter presents its findings. The chapter begins with a discussion of the sexual and reproductive health situation of study participants, including menstrual hygiene practices, recent experiences of sexual and reproductive health problems, and care-seeking for such problems. This is followed by a discussion of the mental health situation of study participants, their experience of injuries, substance use among them, and their engagement in physical activities. The chapter also presents evidence on study participants' confidence about accessing sexual and reproductive health services and their awareness of and access to government programmes and measures intended to provide health information to adolescents and meet their health needs. These included the Rashtriya Kishor Swasthya Karyakram, the School Health Programme, ${ }^{1}$ the community-level health worker programme, adolescent friendly health clinics, the sanitary napkin distribution programme, and village health and nutrition days programme.

\subsection{Sexual and reproductive health practices}

In addition to our exploration of contraceptive use within premarital sexual relationships and marriage (see Chapters 9 and 10) and our enquiry into maternal and newborn care practices with respect to the first birth (see Chapter 10), we sought to further our understanding on the sexual and reproductive health practices of adolescents by collecting data on selected indicators of such practices. Thus, we asked girls questions on menstrual hygiene practices, and we asked all adolescents about their recent experiences of sexual and reproductive health problems and care-seeking related to these problems. Findings are summarised in the following sections.

\subsubsection{Menstrual hygiene practices}

The promotion of menstrual hygiene has been a major focus of the adolescent health strategy in the country, and the free distribution of sanitary napkins in schools and communities by outreach workers is testimony to this commitment. The survey included questions on the materials girls used to manage menstruation, and if they did not use sanitary napkins at all, the reasons for not using them.

Among younger girls, 33 percent reported that they were not aware of menstruation ( $27 \%$ and $33 \%$ in urban and rural areas, respectively) and an additional 32 percent, although aware of menstruation, reported that they had not yet started menstruating ( $28 \%$ and $32 \%$ in urban and rural areas, respectively, not shown in table). Among unmarried older girls, less than one percent reported that they had not yet started menstruating.

Findings related to menstrual hygiene practices among girls who had begun menstruating are described in Table 11.1. Among those who had begun menstruating, 20-28 percent reported that they used only sanitary napkins, 43-52 percent reported that they used only pieces of cloth, and 21-27 percent reported that they used both. While differences in the proportion of girls who used only sanitary napkins by age were narrow (28\% each of younger girls and unmarried older girls and $20 \%$ among married older girls), differences by marital status among older girls and differences by residence in rural or urban areas among all girls were wide. More of unmarried than married older girls reported that they used only sanitary napkins ( $28 \%$ versus $20 \%)$ and more of urban than rural girls so reported ( $40-57 \%$ versus $17-25 \%)$.

Those who reported that they did not use sanitary napkins at all cited lack of affordability of sanitary napkins, difficulty in or shyness about obtaining them, and lack of awareness about sanitary napkins as the leading reasons for not using them. Thus, 53 percent of younger girls and 55-62 percent of unmarried and married older girls who did not use sanitary napkins reported that they could not afford the cost of sanitary napkins; 24 percent of younger girls and 36-40 percent of unmarried and married older girls attributed their non-use to difficulty in obtaining sanitary napkins; and 22 percent of younger girls and 12-15 percent of unmarried and married older girls reported that they were not aware of sanitary napkins.

\footnotetext{
${ }^{1}$ It needs to be noted that our question encompasses but is not restricted to the formal School Health Programme.
} 


\section{Table 11.1: Menstrual hygiene practices}

Percentage of girls who had begun menstruating by materials used during menstrual period and reasons for not using sanitary napkins, according to residence, Bihar, 2016

\begin{tabular}{|c|c|c|c|}
\hline $\begin{array}{l}\text { Materials used during menstrual period and reasons for } \\
\text { not using sanitary napkins }\end{array}$ & $\begin{array}{c}\text { Girls } \\
(10-14)\end{array}$ & $\begin{array}{c}\text { Girls } \\
(15-19)\end{array}$ & $\begin{array}{l}\text { Married girls } \\
\qquad(15-19)\end{array}$ \\
\hline \multicolumn{4}{|c|}{ Combined (percent) } \\
\hline \multicolumn{4}{|l|}{ Materials used during menstrual period } \\
\hline Sanitary napkins & 27.6 & 27.9 & 19.7 \\
\hline Pieces of cloth & 51.2 & 43.3 & 51.7 \\
\hline Both & 20.5 & 27.4 & 26.7 \\
\hline Nothing & 0.7 & 1.4 & 1.9 \\
\hline Number of respondents who had begun menstruating & 310 & 3,406 & 3,402 \\
\hline \multicolumn{4}{|l|}{ Reasons for not using sanitary napkins } \\
\hline Cannot afford & 52.8 & 61.8 & 55.4 \\
\hline Difficult to get/feel shy to get & 23.7 & 36.0 & 39.6 \\
\hline Do not know where to get & 6.2 & 4.1 & 5.8 \\
\hline Difficult to dispose & 1.5 & 3.1 & 3.6 \\
\hline Do not know about sanitary napkins & 22.1 & 11.9 & 15.0 \\
\hline Do not like/not comfortable using sanitary napkins & 3.9 & 1.9 & 2.1 \\
\hline Do not know how to use/never used earlier & 0.0 & 0.1 & 0.1 \\
\hline No specific reason & 0.9 & 1.2 & 0.8 \\
\hline Number of respondents who did not use sanitary napkins at all & 121 & 1,147 & 1,660 \\
\hline \multicolumn{4}{|c|}{ Urban (percent) } \\
\hline \multicolumn{4}{|l|}{ Materials used during menstrual period } \\
\hline Sanitary napkins & 57.4 & 55.9 & 40.2 \\
\hline Pieces of cloth & 17.3 & 17.9 & 30.5 \\
\hline Both & 25.3 & 25.7 & 29.0 \\
\hline Nothing & 0.0 & 0.4 & 0.3 \\
\hline Number of respondents who had begun menstruating & 177 & 1,729 & 1,363 \\
\hline \multicolumn{4}{|l|}{ Reasons for not using sanitary napkins } \\
\hline Cannot afford & $(58.5)$ & 67.9 & 63.1 \\
\hline Difficult to get/feel shy to get & $(2.8)$ & 15.1 & 22.5 \\
\hline Do not know where to get & $(0.0)$ & 4.4 & 1.9 \\
\hline Difficult to dispose & $(3.8)$ & 6.3 & 8.5 \\
\hline Do not know about sanitary napkins & $(26.6)$ & 6.7 & 10.1 \\
\hline Do not like/not comfortable using sanitary napkins & $(11.1)$ & 5.0 & 6.8 \\
\hline Do not know how to use/never used earlier & $(0.0)$ & 0.2 & 0.0 \\
\hline No specific reason & $(0.0)$ & 3.5 & 0.9 \\
\hline Number of respondents who did not use sanitary napkins at all & 40 & 342 & 478 \\
\hline
\end{tabular}


Table 11.1 Cont.

\begin{tabular}{|c|c|c|c|}
\hline $\begin{array}{l}\text { Materials used during menstrual period and reasons for } \\
\text { not using sanitary napkins }\end{array}$ & $\begin{array}{l}\text { Girls } \\
(10-14)\end{array}$ & $\begin{array}{l}\text { Girls } \\
(15-19)\end{array}$ & $\begin{array}{l}\text { Married girls } \\
\qquad(15-19)\end{array}$ \\
\hline \multicolumn{4}{|c|}{ Rural (percent) } \\
\hline \multicolumn{4}{|l|}{ Materials used during menstrual period } \\
\hline Sanitary napkins & 22.8 & 24.5 & 17.4 \\
\hline Pieces of cloth & 56.6 & 46.3 & 54.1 \\
\hline Both & 19.8 & 27.6 & 26.4 \\
\hline Nothing & 0.8 & 1.5 & 2.1 \\
\hline Number of respondents who had begun menstruating & 133 & 1,677 & 2,039 \\
\hline \multicolumn{4}{|l|}{ Reasons for not using sanitary napkins } \\
\hline Cannot afford & 52.6 & 61.6 & 54.9 \\
\hline Difficult to get/feel shy to get & 24.7 & 36.9 & 40.6 \\
\hline Do not know where to get & 6.5 & 4.1 & 6.0 \\
\hline Difficult to dispose & 1.4 & 3.0 & 3.2 \\
\hline Do not know about sanitary napkins & 21.9 & 12.2 & 15.3 \\
\hline Do not like/not comfortable using sanitary napkins & 3.5 & 1.8 & 1.8 \\
\hline Do not know how to use/never used earlier & 0.0 & 0.1 & 0.1 \\
\hline No specific reason & 0.9 & 1.1 & 0.8 \\
\hline Number of respondents who did not use sanitary napkins at all & 81 & 805 & 1,182 \\
\hline
\end{tabular}

Notes: All Ns are unweighted. () Based on 25-49 unweighted cases.

Unmarried and married older girls were more likely than younger girls to report difficulty in or shyness about obtaining sanitary napkins (36-40\% versus $24 \%$ ), while younger girls were more likely to report lack of awareness of sanitary napkins (22\% versus $12-15 \%)$. Unmarried older girls were somewhat more likely than younger girls and married older girls to mention lack of affordability ( $62 \%$ versus $53 \%$ of younger girls and $55 \%$ of married older girls).

While the leading reasons for not using sanitary napkins mentioned by rural and urban girls were same, the proportions citing these reasons differed between rural and urban girls. Girls in urban areas were more likely than rural girls to attribute non-use to lack of affordability (59\% versus 53\% among younger girls and $63-68 \%$ versus $55-62 \%$ among unmarried and married older girls) and dislike or discomfort in using sanitary napkins (11\% versus $4 \%$ of younger girls and $7 \%$ versus $2 \%$ of married older girls), but less likely to mention difficulty in or shyness about obtaining them (3\% versus 25\% among younger girls and $15-23 \%$ versus $37-41 \%$ among unmarried and married older girls), Younger girls in rural areas were more likely than urban younger girls to mention that they did not know where they could get sanitary napkins ( $7 \%$ versus none), while they were less likely to mention lack of awareness of sanitary napkins (22\% versus $27 \%$ ). Older girls in rural areas were more likely than urban older girls to cite lack of awareness of sanitary napkins (12\% versus $7 \%$ among unmarried girls and $15 \%$ versus $10 \%$ among married girls). Finally, married older girls in urban areas were more likely than those in rural areas to attribute their non-use of sanitary napkins to difficulty in disposing sanitary napkins (9\% versus $3 \%$ ).

\subsubsection{Recent experience of sexual and reproductive health problems and care-seeking}

We probed adolescents' experiences of sexual and reproductive health problems that may have occurred in the three months prior to our interview with them. These included symptoms suggestive of genital infection (for example, burning sensation during urination, genital ulcers, genital itching, swelling in the groin, and genital discharge) and, additionally, menstrual problems for girls who had begun menstruating. Findings are presented in Table 11.2. We note that these findings are based on self-reports and not on clinical examinations or laboratory testing and, therefore, they must be interpreted with caution. 
Notable proportions of adolescents reported symptoms suggestive of genital infection-14-26 percent of boys and 7-26 percent of girls-in the three months preceding the interview. Frequently cited symptoms among boys included itching in the genital area (8-15\%), genital ulcers (6-12\%), and burning sensation during urination (4-6\%), and, among girls, abnormal vaginal discharge (3-17\%), burning sensation during urination (3-15\%), and itching in the genital area (2-7\%). Boys were somewhat more likely than girls to report symptoms of genital infection (14\% versus $7 \%$ among younger adolescents and $26 \%$ among older boys versus $17 \%$ among unmarried older girls). Among older girls, married girls were more likely than the unmarried to report such an experience ( $26 \%$ versus $17 \%)$. Differences between rural adolescents and urban adolescents with regard to symptoms of genital infection were narrow, except that rural older boys were somewhat more likely than urban older boys to report at least one symptom that had occurred in the three months prior to the interview (26\% versus $19 \%)$.

\section{Table 11.2: Self-reported sexual and reproductive health problems}

Percentage of adolescents reporting experience of selected sexual and reproductive health problems in the three months prior to the interview, by reported symptoms, according to residence, Bihar, 2016

\begin{tabular}{|c|c|c|c|c|c|}
\hline Sexual and reproductive health problems experienced & $\begin{array}{c}\text { Boys } \\
(10-14)\end{array}$ & $\begin{array}{c}\text { Boys } \\
(15-19)\end{array}$ & $\begin{array}{c}\text { Girls } \\
(10-14)\end{array}$ & $\begin{array}{c}\text { Girls } \\
(15-19)\end{array}$ & $\begin{array}{l}\text { Married girls } \\
\qquad(15-19)\end{array}$ \\
\hline \multicolumn{6}{|c|}{ Combined (percent) } \\
\hline Genital ulcers & 6.3 & 12.1 & 0.7 & 2.8 & 3.4 \\
\hline Itching in genital area & 7.6 & 15.1 & 1.8 & 3.7 & 7.3 \\
\hline Swelling in the groin & 1.0 & 2.2 & 1.0 & 3.8 & 5.2 \\
\hline Burning sensation while passing urine & 3.9 & 5.9 & 2.7 & 7.6 & 15.4 \\
\hline Abnormal vaginal/urethral discharge & 0.2 & 4.4 & 2.8 & 11.5 & 16.8 \\
\hline At least one of the above & 13.6 & 25.6 & 6.9 & 16.7 & 25.9 \\
\hline Number of respondents & 1,012 & 1,821 & 764 & 3,428 & 3,408 \\
\hline Menstrual problems & NA & NA & 4.4 & 9.9 & 10.4 \\
\hline Girls who had begun menstruating & & & 310 & 3,406 & 3,402 \\
\hline \multicolumn{6}{|c|}{ Urban (percent) } \\
\hline Genital ulcers & 4.3 & 7.3 & 0.2 & 2.1 & 3.0 \\
\hline Itching in genital area & 6.5 & 12.2 & 1.3 & 4.1 & 6.8 \\
\hline Swelling in the groin & 1.0 & 1.2 & 1.4 & 2.7 & 3.4 \\
\hline Burning sensation while passing urine & 1.6 & 5.4 & 3.6 & 8.2 & 12.7 \\
\hline Abnormal vaginal/urethral discharge & 0.2 & 3.5 & 4.2 & 12.0 & 16.4 \\
\hline At least one of the above & 11.1 & 19.2 & 7.4 & 17.8 & 23.7 \\
\hline Number of respondents & 452 & 1,008 & 387 & 1,738 & 1,366 \\
\hline Menstrual problems & NA & NA & 6.6 & 9.7 & 6.5 \\
\hline Number of respondents & & & 177 & 1,729 & 1,363 \\
\hline \multicolumn{6}{|c|}{ Rural (percent) } \\
\hline Genital ulcers & 6.6 & 12.7 & 0.8 & 2.9 & 3.5 \\
\hline Itching in genital area & 7.8 & 15.5 & 1.8 & 3.6 & 7.3 \\
\hline Swelling in the groin & 1.1 & 2.3 & 1.0 & 4.0 & 5.4 \\
\hline Burning sensation while passing urine & 4.2 & 6.0 & 2.6 & 7.5 & 15.7 \\
\hline Abnormal vaginal/urethral discharge & 0.2 & 4.5 & 2.6 & 11.4 & 16.9 \\
\hline At least one of the above & 13.9 & 26.4 & 6.8 & 16.5 & 26.2 \\
\hline Number of respondents & 560 & 813 & 377 & 1,690 & 2,042 \\
\hline Menstrual problems & NA & NA & 4.1 & 9.9 & 10.9 \\
\hline Girls who had begun menstruating & & & 133 & 1,677 & 2,039 \\
\hline
\end{tabular}

Notes: All Ns are unweighted. NA: not applicable. 
With regard to girls' experience of menstrual problems in the three months preceding the interview, findings show that four percent of younger girls and 10 percent each of unmarried and married older girls who had begun menstruating had experienced menstrual problems. There was little variation between rural and urban adolescents with regard to menstrual problems.

Treatment-seeking for sexual and reproductive health problems was limited (Table 11.3). While age differences were muted, differences by sex were wide-boys were more likely than girls to have sought treatment for symptoms suggestive of genital infection (59\% versus $15 \%$ among younger adolescents and $64 \%$ versus $20-32 \%$ among older adolescents). Among older girls, the married were more likely than the unmarried to have sought treatment (32\% versus $20 \%$ ), and differences in treatment-seeking between rural and urban adolescents were narrow, except that more unmarried older girls in urban than rural areas had sought treatment (28\% versus $18 \%$ ).

The majority of adolescents who had sought care did so from a range of providers, including private sector providers, public sector providers, medical shop/chemist, and unqualified providers, although the proportions who sought care from these providers varied across sub-groups. Among younger boys who had sought care, 42 percent did so from a private sector provider, 25 percent had relied on unqualified providers, traditional practitioners, or home remedies, 25 percent had approached a medical shop/chemist, and just 10 percent had gone to a government health facility or provider. ${ }^{2}$ Among older boys, a considerable proportion, 38-39 percent, had approached a private sector provider or a medical shop/chemist, followed by 15 percent who had approached an unqualified provider or taken home remedies. Some 10 percent had relied on a government health facility or provider. Among unmarried and married older girls who had sought care, 62-77 percent sought care from a private sector provider, followed by 10-18 percent from a government health facility or provider, and 6-13 percent from a medical shop/chemist. Some 9-12 percent relied on unqualified practitioners and home remedies. As seen above, older boys were less likely than their female counterparts to seek services from a government health facility or provider (10\% versus 18\%) and a private sector provider (39\% versus $62 \%$ ), but more likely to rely on a medical shop/chemist (38\% versus $13 \%$ ). Unmarried older girls were more likely than married older girls to have sought treatment from a government health facility or doctor (18\% versus $10 \%)$ and a medical shop/chemist (13\% versus $6 \%$ ), but were less likely to go to a private sector provider (62\% versus $77 \%)$.

Differences by residence show that boys in urban areas were more likely than their rural counterparts to have approached a medical shop/chemist (45-51\% versus $23-38 \%$ ), but less likely to have relied on unqualified providers or home remedies (10\% versus $26 \%$ among younger boys). Among girls, differences between those from rural and those from urban areas were narrow for the most part; even so, unmarried older girls in urban areas were more likely than their rural counterparts to rely on private sector providers ( $71 \%$ versus $60 \%$ ) and married older girls in urban areas were more likely than their counterparts in rural areas to seek treatment from public sector providers (15\% versus $10 \%)$.

Among older girls who had experienced menstrual problems in the three months prior to the interview, just 27 percent of unmarried girls and 42 percent of married girls had sought treatment. As with treatment for symptoms suggestive of genital infection, the majority of older girls who had sought treatment relied on private sector providers (68\% of unmarried girls and $86 \%$ of married girls). Some 24 percent of unmarried girls and eight percent of married girls sought care from government sector providers, 14 percent of unmarried girls and two percent of married girls approached a medical shop/chemist, and 8-9 percent accessed care from unqualified providers or relied on home remedies. As seen above, unmarried girls were more likely than married girls to rely on government sector facilities or providers and medical shops/chemists, but less likely to have received care from private sector providers. Differences in care-seeking between older girls from rural areas and those from urban areas show that urban unmarried girls were more likely than their rural counterparts to have approached a medical shop/chemist (22\% versus $12 \%)$, but less likely to have sought care from private sector providers (58\% versus 69\%). Among married girls, urban girls were less likely than rural girls to have sought care from private sector providers ( $78 \%$ versus $87 \%$ ) or relied on unqualified providers or home remedies (none versus $9 \%$ ), but more likely to have sought care from government health facilities or providers (23\% versus $7 \%$ ).

\footnotetext{
${ }^{2}$ The small number of cases precludes a corresponding discussion for younger girls.
} 


\section{Table 11.3 Care-seeking for sexual and reproductive health problems}

Percentage of adolescents who experienced sexual and reproductive health problems in the three months preceding the interview by reported care-seeking and place of treatment, according to residence, Bihar, 2016

\begin{tabular}{|c|c|c|c|c|c|}
\hline Care-seeking & $\begin{array}{c}\text { Boys } \\
(10-14)\end{array}$ & $\begin{array}{c}\text { Boys } \\
(15-19)\end{array}$ & $\begin{array}{c}\text { Girls } \\
(10-14)\end{array}$ & $\begin{array}{c}\text { Girls } \\
(15-19)\end{array}$ & $\begin{array}{l}\text { Married girls } \\
\qquad(15-19)\end{array}$ \\
\hline \multicolumn{6}{|c|}{ Combined (percent) } \\
\hline Sought treatment for symptoms of genital infection ${ }^{1}$ & 59.4 & 64.3 & 15.1 & 19.5 & 31.6 \\
\hline Number reporting symptoms of genital infection & 136 & 404 & 65 & 574 & 853 \\
\hline \multicolumn{6}{|l|}{$\begin{array}{l}\text { Type of provider or facility from whom/which treatment was } \\
\text { sought for symptoms of genital infection }{ }^{1}\end{array}$} \\
\hline Government facility/doctor/ANM & 10.0 & 9.5 & * & 18.4 & 10.4 \\
\hline Private facility/doctor & 41.9 & 38.7 & * & 61.9 & 77.4 \\
\hline $\begin{array}{l}\text { Unqualified medical practitioners, traditional healers, or } \mathrm{h} \\
\text { remedies }\end{array}$ & 24.5 & 15.2 & * & 12.4 & 9.3 \\
\hline Medical shop/chemist & 25.3 & 38.1 & * & 13.1 & 5.9 \\
\hline $\begin{array}{l}\text { Number who sought treatment for symptoms of genital } \\
\text { infection }\end{array}$ & 83 & 250 & 11 & 130 & 241 \\
\hline Sought treatment for menstrual problems & NA & NA & * & 26.5 & 42 \\
\hline Number reporting menstrual problems & NA & NA & 19 & 332 & 302 \\
\hline \multicolumn{6}{|l|}{$\begin{array}{l}\text { Type of provider or facility from whom/which treatment was } \\
\text { sought for menstrual problems }\end{array}$} \\
\hline Government facility/doctor/ANM & NA & NA & * & 24.2 & 7.8 \\
\hline Private facility/doctor & NA & NA & * & 67.7 & 86.3 \\
\hline $\begin{array}{l}\text { Unqualified medical practitioners, traditional healers, or } \mathrm{h} \\
\text { remedies }\end{array}$ & NA & NA & * & 9.2 & 8.4 \\
\hline Medical shop/chemist & NA & NA & * & 13.5 & 2.1 \\
\hline Number who sought treatment for menstrual problems & NA & NA & 3 & 104 & 106 \\
\hline \multicolumn{6}{|c|}{ Urban (percent) } \\
\hline Sought treatment for symptoms of genital infection ${ }^{1}$ & 61.1 & 59.8 & $(13.9)$ & 28.4 & 32.8 \\
\hline Number reporting symptoms of genital infection & 50 & 187 & 33 & 301 & 350 \\
\hline \multicolumn{6}{|l|}{$\begin{array}{l}\text { Type of provider or facility from whom/which treatment was } \\
\text { sought for symptoms of genital infection }{ }^{1}\end{array}$} \\
\hline Government facility/doctor/ANM & $(6.1)$ & 8.9 & * & 15.0 & 14.5 \\
\hline Private facility/doctor & $(37.5)$ & 39.5 & * & 70.5 & 74.3 \\
\hline $\begin{array}{l}\text { Unqualified medical practitioners, traditional healers, or } \mathrm{h} \\
\text { remedies }\end{array}$ & $(10.2)$ & 13.0 & * & 10.0 & 8.9 \\
\hline Medical shop/chemist & $(51.0)$ & 44.7 & * & 15.4 & 6.6 \\
\hline $\begin{array}{l}\text { Number who sought treatment for symptoms of genital } \\
\text { infection }\end{array}$ & 30 & 113 & 6 & 80 & 104 \\
\hline Sought treatment for menstrual problems & NA & NA & * & 37.6 & 45.2 \\
\hline Number reporting menstrual problems & NA & NA & 13 & 176 & 93 \\
\hline
\end{tabular}


Table 11.3 Cont.

\begin{tabular}{|c|c|c|c|c|c|}
\hline Care-seeking & $\begin{array}{c}\text { Boys } \\
(10-14)\end{array}$ & $\begin{array}{l}\text { Boys } \\
(15-19)\end{array}$ & $\begin{array}{l}\text { Girls } \\
(10-14)\end{array}$ & $\begin{array}{l}\text { Girls } \\
(15-19)\end{array}$ & $\begin{array}{l}\text { Married girls } \\
\qquad(15-19)\end{array}$ \\
\hline \multicolumn{6}{|l|}{$\begin{array}{l}\text { Type of provider or facility from whom/which treatment was } \\
\text { sought for menstrual problems }\end{array}$} \\
\hline Government facility/doctor/ANM & NA & NA & * & 27.3 & $(23.4)$ \\
\hline Private facility/doctor & NA & NA & * & 57.5 & $(78.4)$ \\
\hline $\begin{array}{l}\text { Unqualified medical practitioners, traditional healers, or } \mathrm{h} \\
\text { remedies }\end{array}$ & NA & NA & * & 10.1 & $(0.0)$ \\
\hline Medical shop/chemist & NA & NA & * & 22.1 & $(0.9)$ \\
\hline Number who sought treatment for menstrual problems & NA & NA & 2 & 64 & 32 \\
\hline \multicolumn{6}{|c|}{ Rural (percent) } \\
\hline Sought treatment for symptoms of genital infection ${ }^{1}$ & 59.2 & 64.7 & $(15.3)$ & 18.4 & 31.5 \\
\hline Number reporting symptoms of genital infection & 86 & 217 & 32 & 273 & 503 \\
\hline \multicolumn{6}{|l|}{$\begin{array}{l}\text { Type of provider or facility from whom/which treatment was } \\
\text { sought for symptoms of genital infection }{ }^{1}\end{array}$} \\
\hline Government facility/doctor/ANM & 10.4 & 9.6 & * & 19.0 & 9.9 \\
\hline Private facility/doctor & 42.3 & 38.6 & * & 60.2 & 77.7 \\
\hline $\begin{array}{l}\text { Unqualified medical practitioners, traditional healers, or } \mathrm{h} \\
\text { remedies }\end{array}$ & 25.9 & 15.4 & * & 12.9 & 9.3 \\
\hline Medical shop/chemist & 22.8 & 37.6 & * & 12.6 & 5.8 \\
\hline $\begin{array}{l}\text { Number who sought treatment for symptoms of genital } \\
\text { infection }\end{array}$ & 53 & 137 & 5 & 50 & 137 \\
\hline Sought treatment for menstrual problems & NA & NA & * & 25.2 & 41.8 \\
\hline Number reporting menstrual problems & NA & NA & 6 & 156 & 209 \\
\hline \multicolumn{6}{|l|}{$\begin{array}{l}\text { Type of provider or facility from whom/which treatment was } \\
\text { sought for menstrual problems }\end{array}$} \\
\hline Government facility/doctor/ANM & NA & NA & * & $(23.7)$ & 6.7 \\
\hline Private facility/doctor & NA & NA & * & $(69.4)$ & 86.8 \\
\hline $\begin{array}{l}\text { Unqualified medical practitioners, traditional healers, or } \mathrm{h} \\
\text { remedies }\end{array}$ & NA & NA & * & $(9.1)$ & 9.1 \\
\hline Medical shop/chemist & NA & NA & * & $(12.0)$ & 2.2 \\
\hline Number who sought treatment for menstrual problems & NA & NA & 1 & 40 & 74 \\
\hline
\end{tabular}

Notes: All Ns are unweighted. Column totals may not equal to $100 \%$ owing to multiple responses. *Percentage not shown, as this was based on fewer than 25 unweighted cases. () Based on 25-49 unweighted cases. NA: not applicable; ANM: auxiliary nurse midwife. ${ }^{1}$ Includes genital ulcers, genital itching, swelling in the groin, genital discharge, burning during urination, etc.

\subsection{Mental health condition}

The mental health condition of adolescents was assessed based on a series of questions. We administered the Patient Health Questionnaire (PHQ-9) to all respondents to assess the prevalence of depression-related symptoms in the two weeks prior to the interview. This questionnaire is a nine-item depression-screening module; the PHQ-9 score ranges from 0 to 27 with cut-off points of 5,10,15, and 20 that represent the thresholds for mild, moderate, moderately severe, and severe depression, respectively (Kroenke, Spitzer, and Williams, 2001). Adolescents aged 13 and above were additionally asked whether they had seriously considered committing suicide in the 12 months preceding the interview, whether they had made any plans about how to commit suicide, and the number of times 
they had attempted suicide during the same reference period. Finally, all adolescents were asked whether they had inflicted such acts of self-harm as cutting or biting themselves, pulling their hair and banging their head against something, or hitting themselves when they were agitated, angry, or sad in the 12 months preceding the interview.

Findings related to PHQ-9 scores obtained by participants are presented in Table 11.4. Findings show that the vast majority of adolescents displayed no mental health problems (a score of 0-4) in the two weeks prior to the interview (94-96\% of younger adolescents and $76-90 \%$ of older adolescents). Girls, particularly unmarried and married older girls, scored higher than boys, indicating the poorer mental health condition of girls compared with boys. Specifically, four percent of younger boys and nine percent of older boys displayed symptoms of mild depressive disorders (a score of 5-9) in the two weeks prior to the interview as did five percent of younger girls, 14 percent of unmarried older girls, and 17 percent of married older girls. Hardly any younger adolescents displayed symptoms of moderate to severe depressive disorders (a score of 10-27; none of the boys and 1.2\% of girls); however, one percent of older boys, five percent of unmarried older girls, and seven percent of married older girls displayed such symptoms in the two weeks prior to the interview. Differences by residence in rural or urban areas with regard to prevalence of symptoms of depression were narrow. We found that differences in the prevalence of symptoms of moderate to severe depression in the two weeks prior to the interview by age, religion, caste, education, current schooling status, engagement in paid work (in the year preceding the interview), household wealth status, and mother's education were narrow or erratic at best across all three categories of older adolescents (not shown in table).

\section{Table 11.4: Prevalence of depression-related symptoms}

Percent distribution of adolescents by scores obtained in patient health questionnaire (PHQ-9) for the two weeks preceding the interview, according to residence, Bihar, 2016

\begin{tabular}{|c|c|c|c|c|c|}
\hline Categories of PHQ-9 score & $\begin{array}{r}\text { Boys } \\
(10-14)\end{array}$ & $\begin{array}{r}\text { Boys } \\
(15-19)\end{array}$ & $\begin{array}{r}\text { Girls } \\
(10-14)\end{array}$ & $\begin{array}{r}\text { Girls } \\
(15-19)\end{array}$ & $\begin{array}{r}\text { Married girls } \\
(15-19)\end{array}$ \\
\hline \multicolumn{6}{|l|}{ Combined (percent) } \\
\hline Minimal (0-4) & 95.6 & 90.3 & 94.2 & 80.9 & 76.2 \\
\hline Mild (5-9) & 4.4 & 8.6 & 4.5 & 14.1 & 16.9 \\
\hline Moderate (10-14) & 0.0 & 1.0 & 1.0 & 2.9 & 4.3 \\
\hline Moderately severe (15-19) & 0.0 & 0.1 & 0.0 & 1.5 & 1.9 \\
\hline Severe (20-27) & 0.0 & 0.0 & 0.2 & 0.6 & 0.8 \\
\hline Number of respondents & 1,012 & 1,821 & 764 & 3,428 & 3,408 \\
\hline \multicolumn{6}{|c|}{ Urban (percent) } \\
\hline Minimal (0-4) & 96.6 & 91.7 & 87.7 & 80.7 & 74.8 \\
\hline Mild (5-9) & 3.4 & 7.2 & 9.7 & 13.2 & 18.6 \\
\hline Moderate (10-14) & 0.0 & 0.8 & 1.4 & 3.7 & 3.8 \\
\hline Moderately severe (15-19) & 0.0 & 0.3 & 0.4 & 1.5 & 2.1 \\
\hline Severe (20-27) & 0.0 & 0.0 & 0.9 & 1.0 & 0.7 \\
\hline Number of respondents & 452 & 1,008 & 387 & 1,738 & 1,366 \\
\hline \multicolumn{6}{|c|}{ Rural (percent) } \\
\hline Minimal $(0-4)$ & 95.5 & 90.1 & 95.0 & 81.0 & 76.4 \\
\hline Mild (5-9) & 4.5 & 8.8 & 3.9 & 14.2 & 16.6 \\
\hline Moderate (10-14) & 0.0 & 1.0 & 1.0 & 2.8 & 4.3 \\
\hline Moderately severe (15-19) & 0.0 & 0.1 & 0.0 & 1.5 & 1.9 \\
\hline Severe (20-27) & 0.0 & 0.0 & 0.2 & 0.5 & 0.8 \\
\hline Number of respondents & 560 & 813 & 377 & 1,690 & 2,042 \\
\hline
\end{tabular}

Note: All Ns are unweighted. 
We asked those who reported symptoms of depressive disorders in the two weeks prior to the interview their reasons for feeling depressed, but several opted not to reveal them. Table 11.5 describes the reasons for feeling depressed among unmarried and married older girls who displayed symptoms of moderate to severe depression (the number of older boys who displayed symptoms of moderate to severe depression were small and, therefore, percentages for older boys are not shown in the table); we observed that 55 percent of unmarried older girls and 52 percent of married older girls did not reveal any reasons, and, therefore, findings need to be interpreted with caution.

Reasons for feeling depressed differed by marital status. Unmarried girls attributed their feeling depressed to tension related to their education ( $17 \%$, that is, school discontinuation, worries about examination and failure), a recent episode of illness or injury (11\%), family poverty and tension for unspecified reasons (8\%), and death of a family member (5\%). For married girls, the main reasons for feeling depressed were stress related to childbearing (17\%, that is, tension related to current or recent pregnancy, miscarriage, infant death, and tension due to inability to conceive a child), domestic violence (11\%), and family poverty and tension for unspecified reasons (9\%).

\section{Table 11.5: Reasons for feeling depressed}

Percentage of adolescent girls in ages 15-19 who displayed symptoms of moderate to severe depression in the two weeks prior to the interview by reasons for feeling depressed, Bihar, 2016

\begin{tabular}{|c|c|c|}
\hline Reasons (percent) & $\begin{array}{c}\text { Girls } \\
(15-19)\end{array}$ & $\begin{array}{c}\text { Married girls } \\
(15-19)\end{array}$ \\
\hline Education-related stress (discontinuation, fear of failure, examination-related stress) & 16.5 & 2.6 \\
\hline Employment-related stress (tensions about finding a good job) & 0.1 & 0.6 \\
\hline Burden of household chores & 0.9 & 0.0 \\
\hline Relationship issues with premarital romantic partner & 1.1 & 0 \\
\hline $\begin{array}{l}\text { Marriage-related stress (elopement, pressure to marry early or early marriage, tension about } \\
\text { finding money for dowry payment at the time of marriage) }\end{array}$ & 1.8 & 0.8 \\
\hline Pregnancy-related stress (current pregnancy, pregnancy loss, infant death, and infertility) & 1.5 & 17.4 \\
\hline Current/recent pregnancy & 1.5 & 13.3 \\
\hline Miscarriage and infant death & 0.0 & 2.7 \\
\hline Infertility & 0.0 & 1.4 \\
\hline Domestic violence & 3.6 & 11.1 \\
\hline Experienced parental violence & 3.3 & 0 \\
\hline Experienced violence by other family members & 0.3 & 6.5 \\
\hline Experienced marital violence & 0 & 6.3 \\
\hline Experienced dowry harassment by in-laws & 0 & 0.7 \\
\hline Family poverty and tension & 8.3 & 9.2 \\
\hline Family poverty & 2.6 & 2.3 \\
\hline Family tension (reason for which was not specified) & 5.8 & 7.4 \\
\hline Recent episode of illness/injury experienced by respondent & 11.1 & 5.9 \\
\hline Recent episode of illness of respondent's family member & 0.1 & 2.1 \\
\hline Death of a family member & 4.9 & 1.3 \\
\hline Substance use by family members & 1.0 & 0.7 \\
\hline Experience of verbal harassment in public spaces & 0.1 & 0.0 \\
\hline Did not reveal the reason & 55.2 & 52.0 \\
\hline Respondents who reported symptoms of moderate to severe symptoms of depression & 185 & 237 \\
\hline
\end{tabular}


Findings presented in Table 11.6 on suicidal ideation among adolescents aged 13 and above show that 0.2 and 0.3 percent of younger boys and girls, respectively, had seriously contemplated committing suicide in the year preceding the interview. Among older adolescents, two percent of boys, three percent of unmarried older girls, and seven percent of married older girls reported that they had contemplated suicide. None of the younger adolescents had made a plan on how to commit suicide or had made an attempt to commit suicide. Among older adolescents, 0.5 percent each of boys and unmarried girls and 1.1 percent of married girls had made a plan on how to commit suicide. Finally, 0.1 and 0.5 percent of older boys and unmarried older girls, respectively, and one percent of married older girls had made at least one attempt to commit suicide. Differences by residence in rural or urban areas were muted for the indicators of suicidal ideation.

\section{Table 11.6: Suicidal ideation}

Percentage of adolescents in ages 13-19 reporting suicidal ideation experienced in the 12 months preceding the interview, according to residence, Bihar, 2016

\begin{tabular}{|c|c|c|c|c|c|}
\hline Indicators of suicidal ideation & $\begin{array}{l}\text { Boys } \\
(13-14)\end{array}$ & $\begin{array}{l}\text { Boys } \\
(15-19)\end{array}$ & $\begin{array}{c}\text { Girls } \\
(13-14)\end{array}$ & $\begin{array}{c}\text { Girls } \\
(15-19)\end{array}$ & $\begin{array}{l}\text { Married girls } \\
(15-19)\end{array}$ \\
\hline \multicolumn{6}{|c|}{ Combined (percent) } \\
\hline Seriously considered attempting suicide & 0.2 & 1.7 & 0.3 & 3.4 & 7 \\
\hline Made a plan on how to commit suicide & 0.0 & 0.5 & 0.0 & 0.5 & 1.1 \\
\hline Made at least one attempt to commit suicide & 0.0 & 0.1 & 0.0 & 0.5 & 1.0 \\
\hline Number of respondents aged 13 and above & 378 & 1,821 & 318 & 3,428 & 3,408 \\
\hline \multicolumn{6}{|c|}{ Urban (percent) } \\
\hline Seriously considered attempting suicide & 0.0 & 2.2 & 2.3 & 3.7 & 5.6 \\
\hline Made a plan on how to commit suicide & 0.0 & 0.7 & 0.0 & 1.0 & 1.5 \\
\hline Made at least one attempt to commit suicide & 0.0 & 0.6 & 0.0 & 1.0 & 1.5 \\
\hline Number of respondents aged 13 and above & 168 & 1,008 & 168 & 1,738 & 1,366 \\
\hline \multicolumn{6}{|c|}{ Rural (percent) } \\
\hline Seriously considered attempting suicide & 0.2 & 1.6 & 0.0 & 3.3 & 7.2 \\
\hline Made a plan on how to commit suicide & 0.0 & 0.5 & 0.0 & 0.5 & 1.1 \\
\hline Made at least one attempt to commit suicide & 0.0 & 0.1 & 0.0 & 0.5 & 0.9 \\
\hline Number of respondents aged 13 and above & 210 & 813 & 150 & 1,690 & 2,042 \\
\hline
\end{tabular}

Note: All Ns are unweighted.

Findings also show that a small minority of adolescents had inflicted acts of self-harm in the year preceding the interview (Table 11.7). Specifically, 2-3 percent of boys and 1-3 percent of girls had cut or bitten themselves at least once in the year preceding the interview; two percent of boys and 1-3 percent of girls had pulled their own hair; and 1-2 percent of boys and girls had banged their head against something or hit themselves. In total, 4-5 percent of boys and 2-4 percent of girls had inflicted at least one of these acts of self-harm. Differences by residence in rural or urban areas were negligible (Figure 11.1). 


\section{Health and health-seeking behaviour}

Table 11.7: Infliction of self-harm

Percentage of adolescents reporting that they had inflicted acts of self-harm in the 12 months preceding the interview, Bihar, 2016

\begin{tabular}{lrrrrr}
\hline Indicators of self-harm (percent) & $\begin{array}{c}\text { Boys } \\
(10-14)\end{array}$ & $\begin{array}{c}\text { Boys } \\
(15-19)\end{array}$ & $\begin{array}{c}\text { Girls } \\
(10-14)\end{array}$ & $\begin{array}{c}\text { Girls } \\
(15-19)\end{array}$ & $\begin{array}{c}\text { Married girls } \\
(15-19)\end{array}$ \\
\hline Cut/bitten self & & & & & \\
1-2 times & 1.4 & 0.9 & 0.6 & 0.8 & 2.2 \\
3-4 times & 1.3 & 0.4 & 2.0 & 0.4 & 0.5 \\
5+ times & 0.0 & 0.4 & 0.3 & 0.2 & 0.2 \\
$\quad$ Never & 97.3 & 98.3 & 97.1 & 98.6 & 97.0 \\
Pulled own hair & & & & & \\
1-2 times & 0.4 & 0.8 & 1.4 & 0.5 & 1.7 \\
3-4 times & 0.8 & 0.6 & 0.5 & 0.3 & 0.6 \\
5+ times & 0.7 & 0.5 & 0.1 & 0.1 & 0.2 \\
Never & 98.1 & 98.1 & 98.0 & 99.1 & 97.6 \\
Banged their head against something or hit themselves & & & & & 0.7 \\
1-2 times & 0.3 & 0.4 & 0.8 & 0.5 & 0.7 \\
3-4 times & 0.6 & 1.1 & 0.5 & 0.3 & 0.4 \\
5+ times & 0.9 & 0.3 & 0.2 & 0.2 & 0.3 \\
Never & 98.2 & 98.2 & 98.5 & 99.0 & 98.6 \\
Any one of the above & 5.0 & 3.7 & 4.2 & 2.1 & 3.7 \\
Number of respondents & $\mathbf{1 , 0 1 2}$ & $\mathbf{1 , 8 2 1}$ & $\mathbf{7 6 4}$ & $\mathbf{3 , 4 2 8}$ & $\mathbf{3 , 4 0 8}$ \\
\hline
\end{tabular}

Note: All Ns are unweighted.

Figure 11.1: Percentage of adolescents reporting that they had inflicted acts of self-harm in the 12 months preceding the interview, according to residence, Bihar, 2016

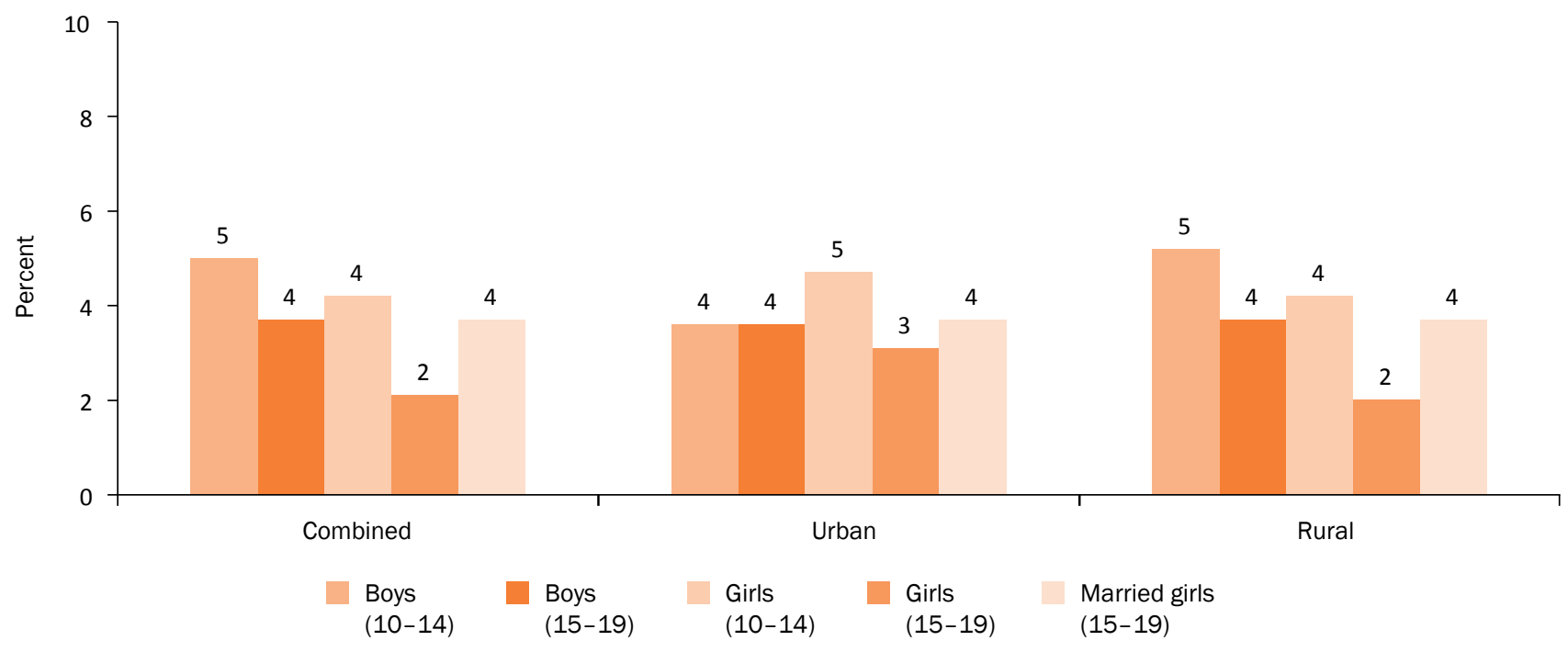




\subsection{Injuries}

Adolescents contribute disproportionately to all-age injuries (Sawyer et al., 2012). We asked study participants about any injuries that they may have sustained in the three months prior to our interview with them. We sought information on whether they had experienced injuries in a road accident or in other circumstances, for example, in a physical fight, from a fall, from an animal bite, or any other circumstances, during the three months prior to the interview. Findings are described in Table 11.8. Boys were more likely than girls to have experienced injuries in a road accident in the three months prior to the interview (9-11\% versus 2-3\%). Differences by age and residence in rural or urban areas and, among older girls, by marital status were narrow. Larger proportions of adolescents reported experiences of injury in other circumstances, and more boys than girls reported injuries in other circumstances (22-32\% versus 15-22\%). Younger adolescents were somewhat more likely than older adolescents to report injuries in other circumstances (32\% versus 22\% among boys and 22\% versus $14-16 \%$ among girls). Differences were narrow by marital status among older girls and by residence in rural or urban areas among all categories of adolescents. On the whole, 37 percent of younger boys and 29 percent of older boys reported at least one injury in the three months prior to the interview as did 24 percent of younger girls, 18 percent of unmarried older girls, and 15 percent of married older girls.

\section{Table 11.8: Injuries}

Percentage of adolescents reporting experiences of injuries in the three months prior to the interview, according to residence, Bihar, 2016

\begin{tabular}{|c|c|c|c|c|c|}
\hline Injuries & $\begin{array}{c}\text { Boys } \\
(10-14)\end{array}$ & $\begin{array}{c}\text { Boys } \\
(15-19)\end{array}$ & $\begin{array}{c}\text { Girls } \\
(10-14)\end{array}$ & $\begin{array}{c}\text { Girls } \\
(15-19)\end{array}$ & $\begin{array}{l}\text { Married girls } \\
\text { (15-19) }\end{array}$ \\
\hline \multicolumn{6}{|c|}{ Combined (percent) } \\
\hline Injured in a road accident & 8.9 & 10.9 & 2.6 & 3.3 & 1.5 \\
\hline Injured in other circumstances (fight, fall, animal bite, etc.) & 31.5 & 22.2 & 21.8 & 16.1 & 14.6 \\
\hline Any of the above & 37.1 & 28.6 & 23.6 & 17.6 & 15.2 \\
\hline Number of respondents & 1,012 & 1,821 & 764 & 3,428 & 3,408 \\
\hline \multicolumn{6}{|c|}{ Urban (percent) } \\
\hline Injured in a road accident & 11.9 & 10.2 & 3.2 & 4.3 & 0.9 \\
\hline Injured in other circumstances (fight, fall, animal bite, etc.) & 27.9 & 20.5 & 19.2 & 16.8 & 11.7 \\
\hline Any of the above & 35.4 & 28.0 & 21.1 & 19.0 & 12.1 \\
\hline Number of respondents & 452 & 1,008 & 387 & 1,738 & 1,366 \\
\hline \multicolumn{6}{|c|}{ Rural (percent) } \\
\hline Injured in a road accident & 8.5 & 11.0 & 2.6 & 3.2 & 1.6 \\
\hline Injured in other circumstances (fight, fall, animal bite, etc.) & 31.9 & 22.4 & 22.2 & 16.0 & 14.9 \\
\hline Any of the above & 37.3 & 28.7 & 23.9 & 17.5 & 15.5 \\
\hline Number of respondents & 560 & 813 & 377 & 1,690 & 2,042 \\
\hline
\end{tabular}

Note: All Ns are unweighted.

\subsection{Substance use}

Research has shown that substance use can directly compromise the health of adolescents and youth. Evidence suggests, for example, that the use of alcohol and drugs among youth is associated with physical fights, risky sexual activity, depression, and suicide as well as irregular school or work attendance and other negative outcomes (DiClemente, 1992; Ellickson, Saner, and McGuigan, 1997; Gruber et al., 1996; Lowry et al., 1994; Mohan, Sankara Sarma, and Thankappan, 2005; Singh and Saini, 2007). 
This survey probed alcohol consumption, drug use-including brown sugar (a heroin product), cocaine, and such cannabis products as ganja, charas, and bhang-and tobacco use among adolescents. Among those who reported substance use, we also sought information on the frequency of use in the month prior to our interview. Findings suggest that hardly any boys and girls $(0.5 \%$ or fewer) reported drug use. However, a substantial proportion of older boys and a small minority of younger adolescents and unmarried and married older girls reported the consumption of tobacco (Table 11.9). Five percent of younger boys and 20 percent of older boys had ever consumed tobacco products as had 1-2 percent of younger girls and older girls. However, frequent consumption of tobacco products, that is, once a week or more frequently in the month prior to the interview, was reported by fewer adolescents-two percent and 13 percent of younger and older boys, respectively, and less than one percent of girls. Differences by residence in rural or urban areas with regard to consumption of tobacco were narrow.

Fewer adolescents reported alcohol consumption-two percent of younger boys, eight percent of older boys, and hardly any in all three categories of girls reported ever consuming alcohol; very few boys (1\% or less) and hardly any girls $(0.1 \%$ of married girls and not a single younger girl or unmarried older girl) reported frequent alcohol consumption in the month prior to the interview. Differences by residence in rural or urban areas were negligible.

\section{Table 11.9 Substance use}

Percentage of adolescents reporting lifetime and recent substance use, according to residence, Bihar, 2016

\begin{tabular}{|c|c|c|c|c|c|}
\hline Substance use & $\begin{array}{c}\text { Boys } \\
(10-14)\end{array}$ & $\begin{array}{l}\text { Boys } \\
(15-19)\end{array}$ & $\begin{array}{c}\text { Girls } \\
(10-14)\end{array}$ & $\begin{array}{c}\text { Girls } \\
(15-19)\end{array}$ & $\begin{array}{c}\text { Married girls } \\
(15-19)\end{array}$ \\
\hline \multicolumn{6}{|c|}{ Combined (percent) } \\
\hline \multicolumn{6}{|l|}{ Ever consumed } \\
\hline Tobacco and its products & 4.8 & 20.2 & 1.2 & 1.7 & 1.5 \\
\hline Alcohol & 1.9 & 8.0 & 0.0 & 0.2 & 0.3 \\
\hline Drugs $^{1}$ & 0.4 & 1.1 & 0.0 & 0.1 & 0.0 \\
\hline \multicolumn{6}{|c|}{$\begin{array}{l}\text { Consumed once a week or more frequently in the month } \\
\text { preceding the interview }\end{array}$} \\
\hline Tobacco and its products & 2.3 & 12.5 & 0.2 & 0.6 & 0.5 \\
\hline Alcohol & 0.4 & 1.2 & 0.0 & 0.0 & 0.1 \\
\hline Drugs $^{1}$ & 0.0 & 0.4 & 0.0 & 0.0 & 0.0 \\
\hline Number of respondents & 1,012 & 1,821 & 764 & $\mathbf{3 , 4 2 8}$ & 3,408 \\
\hline \multicolumn{6}{|c|}{ Urban (percent) } \\
\hline \multicolumn{6}{|l|}{ Ever consumed } \\
\hline Tobacco and its products & 3.3 & 17.3 & 1.8 & 1.3 & 2.0 \\
\hline Alcohol & 0.6 & 8.4 & 0.0 & 0.2 & 0.4 \\
\hline Drugs $^{1}$ & 0.0 & 1.3 & 0.0 & 0.0 & 0.0 \\
\hline \multicolumn{6}{|c|}{$\begin{array}{l}\text { Consumed once a week or more frequently in the month } \\
\text { preceding the interview }\end{array}$} \\
\hline Tobacco and its products & 1.6 & 10.9 & 0.2 & 0.4 & 0.3 \\
\hline Alcohol & 0.2 & 1.1 & 0.0 & 0.1 & 0.1 \\
\hline Drugs $^{1}$ & 0.0 & 0.4 & 0.0 & 0.0 & 0.0 \\
\hline Number of respondents & 452 & 1,008 & 387 & 1,738 & 1,366 \\
\hline
\end{tabular}


Table 11.9 Cont.

\begin{tabular}{|c|c|c|c|c|c|}
\hline Substance use & $\begin{array}{c}\text { Boys } \\
(10-14)\end{array}$ & $\begin{array}{c}\text { Boys } \\
(15-19)\end{array}$ & $\begin{array}{c}\text { Girls } \\
(10-14)\end{array}$ & $\begin{array}{c}\text { Girls } \\
(15-19)\end{array}$ & $\begin{array}{c}\text { Married girls } \\
(15-19)\end{array}$ \\
\hline \multicolumn{6}{|c|}{ Rural (percent) } \\
\hline \multicolumn{6}{|l|}{ Ever consumed } \\
\hline Tobacco and its products & 5.0 & 20.5 & 1.1 & 1.7 & 1.4 \\
\hline Alcohol & 2.1 & 7.9 & 0.0 & 0.2 & 0.3 \\
\hline Drugs $^{1}$ & 0.5 & 1.0 & 0.0 & 0.1 & 0.0 \\
\hline \multicolumn{6}{|c|}{$\begin{array}{l}\text { Consumed once a week or more frequently in the month } \\
\text { preceding the interview }\end{array}$} \\
\hline Tobacco and its products & 2.4 & 12.8 & 0.2 & 0.6 & 0.5 \\
\hline Alcohol & 0.4 & 1.3 & 0.0 & 0.0 & 0.1 \\
\hline Drugs $^{1}$ & 0.0 & 0.3 & 0.0 & 0.0 & 0.0 \\
\hline Number of respondents & 560 & 813 & 377 & 1,690 & 2,042 \\
\hline
\end{tabular}

Notes: All Ns are unweighted. ${ }^{1}$ Includes ganja, charas, brown sugar, cocaine, or locally made substances (e.g., sulochon).

\subsection{Engagement in sports and games or other physical activities}

Physical inactivity has been identified as the fourth leading risk factor for non-communicable diseases, and it accounted for more than three million preventable deaths in 2009 (WHO, 2009; Hallal et al., 2012). Further, inactivity levels in adolescence are a strong predictor of adult physical inactivity (Azevedo et al., 2007). We asked all study participants whether they typically played any sports and games or engaged in physical activities like walking, skipping, running, yoga, and so on. We asked those who reported physical activity the type of sports, games, or other physical activities in which they typically engaged and the frequency with which they engaged in these activities in the month preceding the interview. Findings are presented in Table 11.10.

Findings show that engagement in sports and games or other physical activities among adolescents differed by age, sex, and, among older girls, by marital status. Younger adolescents were more likely than older adolescents to report engagement in sports and games or other physical activities-95 percent of younger boys compared with 86 percent of older boys and 81 percent of younger girls compared with 17-51 percent of unmarried and married older girls were usually engaged in sports and games or other physical activities. As seen above, boys were more likely than girls to report physical activity. Among older girls, the unmarried were more likely than the married to report such engagement (51\% versus 17\%). However, engagement in such activities did not differ by residence in rural or urban areas, except for unmarried older girls, among whom more urban than rural girls reported engagement in sports and games or other physical activities (59\% versus $50 \%$ ).

The majority of younger and older boys and younger girls who were usually engaged in sports and games or other physical activities had engaged in such activities daily or several times a week in the month preceding the interview ( $88 \%, 82 \%$, and $70 \%$, respectively). A considerably smaller proportion of unmarried and married older girls reported regular engagement in sports or other physical activities (37\% of unmarried older girls and $20 \%$ of married older girls). Indeed, 22 percent of unmarried older girls and 53 percent of married older girls reported that they had not played any sports and games or engaged in other physical activities in the month preceding the interview. Differences were narrow between those from rural and those from urban areas among younger adolescents; however, they were apparent for older adolescents-a larger proportion of rural than urban older boys reported that they had engaged in sports and games or other physical activities daily or several times a week (83\% versus $74 \%$ ), but a reverse pattern was evident among unmarried and married older girls (36\% versus $42 \%$ among unmarried older girls and $19 \%$ versus $29 \%$ among married older girls). 
Table 11.10: Engagement in sports and games or other physical activities

Percentage of adolescents reporting engagement in sports and games or other physical activities by frequency of such engagement, according to residence, Bihar, 2016

\begin{tabular}{|c|c|c|c|c|c|}
\hline $\begin{array}{l}\text { Engagement in sports and games or other physical } \\
\text { activities }\end{array}$ & $\begin{array}{l}\text { Boys } \\
(10-14)\end{array}$ & $\begin{array}{l}\text { Boys } \\
(15-19)\end{array}$ & $\begin{array}{l}\text { Girls } \\
(10-14)\end{array}$ & $\begin{array}{l}\text { Girls } \\
(15-19)\end{array}$ & $\begin{array}{l}\text { Married girls } \\
\qquad(15-19)\end{array}$ \\
\hline \multicolumn{6}{|c|}{ Combined (percent) } \\
\hline Engaged in sports and games or other physical activities & 94.8 & 86.3 & 81.2 & 51.1 & 16.7 \\
\hline Number of respondents & 1,012 & 1,821 & 764 & 3,428 & 3,408 \\
\hline \multicolumn{6}{|l|}{$\begin{array}{l}\text { Frequency of engaging in sports and games or other } \\
\text { physical activities in the month prior to the interview }\end{array}$} \\
\hline Daily & 61.1 & 46.6 & 34.7 & 12.5 & 5.5 \\
\hline More than once a week & 27.0 & 35.5 & 34.9 & 24.4 & 14.2 \\
\hline Once a week & 7.5 & 7.2 & 16.3 & 18.6 & 8.7 \\
\hline Once or twice a month & 3.8 & 6.5 & 8.2 & 22.2 & 18.4 \\
\hline Never & 0.6 & 4.1 & 5.9 & 22.2 & 53.1 \\
\hline $\begin{array}{l}\text { Number of respondents who usually engage in sports and } \\
\text { games or other physical activities }\end{array}$ & 961 & 1,594 & 636 & 1,854 & 560 \\
\hline \multicolumn{6}{|c|}{ Urban (percent) } \\
\hline Engaged in sports and games or other physical activities & 95.5 & 88.4 & 84.7 & 59.4 & 19.1 \\
\hline Number of respondents & 452 & 1,008 & 387 & 1,738 & 1,366 \\
\hline \multicolumn{6}{|l|}{$\begin{array}{l}\text { Frequency of engaging in sports and games or other } \\
\text { physical activities in the month prior to the interview }\end{array}$} \\
\hline Daily & 65.4 & 43.6 & 38.0 & 16.5 & 10.2 \\
\hline More than once a week & 26.1 & 30.6 & 30.2 & 25.6 & 18.3 \\
\hline Once a week & 6.5 & 14.6 & 12.2 & 16.2 & 8.2 \\
\hline Once or twice a month & 1.8 & 8.1 & 13.2 & 22.7 & 15.5 \\
\hline Never & 0.2 & 3.1 & 6.5 & 19.0 & 47.8 \\
\hline $\begin{array}{l}\text { Number of respondents who usually engage in sports and } \\
\text { games or other physical activities }\end{array}$ & 431 & 887 & 334 & 1,016 & 240 \\
\hline \multicolumn{6}{|c|}{ Rural (percent) } \\
\hline Engaged in sports and games or other physical activities & 94.7 & 86.0 & 80.7 & 50.1 & 16.4 \\
\hline Number of respondents & 560 & 813 & 377 & 1,690 & 2,042 \\
\hline \multicolumn{6}{|l|}{$\begin{array}{l}\text { Frequency of engaging in sports and games or other } \\
\text { physical activities in the month prior to the interview }\end{array}$} \\
\hline Daily & 60.6 & 47.0 & 34.3 & 11.9 & 4.9 \\
\hline More than once a week & 27.2 & 36.2 & 35.5 & 24.3 & 13.7 \\
\hline Once a week & 7.7 & 6.3 & 16.8 & 19.0 & 8.8 \\
\hline Once or twice a month & 4.0 & 6.3 & 7.6 & 22.2 & 18.8 \\
\hline Never & 0.6 & 4.2 & 5.9 & 22.7 & 53.8 \\
\hline $\begin{array}{l}\text { Number of respondents who usually engage in sports and } \\
\text { games or other physical activities }\end{array}$ & 530 & 707 & 302 & 838 & 320 \\
\hline
\end{tabular}

Note: All Ns are unweighted. 


\subsection{Hesitation to access contraceptive supplies}

In order to capture the extent to which adolescents perceived that they could approach healthcare professionals for sexual and reproductive health services, we asked older adolescents whether they would feel shy to approach a healthcare provider or a pharmacy/medical shop for contraceptives. Findings are presented in Table 11.11, and they confirm that large proportions of adolescents would indeed feel shy to approach a healthcare provider or pharmacy/medical shop for contraceptive supplies. Boys were more hesitant to obtain supplies from a healthcare provider than from a pharmacy or medical shop (36\% versus $29 \%$ ). The proportions of unmarried older girls who reported discomfort in approaching a healthcare provider (36\%) and a pharmacy or medical shop (38\%) showed little variation for both. Among married older girls, a somewhat larger proportion reported discomfort in approaching a pharmacy or medical shop (50\%) than a healthcare provider (46\%).

As seen above, differences by marital status among girls show that the unmarried were less likely than their married counterparts to express discomfort in accessing contraceptive supplies from sources such as pharmacies or healthcare providers. Differences by residence in urban or rural areas were narrow among unmarried and married older girls, but marked for older boys, among whom more rural respondents than urban respondents reported discomfort in accessing contraceptive supplies from a healthcare provider (37\% versus $29 \%$ ) or pharmacy or medical shop (30\% versus $23 \%$ ). Findings confirm that many adolescents would indeed find it difficult to seek appropriate services for sexual and reproductive matters.

\section{Table 11.11: Hesitation to access contraceptive supplies}

Percentage of adolescents in ages 15-19 reporting hesitation to access contraceptive supplies from a healthcare provider or a pharmacy or medical shop, according to residence, Bihar, 2016

\begin{tabular}{|c|c|c|c|}
\hline Diffidence in accessing contraceptives & $\begin{array}{c}\text { Boys } \\
(15-19)\end{array}$ & $\begin{array}{c}\text { Girls } \\
(15-19)\end{array}$ & $\begin{array}{c}\text { Married girls } \\
\text { (15-19) }\end{array}$ \\
\hline \multicolumn{4}{|c|}{ Combined (percent) } \\
\hline Would feel shy to approach a healthcare provider for contraceptives & 36.1 & 35.6 & 45.8 \\
\hline Would feel shy to approach a pharmacy/medical shop for contraceptives & 28.8 & 37.7 & 50.0 \\
\hline Number of respondents & 1,821 & 3,428 & 3,408 \\
\hline \multicolumn{4}{|l|}{ Urban (percent) } \\
\hline Would feel shy to approach a healthcare provider for contraceptives & 29.3 & 36.5 & 48.1 \\
\hline Would feel shy to approach a pharmacy/medical shop for contraceptives & 23.1 & 38.2 & 53.4 \\
\hline Number of respondents & 1,008 & 1,738 & 1,366 \\
\hline \multicolumn{4}{|l|}{ Rural (percent) } \\
\hline Would feel shy to approach a healthcare provider for contraceptives & 36.9 & 35.5 & 45.5 \\
\hline Would feel shy to approach a pharmacy/medical shop for contraceptives & 29.5 & 37.6 & 49.7 \\
\hline Number of respondents & 813 & 1,690 & 2,042 \\
\hline
\end{tabular}

Note: All Ns are unweighted.

\subsection{Awareness and reach of government programmes intended to impart health information to adolescents and meet their health needs}

Several programmes have been initiated in India that either exclusively focus on adolescents and youth or incorporate a special focus on adolescents and youth in a more broad-based programme. This survey contained several questions to better understand study participants' awareness of and access to government programmes intended to impart health-related information to them and meet their needs. It also sought to determine whether they were aware of frontline health workers, namely, accredited social health activists (ASHAs) and anganwadi workers (AWWs), whether 
they had received health-related information and services from them, and, if so, the content of such information and services. Government programmes to benefit adolescents include the Rashtriya Kishor Swasthya Karykram, the School Health Programme, the community-level health worker programme, adolescent friendly health clinics, and the sanitary napkin distribution programme. The survey also sought particulars from adolescents in only rural areas about village health and nutrition days.

\subsubsection{Awareness of the Rashtriya Kishor Swasthya Karyakram (RKSK)}

The Rashtriya Kishor Swasthya Karyakram (RKSK, the National Adolescent Health Programme) launched in 2014 seeks to enable all adolescents to realise their full potential by helping them to make informed and responsible decisions concerning their health and well-being and to access the services and support they need to implement their decisions (Ministry of Health and Family Welfare, 2014b). Although the programme has not yet been rolled out widely, we included a question at the request of the Ministry of Health and Family Welfare to assess study participants' awareness of one of the components of the programme, namely, the peer education component and its reach. Specifically, we asked study participants whether they were aware of a government programme under which some adolescent boys and girls are trained to provide health-related information to their peers in their village or ward.

Findings presented in Figure 11.2 show that one percent of boys and 2-3 percent of girls had heard about a peer education programme, with little differences in this regard between those from rural and those from urban areas. However, we cannot rule out the possibility that these respondents could have been referred to peer education programmes by non-governmental organisations.

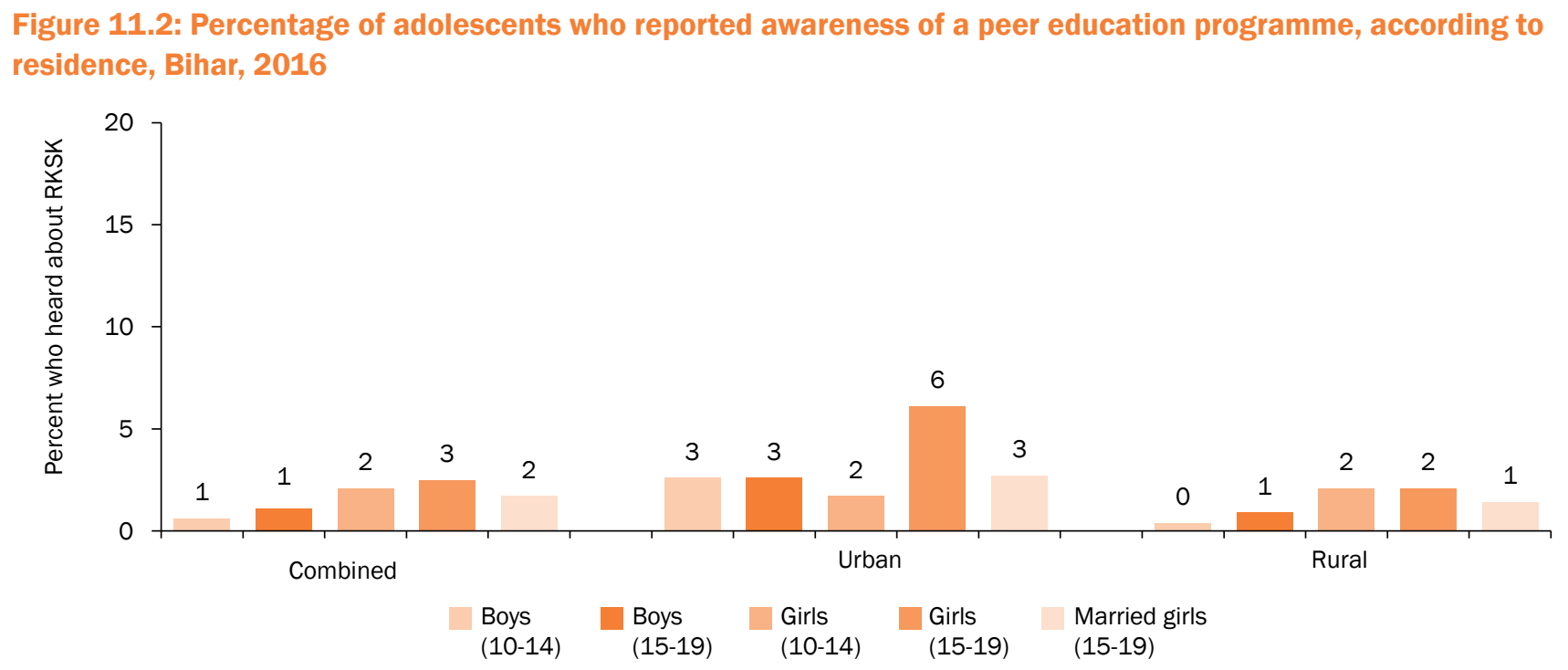

\subsubsection{Health services received in school settings}

We asked adolescents who were enrolled in school/college at the time of the interview whether they had received any health information or services from a doctor or nurse in their school/college, as part of the School Health Programme or other programmes, in the year preceding the interview. Findings presented in Figure 11.3 underscore that the reach of health services, including those offered by the School Health Programme across all categories of adolescents was limited, particularly among older adolescents. Among adolescents who were enrolled in school/college at the time of the interview, just 31-32 percent of younger adolescents and 15-19 percent of older adolescents reported that they had received health-related information or services from a healthcare provider in their school/college in the year preceding the interview. Differences by sex were narrow. Among older girls, the unmarried were more likely than the married to have received health-related information or services from their school (19\% versus $15 \%)$. Differences by residence in rural or urban areas show that more of older boys and married older girls in rural than urban areas reported that they had received health-related services and information at school (19\% versus $14 \%$ among older boys and $16 \%$ versus $9 \%$ among married older girls). 
Figure 11.3: Percentage of adolescents enrolled in school/college at the time of the interview reporting healthrelated information or services at school in the year preceding the interview, according to residence, Bihar, 2016

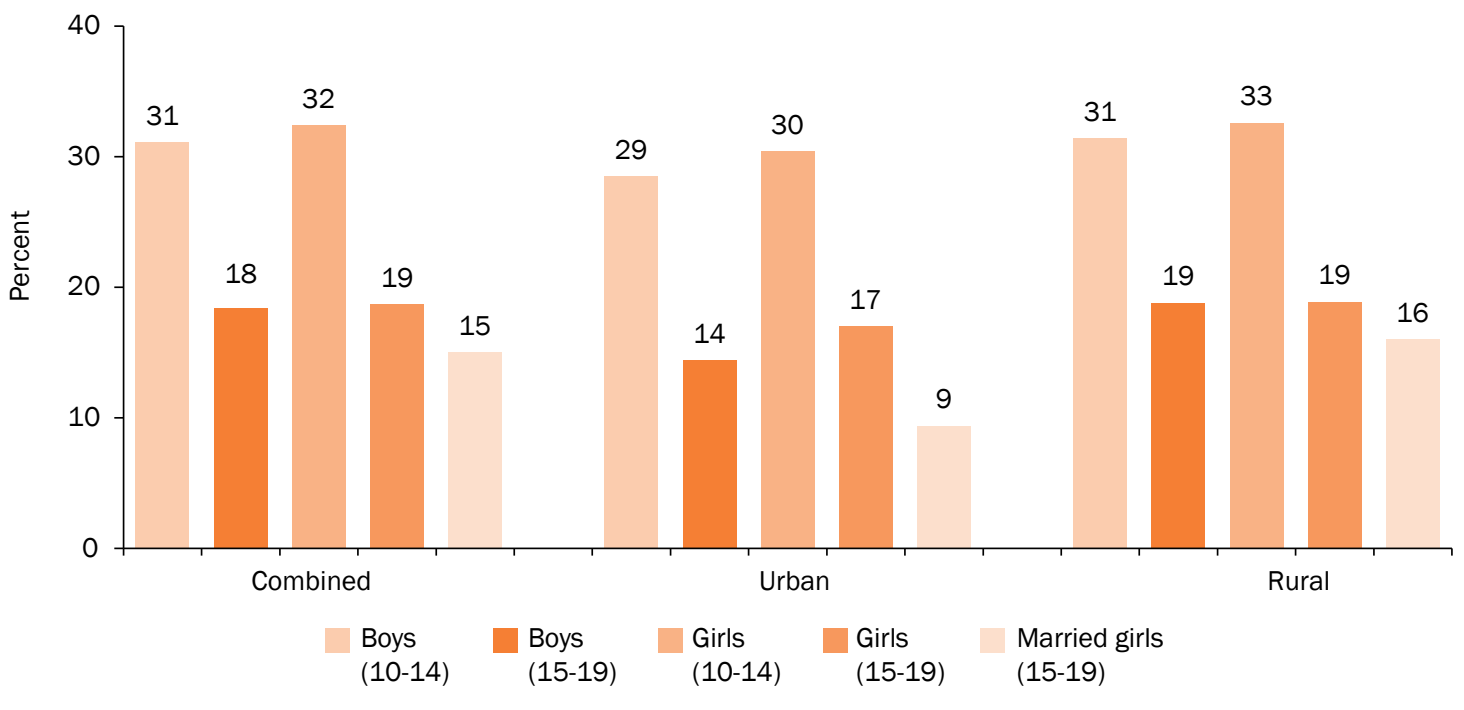

\subsubsection{Awareness of frontline workers (FLWs) and interactions with them}

The survey also included an assessment of adolescents' awareness of frontline health workers (FLWs), namely, accredited social health activists (ASHAs) and anganwadi workers (AWWs), and their interactions with them in the year preceding our interview with them. Table 11.12 describes adolescents' awareness of AWWs and ASHAs; findings show that a large number of adolescents had heard about these healthcare providers, particularly about AWWs. Moreover, somewhat larger proportions of older than younger adolescents were aware of ASHAs. Specifically, 93-96 percent of boys and 96-97 percent of girls had heard about AWWs. Fewer adolescents had heard about ASHAs-58 percent of younger boys compared with 80 percent of older boys and 77 percent of younger girls compared with 92-93 percent of unmarried and married older girls. Differences by sex were narrow with respect to awareness of AWWs, but wider with respect to awareness of ASHAs; girls were more likely than boys to be aware of ASHAs. Among older girls, differences by marital status were narrow. Difference by residence in rural or urban areas were narrow regarding awareness of AWWs, except among younger adolescents among whom more rural than urban respondents had heard about AWWs (94\% versus $87 \%$ among boys and $98 \%$ versus $90 \%$ among girls). Findings also show that rural respondents were considerably more likely than their urban counterparts to have heard of ASHAs across all categories of adolescents.

Findings related to adolescents' interactions with FLWs in the year preceding the interview are summarised in Table 11.13; they highlight that adolescents' interactions with AWWs and ASHAs in the year preceding the interview were limited. Just four to seven percent of younger and older boys, 10 percent each of younger and unmarried older girls, and 30 percent of married older girls had received any health information or services from AWWs during the reference period. Differences in adolescents' interaction with AWWs between those from rural areas and those from urban areas were narrow, except that somewhat more of younger girls in rural than urban areas reported interaction with AWWs (11\% versus 6\%).

Similar proportions of adolescents had received health information or services from ASHAs during the same reference period as reported above for AWWs-four percent of boys, 8-9 percent of younger and unmarried older girls, and 30 percent of married older girls. Differences by residence in urban or rural areas were apparent for girls, among whom more rural than urban respondents reported that they had received health information or services from ASHAs in the year preceding the interview (9-10\% versus 1-3\% among younger girls and unmarried older girls and $32 \%$ versus $19 \%$ among married older girls). 


\section{Health and health-seeking behaviour}

Table 11.12: Awareness of FLWs

Percentage of adolescents who reported awareness of FLWs, according to residence, Bihar, 2016

\begin{tabular}{|c|c|c|c|c|c|}
\hline Category of FLWs & $\begin{array}{c}\text { Boys } \\
(10-14)\end{array}$ & $\begin{array}{c}\text { Boys } \\
(15-19)\end{array}$ & $\begin{array}{c}\text { Girls } \\
(10-14)\end{array}$ & $\begin{array}{c}\text { Girls } \\
(15-19)\end{array}$ & $\begin{array}{c}\text { Married girls } \\
(15-19)\end{array}$ \\
\hline \multicolumn{6}{|c|}{ Combined (percent) } \\
\hline Anganwadi worker & 93.0 & 95.9 & 97.2 & 97.3 & 96.3 \\
\hline ASHA & 57.7 & 79.7 & 77.0 & 93.2 & 92.4 \\
\hline Number of respondents & 1,012 & 1,821 & 764 & 3,428 & 3,408 \\
\hline \multicolumn{6}{|c|}{ Urban (percent) } \\
\hline Anganwadi worker & 87.4 & 94.1 & 90.2 & 94.3 & 93.3 \\
\hline ASHA & 25.3 & 46.9 & 48.9 & 74.4 & 81.8 \\
\hline Number of respondents & 452 & 1,008 & 387 & 1,738 & 1,366 \\
\hline \multicolumn{6}{|c|}{ Rural (percent) } \\
\hline Anganwadi worker & 93.7 & 96.1 & 98.1 & 97.7 & 96.6 \\
\hline ASHA & 61.6 & 83.8 & 80.4 & 95.5 & 93.6 \\
\hline Number of respondents & 560 & 813 & 377 & 1,690 & 2,042 \\
\hline
\end{tabular}

Note: All Ns are unweighted.

\section{Table 11.13: Interactions with FLWs}

Percentage of adolescents who received health-related information or services from FLWs in the year preceding the interview, according to residence, Bihar, 2016

\begin{tabular}{|c|c|c|c|c|c|}
\hline $\begin{array}{l}\text { FLWs from whom adolescents received health } \\
\text { information or services }\end{array}$ & $\begin{array}{c}\text { Boys } \\
(10-14)\end{array}$ & $\begin{array}{c}\text { Boys } \\
(15-19)\end{array}$ & $\begin{array}{c}\text { Girls } \\
(10-14)\end{array}$ & $\begin{array}{c}\text { Girls } \\
(15-19)\end{array}$ & $\begin{array}{l}\text { Married girls } \\
\text { (15-19) }\end{array}$ \\
\hline \multicolumn{6}{|c|}{ Combined (percent) } \\
\hline Anganwadi worker ${ }^{1}$ & 6.8 & 4.0 & 10.3 & 9.8 & 29.9 \\
\hline ASHA & 4.2 & 3.8 & 8.3 & 9.3 & 30.3 \\
\hline Any of the above & 10.5 & 7.5 & 16.6 & 16.4 & 40.4 \\
\hline Number of respondents & 1,012 & 1,821 & 764 & 3,428 & 3,408 \\
\hline \multicolumn{6}{|c|}{ Urban (percent) } \\
\hline Anganwadi worker ${ }^{1}$ & 5.5 & 2.5 & 6.3 & 7.8 & 31.8 \\
\hline ASHA & 1.0 & 0.5 & 1.2 & 2.7 & 18.6 \\
\hline Any of the above & 6.5 & 3.0 & 7.3 & 9.6 & 35.8 \\
\hline Number of respondents & 452 & 1,008 & 387 & 1,738 & 1,366 \\
\hline \multicolumn{6}{|c|}{ Rural (percent) } \\
\hline Anganwadi worker ${ }^{1}$ & 7.0 & 4.2 & 10.8 & 10.0 & 29.7 \\
\hline ASHA & 4.5 & 4.2 & 9.1 & 10.1 & 31.6 \\
\hline Any of the above & 11.0 & 8.1 & 17.7 & 17.3 & 40.9 \\
\hline Number of respondents & 560 & 813 & 377 & 1,690 & 2,042 \\
\hline
\end{tabular}

Notes: All Ns are unweighted. ${ }^{1}$ Less than one percent of respondents reported that there was no anganwadi worker in their village or ward and one percent reported non-availability of ASHAs. 
In total, 8-11 percent of boys had received health-related information or services from FLWs in the year preceding the interview as had 16-17 of younger and unmarried older girls. A larger proportion of married older girls had received information or services from FLWs during the same reference period (40\%). Not surprisingly, rural adolescents, except younger boys, were more likely than urban adolescents to have received information or services from FLWs across all categories of adolescents.

Table 11.14 describes the differentials in adolescents' interactions with FLWs in the year preceding the interview by selected background characteristics. Findings show that interactions with FLWs did not differ by age except for married older girls, among whom respondents in ages 18-19 were more likely than those in ages 15-17 to report such interactions (46\% versus $29 \%$ ). Differences by religion were apparent for boys and younger girls, among whom Hindu respondents were somewhat more likely than Muslim respondents to have received health information or services from FLWs (8-11\% versus $2-6 \%$ among boys and $17 \%$ versus $11 \%$ among younger girls). Caste-wise differentials show that older boys and married older girls (but not younger boys, younger girls, and unmarried older girls) who belonged to general castes were less likely than those who belonged to scheduled castes to have received such information or services (5\% versus $11 \%$ among older boys and $29 \%$ versus $42 \%$ among married older girls). The association between respondents' educational levels and interactions with FLWs was erratic for the most part. Association between current schooling status and interactions with FLWs varied across categories of adolescentsamong boys, more of those who were pursuing their studies at the time of the interview than those who were not had reported such interactions. Among married older girls, however, more of those who were not enrolled in school/college than those who were enrolled at the time of the interview had reported such interactions ( $45 \%$ versus $31 \%)$. An association was evident between engagement in paid work and interactions with FLWs in the year preceding the interview only among older boys and younger girls-while older boys who were engaged in paid work were less likely than those who were not to have had an interaction with FLWs (3\% versus 9\%), a reverse pattern was apparent for younger girls (33\% versus 15\%). No consistent pattern of association was observed between interactions with FLWs and household wealth status and mothers' education; even so, older boys whose mother had 10 or more years of schooling were more likely than those whose mother had fewer years of schooling to report an interaction with FLWs (18\% versus $4-12 \%$ ), while a reverse pattern was noted for married older girls, among whom those whose mother had no education were more likely than those whose mother had more education to so report ( $42 \%$ versus $32-36 \%)$.

\section{Table 11.14: Interactions with FLWs by selected background characteristics}

Percentage of adolescents who had received health-related information or services from FLWs in the year preceding the interview, by selected background characteristics, Bihar, 2016

\begin{tabular}{|c|c|c|c|c|c|}
\hline Background characteristics (percent) & $\begin{array}{c}\text { Boys } \\
(10-14)\end{array}$ & $\begin{array}{c}\text { Boys } \\
(15-19)\end{array}$ & $\begin{array}{c}\text { Girls } \\
(10-14)\end{array}$ & $\begin{array}{c}\text { Girls } \\
\text { (15-19) }\end{array}$ & $\begin{array}{c}\text { Married girls } \\
\quad(15-19)\end{array}$ \\
\hline \multicolumn{6}{|l|}{ Age } \\
\hline $10-12$ & 11.7 & NA & 16.6 & NA & NA \\
\hline $13-14$ & 8.5 & NA & 16.6 & NA & NA \\
\hline $15-17$ & NA & 7.6 & NA & 16.0 & 29.1 \\
\hline $18-19$ & NA & 7.3 & NA & 17.9 & 46.1 \\
\hline \multicolumn{6}{|l|}{ Religion ${ }^{1}$} \\
\hline Hindu & 11.2 & 8.4 & 17.6 & 17.2 & 40.5 \\
\hline Muslim & 6.4 & 1.9 & 11.1 & 12.6 & 39.8 \\
\hline \multicolumn{6}{|l|}{ Caste $^{2}$} \\
\hline SC & 11.9 & 11.2 & 15.5 & 17.1 & 42 \\
\hline OBC & 10.6 & 7.1 & 17.1 & 16.4 & 41.1 \\
\hline General $^{3}$ & 8.3 & 4.7 & 13.6 & 15.5 & 29 \\
\hline
\end{tabular}


Table 11.14 Cont.

\begin{tabular}{|c|c|c|c|c|c|}
\hline Background characteristics (percent) & $\begin{array}{c}\text { Boys } \\
(10-14)\end{array}$ & $\begin{array}{c}\text { Boys } \\
(15-19)\end{array}$ & $\begin{array}{c}\text { Girls } \\
(10-14)\end{array}$ & $\begin{array}{c}\text { Girls } \\
(15-19)\end{array}$ & $\begin{array}{c}\text { Married girls } \\
\text { (15-19) }\end{array}$ \\
\hline \multicolumn{6}{|l|}{ Completed years of schooling } \\
\hline None $^{4}$ & * & 4.2 & $(18.6)$ & 10.2 & 37.2 \\
\hline $1-4$ & 9.7 & 1.7 & 21.2 & 14.3 & 37.9 \\
\hline $5-7$ & 12.8 & 3.1 & 13.8 & 16.7 & 40.4 \\
\hline $8-9$ & 5.5 & 9.7 & 16.6 & 18.4 & 40.6 \\
\hline $10-11$ & NA & 4.4 & NA & 18.2 & 45.9 \\
\hline 12 and above & NA & 12.6 & NA & 10.2 & 44.6 \\
\hline \multicolumn{6}{|l|}{ Current schooling status $^{5}$} \\
\hline Yes & 11.0 & 8.7 & 16.3 & 18.1 & 31.4 \\
\hline No & $(2.6)$ & 2.7 & $(20.1)$ & 13.8 & 44.6 \\
\hline \multicolumn{6}{|c|}{ Paid work in the 12 months prior to the interview } \\
\hline Yes & 7.3 & 2.5 & 33.4 & 19.8 & 38.3 \\
\hline No & 10.8 & 9.2 & 15.1 & 15.8 & 40.7 \\
\hline \multicolumn{6}{|l|}{ Wealth quintile } \\
\hline First & 14.7 & 12.5 & 12.9 & 15.4 & 37.2 \\
\hline Second & 8.4 & 6.2 & 18.5 & 13.8 & 38.0 \\
\hline Third & 10.4 & 6.0 & 20.0 & 20.6 & 38.4 \\
\hline Fourth & 11.4 & 8.5 & 14.5 & 17.5 & 44.8 \\
\hline Fifth & 9.8 & 7.3 & 16.4 & 14.3 & 41.4 \\
\hline \multicolumn{6}{|c|}{ Mother's education (in years of schooling completed) } \\
\hline None $^{4}$ & 9.8 & 6.5 & 18.3 & 16.6 & 41.9 \\
\hline $1-7$ & 6.6 & 3.5 & 12.3 & 17.4 & 32.0 \\
\hline $8-9$ & 19.8 & 11.5 & 5.9 & 9.7 & 36.1 \\
\hline 10 and above & 14.9 & 17.5 & 10.5 & 20.2 & 33.5 \\
\hline Total & 10.5 & 7.5 & 16.6 & 16.4 & 40.4 \\
\hline
\end{tabular}

Notes: *Percentage not shown, as this was based on fewer than 25 unweighted cases. () Based on 25-49 unweighted cases. NA: not applicable; OBC: other backward caste; SC: scheduled caste; ST: scheduled tribe. ${ }^{1}$ Percentages not shown for those belonging to other religions as less than one percent of surveyed adolescents belonged to other religions. ${ }^{2}$ Percentages not shown for those belonging to STs as less than one percent of surveyed adolescents belonged to STs. ${ }^{3}$ Includes all those not belonging to SCs, STs, or OBCs. ${ }^{4}$ Includes non-literate and literate with no formal schooling. ${ }^{5}$ Percentages not shown for adolescents who were pursuing their education through distance education courses at the time of interview or those who never went to school.

Table 11.15 describes the type of health-related information and services that unmarried and married older girls had received from ASHAs in the year preceding the interview. ${ }^{3}$ Findings show that among older girls who had interacted with ASHAs, married older girls were almost four times as likely as the unmarried older girls to have received health information from them (88\% versus $24 \%$ ). The content of health information received also differed between married and unmarried older girls. Unmarried older girls typically received information on general health and hygiene, while married older girls typically received sexual and reproductive health information, followed by nutrition-related information. Specifically, 22 percent of unmarried older girls compared with 17 percent of married older girls reported that the ASHA had informed them on matters of general health and hygiene. In contrast, three percent of unmarried older girls and 12 percent of married older girls received nutrition-related information and five percent of unmarried older girls and 77 percent of married older girls received sexual and reproductive health information. Sexual and ${ }^{3}$ Findings are not presented for younger adolescents and older boys because of the small number of younger adolescents and older boys who had
received health-related information or services from an ASHA in the year preceding the interview. 
reproductive health information imparted to unmarried older girls focused mainly on physical changes during adolescence, which was most likely to be on menstruation (4\%), while it comprised information related to pregnancyrelated care (22\%) and immunisation and newborn care practices (63\%) among married older girls. Information on contraception and safe sex was rarely reported even by married older girls. One percent of unmarried older girls and four percent of married older girls in rural areas had received information related to village health and nutrition days.

\section{Table 11.15: Health-related information or services received from an ASHA}

Percentage of adolescent girls in ages 15-19 who received information or services from an ASHA in the year prior to the interview by type of information and services received, according to residence, Bihar, 2016

\begin{tabular}{|c|c|c|c|c|c|c|}
\hline $\begin{array}{l}\text { Type of information and services } \\
\text { (percent) }\end{array}$ & $\begin{array}{l}\text { Girls } \\
(15-19)\end{array}$ & $\begin{array}{l}\text { Married } \\
\text { girls } \\
(15-19)\end{array}$ & $\begin{array}{l}\text { Girls } \\
(15-19)\end{array}$ & $\begin{array}{l}\text { Married } \\
\text { girls } \\
(15-19)\end{array}$ & $\begin{array}{l}\text { Girls } \\
(15-19)\end{array}$ & $\begin{array}{c}\text { Married } \\
\text { girls } \\
(15-19)\end{array}$ \\
\hline & \multicolumn{2}{|c|}{ Combined } & \multicolumn{2}{|c|}{ Urban } & \multicolumn{2}{|c|}{ Rural } \\
\hline Received any health information & 24.0 & 87.6 & (29.8) & 90.5 & 23.8 & 87.4 \\
\hline $\begin{array}{l}\text { General health and hygiene-related } \\
\text { information }\end{array}$ & 22.0 & 16.9 & $(17.8)$ & 16.8 & 22.1 & 16.9 \\
\hline Nutrition-related information & 2.6 & 12.3 & $(1.7)$ & 17.0 & 2.7 & 12.0 \\
\hline Sexual and reproductive health information & 4.5 & 77.1 & (10.3) & 81.3 & 4.3 & 76.8 \\
\hline Physical changes during adolescence & 4.0 & 1.7 & (4.6) & 3.2 & 4.0 & 1.5 \\
\hline $\begin{array}{l}\text { Information related to safe sex practices and } \\
\text { STI/HIV/AIDS }\end{array}$ & 0.7 & 1.3 & (3.9) & 0.7 & 0.6 & 1.3 \\
\hline Contraception-related information & 0.1 & 3.9 & $(1.8)$ & 3.5 & 0.0 & 3.9 \\
\hline Safe pregnancy related information & 0.8 & 22.2 & $(0.0)$ & 22.7 & 0.9 & 22.1 \\
\hline Immunisation and infant care information & 0.0 & 62.5 & $(0.0)$ & 67.1 & 0.0 & 62.2 \\
\hline Information related to VHND & NA & NA & NA & NA & 0.8 & 4.2 \\
\hline Received any health services & 86.6 & 32.8 & (76.7) & 25.6 & 86.9 & 33.3 \\
\hline Sanitary napkins & 11.1 & 0.4 & (12.5) & 2.0 & 11.0 & 0.3 \\
\hline IFA/deworming tablets & 73.7 & 14.2 & $(53.9)$ & 8.6 & 74.3 & 14.6 \\
\hline Condom/oral pills & 0.0 & 0.6 & $(0.0)$ & 10.4 & 0.0 & 0.7 \\
\hline Escorted to health facility & 0.3 & 15.2 & (9.0) & 9.0 & 0.3 & 15.6 \\
\hline Facilitated health check-up & 5.5 & 9.9 & (1.3) & 0.0 & 5.4 & 9.9 \\
\hline Other medicines & 2.1 & 0.1 & $(0.0)$ & 0.0 & 2.1 & 0.1 \\
\hline $\begin{array}{l}\text { Number of respondents who had received } \\
\text { any information or services from ASHAs }\end{array}$ & 237 & 872 & 48 & 266 & 189 & 606 \\
\hline
\end{tabular}

Notes: All Ns are unweighted. () Based on 25-49 unweighted cases. NA: not applicable; VHND: village health and nutrition day; IFA: iron and folic acid.

Among older girls who had interacted with ASHAs in the year preceding the interview, a larger proportion of unmarried than married older girls, surprisingly, reported that they had received health services from an ASHA (87\% versus $33 \%$ ), largely because more unmarried than married girls had received IFA or deworming tablets from an ASHA. Health services received by unmarried older girls, for example, typically comprised iron and folic acid supplements or deworming tablets $(74 \%)$ and sanitary napkins (11\%), while married older girls reported that ASHAs had escorted them to a health facility (15\%), had provided iron and folic acid supplements (14\%), and had facilitated a health check-up (10\%). None of the unmarried older girls and less than one percent of married older girls reported that they had received condoms or oral pills from an ASHA.

The content of information and services received by unmarred and married older girls differed in urban and rural areas. Urban married older girls were more likely than their rural counterparts to have received nutrition-related information from an ASHA (17\% versus 12\%) and information related to immunisation and infant care (67\% versus $62 \%)$, while urban unmarried older girls were more likely than their rural counterparts to have received sexual and 
reproductive health information (10\% versus $4 \%$ ). Rural unmarried and married older girls were more likely than their urban counterparts to have received health services from an ASHA ( $87 \%$ versus $77 \%$ among unmarried older girls and $33 \%$ versus $26 \%$ among married older girls). Specifically, more of rural than urban unmarried and married girls had received iron and folic acid supplements (74\% versus $54 \%$ among unmarried older girls and $15 \%$ versus $9 \%$ among married older girls). Rural married older girls, additionally, were more likely than their urban counterparts to report that ASHAs had escorted them to a health facility (16\% versus $9 \%$ ) and had helped them to have a health check-up (10\% versus none). In contrast, married older girls in urban areas were more likely than those in rural areas to have received condoms or oral pills (10\% versus $1 \%)$ and unmarried older girls in urban areas were more likely than those in rural areas to report that an ASHA had escorted them to a health facility ( $9 \%$ versus less than $1 \%$ ). Given the small number of unmarried older girls who had interacted with an ASHA in the year preceding the interview in urban areas, these findings need to be interpreted with caution.

Table 11.16 describes the type of health-related information and services that unmarried and married older girls had received from AWWs in the year preceding the interview. ${ }^{4}$ As with the content of information received from ASHAs, findings show that among older adolescent girls who had interacted with AWWs, married older girls were twice as likely as the unmarried older girls to have received health information from them (68\% versus $32 \%)$. The content of health information received also differed between married and unmarried older girls. Unmarried older girls typically received general health and hygiene-related information, while married older girls typically received sexual and reproductive health information, followed by nutrition-related information. Specifically, 23 percent of unmarried older girls compared with nine percent of married older girls reported that the AWW had informed them about general health and hygiene-related matters. In contrast, 13 percent of unmarried older girls and 19 percent of married older girls received nutrition-related information and four percent of unmarried older girls and 57 percent of married older girls received sexual and reproductive health information. Sexual and reproductive health information imparted to unmarried girls focused on physical changes, largely menstruation, taking place in adolescence, while information imparted to married older girls comprised information related to pregnancy-related care (14\%) and immunisation and newborn care practices (48\%). Information on contraception and safe sex was rarely reported even by married older girls.

Although more married than unmarried older girls who had interacted with AWWs in the year preceding the interview had received information from the AWW, a larger proportion of unmarried than married older girls reported that they had received health services from an AWW (82\% versus 55\%), again because they had received IFA and deworming tablets from AWWs. Health services received by unmarried older girls typically comprised iron and folic acid supplements or deworming tablets (46\%), facilitating health check-ups, which was most likely measurement of height and weight (25\%), and nutritional supplementation (16\%), while services received by married older girls comprised nutritional supplementation (31\%), facilitating health check-ups (20\%), and iron and folic acid supplements or deworming tablets (15\%).

The content of information and services received by unmarried and married older girls in rural and urban areas largely mirrored the pattern described above for the combined sample. Even so, some differences were evident. Unmarried older girls in rural areas were more likely than their urban counterparts to have received general health and hygiene-related information (24\% versus $12 \%$ ), and married older girls in rural areas were more likely than their urban counterparts to have received iron and folic acid supplements or deworming tablets (16\% versus $9 \%$ ). In contrast, married older girls in urban areas were more likely than those in rural areas to have received nutritionrelated information (26\% versus $18 \%$ ) and urban unmarried and married older girls were more likely than their rural counterparts to have received nutritional supplementation (23\% versus 16\% among unmarried older girls and $37 \%$ versus 30\% among married older girls).

\footnotetext{
${ }^{4}$ Findings are not presented for younger adolescents and older boys because of the small number of younger adolescents and older boys who had received health-related information or services from an AWW in the year preceding the interview.
} 
Table 11.16: Health-related information and services received from an anganwadi worker

Percentage of adolescent girls in ages 15-19 who received health-related information and services from an anganwadi worker in the year preceding the interview by type of information and services received, according to residence, Bihar, 2016

\begin{tabular}{|c|c|c|c|c|c|c|}
\hline $\begin{array}{l}\text { Type of information and services } \\
\text { (percent) }\end{array}$ & $\begin{array}{l}\text { Girls } \\
(15-19)\end{array}$ & $\begin{array}{l}\text { Married } \\
\text { girls } \\
(15-19)\end{array}$ & $\begin{array}{l}\text { Girls } \\
(15-19)\end{array}$ & $\begin{array}{l}\text { Married } \\
\text { girls } \\
(15-19)\end{array}$ & $\begin{array}{l}\text { Girls } \\
(15-19)\end{array}$ & $\begin{array}{l}\text { Married } \\
\text { girls } \\
(15-19)\end{array}$ \\
\hline & \multicolumn{2}{|c|}{ Combined } & \multicolumn{2}{|c|}{ Urban } & \multicolumn{2}{|c|}{ Rural } \\
\hline Received any health information & 32.1 & 67.5 & 23.9 & 68.9 & 32.8 & 67.7 \\
\hline General health and hygiene- related information & 22.6 & 8.9 & 12.2 & 10.1 & 23.6 & 9.2 \\
\hline Nutrition-related information & 12.6 & 18.6 & 8.7 & 26.1 & 12.9 & 18.4 \\
\hline Sexual and reproductive health information & 3.8 & 56.8 & 5.5 & 52.7 & 3.6 & 57.3 \\
\hline Body changes during adolescence & 3.2 & 1.7 & 4.8 & 1.9 & 3.0 & 1.7 \\
\hline $\begin{array}{l}\text { Information related to safe sex practices and STI/ } \\
\text { HIV/AIDS }\end{array}$ & 0.6 & 0.5 & 0.7 & 0.4 & 0.6 & 0.5 \\
\hline Contraception-related information & 0.0 & 1.1 & 0.0 & 0.5 & 0.0 & 1.2 \\
\hline Safe pregnancy related information & 0.6 & 13.7 & 0.7 & 11.6 & 0.6 & 14.4 \\
\hline Immunisation and infant care information & 0.0 & 48.1 & 0.0 & 44.3 & 0.0 & 48.3 \\
\hline Information related to VHND & NA & NA & NA & NA & 2.7 & 4.1 \\
\hline Received any health services & 81.8 & 55.1 & 81.8 & 54.3 & 81.9 & 55.5 \\
\hline Sanitary napkins & 3.5 & 0.6 & 3.4 & 0.1 & 3.5 & 0.7 \\
\hline IFA/deworming tablets & 46.3 & 15 & 42.5 & 8.9 & 46.6 & 16.2 \\
\hline Condom/oral pills & 0.0 & 0.3 & 0.0 & 0.4 & 0.0 & 0.3 \\
\hline Escorted to health facility & 1.5 & 1.7 & 0.0 & 0.8 & 1.7 & 1.9 \\
\hline Facilitated health check-up & 25.3 & 20.3 & 25.1 & 18.9 & 25.3 & 21.1 \\
\hline Nutritious food & 16.4 & 31.3 & 22.9 & 37.2 & 15.8 & 30.1 \\
\hline $\begin{array}{l}\text { Number of respondents who had received any } \\
\text { information or services from AWWs }\end{array}$ & 299 & 1,032 & 138 & 432 & 161 & 600 \\
\hline
\end{tabular}

Notes: All Ns are unweighted. NA: not applicable; VHND: village health and nutrition day; IFA: iron and folic acid.

\subsubsection{Adolescent friendly health clinics}

Findings show that hardly any adolescents had heard about adolescent friendly health clinics, regardless of age, sex, place of residence, and, among older girls, marital status (1\% of boys and $2-5 \%$ of girls; not shown in tabular form). Not surprisingly, hardly any adolescents had received services from the adolescent friendly health clinics in the year preceding the interview (0.0-0.3\% of boys and girls; not shown in tabular form).

\subsubsection{Sanitary napkin distribution}

Awareness of the sanitary napkin distribution programme among girls who had begun menstruating was somewhat limited. ${ }^{5}$ Half of younger girls and unmarried older girls and about two-fifths of married older girls were aware of it (Figure 11.4). Differences by residence in rural or urban areas were evident for younger girls, among whom those in urban areas were less likely than their rural counterparts to be aware of this programme (38\% versus $54 \%$ ).

\footnotetext{
${ }^{5}$ This question was not posed to boys.
} 


\section{Health and health-seeking behaviour}

Among girls who had begun menstruating, few reported that they had received sanitary napkins through their school or from community-level health workers in the year preceding the interview (21\% of younger girls and $4-13 \%$ of unmarried and married older girls). Urban younger girls were less likely than their rural counterparts to have received sanitary napkins from such sources (12\% versus $22 \%)$.

Figure 11.4: Awareness and reach of sanitary napkin distribution scheme among girls who had begun menstruating, according to residence, Bihar, 2016

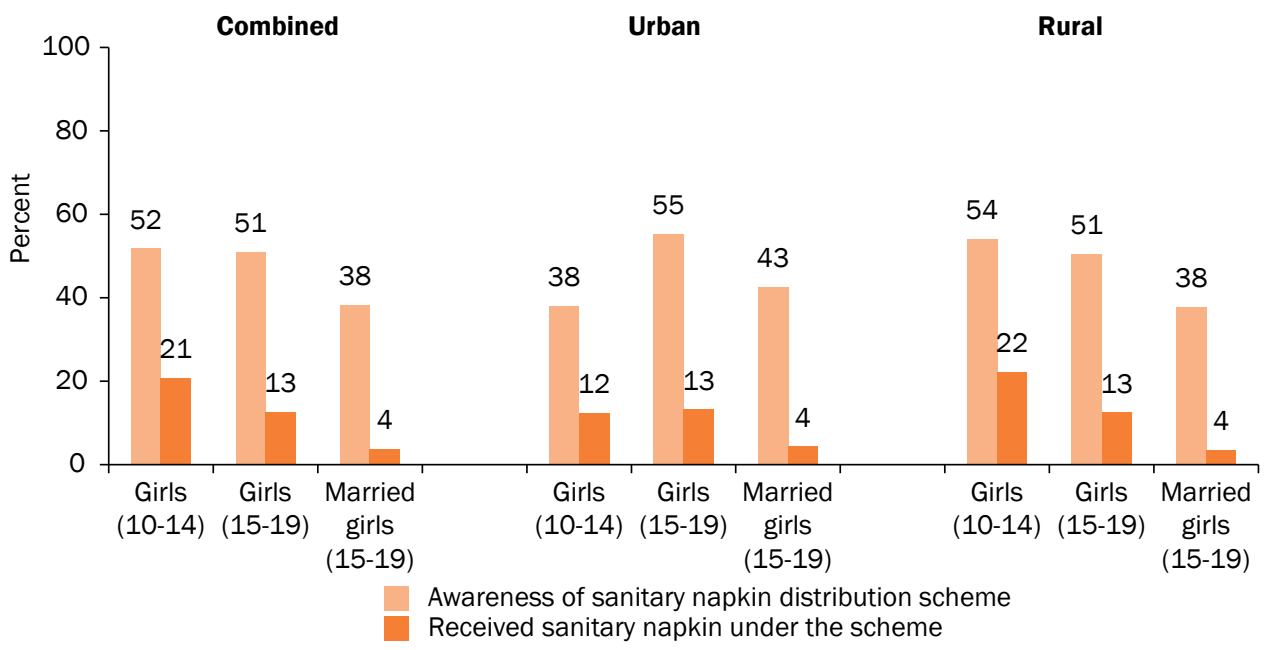

\subsubsection{Village health and nutrition days}

Awareness of village health and nutrition days (VHNDs) among rural adolescents ${ }^{6}$ differed by age, sex, and, among older girls, by marital status (Figure 11.5). Younger adolescents were less likely than older adolescents to have heard about VHNDs (31\% versus $47 \%$ among boys; $26 \%$ versus $37-42 \%$ among girls). A larger proportion of older boys than unmarried and married older girls were aware of VHNDs (47\% versus 37-42\%). Among older girls, the married were somewhat more likely than the unmarried to be aware of VHNDs (42\% versus $37 \%$ ). In contrast, hardly any boys, younger girls, and unmarried older girls ( $0-1 \%$ of boys, $2-4 \%$ of girls) had attended a VHND in the year preceding the interview-just slightly more married girls $(8 \%)$ had done so.

Figure 11.5: Awareness of and attendance at village health and nutrition days, rural Bihar, 2016

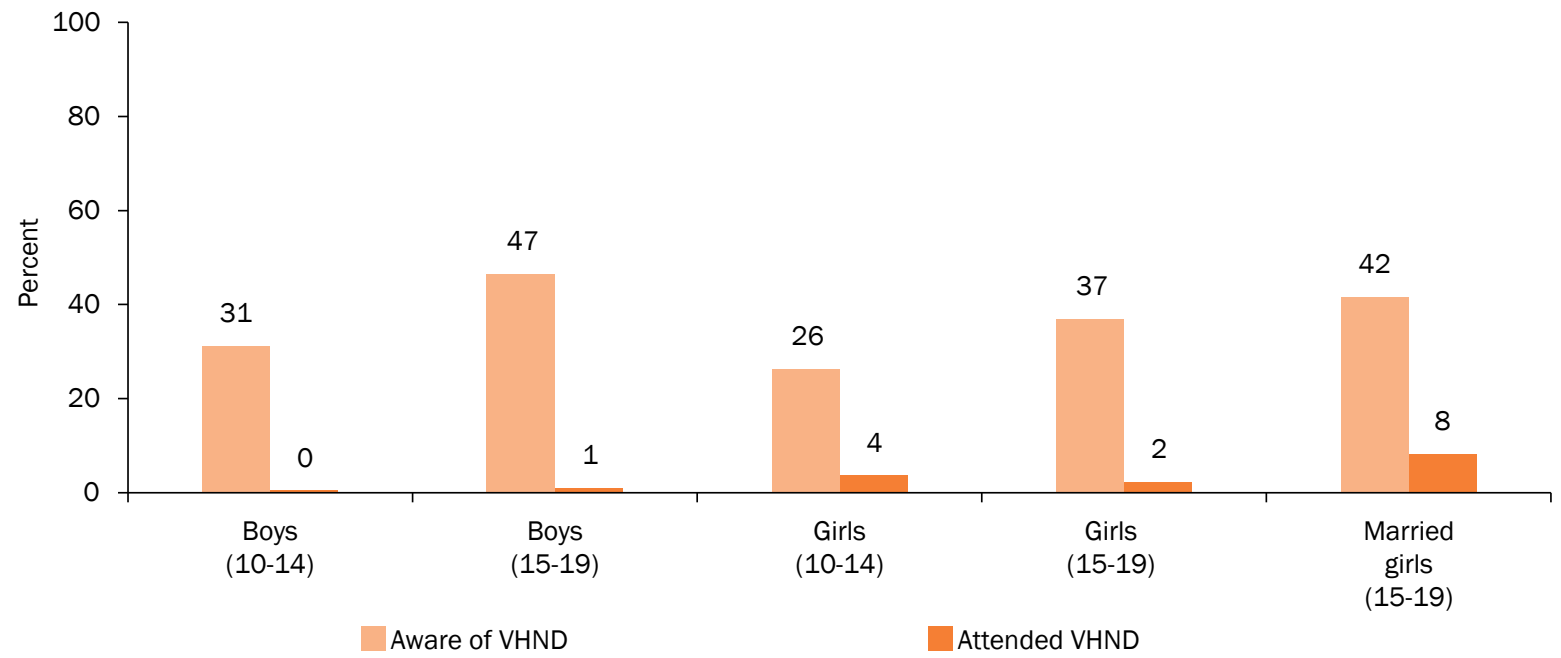

\footnotetext{
${ }^{6}$ This question was posed to rural respondents only.
} 


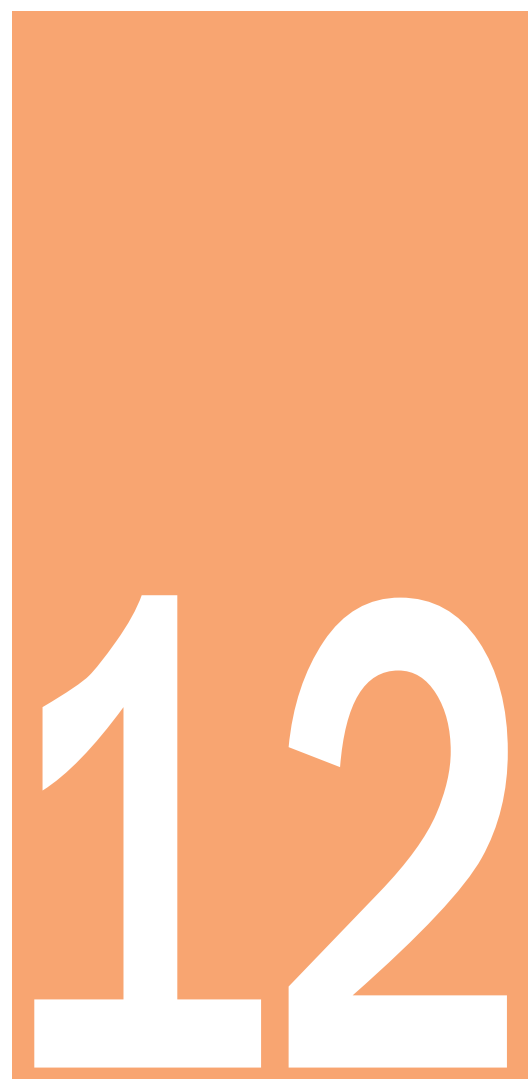

DIETARY HABITS AND NUTRITION SITUATION

\section{A Snapshot}

Dietary practices among adolescents are poor:
- $42 \%$ of younger boys

- $44 \%$ of older boys

- $34 \%$ of younger girls

- $36 \%$ of unmarried older girls

- $31 \%$ of married older girls consumed dairy products daily

More boys than girls are thin:

- $28 \%$ of younger boys

- $23 \%$ of older boys

- $17 \%$ of younger girls

- 9\% of unmarried older girls

- $7 \%$ of married older girls were thin
- $8 \%$ of younger boys

- $11 \%$ of older boys

- $12 \%$ of younger girls

- $15 \%$ of unmarried older girls

- $16 \%$ of married older girls consumed dark green leafy vegetables daily
More girls than boys are moderately or severely anaemic

- $3 \%$ of younger boys

- $9 \%$ of older boys

- $10 \%$ of younger girls

- $15 \%$ of unmarried older girls

- $23 \%$ of married older girls

Prevalence of overweight, including obesity is rare but evident:

- $2 \%$ of younger boys

- $3 \%$ of older boys

- $2 \%$ of younger girls

- $2 \%$ of unmarried older girls

- $3 \%$ of married older girls

Awareness and reach of government programmes intended to improve nutritional status of adolescents vary:

Several were aware of the weekly iron and folic acid supplementation (WIFS) programme:

- $66 \%$ of younger boys

- $55 \%$ of older boys

- $63 \%$ of younger girls

- $64 \%$ of unmarried older girls

- $51 \%$ of married older girls
- $2 \%$ each of younger boys, older boys, and younger girls

- $6 \%$ of unmarried older girls

- $4 \%$ of married older girls had received iron and folic acid tablets from the WIFS programme in the year preceding the interview 


\section{A Snapshot}

Awareness and reach of government programmes intended to improve nutritional status of adolescents vary:

- $53 \%$ of younger boys

- $28 \%$ of older boys

- $44 \%$ of younger girls

- $23 \%$ of unmarried older girls

- $8 \%$ of married older girls had received de-worming tablets from the WIFS programme in the year preceding the interview

Differences by residence in rural and urban areas were mixed: urban adolescents were more likely than rural adolescents to have better dietary intake, but they were also more likely to be overweight or obese, while rural adolescents were more likely to be thin; rural adolescents were more likely than urban adolescents to be aware of and to benefit from the weekly iron and folic acid programme 
Adolescence is considered a critical stage of life as far as nutrition is concerned, because the accelerated physical growth characteristic of this stage creates a dramatic increase in the requirement for energy, protein, and micronutrients. Moreover, changes in lifestyle and food habits and psychological changes during adolescence affect nutrient intake and needs (WHO, 2006). Adolescence is the second and last opportunity (following early childhood) to catch up on growth. (Gopalan, 1989). Given the importance of nutrition for the growth and health of adolescents, this survey sought information on food consumption patterns among adolescents, and it also sought to assess their nutritional status by collecting biomarkers of adolescents participating in the survey. Findings with regard to dietary habits and nutrition are described in this chapter, and it also presents findings related to study participants' awareness of government programmes that aim to improve the nutritional status of adolescents.

\subsection{Dietary practices}

As per the dietary guidelines prepared by the National Institute of Nutrition, a balanced diet for adolescents should include 8-15 portions of cereals and millets, 2-3 portions of pulses (one portion of which may be replaced with one portion of egg, meat, poultry, or fish), five portions of milk and milk products, 1-2 portions of roots and tubers, one portion of green leafy vegetables, two portions of other vegetables, one portion of fruits, 4-6 portions of sugar, and 7-10 portions of oils and fats daily (National Institute of Nutrition, 2011). ${ }^{1}$ We collected data on food consumption patterns by asking study participants about their typical frequency of consuming selected food items, namely, pulses or beans, dairy products, dark green leafy vegetables, other vegetables, fruits, eggs, fish and other seafood, and meat. Responses were coded into four categories of frequency: daily (4-7 days per week), weekly (1-3 days per week), occasionally (less than once a week), and never. We acknowledge the limitations of our data to assess the extent to which adolescents have been following a balanced diet as recommended by the National Institute of Nutritionwe have not used standard reference periods such as a 24-hour recall or a seven-day recall; we have not collected data on the number of portions consumed; and we have not probed about the consumption of such items as cereals and millets, roots and tubers, sugar, and oils and fats included in the balanced diet recommended for adolescents.

The percentages of adolescents who typically consumed such items as pulses and beans, dairy products, dark green leafy vegetables, other vegetables, fruits, and egg/fish/poultry/meat daily and weekly are presented in Table 12.1. Findings show that the only item prescribed in the balanced diet for adolescents and included in our study that was consumed daily by the vast majority of adolescents, regardless of age, sex, and, among older girls, marital status, was vegetables other than dark green leafy vegetables (76\% of boys and $86-93 \%$ of girls). No more than half of the boys and girls consumed most of the other food items daily. Specifically, 41-48 percent of boys and 49-51 percent of girls reported daily consumption of pulses and 42-44 percent of boys and 31-36 percent of girls reported daily consumption of dairy products. Even fewer reported daily consumption of such items as dark green leafy vegetables ( $8-11 \%$ of boys and $12-16 \%$ of girls), fruits ( $4-5 \%$ of boys and $5-7 \%$ of girls), and egg, fish and other seafood, and meat ( $5-6 \%$ of boys and $1-2 \%$ of girls).

Even weekly consumption of several of these items was far from common. Just 25-27 percent of boys and 26-28 percent of girls, for example, reported that they consumed dairy products weekly; 46-50 percent of boys and 58-60 percent of girls consumed dark green leafy vegetables weekly; just 25 percent of boys and 24-31 percent of girls consumed fruits weekly; and just 38-45 percent of boys and 37percent of girls consumed egg, fish and other seafood items, and meat weekly.

Although dietary practices were similar between younger and older adolescents, some differences were evident. A smaller proportion of younger than older boys consumed pulses or beans daily (41\% versus $48 \%$ ) and egg, fish and other seafood items, and meat weekly ( $38 \%$ versus $45 \%$ ), and a smaller proportion of younger girls consumed fruits weekly compared with unmarried older girls ( $24 \%$ versus $31 \%$ ).

Differences by sex in dietary practices were evident. Boys were more likely than girls to have consumed dairy products daily (42\% and 34\% among younger boys and younger girls, respectively; $44 \%$ and $31-36 \%$ among older boys and unmarried and married older girls, respectively). They were less likely than their female counterparts to have consumed vegetables other than dark green leafy vegetables daily ( $76 \%$ of boys and $86-93 \%$ of girls). Younger boys, in addition, were less likely than younger girls to report daily consumption of pulses and beans (41\% versus $50 \%$ ).

\footnotetext{
${ }^{1}$ Portions are given in ranges because portions differ for adolescents in ages 10-12 years, 13-15 years, and 16-18 years.
} 
Dietary practices did not differ among older girls by marital status except that more of unmarried than married older girls reported daily consumption of dairy products (36\% versus $31 \%$ ) and vegetables other than green leafy vegetables (92\% versus $86 \%$ ). Dietary practices in rural and urban areas resembled the patterns described above for the combined sample. Even so, some differences between those from rural and those from urban areas were evident. Younger and older adolescents in urban areas were more likely than their rural counterparts to report daily consumption of pulses and beans (62-68\% versus 39-46\% among boys and $57-64 \%$ versus $48-49 \%$ among girls), dark green leafy vegetables (17\% versus $7-10 \%$ among boys and $19-24 \%$ versus $11-15 \%$ among girls), and fruits (12\% versus $3-4 \%$ among boys and $12-17 \%$ versus $4-6 \%$ among girls). Younger and older boys and younger girls in urban areas were also more likely to consume dairy products daily (50-51\% versus $41-43 \%$ among boys and $40 \%$ versus $33 \%$ among younger girls). Finally, a larger proportion of urban than rural younger boys consumed egg, fish and other seafood items, and meat daily ( $9 \%$ versus $4 \%$ ) and a larger proportion of urban than rural older boys consumed vegetables other than green leafy vegetables daily ( $80 \%$ versus $75 \%$ ).

\section{Table 12.1: Dietary practices}

Percentage of adolescents who consumed selected food items by frequency of consumption, according to residence, Bihar, 2016

\begin{tabular}{|c|c|c|c|c|c|c|c|c|c|c|}
\hline \multirow{3}{*}{ Type of food } & \multicolumn{2}{|c|}{$\begin{array}{c}\text { Boys } \\
(10-14)\end{array}$} & \multicolumn{2}{|c|}{$\begin{array}{c}\text { Boys } \\
(15-19)\end{array}$} & \multicolumn{2}{|c|}{$\begin{array}{c}\text { Girls } \\
(10-14)\end{array}$} & \multicolumn{2}{|c|}{$\begin{array}{c}\text { Girls } \\
(15-19)\end{array}$} & \multicolumn{2}{|c|}{$\begin{array}{l}\text { Married girls } \\
(15-19)\end{array}$} \\
\hline & \multicolumn{10}{|c|}{ Frequency of consumption } \\
\hline & Daily & Weekly & Daily & Weekly & Daily & Weekly & Daily & Weekly & Daily & Weekly \\
\hline \multicolumn{11}{|c|}{ Combined (percent) } \\
\hline Pulses/beans & 41.1 & 51.8 & 48.4 & 44.0 & 50.3 & 40.6 & 50.6 & 41.4 & 49.2 & 43.7 \\
\hline Dairy products & 42.3 & 24.9 & 43.6 & 26.7 & 33.7 & 28.3 & 35.6 & 26.9 & 31.1 & 26.4 \\
\hline Dark green leafy vegetables & 8.1 & 45.9 & 10.8 & 49.6 & 11.5 & 58.8 & 15.2 & 59.5 & 15.6 & 58.1 \\
\hline Other vegetables & 76.4 & 18.8 & 75.6 & 19.8 & 92.5 & 5.8 & 92.1 & 6.2 & 86.4 & 11.2 \\
\hline Fruits & 3.5 & 24.8 & 5.2 & 24.5 & 5.2 & 24.0 & 6.9 & 30.6 & 5.6 & 24.2 \\
\hline Egg/fish/poultry/meat & 4.7 & 37.9 & 5.5 & 45.0 & 2.0 & 36.9 & 1.1 & 37.4 & 1.7 & 37.3 \\
\hline Number of respondents & \multicolumn{2}{|c|}{1,012} & \multicolumn{2}{|c|}{1,821} & \multicolumn{2}{|c|}{764} & \multicolumn{2}{|c|}{3,428} & \multicolumn{2}{|c|}{3,408} \\
\hline \multicolumn{11}{|c|}{ Urban (percent) } \\
\hline Pulses/beans & 61.9 & 32.5 & 67.7 & 27.7 & 60.7 & 31.4 & 63.5 & 30.2 & 56.6 & 37.1 \\
\hline Dairy products & 51.0 & 25.1 & 49.9 & 22.8 & 39.6 & 20.7 & 37.1 & 24.7 & 32.0 & 26.6 \\
\hline Dark green leafy vegetables & 16.8 & 47.8 & 17.0 & 50.0 & 18.5 & 53.2 & 23.9 & 55.3 & 20.1 & 58.3 \\
\hline Other vegetables & 76.8 & 18.6 & 80.1 & 16.3 & 92.0 & 5.9 & 91.7 & 7.4 & 87.3 & 11.8 \\
\hline Fruits & 11.8 & 31.9 & 11.9 & 33.2 & 17.0 & 34.5 & 16.0 & 40.0 & 12.1 & 34.5 \\
\hline Egg/fish/poultry/meat & 9.0 & 45.0 & 8.3 & 49.3 & 2.0 & 48.6 & 2.6 & 47.7 & 4.1 & 50.4 \\
\hline Number of respondents & \multicolumn{2}{|c|}{452} & \multicolumn{2}{|c|}{1,008} & \multicolumn{2}{|c|}{387} & \multicolumn{2}{|c|}{1,738} & \multicolumn{2}{|c|}{1,366} \\
\hline \multicolumn{11}{|c|}{ Rural (percent) } \\
\hline Pulses/beans & 38.6 & 54.1 & 46.0 & 46.1 & 49.1 & 41.8 & 49.1 & 42.8 & 48.4 & 44.4 \\
\hline Dairy products & 41.3 & 24.9 & 42.8 & 27.2 & 33.0 & 29.3 & 35.4 & 27.1 & 31.0 & 26.4 \\
\hline Dark green leafy vegetables & 7.1 & 45.7 & 10.0 & 49.5 & 10.6 & 59.5 & 14.2 & 59.9 & 15.1 & 58.1 \\
\hline Other vegetables & 76.4 & 18.9 & 75.0 & 20.3 & 92.6 & 5.8 & 92.1 & 6.0 & 86.3 & 11.1 \\
\hline Fruits & 2.5 & 23.9 & 4.4 & 23.4 & 3.7 & 22.8 & 5.8 & 29.5 & 4.8 & 23.0 \\
\hline Egg/fish/poultry/meat & 4.1 & 37.0 & 5.1 & 44.5 & 2.0 & 35.5 & 0.9 & 36.2 & 1.4 & 35.8 \\
\hline Number of respondents & \multicolumn{2}{|c|}{560} & \multicolumn{2}{|c|}{813} & \multicolumn{2}{|c|}{377} & \multicolumn{2}{|c|}{1,690} & \multicolumn{2}{|c|}{2,042} \\
\hline
\end{tabular}

Note: All Ns are unweighted. 
Table 12.2 presents the mean score on the index of dietary diversity, which is an additive index calculated by giving a score of 1 for each of the five following items that is consumed daily and 0 if not consumed daily: (1) pulses and beans or egg/fish/poultry/meat; (2) dairy products; (3) dark green leafy vegetables; (4) other vegetables; and (5) fruits. As mentioned earlier, we did not ask the respondents about their consumption of cereals and millets, roots and tubers, sugar, and oils and fat and, therefore, findings should be interpreted with caution. We note that scores are given irrespective of the amount of each item consumed. The value of the index ranged from zero to five.

Findings show limited diversity in the food intake of adolescents. Some 6-8 percent of boys and 3-7 percent of girls did not consume any of the five selected food groups daily. One percent or less consumed all five food groups daily. The mean score on the index of dietary diversity was 1.7-2.0 across all categories of adolescents. Differences by age, sex, residence in rural or urban areas, and, among older girls, marital status were narrow.

\section{Table 12.2: Dietary diversity}

Percent distribution of adolescents by number of selected food groups consumed daily and average number of food groups consumed daily according to residence, Bihar, 2016

\begin{tabular}{|c|c|c|c|c|c|}
\hline Number of food groups & $\begin{array}{c}\text { Boys } \\
(10-14)\end{array}$ & $\begin{array}{c}\text { Boys } \\
(15-19)\end{array}$ & $\begin{array}{c}\text { Girls } \\
(10-14)\end{array}$ & $\begin{array}{c}\text { Girls } \\
(15-19)\end{array}$ & $\begin{array}{l}\text { Married girls } \\
\qquad(15-19)\end{array}$ \\
\hline \multicolumn{6}{|c|}{ Combined (percent) } \\
\hline 0 & 7.6 & 6.1 & 2.9 & 3.1 & 6.5 \\
\hline 1 & 34.9 & 31.0 & 36.3 & 31.1 & 31.1 \\
\hline 2 & 37.0 & 38.6 & 31.6 & 36.5 & 36.9 \\
\hline 3 & 17.6 & 19.5 & 23.7 & 22.1 & 19.4 \\
\hline 4 & 2.6 & 4.5 & 4.2 & 6.0 & 5.1 \\
\hline 5 & 0.3 & 0.3 & 1.4 & 1.3 & 1.0 \\
\hline Average number of food groups consumed daily & 1.7 & 1.9 & 1.9 & 2.0 & 1.9 \\
\hline Number of respondents & 1,012 & 1,821 & 764 & 3,428 & 3,408 \\
\hline \multicolumn{6}{|c|}{ Urban (percent) } \\
\hline 0 & 4.7 & 2.6 & 2.8 & 2.5 & 5.0 \\
\hline 1 & 18.9 & 21.7 & 23.3 & 22.2 & 26.2 \\
\hline 2 & 37.0 & 34.6 & 35.3 & 35.2 & 34.8 \\
\hline 3 & 29.6 & 28.9 & 21.4 & 23.9 & 24.2 \\
\hline 4 & 9.0 & 10.4 & 15.7 & 12.5 & 7.9 \\
\hline 5 & 0.8 & 1.8 & 1.5 & 3.6 & 1.9 \\
\hline Average number of food groups consumed daily & 1.7 & 1.9 & 1.9 & 2.0 & 1.9 \\
\hline Number of respondents & 452 & 1,008 & 387 & 1,738 & 1,366 \\
\hline \multicolumn{6}{|c|}{ Rural (percent) } \\
\hline 0 & 8.0 & 6.6 & 2.9 & 3.1 & 6.7 \\
\hline 1 & 36.8 & 32.2 & 37.9 & 32.1 & 31.7 \\
\hline 2 & 37.0 & 39.1 & 31.2 & 36.6 & 37.1 \\
\hline 3 & 16.2 & 18.3 & 24.0 & 21.8 & 18.8 \\
\hline 4 & 1.8 & 3.7 & 2.8 & 5.2 & 4.8 \\
\hline 5 & 0.2 & 0.1 & 1.3 & 1.0 & 0.9 \\
\hline Average number of food groups consumed daily & 2.2 & 2.3 & 2.3 & 2.3 & 2.1 \\
\hline Number of respondents & 560 & 813 & 377 & 1,690 & 2,042 \\
\hline
\end{tabular}

Note: All Ns are unweighted. 


\subsection{Nutritional status}

To assess nutritional status, the survey included an anthropometric component, in which a representative subsample of adolescents were weighed and their height measured (please see Chapter 1 for selection of sub-sample for anthropometric measures). Every interviewing team included a health investigator who conducted the anthropometric measurements. Each health investigator carried a scale and a stadiometer. The SECA 874 electronic scale with a digital display was used for measuring weight; it has a precision of measuring weight up to the nearest 100 grams and is designed for survey settings. The stadiometer with accuracy level of $0.1 \mathrm{~cm}$ was also procured from SECA (SECA 213) for measuring height in survey settings.

The tables on nutritional status show estimates based on WHO reference values for assessing overweight and under nutrition among children and adolescents from ages 5-19 years as released by WHO in 2007 (de Onis et al., 2007). The WHO Reference 2007 is a reconstruction of the 1977 National Center for Health Statistics (NCHS)/WHO reference. The WHO recommended cut-off points for overweight and obesity were BMI-for-age Z-score $>+1$ SD and $>+2$ SD, respectively. BMI-for-age Z -score <-2SD and <-3SD were set as the cut-off points for thinness and severe thinness, respectively.

The height and weight measurements are used to calculate the BMI-for-age Z-scores. We excluded girls who were pregnant at the time of the survey and girls who had given birth during the two months preceding the survey. It needs to be noted that the survey was not able to measure the height and weight of all selected adolescents, usually either because the respondent was not at home at the time of the health investigator's visits or because the parents/guardians refused to allow the adolescent to be weighed and measured. We did not measure six percent of adolescents, and we also excluded 0.1 percent of adolescents who had grossly improbable height or weight measurements from the analysis.

Table 12.3 shows that notable proportions of adolescents were thin ( $\leq-2 \mathrm{SD})$, and as found in the National Family Health Survey (IIPS and Macro International, 2007) and the National Nutrition Monitoring Bureau survey (National Institute of Nutrition, 2012), we found that a larger proportion of younger adolescents were thin compared with older adolescents (28\% of younger boys versus $23 \%$ of older boys and $17 \%$ of younger girls versus $7-9 \%$ of unmarried and married older girls) and more boys than girls were thin ( $28 \%$ of younger boys versus $17 \%$ of younger girls and $23 \%$ of older boys versus $7-9 \%$ of unmarried and married older girls). Some 6-7 percent among boys and two percent or less among girls were severely thin (<-3SD). Differences by marital status among older girls were narrow. We note that 20 percent of married older girls had a height below 145 centimetres, with no difference in this regard between those from rural and those from urban areas (not shown in table). Differences by residence in rural or urban areas in the prevalence of thinness were marked for younger and older boys and younger girls, among whom a larger proportion of rural than urban adolescents were found to be thin (29\% versus $20 \%$ among younger boys; $24 \%$ versus $19 \%$ among older boys; and $18 \%$ versus $11 \%$ among younger girls).

\section{Table 12.3: Nutritional status}

Percentage of adolescents by specific levels of body mass index for age, using WHO growth reference for children and adolescents, according to residence, Bihar, 2016

\begin{tabular}{lrrrrr}
\hline BMIl-for-age (distribution of Z-score) & $\begin{array}{c}\text { Boys } \\
(\mathbf{1 0}-\mathbf{1 4})\end{array}$ & $\begin{array}{c}\text { Boys } \\
(\mathbf{1 5}-\mathbf{1 9})\end{array}$ & $\begin{array}{c}\text { Girls } \\
(\mathbf{1 0}-\mathbf{1 4})\end{array}$ & $\begin{array}{c}\text { Girls } \\
(\mathbf{1 5}-\mathbf{1 9})\end{array}$ & $\begin{array}{c}\text { Married girls } \\
(\mathbf{1 5}-\mathbf{1 9})\end{array}$ \\
\hline Normal & Combined (percent) & & & & \\
Thinness & 70.1 & 74.2 & 81.1 & 89.2 & 90.4 \\
$\quad$ Severe thinness & 28.3 & 23.3 & 17.3 & 9.3 & 6.7 \\
Overweight & 7.1 & 5.7 & 2.0 & 0.4 & 0.8 \\
$\quad$ Obesity & 1.6 & 2.6 & 1.6 & 1.6 & 2.9 \\
Number of respondents whose weight and height were taken ${ }^{1}$ & $\mathbf{9 6 5}$ & $\mathbf{6 5 4}$ & $\mathbf{7 3 6}$ & $\mathbf{5 3 0}$ & $\mathbf{1 , 0 2 0}$ \\
\hline
\end{tabular}


Table 12.3 Cont.

\begin{tabular}{|c|c|c|c|c|c|}
\hline BMI-for-age (distribution of Z-score) & $\begin{array}{c}\text { Boys } \\
(10-14)\end{array}$ & $\begin{array}{c}\text { Boys } \\
(15-19)\end{array}$ & $\begin{array}{c}\text { Girls } \\
(10-14)\end{array}$ & $\begin{array}{c}\text { Girls } \\
(15-19)\end{array}$ & $\begin{array}{l}\text { Married girls } \\
\qquad(15-19)\end{array}$ \\
\hline \multicolumn{6}{|c|}{ Urban (percent) } \\
\hline Normal & 75.2 & 75.6 & 84 & 83.9 & 88.4 \\
\hline Thinness & 19.9 & 18.7 & 10.8 & 9.1 & 8.8 \\
\hline Severe thinness & 4.8 & 3.4 & 2.1 & 0.7 & 0.4 \\
\hline Overweight & 5.0 & 5.7 & 5.1 & 6.9 & 2.8 \\
\hline Obesity & 1.2 & 1.4 & 0.9 & 1.4 & 0.0 \\
\hline Number of respondents whose weight and height were taken ${ }^{1}$ & 417 & 375 & 376 & 265 & 336 \\
\hline \multicolumn{6}{|c|}{ Rural (percent) } \\
\hline Normal & 69.5 & 74.0 & 80.7 & 89.8 & 90.6 \\
\hline Thinness & 29.2 & 23.8 & 18.1 & 9.3 & 6.5 \\
\hline Severe thinness & 7.3 & 6.0 & 2.0 & 0.4 & 0.9 \\
\hline Overweight & 1.3 & 2.2 & 1.2 & 0.9 & 2.9 \\
\hline Obesity & 0.0 & 0.4 & 0.2 & 0.0 & 0.5 \\
\hline Number of respondents whose weight and height were taken ${ }^{1}$ & 548 & 279 & 360 & 265 & 684 \\
\hline
\end{tabular}

Notes: All Ns are unweighted. ${ }^{1}$ Excludes girls who were pregnant or had given birth in the preceding two months; also excludes respondents with outlier BMI-for-age Z-score (<-5SD; > +5SD); normal ( $\geq-2 S D$ and $\leq 1 S D)$; thinness ( $\leq-2 S D)$; severe thinness (<-3SD); overweight (> 1 SD and $\leq 2 S D$ ); Obesity ( $>2 S D$.)

Findings also show that 2-3 percent each of boys and girls were overweight or obese. Urban adolescents, other than married older girls, were slightly more likely than their rural counterparts to be overweight or obese.

Table 12.4 describes the differentials in the prevalence of any thinness among adolescents by selected background characteristics. The prevalence of thinness declined with age for younger adolescents (but not for older adolescents), among whom a larger proportion of those in ages 10-12 were thin compared with those in ages 13-14 (30\% versus $25 \%$ among boys and $20 \%$ versus $13 \%$ among girls). Religious differences were erratic-among younger boys and unmarried older girls, somewhat more of Muslim respondents than Hindu respondents were thin (33\% versus $28 \%$ among younger boys and $14 \%$ versus $9 \%$ among unmarried older girls), while a reverse pattern was observed among older boys (4\% versus $26 \%$ ), and the differences were narrow among younger girls and married older girls. Caste-wise differences were observed for boys, younger girls, and unmarried older girls. Among younger boys and unmarried older girls, fewer of those who belonged to other backward castes than those who belonged to general castes and scheduled castes were thin (25\% versus $32-35 \%$ among younger boys and $8 \%$ versus $12-13 \%$ among unmarried older girls), while among older boys and younger girls, more of those who belonged to scheduled castes than those who belonged to other castes were thin (37\% versus $19 \%$ among older boys and $22 \%$ versus $13-16 \%$ among younger girls). Differences by educational levels were inconsistent, although among boys and younger girls, the better educated were less likely than those with fewer years of education to be thin, while no such pattern was evident among unmarried and married older girls. Differences in the prevalence of thinness by current enrolment in school were narrow, except for younger girls and unmarried older girls among whom more of those currently enrolled in school than those who were not were thin (18\% versus $12 \%$ among younger girls and $10 \%$ versus $5 \%$ among unmarried older girls). The prevalence of thinness was lower among younger and older boys and younger girls who were engaged in paid work in the year preceding the interview than those who were not ( $21 \%$ versus $29 \%$ among younger boys; $14 \%$ versus $27 \%$ among older boys; and $8 \%$ versus $18 \%$ among younger girls); however, no such differences were observed among unmarried and married older girls. Thinness declined by higher household wealth status among boys and younger girls, but this was inconsistent among unmarried and married older girls. It also declined with higher levels of mother's education among older boys and younger girls but not among younger boys or unmarried and married older girls. 
Table 12.4 Prevalence of thinness

Percentage of adolescents who were thin by selected background characteristics, Bihar, 2016

\begin{tabular}{|c|c|c|c|c|c|}
\hline Background characteristics (percent) & $\begin{array}{c}\text { Boys } \\
(10-14)\end{array}$ & $\begin{array}{c}\text { Boys } \\
(15-19)\end{array}$ & $\begin{array}{c}\text { Girls } \\
(10-14)\end{array}$ & $\begin{array}{c}\text { Girls } \\
(15-19)\end{array}$ & $\begin{array}{c}\text { Married girls } \\
(15-19)\end{array}$ \\
\hline \multicolumn{6}{|l|}{ Age } \\
\hline $10-12$ & 29.9 & NA & 20.2 & NA & NA \\
\hline $13-14$ & 25.3 & NA & 13.2 & NA & NA \\
\hline $15-17$ & NA & 23.3 & NA & 8.7 & 6.5 \\
\hline $18-19$ & NA & 23.2 & NA & 11.6 & 6.8 \\
\hline \multicolumn{6}{|l|}{ Religion $^{1}$} \\
\hline Hindu & 27.6 & 26.2 & 16.6 & 8.7 & 6.9 \\
\hline Muslim & 32.7 & 3.7 & 21.4 & 13.5 & 4.7 \\
\hline \multicolumn{6}{|l|}{ Caste $^{2}$} \\
\hline SC & 35.1 & 37.4 & 22.0 & 13.3 & 5.8 \\
\hline $\mathrm{OBC}$ & 25.3 & 19.4 & 16.3 & 7.9 & 7.1 \\
\hline General $^{3}$ & 32.3 & 18.5 & 13.0 & 11.8 & 6.7 \\
\hline \multicolumn{6}{|l|}{ Completed years of schooling } \\
\hline None $^{4}$ & * & * & $(15.4)$ & 16.1 & 6.7 \\
\hline $1-4$ & 31.9 & * & 26.4 & 10.2 & 3.5 \\
\hline $5-7$ & 25.9 & 34.9 & 15.4 & 5.7 & 7.5 \\
\hline $8-9$ & 27.2 & 21.2 & 5.0 & 8.7 & 4.7 \\
\hline $10-11$ & NA & 21.9 & NA & 7.2 & 10.2 \\
\hline 12 and above & NA & 15.5 & NA & 14.3 & 7.1 \\
\hline \multicolumn{6}{|l|}{ Current schooling status ${ }^{5}$} \\
\hline Yes & 28.2 & 24.1 & 17.7 & 9.5 & 9.7 \\
\hline No & $(27.9)$ & 23.1 & $(11.9)$ & 4.7 & 5.8 \\
\hline \multicolumn{6}{|c|}{ Paid work in the 12 months prior to the interview } \\
\hline Yes & $(20.7)$ & 14.4 & 8.1 & 8.4 & 4.9 \\
\hline No & 28.8 & 27.0 & 18.1 & 9.5 & 6.9 \\
\hline \multicolumn{6}{|l|}{ Wealth quintile } \\
\hline First & 38.1 & * & 23.5 & $(6.7)$ & 6.7 \\
\hline Second & 32.2 & 29.0 & 11.3 & 20.7 & 7.7 \\
\hline Third & 24.0 & 21.3 & 23.1 & 1.9 & 8.7 \\
\hline Fourth & 30.0 & 25.4 & 14.0 & 12.4 & 5.7 \\
\hline Fifth & 20.7 & 15.2 & 15.8 & 4.9 & 4.6 \\
\hline \multicolumn{6}{|c|}{ Mother's education (in years of schooling completed) } \\
\hline None $^{4}$ & 28.5 & 21.2 & 18.1 & 9.2 & 6.9 \\
\hline $1-7$ & 28.3 & 21.2 & 21.4 & 22.5 & 6.9 \\
\hline $8-9$ & 28.9 & 41.6 & $(5.6)$ & 5.0 & 4.1 \\
\hline 10 and above & 25.6 & 30.3 & 9.3 & 3.7 & 6.1 \\
\hline Total & 28.3 & 23.3 & 17.3 & 9.3 & 6.7 \\
\hline
\end{tabular}

Notes: *Percentage not shown as this was based on fewer than 25 unweighted cases. () Based on 25-49 unweighted cases. NA: not applicable; OBC: other backward caste; SC: scheduled caste; ST: scheduled tribe. ${ }^{1}$ Percentages not shown for those belonging to other religions as less than one percent of surveyed adolescents belonged to other religions. ${ }^{2}$ Percentages not shown for those belonging to STs as less than one percent of surveyed adolescents belonged to STs. ${ }^{3}$ Includes all those not belonging to SCs, STs, or OBCs. ${ }^{4}$ Includes non-literate and literate with no formal schooling. ${ }^{5}$ Percentages not shown for adolescents who were pursuing their education through distance education courses at the time of interview or those who never went to school. 
The prevalence of overweight, including obesity among adolescents did not differ much by age, current schooling status, and engagement in paid work (Table 12.5). However, among older boys, differences by religion and caste were noted-Muslim boys were more likely than Hindu boys to be overweight or obese as were those from general castes compared with those from other castes. Among older boys and married older girls, those who had completed 12 or more years of schooling were more likely to be overweight or obese compared with those with fewer years of education. Among younger and older boys and younger girls, those who belonged to the wealthiest households were somewhat more likely to be overweight or obese compared with those who belonged to poorer households. Finally, a somewhat larger proportion of younger girls and married older girls whose mother had completed 10 or more years of schooling than those whose mother had completed fewer years of schooling were overweight or obese.

\section{Table 12.5 Prevalence of overweight}

Percentage of adolescents who were overweight by selected background characteristics, Bihar, 2016

\begin{tabular}{|c|c|c|c|c|c|}
\hline Background characteristics (percent) & $\begin{array}{c}\text { Boys } \\
(10-14)\end{array}$ & $\begin{array}{l}\text { Boys } \\
(15-19)\end{array}$ & $\begin{array}{c}\text { Girls } \\
(10-14)\end{array}$ & $\begin{array}{c}\text { Girls } \\
(15-19)\end{array}$ & $\begin{array}{l}\text { Married girls } \\
(15-19)\end{array}$ \\
\hline \multicolumn{6}{|l|}{ Age } \\
\hline $10-12$ & 1.2 & NA & 1.9 & NA & NA \\
\hline $13-14$ & 2.5 & NA & 1.2 & NA & NA \\
\hline $15--17$ & NA & 1.5 & NA & 1.4 & 2.1 \\
\hline $18-19$ & NA & 5.9 & NA & 2.1 & 3.4 \\
\hline \multicolumn{6}{|l|}{ Religion $^{1}$} \\
\hline Hindu & 1.8 & 1.8 & 1.8 & 1.4 & 3.2 \\
\hline Muslim & 1.0 & 7.5 & 0.9 & 2.2 & 0.0 \\
\hline \multicolumn{6}{|l|}{ Caste $^{2}$} \\
\hline SC & 2.1 & 1.7 & 0.1 & 4.3 & 4.9 \\
\hline OBC & 1.4 & 1.6 & 2.1 & 0.8 & 2.0 \\
\hline General $^{3}$ & 2.1 & 9.9 & 2.3 & 1.8 & 4.2 \\
\hline \multicolumn{6}{|l|}{ Completed years of schooling } \\
\hline None $^{4}$ & * & * & $(0.4)$ & 0.0 & 2.2 \\
\hline $1-4$ & 1.1 & * & 1.4 & 0.0 & 0.0 \\
\hline $5-7$ & 1.3 & 0.2 & 1.7 & 0.3 & 1.6 \\
\hline $8-9$ & 3.9 & 1.9 & 2.5 & 1.8 & 3.6 \\
\hline $10-11$ & NA & 2.4 & NA & 2.7 & 3.1 \\
\hline 12 and above & NA & 12.7 & NA & 1.2 & 7.3 \\
\hline \multicolumn{6}{|l|}{ Current schooling status ${ }^{5}$} \\
\hline Yes & 1.7 & 2.7 & 1.7 & 0.8 & 4.7 \\
\hline No & $(0.2)$ & 2.6 & $(1.5)$ & 4.5 & 2.0 \\
\hline \multicolumn{6}{|c|}{ Paid work in the 12 months prior to the interview } \\
\hline Yes & $(0.0)$ & 0.2 & 0.0 & 2.1 & 4.0 \\
\hline No & 1.8 & 3.5 & 1.8 & 1.4 & 2.8 \\
\hline
\end{tabular}


Table 12.5 Cont.

\begin{tabular}{|c|c|c|c|c|c|}
\hline Background characteristics (percent) & $\begin{array}{c}\text { Boys } \\
(10-14)\end{array}$ & $\begin{array}{c}\text { Boys } \\
(15-19)\end{array}$ & $\begin{array}{c}\text { Girls } \\
(10-14)\end{array}$ & $\begin{array}{c}\text { Girls } \\
(15-19)\end{array}$ & $\begin{array}{c}\text { Married girls } \\
(15-19)\end{array}$ \\
\hline \multicolumn{6}{|l|}{ Wealth quintile } \\
\hline First & 1.7 & * & 1.1 & $(5.3)$ & 4.3 \\
\hline Second & 0.3 & 0.9 & 0.0 & 0.0 & 0.9 \\
\hline Third & 0.8 & 0.1 & 1.3 & 2.2 & 2.3 \\
\hline Fourth & 0.3 & 4.2 & 0.3 & 1.2 & 2.6 \\
\hline Fifth & 5.6 & 5.1 & 5.1 & 1.5 & 5.2 \\
\hline \multicolumn{6}{|c|}{ Mother's education (in years of schooling completed) } \\
\hline None $^{4}$ & 0.7 & 2.0 & 1.0 & 1.7 & 2.7 \\
\hline $1-7$ & 3.9 & 6.3 & 3.7 & 0.0 & 3.0 \\
\hline $8-9$ & 7.4 & 5.0 & $(1.0)$ & 1.4 & 0.0 \\
\hline 10 and above & 4.5 & 3.6 & 6.1 & 1.9 & 9.6 \\
\hline Total & 1.6 & 2.6 & 1.6 & 1.6 & 2.9 \\
\hline
\end{tabular}

Notes: *Percentage not shown as this was based on fewer than 25 unweighted cases. () Based on 25-49 unweighted cases. NA: not applicable; OBC: other backward caste; SC: scheduled caste; ST: scheduled tribe. ${ }^{1}$ Percentages not shown for those belonging to other religions as less than one percent of surveyed adolescents belonged to other religions. ${ }^{2}$ Percentages not shown for those belonging to STs as less than one percent of surveyed adolescents belonged to STs. ${ }^{3}$ Includes all those not belonging to SCs, STs, or OBCs. ${ }^{4}$ Includes non-literate and literate with no formal schooling. ${ }^{5}$ Percentages not shown for adolescents who were pursuing their education through distance education courses at the time of interview or those who never went to school.

\subsection{Prevalence of anaemia}

Measurement of the haemoglobin levels of a representative sub-sample of adolescents using the HemoCue $\mathrm{Hb} 201+$ analyzer was undertaken. This system uses a single drop of blood taken from a finger and drawn into a cuvette and then inserted into a portable battery-operated instrument. In less than one minute, the haemoglobin concentration is indicated on a digital read-out. Before anaemia testing was undertaken, the health investigator obtained consent from the respondent and, for minors, a parent or an adult who was responsible for the minor's care as well; the consent-taking procedure included our informing that person about anaemia, describing the procedure to be followed for the test, and emphasising the voluntary nature of the test. If the test was performed, the respondent or the parent/responsible adult was given a written record of the haemoglobin levels and was informed about the prevalence of anaemia if indicated by the test. In addition, the health investigator described the meaning of the result and advised the respondent or parent/responsible adult to seek medical treatment, if the result warranted it. In cases of severe anaemia, the respondent or parent/responsible adult was given a referral slip to seek treatment from the nearest public sector health facility.

Three levels of severity of anaemia were distinguished: mild anaemia (10-11.4 g/dl for 10-11-year-olds, 10-11.9 $\mathrm{g} / \mathrm{dl}$ for 12-14-year-olds and non-pregnant girls in ages 15-19 years, 10-10.9 g/dl for pregnant girls in ages 15-19 years, and $12-12.9 \mathrm{~g} / \mathrm{dl}$ for boys in ages $15-19$ years); moderate anaemia (7.0-9.9 g/dl for 10-14-year-olds and girls in ages 15-19 years, regardless of pregnancy status at the time of the interview, and 9.0-11.9 g/dl for boys in ages 15-19 years); and severe anaemia $(<7.0 \mathrm{~g} / \mathrm{dl}$ for 10-14-year-olds and girls in ages 15-19, regardless of pregnancy status, and $<9.0 \mathrm{~g} / \mathrm{dl}$ for boys in ages $15-19$ years).

Findings, presented in Table 12.6, show that 25-26 percent of boys and 58-69 percent of girls were anaemic. Specifically, 16-23 percent of boys were mildly anaemic as were 42-54 percent of all three categories of girls. Some 3-9 percent of boys were moderately anaemic as were nine percent of younger girls and 14-21 percent of unmarried and married older girls. Finally, hardly any boys and 1-2 percent of girls were severely anaemic. While differences between younger and older respondents were narrow among boys, differences among girls show that unmarried and married older girls were more likely to be anaemic (particularly moderately anaemic) than younger girls. While differences between married and unmarried older girls were not apparent on the whole, the married were more likely 
to be moderately or severely anaemic than the unmarried (23\% versus $15 \%)$. Differences by residence in rural or urban areas were narrow among younger and older boys and younger girls. In contrast, patterns varied among older girls: among unmarried older girls, a larger proportion of those in rural than urban areas were mildly anaemic (55\% versus $45 \%$ ), while considerably fewer married older girls in rural than urban areas were mildly anaemic (42\% versus $48 \%$ ) or severely anaemic ( $2 \%$ versus $8 \%$ ).

\section{Table 12.6: Prevalence of anaemia}

Percentage of adolescents who were anaemic, according to residence, Bihar, 2016

\begin{tabular}{|c|c|c|c|c|c|}
\hline Level of anaemia & $\begin{array}{c}\text { Boys } \\
(10-14)\end{array}$ & $\begin{array}{c}\text { Boys } \\
(15-19)\end{array}$ & $\begin{array}{c}\text { Girls } \\
(10-14)\end{array}$ & $\begin{array}{c}\text { Girls } \\
(15-19)\end{array}$ & $\begin{array}{c}\text { Married girls } \\
(15-19)\end{array}$ \\
\hline \multicolumn{6}{|c|}{ Combined (percent) } \\
\hline Any anaemia ${ }^{1}$ & 26.3 & 24.6 & 57.7 & 68.6 & 64.9 \\
\hline Mild $^{2}$ & 23.4 & 15.9 & 47.8 & 53.5 & 42.3 \\
\hline Moderate $^{3}$ & 2.7 & 8.7 & 8.9 & 14.3 & 20.5 \\
\hline Severe $^{4}$ & 0.2 & 0.0 & 1.0 & 0.7 & 2.1 \\
\hline Number of respondents tested for haemoglobin level & 955 & 648 & 723 & 519 & 1,317 \\
\hline \multicolumn{6}{|c|}{ Urban (percent) } \\
\hline Any anaemia ${ }^{1}$ & 23.7 & 21.6 & 59.2 & 62.1 & 68.1 \\
\hline Mild $^{2}$ & 22.4 & 15.8 & 49.3 & 45.1 & 47.8 \\
\hline Moderate $^{3}$ & 1.0 & 5.7 & 8.3 & 15.3 & 18.1 \\
\hline Severe $^{4}$ & 0.3 & 1.0 & 1.8 & 0.7 & 8.1 \\
\hline Number of respondents tested for haemoglobin level & 409 & 371 & 369 & 259 & 430 \\
\hline \multicolumn{6}{|c|}{ Rural (percent) } \\
\hline Any anaemia ${ }^{1}$ & 26.6 & 25.0 & 57.5 & 69.3 & 64.6 \\
\hline Mild $^{2}$ & 23.5 & 15.9 & 47.6 & 54.6 & 41.8 \\
\hline Moderate $^{3}$ & 2.9 & 9.1 & 9.0 & 14.2 & 20.7 \\
\hline Severe $^{4}$ & 0.2 & 0.0 & 1.0 & 0.6 & 2.1 \\
\hline Number of respondents tested for haemoglobin level & 546 & 277 & 354 & 260 & 887 \\
\hline
\end{tabular}

Notes: All Ns are unweighted. Haemoglobin in $\mathrm{g} / \mathrm{dl}=$ grams per decilitre. ${ }^{1}$ Any anaemia: $<11.5 \mathrm{~g} / \mathrm{dl}$ for $10-11$-year-olds; $<12.0 \mathrm{~g} / \mathrm{dl}$ for 12-14-year-olds and non-pregnant girls aged 15 years and above; $<11.0 \mathrm{~g} / \mathrm{dl}$ for pregnant girls aged 15 years and above; $<13.0 \mathrm{~g} / \mathrm{dl}$ for boys aged 15 years and above. ${ }^{2}$ Mild anaemia: $10-11.4 \mathrm{~g} / \mathrm{dl}$ for $10-11$-year-olds; $10-11.9 \mathrm{~g} / \mathrm{dl}$ for 12-14-year-olds and non-pregnant girls in ages 15-19 years; $10-10.9 \mathrm{~g} / \mathrm{dl}$ for pregnant girls in ages $15-19$ years; and 12-12.9 g/dl for boys in ages 15-19 years. ${ }^{3}$ Moderate anaemia: 7.0-9.9 g/dl for 10-14-year-olds and girls in ages 15-19 years, regardless of pregnancy status at the time of the interview; and 9.0-11.9 g/dl for boys in ages 15-19 years. ${ }^{4}$ Severe anaemia: <7.0 g/dl for 10-14-year-olds and girls in ages 15-19, regardless of pregnancy status; and $<9.0 \mathrm{~g} / \mathrm{dl}$ for boys in ages $15-19$ years.

Differences in prevalence of moderate to severe anaemia among boys and girls by selected socio-demographic characteristics are presented in Table 12.7. Findings show that among younger girls, those in ages 10-12 were slightly less likely to be moderately or severely anaemic than those in ages 13-14 (7\% versus 14\%), while among unmarried older girls, those in ages 15-17 were slightly more likely than those in ages $18-19$ to be so (16\% versus 11\%). Age-wise differences were more modest among younger and older boys and married older girls. Differences by religion were narrow, except for older boys and married older girls; a larger proportion of Hindu older boys than Muslim older boys were moderately or severely anaemic (10\% versus none), while a smaller proportion of Hindu married older girls were moderately or severely anaemic, compared with Muslim married older girls ( $22 \%$ versus 27\%). Caste-wise differences were apparent for all adolescents other than younger boys, although the pattern differed. Among older adolescents, those belonging to scheduled castes were somewhat more likely than those from other castes to be moderately or severely anaemic (11\% versus $6-9 \%$ among older boys; $21 \%$ versus $13-15 \%$ among unmarried older girls; and 31\% versus 18-20\% among married older girls), while a reverse pattern was observed 
for younger girls, among whom those who belonged to general castes were more likely than those from other castes to be moderately or severely anaemic (17\% versus $8-9 \%)$. The prevalence of moderate to severe anaemia tended to decline with increasing levels of education across all categories of adolescents other than unmarried older girls. Younger girls and unmarried older girls who were currently enrolled in school were less likely than those who were not to be moderately to severely anaemic (9\% versus $15 \%$ among younger girls and $13 \%$ versus $18 \%$ among unmarried older girls); however, no such pattern was evident among boys or married older girls. Among younger girls and married older girls, those who were engaged in paid work in the 12 months preceding the interview were more likely than those who were not working to be moderately to severely anaemic (19\% versus $9 \%$ among younger girls and $30 \%$ versus $22 \%$ among married older girls); the differences were negligible among the other three categories of adolescents. The association between household wealth and the prevalence of moderate to severe anaemia was erratic across most categories of adolescents, except that among married older girls, the prevalence of moderate or severe anaemia declined with household wealth. Finally, the prevalence of moderate or severe anaemia declined with mother's education among younger girls and married older girls; however, no such association was observed for boys or unmarried older girls.

\section{Table 12.7: Prevalence of moderate to severe anaemia}

Percentage of adolescent boys and girls with moderate to severe anaemia by selected background characteristics, Bihar, 2016

\begin{tabular}{|c|c|c|c|c|c|}
\hline Background characteristics (percent) & $\begin{array}{l}\text { Boys } \\
(10-14)\end{array}$ & $\begin{array}{c}\text { Boys } \\
(15-19)\end{array}$ & $\begin{array}{c}\text { Girls } \\
(10-14)\end{array}$ & $\begin{array}{c}\text { Girls } \\
(15-19)\end{array}$ & $\begin{array}{c}\text { Married girls } \\
(15-19)\end{array}$ \\
\hline \multicolumn{6}{|l|}{ Age } \\
\hline $10-12$ & 3.7 & NA & 7.2 & NA & NA \\
\hline $13-14$ & 1.5 & NA & 13.7 & NA & NA \\
\hline $15-17$ & NA & 9.5 & NA & 16.1 & 24.0 \\
\hline $18-19$ & NA & 6.3 & NA & 10.9 & 21.9 \\
\hline \multicolumn{6}{|l|}{ Religion $^{1}$} \\
\hline Hindu & 3.1 & 10.0 & 10.6 & 15.4 & 22.2 \\
\hline Muslim & 2.0 & 0.0 & 6.5 & 15.0 & 26.6 \\
\hline \multicolumn{6}{|l|}{ Caste $^{2}$} \\
\hline SC & 3.1 & 10.6 & 8.3 & 21.3 & 30.7 \\
\hline OBC & 3.0 & 8.8 & 9.4 & 12.8 & 19.7 \\
\hline General $^{3}$ & 2.4 & 6.2 & 16.7 & 14.7 & 18.3 \\
\hline \multicolumn{6}{|l|}{ Completed years of schooling } \\
\hline None $^{4}$ & * & * & $(23.4)$ & $(21.4)$ & 31.4 \\
\hline $1-4$ & 5.8 & * & 11.3 & * & 22.8 \\
\hline $5-7$ & 1.1 & 17.6 & 8.6 & 7.3 & 23.4 \\
\hline $8-9$ & 1.6 & 7.4 & 6.7 & 19.1 & 18.7 \\
\hline $10-11$ & NA & 6.5 & NA & 9.3 & 15.9 \\
\hline 12 and above & NA & 0.8 & NA & 14.9 & 16.6 \\
\hline \multicolumn{6}{|l|}{ Current schooling status $^{5}$} \\
\hline Yes & 2.9 & 9.2 & 8.9 & 13.4 & 20.1 \\
\hline No & $(0.0)$ & 9.9 & $(15.4)$ & 17.6 & 19.9 \\
\hline
\end{tabular}


Table 12.7 Cont.

\begin{tabular}{|c|c|c|c|c|c|}
\hline Background characteristics (percent) & $\begin{array}{c}\text { Boys } \\
(10-14)\end{array}$ & $\begin{array}{c}\text { Boys } \\
(15-19)\end{array}$ & $\begin{array}{c}\text { Girls } \\
(10-14)\end{array}$ & $\begin{array}{c}\text { Girls } \\
(15-19)\end{array}$ & $\begin{array}{c}\text { Married girls } \\
\text { (15-19) }\end{array}$ \\
\hline \multicolumn{6}{|c|}{ Paid work in the 12 months prior to the interview } \\
\hline Yes & $(0.4)$ & 10.1 & 19.2 & 18.4 & 30.2 \\
\hline No & 3.1 & 8.2 & 9.1 & 14.3 & 21.6 \\
\hline \multicolumn{6}{|l|}{ Wealth quintile } \\
\hline First & 5.9 & * & 12.6 & $(20.6)$ & 36.4 \\
\hline Second & 1.1 & 10.8 & 15.0 & 9.4 & 20.2 \\
\hline Third & 2.9 & 3.0 & 10.3 & 13.9 & 23.3 \\
\hline Fourth & 5.4 & 9.3 & 6.0 & 19.0 & 18.8 \\
\hline Fifth & 0.5 & 8.2 & 7.7 & 13.6 & 20.0 \\
\hline \multicolumn{6}{|c|}{ Mother's education (in years of schooling completed) } \\
\hline None $^{4}$ & 3.4 & 8.5 & 10.9 & 16.6 & 23.4 \\
\hline $1-7$ & 0.0 & 13.4 & 9.1 & 6.1 & 21.9 \\
\hline $8-9$ & 0.4 & 1.4 & 4.8 & (9.9) & 18.3 \\
\hline 10 and above & 3.9 & 13.1 & 3.6 & 14.2 & 13.3 \\
\hline Total & 2.9 & 8.7 & 10.0 & 15.0 & 22.6 \\
\hline
\end{tabular}

Notes: *Percentage not shown as this was based on fewer than 25 unweighted cases. () Based on 25-49 unweighted cases. NA: not applicable; OBC: other backward caste; SC: scheduled caste; ST: scheduled tribe. ${ }^{1}$ Percentages not shown for those belonging to other religions as less than one percent of surveyed adolescents belonged to other religions. ${ }^{2}$ Percentages not shown for those belonging to STs as less than one percent of surveyed adolescents belonged to STs. ${ }^{3}$ Includes all those not belonging to SCs, STs, or OBCs. ${ }^{4}$ Includes non-literate and literate with no formal schooling. ${ }^{5}$ Percentages not shown for adolescents who were pursuing their education through distance education courses at the time of interview or those who never went to school.

\subsection{Awareness and use of government programmes intended to improve nutritional status of adolescents}

We assessed study participants' awareness and use of government programmes that seek to meet the health and nutritional needs of adolescents-for example, weekly iron and folic acid supplementation, health check-ups to assess nutritional status, and food supplementation.

\subsubsection{Weekly iron and folic acid supplementation programme}

Many adolescents were aware of the weekly iron and folic acid supplementation (WIFS) programme-55-66 percent of younger and older boys and 51-64 percent of younger and older girls (Table 12.8). Younger boys were more likely than older boys to be aware of the WIFS programme (66\% versus 55\%), while no such difference was observed among girls. Among older girls, differences by marital status were marked; more of unmarried than married girls were aware of the programme (64\% versus 51\%). Adolescents in rural areas were more likely than their urban counterparts to have heard about the WIFS programme (57-69\% versus $35-45 \%$ among boys; $65 \%$ versus $46 \%$ among younger girls; and $65 \%$ versus 54\% among unmarried older girls); no such difference was observed for married older girls.

Only small proportions of adolescents had received iron and folic acid tablets from the WIFS programme in the year preceding the interview-two percent each of younger and older boys and 2-6 percent of all three categories of girls. However, many more had received deworming tablets during the same reference period-53 percent and 28 percent of younger and older boys, respectively, and 44 percent and 23 percent of younger girls and unmarried older girls, respectively, and eight percent of married older girls. On the whole, 30-53 percent of boys and 10-45 percent of girls had received one of these tablets in the year preceding the interview. While differences in the proportion of adolescents who had received iron and folic acid tablets did not differ by age, sex, residence in rural or urban 
areas and, among older girls, by marital status, differences in the proportion of those who had received deworming tablets were marked. As seen above, younger adolescents were more likely than older adolescents to have received deworming tablets. Differences by sex show that boys were more likely than girls to have received deworming tablets (53\% versus 44\% among younger adolescents and $28 \%$ versus $8-23 \%$ among older adolescents). Among older girls, more of unmarried than married girls had received deworming tablets (23\% versus $8 \%$ ). Rural adolescents were more likely than urban adolescents, except for married older girls, to have received deworming tablets (47-56\% versus 24-27\% among younger adolescents and 25-30\% versus 9-10\% among older adolescents).

\section{Table 12.8: Awareness and receipt of weekly iron and folic acid supplementation (WIFS) programme}

Percentage of adolescents who were aware of the WIFS programme and who had benefited from it in the year preceding the interview, according to residence, Bihar, 2016

\begin{tabular}{|c|c|c|c|c|c|}
\hline WIFS programme & $\begin{array}{c}\text { Boys } \\
(10-14)\end{array}$ & $\begin{array}{c}\text { Boys } \\
(15-19)\end{array}$ & $\begin{array}{c}\text { Girls } \\
(10-14)\end{array}$ & $\begin{array}{c}\text { Girls } \\
(15-19)\end{array}$ & $\begin{array}{c}\text { Married girls } \\
\quad(15-19)\end{array}$ \\
\hline \multicolumn{6}{|c|}{ Combined (percent) } \\
\hline \multicolumn{6}{|l|}{ Awareness } \\
\hline Aware of WIFS ${ }^{1}$ & 66.3 & 54.8 & 62.7 & 63.9 & 51.1 \\
\hline \multicolumn{6}{|c|}{ Receipt of WIFS in the year preceding the interview } \\
\hline Received iron and folic acid tablets & 2.3 & 2.3 & 1.8 & 5.5 & 3.7 \\
\hline Received deworming tablets & 52.5 & 28.0 & 44.1 & 23.2 & 7.7 \\
\hline Either & 53.1 & 29.5 & 44.9 & 26.2 & 10.3 \\
\hline Number of respondents & 1,012 & 1,821 & 764 & 3,428 & 3,408 \\
\hline \multicolumn{6}{|c|}{ Urban (percent) } \\
\hline \multicolumn{6}{|l|}{ Awareness } \\
\hline Aware of WIFS ${ }^{1}$ & 44.5 & 35.3 & 46.0 & 53.7 & 47.9 \\
\hline \multicolumn{6}{|c|}{ Receipt of WIFS in the year preceding the interview } \\
\hline Received iron and folic acid tablets & 0.9 & 0.6 & 2.0 & 2.7 & 3.3 \\
\hline Received deworming tablets & 26.7 & 9.1 & 23.9 & 9.8 & 4.4 \\
\hline Either & 27.4 & 9.3 & 25.5 & 11.5 & 7.1 \\
\hline Number of respondents & 452 & 1,008 & 387 & 1,738 & 1,366 \\
\hline \multicolumn{6}{|c|}{ Rural (percent) } \\
\hline \multicolumn{6}{|l|}{ Awareness } \\
\hline Aware of WIFS ${ }^{1}$ & 68.9 & 57.2 & 64.7 & 65.1 & 51.4 \\
\hline \multicolumn{6}{|c|}{ Receipt of WIFS in the year preceding the interview } \\
\hline Received iron and folic acid tablets & 2.5 & 2.5 & 1.8 & 5.8 & 3.7 \\
\hline Received deworming tablets & 55.6 & 30.4 & 46.6 & 24.8 & 8.1 \\
\hline Either & 56.1 & 32.1 & 47.3 & 27.9 & 10.6 \\
\hline Number of respondents & 560 & 813 & 377 & 1,690 & 2,042 \\
\hline
\end{tabular}

Notes: All Ns are unweighted. ${ }^{1}$ Some girls, particularly married older girls, may not have differentiated between WIFS and the regular IFA supply during pregnancy.

Among those who had received iron and folic acid (IFA) and deworming tablets in the year preceding the interview, findings show that not all had consumed IFA tablets in the month preceding the interview or deworming tablets in the six months preceding the interview (Table 12.9). Thus, among unmarried and married older girls who had received IFA tablets in the year preceding the interview, 49-70 percent reported that they had not consumed a single dose and just 5-13 percent reported that they had consumed it weekly in the month preceding the interview. While unmarried 
older girls were more likely than married older girls to have consumed at least one dose in the month preceding the interview (51\% versus 30\%), they were somewhat less likely to report weekly consumption (5\% versus $13 \%)$. Differences between rural and urban girls show that a larger proportion of unmarried older girls in urban than rural areas had not consumed a single dose (60\% versus $48 \%)$, while more married older girls in rural than urban areas had consumed it weekly (14\% versus $3 \%)$.

Among those who had received deworming tablets, 80 percent of younger boys and 75 percent of older boys had consumed it in the six months prior to the interview as had 86 percent of younger girls, 79 percent of unmarried older girls, and 74 percent of married older girls. Adolescents in rural areas were more likely than their urban counterparts to have consumed it in the six months prior to the interview.

\section{Table 12.9: Consumption of IFA and deworming tablets}

Percentage of adolescents who had consumed IFA tablets in the month preceding the interview and deworming tablets in the six months preceding the interview among those who had received them in the year prior to the interview, Bihar, 2016

\begin{tabular}{|c|c|c|c|c|c|}
\hline IFA and deworming tablets consumed & $\begin{array}{c}\text { Boys } \\
(10-14)\end{array}$ & $\begin{array}{c}\text { Boys } \\
(15-19)\end{array}$ & $\begin{array}{c}\text { Girls } \\
(10-14)\end{array}$ & $\begin{array}{c}\text { Girls } \\
(15-19)\end{array}$ & $\begin{array}{l}\text { Married girls } \\
\qquad(15-19)\end{array}$ \\
\hline \multicolumn{6}{|c|}{ Combined (percent) } \\
\hline \multicolumn{6}{|l|}{$\begin{array}{l}\text { Consumed iron and folic acid tablets in the month preceding } \\
\text { the interview }\end{array}$} \\
\hline None & * & * & * & 48.9 & 69.8 \\
\hline 1 & * & * & * & 29.1 & 11.4 \\
\hline 2 & * & * & * & 11.4 & 2.9 \\
\hline 3 & * & * & * & 5.9 & 3.2 \\
\hline 4 or more & * & * & * & 4.7 & 12.7 \\
\hline Number of respondents who received IFA tablets & 16 & 24 & 20 & 148 & 107 \\
\hline $\begin{array}{l}\text { Consumed deworming tablets in the six months preceding } t \\
\text { interview }\end{array}$ & 80.4 & 75.2 & 86.1 & 78.9 & 74.3 \\
\hline Number of respondents who received deworming tablets & 427 & 329 & 264 & 598 & 232 \\
\hline \multicolumn{6}{|c|}{ Urban (percent) } \\
\hline \multicolumn{6}{|l|}{$\begin{array}{l}\text { Consumed iron and folic acid tablets in the month preceding } \\
\text { the interview }\end{array}$} \\
\hline None & * & * & * & $(60.3)$ & $(69.4)$ \\
\hline 1 & * & * & * & $(21.9)$ & $(10.3)$ \\
\hline 2 & * & * & * & $(5.9)$ & $(13.4)$ \\
\hline 3 & * & * & * & $(4.4)$ & $(4.5)$ \\
\hline 4 or more & * & * & * & $(7.5)$ & $(2.5)$ \\
\hline Number of respondents who received IFA tablets & 5 & 8 & 10 & 48 & 42 \\
\hline $\begin{array}{l}\text { Consumed deworming tablets in the six months preceding } t \\
\text { interview }\end{array}$ & 76.2 & 70.2 & 74.7 & 66.8 & 68.4 \\
\hline Number of respondents who received deworming tablets & 120 & 95 & 92 & 180 & 65 \\
\hline
\end{tabular}


Table 12.9 Cont.

\begin{tabular}{|c|c|c|c|c|c|}
\hline IFA and deworming tablets consumed & $\begin{array}{c}\text { Boys } \\
(10-14)\end{array}$ & $\begin{array}{c}\text { Boys } \\
(15-19)\end{array}$ & $\begin{array}{c}\text { Girls } \\
(10-14)\end{array}$ & $\begin{array}{c}\text { Girls } \\
(15-19)\end{array}$ & $\begin{array}{l}\text { Married girls } \\
\qquad(15-19)\end{array}$ \\
\hline \multicolumn{6}{|c|}{ Rural (percent) } \\
\hline \multicolumn{6}{|l|}{$\begin{array}{l}\text { Consumed iron and folic acid tablets in the month preceding } \\
\text { the interview }\end{array}$} \\
\hline None & * & * & * & 48.2 & 69.9 \\
\hline 1 & * & * & * & 29.5 & 11.5 \\
\hline 2 & * & * & * & 11.7 & 1.8 \\
\hline 3 & * & * & * & 6.0 & 3.1 \\
\hline 4 or more & * & * & * & 4.5 & 13.7 \\
\hline Number of respondents who received IFA tablets & 11 & 16 & 10 & 100 & 65 \\
\hline $\begin{array}{l}\text { Consumed deworming tablets in the six months preceding the } \\
\text { interview }\end{array}$ & 80.7 & 75.4 & 86.8 & 79.5 & 74.7 \\
\hline Number of respondents who received deworming tablets & 307 & 234 & 172 & 418 & 167 \\
\hline
\end{tabular}

Notes: All Ns are unweighted. *Percentage not shown as this was based on fewer than 25 unweighted cases.

\subsubsection{Health check-ups for assessing nutritional status and food supplementation}

Hardly any adolescents had undergone anaemia testing in their school or at the anganwadi centre in the year preceding the interview-4-6 percent of boys and three percent of girls- and differences were negligible, regardless of age, sex, residence in rural or urban areas, and, among older girls, of marital status (Table 12.10).

With regard to measuring height and weight in school or at the anganwadi centre, findings show that somewhat larger proportions of younger than older adolescents reported that their weight (just weight or together with height) had been checked in the year preceding the interview-20-26 percent versus 9-11 percent. Similarly, 15-21 percent of younger adolescents and 3-9 percent of older adolescents reported that their height (just height or together with weight) had been checked in the year preceding the interview. Both height and weight had been measured for 15-21 percent of younger adolescents and 3-9 percent of older adolescents in the year preceding the interview. Differences between those from rural and those from urban areas were narrow with regard to the proportion of adolescents who reported that their height and weight were measured in school or at the anganwadi centre.

\section{Table 12.10: Health check-up to assess nutritional status and provision of nutritional supplementation}

Percentage of adolescents who had undergone a health check-up to assess nutritional status and who had received nutritional supplementation in the year preceding the interview, according to residence, Bihar, 2016

\begin{tabular}{|c|c|c|c|c|c|}
\hline Health check-ups and food supplementation & $\begin{array}{c}\text { Boys } \\
(10-14)\end{array}$ & $\begin{array}{c}\text { Boys } \\
(15-19)\end{array}$ & $\begin{array}{c}\text { Girls } \\
(10-14)\end{array}$ & $\begin{array}{c}\text { Girls } \\
(15-19)\end{array}$ & $\begin{array}{l}\text { Married girls } \\
\qquad(15-19)\end{array}$ \\
\hline \multicolumn{6}{|c|}{ Combined (percent) } \\
\hline Anaemia testing in school or at the anganwadi centre & 5.5 & 3.5 & 2.8 & 2.8 & 3.1 \\
\hline \multicolumn{6}{|l|}{ Measurement of height and weight in school or at the anganwadi centre } \\
\hline Weight only & 4.6 & 2.0 & 5.7 & 3.5 & 6.5 \\
\hline Height only & 0.4 & 0.8 & 0.3 & 0.5 & 0.1 \\
\hline Both weight and height & 21.0 & 8.5 & 14.5 & 6.2 & 2.6 \\
\hline Ration/hot cooked meal to take home from the anganwadi centre & 3.1 & 0.7 & 3.1 & 2.7 & 13.1 \\
\hline Number of respondents & 1,012 & 1,821 & 764 & 3,428 & 3,408 \\
\hline
\end{tabular}


Table 12.10 Cont.

\begin{tabular}{|c|c|c|c|c|c|}
\hline Health check-ups and food supplementation & $\begin{array}{c}\text { Boys } \\
(10-14)\end{array}$ & $\begin{array}{c}\text { Boys } \\
(15-19)\end{array}$ & $\begin{array}{c}\text { Girls } \\
(10-14)\end{array}$ & $\begin{array}{c}\text { Girls } \\
(15-19)\end{array}$ & $\begin{array}{l}\text { Married girls } \\
\qquad(15-19)\end{array}$ \\
\hline \multicolumn{6}{|c|}{ Urban (percent) } \\
\hline Anaemia testing in school or at the anganwadi centre & 4.1 & 1.9 & 5.2 & 2.0 & 4.0 \\
\hline \multicolumn{6}{|l|}{ Measurement of height and weight in school or at the anganwadi centre } \\
\hline Weight only & 2.2 & 1.6 & 4.9 & 2.6 & 6.7 \\
\hline Height only & 1.7 & 0.7 & 0.2 & 0.4 & 0.0 \\
\hline Both weight and height & 20.0 & 5.6 & 14.8 & 4.3 & 2.4 \\
\hline Ration/hot cooked meal to take home from the anganwadi centre & 1.8 & 0.8 & 2.5 & 2.3 & 16.2 \\
\hline Number of respondents & 452 & 1,008 & 387 & 1,738 & 1,366 \\
\hline \multicolumn{6}{|c|}{ Rural (percent) } \\
\hline Anaemia testing in school or at the anganwadi centre & 5.7 & 3.7 & 2.5 & 2.9 & 3.0 \\
\hline \multicolumn{6}{|l|}{ Measurement of height and weight in school or at the anganwadi centre } \\
\hline Weight only & 4.9 & 2.0 & 5.8 & 3.6 & 6.5 \\
\hline Height only & 0.2 & 0.9 & 0.4 & 0.5 & 0.1 \\
\hline Both weight and height & 21.1 & 8.9 & 14.5 & 6.4 & 2.7 \\
\hline Ration/hot cooked meal to take home from the anganwadi centre & 3.2 & 0.7 & 3.2 & 2.7 & 12.7 \\
\hline Number of respondents & 560 & 813 & 377 & 1,690 & 2,042 \\
\hline
\end{tabular}

Note: All Ns are unweighted.

The reach of the scheme in which rations or hot cooked meals are provided by the anganwadi centre was limited-just three percent of younger adolescents had received it in the year preceding the interview as had less than one percent of older boys, three percent of unmarried older girls, and 13 percent of married older girls. Differences by residence in rural and urban areas were narrow. We found that among adolescents (other than married older girls) who were enrolled in classes eligible for entitlements at the time of the interview, 74-82 percent of boys and 92-94 percent of girls had received a midday meal on the last day of school they had attended (see Chapter 3 ). 



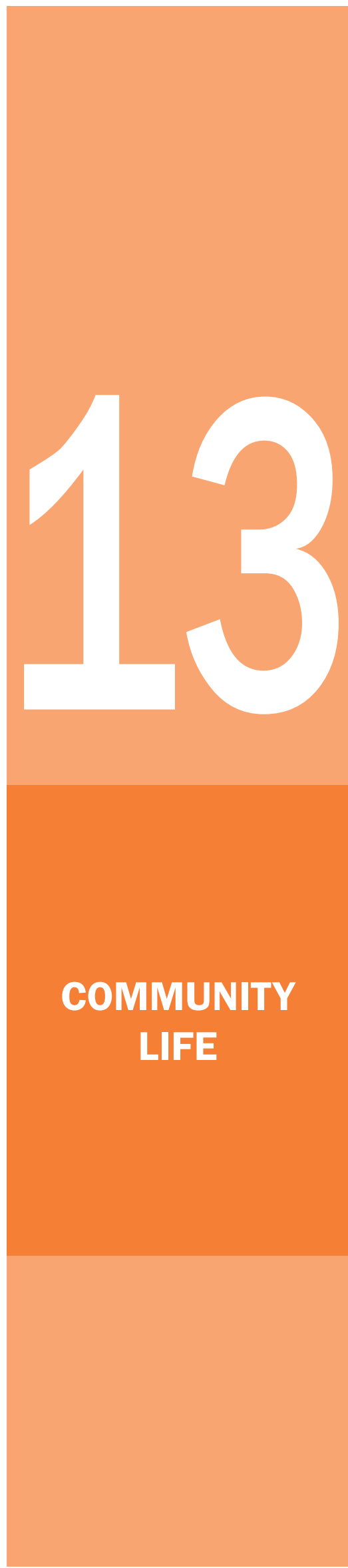

\section{A Snapshot}

Participation of older adolescents in political activities is limited:

- $19 \%$ of boys

- 3\% each of unmarried and married girls had ever been involved in political activities
- $34 \%$ of boys

- $20 \%$ of unmarried girls

- $30 \%$ of married girls in ages 18-19 who were eligible to vote in the last election had voted

Several reported prosocial attitudes:

- $65 \%$ each of older boys and unmarried older girls

- $57 \%$ of married older girls reported that they would interact freely with people of different castes and religion, including eating with a person of another caste/religion

Yet, many found the use of violence acceptable in order to resolve conflicts:

- $48 \%$ each of younger and older boys

- $35 \%$ of younger girls

- $34 \%$ of unmarried older girls

- $30 \%$ of married older girls believed that it is acceptable to beat someone who shows disrespect to a girl/woman from his/her family

Substantial proportions had engaged in antisocial behaviours:

- $46 \%$ of younger boys

- $25 \%$ of older boys

- $30 \%$ of younger girls

- $17 \%$ of unmarried older girls

- $4 \%$ of married older girls had been involved in a physical fight with other boys/girls in the year preceding the interview
- $29 \%$ of younger boys

- $15 \%$ of older boys

- $29 \%$ of younger girls

- $21 \%$ of unmarried older girls

- $5 \%$ of married older girls had bullied a boy/girl who was younger or weaker than them in the year preceding the interview 


\section{A Snapshot}

Markers of trafficking for labour or commercial sexual exploitation were not unknown to adolescents:

- $2 \%$ of younger boys

- $5 \%$ of older boys

- None of the younger girls

- $1 \%$ each of unmarried and married older girls acknowledged some familiarity with work-related markers of trafficking
- $2 \%$ of younger boys

- $3 \%$ of older boys

- $5 \%$ of younger girls

- 9\% of unmarried older girls

- $12 \%$ of married older girls acknowledged some familiarity with marriage-related markers of trafficking

Differences between rural and urban adolescents were narrow on many indicators of community life 
The participation of adolescents and youth in civil society and political processes has been long recognised as an important objective of adolescent and youth development. It is believed that behaviours and attitudes that individuals adopt as young people with respect to participation in civil society and political processes are generally predictive of their lifelong civic affiliations and perspectives (National Research Council [NRC] and Institute of Medicine [IOM], 2005; Smith, 1999). Until recently, data on young people's participation in civil society and political processes came largely from developed countries. In India, findings from the Youth in India: Situation and Needs study in 2005-06 show that for many youth, particularly for young women, opportunities to engage in civil society and political processes were limited and that prosocial values were not uniformly apparent among them (IIPS and Population Council, 2010; Acharya et al., 2010).

Adolescents' transition to adulthood experiences are influenced by the characteristics of the immediate environment in which they live, including access to a safe, that is, non-threatening, community environment. Therefore, our survey included several questions to assess adolescents' perceptions of violence as a means of conflict resolution, their participation in violence within the community, and their familiarity with possible trafficking of adolescent boys and girls.

This chapter begins by presenting a profile of older adolescents with regard to their perceptions on political matters, their involvement in political processes, and the extent to which they express prosocial attitudes about individuals from different religions and caste groups. It then explores the perceptions of all adolescents about violence as a means of conflict resolution, their involvement in bullying and other antisocial behaviours, and their familiarity with possible trafficking of adolescent girls and boys.

\subsection{Perceptions about political matters and participation in political processes}

We posed questions that elicited information related to perceptions about political matters and participation in political processes to older adolescents only. Table 13.1 presents findings on adolescents' perceptions about political matters, notably, their extent of disillusionment with the ability of any political party to achieve change at the community level and the extent to which they believed that people could vote freely and without fear, pressure, or influence; we also inquired whether they were a member of a political party, were involved in any political activities, and, if in ages 18-19, had voted in the last elections.

Considerable proportions of older adolescents reported disillusionment with political parties-three-fifths of boys and between two-fifths and half of girls believed that there would be no improvement in their village/neighbourhood irrespective of the political party governing the state. Among girls, the unmarried were more likely than the married to be disillusioned with political parties (48\% versus $42 \%$ ). At the same time, most adolescents-90 percent of boys and 77-85 percent of girls-felt that one could vote freely and without fear or pressure. Indeed, just eight percent of boys and 10 percent of girls felt that one could not vote freely. As seen above, boys were more likely than girls to believe that one could vote freely and without fear or pressure as were unmarried girls compared with married girls ( $85 \%$ versus $77 \%$ ). Differences between those from rural and those from urban areas with regard to both attitudes were narrow, except that more rural boys than urban boys perceived that there would be no improvement in their village/ neighbourhood irrespective of the political party governing the state (60\% versus $55 \%$ ).

Findings presented in Table 13.1 also suggest that not many adolescents were politically active. Specifically, only five percent of boys and two percent of girls reported membership in a political party. A somewhat larger proportion of adolescents, particularly boys, reported that they had ever been involved in such political activities as attending political protests or election rallies-19 percent of boys and three percent of girls. Differences by marital status among girls and by residence in rural or urban areas were narrow, except that somewhat more rural boys than urban boys reported that they had been involved in political activities at some time (20\% versus $15 \%)$. A somewhat larger proportion of boys than girls in ages 18-19 who were eligible to vote in the election prior to the interview had voted-34 percent of boys compared with 20 percent of unmarried girls and 30 percent of married girls. As many as 46 percent of boys and 52-67 percent of girls reported that they had not registered to vote or had not found their names on the electoral rolls. Larger proportions of rural boys and married girls than their urban counterparts had voted in the last election (36\% versus $21 \%$ of boys and $32 \%$ versus $20 \%$ of married girls). 


\section{Table 13.1: Perceptions about political matters and participation in political processes}

Percentage of adolescents in ages 15-19 reporting their perceptions on political matters and their participation in political activities and percentage of adolescents in ages 18-19 who voted in the last election, according to residence, Bihar, 2016

\begin{tabular}{lcc}
\hline Political perceptions and participation & $\begin{array}{c}\text { Boys } \\
\text { Girls }\end{array}$ & $\begin{array}{c}\text { Married girls } \\
\text { (15-19) }\end{array}$ \\
\hline & (15-19) & (15-19) \\
\hline
\end{tabular}

\section{Perceptions about political matters}

Irrespective of the political party governing the state, there will be no improvement in the village/ward

Agree

$59.4 \quad 48.3 \quad 42.0$

Disagree

$37.4 \quad 46.2$

Cannot say

$3.1 \quad 5.5$

One can vote freely, without fear, pressure, or influence

Agree

$\begin{array}{rrr}90.1 & 85.3 & 77.2 \\ 7.6 & 10.3 & 9.5 \\ 2.2 & 4.5 & 13.3\end{array}$

Participation in political activities

Currently a member of a political party

Involved in any political activities ${ }^{1}$

Never

$80.6 \quad 97.3 \quad 96.8$

Rarely

Sometimes

$\begin{array}{lll}1.6 & 0.2 & 0.2\end{array}$

Often

Number of respondents

$\begin{array}{lll}1,821 & 3,428 & 3,408\end{array}$

Voted in the last election

Yes

$\begin{array}{lll}33.8 & 20.0 & 30.3\end{array}$

No

Name not on the voters' list

$46.2 \quad 66.7$

Number of respondents in ages 18-19 who were eligible to vote in the last election

428

718

Urban (percent)

Perceptions about political matters

Irrespective of the political party governing the state, there will be no improvement in the ward

Agree

$\begin{array}{rrr}55.4 & 51.6 & 44.6 \\ 41.0 & 40.4 & 34.6 \\ 3.6 & 8.0 & 20.8\end{array}$

Cannot say

$93.2 \quad 86.1 \quad 76.0$

Agree

$\begin{array}{lll}5.7 & 7.8 & 7.6\end{array}$

Cannot say

$\begin{array}{lll}1.1 & 6.1 & 16.4\end{array}$


Table 13.1 Cont.

\begin{tabular}{|c|c|c|c|}
\hline Political perceptions and participation & $\begin{array}{c}\text { Boys } \\
(15-19)\end{array}$ & $\begin{array}{c}\text { Girls } \\
(15-19)\end{array}$ & $\begin{array}{c}\text { Married girls } \\
(15-19)\end{array}$ \\
\hline \multicolumn{4}{|l|}{ Participation in political activities } \\
\hline Currently a member of a political party & 5.9 & 1.8 & 1.4 \\
\hline \multicolumn{4}{|l|}{ Involved in any political activities ${ }^{1}$} \\
\hline Never & 84.7 & 96.5 & 96.2 \\
\hline Rarely & 10.2 & 3.0 & 3.1 \\
\hline Sometimes & 1.9 & 0.2 & 0.2 \\
\hline Often & 3.2 & 0.3 & 0.5 \\
\hline Number of respondents & 1,008 & 1,738 & 1,366 \\
\hline \multicolumn{4}{|l|}{ Voted in the last election } \\
\hline Yes & 21.4 & 18.9 & 20.0 \\
\hline No & 21.2 & 13.8 & 19.9 \\
\hline Name not on the voters' list & 57.3 & 67.3 & 60.0 \\
\hline Number of respondents in ages 18-19 who were eligible to vote in the last election & 259 & 403 & 913 \\
\hline
\end{tabular}

\section{Rural (percent)}

Perceptions about political matters

Irrespective of the political party governing the state, there will be no improvement in the village

Agree

$59.9 \quad 48.0$

41.7

Disagree

$37.0 \quad 46.9$

42.5

Cannot say

One can vote freely, without fear, pressure, or influence

Agree

$\begin{array}{rrr}89.8 & 85.2 & 77.3 \\ 7.9 & 10.6 & 9.7\end{array}$

Cannot say

\section{Participation in political activities}

Currently a member of a political party

$\begin{array}{lll}5.3 & 2.5 & 2.4\end{array}$

Involved in any political activities ${ }^{1}$

Never

$\begin{array}{lll}80.0 & 97.4 \quad 96.8\end{array}$

Rarely

Sometimes

Often

$\begin{array}{lll}1.5 & 0.2 & 0.2\end{array}$

Number of respondents

Voted in the last election

$813 \quad 1,690 \quad 2,042$

Yes

$35.7 \quad 20.1 \quad 31.6$

No

$19.8 \quad 13.2$

Name not on the voters' list

$44.5 \quad 66.6$ 


\subsection{Expression of prosocial attitudes}

In order to understand adolescents' attitudes on social interactions with individuals from different castes and religions, we sought their responses on three selected indicators. We inquired whether they mixed freely with those from other castes, whether they did so with those from other religions, and whether they would eat with a person from a different caste or religion. These questions were asked of older adolescents only. A summary measure, based on the proportion of those who expressed prosocial attitudes in all three situations, was computed.

Findings, presented in Table 13.2, suggest that the majority of adolescents expressed prosocial attitudes in response to each of the three questions we had posed to them. Specifically, 96 percent of boys and 86-90 percent of girls reported that they mixed freely with individuals of different castes. Somewhat fewer adolescents reported that they mixed freely with individuals of different religions ( $90 \%$ of boys and $80-84 \%$ of girls). Far fewer adolescents reported however that they would eat with a person from a different caste or religion (67\% of boys and $59-68 \%$ of girls). Among girls, differences by marital status were by and large modest; even so, unmarried girls were somewhat more likely than married girls to report that they would eat with a person from a different caste or religion (68\% versus $59 \%)$. Differences by residence in rural or urban areas were apparent. Unmarried girls in urban areas were more likely than their rural counterparts to report prosocial attitudes in response to each of the three questions that we posed to them. Likewise, married girls in urban areas were more likely than rural married girls to express prosocial attitudes in response to two of the three questions that we posed, namely, mixing freely with individuals of different religions and eating with a person from a different caste or religion. Finally, among boys, those in urban areas were more likely than those in rural areas to report that they would eat with a person from a different caste or religion.

Two-thirds of boys and unmarried girls (65\%) and about three-fifths of married girls (57\%) expressed prosocial views in all three situations. Urban adolescents were considerably more likely than their rural counterparts to express prosocial attitudes in all three situations ( $77 \%$ versus $64 \%$ among boys; $79 \%$ versus $64 \%$ among unmarried girls; and $66 \%$ versus $56 \%$ among married girls).

\section{Table 13.2: Expression of prosocial attitudes}

Percent distribution of adolescents in ages $15-19$ by behaviours and attitudes regarding interaction with people of different castes and religions, according to residence, Bihar, 2016

\begin{tabular}{|c|c|c|c|}
\hline Behaviours/attitudes & $\begin{array}{c}\text { Boys } \\
(15-19)\end{array}$ & $\begin{array}{c}\text { Girls } \\
(15-19)\end{array}$ & $\begin{array}{l}\text { Married girls } \\
\qquad(15-19)\end{array}$ \\
\hline \multicolumn{4}{|c|}{ Combined (percent) } \\
\hline \multicolumn{4}{|l|}{ Mixes freely with people of other castes } \\
\hline Yes & 95.5 & 89.7 & 86.4 \\
\hline No & 4.4 & 10.3 & 13.6 \\
\hline Cannot say & 0.1 & 0.0 & 0.0 \\
\hline \multicolumn{4}{|l|}{ Mixes freely with people of other religions } \\
\hline Yes & 89.9 & 83.9 & 79.5 \\
\hline No & 10.0 & 16.1 & 20.5 \\
\hline Cannot say & 0.1 & 0.0 & 0.0 \\
\hline \multicolumn{4}{|l|}{ Would eat with a person of another caste/religion } \\
\hline Yes & 67.0 & 67.6 & 59.1 \\
\hline No & 32.3 & 32.4 & 40.8 \\
\hline Cannot say & 0.7 & 0.0 & 0.1 \\
\hline Expressed prosocial attitudes in all three situations & 65.4 & 65.3 & 57.3 \\
\hline Number of respondents & 1,821 & 3,428 & 3,408 \\
\hline
\end{tabular}


Table 13.2 Cont.

\begin{tabular}{|c|c|c|c|}
\hline Behaviours/attitudes & $\begin{array}{c}\text { Boys } \\
(15-19)\end{array}$ & $\begin{array}{c}\text { Girls } \\
(15-19)\end{array}$ & $\begin{array}{c}\text { Married girls } \\
\text { (15-19) }\end{array}$ \\
\hline \multicolumn{4}{|c|}{ Urban (percent) } \\
\hline \multicolumn{4}{|l|}{ Mixes freely with people of other castes } \\
\hline Yes & 96.3 & 94.5 & 89.7 \\
\hline No & 3.7 & 5.5 & 10.2 \\
\hline Cannot say & 0.1 & 0.0 & 0.0 \\
\hline \multicolumn{4}{|l|}{ Mixes freely with people of other religions } \\
\hline Yes & 93.4 & 91.3 & 84.8 \\
\hline No & 6.6 & 8.7 & 15.1 \\
\hline Cannot say & 0.0 & 0.0 & 0.1 \\
\hline \multicolumn{4}{|l|}{ Would eat with a person of another caste/religion } \\
\hline Yes & 79.0 & 80.1 & 66.5 \\
\hline No & 20.4 & 19.6 & 33.4 \\
\hline Cannot say & 0.6 & 0.3 & 0.1 \\
\hline Expressed prosocial attitudes in all three situations & 77.0 & 79.2 & 65.5 \\
\hline Number of respondents & 1,008 & 1,738 & 1,366 \\
\hline \multicolumn{4}{|c|}{ Rural (percent) } \\
\hline \multicolumn{4}{|l|}{ Mixes freely with people of other castes } \\
\hline Yes & 95.5 & 89.1 & 86.0 \\
\hline No & 4.5 & 10.9 & 14.0 \\
\hline Cannot say & 0.1 & 0.0 & 0.0 \\
\hline \multicolumn{4}{|l|}{ Mixes freely with people of other religions } \\
\hline Yes & 89.5 & 83.0 & 78.9 \\
\hline No & 10.4 & 17.0 & 21.1 \\
\hline Cannot say & 0.1 & 0.0 & 0.0 \\
\hline \multicolumn{4}{|l|}{ Would eat with a person of another caste/religion } \\
\hline Yes & 65.5 & 66.1 & 58.2 \\
\hline No & 33.8 & 33.9 & 41.7 \\
\hline Cannot say & 0.7 & 0.0 & 0.1 \\
\hline Expressed prosocial attitudes in all three situations & 63.9 & 63.6 & 56.4 \\
\hline Number of respondents & 813 & 1,690 & 2,042 \\
\hline
\end{tabular}

Note: All Ns are unweighted.

Table 13.3 examines differentials in older respondents' expression of prosocial attitudes (measured by prosocial attitudes in all three situations) by selected background characteristics. Findings show that differences in expression of prosocial attitudes by age were narrow among girls, but notable among boys, with 18-19-year-old boys more likely than 15-17-year-old boys to express prosocial attitudes (74\% versus $62 \%$ ). Differences by religion were pronounced among boys and unmarried girls, but not among married girls; Muslim boys and unmarried girls were more likely than their Hindu counterparts to express prosocial attitudes (79\% versus $63 \%$ among boys and $71 \%$ versus $64 \%$ among unmarried girls). Differences by caste were varied between boys and girls; boys from households belonging to general castes were more likely to express prosocial attitudes than boys from other castes ( $72 \%$ versus $63-65 \%$ ), while a reverse pattern was observed for unmarried and married girls (63\% versus $65-69 \%$ among unmarried girls and 
$50 \%$ versus 58\% among married girls). Differences by educational attainment levels were pronounced; expression of prosocial attitudes increased with higher levels of schooling among boys and girls. The proportion of boys who expressed prosocial attitudes increased from 48-56 percent among those with no education or less than five years of schooling to 69-84 percent among those with 10 or more years of schooling, while the corresponding increase was from 46-54 percent to 74 percent among unmarried girls and from 41-50 percent to 67-70 percent among married girls. Expression of prosocial attitudes was positively associated with current schooling status among unmarried girls (but not among boys or married girls)-those who were enrolled in school at the time of the interview were more likely than those who were not to express prosocial attitudes (70\% versus 59\%). Differences by engagement in paid work were evident only among unmarried girls, among whom those engaged in paid work were more likely than those not engaged to express prosocial attitudes (70\% versus 59\%). A positive relationship was observed between household economic status and expression of prosocial attitudes among boys and unmarried girls; among boys, the proportion of respondents expressing prosocial attitudes increased from 55 percent among those from the poorest households to 79 percent among those from the richest households, and, for unmarried girls, from 57 percent to 71 percent correspondingly. However, differences were erratic among married girls. Differences by mother's education were erratic across all three categories of adolescents.

\section{Table 13.3: Expression of prosocial attitudes by background characteristics}

Percentage of adolescents in ages 15-19 who expressed prosocial attitudes in all three situations by selected background characteristics, Bihar, 2016

\begin{tabular}{|c|c|c|c|}
\hline Background characteristics (percent) & $\begin{array}{c}\text { Boys } \\
(15-19)\end{array}$ & $\begin{array}{c}\text { Girls } \\
(15-19)\end{array}$ & $\begin{array}{c}\text { Married girls } \\
(15-19)\end{array}$ \\
\hline \multicolumn{4}{|l|}{ Age } \\
\hline $15-17$ & 62.4 & 64.7 & 56.5 \\
\hline $18-19$ & 73.7 & 67.6 & 57.7 \\
\hline \multicolumn{4}{|l|}{ Religion $^{1}$} \\
\hline Hindu & 63.1 & 64.2 & 57.3 \\
\hline Muslim & 79.3 & 70.8 & 56.9 \\
\hline \multicolumn{4}{|l|}{ Caste $^{2}$} \\
\hline SC & 63.0 & 68.5 & 57.7 \\
\hline $\mathrm{OBC}$ & 64.9 & 64.8 & 57.9 \\
\hline General $^{3}$ & 72.3 & 62.9 & 50.3 \\
\hline \multicolumn{4}{|l|}{ Completed years of schooling } \\
\hline $\mathrm{None}^{4}$ & 56.0 & 45.8 & 50.2 \\
\hline $1-4$ & 47.5 & 53.9 & 40.6 \\
\hline $5-7$ & 57.8 & 63.4 & 58.1 \\
\hline $8-9$ & 64.4 & 64.6 & 60.4 \\
\hline $10-11$ & 69.0 & 73.6 & 66.8 \\
\hline 12 and above & 84.3 & 74.4 & 69.7 \\
\hline \multicolumn{4}{|l|}{ Current schooling status ${ }^{5}$} \\
\hline Yes & 65.7 & 69.7 & 63.3 \\
\hline No & 64.5 & 59.0 & 58.7 \\
\hline \multicolumn{4}{|c|}{ Paid work in the 12 months prior to the interview } \\
\hline Yes & 67.2 & 63.1 & 60.8 \\
\hline No & 64.7 & 65.7 & 56.9 \\
\hline
\end{tabular}


Table 13.3 Cont.

\begin{tabular}{lccc}
\hline Background characteristics (percent) & $\begin{array}{c}\text { Boys } \\
(15-19)\end{array}$ & $\begin{array}{c}\text { Girls } \\
(15-19)\end{array}$ & $\begin{array}{c}\text { Married girls } \\
(15-19)\end{array}$ \\
\hline Wealth quintile & 54.5 & 57.1 & 56.6 \\
First & 52.6 & 63.0 & 57.1 \\
Second & 60.5 & 63.4 & 55.4 \\
Third & 67.4 & 64.9 & 58.0 \\
Fourth & 79.2 & 71.2 & 59.3 \\
Fifth & & 62.3 \\
Mother's education (in years of schooling completed) & 64.7 & 62.3 \\
None ${ }^{4}$ & 68.2 & 71.6 & 57.9 \\
$1-7$ & 55.9 & 68.5 & 50.4 \\
$8-9$ & 75.4 & 78.7 & 58.5 \\
Total & 65.4 & 65.3 & 57.3 \\
\hline
\end{tabular}

Notes: OBC: other backward caste; SC: scheduled caste; ST: scheduled tribe. ${ }^{1}$ Percentages not shown for those belonging to other religions as less than one percent of surveyed adolescents belonged to other religions. ${ }^{2}$ Percentages not shown for those belonging to STs as less than one percent of surveyed adolescents belonged to STs. ${ }^{3}$ Includes all those not belonging to SCs, STs, or OBCs. ${ }^{4}$ Includes non-literate and literate with no formal schooling. ${ }^{5}$ Percentages not shown for adolescents who were pursuing their education through distance education courses at the time of interview or those who never went to school.

\subsection{Acceptance of violence as a means of conflict resolution}

This study also explored the attitudes of all adolescents towards violence as a means of conflict resolution. We sought their responses on two situations of violence-whether it is acceptable to beat a person who shows disrespect to a woman or girl in the respondent's family and whether it is acceptable to defend one's religion through physical fights if someone shows disrespect to one's religion. A summary measure-the proportion of adolescents who condoned the use of violence for the resolution of conflict in both situations-was also constructed.

Findings presented in Table 13.4 and Figure 13.1 show that a substantial proportion of boys and girls, irrespective of age, found violent ways of resolving conflicts acceptable. Thus, 48 percent of boys and 30-35 percent of girls believed that it was acceptable to beat a person who showed disrespect to a female family member, and 35-40 percent of boys and 27-33 percent of girls believed that that it was acceptable to defend one's religion by using violence if someone disrespected it. Differences by marital status among older girls were narrow. With regard to differences by residence in rural or urban areas, a somewhat larger proportion of older boys from urban areas compared with their counterparts in rural areas justified beating a person who showed disrespect to a female family member ( $52 \%$ versus $47 \%$ ), while somewhat fewer younger girls from urban than rural areas so reported (29\% versus $36 \%)$; differences were narrow for the remaining three categories of adolescents. Findings also show that a larger proportion of boys and younger girls from rural areas justified resorting to physical violence if someone showed disrespect to their religion compared with their urban counterparts (36-41\% versus $30-31 \%$ among boys and $34 \%$ versus 25\% among younger girls); no such differences were observed for unmarried and married older girls.

On the whole, as many as 31-38 percent of boys and 24-30 percent of girls found the use of violence acceptable in both situations posed to them (Figure 13.1). While differences by age were somewhat narrow among girls, younger boys were more likely than older boys to report acceptability of violence (38\% versus $31 \%$ ). Differences by marital status among older girls were narrow. Differences by residence in rural or urban areas show that rural younger adolescents (but not older adolescents) were more likely than urban younger adolescents to condone violence in both situations. 
Table 13.4: Acceptance of violence as a means of conflict resolution

Percent distribution of adolescents by attitudes towards resorting to violence as a means of conflict resolution in selected situations, according to residence, Bihar, 2016

\begin{tabular}{|c|c|c|c|c|c|}
\hline Situations & $\begin{array}{l}\text { Boys } \\
(10-14)\end{array}$ & $\begin{array}{l}\text { Boys } \\
(15-19)\end{array}$ & $\begin{array}{l}\text { Girls } \\
(10-14)\end{array}$ & $\begin{array}{l}\text { Girls } \\
(15-19)\end{array}$ & $\begin{array}{l}\text { Married girls } \\
\qquad(15-19)\end{array}$ \\
\hline \multicolumn{6}{|c|}{ Combined (percent) } \\
\hline \multicolumn{6}{|c|}{$\begin{array}{l}\text { Believes that it is acceptable to beat someone who shows } \\
\text { disrespect to a girl/woman from respondent's family }\end{array}$} \\
\hline Yes & 48.4 & 47.5 & 35.2 & 34.0 & 30.0 \\
\hline No & 49.1 & 51.9 & 61.8 & 65.5 & 69.7 \\
\hline Cannot say & 2.5 & 0.6 & 3.0 & 0.5 & 0.3 \\
\hline \multicolumn{6}{|c|}{$\begin{array}{l}\text { Believes it is acceptable to defend one's religion through } \\
\text { physical fights if someone shows disrespect to that religion }\end{array}$} \\
\hline Yes & 40.2 & 35.1 & 32.6 & 28.8 & 27.1 \\
\hline No & 55.7 & 64.5 & 64.2 & 70.7 & 72.8 \\
\hline Cannot say & 4.1 & 0.4 & 3.2 & 0.4 & 0.2 \\
\hline Number of respondents & 1,012 & 1,821 & 764 & 3,428 & 3,408 \\
\hline \multicolumn{6}{|c|}{ Urban (percent) } \\
\hline \multicolumn{6}{|c|}{$\begin{array}{l}\text { Believes that it is acceptable to beat someone who shows } \\
\text { disrespect to a girl/woman from respondent's family }\end{array}$} \\
\hline Yes & 44.5 & 52.0 & 28.8 & 31.2 & 28.5 \\
\hline No & 50.7 & 46.3 & 68.5 & 68.3 & 71.1 \\
\hline Cannot say & 4.7 & 1.7 & 2.7 & 0.6 & 0.4 \\
\hline \multicolumn{6}{|c|}{$\begin{array}{l}\text { Believes it is acceptable to defend one's religion through } \\
\text { physical fights if someone shows disrespect to that religion }\end{array}$} \\
\hline Yes & 30.4 & 31.2 & 24.8 & 24.9 & 24.8 \\
\hline No & 66.1 & 67.8 & 71.7 & 74.7 & 74.9 \\
\hline Cannot say & 3.5 & 1.0 & 3.6 & 0.4 & 0.4 \\
\hline Number of respondents & 452 & 1,008 & 387 & 1,738 & 1,366 \\
\hline \multicolumn{6}{|c|}{ Rural (percent) } \\
\hline \multicolumn{6}{|c|}{$\begin{array}{l}\text { Believes that it is acceptable to beat someone who shows } \\
\text { disrespect to a girl/woman from respondent's family }\end{array}$} \\
\hline Yes & 48.9 & 47.0 & 36.0 & 34.4 & 30.1 \\
\hline No & 48.9 & 52.5 & 61.0 & 65.2 & 69.6 \\
\hline Cannot say & 2.2 & 0.5 & 3.0 & 0.4 & 0.3 \\
\hline \multicolumn{6}{|c|}{$\begin{array}{l}\text { Believes it is acceptable to defend one's religion through } \\
\text { physical fights if someone shows disrespect to that religion }\end{array}$} \\
\hline Yes & 41.4 & 35.6 & 33.6 & 29.3 & 27.3 \\
\hline No & 54.5 & 64.1 & 63.2 & 70.2 & 72.5 \\
\hline Cannot say & 4.2 & 0.3 & 3.2 & 0.4 & 0.1 \\
\hline Number of respondents & 560 & 813 & 377 & 1,690 & 2,042 \\
\hline
\end{tabular}

Note: All Ns are unweighted. 
Figure 13.1: Percentage of adolescents who condoned violence to resolve conflicts in selected situations, according to residence, Bihar, 2016

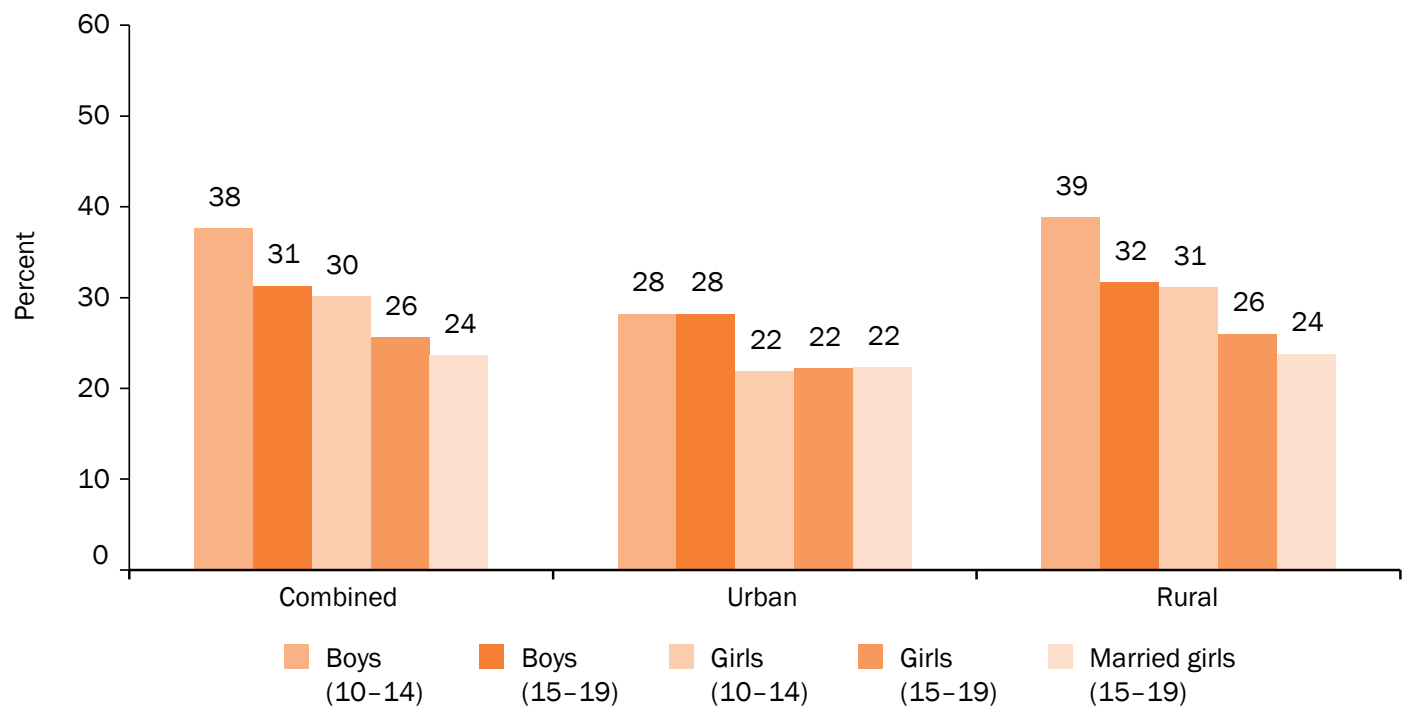

\subsection{Engagement in antisocial behaviours: physical fights, bullying, robbing, and attacking with acid}

We inquired about study participants' personal involvement in a number of antisocial activities. We asked all adolescents, for example, whether, in the recent past, they had been involved in a physical fight with others (of the same sex) or had bullied a boy or girl younger or weaker than themselves, and we asked all boys whether they had robbed anyone. The study also included questions about acid attacks. Specifically, we asked older boys whether they, any boy in their family, their friends, or any boy in their village/ward had ever threatened to throw/ had thrown acid on a girl or woman. Similarly, we asked younger and older girls whether anyone had ever threatened to throw/had thrown acid on them, on any girl in their family, on their friends, or on any girl in their village/ward.

Findings, presented in Table 13.5, suggest wide differences by age and sex in adolescents' involvement in antisocial behaviours. Specifically, a larger proportion of younger than older adolescents reported involvement in physical fights with same-sex adolescents in the year preceding the interview (46\% versus $25 \%$ of boys and $30 \%$ versus $4-17 \%$ of girls). Boys were more likely than girls to have been involved in such fights, and, among older girls, the unmarried were more likely than the married to report such physical fights (17\% versus $4 \%$ ). Differences by residence in rural or urban areas were modest among all categories of adolescents, except for younger boys, among whom rural respondents were more likely than urban respondents to report involvement in physical fights with other boys ( $47 \%$ versus 39\%).

Findings also show that 2-4 percent of younger and older boys ${ }^{1}$ had robbed someone in the year preceding the interview, with little differences between those from rural and those from urban areas in this regard.

Findings also show that bullying practices were common among adolescents other than married older girls. As many as 29 percent of younger boys and girls had bullied someone of the same sex who was younger or weaker than them in the 12 months preceding the interview. Somewhat fewer older boys (15\%), unmarried older girls (21\%), and married older girls $(5 \%)$ reported so. Differences were narrow between those from rural and those from urban areas, except for younger boys and unmarried older girls among whom rural respondents were somewhat more likely than urban respondents to report the perpetration of bullying in the year preceding the interview (29\% versus $24 \%$ among younger boys and $21 \%$ versus $16 \%$ among unmarried older girls).

\footnotetext{
${ }^{1}$ The question related to robbing was asked of boys only.
} 
Finally, less than one percent ( $0.4 \%)$ of older boys (younger boys were not asked this question) acknowledged that a boy in their family, a friend, or a boy in their village/ward had ever threatened to throw/had thrown acid on a girl or woman. Similarly, less than one percent $(0.6 \%)$ of younger girls and two percent each of unmarried and married older girls reported that someone had ever threatened to throw/had thrown acid on them or on an acquaintance (a girl in their family, friends, a girl in their village). Differences by residence in rural or urban areas were modest in this regard.

\section{Table 13.5: Engagement in antisocial behaviours}

Percentage of adolescents involved in antisocial behaviours in the last 12 months, according to residence, Bihar, 2016

\begin{tabular}{|c|c|c|c|c|c|}
\hline Antisocial behaviours & $\begin{array}{c}\text { Boys } \\
(10-14)\end{array}$ & $\begin{array}{l}\text { Boys } \\
(15-19)\end{array}$ & $\begin{array}{c}\text { Girls } \\
(10-14)\end{array}$ & $\begin{array}{l}\text { Girls } \\
(15-19)\end{array}$ & $\begin{array}{l}\text { Married girls } \\
\text { (15-19) }\end{array}$ \\
\hline \multicolumn{6}{|c|}{ Combined (percent) } \\
\hline $\begin{array}{l}\text { Involved in a physical fight with other boys/girls in the } 12 \text { months } \\
\text { preceding the interview }\end{array}$ & 46.4 & 24.8 & 29.5 & 16.9 & 4.1 \\
\hline Robbed someone in the 12 months preceding the interview & 3.9 & 1.5 & NA & NA & NA \\
\hline $\begin{array}{l}\text { Teased or beaten a boy/girl younger/weaker than respondent for } \\
\text { any reason in the } 12 \text { months preceding the interview }\end{array}$ & 28.5 & 14.9 & 28.7 & 20.8 & 4.9 \\
\hline \multicolumn{6}{|l|}{$\begin{array}{l}\text { Male respondent or his acquaintances had ever threatened } \\
\text { to throw acid/had thrown acid on a girl/woman; or a boy/ } \\
\text { someone had ever threatened to throw/had thrown acid on } \\
\text { female respondent or her acquaintances }\end{array}$} \\
\hline Respondent & NA & 0.0 & 0.0 & 0.1 & 0.1 \\
\hline Someone in respondent's family & NA & 0.0 & 0.2 & 0.1 & 0.2 \\
\hline Respondent's friend & NA & 0.2 & 0.4 & 0.3 & 0.2 \\
\hline Someone in respondent's village & NA & 0.2 & 0.2 & 1.5 & 1.5 \\
\hline Any of the above & NA & 0.4 & 0.6 & 1.9 & 1.9 \\
\hline Number of respondents & 1,012 & 1,821 & 764 & 3,428 & 3,408 \\
\hline \multicolumn{6}{|c|}{ Urban (percent) } \\
\hline $\begin{array}{l}\text { Involved in a physical fight with other boys/girls in the } 12 \text { months } \\
\text { preceding the interview }\end{array}$ & 39.3 & 23.5 & 30.5 & 14.6 & 2.7 \\
\hline Robbed someone in the 12 months preceding the interview & 1.4 & 2.0 & NA & NA & NA \\
\hline $\begin{array}{l}\text { Teased or beaten a boy/girl younger/weaker than respondent for } \\
\text { any reason in the } 12 \text { months preceding the interview }\end{array}$ & 23.7 & 12.5 & 26.9 & 16.1 & 3.4 \\
\hline \multicolumn{6}{|l|}{$\begin{array}{l}\text { Male respondent or his acquaintances had ever threatened } \\
\text { to throw acid/had thrown acid on a girl/woman; or a boy/ } \\
\text { someone had ever threatened to throw/had thrown acid on } \\
\text { female respondent or her acquaintances }\end{array}$} \\
\hline Respondent & NA & 0.0 & 0.0 & 0.1 & 0.0 \\
\hline Someone in respondent's family & NA & 0.1 & 0.0 & 0.1 & 0.0 \\
\hline Respondent's friend & NA & 0.3 & 0.0 & 0.2 & 0.1 \\
\hline Someone in respondent's village & NA & 0.4 & 0.5 & 1.0 & 2.1 \\
\hline Any of the above & NA & 0.8 & 0.5 & 1.4 & 2.2 \\
\hline Number of respondents & 452 & 1,008 & 387 & 1,738 & 1,366 \\
\hline
\end{tabular}


Table 13.5 Cont.

\begin{tabular}{|c|c|c|c|c|c|}
\hline Antisocial behaviours & $\begin{array}{c}\text { Boys } \\
(10-14)\end{array}$ & $\begin{array}{c}\text { Boys } \\
(15-19)\end{array}$ & $\begin{array}{c}\text { Girls } \\
(10-14)\end{array}$ & $\begin{array}{c}\text { Girls } \\
(15-19)\end{array}$ & $\begin{array}{l}\text { Married girls } \\
\qquad(15-19)\end{array}$ \\
\hline \multicolumn{6}{|c|}{ Rural (percent) } \\
\hline $\begin{array}{l}\text { Involved in a physical fight with other boys/girls in the } 12 \text { months } \\
\text { preceding the interview }\end{array}$ & 47.3 & 25 & 29.4 & 17.1 & 4.2 \\
\hline Robbed someone in the 12 months preceding the interview & 4.2 & 1.4 & NA & NA & NA \\
\hline $\begin{array}{l}\text { Teased or beaten a boy/girl younger/weaker than respondent for } \\
\text { any reason in the } 12 \text { months preceding the interview }\end{array}$ & 29.0 & 15.2 & 28.9 & 21.4 & 5.0 \\
\hline \multicolumn{6}{|l|}{$\begin{array}{l}\text { Male respondent or his acquaintances had ever threatened } \\
\text { to throw acid/had thrown acid on a girl/woman; or a boy/ } \\
\text { someone had ever threatened to throw/had thrown acid on } \\
\text { female respondent or her acquaintances }\end{array}$} \\
\hline Respondent & NA & 0.0 & 0.0 & 0.0 & 0.1 \\
\hline Someone in respondent's family & NA & 0.0 & 0.2 & 0.1 & 0.2 \\
\hline Respondent's friend & NA & 0.2 & 0.5 & 0.3 & 0.2 \\
\hline Someone in respondent's village & NA & 0.2 & 0.1 & 1.5 & 1.4 \\
\hline Any of the above & NA & 0.3 & 0.6 & 2.0 & 1.9 \\
\hline Number of respondents & 560 & 813 & 377 & 1,690 & 2,042 \\
\hline
\end{tabular}

Notes: All Ns are unweighted. NA: not applicable.

\subsection{Markers of trafficking}

Trafficking of children and adolescents for labour and commercial sexual exploitation is widespread in India (Mukherjee and Mukherjee, 2004; Sen and Nair, 2004). A synthesis of available evidence on trafficking of minor girls for commercial sexual exploitation in India shows that traffickers use various strategies to lure minor girls, such as promises of jobs and marriage, although there are also reports of kidnapping and abduction; traffickers also lure parents with direct payments as well as promises of good jobs for their daughter and promises of continued remittances from their daughter once employed (Santhya, Jejeebhoy, and Basu, 2014). While assessing experiences of trafficking is difficult in a survey such as UDAYA, which is not dedicated to the topic of trafficking, we included a few questions to capture adolescents' familiarity with markers of trafficking. Specifically, we asked all adolescents whether they or any other boys/girls of their age in their family had been taken elsewhere with false promises of a good job in towns and cities. We also asked girls whether they or any other girls of their age in their family had ever been taken elsewhere with false promises of marriage and whether their parents or guardians had ever been approached by acquaintances or strangers with offers of marriage to grooms from outside their state for themselves or any other girl of their age in their family. Boys were asked whether their sisters or any other girls of their age in their family had received such offers. We acknowledge that responses to these questions may include both genuine and exploitative offers of employment and marriage and caution that findings may overestimate the extent of the potential risk of trafficking; on the other hand, it is also likely that genuine cases of trafficking may not be reported in a large survey, and hence, findings may underestimate the risk of trafficking as well. We suggest that findings are viewed in this light.

Findings show that markers of trafficking for labour or commercial sexual exploitation were not unknown to adolescents, and that boys were more likely than girls to report work-related markers of trafficking, while girls were more likely than boys to report marriage-related markers. Specifically, 0.3-1.9 percent of boys and 0.1-0.2 percent of unmarried and married older girls (none of the younger girls) reported that they had been taken elsewhere with false promises of a good job in towns and cities. Another 1-4 percent of boys and one percent of unmarried and married older girls (none of the younger girls) reported that a boy/girl of their age in their family had been taken elsewhere with false promises of a good job in towns and cities. Totally, two percent of younger boys and five percent of older boys reported some familiarity with work-related markers of trafficking. None of the younger girls and one percent each of unmarried and married older girls reported so. 


\section{Table 13.6: Familiarity with markers of trafficking}

Percentage of adolescents reporting familiarity with markers of trafficking, according to residence, Bihar, 2016

\begin{tabular}{|c|c|c|c|c|c|}
\hline Markers of trafficking & $\begin{array}{c}\text { Boys } \\
(10-14)\end{array}$ & $\begin{array}{c}\text { Boys } \\
(15-19)\end{array}$ & $\begin{array}{c}\text { Girls } \\
(10-14)\end{array}$ & $\begin{array}{c}\text { Girls } \\
(15-19)\end{array}$ & $\begin{array}{c}\text { Married girls } \\
(15-19)\end{array}$ \\
\hline
\end{tabular}

\section{Work-related markers}

Respondent had been taken elsewhere with false promises of a good job

$\begin{array}{lllll}0.3 & 1.9 & 0.0 & 0.2 & 0.1\end{array}$

A boy/girl of respondent's age in his/her family had been taken elsewhere with false promises of a good job

$\begin{array}{lllll}1.3 & 3.6 & 0.0 & 0.9 & 1.1 \\ \mathbf{1 . 6} & \mathbf{5 . 4} & \mathbf{0 . 0} & \mathbf{1 . 1} & \mathbf{1 . 3}\end{array}$

Any of the above

1.6

\section{Marriage-related markers}

Respondent had been taken elsewhere with false promises of a marriage

$\begin{array}{lllll}\text { NA } & \text { NA } & 0.0 & 0.0 & 0.1\end{array}$

Respondent's sister/another girl of respondent's age in his/ her family had been taken elsewhere with false promises of a marriage

$\begin{array}{lllll}0.5 & 0.4 & 0.9 & 1.8 & 4.4\end{array}$

Respondent's parents/guardians had been approached with offers of marriage to grooms from outside the state for her

$\begin{array}{lllll}\text { NA } & \text { NA } & 0.4 & 2.3 & 5.0\end{array}$

Respondent's parents/guardians had been approached with offers of marriage to grooms from outside the state for his/her sister/another girl of his/her age in his/her family

\section{Any of the above}

\begin{tabular}{rr}
1,012 \\
\hline Urban (percent)
\end{tabular}

1,01

1,821

764

3,428

3,408

\section{Work-related markers}

Respondent had been taken elsewhere with false promises of a good job

$\begin{array}{lllll}0.0 & 1.2 & 0.0 & 0.2 & 0.2 \\ 0.6 & 1.8 & 0.1 & 0.9 & 1.2 \\ \mathbf{0 . 6} & \mathbf{3 . 0} & \mathbf{0 . 1} & \mathbf{1 . 0} & \mathbf{1 . 4}\end{array}$

A boy/girl of respondent's age in his/her family had been taken elsewhere with false promises of a good job

0.6

$\mathbf{3 . 0}$

0.1

1.4

\section{Marriage-related markers}

Respondent had been taken elsewhere with false promises of a marriage

$\begin{array}{rrrrr}\text { NA } & \text { NA } & 0.0 & 0.1 & 0.2 \\ 0.2 & 0.1 & 1.7 & 2.3 & 2.7 \\ \text { NA } & \text { NA } & 0.0 & 3.0 & 5.8 \\ & & & & \\ 0.7 & 2.4 & 3.6 & 7.4 & 5.4 \\ \mathbf{0 . 9} & \mathbf{2 . 6} & \mathbf{4 . 2} & \mathbf{1 0 . 7} & \mathbf{1 0 . 9} \\ \mathbf{4 5 2} & \mathbf{1 , 0 0 8} & \mathbf{3 8 7} & \mathbf{1 , 7 3 8} & \mathbf{1 , 3 6 6}\end{array}$

Respondent's sister/another girl of respondent's age in his/ her family had been taken elsewhere with false promises of a marriage

Respondent's parents/guardians had been approached with offers of marriage to grooms from outside the state for her

Respondent's parents/guardians had been approached with offers of marriage to grooms from outside the state for his/her sister/another girl of his/her age in his/her family

\section{Any of the above}

Number of respondents

1,008

Cont 
Table 13.5 Cont.

\begin{tabular}{|c|c|c|c|c|c|}
\hline Markers of trafficking & $\begin{array}{l}\text { Boys } \\
(10-14)\end{array}$ & $\begin{array}{l}\text { Boys } \\
(15-19)\end{array}$ & $\begin{array}{l}\text { Girls } \\
(10-14)\end{array}$ & $\begin{array}{c}\text { Girls } \\
(15-19)\end{array}$ & $\begin{array}{l}\text { Married girls } \\
\qquad(15-19)\end{array}$ \\
\hline \multicolumn{6}{|c|}{ Rural (percent) } \\
\hline \multicolumn{6}{|l|}{ Work-related markers } \\
\hline $\begin{array}{l}\text { Respondent had been taken elsewhere with false promises of a } \\
\text { good job }\end{array}$ & 0.3 & 2.0 & 0.0 & 0.2 & 0.1 \\
\hline $\begin{array}{l}\text { A boy/girl of respondent's age in his/her family had been taken } \\
\text { elsewhere with false promises of a good job }\end{array}$ & 1.4 & 3.8 & 0.0 & 0.9 & 1.1 \\
\hline Any of the above & 1.7 & 5.7 & 0.0 & 1.1 & 1.2 \\
\hline \multicolumn{6}{|l|}{ Marriage-related markers } \\
\hline $\begin{array}{l}\text { Respondent had been taken elsewhere with false promises of a } \\
\text { marriage }\end{array}$ & NA & NA & 0.0 & 0.0 & 0.1 \\
\hline $\begin{array}{l}\text { Respondent's sister/another girl of respondent's age in his/ } \\
\text { her family had been taken elsewhere with false promises of a } \\
\text { marriage }\end{array}$ & 0.5 & 0.5 & 0.8 & 1.7 & 4.6 \\
\hline $\begin{array}{l}\text { Respondent's parents/guardians had been approached with } \\
\text { offers of marriage to grooms from outside the state for her }\end{array}$ & NA & NA & 0.5 & 2.3 & 4.9 \\
\hline $\begin{array}{l}\text { Respondent's parents/guardians had been approached with } \\
\text { offers of marriage to grooms from outside the state for his/her } \\
\text { sister/another girl of his/her age in his/her family }\end{array}$ & 1.8 & 2.3 & 3.2 & 6.3 & 7.5 \\
\hline Any of the above & 2.3 & 2.7 & 4.5 & 8.4 & 12.0 \\
\hline Number of respondents & 560 & 813 & 377 & 1,690 & 2,042 \\
\hline
\end{tabular}

Just 0.1 percent of married older girls (none of the younger girls and unmarried older girls) acknowledged that they had been taken elsewhere with false promises of a marriage, and 0.4-0.5 percent of boys and 1-4 percent of younger girls and unmarried and married older girls reported that this had happened to their sister or another girl of their age in their family. Likewise, 0.4 percent of younger girls and 2-5 percent of older girls reported that their parents or guardian had been approached by an acquaintance or a stranger with proposals for marriage to grooms from outside their state for them, and two percent of boys and 3-7 percent of girls reported that this had happened to their sister or another girl of their age in their family. In total, 2-3 percent of boys and 5-12 percent of girls acknowledged some familiarity with marriage-related markers of trafficking.

Differences in reports of familiarity with markers of trafficking by residence in rural or urban areas were narrow. 



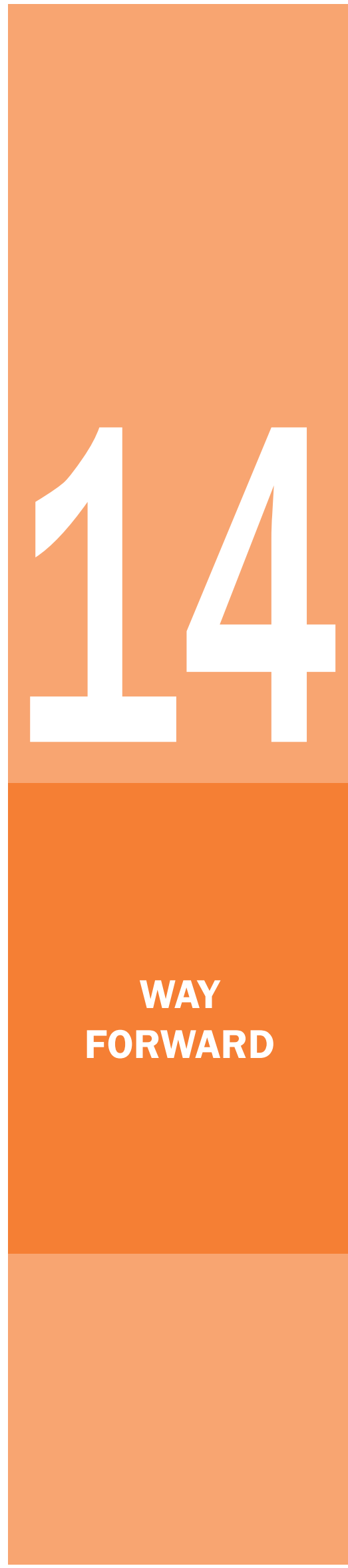

2 POPULATION COUNCIL 
The findings of UDAYA confirm that adolescents are a heterogeneous group with correspondingly diverse needs. While large proportions of adolescents are healthy and have been to school, our findings confirm that they face numerous challenges in making the transition to adulthood. We identify and discuss in this chapter several programmatic areas for action to improve the situation of adolescents.

\section{Universalise quality secondary education attainment}

Although school enrolment was nearly universal, attainment of educational milestones varied. Indeed, even among adolescents in ages 10-14, just two in three had completed Class 5.Concerted efforts are needed if the country is to achieve the Sustainable Development Goal 4 of the United Nations development agenda that seeks to promote learning opportunities universally and ensure quality education that is inclusive and equitable. The government has articulated its commitment to improving the schooling situation in the country, as can be seen in the Right of Children to Free and Compulsory Education Act, 2009, the draft National Educational Policy 2016, and several programmes, such as the Sarva Shiksha Abhiyan and the Rashtriya Madhyamik Shiksha Abhiyan. What is needed is a strong commitment to ensure that these programmes are effectively implemented and that they do indeed reach the most disadvantaged groups. Our theoretical framework, outlined in Chapter 1, identified the attainment of at least a quality secondary education as a key indicator of a successful transition to adulthood, and our findings highlight several areas in need of attention.

\subsection{Support adolescents to complete a secondary education}

Evidence from UDAYA shows that many adolescents do not complete secondary school-among adolescents in ages 18-19,only three-fifths of boys and unmarried girls (60-64\%) and about one-quarter (26\%) of married girls had completed secondary school (Class 10 ). Several factors inhibited secondary school completion; leading reasons among boys were lack of interest in studies and economic constraints; and, among girls, they were parental perceptions that education is not necessary, girls' own lack of interest in studies, economic constraints, and housework-related reasons. UDAYA findings concur with evidence synthesised in a recent review of promising models for supporting adolescents' transitions to adulthood (Jejeebhoy, 2017), and as recommended in the synthesis, multiple initiatives are needed to remove these barriers to educational opportunities and to foreground the relevance of a secondary education among both adolescents themselves and their parents and communities.

At the adolescent level, programmes and approaches must pay attention to adolescents' lack of interest in schooling: schooling that facilitates positive peer support and establishes norms that encourage school completion may motivate adolescents to pursue an education. A school climate that is conducive to learning and that helps adolescents feel connected to their school, particularly among those who display lack of interest, needs to be created. Furthermore, there is a need to incorporate skill-building models for livelihood opportunities within the school setting that will not only raise adolescents' aspirations regarding their education and careers, but also provide them opportunities to gain market-driven job skills. These approaches will go a long way in assuring adolescents about the relevance of a secondary education, on the one hand, and encouraging interest in studies on the other.

At the parent and family level, programmes are needed that promote positive attitudes towards education and school completion, demonstrate to parents the relevance of the curriculum for future opportunities for both their sons and their daughters, raise their aspirations for their children, and encourage greater parental involvement in children's education, particularly with regard to adolescent daughters. Campaigns like Beti Bachao Beti Padhao need to be delivered using multiple channels and formats to achieve saturation and impact.

Economic pressures that dissuade a few parents from enrolling their children in school and many from keeping them in school once enrolled need to be addressed. There are several on-going central- and state-sponsored programmes that aim to reduce the cost of education in the form of conditional and unconditional cash transfers as well as provision of free tuition, scholarships, school uniforms, books, and supplies (Jejeebhoy, 2017). Evaluations of these programmes, for example, the Dhanalakshmi scheme and Apni Beti Apna Dhan, have shown that these schemes have had promising outcomes, at least as seen in the increased retention of girls in primary schools (Sekher and Ram, 2015; Nanda et al., 2016). Findings from UDAYA show that most adolescents in the state who were enrolled at the time of the interview or in the year preceding the interview in a class whose students were eligible 
for entitlements from their school were aware of such entitlements as midday meals, uniforms, textbooks, and scholarships, and large proportions of adolescents had benefited from these entitlements. Our findings that, despite these programmes, economic pressures had prevented many adolescents from completing a secondary education call for, as advocated by many others, restructuring the incentives, modifying conditionalities, simplifying procedures, and, more importantly, adopting targeted approaches to include the poorest and most socially disadvantaged households (Sekher and Ram, 2015; Nanda et al., 2016). Findings also emphasise the need for further research to better understand what economic incentives will work to retain the most vulnerable in school and enable them to complete a secondary education.

Efforts must also be made to remove school-level barriers, particularly to promote secondary school completion among girls. Poor infrastructure and amenities, indifferent quality of education, and, for girls, distant location of the schools are key school-level barriers identified by adolescents. While it may not be practical to have a secondary school in every village, it is important to ensure safe transportation to school for girls. The evaluation of the bicycle scheme to facilitate safe transport in the state has shown that it has contributed to increasing age-appropriate enrolment in secondary schools among girls (Muralidharan and Prakash, 2017). Findings from UDAYA show that although the coverage of the bicycle scheme was widespread, adolescents who belonged to socially and economically disadvantaged groups were less likely than those who belonged to privileged groups to have benefited from the scheme, and, therefore, it is important to ensure that this scheme does indeed reach the most disadvantaged groups of adolescents. At the same time, schools must take note of and address the concerns of the large number of adolescents who drop out because of lack of interest, failure in their examinations, poor quality teaching, the lack of female teachers, or the paucity of amenities. Finally, given the large proportions reporting that schooling had been interrupted because they were required for house work or work on the family farm or business, and given the reality of adolescents' lives and the economic pressures on families, efforts need to be made to adjust school timings, including the establishment of evening schools, to enable children to accommodate work on the family farm or business without sacrificing their education.

\subsection{Ensure regular attendance of those enrolled in school}

Of those enrolled in school, attendance was irregular for many: indeed, just 48 percent of married older girls, 59-62 percent of younger adolescents and unmarried older girls, and 70 percent of older boys reported regular attendance in school in the week preceding the interview. School-related reasons, mainly, poor quality of teaching and teacher absenteeism, economic reasons, namely, their having to work on the family farm or business or for pay, housework, and respondent's lack of interest topped the reasons for absenteeism among both boys and girls. Among girls, lack of transportation or their having no one to escort them to school was also an important reason for missing school. These findings call for multi-level-student, family, and school level-interventions to improve school attendance. Global literature lends support to programmes that enhance students' self-esteem and social skills, that offer after-school tutoring or mentoring to help students overcome academic problems, that provide low-cost attendance incentives, that improve communication between parents and schools, that connect families with relevant counselling services or transportation sources, that reach out to parents of at-risk students, that improve teacher-student relationships, and that offer health and nutrition services in schools (Jejeebhoy, 2017; J-PAL, 2017; Hanover Research, 2016; Kim and Streeter, 2016). Evidence from India on what works to ensure regular attendance is sparse (Jejeebhoy, 2017); however, some of the strategies that have shown promising results included monitoring of teachers, nutritional supplementation in school settings, and engaging parents and school management committees (J-PAL, 2017; Santhya et al., 2016).

\subsection{Expand 'second-chance' programmes}

According to our findings, nine percent of unmarried older girls and 29 percent of married older girls were never enrolled in school and among older adolescents who were ever enrolled in school, 17-20 percent of boys and unmarried girls and 70 percent of married girls had discontinued schooling before completing Class 12 . This calls for creating second-chance' programmes for adolescents who had missed the opportunity to acquire an adequate level of formal education. Our findings lend support to this idea, as one-fifth to one-third of older adolescents who were never enrolled in school and one-third to more than half of older adolescents who had discontinued schooling before completing Class 12 had expressed a desire to get enrolled or return to school. 'Second-chance' programmes are already being run by some NGOs such as Pratham and the MV Foundation, and these may be suitably modified at scale. 


\subsection{Invest in improving learning outcomes}

Concerted efforts to improve learning outcomes are needed, as evident from our findings: just 74 percent of older boys, 69 percent of unmarried older girls,and 53 percent of married older girls could read a Class 2 text fluently in Hindi; 63 percent of older boys, 51 percent of unmarried older girls, and 31 percent of married older girls could solve a simple division problem; not all adolescents who had completed even primary education (that is, Class 8 or more) could read a Class 2 text fluently or solve a simple division problem; and adolescents tended to lose literacy and numeracy skills over time. Indeed, the Government of India has articulated its commitment to improving learning outcomes in several policies and programmes, including the National Policy on Education 1986, the Programme of Action 1992, and the draft National Education Policy 2016 (Ministry of Human Resource Development, Government of India, 2016b). Moreover, the government has recently amended the Central Rules of the Right of Children to Free and Compulsory Education (RTE) Act, 2009, to include class-wise and subject-wise learning outcomes for all elementary classes and to link the achievement of learning outcomes with continuous and comprehensive evaluation (Ministry of Human Resource Development, 2017a). What is needed is a strong commitment to ensure that these policies and programmes are effectively implemented and that they reach the most disadvantaged groups.

Several intervention models have been pilot tested in India to improve learning outcomes, and these have identified a number of strategies that hold promise; for example, adapting curriculum to children's learning levels and providing level-appropriate learning materials instead of grade-level curriculum (Banerjee et al., 2016); providing remedial education by informal teachers hired from the community (Banerjee et al., 2007) or by community volunteers (Lakshminarayana et al., 2013); providing additional teachers (Chin, 2005; Muralidharan and Sundararaman, 2013); providing incentive payments to teachers based on improvement in their students' test scores (Muralidharan and Sundararaman, 2011); information and communication technology (ICT) based instruction (Linden, 2008); and engaging parents and school management committees to bring accountability in secondary education for girls (Santhya et al., 2016). Investments are also required to adapt, re-evaluate, and upscale these promising models.

\subsection{Target first-generation learners}

Our findings highlight that the first-generation learners have a long way to catch up in secondary school completion and learning outcomes. Older adolescents whose mother was uneducated or poorly educated were less likely to have completed secondary school than those whose mother was better educated; learning outcomes likewise improved steadily with the mother's level of education attained. Activities that seek to improve enrolment in secondary schools, ensure secondary education completion, and enhance learning outcomes, targeted at adolescents and their parents/ families, should be specially targeted toward first-generation learners.

\subsection{Build teacher capacity}

Findings that poor quality of teaching and teacher absenteeism topped the list of reasons for irregular attendance, that many relied on private tuition, and that learning outcomes remain poor even among those who had completed primary education highlight the need for focusing on providing better training to teachers and ensuring accountability from them. It is to be noted that efforts in this direction have been initiated by the Government of India (Ministry of Human Resource Development, 2017b). Teachers need to be aware that many students are first-time learners with parents who have never been to school or have only modest levels of education; they should be made aware that reasons for dropping out of school, such as lack of interest, may at least partly be attributed to their own failure to communicate the curriculum; and they need to be trained to make instruction more stimulating and adolescent friendly. Further, they need to be held accountable for the performance of their students. Promising evidence from a programme that provided incentive payments to teachers based on the average improvement of their students' test scores (Muralidharan and Sundararaman, 2011) needs to be reviewed and considered for replication.

\section{Prepare adolescents for skilled employment}

The National Policy on Skill Development and Entrepreneurship (Ministry of Skill Development and Entrepreneurship, 2015) places emphasis on the need for a skilled workforce, and, towards this objective, the National Skill

Development Mission aims to skill or upgrade the skills of 150 million people, mostly youth, by 2022. Indeed, a 
transition into productive work roles at appropriate ages is a key indicator of a successful transition to adulthood, and our findings highlight that in order for adolescents to make this transition and for the Skill Mission to achieve its goal, several challenges will need to be overcome.

\subsection{Strengthen efforts to prevent child labour}

Findings show that 4-10 percent of adolescents were initiated into paid work in childhood (before age 14), and this reinforces the recommendation highlighted earlier on the need to provide conditional grants and targeted subsidies to disadvantaged groups in order to encourage parents to opt for schooling instead of work for their children. At the same time, it is important to vigorously enforce existing laws that prohibit child labour.

\subsection{Enhance skills to improve employment potential}

Findings suggest that significant proportions of adolescents are not employable, as they lack adequate skills. As mentioned above, not all older adolescents had completed a secondary school education, and reading and mathematics skills were generally limited. Moreover, just eight percent of older boys and 12-16 percent of unmarried and married older girls had attended a formal vocational training programme. Even among adolescents who had attended a vocational training programme, exposure to marketable skills was limited, especially among girls. While considerable proportions of boys $(65 \%)$ reported exposure to computer skills, girls tended to opt for relatively traditional vocational skills such as tailoring (69-88\%) and may not have had the opportunity to learn about market needs or to develop appropriate skills for which a demand exists. It is also notable that those who were engaged in paid work were working largely as agricultural and unskilled non-agricultural labourers. Considerable proportions of adolescents were actively seeking employment-24 percent of older boys and 10-11 percent of older girls; notably, 59 percent of older boys and 27-34 percent of older girls who had completed 12 or more years of schooling were actively seeking employment. These percentages suggest a possible disconnect between adolescent skills and market needs.

The state needs to significantly strengthen investments in programmes that enable adolescents to make a successful transition to work roles. Enhancing employment potential would depend to a considerable extent on improvements in the school system and ensuring secondary school completion, as discussed above, and also on greater investment towards enabling adolescents to acquire vocational skills. There exists a considerable unmet need among older adolescents for vocational training programmes: one in ten boys and almost two in five girls had wanted to attend a training programme but had been unable to do so, largely for such demand-side reasons as constraints in affording the cost of the course, unsuitable course timings, and objections from their family, and such supply-side reasons as the paucity of training centres and lack of awareness about these centres and their locations.

Formal mechanisms need to be developed that provide opportunities for potential employers to partner with schools and vocational institutions to increase adolescents' exposure to the world of work, including an understanding of the jobs available in the local economy, avenues for pursuing those jobs, and skills and experience necessary for obtaining them. Efforts are also needed to offer demand-driven training-to-employment programmes that focus intensively on the requirements of specific available jobs and include a post-training placement component. There is also a need to promote a more positive image for vocational education. The Bihar Skill Development Mission is a step in the right direction; however, just 18 percent of older boys and 15-22 percent of unmarried and married older girls had heard about it, and even fewer (4-5\%) were aware of any vocational training centres that offer training under this mission. It is important that this initiative is popularised more vigorously and centres that offer vocational skills training under the mission are expanded. Efforts are needed to bridge the gap between the huge demand that adolescents have for acquiring livelihood skills and their access to available entitlements through which to acquire these skills.

The mere availability of skill-building programmes is not sufficient, particularly for girls. Adolescents need to be made aware of the range of training programmes available and need to be counselled about skills for which there is a market demand. Further, trained adolescents require support in accessing apprenticeship or employment opportunities and in overcoming challenges that may inhibit their availing of opportunities, such as parental disapproval, transportation concerns, and so on.

Efforts are required to create alternative models to traditional training institutes, such as mobile camps, community colleges, and courses on vocational skills in high schools. Attention needs to be drawn to improving the quality of 
vocational training programmes, updating curricula based on emerging industry requirements, improving the quality of trainers, and increasing the focus on soft skills, including how to prepare curriculum vitae and present oneself at interviews.

Evaluation of the effect of skilling programmes on adolescents and young people are sparse in India (Jejeebhoy, 2017). Existing programmes implemented by government and civil society partners that are aimed at job creation need to be evaluated, so that their reach and impact in enabling adolescents and youth to make a successful transition to work roles may be assessed. Evaluation findings will provide evidence for the upscaling of successful models or for the revamping of existing programmes based on lessons learned.

\section{Empower adolescents and establish egalitarian norms}

The markers of a successful transition to adulthood also include the ability of adolescents to navigate this transition in an informed and equitable manner, that is, to make informed choices and hold equitable notions of masculinity and femininity. Several programmes have been implemented-for example, SABLA/Kishori Shakti Yojana (KSY), the Nehru Yuva Kendra Sangathan (NYKS) youth club movement, and the Beti Bachao Beti Padhao programmethat focus on building girls' agency, on the one hand, and changing notions of male superiority and female submissiveness, on the other. However, findings highlight the persisting limited agency of adolescents and the striking gender divide in all dimensions of adolescents' agency. Although adolescent girls were far more disadvantaged than adolescent boys, many boys were also not able to exercise agency in their everyday lives. Adherence to gender egalitarian attitudes was limited. Initiatives to reverse this situation need to be prioritised.

\subsection{Promote gender transformative life skills programme for boys and girls}

Evidence shows that adolescents in Bihar have limited agency and many hold gender in egalitarian attitudes about masculinity and femininity-for example, while almost all older boys were free to visit various places unescorted, just half of unmarried older girls and one-fifth of married older girls were accorded such liberty. Control over money was also limited and gendered-while half of older boys and unmarried older girls and one-third of married girls owned a savings account, almost three out of four of boys who owned an account compared with two out of three girls operated the account themselves. While both boys and girls reported an average of three friends, boys were more likely than girls to meet their friends frequently, and far more likely to meet them in venues outside the home, school, and those related to their daily chores. Egalitarian gender role attitudes were held, moreover, by just half of younger boys, about three-quarters of older boys, younger girls, and unmarried older girls, and two-thirds of married older girls.

Findings call for the promotion of gender transformative life skills programmes for adolescent boys and girls that will not only raise their awareness of new ideas and the world around them, but also enable them to put information into practice, encourage them to question gender stereotypes and promote new concepts of masculinity and femininity, develop self-esteem, and strengthen their skills in problem-solving, decision-making, communication, and interpersonal relations and negotiation. Given girls' limited mobility and opportunities to build/nurture supportive friendships, it is important that girls are offered a safe space in which to gather and develop strong support systems.

An increasing number of intervention models to build agency and promote egalitarian gender role attitudes among adolescents have been tested in India (Acharya et al., 2009; Achyut et al., 2011; Das et al., 2012; Jejeebhoy et al., 2017; Mehra et al., 2016; Verma et al., 2006). As noted in a recent synthesis of promising interventions (Jejeebhoy, 2017), these models could be reviewed and replicated or scaled-up as appropriate. The potential that programmes (such as the Rashtriya Kishor Swasthya Karyakram of the Ministry of Health and Family Welfare, SABLA and Kishori Shakti Yojana of the Ministry of Women and Child Development, and the NYKS youth club programme of the Ministry of Youth Affairs and Sports) hold for scaling-up successful lessons learned from these intervention models must be exploited to reach a critical mass of adolescents.

Programmes to promote gender equitable norms and practices among adolescents must also target parents and other adults who influence and control the lives of adolescents for the latter to benefit from such programmes. These influential adults need to be sensitised to equitable gender norms and thereby persuaded to adopt new notions about gender and egalitarian socialisation practices for boys and girls. 
All programmes to which adolescents are exposed need to be viewed and structured through a gender lens. School textbooks need to be evaluated as a medium to introduce ideas that promote gender equity. Teachers and healthcare providers require sensitisation about gender inegalitarian attitudes and girls' limited agency and orientation about ways of redressing these imbalances. Teachers, in particular, need training to ensure that classroom interaction does not inadvertently favour boys.

\subsection{Strengthen family life education for those in school and out of school}

The findings of UDAYA provide considerable evidence that family life or comprehensive sexuality education is urgently needed among adolescents, for both those in school and those who have discontinued their education. Findings demonstrate a limited understanding of sexual and reproductive matters among adolescents, including among the married older girls. Misconceptions abound on most topics: sex and pregnancy, contraceptive methods, STIs and HIV/AIDS, and maternal and newborn care practices. Where adolescents have shown awareness of sexual and reproductive health matters, many of them exhibited only superficial knowledge. While few adolescents had been exposed to family life education, key topics covered related to HIV/AIDS rather than sexual and reproductive topics more generally. Even so, those who had been exposed to such an education were more likely than those who had not been to display in-depth awareness of sexual and reproductive matters. Moreover, notable proportions of adolescents-one-tenth to two-fifths-indicated a preference for receiving information about sexual and reproductive matters from teachers, healthcare providers, or other influential adults in the community.

These findings reinforce the need to expand the content and reach of the Adolescence Education Programme (AEP). They call for a commitment to strengthen age-appropriate family life or comprehensive sexuality education for all adolescents, that is, for those in school and those out of school, those who are married and those who are unmarried, and those from rural and those from urban areas. Moreover, there is a need to expand the content of existing awareness-raising programmes to include not just HIV-related information, but broader sexual and reproductive topics. These programmes should be designed not only to raise awareness among adolescents, but also to enable adolescents to correctly understand and assess the risks they face and, thereby, to adopt appropriate protective actions. Comprehensive sexuality education should also promote gender egalitarian attitudes and empower adolescents with the communication and negotiation skills that will allow them to make informed choices and an understanding of their entitlements.

Peers have also been identified as acceptable sources of information, especially by boys (26-53\% of boys and $12-$ $21 \%$ of girls in ages 13-19), and while there is a debate about the effectiveness of peer educators in other settings, there is some evidence from India that suggests that young people may indeed be a reliable source of information for their peers (Pandey et al., 2016; Mehra et al., 2016; Jejeebhoy et al., 2017a). The Rashtriya Kishor Swasthya Karyakram has invested heavily in a peer educator approach to inform and counsel youth, and its programmes offer a unique opportunity through which to inform and empower adolescents about sexual and reproductive matters as well as many other health-related matters that may place adolescents at risk. Efforts to identify and build the capacity of peer educators and to build networks of peer educators would be a measure towards addressing the sexual and reproductive health needs of adolescents.

While evaluations of government-initiated family life or sexuality education programmes are limited, evidence from NGO-led programmes that combine sexuality education and life skills education have shown promise not only in raising awareness of sexual and reproductive matters among adolescents, but also in helping them to adopt protective behaviours (Pandey et al., 2016; Mehra et al., 2016). Investments are also required to adapt, re-evaluate, and upscale these promising models.

\subsection{Invest in violence-prevention activities}

Violence-witnessed, experienced, and perpetrated-in public and private spaces marked the lives of many adolescents in the state. One-sixth of boys and between one-quarter and one-third of girls with both parents alive at the time of the interview had ever witnessed incidents where their father had beaten their mother and one-third to two-thirds of adolescents with at least one parent alive at the time of the interview reported their having been slapped or otherwise physically abused by a parent since they had turned 10 years of age. As many as 22 percent of younger girls had ever experienced teasing and verbal harassment of a sexual nature, and 1-2 percent of boys 
and 7-11 percent of girls had experienced unwanted sexual touch. While 3-19 percent of boys had ever verbally harassed a girl in a sexual way, five percent of older boys reported the perpetration of forced sex, including on their romantic partner/s. Violence within marriage-emotional, physical, or sexual-was experienced by 28-37 percent of girls who had begun cohabiting. As many as 46 percent of younger boys and 25 percent of older boys reported involvement in physical fights with other boys or men in the year preceding the interview; likewise, 30 percent of younger girls, 17 percent of unmarried older girls, and four percent of married older girls reported involvement in physical fights with other girls or women. As many as 29 percent of younger boys and girls had bullied a boy/girl who was younger or weaker than them in the 12 months preceding the interview as had 15 percent of older boys, 21 percent of unmarried older girls, and five percent of married older girls.

These findings stress the urgent need for pilot testing multi-pronged interventions to prevent violence. A WHO review of evidence on what works to prevent violence suggests that programmes should include: interventions that encourage stable and nurturing relationships between parents and children in their early years; life skills programmes that seek to build social, emotional, and behavioural competencies among adolescents and preschool enrichment programmes which provide children with academic and social skills; school- and community-based programmes to promote gender equality; interventions that challenge cultural and social norms supportive of violence; and interventions to identify victims of interpersonal violence and provide them with effective care and support (WHO, 2010). Programmes must focus on both boys and girls, and they should be tailored to address their individual needs. While evidence on workable models in these areas are lacking for the most part in India, some recent experiments focused on boys hold promise, namely, the Do Kadam programme and the Parivartan programme, both of which used gender transformative life skills education and sports coaching to impart values that encouraged adolescent boys and young men to denounce attitudes that justify violence against women and girls. A second project of the Do Kadam Barabari ki Ore programme trained frontline workers to identify young women at risk of violence and link them with support services (Jejeebhoy et al., 2017a; 2017b; Das et al., 2012). Other life skills education programmes, such as Action for Adolescent Girls by UNFPA and the Better Life Options by the Centre for Catalysing Change have included components that raise awareness among girls about protecting themselves against violence and taking action in case they experience it (CEDPA, 2006; UNFPA, 2014). Investments are required to adapt, re-evaluate, and upscale these promising models.

\section{Promote good health and informed health choices}

The National Health Policy 2017 pays special attention to adolescent health, affirming a commitment to "pre-emptive care' as well as to school health programmes that promote health and hygiene. It calls for activities to provide sexual and reproductive health services, as well as those that address other concerns such as inadequate calorie intake, poor nutrition, and mental health problems (Ministry of Health and Family Welfare, 2017). Likewise, but more sharply focused on adolescents, the Rashtriya Kishor Swasthya Karyakram has prioritised six key concerns of adolescents that may result in ill-health during adolescence itself or that may manifest in adulthood owing to practices initiated in adolescence. They comprise sexual and reproductive health, nutrition, mental health, substance abuse, noncommunicable diseases, and violence. UDAYA collected data on each of these areas, and findings underscore that many adolescents are at risk of failing to make a healthy transition into adulthood. Insights from the project suggest the need for interventions that will promote a better understanding of risks and enable adolescents to modify behaviours to reduce these risks.

\subsection{Ensure that when premarital sex takes place, it is safe and wanted}

While sexual activity is initiated within marriage for the vast majority of adolescents, findings show that a sizeable proportion of older boys and girls had engaged in sex before marriage-14 percent of boys, and six percent of both unmarried and unmarried girls. As documented in this report, many adolescents had initiated sexual activities uninformed, which reinforces our earlier recommendation for the need to provide family life or comprehensive sexuality education to adolescents. Moreover, for many adolescents, premarital sexual experiences were unsafe (30\% of older boy, $5 \%$ of unmarried older girls, and $27 \%$ of married older girls who had engaged in premarital sex reported multiple partners; just $20 \%$ of older boys and $1-8 \%$ of unmarried and married older girls reported consistent condom use in premarital relationships). These findings of uninformed, unsafe, and sometimes unwanted sexual experiences 
call for programmes that focus on building sexual and reproductive health awareness among adolescents, on developing their skills in negotiating safe sex, and in communicating with their partners on sexual and reproductive health matters. These measures should be preferably included in the gender transformative life skills education and the comprehensive sexuality education programmes discussed earlier as well as in the community-level programmes of the Rashtriya Kishor Swasthya Karyakram (RKSK). At the same time, programmes should make available appropriate family planning and infection-prevention services for unmarried adolescent boys and girls in a manner acceptable to them.

\subsection{Translate policy commitments into effective measures to promote mental health}

The National Mental Health Policy 2014 has made several promises to improve the mental health of the country's population, including that of adolescents and youth. Our findings highlight the need to put these promises into action. Disturbing minorities of adolescents in ages 15-19 displayed symptoms of depression or suicidal ideation: one percent of older boys, five percent of unmarried older girls, and seven percent of married older girls displayed symptoms of moderate to severe depressive disorders during the two weeks prior to the interview, and two percent of older boys, three percent of unmarried older girls, and seven percent of married older girls reported suicidal tendencies in the year preceding the interview.

While very few mental health interventions for adolescents have been evaluated in India, some pilot interventions have shown promise. One such intervention is the life skills education programme for adolescents in ages 14-16 in schools in urban and rural Karnataka, which teachers had conducted over the course of a year. This programme showed that adolescents who received the intervention had improved coping skills and higher self-esteem and selfefficacy (Srikala and Kumar, 2010). A community-based multi-component intervention aiming to address mental disorders, interpersonal violence, and substance abuse among young people in ages16-24 in Goa found a significant decrease in symptoms of depression and violence (Balaji et al., 2011). Small-scale studies have shown promise in employing lay persons in schools and heathcare facilities rather than specialised health personnel for general health promotion in resource-constrained settings (Rajaram et al., 2012; Patel et al., 2010). Investments are required to adapt, re-evaluate, and upscale these promising models. Based on studies in other countries, evidence suggests that reaching and engaging with adolescents through the internet also presents a possible avenue for exploration in India (Clarke et al., 2015).

\subsection{Promote healthy dietary practices}

Our findings confirm the poor dietary practices of adolescents. Just one percent of adolescents or fewer consumed daily the five food groups that was included in the study and recommended as part of a balanced diet. Findings show, moreover, that notable proportions of adolescent boys (3-9\%) and particularly girls (10-23\%), were moderately or severely anaemic. These findings highlight the need for implementing programmes to promote the intake of healthy foods from an early age. Context-specific nutrition information must be disseminated in a simple, understandable, and accessible manner to adolescents and their parents.

Although there are several programmes intended to improve the nutritional status of adolescents, unfortunately, the awareness and reach of these programmes remain mixed and uneven. While many adolescents were aware of the weekly iron and folic acid supplementation (WIFS) programme (55-66\% of boys and $51-64 \%$ of girls), just two percent of boys and 2-6 percent of girls had received iron and folic acid tablets from the WIFS programme and 28-53 percent of boys and 8-44 percent of girls had received deworming tablets in the year preceding the interview. Likewise, just 4-6 percent of boys and three percent of girls had undergone anaemia testing in their school or at the anganwadi centre in the year preceding the interview. These findings highlight the need for revamping these government programmes.

\subsection{Address other health risks}

The findings from UDAYA show that adolescents face other risks-injuries, substance abuse, and lack of exerciseand these affect boys and girls differently. Injuries in a road accident in the previous three months were experienced by $9-11$ percent of boys but by far fewer (2-3\%) girls. Among older boys, tobacco and alcohol consumption were reported by 20 percent and eight percent, respectively. Programmes are needed specifically for boys to deter them 
from substance abuse and practices that have potential to cause injury (for example, motorcycle riding without helmets, physical fights). Clearly this requires the internalisation of new notions of masculinity among them and gender transformative life skills education, discussed earlier, needs to incorporate messages that will influence risktaking behaviour change in these areas.

Lack of physical activity is notable among adolescents, and differences by gender are wide. While five percent of younger boys and 14 percent of older boys reported no physical activity, the proportions were 19 percent, 49 percent, and 83 percent for younger girls, unmarried older girls, and married older girls, respectively. Schools would do well to encourage fitness from an early age, by providing opportunities to exercise for one hour daily among students of all ages, especially girls, and helping girls to overcome parental misgivings about their engagement in sports activities. Similarly, the SABLA and other community-level programmes for girls can also incorporate a physical activity component.

\subsection{Sensitise and train frontline workers(FLWs) to respond to the needs of all adolescents}

Findings indicate that no more than weak links exist between adolescents and frontline workers (FLWs), namely, the accredited social health activists (ASHAs) and anganwadi workers (AWWs). Although FLWs were widely known to adolescents, just 8-11 percent of boys, 16-17 percent of younger girls and unmarried older girls, and 40 percent of married older girls had received health-related information or services from FLWs in the year preceding the interview. FLWs need to be equipped with adolescent friendly IEC (information, education, and communication) materials to serve adolescents' need for information and services and also with supplies such as sanitary pads and contraceptives to meet their sexual and reproductive health needs. Familiarisation of FLWs with the referral network is imperative to link adolescents in need with higher-order facilities. They must be also made responsible for informing adolescents and their gatekeepers about services to which adolescents are entitled.

The goals of training programmes for FLWs should include developing their communication skills to a much greater extent than is currently demonstrated, removing inhibitions and enabling them to overcome discomfort about disseminating information, providing counselling to adolescents, and offering referrals. Training must also build FLWs' skills with regard to addressing service needs (including the provision of condoms, for example) for all categories of adolescents in a manner that is open and non-threatening. Community-level and peer education activities introduced by the RKSK programme requires, moreover, specific training for ASHAs to serve as mentors to peer educators and as mediators between adolescents and the health system. Training and sensitisation programmes for FLWs must be supplemented with audio-visual aids, frequently asked questions (FAQs), and case studies that providers may keep in their possession to consult in the course of their interactions with different categories of adolescents and youth. Supportive supervision is also essential in order to support FLWs to incorporate a new set of activities and a new target group (adolescent girls and boys) into their regular responsibilities.

\section{Delay marriage and recognise the vulnerabilities of married girls}

Evidence from our findings indicates that hardly any girls preferred to marry below age 18 or boys below age 21 ( $2 \%$ and $5 \%$, respectively of unmarried $15-19$-year-olds) and that the prevalence of child marriage has declined when compared with what was reported a decade ago in the National Family Health Survey. Even so, as many as 44 percent of girls in ages 18-19 were married before age 18, and the median age at marriage was 16 , which is well below the legal minimum age of marriage for girls. Moreover, marriages were often arranged without consulting adolescent girls themselves, and girls rarely had an opportunity to meet their husband-to-be prior to the wedding day.

Married girls are hugely vulnerable. Notable proportions of married girls experienced physical (28\%) and sexual (37\%) violence perpetrated by their husband; husband-wife communication on sexual and reproductive matters was limited ( $54 \%$ had discussed the number of children to have and $20 \%$ had discussed contraception). Family pressure to bear children as soon as possible following marriage was reported by one in three girls. Despite the fact that more than two in five girls wished to delay the first pregnancy, just nine percent had used a contraceptive in the first two years of marriage. Numerous forces work against delaying the first pregnancy-objections from the husband and other family members, lack of awareness of appropriate methods of contraception or sources for methods, limited access and method-related concerns, and the lack of attention from healthcare providers. At the same time, pregnancy-related 
care is also compromised. Although almost all girls (98\%) had received at least one antenatal check-up and most had skilled attendance at the first delivery (84\%), just 39 percent had received at least one post-partum check-up, which underscores the many missed opportunities to provide a continuum of care from maternal care to newborn care for adolescent girls. Action should be taken to address child marriage and the huge health and social vulnerabilities of married girls.

\subsection{Capitalise on adolescents' preference to delay marriage and accelerate the pace of decline in child marriage}

There is a need for a multi-pronged approach to eliminate the practice of child marriage. The disconnect between preferred and actual age at marriage calls for measures that supplement information campaigns with measures to address the underlying factors, that is, social norms and economic constraints, driving child marriage. Strategies are needed to mobilise communities to help parents resist pressures that compel the practice of child marriage. Moreover, initiatives are needed to establish new norms and practices and to actively engage influential persons in the community, including religious and political leaders, towards this end. Strategies for community mobilisation must involve adolescents as well as their families. Community-based and frontline workers must play a greater role in identifying girls at risk of child marriage and prevent such marriages. Messages that raise awareness about marriage laws and, in particular, the fact that the law advocates prosecution for all those who play any role in child marriage need to be disseminated.

Equally important is to ensure greater commitment from relevant authorities to enforce existing laws on the minimum age of marriage and the registration of marriages and to levy penalties on violators. Allowing for anonymous reporting, making law enforcement agencies and others aware that the practice of early marriage is not a minor violation, and making the guidelines for penalties clear to enforcement agencies and the wider community are possible steps in this direction.

Efforts to delay marriage also require providing girls with viable alternatives to marriage in the form of accessible and quality schooling, opportunities to build (and use) livelihood skills, and employment opportunities they can avail. Working with the education sector to make schooling for girls more accessible and to make classrooms gender sensitive and responsive to the needs of girls and the concerns of their parents is also important. Meaningful, affordable, and easily accessible livelihoods training to girls, within and outside the educational system, would help to expand choices for girls, instead of one that restricts them to early marriage. Furthermore, family life education and gender transformative programmes, including the Adolescence Education Programme and the SABLA programme,need to incorporate sessions that reinforce messages against child marriages and build girls' ability to have a key voice in when and whom they marry.

Efforts to prevent child marriage should be particularly targeted at families of girls who are most at risk of discontinuing their studies before completing Class 10 and those belonging to socially and economically disadvantaged groups.

\subsection{Sensitise adolescents and parents to adolescents' right to participate in marriage-related decisions}

The failure to engage adolescents in decision-making with respect to their marriage calls for measures to sensitise parents about the need to involve their children in marriage-related decisions and also the need for adolescents to interact with their prospective spouse prior to the wedding day. It is also important to make parents aware of the physical and mental health consequences of child marriage and the adverse experiences of many girls who were married early or who were unprepared for marriage. They need to be apprised about the benefits of the participation of adolescent girls and young women in the selection of their husband for later married life.

There is also a need for expanding the policy discourse that stresses the need to raise marriage age to include ensuring, as advocated by the Convention on the Elimination of All Forms of Discrimination Against Women, the 'free and full consent' of youth in the selection of their spouse. 


\subsection{Address power imbalances within marriage}

Findings demonstrate that relationships within marriage remain unequal: notable proportions of married girls had experienced physical and sexual violence perpetrated by their husband; husband-wife communication on sexual and reproductive matters was limited; and several girls who had desired to delay their first pregnancy faced objections to contraception from their husband. Efforts are needed to encourage couple communication on sensitive issues (contraception, for example), negotiation, and conflict management skills early in the marriage. Efforts are also needed to inform married girls of their rights so that they have the opportunity to exercise control over their own lives; at the same time, efforts must be made to promote new concepts of masculinity and femininity and egalitarian couple relations among adolescents and youth. The gender transformative life skills education discussed earlier provides an important platform through which these norm changes may be encouraged. At the same time, efforts to reach newly married young couples with counselling, information, and opportunities for interaction would go a long way in enabling equitable marital relations.

\subsection{Support adolescents to exercise reproductive choices and receive continuum of care}

Our findings indicate that not all RMNCH+A (reproductive, maternal, newborn, child and adolescent health) programme services reach married adolescents. Programmes are needed,for example, that reach newly married girls and their husbands to inform them about their pregnancy postponement options and enable them to access appropriate contraception before pregnancy takes place. Concomitantly, providers, including such outreach workers as ASHAs, need to be trained and charged with the responsibility of ensuring that married adolescents who have not yet experienced pregnancy receive information on contraception and other reproductive health matters and are also given contraceptive supplies. The misconception held by healthcare providers that married adolescents will not seek contraception until they have experienced one pregnancy needs to be changed. Similarly, the duties of healthcare providers towards those who have experienced pregnancy are to ensure that they receive information on the importance of seeking the full continuum of care. Many married girls lack the freedom of movement to seek healthcare, which demonstrates the need for health workers to reach these girls-particularly those newly married and first time pregnant-in their homes.

\section{Create awareness of citizenship responsibilities}

Findings have shown that 34 percent of eligible boys and 20-30 percent of eligible girls had exercised their right to vote in the most recent elections preceding the survey. Prosocial attitudes were far from universal, with one third to two-fifths of adolescents reporting that they would not eat with a person of a different caste or religion, and between one-quarter and half justifying their right to retaliate with violence if disrespect is shown to a female family member or to the respondent's religion. Inculcating citizenship values and practices from an early age are necessary for adolescents to develop civic consciousness and equitable attitudes.

\subsection{Promote active participation of adolescents in political processes and inculcate prosocial values}

Our survey findings demonstrate that programmes are needed at the school, college, and community level that encourage political participation, incorporate value-building components, and reinforce prosocial attitudes and values that espouse responsible citizenship. These can be introduced through the participation of adolescents in national service programmes, sports, and other non-formal mechanisms. Educational institutions, locally elected representatives (from PRIs), and communities should also provide opportunities to foster interaction between adolescents of different castes and religions. Findings also emphasise that the political system in the country needs to make special efforts to address the disillusionment of many adolescents about political matters and encourage their participation in the political processes in more meaningful ways. 


\section{Realise the potential of the mass media and new technologies to reach adolescents with new ideas and opportunities}

We observed from our study that multiple media channels have a wide reach among adolescents, which suggests that the media can play a powerful role in conveying new ideas and pertinent information in the health, skilling, and employment realms to adolescents.

\subsection{Leverage adolescents' access to the mass media, social media, and mobile phones to impart beneficial information}

We observed that large proportions of adolescents access the media-radio (10-32\%), television (61-86\%), and films (76-91\%). They also have access to mobile phones (76-97\%), the internet, and social media (13-39\% of boys and $1-7 \%$ of girls). The media can play an important role in enhancing their awareness of health-promoting behaviours and their entitlements, promoting supportive norms with regard to secondary school completion, inculcating positive notions of masculinity and femininity, and encouraging the adoption of healthy behaviours. Information about skilltraining programmes and employment opportunities may also be accessed through the media. Greater use of IVRS (interactive voice response) may offer opportunities to share health-promoting information with adolescents. Efforts are required to evaluate existing media and mobile-phone-based interventions for adolescents to assess their reach and impact in raising adolescents' awareness and enabling them to make informed choices. Efforts to employ the internet and social media to advance positive messaging to adolescents must take note of the wide gender discrepancies in access and ensure the continuation of more traditional modes of information provision for girls.

\section{Reach parents and families with new ideas about child socialisation}

Study findings indicate that parents and families play an enormous decision-making role in the life of their children, particularly in their daughters' lives. Notable proportions of boys and girls acknowledged gender discriminatory practices in their home, and many adolescents reported that their family life was marked by violence, both witnessed and experienced. They also reported that communication with parents on issues relevant to adolescents-such as school performance, friendship, experiences of being teased or bullied, and physical changes during adolescence, and reproductive processes-was limited. At the same time, leading individuals from whom all adolescents learnt social behaviours were their parents, and of those adolescents who reported a role model, the majority reported someone from their family as their role model. In short, key life choices of adolescents are shaped by their parents and family, and,hence, programmes are needed that address parental mindsets, socialisation practices, and aspirations for sons and daughters.

\subsection{Create a supportive family environment}

Findings from UDAYA call for the introduction of programmes that focus on changing traditional socialisation patterns among parents. These programmes need to raise parental awareness of girls' abilities, opportunities, and rights; enable parents to reduce inhibitions about communicating with their adolescent children, including on such sensitive issues as harassment, violence, and sexual matters; and persuade them to treat daughters and sons equally and give both of them the same rights and responsibilities within the family, opportunities for education and vocational skill development, and access to money. Familiarising parents about the negative impact of the intergenerational transmission of norms relating to the acceptability of violence and encouraging them to socialise their children to reject violence against women and girls are steps that would help to create positive attitudes and behaviours in their children during adolescence itself and in adulthood.

Evidence on models that are effective in bridging the distance between parents and their adolescent children or that enable parents to adopt more gender egalitarian socialisation practices is currently limited in India. A pilot study in rural Bihar had disappointing results, and it showed that there were very few changes in awareness, attitudes, and socialisation and communication practices that were attributable to participation in an intervention designed to sensitise parents on these issues (Jejeebhoy et al., 2014).There is a need to develop and pilot test new models that are both effective for and acceptable to parents. 
Instead of a dedicated parenting programme, a possible alternative way to reach parents is through existing platforms-unrelated to parenting-that attract fathers or mothers of adolescents. For example, sessions on parenting may be folded into the sessions of self-help group meetings for women or in livelihood-training activities in which men and women participate; messages may be delivered to parents through mobile phones as well.

While parents of boys and girls in adolescent ages may be the most in need of exposure to new parenting skills, intervening with parents of younger children is likely to have more strategic impact, since it would prepare them to build closer relationships, foster more effective communication with children, and provide constructive support to children as they transition into adolescent and then adult roles. Presenting role models, that is, parents who have deviated from traditional norms and have communicated openly with their sons and daughters, may be an effective confidence-building measure for parents who hold more traditional views. This would reassure them that close parent-child relations and open communication about sexual and reproductive health matters would not lead boys and girls astray, and, on the contrary, would demonstrate that children of progressive parents had made successful transitions into higher education, employment, and positions of leadership. Efforts to solicit the support of community influentials and local leadership and conducting community-level behaviour change communication events may be needed in order to enable parents of adolescent children to gain confidence about engaging in new practices.

Parents have also been identified as a preferred source of information, especially by girls; yet very few reported actually receiving any information related to reproductive processes from a parent. Also needed, therefore, are efforts to engage parents by providing them with accurate information and working with them to overcome inhibitions about imparting information to their adolescent children,particularly their daughters.

\section{Remove hindrances to awareness and use of entitlements}

Although the government has provided a large number of entitlements and services that can have a direct impact on adolescent well-being, few adolescents are aware of many of these entitlements and services, and bottlenecks have hampered their reach. In many instances, the most vulnerable and needy adolescents, such as the poorest, those from socially disadvantaged communities, and those whose parents are uneducated are excluded from the ambit of these services. Programmes need to explore ways of overcoming obstacles in accessing entitlements and services.

\subsection{Revamp adolescent programmes}

The reach of programmes intended to meet the development and health needs of adolescents remains strikingly uneven in the state. While schemes to promote school completion, such as the provision of midday meals, free textbooks and uniforms, and scholarships, are widely known and have reached large proportions of adolescents, programmes to promote skill-building and employment generation, programmes to impart health information to adolescents and to meet their health needs, such as the health programmes in schools and colleges, adolescent friendly health clinics, the sanitary napkins distribution scheme, and the family life education programme are less known and their reach is limited. These findings call for efforts to build awareness among adolescents and their gatekeepers about the availability of these entitlements through better branding of these schemes, on the one hand, and improved delivery of programmes and stronger linkages across programmes, on the other.

\section{Ensure the inclusion of the most vulnerable}

While almost all adolescents are in need of the benefits of the many programmes and entitlements available to them, ensuring that the most vulnerable groups of adolescents are not left out is imperative. Our findings highlight that married adolescent girls, those who had never been to school or had discontinued schooling, those with poorly educated mothers, and those who belonged to socio-economically vulnerable groups consistently scored poorly on markers of successful transitions to adulthood. These findings, therefore, call for special attention and strategic investment in these vulnerable groups. Finally, our findings indicate that vulnerabilities are manifested in early adolescence and, therefore, investments starting in early adolescence or even earlier are crucial for their development. 


\section{References}

Abraham, L. 2002. "Bhai-behen, true love, time pass: Friendships and sexual partnerships among youth in an Indian metropolis," Culture, Health and Sexuality 4(3): 337-53.

Abraham, L. and K. A. Kumar. 1999. "Sexual experiences and their correlates among college students in Mumbai city, India," International Family Planning Perspectives 25(3): 139-46.

Acharya, R., S. Kalyanwala, and S. J. Jejeebhoy. 2009. Broadening Girls' Horizons: Effects of a Life Skills Education

Programme in Rural Uttar Pradesh. New Delhi: Population Council.

Acharya, R., A. Singh, K. G. Santhya, et. al. 2010. "Participation in civil society and political life among young people in Maharashtra: Findings from the Youth in India - Situation and Needs study," Journal of Adolescence 33(4): 553-61.

Achyut, P., N. Bhatla, S. Khandekar, et al. 2011. Building Support for Gender Equality among Young Adolescents in School: Findings from Mumbai, India. New Delhi: ICRW.

Alexander, M., L. Garda, S. Kanade et al. 2006a. Formation of Partnerships among Young Women and Men in Pune District, Maharashtra. New Delhi: Population Council.

Alexander, M., L. Garda, S. Kanade et al. 2006b. "Romance and sex: Pre-marital partnership formation among young women and men, Pune district, India," Reproductive Health Matters 14(28): 144-55.

ASER Centre. 2017. Annual Status of Education Report (Rural) 2016, Provisional. New Delhi: ASER Centre.

Awasthi, S., M. Nichter and V. K. Pande. 2000. "Developing an interactive STD prevention programme for youth: Lessons from a North Indian slum," Studies in Family Planning 31(2): 138-50.

Azevedo, M. R., C. L. Araújo, M. C. da Silva, et al. 2007. "Tracking of physical activity from adolescence to adulthood: A population-based study," Journal of Public Health 41(1): 69-75.

Azmi, S. A, A. Ahmed, N. Khalique et al. 2014. "Role models and occupational ambitions of in school male adolescents," Industrial Psychiatry of India 23(1): 36-39.

Balaji, M., T. Andrews, G. Andrew, et al. 2011. "The acceptability, feasibility, and effectiveness of a population based intervention to promote youth health: An exploratory study in Goa, India," Journal of Adolescent health 48(5): 453-60.

Banerjee, A., S. Cole, E. Duflo et al. 2007. "Remedying education: Evidence from two randomized experiments in India," The Quarterly Journal of Economics 122(3): 1235-64.

Banerjee, A., R. Banerji, J. Berry et al. 2016. Mainstreaming an effective intervention: Evidence from randomized evaluations of "Teaching at the Right Level" in India. National Bureau of Economic Research (NBER), Working Paper No. 22746. Accessed on 11 August 2017 at http://www.nber.org/papers/w22746.pdf.

Barnes, L. 2007. "Women's experience of childbirth in rural Jharkhand," Economic and Political Weekly 41(48): 62-70.

Bhat, P. N. Mari and A. J. Francis Zavier. 2007. "Factors influencing the use of prenatal diagnostic technique and the sex ratio at birth in India," Economic and Political Weekly 42(24): 2292-303.

Bhuiya, I., U. Rob, M. E. Khan et al. 2003. "Reproductive health services for adolescents: Recent experiences from a pilot project in Bangladesh," in Towards Adulthood: Exploring the Sexual and Reproductive Health of Adolescents in South Asia, eds. S. Bott, S.J. Jejeebhoy, I. Shah et al. Geneva: World Health Organisation, pp. 203-06.

Bruce, J., M. Temin and K. Hallman. 2012. Evidence-Based Approaches to Protecting Adolescent Girls at Risk of HIV. Washington, DC: AIDSTAR-One Spotlight on Gender, USAID.

Camarena, P. M., K. Minor, T. Melmer, et. al. 1998. “The nature and support of adolescent mothers' life aspirations," National Council on Family Relations 47(2): 129-37.

Centre for Development and Population Activities (CEDPA). 2006. Empowering Adolescents in India: The Better Life Options Program. Accessed on 1 November 2017 at https://www.popline.org/node/191418.

Chin, A. 2005. "Can redistributing teachers across schools raise educational attainment? Evidence from operation black-board in India," Journal of Development Economics 78(2): 384-405. 
Clarke, A. M., T. Kuosmanen and M. M. Barry. 2015. "A systematic review of online youth mental health promotion and prevention interventions," Journal of Youth and Adolescence 44(1): 90-113.

Dagar, R. 2007. "Rethinking female foeticide: Perspective and issues" in Sex Selective Abortion in India: Gender, Society and New Reproductive Technologies ed. T. Patel. New Delhi: Sage Publishers, pp. 91-134.

Das, M., S. Ghosh, E. Miller et al. 2012. Engaging Coaches and Athletes in Fostering Gender Equity: Findings from the Parivartan Program in Mumbai, India. New Delhi: ICRW \& Futures Without Violence.

Department of Education, Government of Bihar. 2014a. Mukhyamantri Balak and Balika Cycle Yojana, 2013-14. Patna: Government of Bihar. Accessed on 25 September 2017 at http://www.educationbihar.gov.in/ PSchemesPdf/08Jan201454051.pdf.

Department of Education, Government of Bihar. 2014b. Mukhyamantri Poshak Yojana. Patna: Government of Bihar. Accessed on 25 September 2017 at http://www.educationbihar.gov.in/PSchemesPdf/08Jan201453954.pdf.

Department of Education, Government of Bihar. 2014c. Mukhyamantri Balika Protsahan Yojana. Patna: Government of Bihar. Accessed on 25 September 2017 at http://www.educationbihar.gov.in/PSchemesPdf/08Jan201443354. pdf.

Department of Industries, Government of Bihar. 2016. Bihar Start-up Policy, 2016. Patna: Department of Industries, Government of Bihar.

Department of Labour Resources, Government of Bihar. n.d. Skill Development in Bihar Vision \& Strategy.

Patna: Bihar Skill Development Mission, Government of Bihar.

Department of Social Welfare, Government of Bihar. 2008. Mukhyamantri Kanya Suraksha Yojana (MKSY) Guidelines. Patna: Women Development Corporation, Government of Bihar.

Department of Social Welfare, Government of Bihar. n.d. Mukhyamantri Kanya Vivah Yojana (MKVY). Patna: Women Development Corporation, Government of Bihar.

Directorate of Integrated Child Development Services, Government of Bihar. n.d. Rajiv Gandhi Scheme for Empowerment of Adolescent Girls (RGSEAG) - SABLA. Accessed on 17 October 2017 at http://www.icdsbih.gov.in/ Scheme1.aspx?GL=9\&PL=2.

De Onis, M., A. W. Onyango, E. Borghi. et al. 2007. "Development of a WHO growth reference for school-aged children and adolescents," Bulletin of the World Health Organization 85(9): 649-732.

DiClemente, R. J. 1992. "Psychosocial determinants of condom use among adolescents," in Adolescents and AIDS: A Generation in Jeopardy, ed. R. J. DiClemente. Newbury Park, CA: Sage, pp. 34-51.

Educational Initiatives. 2010. Student Learning Study: Status of Student Learning across 18 States of India in Urban and Rural Schools. Accessed on 22 April 2017 at http://www.ei-india.com/student-learning-study-an-india-report/.

Ellickson, P., H. Saner, and K. A. McGuigan. 1997. "Profiles of violent youth: Substance use and other concurrent problems," American Journal of Public Health 87(6): 985-91.

Garda, L. and M. Alexander. 2009. "Parent-child connectedness: A pressing need to be addressed in rural and urban India," Paper presented at XXVI IUSSP International Population Conference, Marrakech, Morocco.

Gopalan, C. 1989. "Women and nutrition in India - general considerations" in Women and Nutrition in India, eds. C. Gopalan and S. Kaur. Special publication series 5. New Delhi: Nutrition Foundation of India, pp.1-16.

Government of Bihar. n.d. State Profile. Patna: Government of Bihar. Accessed on 1 November at http://gov.bih.nic.in/ Profile/default.htm.

Gruber, E., R. J. DiClemente, M. M. Anderson et al. 1996. "Early drinking onset and its association with alcohol use and problem behavior in late adolescence," Preventive Medicine 25(3): 293-300.

Hallal, P. C., L. B. Andersen, F. C. Bull et al. 2012. "Global physical activity levels: Surveillance progress, pitfalls, and prospects," The Lancet 380 (9838): 247-57.

Hanover Research. 2016. Best Practices in Improving Student Attendance. Arlington: Hanover Research. International Institute for Population Sciences (IIPS) and Macro International. 2007. National Family Health Survey (NFHS-3), 2005-06: India, Volume I. Mumbai: IIPS. 
International Institute for Population Sciences (IIPS) and Population Council. 2010. Youth in India: Situation and Needs, 2006-2007. Mumbai: IIPS.

International Institute for Population Sciences. 2014. National Family Health Survey, India - 2015-2016 (NFHS-4), Woman's questionnaire. Accessed on 18 April 2017 at http://rchiips.org/NFHS/NFHS4/schedules/NFHS-4Womans.pdf.

International Institute for Population Sciences. 2017a. National Family Health Survey, State Factsheet Bihar - 20152016 (NFHS-4). Accessed on 17 April 2017 at http://rchiips.org/NFHS/pdf/NFHS4/BR_FactSheet.pdf.

International Institute for Population Sciences. 2017b. National Family Health Survey, India - 2015-2016 (NFHS-4). Accessed on 17 April 2017 at http://rchiips.org/nfhs/pdf/NFHS4/India.pdf.

J-PAL. 2017. Roll Call: Getting Children into School. J-PAL Policy Bulletin. Cambridge, MA: Abdul Latif Jameel Poverty Action Lab.

Jejeebhoy, S. J. and K. G. Santhya. 2011. Parent-child Communication on Sexual and Reproductive Health Matters: Perspectives of Mothers and Fathers of Youth in India. New Delhi: Population Council.

Jejeebhoy, S. J. and R. Acharya. 2014. Adolescents in Rajasthan 2012: Changing Situation and Needs. New Delhi: Population Council.

Jejeebhoy. S. J., A. J. F. Zavier, K. G. Santhya et al., 2014. Promoting Parent-Child Interaction and Communication for Healthy Development of Adolescents: Lessons from a Pilot Project in Rural Bihar. New Delhi: Population Council.

Jejeebhoy, S. J. 2017. Supporting Transitions from Adolescence to Adulthood: Evidence-informed Leads for Investment. New Delhi: Bill and Melinda Gates Foundation.

Jejeebhoy, S. J., R. Acharya, N. Pandey et al. 2017a. The Effect of a Gender Transformative Life Skills Education and Sports-Coaching Programme on the Attitudes and Practices of Adolescent Boys and Young Men in Bihar. New Delhi: Population Council.

Jejeebhoy, S. J., K. G. Santhya, S. Singh et al. 2017b. Feasibility of Screening and Referring Women Experiencing Marital Violence by Engaging Frontline Workers: Evidence from Rural Bihar. New Delhi: Population Council.

Kabeer, N. 2001. "Resources, agency, achievements: Reflections on the measurement of women's empowerment" in Discussing Women's Empowerment: Theory and Practice, ed. A. Sisask. Stockholm: Sida, pp. 20-27.

Kaur, K. 2014. "Adolescents and their role models," Global Journal for Research Analysis 3(10): 53-54.

Kim, J. S., C. L. Streeter. 2016. "Strategies and interventions for improving school attendance," Encyclopedia of Social Work. Accessed on 1 November 2017 at http://socialwork.oxfordre.com/view/10.1093/ acrefore/9780199975839.001.0001/acrefore-9780199975839-e-1227.

Kroenke, K., R. L. Spitzer, and J. B. Williams. 2001. "The PHQ-9: Validity of a brief depression severity measure," Journal of General Internal Medicine 16(9): 606-13.

Laird, R. D., G. S. Pettit, K. A. Dodge et al. 2003. “Change in parents' monitoring knowledge: Links with parenting, relationship quality, adolescent beliefs, and antisocial behaviour," Social Development 12(3): 401-19.

Lakshminarayana, R., A. Eble, P. Bhakta et al. 2013. "The support to rural India's public education system (STRIPES) trial: A cluster randomised controlled trial of supplementary teaching, learning material and material support," PLoS One 8 (7): e65775.

Linden, L. 2008. “Complement or substitute? The effect of technology on student achievement in India," J-PAL Working paper. Accessed on 11 August 2017 at https://www.povertyactionlab.org/evaluation/ complement-or-substitute-effect-technology-student-achievement-india.

Lowry, R., D. Holtzman, B. I. Truman et al. 1994. "Substance use and HIV-related sexual behaviors among US high school students: Are they related?," American Journal of Public Health 84(7): 1116-120.

Mahajan, P. and N. Sharma. 2005. "Parents attitude towards imparting sex education to their adolescent girls," Anthropologist 7(3): 197-99.

Malhotra, A., Schuler, S. R. and Boender, C. 2002. "Measuring women's empowerment as a variable in international development," Background paper prepared for the World Bank Workshop on Poverty and Gender: New Perspectives.

Marta, E. 1997. "Parent-adolescent interactions and psychosocial risk in adolescents: An analysis of communication, support and gender," Journal of Adolescence 20(5): 473-87. 
Mehra, S., R. R. Singh, V. Nair, et.al. 2016. Addressing Adolescent Girls' Vulnerability to HIV/AIDS: Lessons from the Meri Life Meri Choice project. New Delhi: Population Council.

Mensch, B. 2006. "Issues in defining, measuring and evaluating interventions to enhance agency among young women," Presentation made at the meeting Programming for Young People: New Evidence on Young People's Situation and Needs, New Delhi.

Ministry of Health and Family Welfare. 2014a. Rashtriya Kishor Swasthya Karyakram Strategy Handbook. New Delhi: Ministry of Health and Family Welfare, Government of India.

Ministry of Health and Family Welfare. 2014b. Rashtriya Kishor Swasthya Karyakram Operational Workbook. New Delhi: Ministry of Health and Family Welfare, Government of India.

Ministry of Health and Family Welfare. 2017. National Health Policy 2017. New Delhi: Ministry of Health and Family Welfare, Government of India.

Ministry of Human Resource Development (MOHRD). 2009. Rashtriya Madhyamik Shiksha Abhiyan (RMSA). New Delhi: Ministry of Human Resource Development, Government of India.

Ministry of Human Resource Development (MOHRD). 2011. Sarva Shiksha Abhiyan (SSA): Framework for Implementation, Based on the Right of Children to Free and Compulsory Education Act, 2009. New Delhi: Ministry of Human Resource Development, Government of India.

Ministry of Human Resource Development (MOHRD). 2014. Statistics of School Education 2011-12. New Delhi: Ministry of Human Resource Development, Government of India.

Ministry of Human Resource Development (MOHRD). 2016a. Educational Statistics at a Glance. New Delhi: Department of School Education and Literacy, Government of India.

Ministry of Human Resource Development (MOHRD). 2016b. Some inputs for Draft National Education policy. New Delhi: Ministry of Human Resource Development, Government of India. Accessed on 29 June 2017 at http:// mhrd.gov.in/sites/upload_files/mhrd/files/document-reports/NPE86-mod92.pdf.

Ministry of Human Resource Development (MOHRD). 2017a. New measures to assess learning outcomes. New Delhi: Ministry of Human Resource Development, Government of India. Accessed on 10 August 2017 at http://mhrd.gov.in/ new-measures-assess-learning-outcomes.

Ministry of Human Resource Development (MOHRD). 2017b. Quality education in government schools. New Delhi: Ministry of Human Resource Development, Government of India. Accessed on 10 August 2017 at http://mhrd.gov.in/ quality-education-government-schools.

Ministry of Labour and Employment. 2016. The Child Labour (Prohibition and Regulation) Amendment Act, 2016. New Delhi: Ministry of Labour and Employment, Government of India.

Ministry of Skill Development and Entrepreneurship. 2015. National Policy for Skill Development and Entrepreneurship. New Delhi: Ministry of Skill Development and Entrepreneurship, Government of India.

Ministry of Statistics and Programme Implementation. 2015. State Domestic Product and Other Aggregates, 2004-05 Series. Accessed on 17 August 2017 at http://mospi.nic.in/sites/default/files/press_releases_statements/ State_\%20wise\%20_SDP-31.07.2015.xls.

Ministry of Women and Child Development (MOWCD). 2015. Beti Bachao Beti Padhao: Implementation guidelines. New Delhi: MOWCD, Government of India.

Mohan, S., P. S Sarma, and K. R. Thankappan. 2005. "Access to pocket money and low educational performance predict tobacco use among adolescent boys in Kerala, India," Preventive Medicine 41(2): 685-92.

Mukherjee, K. K. and S. S. Mukherjee. 2004. Girls/Women in Prostitution in India. A National Study. Ghaziabad: Gram Niyojan Kendra. Supported by Department of Women and Child Development, Government of India, New Delhi.

Muralidharan, K. and N. Prakash. 2017. "Cycling to school: Increasing secondary school enrollment for girls in India," American Economic Journal: Applied Economics 9(3): 321-50.

Muralidharan, K. and V. Sundararaman. 2011. "Teacher performance pay: Experimental evidence from India," Journal of Political Economy 119(1): 39-77. 
Muralidharan, K. and V. Sundararaman. 2013. "Contract teachers: Experimental evidence from India," National Bureau of Economic Research (NBER), Working paper 19440. Accessed on 11 August 2017 at http://www.nber.org/ papers/w19440.

Nanda, P., P. Das, N. Datta, et al. 2016. "Making change with cash? Impact of a conditional cash transfer program on girls' education in India," in Impact on Marriage: Program Assessment of Conditional Cash Transfers. Washington DC: ICRW

National Council of Educational Research and Training (NCERT). 2012. What Students of Class VIII know and can do: A Summary of India's National Achievement Survey, Class VIII, 2012. New Delhi: National Council of Educational Research and Training.

National Institute of Nutrition. 2011. Dietary Guidelines for Indians- A Manual. Hyderabad: National Institute of Nutrition.

National Institute of Nutrition. 2012. Diet and Nutritional Status of Rural Population, Prevalence of Hypertension and Diabetes Among Adults and Infant and Young Child Feeding Practices - Report of Third Repeat Survey. Hyderabad: National Institute of Nutrition.

National Research Council (NRC) and Institute of Medicine (IOM). 2005. Growing Up Global: The Changing Transition to Adulthood in Developing Countries. Washington, DC: National Academies Press.

National Sample Survey Organization (NSSO). 2014. Employment and Unemployment Situation in India, NSS 68th Round (July 2011-June 2012). New Delhi: National Sample Survey Organization, Government of India.

Office of the Registrar General and Census Commissioner, India. 2013. Census of India 2011: Primary Census Abstract, Data Highlights, India, Series 1. New Delhi: Office of the Registrar General and Census Commissioner, Government of India.

Office of the Registrar General and Census Commissioner, India. 2015a. Adolescent and youth population. New Delhi: Office of the Registrar General and Census Commissioner, Government of India. Accessed on 20 August 2017 at http://www.censusindia.gov.in/2011census/PCA_AY_2011_Revised.xlsx.

Office of the Registrar General \& Census Commissioner, India. 2015b. Religion PCA: Bihar. New Delhi: Office of the Registrar General and Census Commissioner, Government of India. Accessed on 21 August 2017 at http://www. censusindia.gov.in/2011census/Religion_PCA.html.

Office of the Registrar General \& Census Commissioner, India. 2015c. Migrants by Place of Last Residence, Age, Sex, Reason for Migration and Duration of Residence - 2011, D-5 Table. New Delhi: Office of the Registrar General and Census Commissioner, Government of India. Accessed on 21 August 2017 at http://www.censusindia.gov. in/2011census/2011-D05-00-Prov.xls.

Office of the Registrar General \& Census Commissioner, India. 2015d. Table 1: Maternal Mortality Ratio (MMR), Maternal Mortality Rate and Life Time Risk; India, EAG \& Assam, South and Other States, 2011-13. New Delhi: Office of the Registrar General and Census Commissioner, Government of India. Accessed on 30 September 2017 at http:// www.censusindia.gov.in/vital_statistics/mmr_bulletin_2011-13.pdf.

Office of the Registrar General \& Census Commissioner, India. 2015e. HH-7: Households by Main Source of Lighting. New Delhi: Office of the Registrar General and Census Commissioner, Government of India. Accessed on 18 April 2017 at http://www.censusindia.gov.in/2011census/Hlo-series/HH07.html.

Office of the Registrar General \& Census Commissioner, India. 2015f. HH-6: Households by Main Source of Drinking Water and Location. New Delhi: Office of the Registrar General \& Census Commissioner, Government of India. Accessed on 18 April 2017 at http://www.censusindia.gov.in/2011census/Hlo-series/HH06.html.

Office of the Registrar General \& Census Commissioner, India. 2015g. HH-8: Households by Availability of Type of Toilet Facility. New Delhi: Office of the Registrar General \& Census Commissioner, Government of India. Accessed on 18 April 2017 at http://www.censusindia.gov.in/2011census/Hlo-series/HH08.html.

Office of the Registrar General and Census Commissioner, India. 2015h. C-8: Educational Level by Age and Sex for Population 7 and above- 2011. New Delhi: Office of the Registrar General and Census Commissioner, Government of India. Accessed on 22 April 2017 at http://www.censusindia.gov.in/2011census/C-series/C-08/DDW-0000C-08.xlsx.

Office of the Registrar General of India and Census Commissioner, India. 2016. SRS Based Abridged Life Tables 2010-14. New Delhi: Office of the Registrar General of India and Census Commissioner, Government of India 
Pandey, N., S. J. Jejeebhoy, R. Acharya et al. 2016. Effects of the PRACHAR Project's Reproductive Health Training Programme for Adolescents: Findings from a Longitudinal Study. New Delhi: Population Council.

Patel, V., H. A. Weiss, N. Chowdhary et al. 2010. "Effectiveness of an intervention led by lay health counsellors for depressive and anxiety disorders in primary care in Goa, India (MANAS): A cluster randomised controlled trial," The Lancet 376(9758): 2086-95.

Patton, G. C, Sawyer. S. M. et al. 2016. "Our future: A Lancet commission on adolescent health and wellbeing," The Lancet 387(10036): 2423-78.

Planning Commission. 2014. Data-book Compiled for Use of Planning Commission. New Delhi: Planning Commission, Government of India.

Pulerwitz, Julie and Gary Barker, 2008. "Measuring attitudes toward gender norms among young men in Brazil: Development and psychometric evaluation of the GEM scale," Men and Masculinities 10(3): 322-38.

Rajaraman, D., S. Travasso, A. Chatterjee, et al. 2012. "The acceptability, feasibility and impact of a lay health counsellor delivered health promoting schools programme in India: A case study evaluation," BMC Health Services Research 12:127.

Sachdev, P. 1998. "Sex on campus: A preliminary study of knowledge, attitudes and behaviour of university students in Delhi, India," Journal of Biosocial Science 30(1): 95-105.

Santhya, K. G., R. Acharya and S. J. Jejeebhoy. 2011. "Condom use before marriage and its correlates: Evidence from India," International Perspectives on Sexual and Reproductive Health 37(4): 170-80.

Santhya, K. G., S. J. Jejeebhoy, I. Saeed et al. 2013. "Growing Up in Rural India: An Exploration into the Lives of Younger and Older Adolescents in Madhya Pradesh and Uttar Pradesh." New Delhi: Population Council.

Santhya, K. G. and S. J. Jejeebhoy. 2014. "Adolescents and Youth in India: Challenges and opportunities." in Population and Reproductive Health in India: An Assessment of the Current Situation and Future Needs, eds. S. J. Jejeebhoy, P. M Kulkarni, K G Santhya et. al. New Delhi: Oxford University Press, pp. 175-246.

Santhya, K. G, S. J. Jejeebhoy and S. Basu. 2014. Trafficking of Minor Girls for Commercial Sexual Exploitation in India: A synthesis of Available Evidence. New Delhi: Population Council.

Santhya, K. G., A. J. Francis Zavier, P. Patel et al. 2016. Engaging Parents to Promote Girls' Transition to Secondary Education: Evidence from a Cluster Randomised Trial in Rural Gujarat, India. New Delhi: Population Council.

Sawyer, S. M., R. A. Afifi, L. H. Bearinger, et al. 2012. "Adolescence: a foundation for future health," The Lancet 379(9826): 1630-40.

Sebstad, J. and J. Bruce. 2004. "Building assets for safe and productive lives: A report on a workshop on adolescent girls' livelihoods," Presented at Adolescent Girls Livelihoods Meeting. New York: Population Council.

Sekher, T.V. and F. Ram. 2015. Conditional Cash Transfers for Girls in India: Assessment of a Girl Child Promotion Scheme from Beneficiary Perspective. Mumbai: International Institute for Population Sciences (IIPS).

Sen, S. and P. M. Nair. 2004. A Report on Trafficking in Women and Children in India 2002-2003: Volume 1. New Delhi: Institute of Social Sciences, National Human Rights Commission and UNIFEM.

Sharma, R., V. L. Grover, and S. Chaturvedi. 2010. "Tobacco use among adolescent students and the influence of role models," Indian Journal of Community Medicine 35(2): 272-75.

Singh, S. and S. Saini. 2007. "HIV risk perception in relation to peer pressure and drug abuse behaviour among adolescents," Indian Journal of Sexually Transmitted Diseases and AIDS 28(1): 53-54.

Smith, E. S. 1999. "The effects of investments in the social capital of youth on political and civic behaviour in young adulthood: a longitudinal analysis," Political Psychology 20(3): 553-80.

Soletti, A.B., V. Guilamo-Ramos, D. Burnette et al. 2009. "India-US collaboration to prevent adolescent HIV infection: The feasibility of a family-based HIV-prevention intervention for rural Indian youth," Journal of the International AIDS Society 12(35): 1-13.

Srikala, B and Kishore Kumar K. V. 2010. "Empowering adolescents with life skills education in schools - School mental health program: Does it work?," Indian Journal of Psychiatry 52(4): 344-49. 
Sroufe, J. W. 1991. “Assessment of parent-adolescent relationships: Implications for adolescent development," Journal of Family Psychology 5(1): 21-45.

Stromquist, N. P. 1995. The Theoretical and Practical Bases for Empowerment, in Carolyn Medel-Anonuevo ed. Women, education and empowerment: Pathways towards autonomy. Report of the international seminar held at UIE, Hamburg, 27 January-2 February 1993. Paris: UNESCO.

Stromquist, N. P. and G. E. Fischman. 2009. "Introduction-from denouncing gender inequities to undoing gender in education: practices and programmes toward change in the social relations of gender," International Review of Education 55(5-6): 463-82.

UI Haque, M. and A. Faizunnisa. 2003. "Access to reproductive health information in Punjab and Sindh, Pakistan: The perspectives of adolescents and parents," in Towards Adulthood: Exploring the Sexual and Reproductive Health of Adolescents in South Asia, eds. S. Bott, S. J. Jejeebhoy, I. Shah et al. Geneva: World Health Organisation, pp.153-55. United Nations Children's Fund (UNICEF). n.d. Meena Manch Prevents Child Marriage. Bihar: UNICEF. Accessed on 1 September 2017 at http://unicef.in/Story/71/Meena-Manch-prevents-child-marriage.

United Nations Children's Fund (UNICEF). 2011. The State of the World's Children 2011: Adolescence an Age of Opportunity. USA: UNICEF.

United Nations, Department of Economic and Social Affairs, Population Division. 2015a. World Population Prospects: The 2015 Revision, Volume I: Comprehensive Tables (ST/ESA/SER.A/379). New York: United Nations.

United Nations Population Fund (UNFPA). 2014. Action for Adolescent Girls. New York: UNFPA.

United Nations Population Fund (UNFPA). 2016. The State of World Population 2016. New York: UNFPA.

Verma, R. K., J. Pulerwitz, V. Mahendra, et al. 2006. "Challenging and changing gender attitudes among young men in India," Reproductive Health Matters 14(28): 135-43.

Viner, R. M., E. M. Ozer, S. Denny, et. al. 2012. "Adolescence and the social determinants of health," The Lancet 379(9826): 1641-652.

World Health Organization. 2006. Adolescent Nutrition: A Review of the Situation in Selected South-East Asian Countries. New Delhi: World Health Organization.

World Health Organization. 2009. Physical activity, Fact sheet (Updated February 2017). WHO: Media centre. Accessed on 29 June 2107 at http://www.who.int/mediacentre/factsheets/fs385/en/.

World Health Organization. 2010. Violence Prevention the Evidence: Series of Briefings on Violence Prevention. Geneva: World Health Organization. 


\section{Technical Advisory Group}

\section{Dr. Sushma Dureja}

Ministry of Health \& Family Welfare

Dr. Shireen Jejeebhoy

Independent Consultant

Dr. A.K. Shiva Kumar

International Centre for Human Development

Mr. Manak Matiyani

The YP Foundation

Dr. Vikram Patel

Public Health Foundation of India

Dr. Vinod K Paul

All India Institute of Medical Sciences

\section{Prof. T. K. Roy}

Independent Consultant

Dr. Venkatesh Srinivasan

United Nations Population Fund

\section{Dr. Ravi Verma}

International Center for Research on Women (ICRW)

Dr. Sheila C. Vir

Public Health Nutrition and Development Centre

Dr. Wilima Wadhwa

ASER Centre 


\section{List of Investigators}

Field Investigators

Anshu Agarwal

Shamim Ahmad

Rinki Ansari

Meena Arya

Alka Bajpai

Aradhana Bharti

Kanchan Chauhan

Neetesh Kumar Choudhary

Saraswati Choudhari

Deepshikha

Dilip Kumar Dubey

Kiran Devi

Ranju Devi

Sarita Deshbhratar

Soni Devi

Vijay Kumar Dixit

Tasnim Faruque

Arsi Fatima

Sulekha Gautam

Binit Jha

Anita Kumari

Annapurna Kumari

Krishna Kumari

Deepak Kumar

Dhirendra Kumar

Neeraj Kumari

Kamlesh Kumar

Premlata Kumari

Priyanka Kumari

Ramesh Kumar

Rekha Kori

Rekha Kumari

Rinki Kumari

Ruchi Kumari

Supriya Kumari

Shahida Khatoon

Bhaskar Mishra

Diwakar Maji

Priya Maurya
Rita Mishra

Sunita Malviya

Noori

Bhagwandas Pal

Renu Kumari Prabha

Satish Kumar Pal

Jalendri Rana

Nasim Kousar Rizvi

Rajnikant

Ruby

Sarita Rajpoot

Shiv Ram

Snehlata Rana

Nanda Sahu

Roshni Sahu

Ashutosh Sharma

Om Prakash Sharma

Anju Sharma

Preeti Sharma

Sharqa Shams

Shubhangini Shende

Pramod Shukla

Baljeet Singh

Jitendra Singh

Juli Singh

Kaushal Singh

Lakshman Singh

Rachna Singh

Raja Singh

Rinky Sinha

Shikha Sinha

Sanjna Kumari Singh

Pradeep Srivastava

Shveta Sriwastav

Yograj Tiwari

Satyendra Kumar Tiwari

Priyanka Vaishnav

Kiran Verma

Pooja Yadav 
Household Listers and Mappers

Kundan Kumar Bhardwaj

Abhishek Kumar

Jitendra Kumar

Kundan Kumar

Mukesh Kumar

Ravindra Kumar

Devendra Kumar

Sonu Kumar Mishra

Umapati Shivgautam Narayan

Deepak Kumar Pandey

Hrishikesh Pandey
Brahmanand Saraswati

Jai Prakash Sahu

SonaramSahu

Vikash Kumar Sahu

Pramod Sharma

Anil Kumar Sinha

Avadhesh Singh

Ajay Shukla

Ajay Singh

Subodh Kumar Tiwari

Jai Shankar Tiwari 
Designed by: Auriga Consultancy and Management Services and Mensa Design Private Limited.

Printed by: Mensa Design Private Limited - design.mensa@gmail.com 


\section{Study supported by:}

\section{BILL\& MELINDA \\ GATES foundation}

the David

Lucile Packard FOUNDATION 